\title{
Effects of Radioactive Hot Particles on Pig Skin
}

Manuscript Completed: June 1997

Date Published: June 1997

Prepared by

D.G. Kaurin, J.W. Baum, A.L. Carsten, J.O. Archambeau*, C.W. Schaefer

Brookhaven National Laboratory

Upton, NY 11973-5000

S. Schneider, NRC Project Manager

Prepared for

DISTRESAR OF THIS DOCUMENT SS UREATTEO

Division of Regulatory Applications

Office of Nuclear Regulatory Research

U.S. Nuclear Regulatory Commission

Washington, DC 20555-0001

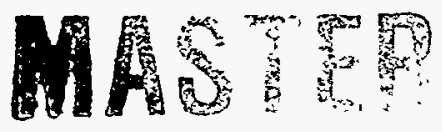

NRC Job Code A3990

*Loma Linda University Medical Center, Loma Linda, CA 92354

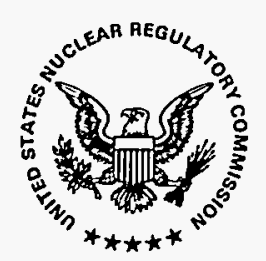




\section{NUREG/CR-6531 has been reproduced from the best available copy.}

For sale by the US Government Printing Office 


\section{DISCLAIMIER}

Portions of this document may be illegible in electronic image products. Images are produced from the best available original document. 


\section{DISCLAIMER}

This report was prepared as an account of work sponsored by an agency of the United States Government. Neither the United States Government nor any agency thereof, nor any of their employees, make any warranty, express or implied, or assumes any legal liability or responsibility for the accuracy, completeness, or usefulness of any information, apparatus, product, or process disclosed, or represents that its use would not infringe privately owned rights. Reference herein to any specific commercial product, process, or service by trade name, trademark, manufacturer, or otherwise does not necessarily constitute or imply its endorsement, recommendation, or favoring by the United States Government or any agency thereof. The views and opinions of authors expressed herein do not necessarily state or reflect those of the United States Government or any agency thereof. 


\begin{abstract}
The purpose of these studies was to determine the incidence and severity of lesions resulting from very localized deposition of dose to skin from small $(<0.5 \mathrm{~mm})$ discrete radioactive particles as produced in the work environments of nuclear reactors. Hanford mini-pigs were exposed, both on and slightly off the skin, to localized replicate doses from 0.31 to 64 Gy (averaged over $1 \mathrm{~cm}^{2}$ at $70 \mu \mathrm{m}$ depth unless noted otherwise) using Sc-46, Yb-175, Tm-170, and fissioned $\mathrm{UC}_{2}$ isotopes having maximum beta-particle energies from about 0.3 to $3 \mathrm{MeV}$. Erythema and scabs (indicating ulceration) were scored for up to 71 days post-irradiation. The responses followed normal cumulative probability distributions, and therefore, no true threshold could be defined. Hence, 10 and $50 \%$ scab incidence rates were deduced using probit analyses. The lowest dose which produced $10 \%$ incidence was about $1 \mathrm{~Gy}$ for $\mathrm{Yb}-175$ ( $0.5 \mathrm{MeV}$ maximum energy) beta particle exposures, and about 3 to $9 \mathrm{~Gy}$ for other isotopes. The histopathology of lesions was determined at several doses. Single exposures to doses as large as 1,790 Gy were also given, and results were observed for up to 144 days post-exposure. Severity of detriment was estimated by analyzing the results in terms of lesion diameter, persistence, and infection. Over 1,100 sites were exposed. Only two exposed sites became infected after doses near $500 \mathrm{~Gy}$; the lesions healed quickly on treatment.
\end{abstract}





\section{CONTENTS}

Page

ABSTRACT $\ldots \ldots \ldots \ldots \ldots \ldots \ldots \ldots \ldots \ldots \ldots \ldots \ldots \ldots \ldots \ldots \ldots \ldots \ldots \ldots \ldots$

LIST OF FIGURES $\ldots \ldots \ldots \ldots \ldots \ldots \ldots \ldots \ldots \ldots \ldots \ldots \ldots \ldots \ldots \ldots \ldots$

LIST OF TABLES $\ldots \ldots \ldots \ldots \ldots \ldots \ldots \ldots \ldots \ldots \ldots \ldots \ldots \ldots \ldots \ldots \ldots \ldots \ldots$

FOREWORD $\ldots \ldots \ldots \ldots \ldots \ldots \ldots \ldots \ldots \ldots \ldots \ldots \ldots \ldots \ldots \ldots \ldots \ldots \ldots$

EXECUTIVE SUMMARY $\ldots \ldots \ldots \ldots \ldots \ldots \ldots \ldots \ldots \ldots \ldots \ldots \ldots \ldots \ldots \ldots$ xiii

ACKNOWLEDGMENTS $\ldots \ldots \ldots \ldots \ldots \ldots \ldots \ldots \ldots \ldots \ldots \ldots \ldots \ldots \ldots \ldots$ xxii

ABBREVIATIONS $\ldots \ldots \ldots \ldots \ldots \ldots \ldots \ldots \ldots \ldots \ldots \ldots \ldots \ldots \ldots \ldots \ldots \ldots$

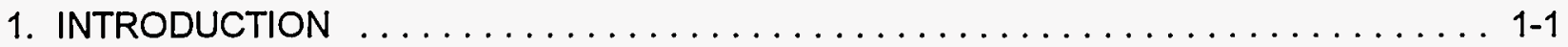

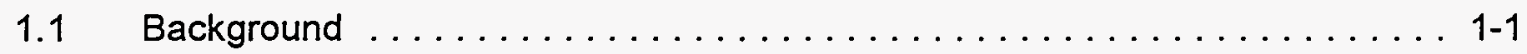

1.2 NCRP Recommendations . . . . . . . . . . . . . . . . . . 1-2

1.3 ICRP Recommendations . . . . . . . . . . . . . . . . . .

1.4 Summary of Earlier Studies by Brookhaven National Laboratory . . . . . . . . . 1-3

1.5 Objectives of These Studies . . . . . . . . . . . . . . . .

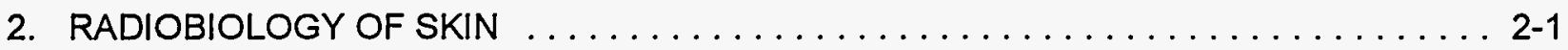

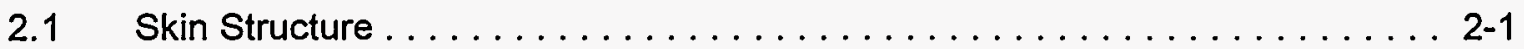

2.2 Radiation Effects on Skin .................

3. GENERAL EXPERIMENTAL PROTOCOL . . . . . . . . . . . . . . . . . 3-1

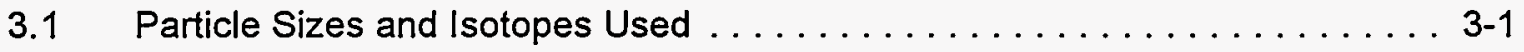

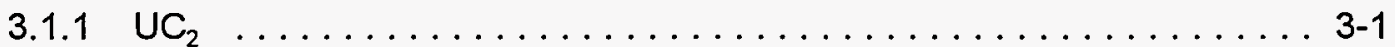

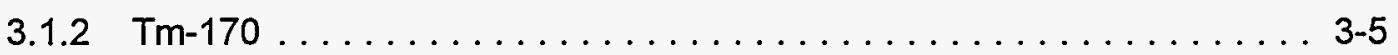

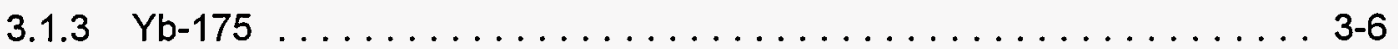

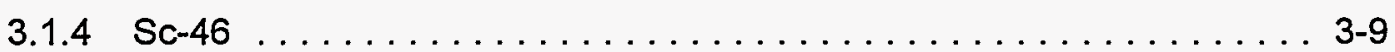

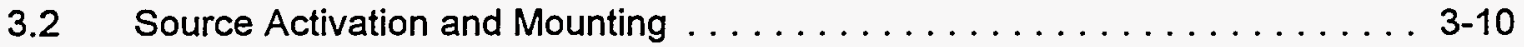

3.2.1 Sealing the Particles in Quartz Ampules . . . . . . . . . . . . . 3-10

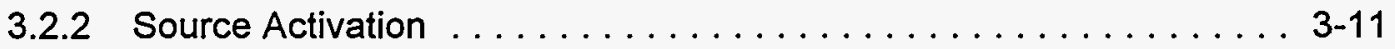

3.2.3 Radiation and Contamination Controls During Source Mounting . . . 3-12

3.2.4 Source-Mounting Block . . . . . . . . . . . . . . . . 3-12

3.2 .5 Source Mounting and Geometry . . . . . . $\ldots \ldots \ldots \ldots$ 3-18 


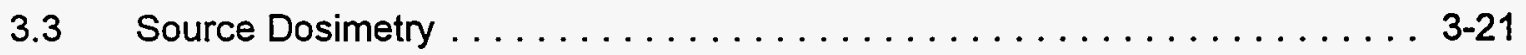

3.3.1 GafChromic Dye Films $\ldots \ldots \ldots \ldots \ldots \ldots \ldots \ldots \ldots \ldots .3-22$

3.3.1.1 GafChromic Dye: Description $\ldots \ldots \ldots \ldots \ldots \ldots \ldots$ 3-22

3.3.1.2 GafChromic Dye: Exposure ................ 3-23

3.3.1.3 Film Calibration ..................... 3-24

3.3.1.4 GafChromic Dye: Readout ................ 3-24

3.3.1.5 Dose and Beta Particle Emissions Determination from

GafChromic Dye Measurements ............... 3-24

3.3.2 Ionization Chamber . . . . . . . . . . . . . . . . . . . 3-27

3.3.3 Dosimetry Intercomparisons . . . . . . . . . . . . . . . . 3-27

3.4 Pig Husbandry, Training, and Preparations $\ldots \ldots \ldots \ldots \ldots \ldots \ldots \ldots .3 .28$

3.4.1 Experimental Animals . . . . . . . . . . $\ldots \ldots \ldots \ldots \ldots \ldots . \ldots \ldots$

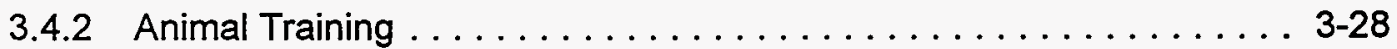

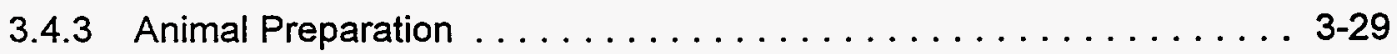

$3.5 \quad$ Irradiation of Pigs $\ldots \ldots \ldots \ldots \ldots \ldots \ldots \ldots \ldots \ldots \ldots \ldots \ldots \ldots \ldots \ldots \ldots \ldots . .29$

3.5.1 Beta Shields During Irradiations $\ldots \ldots \ldots \ldots \ldots \ldots \ldots \ldots \ldots \ldots \ldots \ldots \ldots$

3.5.2 Placement of Hot Particles on the Pigs ............... 3-30

3.5.2.1 Denim Source-Holding Harness ............. 3-30

3.5.2.2 Cone/Rod for Placing the Source . . . . . . . . . 3.35

3.5.3 Video Documentation of the Pig Irradiation ............ 3-36

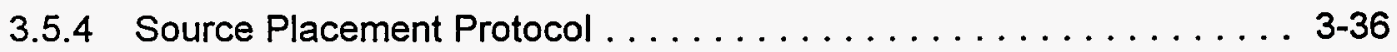

3.5.5 Treatment of Control Sites . . . . . . . . . . . . . . . . . 3-37

3.6 Observation of Lesions and Scoring Procedure $\ldots \ldots \ldots \ldots \ldots \ldots .3-37$

3.6.1 Observation Cubicle ...................... 3-37

3.6 .2 Observation Procedure $\ldots \ldots \ldots \ldots \ldots \ldots \ldots \ldots \ldots \ldots \ldots \ldots \ldots \ldots \ldots \ldots$

3.6.3 Photo Documentation ...................... 3-38

3.6.4 Histological Determinations and Histopathological Evaluation ... . . 3-38

3.6.4.1 Thickness of Keratin Layer . . . . . . . . . . . . 3-38

3.6.4.2 Depth of Basal Cells .................. 3-39

3.6.4.3 Methodology for Histological and Histopathological Studies 3-39

3.6.4.4 Characterization Skin Changes .............. 3-40

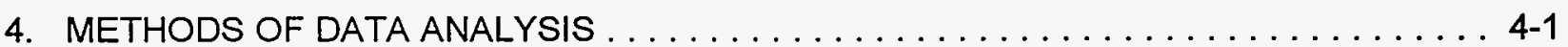

4.1 Criteria for Lesion Assessment ....................... 4-1

4.1 .1 Scab Criteria for Method "E" $\ldots \ldots \ldots \ldots \ldots \ldots \ldots \ldots \ldots . \ldots \ldots$ 4-1

4.1.2 Scab Criteria for Method "A" . . . . . . . . . . . . . . . . 4-1

4.1 .3 Scab Criteria for Method "B" . . . . . . . . . . . . . . . 4-2

4.1.4 Scab Criteria for Method "C" . . . . . . . . . . . . . . 4-2

4.2 Scab Diameter Regression Analyses . . . . . . . . . . . . . . . 4-2

4.2.1 Scab Diameter: Experimental Description ............. 4-2 
4.2.2 Advantages of the Scab-Size Method of Analysis . . . . . . . . . . 4-3

4.2.3 Disadvantages of the Scab-Size Method of Analysis . . . . . . . . . . 4-3

4.3 Dose-response Analysis of Percent Scab Incidence . . . . . . . . . . . . 4-4

4.3.1 PSI: Experimental Description . . . . . . . . . . . . . . . 4-4

4.3.2 Probit Analysis Method ... . . . . . . . . . . . . . . . . 4-4

4.3.3 Advantages of the PSI Experiment . . . . . . . . . . . 4-5

4.3.4 Disadvantages of the PSI Experiment . . . . . . . . . . . . . 4-5

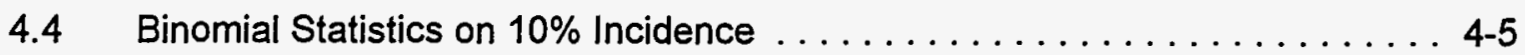

4.5 Analyses of Scab Persistence and Erythema Results . . . . . . . . . . . . . . 4-6

4.5.1 Percent-Scab-Days (PSD) Methodology . . . . . . . . . . . . . 4 4-6

4.5.2 Advantages of the PSD Methodology . . . . . . . . . . . . . 4-6

4.5.3 Disadvantages of the PSD Methodology . . . . . . . . . . . 4-6

4.6 Evaluation of Histology Measurements . . . . . . . . . . . . . . . . 4-6

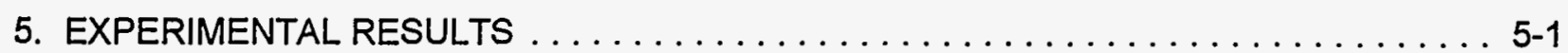

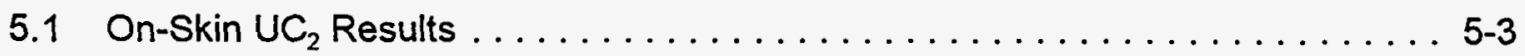

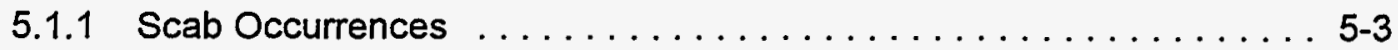

5.1.2 Comparisons of Erythema and Scab Occurrences ........ 5-3

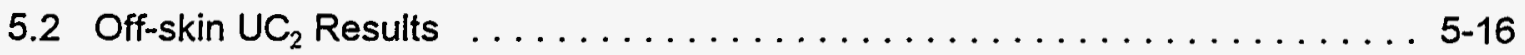

5.3 On-skin $\mathrm{Tm}-170$ Results . . . . . . . . . . . . . . . . . . . . . . . .

5.3.1 Experiment 3 using $\mathrm{Tm}-170 \ldots \ldots \ldots \ldots \ldots \ldots \ldots \ldots \ldots$ 5-16

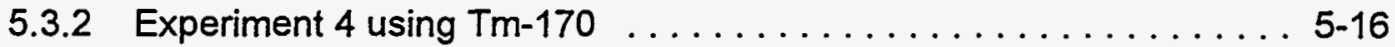

5.3.3 Experiment 5 using $\mathrm{Tm}-170 \ldots \ldots \ldots \ldots \ldots \ldots \ldots . \ldots \ldots$ 5-19

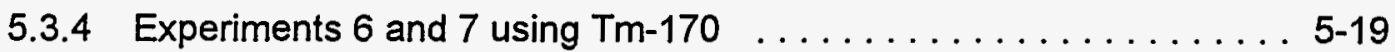

5.3.5 Experiments 8,9 , and 10 using $\mathrm{Tm}-170 \ldots \ldots \ldots \ldots \ldots$ 5-22

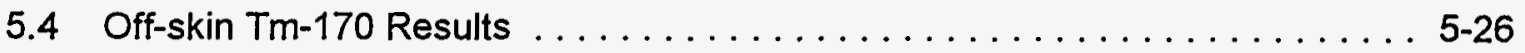

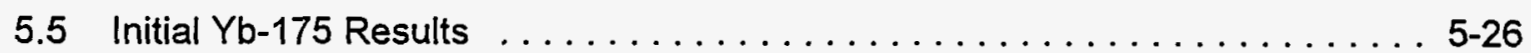

5.6 Additional $\mathrm{Yb}-175$ Studies . . . . . . . . . . . . . . . . . . $5-31$

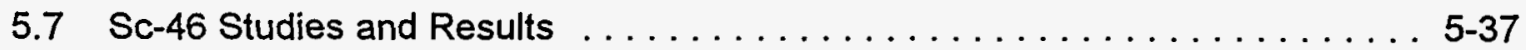

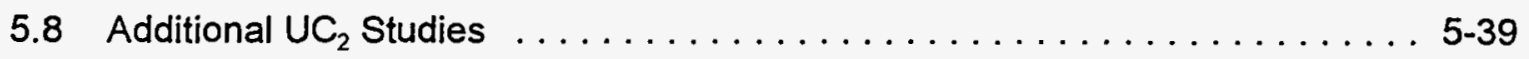

5.9 Evaluation of Scab Diameter Regression Analysis . . . . . . . . . . . . . . 5 5-43

5.10 Comparability of Results for Different Observers . . . . . . . . . . . . . . 5-46

5.11 Evaluation of Scoring Methods . . . . . . . . . . . . . . . 5-47

5.12 Scab-Days and Erythema Criteria for Detriment . . . . . . . . . . . 5-67

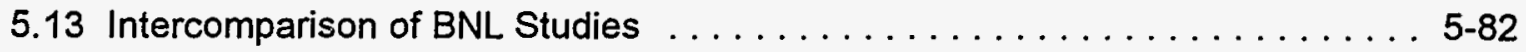

5.14 Scab Onset and Persistence . . . . . . . . . . . . . . . . . . . . . 5-84

5.15 Backscatter Experiments . . . . . . . . . . . . . . . . . 5-89

5.16 Dosimetry Intercomparison Results . . . . . . . . . . . . . . . . . . . 5-89

5.17 Keratin Thickness and Basal Cell Depth . . . . . . . . . . . . . 5-90

5.18 Effects of Close Shaving . . . . . . . . . . . . . . . . . . 5-93 
5.19 Histopathology Analysis . . . . . . . . . . . . . . . . . 5-94

5.19.1 Orientation Model from Preclinical Studies on Pig Skin ....... 5-95

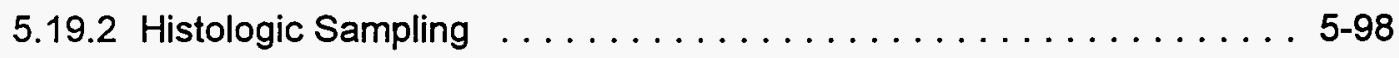

5.19 .3 General Comments . . . . . . . . . . . . . . . . . . . 5-98

5.20 Uncertainties, Background Studies, and Sensitivity Studies . . . . . . . 5-109

5.20 .1 Scoring Scab Incidence During 71 DPI ............ 5-109

5.20.2 Scoring Scabs as a Percentage of Total Observations (Scab Days) 5-111

5.20 .3 Control Data . . . . . . . . . . . . . . . . . . . . . 5-115

6. COMPARISONS WITH OTHER STUDIES AND UNCERTAINTIES $\ldots \ldots \ldots \ldots \ldots .6-1$

6.1 Fissioned U-235 Comparisons with Other Studies ............. 6-1

6.1.1 Comparisons with Forbes and Mikhail's Results with $U C_{2} \ldots \ldots \ldots 6-1$

6.1.2 Comparisons of Reece et al.'s and BNL's Results for Activated U

Exposures .......................... 6-7

6.1.2.1 On-skin Activated U Results ................. 6-7

6.1.2.2 Off-Skin Activated U Results ............... 6-10

6.2 Tm-170 Comparisons with Other Studies ................. 6-11

6.2.1 BNL Tm-170 Results Compared with Those of Hopewell (1991) ... 6-11

6.2.2 BNL On-skin Tm-170 Results Compared with Those of Reece et al. (1994) ........................... $6-11$

6.2.3 Off-Skin Tm-170 Results Compared with Those of Reece et al. (1994) ........................... 6-14

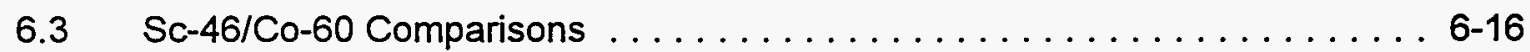

6.4 Comparisons with Results of Hopewell (1986) for Pm-147, Tm-170, and $\mathrm{Sr} / \mathrm{Y}-90 \ldots \ldots \ldots \ldots \ldots \ldots \ldots \ldots \ldots \ldots \ldots \ldots \ldots \ldots \ldots \ldots \ldots$

7. SUMMARY, DISCUSSION, AND CONCLUSIONS $\ldots \ldots \ldots \ldots \ldots \ldots \ldots \ldots \ldots \ldots \ldots \ldots .1$

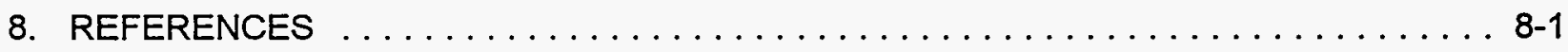

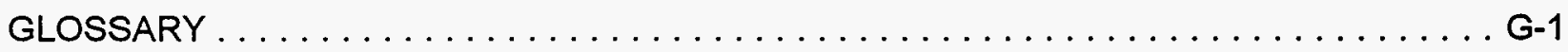

APPENDIX: Hot Particle Dosimetry: Intercomparisons .................. A-1

NUREG/CR-6531 viii 


\section{LIST OF FIGURES}

Figure 2.1 Schematic drawing of the skin showing the epidermal, dermal, and subcutaneous layers and emphasizing the critical microvascular components

Figure 3.1 Beta particle energy spectra determined from DEXRAX Version 2.0 (Eckerman et al., 1994)

Figure 3.2 The shape of the Tm-170, Yb-175, and Sc-46 sources approximated that of a three-dimensional trapezoid . . . . . . . . . . . . . . . . . . . .

Figure 3.3 On-skin $\mathrm{UC}_{2}$ source placement block used for experiments 1 and $2 \ldots$

Figure 3.4 Off-skin fissioned $\mathrm{UC}_{2}$ source placement block used for experiment $2 \ldots$

Figure 3.5 On-skin Tm-170 placement block for 120- and 280- $\mu$ m diameter sources

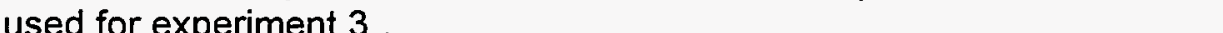

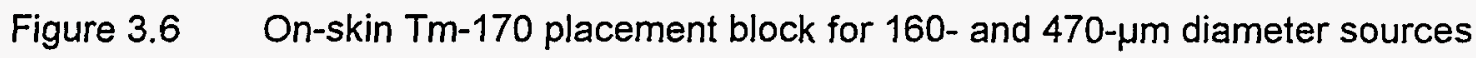
used for experiment $3 \ldots \ldots \ldots \ldots \ldots \ldots \ldots \ldots \ldots$

Figure 3.7 Off-skin Tm-170 placement block for 120- and 280- $\mu$ m diameter sources used for experiment $3 \ldots \ldots \ldots \ldots \ldots \ldots \ldots \ldots \ldots \ldots \ldots \ldots \ldots$

Figure 3.8 Off-skin Tm-170 placement block for 160- and 470- $\mu \mathrm{m}$ diameter sources used for experiment $3 \ldots \ldots \ldots \ldots \ldots \ldots \ldots$

Figure 3.9 Source placement block for 160 - and $470-\mu \mathrm{m}$ diameter $\mathrm{Tm}-170$ sources used for experiments 4 and 5

Figure 3.10 Source placement block used for Tm-170 experiments 6 and 7;

$\mathrm{Yb}-175$ experiments $11,12,13,15$, and 17 ; and $\mathrm{UC}_{2}$ experiments

Figure $3.11 \quad \mathrm{Tm}-170$ source placement block used for experiment $10 \ldots \ldots$ 3-17

Figure 3.12 Sc-46 source placement block used for experiments 13,16 , and $17 \ldots$ 3-17

Figure 3.13 Off-skin $U_{2}$ source placement block used for experiments 18 and $19 \ldots$

Figure 3.14 GafChromic dye film construction with manufacturer-specified dimensions except for the density of the polyester base, which was determined by measuring the film 
Figure 3.15 Radial dose profile for $\mathrm{Tm}-170$ particle at a film density thickness of

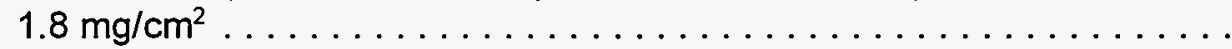

Figure 3.16 Denim source-holding harness $\ldots \ldots \ldots \ldots \ldots \ldots \ldots \ldots$

Figure 3.17 Cone-rod assembly used to hold the source mounting blocks

(Figures 3.3-3.13) on the pig for irradiations lasting less than 45 seconds.

Figure 5.1 Scab diameters resulting from on-skin $\mathrm{UC}_{2}$ exposures as a function of the number of beta particles emitted from source for experiment $1 \ldots$

Figure 5.2 Scab diameters from on-skin $\mathrm{UC}_{2}$ exposures as a function of the number of beta particles emitted from source for experiment $2 \ldots \ldots \ldots \ldots$

Figure 5.3 Scab diameters resulting from an on-skin $\mathrm{UC}_{2}$ exposures as a function

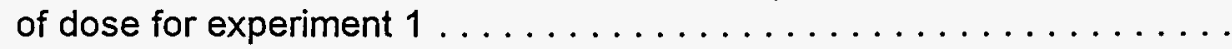

Figure 5.4 Scab diameters resulting from on-skin $U_{2}$ exposures as a function of

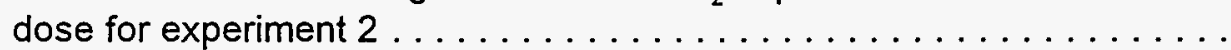

Figure 5.5 Histograms of erythema and scab results for $\mathrm{UC}_{2}$ on-skin exposures for experiment 2 (scaled to maximal occurrence) $\ldots \ldots \ldots \ldots \ldots$. . . .

Figure 5.6 Histograms of erythema and scab results for $\mathrm{UC}_{2}$ on-skin exposures for experiment 2 (scaled to maximal occurrence)

Figure 5.7 Histograms of erythema and scab results for $\mathrm{UC}_{2}$ on-skin exposures for experiment 2 (scaled to maximal occurrence) . . . . . . . . . . . .

Figure 5.8 Histograms of erythema and scab results for $\mathrm{UC}_{2}$ on-skin exposures for experiment 2 (scaled to maximal occurrence) $\ldots \ldots \ldots \ldots \ldots$

Figure 5.9 Histograms of erythema and scab results for $\mathrm{UC}_{2}$ off-skin exposures for experiment 2 (scaled to maximal occurrence) $\ldots \ldots \ldots \ldots \ldots$

Figure 5.10 Histograms of erythema and scab results for $U_{2}$ off-skin exposures for experiment 2 (scaled to maximal occurrence) . . . . . . . . . . .

Figure 5.11 Histograms of erythema and scab results for $\mathrm{UC}_{2}$ off-skin exposures for experiment 2 (scaled to maximal occurrence) . . . . . . . . . . . .

Figure 5.12 Histograms of erythema results for $U_{2}$ on- and off-skin exposures that only produced erythema in experiment 2 (scaled to maximal

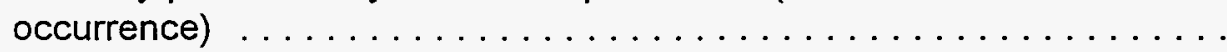


Figure 5.14 Comparison of off-skin $\mathrm{UC}_{2}$ scab and erythema diameters

Figure 5.15 Scab diameters for pig irradiated with off-skin $U_{2}$ particles as a

function of the numbers of beta particles emitted from the source.

Figure 5.16 Scab diameters for pig irradiated with off-skin $U C_{2}$ particles as a

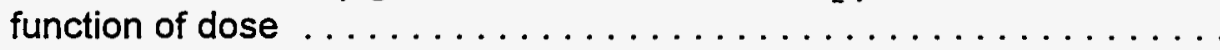

Figure 5.17 Scab diameters for on-skin Tm-170 irradiation as a function of dose for

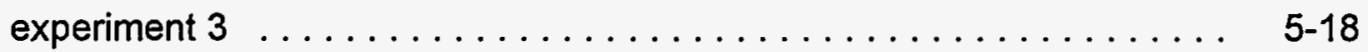

Figure 5.18 Scab incidence for 13.6-month-old pig irradiated with $\mathrm{Tm}-170$ in

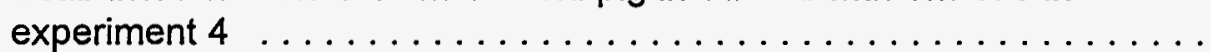

Figure 5.19 Scab diameters for pig irradiated with $\mathrm{Tm}-170$ in experiment $4 \ldots \ldots$

Figure 5.20 Scab diameters for pig irradiated with $\mathrm{Tm}-170$ in experiment $5 \ldots \ldots$

Figure 5.21 Scab diameters for pig irradiated with $\mathrm{Tm}-170$ in experiment $6 \ldots \ldots$

Figure 5.22 Scab diameters for pig irradiated with $\mathrm{Tm}-170$ in experiment $7 \ldots \ldots$

Figure 5.23 Scab incidence from a $470 \mu \mathrm{m}$ Tm-170 particle for scoring Method $E$ for

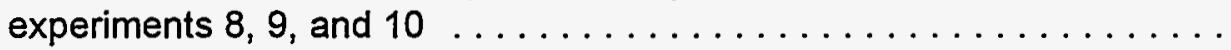

Figure 5.24 Scab incidence data from Tm-170 experiments 9 and 10 for 3.8-month-old pig using BNL Method E scoring technique compared with Hopewell's (1991)

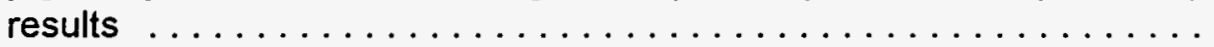

Figure 5.25 Scab incidence data from Tm-170 experiments 9 and 10 for 3.8-month-old pig using Hopewell scoring technique compared with Hopewell's (1991)

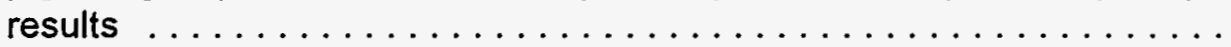

Figure 5.26 Scab incidence from Tm-170 for 9.6-month-old pig using BNL Method E scoring technique compared with Hopewell's (1991) results . . . . . . .

Figure 5.27 Scab incidence from Tm-170 for 9.6-month-old pig using Hopewell scoring technique compared with Hopewell's (1991) results . . . . . . . .

Figure 5.28 Scab incidence data from Tm-170 experiments 9 and 10 for 3.8-month-old pig using BNL scoring Method $\mathrm{C} \ldots \ldots \ldots \ldots \ldots \ldots \ldots$

Figure 5.29 Comparison of scab incidence data from Tm-170 experiments for 3.8- and 9.6-month-old pigs using BNL scoring Method $\mathrm{C} \ldots \ldots \ldots \ldots$

Figure 5.30 Scab diameters from on- and off-skin Tm-170 particles for pig irradiated

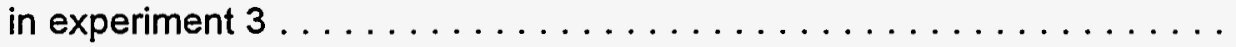


Figure 5.31 Scab diameter using scoring Method E for 3.3- and 11.3-month-old pigs exposed to $\mathrm{Yb}-175$ in experiments 11 and $12 \ldots \ldots \ldots \ldots$

Figure 5.32 Scab incidence using scoring Method E for 3.3- and 11.3-month-old pigs exposed to $\mathrm{Yb}-175$ in experiments 11 and $12 \ldots \ldots \ldots \ldots$

Figure 5.33 Scab incidence for scoring Method $\mathrm{C}$ and pigs exposed to $\mathrm{Yb}-175$ particles in experiments 13,15 , and $17 \ldots \ldots \ldots \ldots \ldots$

Figure 5.34 Scab incidence for pigs exposed to $\mathrm{Yb}-175$ in 1994 (scab-scoring Method C, $71 \mathrm{DPI}$ ), and for 12 areas exposed to doses greater than 14 Gy in 1991 (scab-scoring method modified E, $62 \mathrm{DPI}$ ) . . . . . . . .

Figure 5.35 Scab incidence for pigs exposed to $\mathrm{Yb}-175$ in 1994, including all 1992

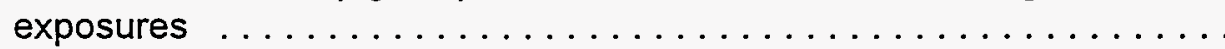

Figure 5.36 Scab diameter for $\mathrm{Yb}-175$ for 1994 experiments 13,15 , and $17 \ldots \ldots$

Figure 5.37 Scab incidence using Method $C$ for given doses from 440- $\mu$ m diameter Sc-46 hot particles

Figure 5.38 Scab diameters in experiments 14, 16, and 17 using scoring Method B for pigs irradiated with Sc-46 hot particles $\ldots \ldots \ldots \ldots \ldots \ldots$

Figure 5.39 Scab incidence using Method $\mathrm{C}$ for $56 \mathrm{DPI}$ data for on-skin $\mathrm{UC}_{2}$ exposures

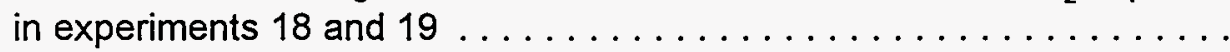

Figure 5.40 Scab incidence using scoring Method $\mathrm{C}$ for $56 \mathrm{DPI}$ data for

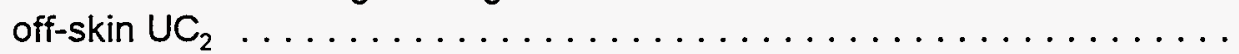

Figure 5.41 Comparison of confidence limits for scab incidence from exposure to onand off-skin $U C_{2}$ hot particles $\ldots \ldots \ldots \ldots \ldots \ldots \ldots \ldots \ldots \ldots \ldots$

Figure 5.42 BNL UC $\mathrm{CH}_{2}$ on- and off-skin, 1995, scab diameter results using scoring Method B

Figure $5.43 \quad E D_{10}, E D_{50}$, and $95 \%$ confidence limits for dark scabs induced by $\mathrm{Yb}-175$

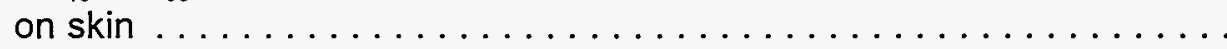

Figure $5.44 \quad E D_{10}, E D_{50}$, and $95 \%$ confidence limits for combined white and dark scabs

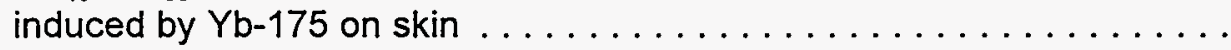

Figure $5.45 \quad E D_{10}, E D_{50}$, and $95 \%$ confidence limits for dark scabs induced by Sc-46

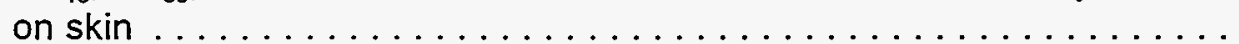

Figure $5.46 \quad E D_{10}, E D_{50}$, and $95 \%$ confidence limits for combined white and dark scabs induced by $\mathrm{Sc}-46$ on skin $\ldots \ldots \ldots \ldots \ldots \ldots \ldots$ 
Figure $5.47 E D_{10}, E D_{50}$, and $95 \%$ confidence limits for dark scabs induced by Tm-170

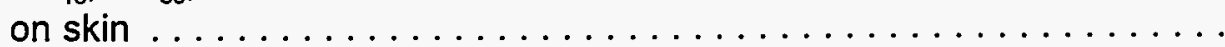

Figure $5.48 \quad E D_{10}, E D_{50}$, and $95 \%$ confidence limits for combined white and dark scabs

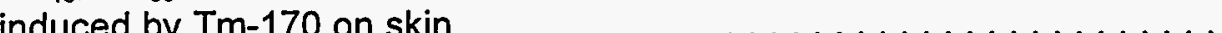

Figure $5.49 E D_{10}, E D_{50}$, and $95 \%$ confidence limits for dark scabs induced by $U C_{2}$

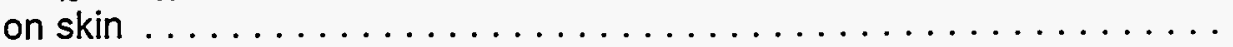

Figure $5.50 \quad E D_{10}, E D_{50}$, and $95 \%$ confidence limits for combined white and dark scabs

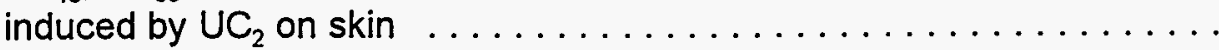

Figure $5.51 E D_{10}, E D_{50}$, and $95 \%$ confidence limits for white and dark scabs induced

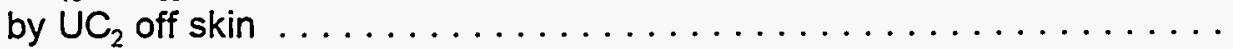

Figure $5.52 \quad E D_{10}, E D_{50}$, and $95 \%$ confidence limits for dark scabs induced by $U C_{2}$

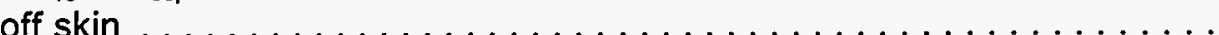

Figure $5.53 \quad E D_{50}$ values versus maximum beta particle energy for production of dark scabs for various scoring periods and methods .............

Figure 5.54 $E D_{10}$ values versus maximum beta particle energy for production of dark scabs for various scoring periods and methods . . . . . . . . . . .

Figure 5.55 $\quad E D_{50}$ values versus maximum beta particle energy for production of white and dark scabs for various scoring periods and methods . . . . . . . .

Figure 5.56 $E D_{10}$ values versus maximum beta particle energy for production of white and dark scabs for various scoring periods and methods ..........

Figure 5.57 Doses averaged over $1 \mathrm{~cm}^{2}$ at $70 \mu \mathrm{m}$ depth required to induce scabs with 10 and $50 \%$ incidence using scoring Method $\mathrm{C}$ for $71 \mathrm{DPI}$ data (Tm-170, $\mathrm{Yb}-175, \mathrm{Sc}-46)$ or $56 \mathrm{DPI}$ data $\left(\mathrm{UC}_{2}\right)$ for on-skin hot particles . . . . . .

Figure 5.58 Doses averaged aver $1.1 \mathrm{~mm}^{2}$ at $70 \mu \mathrm{m}$ depth required to induce on-skin scabs with 10 and $50 \%$ incidence using scoring Method $C$ for 71 DPI data (Tm-170, Yb-175, Sc-46) or 56 DPI data $\left(\mathrm{UC}_{2}\right)$. . . . . .

Figure 5.59 Percent-scab-days (dark plus white) for doses from $440 \mu \mathrm{m} \mathrm{Sc-46}$ hot particles

Figure 5.60 Percent-scab-days (dark plus white) for doses from 440 to $460 \mu \mathrm{m}$ Yb-175 hot particles . . . . . . . . . . . . . . . . .

Figure 5.61a Percent-effect-days for Sc-46 control (O Gy) exposures . . . . . . . .

Figure 5.61b Cumulative percent-effect-days for Sc-46 exposures 
Figure 5.61c Cumulative percent-effect-days for Sc-46 exposures

(range $4.4-4.7 \mathrm{~Gy}$ ) . . . . . . . . . . . . . . . . .

Figure 5.61d Cumulative percent-effect-days for Sc-46 exposures

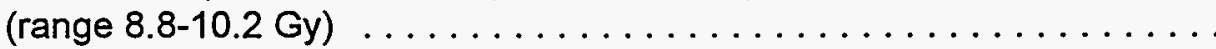

Figure 5.61e Cumulative percent-effect-days for Sc-46 exposures

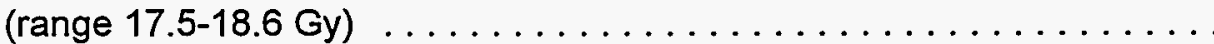

Figure 5.61f Cumulative percent-effect-days for Sc-46 exposures

(range $39.0-61.6 \mathrm{~Gy}$ ) . . . . . . . . . . . . . . . . . . . .

Figure 5.62a Cumulative percent-effect-days for $\mathrm{Yb}-175$ control (zero dose)

exposures

Figure $5.62 \mathrm{~b}$

Cumulative percent-effect-days for $\mathrm{Yb}-1750.31$ Gy exposures

Figure 5.62c

Cumulative percent-effect-days for $\mathrm{Yb}-175$ exposures $(0.60-0.63 \mathrm{~Gy}) \quad$.

$5-73$

Figure 5.62d

Cumulative percent-effect-days for $\mathrm{Yb}-175$ exposures $(0.78 \mathrm{~Gy}) \ldots \ldots$

Figure 5.62e Cumulative percent-effect-days for $\mathrm{Yb}-175$ exposures

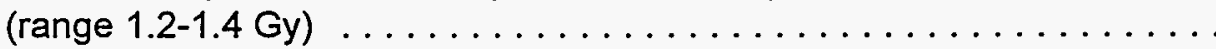

Figure 5.62f Cumulative percent-effect-days for $\mathrm{Yb}-175$ exposures (2.4-2.5 Gy) . . .

Figure 5.62g Cumulative percent-effect-days for $Y b-175$ exposures (3.7 Gy) $\ldots \ldots$

Figure 5.62h Cumulative percent-effect-days for $\mathrm{Yb}-175$ exposures (14.5-14.9 Gy) . .

Figure 5.63a

Cumulative percent-effect-days for $\mathrm{Tm}-170$ exposures (3 Gy) . . . . . .

5-76

Figure 5.63b

Cumulative percent-effect-days for $\mathrm{Tm}-170$ exposures ( $4.8 \mathrm{~Gy}) \ldots \ldots$

Figure $5.63 \mathrm{c}$

Cumulative percent-effect-days for $\mathrm{Tm}-170$ exposures $(7.7 \mathrm{~Gy}) \ldots \ldots$

Figure $5.63 \mathrm{~d}$ Cumulative percent-effect-days for $\mathrm{Tm}-170$ exposures $(9.9 \mathrm{~Gy}) \ldots \ldots$

Figure $5.64 a \quad \mathrm{UC}_{2}$ controls ( 0 dose). Cumulative percent effect observed $\ldots \ldots \ldots$

Figure 5.64b $\quad \mathrm{UC}_{2}$ on-skin exposures (avg. $2.21 \mathrm{~Gy}$ ). Cumulative percent effect observed

Figure 5.64c Cumulative percent-effect-days for $\mathrm{UC}_{2}$ on-skin exposures

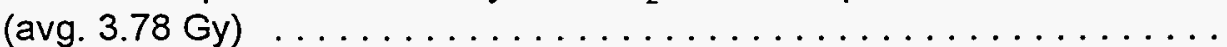

Figure 5.64d Cumulative percent-effect-days for $\mathrm{UC}_{2}$ on-skin exposures (avg. 8.7 Gy) 
Figure 5.64e Cumulative percent-effect-days for $U_{2}$ on-skin exposures

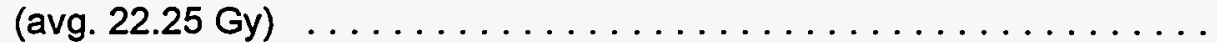

Figure 5.64f Cumulative percent-effect-days for $\mathrm{UC}_{2}$ off-skin exposures

(Avg. 28.82 Gy) . . . . . . . . . . . . . . . . . . . . . . . . .

Figure $5.64 \mathrm{~g}$ Cumulative percent-effect-days for $\mathrm{UC}_{2}$ on-skin exposures

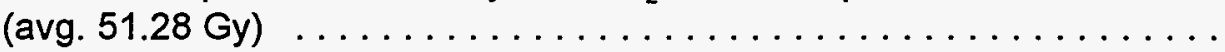

Figure 5.64h Cumulative percent-effect-days for $\mathrm{UC}_{2}$ off-skin exposures

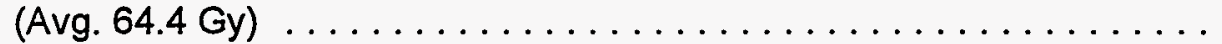

Figure 5.65 Scab-diameter regression thresholds and $E D_{10}$ values for $U C_{2}$ and

$\mathrm{Tm}-170$ as a function of pig's age $\ldots \ldots \ldots \ldots \ldots \ldots \ldots \ldots$

Figure 5.66 Time-of-onset of scabs using scoring Method B for replicate exposures at selected doses from on-skin $\mathrm{UC}_{2}$ hot particles $\ldots \ldots \ldots \ldots \ldots \ldots$

Figure 5.67 Time-of-onset of scabs using scoring Method B for replicate exposures at selected doses from off-skin $U C_{2}$ hot particles $\ldots \ldots \ldots \ldots \ldots$

Figure 5.68 Time-of-onset of scabs using scoring Method B for replicate exposures at selected doses from on-skin Tm-170 hot particles

Figure 5.69 Time-of-onset of scabs using scoring Method B for replicate exposures at selected doses from on-skin $\mathrm{Yb}-175$ particles . . . . . . . . . . .

Figure 5.70 Time-of-onset of scabs using scoring Method B for replicate exposures at selected doses from on-skin Sc-46 hot particle

Figure 5.71 Scab persistence for on- and off-skin $U_{2} C_{2}$ irradiations in experiment $2 \ldots$

$5-87$

Figure 5.72 On-skin Tm-170 induced scab days, where "percent-scab-days" is 100 times the number of days the scab was seen divided by the number

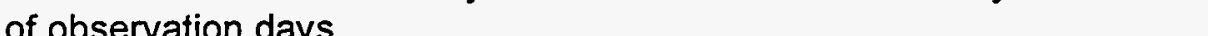

Figure 5.73 Mean keratin thickness for skin areas used for hot particle exposures

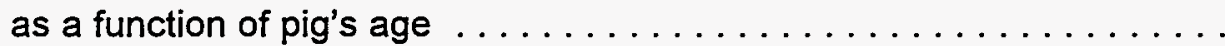

Figure 5.74 Mean basal layer depth for skin areas used for hot particle exposure as a function of pig's age $\ldots \ldots \ldots \ldots \ldots \ldots \ldots \ldots \ldots \ldots \ldots$

Figure 5.75 Photomicrograph of an unirradiated section of skin

Figure 5.76 A photomicrograph (X200) 19 days following a 53 Gy Sc-46 exposure to pig 37-2L. 
Figure 5.77 A photomicrograph (X100) 28 days following a 20 Gy $\mathrm{Yb}-175$ exposure to pig $50-3 R$

Figure 5.78 A photomicrograph (X100) 28 days following a 20 Gy $\mathrm{Yb}-175$ exposure to pig 50-3L

Figure 5.79 A photomicrograph (X100) 64 days following a 22 Gy UC2 "on-skin" exposure to pig $90-2 R$

Figure 5.80 A photomicrograph (X100) 64 days following an off-skin 62 Gy $\mathrm{UC}_{2}$ exposure of pig $90-2 R$.

Figure 5.81 A photomicrograph (X200) 64 days following an off-skin 62 Gy $\mathrm{UC}_{2}$ exposure to pig $90-2 R$.

Figure 5.82 A photomicrograph (X100) 96 days following a 53 Gy Sc-46 exposure to pig $50-2 \mathrm{R}$

Figure 5.83 A photomicrograph $(X 400)$ from another area of Figure 5.8296 days following 53 Gy Sc-46 exposure to pig $50-2 R$.

Figure 5.84 A photomicrograph (X100) of a white scab 2.4-mm long and 1-mm thick over a field 64 days following 60 Gy UC2 exposure to pig $90-2 \ldots \ldots \ldots$.

Figure 5.85 Comparison of percent scab incidence and scab days for $71 \mathrm{DPI}$ Sc-46-induced scabs

Figure 5.86 Comparison of percent scab incidence and scab days for $71 \mathrm{DPI}$ Yb-175-induced lesions

Figure 5.87 $E D_{10}$ for Sc-46 at $71 \mathrm{DPI}$ (without brown spots) as a function of background scab incidence for scab scoring Method B

Figure 5.88 $\quad \mathrm{ED}_{10}$ for $\mathrm{Yb}-175$ at $71 \mathrm{DPI}$ (with and without brown spots) as a function of background scab incidence for scab scoring Method B

Figure 6.1 On- and off-skin $\mathrm{UC}_{2}$ data from BNL results for 1991 compared with those of Forbes and Mikhail

Figure 6.2 On- and off-skin $\mathrm{UC}_{2}$ data from BNL results for 1995 compared with those of Forbes and Mikhail

Figure 6.3 Scab size from the Forbes and Mikhail data set (1971) $6-5$

Figure $6.4 \quad$ Scab sizes for the BNL $U_{2}$ experiment $2 \ldots \ldots \ldots \ldots \ldots$ 6-6

Figure 6.5 Scab sizes for different size Tm-170 particles carried out for experiment 3 
Figure 6.6 Comparison of $95 \%$ confidence limits for BNL's on-skin 0.29-mm UC ${ }_{2}$ hot particle with results of Reece et al. (1994) for on-skin 0.3- and 1.0-mm

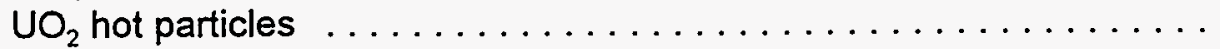

Figure 6.7 Percent-effect for days on which scabs were scored for 19 areas receiving a dose of $22 \mathrm{~Gy}$ from BNL on-skin $\mathrm{UC}_{2}$ exposures $\ldots \ldots \ldots \ldots \ldots$

Figure 6.8 Comparison of probit regressions for Hopewell (1991) data for a 500- $\mu \mathrm{m}$

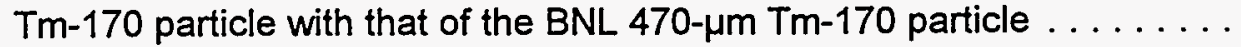

Figure 6.9 Comparison of 95\% confidence intervals for Hopewell (1991) and BNL's scab induction from $500-\mu \mathrm{m}$ and $470-\mu \mathrm{m}$ (BNL) $\mathrm{Tm}-170$ particles, respectively

Figure 6.10 Comparison of probit regression for Hopewell's combined 0.1-, 0.5-, and

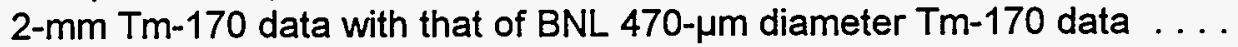

Figure 6.11 Comparison of scabs induced by Reece et al. (1994) 1-mm on-skin $\mathrm{Tm}-170$ particle with that of BNL $0.47-\mathrm{mm}$ on-skin Tm-170 particle.

Figure 6.12 Probit analysis of Reece et al. (1994) 0.8-mm and 1.6-mm off-skin Tm-170 results

Figure 6.13 Comparison of Reece et al.'s (1994) 1-mm $\times 1-\mathrm{mm} \times 0.4-\mathrm{mm}$ Co-60 source and 1-mm long, 200- $\mu$ m thick Co-60 wire with BNL's $0.44-\mathrm{mm}$ Sc-46 particle

Figure 6.14 Comparison of $B N L$ and Hopewell $E D_{10}$ with average and maximum

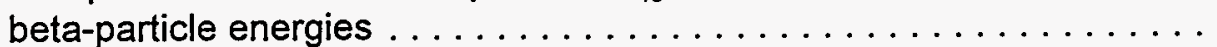

Figure 6.15 Comparison of $B N L$ and Hopewell $E D_{50}$ with average and maximum

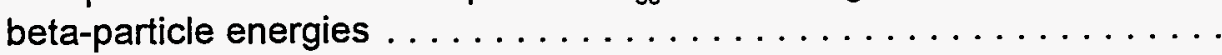

Figure 6.16 Probit regression results for all BNL's on-skin hot particle data

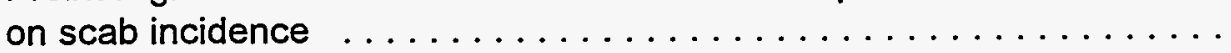

Figure 6.17 Scab incidence results for all BNL on-skin hot particles 


\section{LIST OF TABLES}

Table 3.1 Isotopic information for particles used in the BNL pig irradiations $\ldots \ldots \ldots . . .3-1$

Table 3.2 Efficiency measurement for the natural uranium $\mathrm{O}_{3} \mathrm{O}_{8}$ standard $\ldots \ldots \ldots$ 3-3

Table 3.3 Activity measurements of the $93 \%$ enriched ${ }^{235}$ UC sources. . . . . . . . . 3-3

Table 3.4 Characteristics of BNL particles before activation $\ldots \ldots \ldots \ldots \ldots \ldots \ldots$

Table 3.5 Comparison of $\mathrm{Co}-60$ and Sc-46 characteristics $\ldots \ldots \ldots \ldots \ldots \ldots$

Table 3.6 Co-60 beta to gamma particle dose ratios for selected right cylinders calculated using VARSKIN MOD2 (Durham, 1992) $\ldots \ldots \ldots \ldots \ldots \ldots \ldots \ldots \ldots \ldots . \ldots \ldots$

Table 3.7 Facilities and conditions used for neutron activation of particles $\ldots \ldots \ldots \ldots$ 3-11

Table 3.8 Specifications for materials used for the hot particle source-mounting block . . 3-19

Table 3.9 Number of beta particles emitted from the source and containment material per unit dose for hot particles and geometries used in the study. . . . . . . 3-27

Table 3.10 Details of each pig irradiation experiment $\ldots \ldots \ldots \ldots \ldots \ldots \ldots \ldots$

Table 5.1 Results for each of the experiments listed in Table $3.10 \ldots \ldots \ldots \ldots$. . . . . .

Table 5.2 Effects of scoring technique and observation periods on $5 \%$ scab incidence estimates for 3.8 -month-old pig exposed to $\mathrm{Tm}-170 \ldots \ldots \ldots \ldots \ldots$ 5-23

Table 5.3 Summary of scab incidence using $\mathrm{Yb}-175$ for experiments 11 and $12 \ldots \ldots 5-28$

Table 5.4 Net scab incidence with background subtracted for the 3.3-month-old pig exposed to $\mathrm{Yb}-175$ in an initial experiment. . . . . . . . . . .

Table 5.5 Reanalysis of $\mathrm{Yb}-175$ data listed in Table 5.3 using four scab sightings on the right flank and five scab sightings on the left flank and modified Method E scoring criteria ...................... 5-34

Table 5.6 Probit regression results for $1994 \mathrm{Yb}-175$ data combined with the 1992

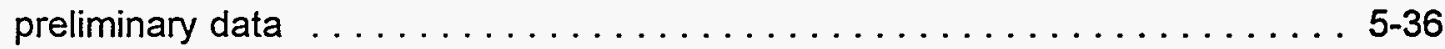

Table 5.7 Number of scabs, by diameter, for given doses from $\mathrm{Yb}-175$ particles using scoring Method $B \ldots \ldots \ldots \ldots \ldots \ldots \ldots . \ldots \ldots$. . . . . . . . . . . . . . . .

Table 5.8 Number of scabs, by diameter, for given doses from Sc-46 particles using scoring Method B 
Table 5.9 Coefficients of linear correlation for scab diameter regressions

Table 5.10 Percent scab incidence (PSI) for on-skin $\mathrm{UC}_{2}$ scabs

Table 5.11 Percent scab incidence (PSI) for off-skin $\mathrm{UC}_{2}$ scabs

Table 5.12 Percent scab incidence (PSI) for on-skin Tm-170 scabs. .

Table 5.13 Percent scab incidence (PSI) for on-skin Yb-175 scabs.

Table 5.14 Percent scab incidence (PSI) for on-skin Sc-46 scabs

Table 5.15 Probit analysis results for scoring methods $A, B$, and C.

Table 5.16 Values of $E D_{10}$ and $E D_{50}$ for doses averaged over selected areas and at selected depths

Table 5.17 Keratin thickness and basal cell depth for pig skin sites used for hot particle placements

Table 5.18 Keratin thickness before and after close shave

Table 5.19 Summary of biopsy schedule for histologic orientation

Table 5.20 Time-related events in evolution of scabs and healing

Table 5.21 Comparison of hot particle skin reactions with those produced by 10-cm diameter preclinical field exposures

Table 5.22 Keratin thickness and basal layer depth for sites exposed to $\mathrm{UC}_{2}, \mathrm{Sc}-46$, and $\mathrm{Yb}-175$ particles

Table 5.23 The 71 DPI scoring results for Sc-46 and $\mathrm{Yb}-175$ using scoring Method $\mathrm{B}$ for animals $37-1$ ( $L \& R), 39-3,50-2$, and $50-3$

Table 5.24 Probit results for Sc-46 with and without brown spots included using scoring Method B for 71 DPI data listed in Table 5.23 for selected background percentages

Table 5.25 Probit results for $Y b-175$ with and without brown spots using scoring Method $B$ for 71 DPI data listed in Table 5.23 for selected background percentages . . . 5-111

Table 5.26 Scab days analysis of Sc-46 71 DPI data. $\ldots \ldots \ldots \ldots \ldots \ldots \ldots$

Table 5.27 Analysis of scab days for Sc-46 control sites. . . . . . . . . . . 5-112

Table 5.28 Analysis of Sc-46 PSD data with corrections for background $\ldots \ldots \ldots$ 5-112 
Table 5.29 PSD analysis of $\mathrm{Yb}-175$ for $71 \mathrm{DPI}$ data

Table 5.30 Analysis of scab days for $\mathrm{Yb}-175$ control sites (36) for 71 DPI data $\ldots \ldots$. . 5-113

Table 5.31 Analysis of $\mathrm{Yb}-175$ PSD with corrections for natural background . . . . . . 5 5-114

Table 5.32 Background results for scab scoring Method $B \ldots \ldots \ldots \ldots \ldots \ldots$ 5-116

Table 6.1 Dose (or number of beta particles emitted from the particle) axis intercepts for zero scab diameter from linear regressions of the logarithm of the dose (independent axis) and scab diameter (dependent axis) . . . . . . . . . 6-2

Table 6.2 Results obtained by Reece et al. (1994) for fissioned $\mathrm{UO}_{2}$ particles. . . . . . 6-8

Table 6.3 Doses given to pig skin for on-skin 1-mm Tm-170 sources during the Reece et al. (1994) study. . . . . . . . . . . . . . . . . . . . . . 6-14

Table $6.4 \mathrm{Tm}-170$ particle off-skin results. $\ldots \ldots \ldots \ldots \ldots \ldots \ldots \ldots \ldots \ldots \ldots$

Table 6.5 Comparison of Hopewell et al.'s (1986), BNL's, and Reece et al.'s (1994)

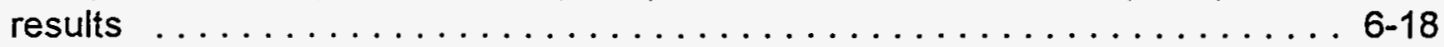




\section{FOREWORD}

In 1991, the Nuclear Regulatory Commission (NRC) revised its occupational dose limit for the skin of the whole body to 0.5 sieverts (50 rems) per year (May 21, 1991; 56 FR 23360). The NRC noted in this rulemaking that a related issue, "limits and calculation procedures for dealing with the 'hot particle' issue (small particles found in nuclear reactors that, because of their small size, produce highly localized doses to skin)," would be resolved in a separate rulemaking.

Despite studies by various researchers on the effects of hot particles on the skin of a human volunteer, monkeys, and pigs, the results were inadequate to form the technical basis necessary to proceed with a rulemaking on limiting hot particle exposures. Consequently, the NRC contracted with Brookhaven National Laboratory (BNL) to conduct research with the primary objectives of providing an adequate technical basis to understand the health risks posed by hot particles and of defining thresholds for the biological effects of concern. Specifically, the research was to (1) establish the energy dependence of the predicted ulcer threshold for hot particles on the skin, (2) determine the effect on the ulcer threshold when a hot particle is not in contact but is near the skin, (3) examine the persistence of biological effects, and (4) study the histopathology of exposed skin irradiated by hot particles.

A secondary objective of the research was to determine whether BNL's deduced threshold doses differ from or confirmed those derived from data in the current literature for hot particles containing fission and activation products. This objective included resolution of the several discrepancies noted in independent data sets that exist from other hot particle studies. A workshop on Hot Particle Dosimetry Intercomparisons was held at BNL in September 1994 so that BNL could determine how to best assess and combine BNL's data and findings of other investigators. The findings of this workshop are discussed in the Appendix to this report.

As part of the NRC's sponsored study, BNL issued in February 1992 a report entitled "Progress Report on Hot Particle Studies," NUREG/CR-5725. In that report, BNL critically reviewed and reassessed NCRP Report 106 on the effects of hot particles on the skin of pigs, monkeys, and humans. The design and conduct of the BNL hot particle research were based, in part, on the results of NUREG/CR-5725.

Now that the project has been completed, the results of the BNL research, together with their examination of biopsies of lesions and unirradiated skin, provide a solid technical basis that will be considered by the NRC staff in setting limits for hot particle exposures to the skin. The results, approaches, and methods described in this NUREG/CR-6531 are provided for information only. Publication of this report does not necessarily constitute NRC approval of, or agreement with, the information contained herein.

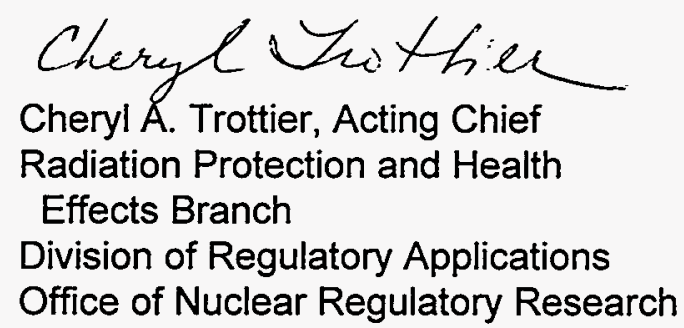





\section{EXECUTIVE SUMMARY}

The objective of the research was to provide an adequate technical basis for the U.S. Nuclear Regulatory Commission's staff to conduct rulemaking to resolve the hot particle issue. Specifically, it wa necessary to (1) establish the energy dependence of the predicted ulcer threshold(s) for hot particles on the skin, (2) determine the ulcer threshold(s) when a hot particle is slightly off the skin, (3) examine the persistence of biological effects, (4) study the histopathology of exposed skin irradiated by hot particles, and (5) determine whether Brookhaven National Laboratory's (BNL's) deduced threshold doses differ from or confirm those derived from data in the current literature for both fission (e.g., ${ }^{235} \mathrm{UC}_{2}$ ) and activation (e.g., Co-60) products.

The occurrence of hot particles in nuclear-power-plant environs has been a concern since the mid-1980s. Hot particles are small radioactive particles that are less than one millimeter in the largest dimension, and are typically fuel fragments or activated metal, principally Co-60. These particles can deposit large doses to small areas of skin. Induction of cancer from these particles is less of a concern than the deterministic effect of causing a break in the skin barrier, which is followed by formation of a scab.

In the National Council on Radiation Protection and Measurements (NCRP) Report 106 (NCRP, 1989), $10^{10}$ beta particles emitted from the source was recommended as the limit for hot particles on the skin to prevent deep ulceration. This recommendation was derived primarily from data on fissioned ${ }^{235} \mathrm{UC}_{2}$ hot particles. For a source emitting $2 \mathrm{MeV}$ (maximum energy) beta particles, this dose is approximately $5 \mathrm{~Gy}$ averaged over $1 \mathrm{~cm}^{2}$ at a depth of $70 \mu \mathrm{m}$. At about the same time as the NCRP recommendation was made, the International Commission on Radiological Protection (ICRP) Task Group on the Biological Basis for Dose Limitation in the Skin in Publication 59 (ICRP, 1991a) recommended a dose limit of $1 \mathrm{~Gy}$ averaged over $1 \mathrm{~cm}^{2}$ at a depth between 100 and $150 \mu \mathrm{m}$ to prevent transient ulceration. This limit was based primarily on Tm-170 data, which has a maximum beta energy of about $1 \mathrm{MeV}$. The latest ICRP recommendation (ICRP, $1991 \mathrm{~b}$ ) retains a limit of $0.5 \mathrm{~Sv}$ averaged over $1 \mathrm{~cm}^{2}$ at a skin depth of $70 \mu \mathrm{m}$.

BNL's biological studies, using particles with largest dimension from 120 to $510 \mu \mathrm{m}$, partially reconcile these two seemingly different recommendations by demonstrating the beta- particleenergy dependence of the effects. Experiments were carried out using fissioned ${ }^{235} \mathrm{UC}_{2}, \mathrm{Tm}^{-170}$, $\mathrm{Yb}-175$, and Sc-46 hot particles, which have maximum beta-particle energies of $\sim 2$ (average), 1 , 0.5 , and $0.36 \mathrm{MeV}$, respectively. The Sc-46 hot particles were used as a surrogate for Co-60, since their photon and beta particle emissions are similar but Sc-46 could be produced with a $\beta$ to $y$ dose ratio that would simulate that from smaller Co-60 sources.

The procedure used in deriving the NCRP recommendation was to perform regression analysis of scab diameter as a function of the logarithm of dose to obtain a "threshold" at the $x$-axis intercept. While this regression methodology was simple and did not require a large number of exposures, large variations between different pigs (factors of 2 to 5) were found in the thresholds for the same hot particle. However, while not giving a definitive value, this methodology was useful in establishing a dose range for future experiments as described below.

A major source of data used by the ICRP authors was British data in which replicate exposures were made at selected doses. For these data, probit analyses were used to determine dose 
values for 10 and 50 percent ulcer incidence. The same technique was used for the BNL data in which effects were scored as erythema and/or scabs (the latter because the lesions were not usually open festering wounds).

Results for $E D_{10}$ and $E D_{50}$ are summarized in terms of (a) point dose at 100- $\mu \mathrm{m}$ depth in tissue, (b) dose averaged over $1.1 \mathrm{~mm}^{2}$ at $16-\mu \mathrm{m}$ and at $70-\mu \mathrm{m}$ depth in tissue, (c) dose averaged over $1 \mathrm{~cm}^{2}$ at $70-\mu \mathrm{m}$ depth in tissue, at $100 \mu \mathrm{m}$ in tissue and at $150 \mu \mathrm{m}$ in tissue, and (d) number of beta particles emitted in the source, and from the source. Conversion factors for expressing results in units other than dose averaged over $1 \mathrm{~cm}^{2}$ were also calculated. These results are presented in Table 5.16 for comparison with the recommendations of the NCRP, the ICRP, and current regulations. Other findings and conclusions include the following: ${ }^{1}$

- The principal effects observed were the production of erythema and scabs.

- Both the probability of effect and the severity of effect (as measured by diameter of the lesion or its persistence) increased with doses above 1 to $10 \mathrm{~Gy}$ (dependent on beta-particle energy).

- The probability of inducing a scab following irradiation was $50 \%$ after a dose of about 6 Gy (averaged over $1 \mathrm{~cm}^{2}$ at a depth of $70 \mu \mathrm{m}$ in tissue) for exposures to $\mathrm{Yb}-175$ ( $0.12 \mathrm{MeV}$ average energy) and $\mathrm{Tm}-170$ (0.29 MeV average energy), and after 11-12 Gy for exposures to hot particles that were both lower (Sc-46, $0.096 \mathrm{MeV}$ ) and higher (fissioned $\mathrm{UC}_{2}, 0.71 \mathrm{MeV}$ ) in average beta-particle energy, although exposures from these two latter isotopes both included a significant dose from gamma rays.

- The $\mathrm{ED}_{10}$ for scab incidence was about 1.3 Gy for $\mathrm{Yb}-175,2.8 \mathrm{~Gy}$ for Tm-170, 5.1 Gy for Sc-46, 8.5 Gy for $U C_{2}$ on the skin, and $4.5 \mathrm{~Gy}$ for $U C_{2}$ off the skin exposures (Figure 5.57). Except for $Y b-175$, these values were generally about 0.5 of the $E D_{50}$.

- The method of deducing an apparent threshold from measurements of scab diameters as a function of dose did not yield reproducible results, but was helpful in establishing the dose range of interest for more detailed studies.

- At $50 \%$ and $10 \%$ scab incidence, the results for exposures to Tm-170 were within about 31 and $47 \%$, respectively, of those obtained by Hopewell.

- At $50 \%$ incidence, the doses required in these studies were factors of about 3 and 3.5 lower than required in Reece's studies for Tm-170 and activated U, respectively.

- Regression analyses of scab diameter vs. dose from fissioned $\mathrm{UC}_{2}$ particles yielded dose axis intercepts about one-half to one-fourth those of Forbes and Mikhail as reported in NCRP (1989) Report 106.

${ }^{1}$ Doses for the findings and conclusions listed here were averaged over $1 \mathrm{~cm}^{2}$ at $70 \mu \mathrm{m}$ depth. 
- $\mathrm{UC}_{2}$ particles held $0.4 \mathrm{~mm}$ off the skin by denim were approximately equally effective per unit dose in producing $50 \%$ incidence of scabs; however, at doses above $50 \%$ incidence the scabs tended to be larger for exposures off the skin.

- At $50 \%$ incidence, scoring methods were shown to affect results by a factor of about 0.5 to 1.5 and background corrections by a factor of about 0.8 to 1.2.

- Of 1,100 spots exposed, about 560 developed detectable scabs and two became infected, these at doses near $500 \mathrm{~Gy}$.

- A dose of about 100 to $300 \mathrm{~Gy}$, regardless of beta energy or depth in skin, was needed to produce a 4- to 7-mm diameter scab. Scabs of this size routinely healed after 20 to 100 days.

- The most effective beta-particle energy based on $\mathrm{ED}_{10}$ values was $0.12 \mathrm{MeV}_{\text {avg }}$ from $\mathrm{Yb}-175$ which had an $E D_{10}$ value of $1.3 \mathrm{~Gy}(0.89$ to $1.8,95 \%$ confidence limit). This particle deposits $85 \%$ of its emitted beta-particle energy within a distance of $0.5 \mathrm{~mm}$ in tissue.

- Basal cell depth increased significantly $(P<0.05)$ due to increased cell divisions (hyperplasia) after an $E D_{50}$ for $U C_{2}$ or Sc-46 exposure ( $\beta / Y$ emitters) but not after $\mathrm{Yb}-175$ exposures (a $\beta$ emitter with negligible $X$-ray contributions).

- Keratin thickness increased significantly $(P<0.05)$ after $E D_{50}$ from $U C_{2}$, or $S c-46$, but not after $\mathrm{Yb}-175$ exposures.

- Calculations showed that dose from Co-60 particles is primarily due to gamma rays for particle diameters greater than $500 \mu \mathrm{m}$.

- Calculations indicated a $200-\mu m$-thick disk of Sc-46 has a $\beta / Y$ dose ratio similar to that of a $75-\mu \mathrm{m}$-diameter Co-60 sphere. Because of this similar emission ratio, $\mathrm{Sc}-46$ can be used to simulate the smaller Co- 60 particles.

- Dosimetry intercomparisons confirmed that a commonly employed portable ionization chamber survey meter (such as the Eberline RO-2), when properly calibrated, can yield highly reliable and accurate $( \pm 15 \%)$ measurements of dose to a $1 \mathrm{~cm}^{2}$ area of tissue at $70 \mu \mathrm{m}$ depth in tissue for the range of beta-particle energies studied.

- GafChromic dye film dosimeters proved exceptionally convenient for providing radial and depth dose profiles from hot particles.

- Elastic bands successfully held particles on the skin of anesthetized pigs with minimum backscatter from Styrofoam backing, which simulated a particle on the skin with air backscatter.

- Animals could be trained to eat in an observation cubicle so that scoring could be carried out every day, if desired, without using anesthesia. 
- Biopsies taken of unirradiated skin confirmed that the keratin thickness and basal cell depth of pig skin used in these studies were similar to human skin.

- For doses less than $65 \mathrm{~Gy}$, there did not appear to be any non-healing lesions. There were, however, several examples of lesions that still retained histologically apparent crusts as long as 64 days post-irradiation with $U C_{2}$. In general, the $U_{2}$ lesions appeared to be more severe than others.

- At high doses, which could inactivate epidermal cells in small volumes, healing appears to have occurred from the edge of the exposed site. Fragmentation or edema occurred in the papillary dermis following higher doses, but there were no epidermal changes to indicate loss of microvessel nutrition during the periods examined. $\mathrm{UC}_{2}$ exposures resulted in hyperkeratosis, epidermal thickening, presence of keratin plugs around hair follicles, and scarring. 


\section{ACKNOWLEDGMENTS}

The success of this project was made possible by the assistance and knowledge of many individuals. Carmen Huckleby (Babcock and Wilcox) supplied the ${ }^{235} \mathrm{UC}_{2}$ micro-spheres. Anant Moorthy assisted in developing a $\mathrm{U}_{3} \mathrm{O}_{8}$ standard, and sealing of the unactivated particles in quartz ampules. John Heiser assembled a system to evacuate the quartz ampules before irradiation and back-fill them with helium. Keith Eckerman (Oak Ridge National Laboratory) carried out calculations using DEXRAX Version 2.0 to determine the beta spectra and average beta energy for Tm-170, Yb-175, Sc-46, and Co-60 sources. Darrel Joel made space and equipment available for housing the pigs, and also anesthetized and medically treated them, as required. Animal caretakers Anthony Chituk and Mary Ann Kershaw assisted with their husbandry.

L.-S. Casper Sun assisted in running probit regression analyses of the results.

The work of Xiao Wen Mao in collaboration with John Archambeau (Loma Linda University Medical Center) in evaluating the histopathological sections and supplying photomicrographs for this document is gratefully acknowledged, as is the advice of Harold Atkins in screening the histopathology slides.

Appreciation is expressed to Richard Clark and his staff (Department of Dermatology at University Hospital, State University of New York at Stony Brook) for their advice in taking biopsies, preparing slides, and the photomicrography and measuring of skin parameters during the early phases of this project.

Eleanor Mitchell and Karen Wagner transcribed dictations of the pig observations and assisted in preparing previous related documents.

Many students and high-school teachers assisted in carrying out the experiments, observing the swine, and analyzing data. Undergraduate students included Christopher Slavinsky ${ }^{1}$, Carl Simon $^{2}$, Susan DeMarino ${ }^{3}$, Viet Minh Do ${ }^{3}$, Raven Yadaf ${ }^{2}$, Daniel Badillo-Montalvo ${ }^{3}$, Christopher Smith $^{2}$, Maria Benincasa ${ }^{3}$, Scott Oosterveen ${ }^{2}$, Timothy Szopa ${ }^{2}$, James Riall ${ }^{3}$, Linda Oulton ${ }^{3}$, Anthony Terrinoni ${ }^{3}$, Vitaly Furman ${ }^{2}$, and Stephanie Lochmann ${ }^{4}$. Graduate students included

\footnotetext{
${ }^{1}$ Technical associate.

${ }^{2}$ Participation made possible through funding provided by the Brookhaven National Laboratory Summer Student Program.

${ }^{3}$ Participation made possible through funding provided by the U.S. Department of Energy's Science and Engineering Research Semester Program.

${ }^{4}$ Participation made possible through funding provided by the U.S. Department of Energy's Science and Engineering Opportunities Program for Minorities and Women.
} 
Sandy (McDaniel) Hodges ${ }^{5}$ and Jo-Ann Ouellette ${ }^{5}$. High school teachers included Patrick Mauch $^{6}$, Vincent Sidlanski ${ }^{6}$, and Patrick Cooney ${ }^{6}$.

The frequent collaborations of Christopher Soares (National Institute of Standards and Technology), Monty Charles and Philip Darley (University of Birmingham), Matthew Scannell (Yankee Atomic Electric Company), and James Durham (Pacific Northwest National Laboratories), and their participation in the dosimetry intercomparisons workshop, and Christopher Soares in interpreting dye film readout throughout this work are appreciated.

P. Donald Forbes (Argus Research Laboratories), John Hopewell (University of Oxford and Oxfordshire Health Authority), Monty Charles (University of Birmingham), Jack Bell, Stewart Schneider (U.S. Nuclear Regulatory Commission), James Durham, and Chris Slavinsky participated in two workshop on the animal studies and the interpretation of results. Michael Fry (Oak Ridge National Laboratory), Thomas Gessell (Idaho State University), Peter Knapp (San Onofre Nuclear Generating Station), and John Hopewell served as a project review panel in April 1993.

The comments and suggestions of Philip Darley, James Durham, P. Donald Forbes, R.J. Michael Fry, James Osborne, Bobby Scott, and Michael Williams on early drafts of this report are gratefully acknowledged. Avril Woodhead and Charles Meinhold provided editorial and technical review, respectively. The efforts of Maria Beckman for diligent and patient work on both the typing and graphical work in the manuscript are especially appreciated.

${ }^{5}$ Participation made possible by funding provided through the Oak Ridge Institute for Science and Education Applied Health Physics Fellowship Program.

${ }^{6}$ Participation made possible by funding provided through the Brookhaven National Laboratory Teacher Research Associate Program. 


\section{ABBREVIATIONS}

\begin{tabular}{|c|c|}
\hline $\begin{array}{l}\mathrm{BNL} \\
\mathrm{Bq}\end{array}$ & $\begin{array}{l}\text { Brookhaven National Laboratory } \\
\text { becquerel }\end{array}$ \\
\hline CLs & confidence limits \\
\hline DPI & days post-irradiation \\
\hline $\begin{array}{l}E D_{10} \\
E D_{50} \\
\text { EPRI }\end{array}$ & $\begin{array}{l}\text { dose predicted to produce a specific effect in } 10 \% \text { of the areas exposed } \\
\text { dose predicted to produce a specific effect in } 50 \% \text { of the areas exposed } \\
\text { Electric Power Research Institute }\end{array}$ \\
\hline FU & skin functional unit \\
\hline Gy & gray \\
\hline HFBR & High Flux Beam Reactor \\
\hline ICRP & International Commission on Radiological Protection \\
\hline $\begin{array}{l}\text { NCRP } \\
\text { NIST } \\
\text { NRC }\end{array}$ & $\begin{array}{l}\text { National Council on Radiation Protection and Measurements } \\
\text { National Institute of Standards and Technology Laboratory } \\
\text { U.S. Nuclear Regulatory Commission }\end{array}$ \\
\hline $\begin{array}{l}\text { PMMA } \\
\text { PSD } \\
\text { PSI } \\
\text { PTP }\end{array}$ & $\begin{array}{l}\text { polymethylmethacrylate } \\
\text { percent scab days } \\
\text { percent scab incidence } \\
\text { polyethylene-terephthalate }\end{array}$ \\
\hline $\begin{array}{l}\text { SI } \\
\text { Sv }\end{array}$ & $\begin{array}{l}\text { scab incidence } \\
\text { sievert }\end{array}$ \\
\hline $\begin{array}{l}\text { UMRR } \\
\text { UVR }\end{array}$ & $\begin{array}{l}\text { University of Missouri Research Reactor } \\
\text { ultraviolet radiation }\end{array}$ \\
\hline
\end{tabular}




\section{INTRODUCTION}

Small radioactive particles, ranging in size typically from one micron to a few hundred microns, have been identified as a problem in the nuclear power industry for some time (James, 1988; NCRP, 1989; Dionne and Baum, 1991; Reece, 1991; Kelly and Gustafson, 1994). These particles have become known as "hot particles" due to their relatively high specific activity and small size. When deposited externally or inhaled, they can cause intense local irradiation of small volumes of tissue. External deposition on skin or on clothing in contact with the skin may produce reddening, ulceration, necrosis, and also, a remote possibility of an increase in the risk of skin cancer (NCRP, 1989; Hopewell, 1991; Charles, 1991; ICRP, 1991a). There is difficulty in eliminating the production of these particles at some facilities, and also difficulties in detecting and removing them from personnel and their clothing.

\subsection{Background}

In 1985, hot particles emerged as a radiation protection issue in nuclear power plants when there were exposures of personnel at three stations. Two incidents involved activated hot particles, and the other a fuel hot particle (containing mixed fission-products). The U.S. Nuclear Regulatory Commission (NRC) responded with Inspection and Enforcement Information Notice 86-23 (NRC, 1986) discussing the incidents, along with the corrective actions taken at the plants. Significantly, the NRC observed that, in each case, the particles may have been transferred to the worker's skin from anti-contamination clothing thought to be clean. The particles were apparently being spread in the laundry system as hot particle-contaminated clothing was mixed with clothing collected from areas free from hot particle contamination.

In August 1987, the NRC issued Information Notice 87-39 (NRC, 1987). Nine more cases of personnel contamination with hot particles were reported. This notice focused primarily on plants operating with significant leakage in the fuel cladding, and it emphasized the need for special control procedures for handling leaking fuel to avoid spreading of hot particles. The NRC also noted that about $75 \%$ of the plants then were using new, high-sensitivity whole-body contamination monitors that had detected most of the particles found. With the improved capability of the new monitors, the chance of detecting the particles had improved and the frequency of discovery increased (James, 1988).

Industrial experiences with hot particles and their control were further summarized in several reports (Warnock et al., 1987; James, 1988; Dionne and Baum, 1991; Kelly and Gustafson, 1994; Mandjukov et al., 1994; Pöllänen and Toivonen, 1994; Likhtariov et al., 1995).

The potential biological effects from hot particles are unusual due to the concentration of a large dose in a very small volume of tissue. Therefore, the NRC, the National Council on Radiation Protection and Measurements (NCRP), and the International Commission on Radiological Protection (ICRP) have given special consideration to the problem of limiting exposures to hot particles without causing greater detriment due to possible increases in whole-body exposures that tend to be incurred when frequent checks for contamination require interrupting jobs. The recent changes in 10 CFR 20 dose limits (NRC, 1991) were somewhat less restrictive as the limit for skin exposure was raised from $7.5 \mathrm{rem}(0.075 \mathrm{~Sv})$ per quarter to $50 \mathrm{rem}(0.5 \mathrm{~Sv})$ per year, 


\section{Introduction}

averaged over an area of one square centimeter at a tissue depth of 0.007 centimeter $(70 \mu \mathrm{m})$ $\left(7 \mathrm{mg} / \mathrm{cm}^{2}\right)$. However, the NRC stated in Information Notice 90-48 (NRC, 1990) their intent to make changes by a rulemaking after further information becomes available.

\subsection{NCRP Recommendations}

In December 1989, the NCRP issued Report No. 106 on 'Limit for Exposure to 'Hot Particles' on the Skin" (NCRP, 1989) in which they reviewed information on the potential biological effects of hot particles on the skin and recommended limits of exposure from hot particles in the workplace based on avoiding deterministic effects. The risk of skin cancer after irradiation of the skin by hot particles was deemed much less than when extended areas of the skin are irradiated due to the smaller number of cells involved and the greater potential for cell killing by the localized betaparticle dose. This was confirmed by the data of Charles et al. (1988).

The NCRP (1989) reviewed the effects of exposure to hot particles on a human volunteer (Dean and Langham, 1969, and Dean et al., 1970), monkeys (Dean et al., 1970), and pigs (Moritz and Henrique, 1952; George and Bustad, 1966; Forbes and Mikhail, 1969; and Hopewell et al., 1986). The NCRP also reviewed and analyzed data in an unpublished report prepared by Forbes and Mikhail, which contained the basic data referred to in the Forbes and Mikhail abstract (1969). Unfortunately, due to circumstances outside the control of the authors, their studies were terminated before exposures sufficiently low to define a threshold could be made. From this review, the Council recommended that a limit of $10^{10}$ beta particles $(75 \mu \mathrm{Ci} \mathrm{h} ; 10 \mathrm{GBq} \mathrm{s})$ emitted from a "point" particle, or a particle less than $1 \mathrm{~mm}$ in diameter, should be used for particles contacting the skin. This limit was intended to prevent "deep" ulceration, but presumably might allow transient effects such as erythema and shallow ulceration which frequently disappear in less than a week, as observed by Hopewell et al. (1986). For beta particles from activated fuel, this exposure causes a dose of about $5 \mathrm{~Sv}$ averaged over $1 \mathrm{~cm}^{2}$ at a depth of $70 \mu \mathrm{m}$ in tissue.

\subsection{ICRP Recommendations}

In 1987, the ICRP formed a Task Group of Committee 1 to consider the biological bases for dose limitation in the skin. The Task Group reviewed much of the same material reviewed by the NCRP. However, they based their recommendations on preventing acute transient ulceration and recommended that the dose delivered within a few hours over an area of $1 \mathrm{~cm}^{2}$ measured between depths of $100-150 \mu \mathrm{m}\left(10-15 \mathrm{mg} / \mathrm{cm}^{2}\right)$ should be restricted to $1 \mathrm{~Sv}($ ICRP, 1991a). The latest recommendations of the ICRP, however, retain the limit of $0.5 \mathrm{~Sv}$ averaged over any $1 \mathrm{~cm}^{2}$, at a nominal depth of $7 \mathrm{mg} / \mathrm{cm}^{2}$, regardless of the area exposed (ICRP, Publication 60 , $1991 b)$. Thus, there is a factor of about ten difference between the recommendations of the NCRP and the ICRP. This difference illustrated the need for more definitive information on the effects expected, their probabilities, severities, and persistence. The objectives of this work were to obtain additional scientific data which could be used in the decisions and recommendations of these committees and regulatory agencies. 
Introduction

\subsection{Summary of Earlier Studies by Brookhaven National Laboratory}

During the first phase of these studies, the literature on biological effects of hot particles was critically reviewed, and weaknesses or gaps in the knowledge identified. It was concluded that there were large uncertainties in both the "threshold" dose for ulcer production, and in dosimetric measurements and calculations for both the Forbes and Mikhail study (1969) that the NCRP relied upon, and the Hopewell et al. (1986) study that the ICRP principally relied upon (1991a, 1991b).

This preliminary work was summarized in the "Progress Report on Hot Particle Studies" (Baum et al., 1992) and in a paper presented at a workshop on skin dosimetry held in 1991 (Baum and Kaurin, 1991). Other related studies reported at the same workshop confirmed the Brookhaven National Laboratory (BNL) investigators' suggestion that non-linear responses should be expected from extrapolation-chamber measurements on small hot particles. Studies by Soares et al. (1991) using radiochromic dye film exposed to the British 1-mm-diameter Sr-Y source and analyzed at the National Institute of Standards and Technology Laboratory (NIST), indicated a factor of about three times higher dose rate when measured by the dye film than when measured by the British extrapolation chamber with a 1.1-mm diameter collecting electrode and using linear extrapolation. The same source was measured by Darley et al. (1991) using the extrapolation chamber and dye film for comparison. The latter, read out using three different systems, yielded about 1.5 times higher results than the extrapolation chamber with non-linear extrapolation. These results demonstrated both the difficulty of accurate dosimetry and the large uncertainties to be expected.

\subsection{Objectives of These Studies}

Because of these uncertainties, the NRC funded BNL to undertake the following tasks:

a. Repeat Forbes and Mikhail's work using activated $U C_{2}$ particles both on and off the skin (separated from it by one or two layers of clothing).

b. Repeat Hopewell et al.'s (1986) studies using Tm-170 particles both on and off the skin.

C. Study the effects of lower energy particles to determine the beta particle energy that would produce lesions most effectively.

d. Make dosimetry intercomparisons to reduce uncertainties, validate BNL's dosimetry techniques, and facilitate comparisons among the biological studies of Forbes and Mikhail (1969, also in NCRP, 1989), Hopewell et al. (1986), Hopewell (1991), and more recently Reece et al. $(1992,1993,1994)$.

e. Determine the doses which can be expected to produce a barely detectable break in the skin (identified by scab formation) with probabilities of $10 \%\left(E D_{10}\right)$ and $50 \%$ 
Introduction

$\left(E D_{50}\right)$, and with statistical power sufficient to produce lower $95 \%$ confidence limits greater than zero for the $10 \%$ incidence results.

f. Study the histopathology and persistence of lesions induced in irradiated pig skin to evaluate their type, depth, and severity. 


\section{RADIOBIOLOGY OF SKIN}

\subsection{Skin Structure}

The skin is the barrier separating humans from the environment. It provides protection against the many hazards of the environment, and is critical in controlling liquid and electrolyte loss as well as in regulating temperature. It has also been shown to have an important immune function (Streilein, 1983). For standard man $(70 \mathrm{~kg})$, the skin accounts for approximately $3 \%$ of the total body weight (approximately $2.1 \mathrm{~kg}$ ), with a surface area of about $1.8 \mathrm{~m}^{2}($ ICRP, 1975). Anatomically, the skin consists of two layers, the outer epidermis and the underlying dermis. The inner layer of the epidermis is marked by a layer of actively dividing basal cells, which, through differentiation and maturation, progress outwardly to become the stratum corneum, made up of flattened dead cells. This layer, often described as the keratin layer, makes up approximately $25 \%$ of the total thickness of the epidermis.

Beneath the epidermis lies the dermis, which can further be subdivided into the superficial papillary dermis, of approximately the same thickness as the epidermis, and the deeper lying reticular dermis. Extending from the dermis into the epidermis are the skin appendages, which include the sebaceous, eccrine (sweat), apocrine glands, and hair follicles.

The basal cells are of most concern in considering radiation damage to the skin because they are the key to replenishing the more superficial layers, and also the papillary dermis, which contains microvessel tufts, which arise from the papillary plexus and furnish nutrition to the basal cells and the rest of the epidermis. Figure 2.1, adapted from Archambeau et al. (1995), illustrates the relationships of these various units.

In the same publication, Archambeau et al. describe pigs' skin as having an epidermal layer 30$300 \mu \mathrm{m}$ thick, which is in agreement with our measured values on pigs and the ICRP values for humans (ICRP Publication 23, 1975). Archambeau further describes the pigs' epidermal layer as having a proliferative basal cell layer containing approximately $2.25 \times 10^{6}$ cells per $\mathrm{cm}^{2}$ of basement membrane. Other characteristics include a generation time of 2.6 days with approximately $4 \%$ of the cells moving daily into and out of the basement membrane, which accounts for the maintenance of a constant population density. The minimum transit time for a labeled cell to pass from the basal layer through the stratum corneum is approximately 26 days.

The dermal layer is approximately $1-3 \mathrm{~mm}$ thick. The upper portion contains the microvessels which feed the epidermis. These groupings of microvessels exist as independent adjacent tufts. In pigs, there are approximately 172 tufts per $\mathrm{cm}$, with each tuft containing an average of 17 lumina, each approximately $5 \mu \mathrm{m}$ in diameter. Below the papillary plexus is the rete dermis, which contains the microvessels, collagen bundles, and fibroblasts (see Figure 5.75).

Archambeau and colleagues have described the skin functional unit (FU) as the "...smallest unit of skin that retains all the characteristics of skin (a unit of skin structure), which consists of a micro vessel with associated epidermis and dermis" (Archambeau and Shymko, 1988). The dimensions of the FU are described as a $30-\mu \mathrm{m}$ diameter core, with a length of approximately 


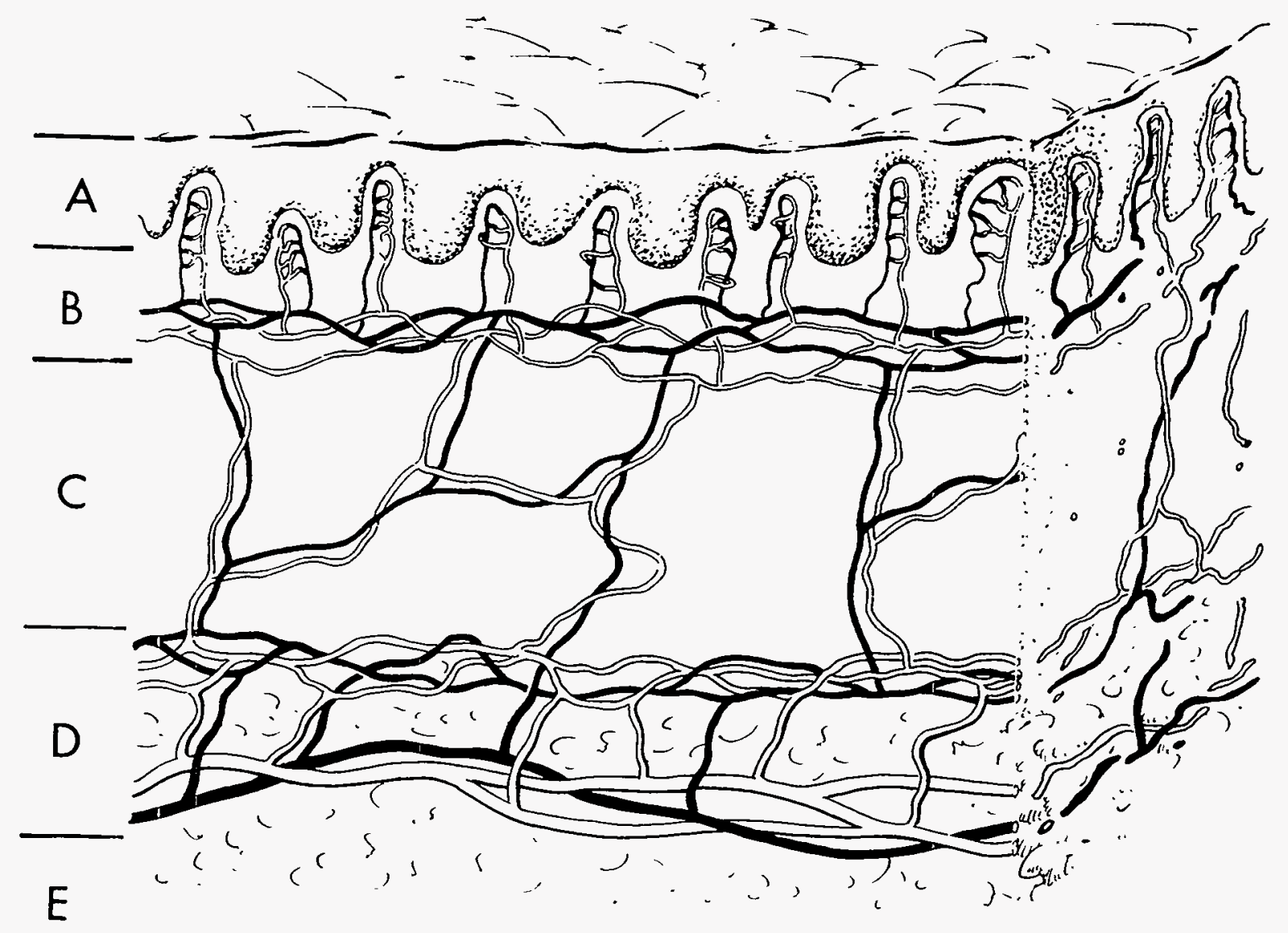

Figure 2.1 Schematic drawing of the skin showing the epidermal, dermal, and subcutaneous layers and emphasizing the critical microvascular components. The part labeled " $A$ " is the epidermis. The rete pegs, which are prolongations of the rete mucosum, are seen as projections from the epidermis into the dermis. The basal cells occur in the area of the interface between the epidermis and the dermis. " $B$ " is the papillary dermis containing microvessel tufts arising from the papillary plexus. " $\mathrm{C}$ " is the rete dermis with arcuate vessels connecting the subdermal and the papillary plexus. " $D$ " is the dermal subcutaneous junction with the dermal plexus. " $E$ " is the subcutaneous layer (from Archambeau et al., 1995). 
Radiobiology of Skin

$350 \mu \mathrm{m}$. In pigs, there are an estimated $30,000 \mathrm{FUs} / \mathrm{cm}^{2}$, with an associated 135 basal cells overlaying a microvessel tuft $80-150 \mu \mathrm{m}$ long.

Detailed descriptions of the structure of the swine skin were also given by Smith and Calhoun (1964), Marcarian and Calhoun (1966), Morris and Hopewell (1985); Hopewell (1990); and ICRP Publication 59 (1991a). Forbes (1969) published detailed information on the vascular supply of pig skin.

\subsection{Radiation Effects on Skin}

Injury to the skin was among the earliest reported radiation effects in humans. Physicists and physicians alike recognized that skin tolerance to radiation was a limiting factor in using $X$ rays and radium both in research and medicine. Much of the work on early radiation effects on skin was reviewed by Lacassagne and Gricouroff (1956), and later by Rubin and Casarett (1968).

More recently, in several papers, Archambeau and his co-workers $(1969,1979,1984,1985$, 1988, 1995); Archambeau and Bennett (1984); Archambeau (1987); Archambeau and Shymko (1988); Hopewell and colleagues (1978, 1979, 1986); Hopewell and Young (1982), Hopewell (1983, 1986, 1990, 1991); Hopewell and Van den Aardweg (1986, 1991); Morris (1987), Morris and Hopewell $(1986,1987,1988,1989)$; Morris et al. (1987); and Peel et al. (1985) have described the morphology of the normal skin and the mechanistic radiobiology of skin damage for both human- and pig-skin models. Pig skin historically has been used to model that of human skin and radiation effects on pig skin can be extrapolated to human skin with a large degree of confidence (Hall, 1988).

In assessing the effects of ionizing radiation on the skin, several of the following factors must be considered:

1. The size of the area exposed,

2. The time of onset of the effect,

3. The type of effect seen, and

4. The mechanisms eliciting the effect.

Considering first the size of the area involved. When the area irradiated is larger than $1 \mathrm{~cm}^{2}$, the acute deterministic effects are characterized by a transient erythema (or, in some cases, a more prolonged erythema), and dry and moist desquamation. These effects are caused by a decrease in the proliferation of the epithelial basal cells. In some cases, the ultimate outcome may be a persistent, moist desquamation leading to secondary ulceration with loss of dermal tissue. This may be followed by apparent healing through invasive fibrosis.

Late nonstochastic effects may be induced without acute changes appearing, most often when large skin areas receive protracted irradiation. Among the changes is fibrosis of the dermis and 


\section{Radiobiology of Skin}

its atrophy, including that of the hair follicles, sebaceous and sweat glands. These changes may be evidenced by a thinning of the dermis resulting in injury-prone tissue.

For areas larger than $1 \mathrm{~cm}^{2}$, faint erythema is usually produced by approximately $8-10 \mathrm{~Gy}$ exposures at 70- $\mu \mathrm{m}$ depth. Ulceration requires doses in the 20-25 Gy range (NCRP, 1989).

The effects and recovery from hot particle exposures of the skin are not comparable to those described above for large area irradiations. When small tissue areas are irradiated by hot particles, migration of basal cells into the areas of damage may prevent moist desquamation. Necrosis or acute ulceration may appear after high exposures to hot-particle radiations, as opposed to large area exposures, where the injury to the basal cells is the primary cause of the effect of hot particles. These effects generally occur in 7-14 days, somewhat earlier than seen with large-area radiation exposures. The early onset has been attributed by Hopewell to the characteristics of cell death during interphase (Hopewell 1986, as noted in NCRP Report 106, 1989).

In addition to the nonstochastic effects of radiation, skin exposure carries with it risk of stochastic effects. The types of skin cancer of major interest are squamous-cell carcinoma and basal-cell carcinoma; the latter is almost never metastatic or fatal. The estimated mortality in the general population for squamous-cell carcinoma is approximately 1\% (Dunn et al., 1965; Epstein et al., 1968; Giles et al., 1988).

More recently, several epidemiology studies have investigated the effect of ionizing radiation on skin cancer incidence. The risks can be calculated from the results of studies by Sevcova et al. (1978, 1984); Van Dahl et al. (1983); Hay et al. (1984); Shore et al. (1984, 1986); Boice et al. (1985); Hildreth et al. (1985); Schneider et al. (1986); Davis et al. (1987); Van Vloten et al. (1987); Ron et al. (1988); and Hrubec et al. (1989).

In its Publication 59, the ICRP (1991a) derived a fatal cancer risk of $2 \times 10^{-4} \mathrm{~Sv}^{-1}$. This derivation was based on a number of assumptions, including a relative-risk projection model, a population of both sexes aged 18-64 years, and that $3,000 \mathrm{~cm}^{2}$ of the total skin is exposed to ultraviolet radiation (UVR), while $15,000 \mathrm{~cm}^{2}$ is shielded from UVR. Ultraviolet-exposed skin has been shown in ICRP Publication 59 to be three to four times more sensitive to the induction of skin cancer.

Using a fatal cancer risk estimate of $2 \times 10^{-4} \mathrm{~Sv}^{-1}\left(2 \times 10^{-6} \mathrm{rem}^{-1}\right)$ for exposure of the skin of the whole body, it can be shown that irradiation of small areas (much less than $1 \mathrm{~cm}^{2}$ ) leads to a risk estimate of less than $1 \times 10^{-8} \mathrm{~Sv}^{-1}\left(1 \times 10^{-10} \mathrm{rem}^{-1}\right)$. This analysis suggests that the skin cancer risk is insignificant, even at the level of several hundred sieverts when deterministic effects such as transient erythemas, scab formation, and severe ulceration occur. 


\section{GENERAL EXPERIMENTAL PROTOCOL}

\subsection{Particle Sizes and Isotopes Used}

BNL investigators used four different types of hot particles for irradiating pigs' skin: fissioned 93\%-enriched $\mathrm{UC}_{2}, \mathrm{Tm}-170, \mathrm{Yb}-175$, and Sc-46 (Table 3.1). The Tm-170 and $\mathrm{Yb}-175$ sources were primarily beta emitters, and the fissioned $\mathrm{UC}_{2}$ and $\mathrm{Sc}-46$ were both beta and photon emitters.

Table 3.1 Isotopic information for particles used in the BNL pig irradiations ${ }^{a, b, c}$

\begin{tabular}{|c|c|c|c|c|c|c|c|}
\hline Isotope & $\begin{array}{c}\text { Half-life } \\
\text { (days) }\end{array}$ & $\begin{array}{c}\text { Maximum } \\
\beta \text { energy } \\
(\mathrm{MeV})\end{array}$ & $\begin{array}{c}\text { Average } \\
\beta \text { energy } \\
\text { (MeV) }\end{array}$ & $\begin{array}{c}\beta \\
\text { abundance } \\
(\%)\end{array}$ & $\begin{array}{c}90 \% \beta \\
\text { particle } \\
\text { range in } \\
\text { water }^{c} \\
(\mathrm{~mm})\end{array}$ & $\begin{array}{c}Y \\
\text { energy } \\
(\mathrm{MeV})\end{array}$ & $\begin{array}{c}Y \\
\text { abundance } \\
(\%)\end{array}$ \\
\hline $\begin{array}{l}\text { Fissioned } \\
\mathrm{UC}_{2}\end{array}$ & varies & $\begin{array}{c}\sim 1.5-2.1 \\
\text { (average) }\end{array}$ & 0.71 & $\sim 100$ & 5.2 & $\sim 1$ & $\sim 100$ \\
\hline Tm-170 & 129 & $\begin{array}{l}0.97 \\
0.88\end{array}$ & 0.31 & $\begin{array}{l}76 \\
24\end{array}$ & 1.6 & 0.084 & 3.25 \\
\hline$Y b-175$ & 4.2 & $\begin{array}{c}0.466 \\
0.35 \\
0.073\end{array}$ & 0.125 & $\begin{array}{l}86 \\
3.3 \\
10\end{array}$ & 0.55 & $\begin{array}{l}0.396 \\
0.282 \\
0.114\end{array}$ & $\begin{array}{c}6.5 \\
3.05 \\
1.9\end{array}$ \\
\hline Sc-46 & 83.8 & 0.35 & 0.112 & 100 & 0.37 & $\begin{array}{c}0.889 \\
\cdot 1.12\end{array}$ & $\begin{array}{l}100 \\
100\end{array}$ \\
\hline
\end{tabular}
a. Weast, 1976.
b. Jarvis et al., 1996.
c. Durham, 1992.

\subsection{1 $\mathrm{UC}_{2}$}

Activated $\mathrm{UC}_{2}$ particles contain a mixture of many fission products. The average maximum energy (of the composite weighted energy spectra) of the $U C_{2}$ beta particles varies with time after neutron bombardment. The calculated average of the maximum energies of the beta particles used for irradiations on $7 / 2 / 91,8 / 26 / 91$, and $2 / 7 / 95$ were between 1.9 and $1.6 \mathrm{MeV}$, based on data of Ulberg and Kochendorfer (1966). The average maximum energies of the beta particles were about $10 \%$ higher and lower for dosimetry measurements before and after the pig irradiations, respectively. Fissioned $\mathrm{UC}_{2}$ also has a gamma component of approximately $1 \mathrm{MeV}$ per disintegration. 


\section{General Experimental Protocol}

The $\mathrm{UC}_{2}$ particles were spherical, with manufacturer specifications of a $252 \mu \mathrm{m}$ average kernel diameter with an average density of $11.24 \mathrm{~g} \mathrm{~cm}^{-3}$. The particles were coated with an $18.5 \mu \mathrm{m}$, $1.82 \mathrm{~g} \mathrm{~cm}^{-3}$ pyrolytic graphite coating. The uranium content was not measured for the first $\mathrm{UC}_{2}$ irradiation, but was carried out for the two subsequent ones. Measurements were made using a germanium lithium drifted detector and multichannel analyzer system. A standard, consisting of a thin layer of $91 \mathrm{mg}$ of natural uranium powder $\left(\mathrm{U}_{3} \mathrm{O}_{8}\right)$, was placed in the bottom of a polyethylene vial and sealed with a thin layer of epoxy. The nonactivated $U_{2}$ particles were individually placed in a similar polyethylene vial and counted using the identical geometry as for the $\mathrm{U}_{3} \mathrm{O}_{8}$ standard. The inner and outer diameters of the polyethylene vial were $0.9 \mathrm{~cm}$ and 1.1 $\mathrm{cm}$, respectively, its base thickness was $1 \mathrm{~mm}$, and its height was $2.5 \mathrm{~cm}$. The diameter of the solid-state detector was $7 \mathrm{~cm}$ and it was protected with a $1-\mathrm{mm}$ thick Lucite cover to prevent its becoming contaminated. The distance from the detector cover to the sensitive area was $5 \mathrm{~mm}$. The solid angle subtended by the detector and $\mathrm{U}_{3} \mathrm{O}_{8}$ powder standard was 5.10 steradians, and 5.27 steradians with the $260 \mu \mathrm{m}$ diameter $\mathrm{UC}_{2}$ kernel. Thus, the geometries of the $\mathrm{U}_{3} \mathrm{O}_{8}$ standard and the $U_{2}$ particle were similar (within $3 \%$ ), such that the $U-235$ content could be determined accurately. The sizes of the $\mathrm{UC}_{2}$ particles were calculated from the measured uranium content, assuming a kernel density of $11.24 \mathrm{~g} / \mathrm{cc}$. The $18.5-\mu \mathrm{m}$ thick pyrolytic coating must be added to the values listed in Table 3.3 to obtain the particles' diameter. Table 3.2 and Table 3.3 give the results of the measurements and the calculations of kernel size.

The mass of the $\mathrm{UC}_{2}$ particle determined by comparison to the standard source using the $145 \mathrm{keV}$ photon peak was $20 \%$ less than that determined using the $185 \mathrm{keV}$ photon peak. Because of the lower photon abundance of the $145 \mathrm{keV}$ peak, the $185 \mathrm{keV}$ measurements are believed to be more accurate.

The half-life of the fissioned $\mathrm{UC}_{2}$ varies with age after activation. As an estimate, for particles activated for times that are short compared to the time after activation, the half-life is approximately equal to the amount of time the $U-235$ has been out of the reactor (derived from equation 3.1 below). Due to this short half-life, new $\cup_{2}$ particles had to be irradiated on the day of the experiment.

The activity of fissioned U-235 varies with time as given by Cember (1983) in Equation 3.1

$$
A=3.81 \times 10^{-6} T^{-1.2}
$$

where

$$
\begin{aligned}
& A=\text { the activity per fission }(B q), \\
& T=\text { the time after the fission (days). }
\end{aligned}
$$

To obtain the activity from fissions occurring over a period rather than in an instantaneous burst, Equation 3.1 is integrated to obtain 
Table 3.2 Efficiency measurement for the natural uranium $\mathrm{O}_{3} \mathrm{O}_{8}$ standard

\begin{tabular}{|c|c|c|c|c|c|c|c|c|c|c|}
\hline $\begin{array}{l}\text { Date } \\
\text { of } \\
\text { count }\end{array}$ & $\begin{array}{c}\mathrm{U}_{3} \mathrm{O}_{8} \\
\text { standard } \\
\text { count } \\
\text { time } \\
\text { (min) }\end{array}$ & $\begin{array}{l}\text { Gross } \\
\text { U-235 } \\
\text { standard } \\
185 \text { keV } \\
\text { (counts) }\end{array}$ & $\begin{array}{l}\text { Gross } \\
\text { U-235 } \\
\text { standard } \\
145 \mathrm{keV} \\
\text { (counts) }\end{array}$ & $\begin{array}{c}P^{a} \\
\text { background } \\
\text { count time } \\
\text { (min) }\end{array}$ & $\begin{array}{c}P^{a} \\
\text { background } \\
185 \mathrm{keV} \\
\text { (counts) }\end{array}$ & $\begin{array}{c}\text { PE }^{2} \\
\text { background } \\
145 \mathrm{keV} \\
\text { (counts) }\end{array}$ & $\begin{array}{l}\text { Net U-235 } \\
\text { standard } \\
185 \mathrm{keV} \\
\text { count rate } \\
\text { (counts/s) }\end{array}$ & $\begin{array}{l}\text { Net U-235 } \\
\text { standard } \\
145 \mathrm{keV} \\
\text { count rate } \\
\text { (counts/s) }\end{array}$ & $\begin{array}{l}\text { Efficiency } \\
185 \mathrm{keV} \\
(\%)\end{array}$ & $\begin{array}{c}\text { Efficiency } \\
145 \mathrm{keV} \\
(\%)\end{array}$ \\
\hline $07-17-91$ & 20 & 4.1E+03 & & $2.0 E+01$ & $4.8 \mathrm{E}+01$ & & 3.4 & & 14 & \\
\hline $07-29-91$ & 40 & $4.8 E+04$ & & $2.4 \mathrm{E}+02$ & $6.6 E+02$ & & 3.3 & & 14 & \\
\hline $08-07-91$ & 697 & $1.4 \mathrm{E}+05$ & & $2.4 E+02$ & $7.0 \mathrm{E}+02$ & & 3.4 & & 14 & \\
\hline $08-22-91$ & 132 & $2.6 \mathrm{E}+04$ & & $1.2 \mathrm{E}+02$ & $2.6 \mathrm{E}+02$ & & 3.2 & & 14 & \\
\hline 01-19-95 & 120 & 2.7E+04 & $9.3 E+03$ & $9.6 E+02$ & $1.4 \mathrm{E}+04$ & $1.2 \mathrm{E}+04$ & 3.5 & 1.1 & 15 & 22 \\
\hline $01-23-95$ & 120 & $2.7 E+04$ & $9.5 E+03$ & $9.6 \mathrm{E}+02$ & $1.4 E+04$ & $1.2 \mathrm{E}+04$ & 3.6 & 1.1 & 15 & 23 \\
\hline
\end{tabular}

a. Refers to polyethylene vial.

$\stackrel{\omega}{\omega}$

Table 3.3 Activity measurements of the $93 \%$ enriched ${ }^{235} \mathrm{UC}$ sources ${ }^{\mathrm{a}}$

\begin{tabular}{|c|c|c|c|c|c|c|c|c|c|c|c|c|}
\hline $\begin{array}{l}\text { Date } \\
\text { of count }\end{array}$ & $\begin{array}{l}\text { Particle } \\
\text { number }\end{array}$ & $\begin{array}{c}\mathrm{UC}_{2} \\
\text { particle } \\
\text { count } \\
\text { time } \\
\text { (min) }\end{array}$ & $\begin{array}{c}\text { Gross } \\
\text { U-235 } \\
\text { enriched } \\
185 \text { keV } \\
\text { (counts) }\end{array}$ & $\begin{array}{l}\text { Bkgd } \\
\text { count } \\
\text { time } \\
\text { (min) }\end{array}$ & $\begin{array}{c}\text { Bkgd } \\
185 \mathrm{keV} \\
\text { (counts) }\end{array}$ & $\begin{array}{c}\text { Net } U_{2} \\
\text { particle } \\
185 \mathrm{keV} \\
\text { count rate } \\
\text { (cnts/s) }\end{array}$ & $\begin{array}{l}\text { U-235 act. } \\
\text { in enriched } \\
185 \mathrm{keV} \\
(\mathrm{Bq})\end{array}$ & $\begin{array}{l}\text { Measured } \\
\mathrm{U}-235 \text { mass } \\
\text { in particle } \\
185 \mathrm{keV}(\mathrm{g})\end{array}$ & $\begin{array}{l}185 \mathrm{keV} \text { total } \\
\mathrm{U} \text { mass } \\
\text { w/93\% } \\
\text { enrich }(\mathrm{g})\end{array}$ & $\begin{array}{l}\text { Mass } \\
\mathrm{UC}_{2}(\mathrm{~g})\end{array}$ & $\begin{array}{c}\mathrm{UC}_{2} \\
\text { kernel } \\
\text { diameter } \\
(\boldsymbol{\mu m})\end{array}$ & $\begin{array}{c}\text { Date } \\
\text { Irradlated }\end{array}$ \\
\hline $7-17-91$ & all 43 & 20 & $2.3 E+04$ & 20 & $4.8 \mathrm{E}+01$ & 19 & 246 & 3.2E-03 & $3.4 \mathrm{E}-03$ & $3.8 \mathrm{E}-03$ & 246 (avg) & \\
\hline $8-07-91$ & 10 & 15 & $3.9 E+02$ & 240 & $7.0 \mathrm{E}+02$ & 0.38 & 5.0 & $6.4 \mathrm{E}-05$ & 6.9E-05 & 7.6E-05 & 235 & $8-26-91$ \\
\hline $8-07-91$ & 11 & 15 & $4.1 \mathrm{E}+02$ & 240 & $7.0 \mathrm{E}+02$ & 0.41 & 5.3 & $6.9 \mathrm{E}-05$ & 7.5E-05 & 8.2E-05 & 241 & $8-26-91$ \\
\hline $1-20-95$ & 25 & 120 & $5.5 E+03$ & 960 & $1.4 \mathrm{E}+04$ & 0.53 & 6.7 & 8.4E-05 & 9.1E-05 & $1.0 \mathrm{E}-04$ & 257 & $2-7-95$ \\
\hline $1-20-95$ & 26 & 120 & $5.5 E+03$ & 960 & $1.4 \mathrm{E}+04$ & 0.53 & 6.7 & 8.5E-05 & $9.1 E-05$ & 1.0E-04 & 257 & $2-7-95$ \\
\hline
\end{tabular}




\section{General Experimental Protocol}

$$
A=\frac{c f}{0.2}\left[T^{-0.2}-\left(t_{l}+T\right)^{-0.2}\right]
$$

where

$$
\begin{aligned}
& c=3.81 \times 10^{-6} \mathrm{~Bq}, \\
& f=\text { number of fissions in one day in the } \mathrm{UC}_{2} \text { particle, } \\
& T=\text { time after the activation (days) } \\
& t_{\mathrm{i}}=\text { irradiation time (days). }
\end{aligned}
$$

The expected number of fissions, $f$, were calculated by

$$
f=n \sigma \phi
$$

where

$$
\begin{aligned}
& n=\text { number of } U-235 \text { atoms in the particle, } \\
& \sigma=\text { thermal neutron cross-section of } U-235=580 \text { barns, } \\
& \phi=\text { thermal neutron fluence rate (neutrons } \mathrm{cm}^{-2} \text { day }^{-1} \text { ). }
\end{aligned}
$$

The expected number of disintegrations in the particle over the period that the source is placed on the pig or on the dosimetry medium, $U$, is determined by integrating Equation 3.2 to obtain

$$
U=2.06 f\left[T_{\theta}^{0.8}-T_{b}^{0.8}-\left(T_{\theta}+t_{i}\right)^{0.8}+\left(T_{b}+t_{i}\right)^{0.8}\right]
$$

where

$$
\begin{aligned}
& T_{e}=\text { end of placement time (days), } \\
& T_{b}=\text { beginning of placement time (days). }
\end{aligned}
$$

There is less than $10 \%$ difference in the "point" dose deposition per particle for beta particle energies between 1.6 and $1.9 \mathrm{MeV}$ for tissue depths ranging from 30 to 1,000 $\mu \mathrm{m}$ (NCRP 1989, Figure 4.1). A dose-per-disintegration factor was calculated from source dosimetry and Equation 3.4. Dosimetry measurements were carried out before and after irradiating the pig to verify that there was negligible change in the dose-per-disintegration factor.

The calculated number of disintegrations in the particle may not give an accurate absolute estimate of its activity. However, Equations 3.1 to 3.4 will give an accurate estimate of the relative activity. As an example, the measured dose rate to $70 \mu \mathrm{m}$ averaged over $1 \mathrm{~cm}^{2}$ for the on-skin $\mathrm{UC}_{2}$ morning dosimetry for the exposures was 0.49 Gy per $\mathrm{s}$. The dose to $70 \mu \mathrm{m}$ averaged over $1 \mathrm{~cm}^{2}$ in the evening after the animal exposures was 0.10 Gy per $\mathrm{s}$, a factor of five lower than the morning dosimetry. However, the dose per calculated disintegration (from Equation 3.4) for the evening dosimetry was $11 \%$ more than that of the morning. This slight 
increase is to be expected from the lower beta particle energies, which have higher LET in the evening (1.6 MeV average maximum beta-particle energy in the evening as compared with 2.0 $\mathrm{MeV}$ average maximum beta-particle energy in the morning). The average of the morning and evening dose-per-disintegration factors was used to determine dose for each area exposed.

\subsubsection{Tm-170}

The maximum energies of the beta particles from $\mathrm{Tm}-170$ are 0.97 and $0.88 \mathrm{MeV}$, which have abundances of 76 and $24 \%$, respectively. Tm-170 has a half-life of 129 days, allowing the same particles to be used for multiple experiments with appropriate corrections for decay. The average beta-particle energy is $0.31 \mathrm{MeV}$ as determined from the computer code DEXRAX Version 2.0 (Eckerman et al., 1994). The distributions employed in this code are illustrated in Figure 3.1. The photon abundances are negligible (Table 3.1).

The Tm particles were cut from a foil of $258-\mu \mathrm{m}$ thickness, measured with a micrometer. The density of the foil was $9.4 \mathrm{~g} / \mathrm{cc}$. The masses of the particles were determined using a microbalance. The shape of these sources approximated that of a three-dimensional trapezoid (Figure 3.2); their dimensions were measured under a microscope.

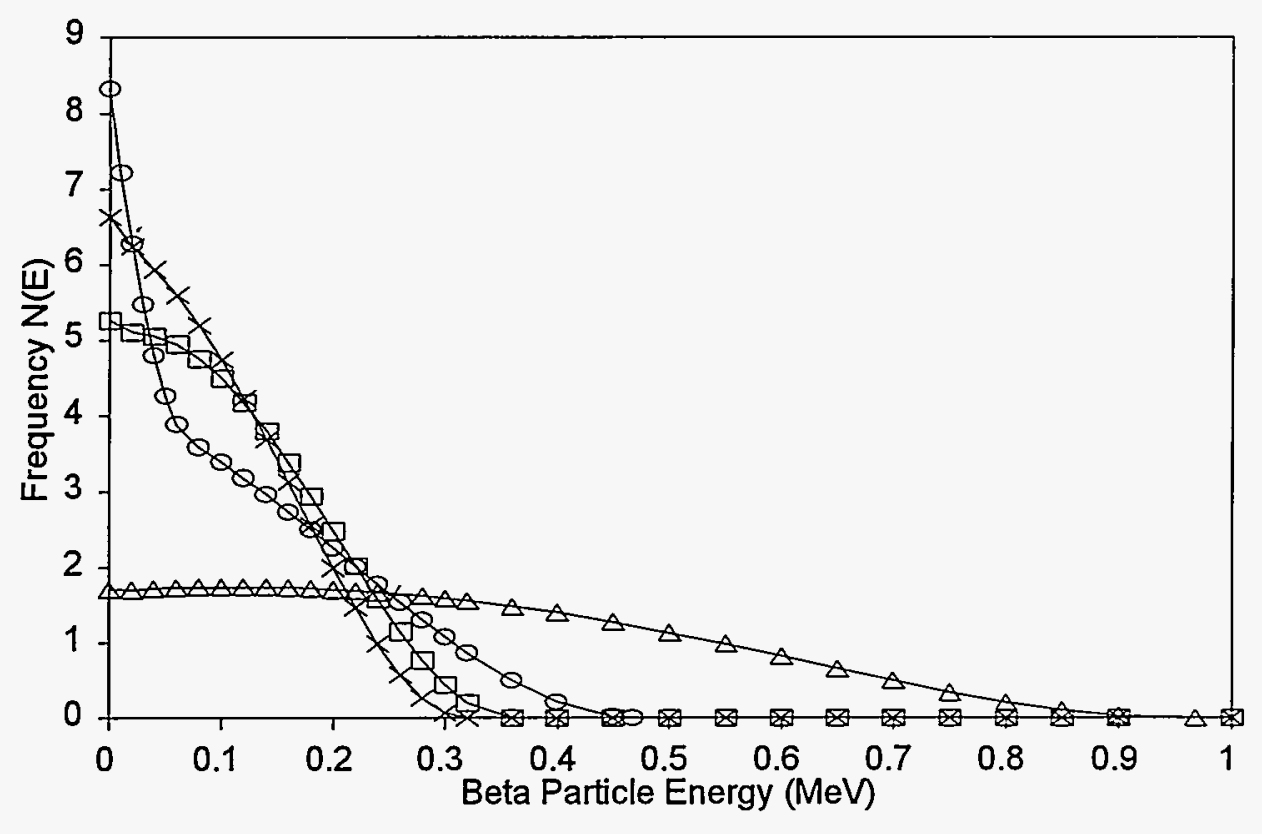

$$
\triangle-\mathrm{Tm}-170 \frown \mathrm{Yb}-175 \curvearrowleft \mathrm{Sc}-46 \quad \leftarrow \mathrm{Co}-60
$$

Figure 3.1 Beta particle energy spectra determined from DEXRAX Version 2.0 (Eckerman et al., 1994). The area under each curve is equal to one. Data were provided by Keith Eckerman. 


\section{General Experimental Protocol}

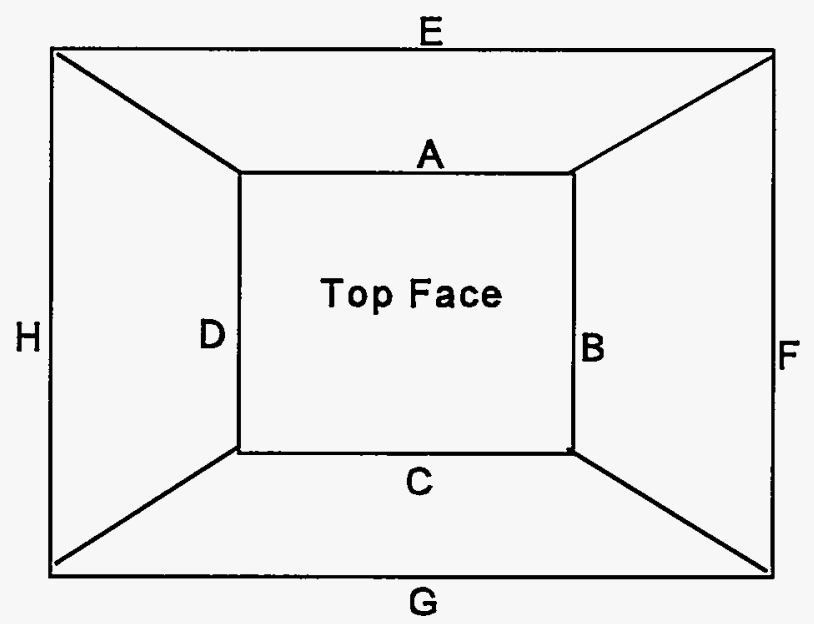

Figure 3.2 The shape of the Tm-170, Yb-175, and $\mathrm{Sc}-46$ sources approximated that of a three-dimensional trapezoid. The length of each edge (not shown to scale), denoted by letters $\mathrm{A}-\mathrm{H}$, is given in Table 3.4. It is not known if the top or bottom face was nearest the dosimeter.

\subsubsection{Yb-175}

The maximum beta-particle energies of $\mathrm{Yb}-175$ are $0.466 \mathrm{MeV}(86 \%), 0.35 \mathrm{MeV}(3.3 \%)$, and $0.073 \mathrm{MeV}(10 \%)$. $\mathrm{Yb}-175$ has a half-life of 4.2 days. $\mathrm{Yb}-177$ is also produced during activation of $\mathrm{Yb}-175$. It has a 1.9 hour half-life and decays to Lu-177, which emits beta particles with maximum energy of $0.497 \mathrm{MeV}(100 \%)$ and has a half-life of 6.74 days. The activity of Lu-177 was less than $5 \%$ of the $\mathrm{Yb}-175$ activity for all irradiations. The radionuclide $\mathrm{Yb}-169$ is also produced and has a half-life of 32.0 days and decays by electron capture. The activity of Yb-169 during the irradiations was about $5 \%$ of the $Y b-175$ activity. While dose contributions from all the activated radionuclides were measured, the $0.466 \mathrm{MeV}$ maximum beta-particle emission predominated, and the source is referred to only as $\mathrm{Yb}-175$ (Table 3.1). The average betaparticle energy is $0.125 \mathrm{MeV}$, as determined from the DEXRAX Version 2.0 code (Eckerman et al., 1994) (Figure 3.1) The short half-life of $\mathrm{Yb}-175$ required new sources to be activated for each experiment.

The $\mathrm{Yb}-175$ particles were cut from a foil $128-\mu \mathrm{m}$ thick, measured with a micrometer. The measured density of the foil was $6.96 \mathrm{~g} / \mathrm{cc}$. Masses of the particles were measured using a microbalance for the 1992 experiment, and calculated from dimensions obtained from microscope measurements in the 1994 experiments (Table 3.4). 
Table 3.4. Characteristics of BNL particles before activation ${ }^{a}$

\begin{tabular}{|c|c|c|c|c|c|c|c|c|c|c|c|c|c|c|c|c|}
\hline \multirow{2}{*}{$\begin{array}{c}\text { Particle } \\
\text { type }\end{array}$} & \multirow{2}{*}{$\begin{array}{l}\text { Particle } \\
\text { number }\end{array}$} & \multirow{2}{*}{$\begin{array}{l}\text { Dates } \\
\text { used }\end{array}$} & \multirow{2}{*}{$\begin{array}{c}\text { Date } \\
\text { activation } \\
\text { started }\end{array}$} & \multirow{2}{*}{$\begin{array}{c}\text { Measured } \\
\text { foil } \\
\text { density }\end{array}$} & \multirow{2}{*}{$\begin{array}{c}\text { Measured } \\
\text { thickness } \\
(\mu \mathrm{m})\end{array}$} & \multirow{2}{*}{$\begin{array}{l}\text { Balance- } \\
\text { measured } \\
\text { mass (mg) }\end{array}$} & \multicolumn{8}{|c|}{ Side $(\mu m)^{a}$} & \multirow{2}{*}{$\begin{array}{c}\text { Calculated } \\
\text { mass from } \\
\text { foil }(\mu \mathrm{g})\end{array}$} & \multirow{2}{*}{$\begin{array}{c}\text { Equivalent } \\
\text { diameter }(\mu \mathrm{m})\end{array}$} \\
\hline & & & & & & & A & B & $\mathrm{C}$ & $D$ & $\mathrm{E}$ & $\mathrm{F}$ & $G$ & $\mathrm{H}$ & & \\
\hline \multirow{5}{*}{$\begin{array}{l}\mathrm{UC}_{2}{ }^{\mathrm{b}} \\
\text { Fissioned } \\
\text { Spheres }\end{array}$} & 1 & 2-Jul-91 & 02-Jul-91 & 8.11 & & & & & & & & & & & & $290^{c}$ \\
\hline & on- $A^{d}$ & 26-Aug-91 & 26-Aug-91 & $8.0 \pm 0.78^{e}$ & & & & & & & & & & & $79 \pm 4.1$ & $270 \pm 4.1$ \\
\hline & off- $A^{\theta}$ & 26-Aug-91 & 26-Aug-91 & $8.0 \pm 0.78^{e}$ & & & & & & & & & & & $79 \pm 4.1$ & $270 \pm 4.1$ \\
\hline & on- $B$ & 7-Feb-95 & 07-Feb 95 & $8.1^{\theta}$ & & & & & & & & & & & 100 & 290 \\
\hline & off-B & 7-Feb-95 & 07-Feb-95 & $8.1^{e}$ & & & & & & & & & & & 100 & 290 \\
\hline \multirow{4}{*}{$\begin{array}{l}\text { Tm-170 } \\
\text { Trapezoid }\end{array}$} & 1 & 8-Nov-91 & 23-Oct-91 & 9.41 & 258 & 0.10 & 170 & 51 & 143 & 92 & & & & & & 120 \\
\hline & 2 & $\begin{array}{l}\text { 8-Nov-91 } \\
27-J a n-92 \\
11-F e b-92 \\
09-M a r-92 \\
10-M a r-92\end{array}$ & 23-Oct-91 & 9.41 & 258 & 0.26 & 46 & 327 & 83 & 336 & & & & & & 160 \\
\hline & 3 & $\begin{array}{l}\text { 8-Nov-91 } \\
\text { 9-Mar-92 } \\
\text { 10-Mar-92 }\end{array}$ & 23-Oct-91 & 9.42 & 258 & 0.22 & 262 & 239 & 248 & 248 & & & & & & 280 \\
\hline & 4 & $\begin{array}{l}\text { 8-Nov-91 } \\
11-F e b-92 \\
9-M a r-92 \\
\text { 10-Mar-92 } \\
\text { 8-Jun-92 }\end{array}$ & 23-Oct-91 & 9.41 & 258 & 0.46 & 446 & 406 & 426 & 386 & & & & & & 470 \\
\hline \multirow{7}{*}{$\begin{array}{l}\text { Yb-175 } \\
\text { Trapezoid }\end{array}$} & $1 \mathrm{~A}$ & 31-Jul-92 & 24-Jul-92 & 6.96 & 130 & 0.09 & 401 & 144 & 361 & 213 & 292 & 332 & 262 & 307 & 70 & 320 \\
\hline & $2 A$ & 31-Jul-92 & 24-Jul-92 & 6.96 & 130 & 0.06 & 149 & 208 & 212 & 248 & 297 & 282 & 301 & 311 & 50 & 270 \\
\hline & $3 A$ & 31-Jul-92 & 24-Jul-92 & 6.96 & 130 & 0.19 & 515 & 454 & 505 & 535 & 337 & 426 & 332 & 415 & 190 & 510 \\
\hline & $18^{f}$ & $\begin{array}{l}25-J u l-94 \\
26-J u l-94\end{array}$ & 14-Jul-94 & 6.96 & 130 & & & & & & & & & & $150 \pm 9.0$ & $460 \pm 13$ \\
\hline & $2 \mathrm{~B}^{\mathrm{e}}$ & 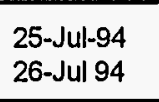 & 14-Jul-94 & 6.96 & 130 & & & & & & & & & & $150 \pm 9.0$ & $460 \pm 13$ \\
\hline & $1 \mathrm{C}^{f}$ & 29-Sep-94 & 23-Sep-94 & 6.96 & 130 & & & & & & & & & & $130 \pm 6.0$ & $440 \pm 10$ \\
\hline & $2 c^{f}$ & 29-Sep-94 & 23-Sep-94 & 6.96 & 130 & & & & & & & & & & $130 \pm 6.0$ & $440 \pm 10$ \\
\hline
\end{tabular}




\begin{tabular}{|c|c|c|c|c|c|c|c|c|c|c|c|c|c|c|c|c|}
\hline \multirow{2}{*}{$\begin{array}{l}\text { Particle } \\
\text { type }\end{array}$} & \multirow{2}{*}{$\begin{array}{l}\text { Particle } \\
\text { number }\end{array}$} & \multirow{2}{*}{$\begin{array}{l}\text { Dates } \\
\text { used }\end{array}$} & \multirow{2}{*}{$\begin{array}{c}\text { Date } \\
\text { activation } \\
\text { started }\end{array}$} & \multirow{2}{*}{$\begin{array}{c}\text { Measured } \\
\text { foil } \\
\text { density } \\
\end{array}$} & \multirow{2}{*}{$\begin{array}{c}\text { Measured } \\
\text { thickness } \\
(\mu \mathrm{m}) \\
\end{array}$} & \multirow{2}{*}{$\begin{array}{l}\text { Balance- } \\
\text { measured } \\
\text { mass (mg) }\end{array}$} & \multicolumn{8}{|c|}{ Side $(\mu \mathrm{m})$} & \multirow{2}{*}{$\begin{array}{l}\text { Calculated } \\
\text { mass from } \\
\text { foil }(\mu \mathrm{g})\end{array}$} & \multirow{2}{*}{$\begin{array}{c}\text { Equivalent } \\
\text { diameter } \\
(\mu \mathrm{m})\end{array}$} \\
\hline & & & & & & & $\mathrm{A}$ & B & C & D & $E$ & $F$ & $G$ & $\mathrm{H}$ & & \\
\hline \multirow[t]{2}{*}{$\begin{array}{l}\text { Sc-46 } \\
\text { Trapezoid }\end{array}$} & $1^{p}$ & $\begin{array}{l}25-J u l-94 \\
1-S e p-94 \\
29-S e p-94\end{array}$ & \multirow[t]{2}{*}{ 28-Jun-94 } & \multirow[t]{2}{*}{2.90} & \multirow[t]{2}{*}{130} & \multirow[t]{2}{*}{0.01} & \multirow{2}{*}{$\begin{array}{l}510 \\
\pm 93\end{array}$} & \multirow{2}{*}{$\begin{array}{l}300 \\
\pm 36\end{array}$} & \multirow{2}{*}{$\begin{array}{l}490 \\
\pm 83\end{array}$} & \multirow{2}{*}{$\begin{array}{l}310 \\
\pm 45\end{array}$} & \multirow{2}{*}{$\begin{array}{l}420 \\
\pm 49\end{array}$} & \multirow{2}{*}{$\begin{array}{l}370 \\
\pm 15\end{array}$} & \multirow{2}{*}{$\begin{array}{l}420 \\
\pm 45\end{array}$} & \multirow{2}{*}{$\begin{array}{l}360 \\
\pm 12\end{array}$} & \multirow[t]{2}{*}{$5.9 \pm 0.39$} & \multirow[t]{2}{*}{$440 \pm 14$} \\
\hline & $2^{f}$ & $\begin{array}{l}\text { 25-Jul-94 } \\
1 \text { 1-Sep-94 }\end{array}$ & & & & & & & & & & & & & & \\
\hline
\end{tabular}

a. The " $\mathrm{A}$ " to " $\mathrm{H}$ " headings refer to the side edges in Figure 3.2.

b. See Section 3.1.1 for a description of the particles and methods of measurement.

c. The dimensions listed were provided by the manufacturers.

d. Two particles with similar sizes were irradiated in the same vial. The quantities given reflect the average and standard deviation for the two particles.

e. Based on an average kernel density and graphite coating thickness and density provided by the manufacturer (Carmen Huckleby for Babcock and Wilcox, personal communication, March 8,1991 ) and measured U-235 content.

f. Three particles with similar sizes were irradiated in the same vial. The quantities given reflect the average and standard deviation for the three particles. 


\subsubsection{Sc-46}

The most commonly occurring hot particle in nuclear power plants is Co-60. However, Sc-46 was used in these studies as a surrogate for Co-60 since the former could be produced with much higher specific activity after only a few days activation in the BNL High Flux Beam Reactor (HFBR). It was important to achieve a high specific activity to permit the use of small particles with low self- absorption of the beta particles emitted to simulate Co-60 particles of less than $100-\mu \mathrm{m}$ diameter. The shorter half-life and lower density of scandium compared to cobalt were critical for this purpose. Table 3.5 summarizes the characteristics of Co-60 and Sc-46.

Table 3.5. Comparison of Co-60 and Sc-46 characteristics ${ }^{a}$

\begin{tabular}{|l|c|c|}
\hline & Co-60 & Sc-46 \\
\hline \hline$\beta$ energy (maximum MeV) & $0.32(99.9 \%)$ & $0.36(100 \%)$ \\
\hline$\gamma$ emissions (MeV) & $1.173(100 \%)$ & $0.889(100 \%)$ \\
& $1.1332(100 \%)$ & $1.12(100 \%)$ \\
\hline$\sigma$ (barns) & $37^{\mathrm{b}}$ & $36^{\mathrm{b}}$ \\
\hline$T_{1 / 2}$ & $5.2 \mathrm{y}$ & $84 \mathrm{~d}$ \\
\hline Density (g/cc) & 8.9 & 3.0 \\
\hline
\end{tabular}

a. Scandium-46 was a practical surrogate for Co- 60 because of its lower self-absorption and higher specific activity for the same neutron activation time.

b. Includes the cross section for activation to a short-lived metastable state that decays by internal transition.

The maximum energy beta particles from Sc-46 are $0.36 \mathrm{MeV}(\sim 100 \%)$ and $1.48 \mathrm{MeV}(0.004 \%)$. Scandium-46 also has accompanying gamma rays of $0.889 \mathrm{MeV}(100 \%)$ and $1.12 \mathrm{MeV}(100 \%)$. The $84 \mathrm{~d}$ half-life of Sc-46 allowed a reasonable activation time, and was long enough to permit experiments several months apart with the same particle. The average beta particle energy is $0.112 \mathrm{MeV}$, which is comparable to the average beta-particle energy of Co-60 (0.096 MeV), as determined from the DEXRAX Version 2.0 code (Eckerman et al., 1994) (Figure 3.1) (Weber et al., 1989).

The importance of using small particles with high specific activity can be illustrated by reference to Table 3.6 which indicates the $\beta / Y$ dose ratios expected from seven $00-60$ particles with right cylindrical shapes (diameter $=$ thickness). The results obtained using the VARSKIN MOD2 code (Durham, 1991) vary from 17 for 20 - $\mu$ m-diameter particles to 0.45 for those of $1-\mathrm{mm}$ diameter. Thus, a 1-mm-diameter particle gives more gamma dose than beta-particle dose when dose is 


\section{General Experimental Protocol}

Table 3.6 Co-60 beta to gamma particle dose ${ }^{2}$ ratios for selected right cylinders calculated using VARSKIN MOD2 (Durham, 1992)

\begin{tabular}{|c|c|}
\hline Disk diameter $(\mu \mathrm{m})$ & $\beta / \mathrm{Y}$ Ratios \\
\hline \hline 20 & 17 \\
\hline 50 & 10 \\
\hline 75 & 7.2 \\
\hline 100 & 5.5 \\
\hline 200 & 2.7 \\
\hline 500 & 1 \\
\hline 1,000 & 0.45 \\
\hline
\end{tabular}

a. Averaged over $1 \mathrm{~cm}^{2}$ at $70-\mu \mathrm{m}$ depth. Co-60 particle on the skin. The density of the Co-60 particles was $8.9 \mathrm{~g} / \mathrm{cc}$. Ratio for $200-\mu \mathrm{m}$ Sc-46 disk covered with $15 \mu \mathrm{m}$ Kapton window = 7.6; with $15 \mu \mathrm{m} \mathrm{Al}$ window, $\beta / Y=6.0$.

averaged over $1 \mathrm{~cm}^{2}$ at $70 \mu \mathrm{m}$ depth. The gamma dose will be much less localized than the beta-particle dose, and therefore, less likely to induce a small ulcer. However, even a 200- $\mu \mathrm{m}$ diameter Sc-46 source of the same geometry, covered with a $15-\mu m$-thick Kapton $\otimes^{1}$ window, has a $\beta / \gamma$ dose ratio of 7.6 ; the same source covered with a $15-\mu m$-thick aluminum foil has a $\beta / \gamma$ dose latio of 6.0 . Thus, this source produces primarily a beta dose with a $\beta / Y$ ratio comparable to a much smaller Co-60 source ( $75 \mu$ m diameter).

The Sc-46 particles were cut from a foil $130-\mu \mathrm{m}$ thick, measured with a micrometer. The measured density of the foil was $2.90 \mathrm{~g} / \mathrm{cc}$. The particle masses were too small to be reasonably measured with a microbalance. Therefore, their particle dimensions were determined under a microscope (Table 3.4), and the masses were calculated from these dimensions and the density of the foil. The $\beta / Y$ dose ratio for the Sc-46 particle used for the experiment was 7.3 , as calculated using VARSKIN MOD2 (Durham, 1991).

\subsection{Source Activation and Mounting}

\subsubsection{Sealing the Particles in Quartz Ampules}

All particles were encapsulated in quartz ampules for activation. The ampules had an inner diameter of $4.4 \mathrm{~mm}$, an outer diameter of $8.6 \mathrm{~mm}$, and were about $3.5 \mathrm{~cm}$ long. The ampules

${ }^{1}$ Kapton is a registered trademark of the Dupont Company. 
were scored to a depth of $500 \mu \mathrm{m}$ around their entire circumference, using a diamond saw at a distance of $2.5 \mathrm{~cm}$ from the base. Before sealing the particles in the quartz ampule, it was tapered about $3.5 \mathrm{~cm}$ from its base so it could be quickly sealed. The inside of the ampule was rinsed with acetone to remove any oil, and then with doubly distilled water to remove any sodium. The inside of the ampule was dried with pressurized air forced through a hypodermic needle. All sources used for each experiment were placed in a single quartz ampule. The quartz ampule was filled with a helium atmosphere and sealed. The helium atmosphere was obtained by repeatedly evacuating the ampule and backfilling it with helium. After the last backfilling, a slight vacuum was applied so the melted quartz would collapse inward during the sealing process, as described next. The tapered portion of the ampule was heated with a natural gas/oxygen flame, and when the quartz was hot enough, a seal was made by pulling the quartz while rotating the top and bottom halves of the ampule in opposite directions. The integrity of the seal was verified by immersing the quartz ampule in doubly distilled water. The outer surface also was rinsed with acetone to remove any oils and sodium from handling.

\subsubsection{Source Activation}

The sources encapsulated in the quartz ampules were given to reactor personnel for activation. The majority of activations were carried out at the BNL HFBR. One Yb-175 source was activated at the University of Missouri Research Reactor (UMRR). Activation times and neutron fluence varied for each experiment (Table 3.7).

Table 3.7 Facilities and conditions used for neutron activation of particles

\begin{tabular}{|c|c|c|c|c|c|c|}
\hline Particle & Facility & $\begin{array}{c}\text { Beam } \\
\text { port }\end{array}$ & $\begin{array}{l}\text { Thermal neutron } \\
\text { fluence rate } \\
\left(\mathrm{cm}^{-2} \mathrm{~s}^{-1}\right)\end{array}$ & $\begin{array}{l}\text { Beginning date } \\
\text { and time }\end{array}$ & $\begin{array}{l}\text { Ending date } \\
\text { and time }\end{array}$ & $\begin{array}{l}\text { Total time, } \\
\text { days } \\
\text { (min) }\end{array}$ \\
\hline \multirow{3}{*}{$\begin{array}{l}\text { Fissioned } \\
\mathrm{UC}_{2}\end{array}$} & \multirow{3}{*}{ BNL HFBR } & $V-11$ & $7.5 \mathrm{E} 13$ & $\begin{array}{c}\text { 02-Jul-91 } \\
07: 15\end{array}$ & $\begin{array}{c}02-J u l-91 \\
07: 38\end{array}$ & $\begin{array}{c}0.016 \\
(23 \mathrm{~min}) \\
\end{array}$ \\
\hline & & $V-14$ & 4.15E14 & $\begin{array}{c}\text { 26-Aug-91 } \\
08: 34\end{array}$ & $\begin{array}{c}\text { 26-Aug-91 } \\
09: 07\end{array}$ & $\begin{array}{c}0.023 \\
(33 \mathrm{~min})\end{array}$ \\
\hline & & $V-14$ & $4.15 \mathrm{E} 14$ & $\begin{array}{c}\text { 07-Feb-95 } \\
07: 57\end{array}$ & $\begin{array}{c}07-F e b-95 \\
08: 30\end{array}$ & $\begin{array}{c}0.023 \\
(33 \mathrm{~min})\end{array}$ \\
\hline Tm-170 & BNL HFBR & $V-14$ & 4.15E14 & $\begin{array}{c}23-O c t-91 \\
13: 49\end{array}$ & $\begin{array}{c}30-O c t-91 \\
09: 38\end{array}$ & 6.8 \\
\hline \multirow{3}{*}{$Y b-175$} & \multirow{2}{*}{ BNL HFBR } & $V-14$ & 4.15E14 & $\begin{array}{c}24-J u l-92 \\
10: 20\end{array}$ & $\begin{array}{c}27-J u l-92 \\
12: 05\end{array}$ & 3.07 \\
\hline & & $V-10$ & $1.35 \mathrm{E} 14$ & $\begin{array}{c}\text { 14-Jul-94 } \\
11: 30\end{array}$ & $\begin{array}{c}\text { 18-Jul-94 } \\
15: 45\end{array}$ & 4.2 \\
\hline & UMRR & $\mathrm{H}-1$ & $8.0 \mathrm{E} 13$ & $\begin{array}{c}\text { 23-Sep-94 } \\
03: 18\end{array}$ & $\begin{array}{c}26-S e p-94 \\
03: 18\end{array}$ & 3.0 \\
\hline \multirow{2}{*}{$S c-46$} & \multirow{2}{*}{ BNL HFBR } & \multirow{2}{*}{$V-14$} & \multirow{2}{*}{ 4.15E14 } & $\begin{array}{c}28-J u n-94 \\
10: 55\end{array}$ & $\begin{array}{c}\text { 02-Jul-94 } \\
14: 10\end{array}$ & \multirow{2}{*}{11.1} \\
\hline & & & & $\begin{array}{c}11-J u l-94 \\
16: 15\end{array}$ & $\begin{array}{c}\text { 18-Jul-94 } \\
15: 35\end{array}$ & \\
\hline
\end{tabular}




\section{General Experimental Protocol}

\subsubsection{Radiation and Contamination Controls During Source Mounting}

The encapsulated sources were shielded in a lead pig after neutron activation. The thickness of the lead varied for each experiment and depended upon the activity of the sources and the photon component. For the earlier experiments (1991-92), the source was mounted in a nonventilated enclosure. For the later experiments (1994-95), a high-efficiency particulate-filtered vented hood was used to minimize the hazards of potential contamination.

A 1-cm-thick plexiglass shield was placed between the sources and the individual who was mounting the sources to absorb the majority of the beta-particle dose. Lead shielding also was used between the experimenter and the particles to minimize gamma dose when working with fissioned $\mathrm{UC}_{2}$ and $\mathrm{Sc}-46$. The sources were manipulated with tongs, $21-\mathrm{cm}$ long, during mounting on exposure blocks.

Protocols were written and practiced before mounting the activated sources. Checklists and radiation work permits were used to verify proper personal dosimetry (film badge, ring dosimeters, self-reading dosimetry), clothing (lab coats, rubber gauntlets, rubber gloves, lead gloves, lead apron, eye protection), and particle transfers. Personnel contamination was checked using portable and portal monitors before and after mounting the sources. The activated sources were transported in a lead pig to the work area. The quartz ampule was removed from the lead pig and examined to make certain that the particles were at the bottom and were not ruptured. The ampule then was placed in a holding jig consisting of an aluminum cylinder about $10 \mathrm{~cm}$ in diameter with an $8.5-\mathrm{mm}$ diameter hole drilled in the center of its top face. The quartz ampule was placed in the hole, which was about $3.25 \mathrm{~cm}$ deep, such that the circumferential scoring on the ampule was flush with the top of the jig. The top $1 \mathrm{~cm}$ of the jig was removable, and was mounted on the bottom half with two pins. A rod with an $8.5-\mathrm{mm}$ hole drilled in it was placed over the portion of the quartz ampule protruding from the jig, and the rod was pulled at an angle to break the ampule. The ampule usually broke cleanly. This operation took place in a plastic bag, to minimize the release of quartz dust, which was radioactive. The top $1 \mathrm{~cm}$ of the aluminum cylinder/jig was then removed, so that the quartz ampule was still positioned upright in its bottom half.

The ampule was then lifted from the jig and the contents poured onto a corner of a tray containing heavy, white-fiber blotting paper. The activated source particles were separated from the quartz fragments with a spatula.

\subsubsection{Source-Mounting Block}

The source-mounting blocks and source geometries were varied for various experiments for reasons given in Section 3.2.5 below. The arrangements for specific experiments are shown in Figures 3.3 to 3.13. The experiment numbers given in the figure captions refer to experiments listed in Table 3.10. The source-mounting block consisted of a Styrofoam $\otimes^{2}$ base, $1.3-\mathrm{cm}$ thick

${ }^{2}$ Styrofoam is a registered trademark for a light, resilient polystyrene plastic. 


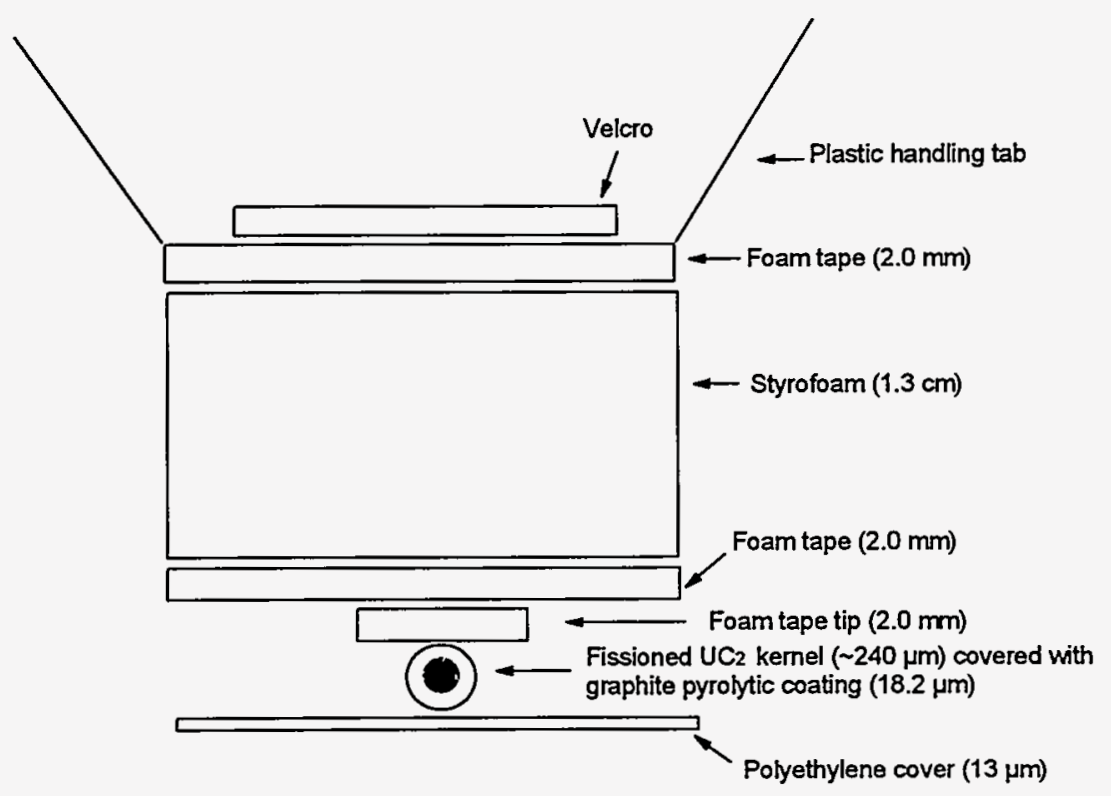

Figure 3.3 On-skin $\mathrm{UC}_{2}$ source placement block used for experiments 1 and 2 . The kernel diameter for experiment 2 was $240 \mu \mathrm{m}$.

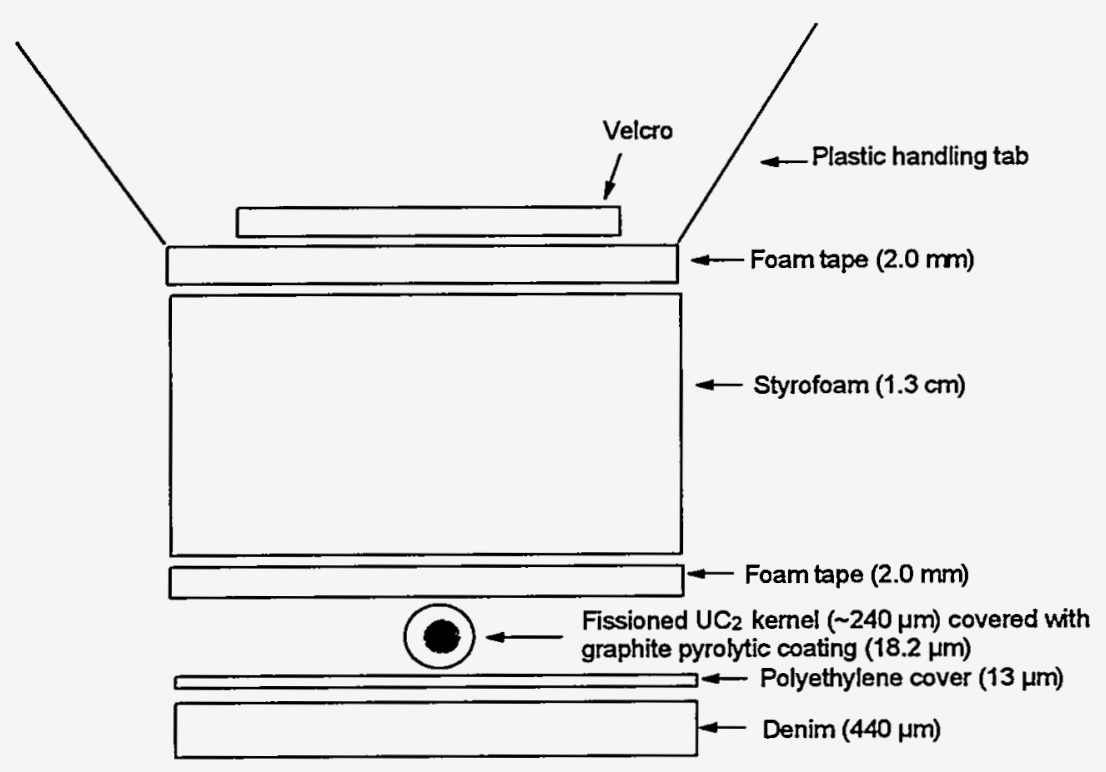

Figure 3.4 Off-skin fissioned $\mathrm{UC}_{2}$ source placement block used for experiment 2. 


\section{General Experimental Protocol}

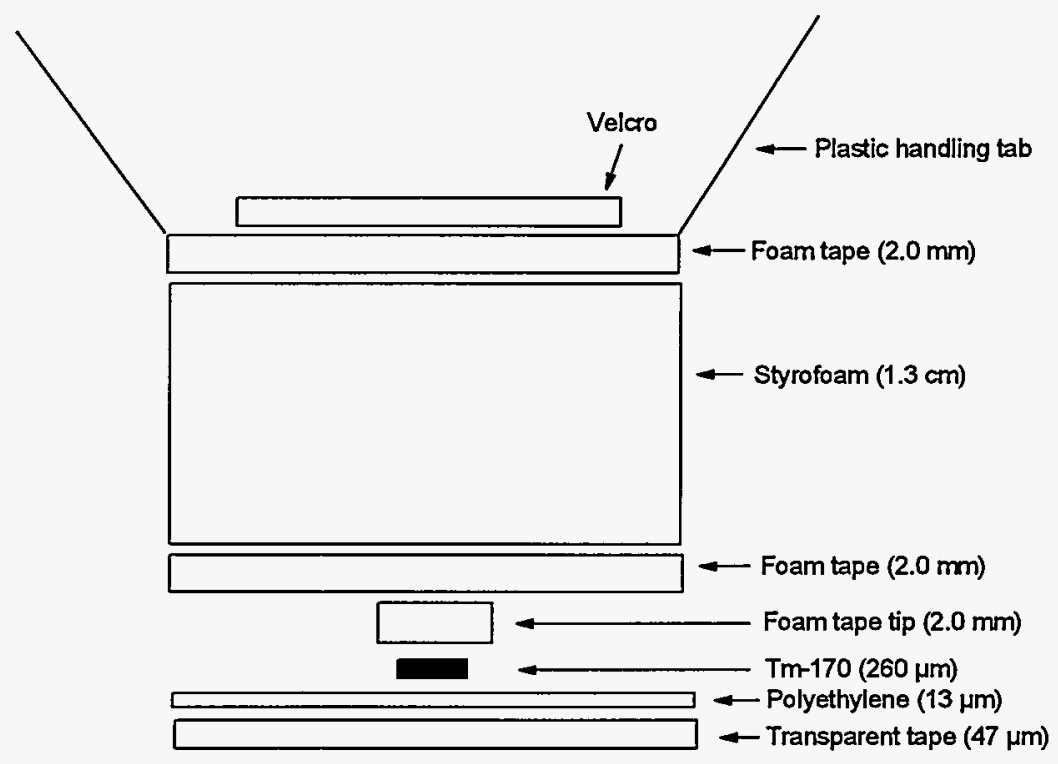

Figure 3.5 On-skin Tm-170 placement block for 120- and 280- $\mu \mathrm{m}$ diameter sources used for experiment 3.

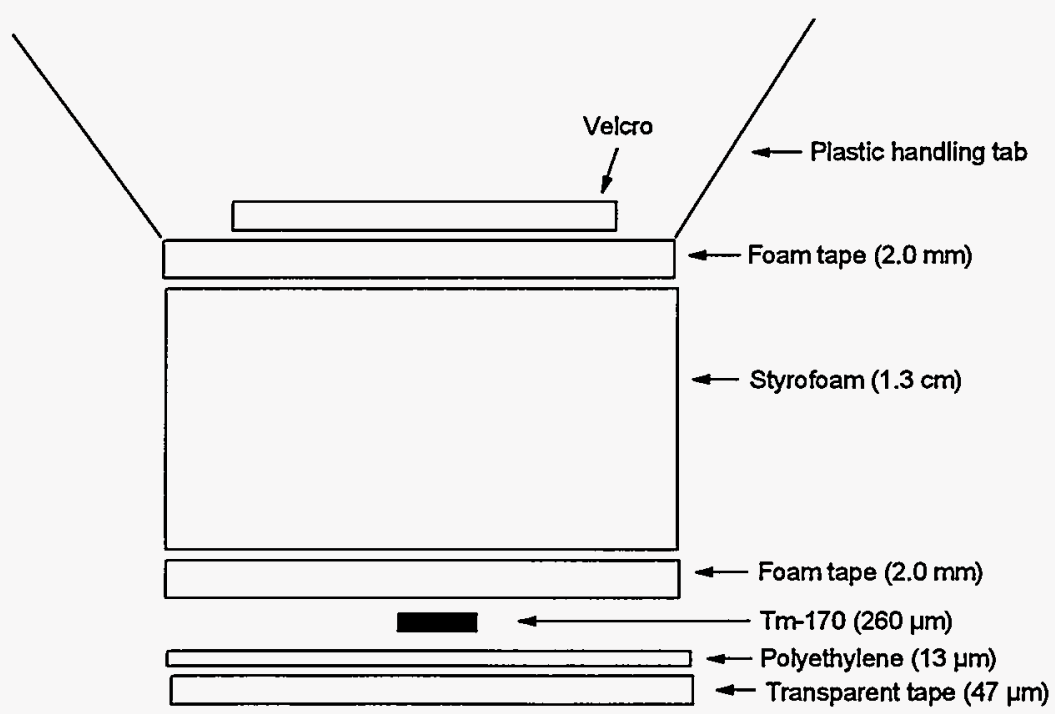

Figure 3.6 On-skin Tm-170 placement block for

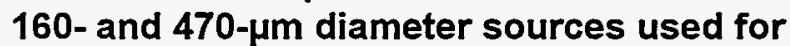
experiment 3. 


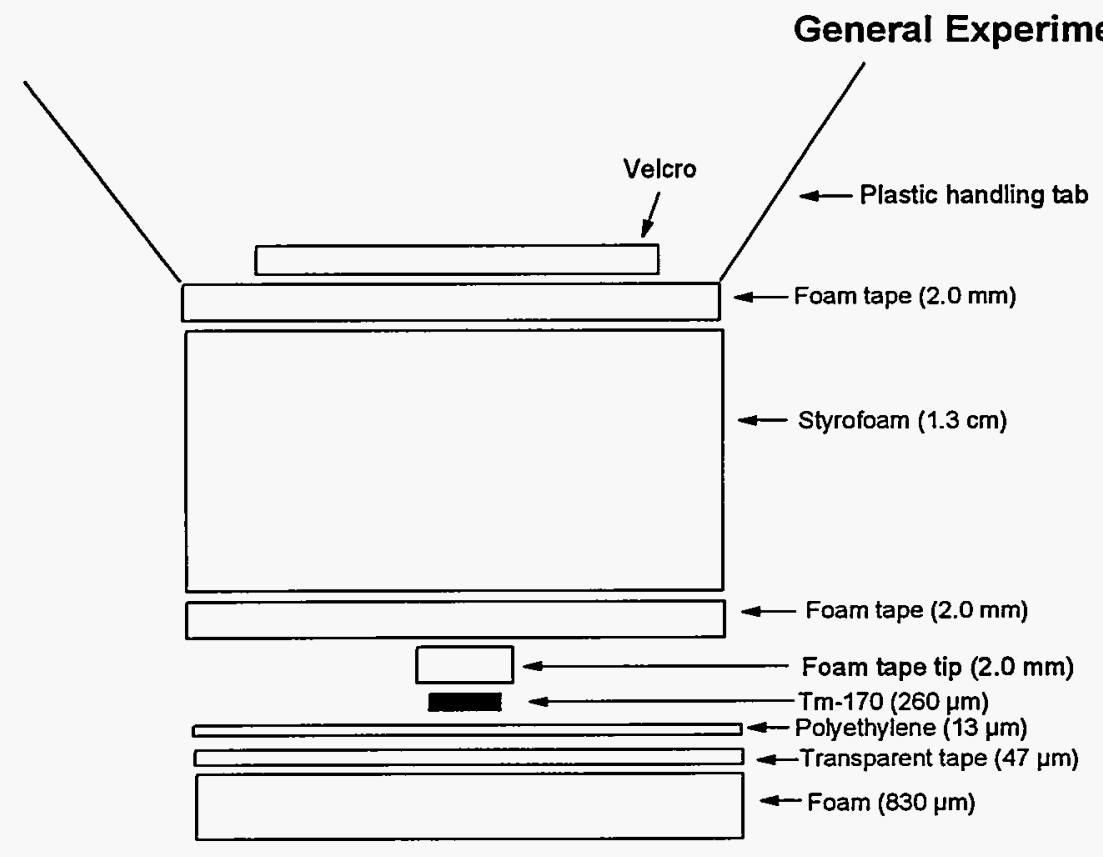

Figure 3.7 Off-skin Tm-170 placement block for 120- and $280-\mu \mathrm{m}$ diameter sources used for experiment 3. The off-skin foam was placed on the animal and the sources were placed on the foam.

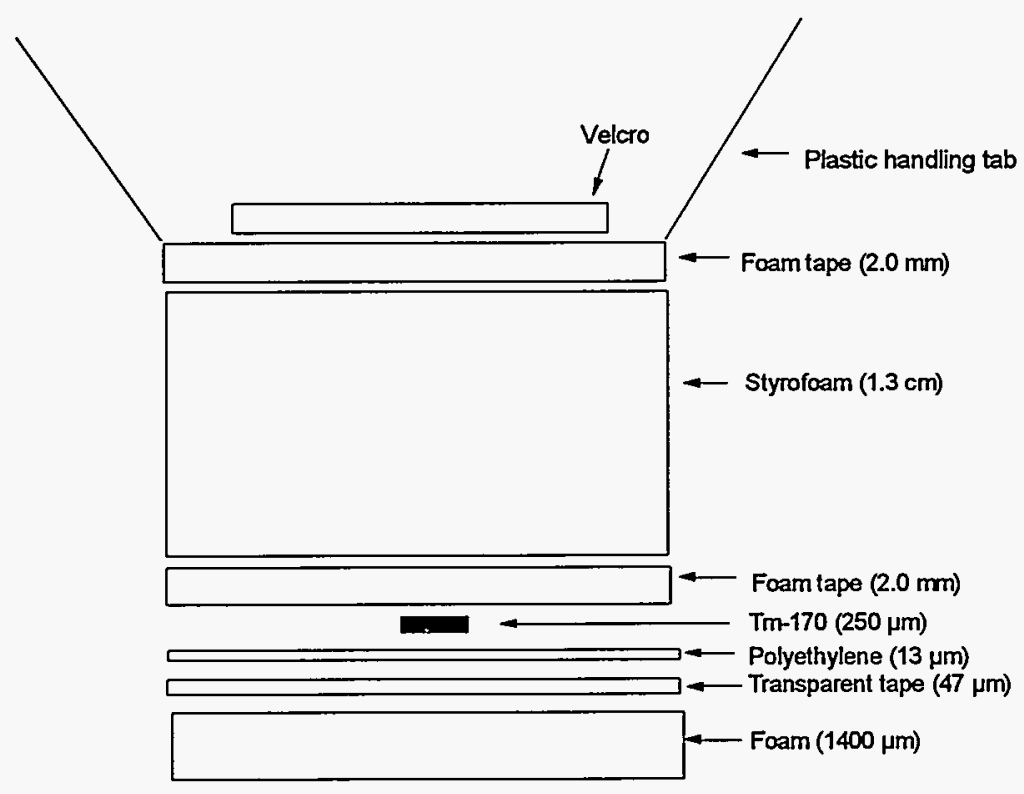

Figure 3.8 Off-skin Tm-170 placement block for 160- and 470-um diameter sources used for experiment 3 . The off-skin foam was placed on the animal and the sources were placed on the foam. 


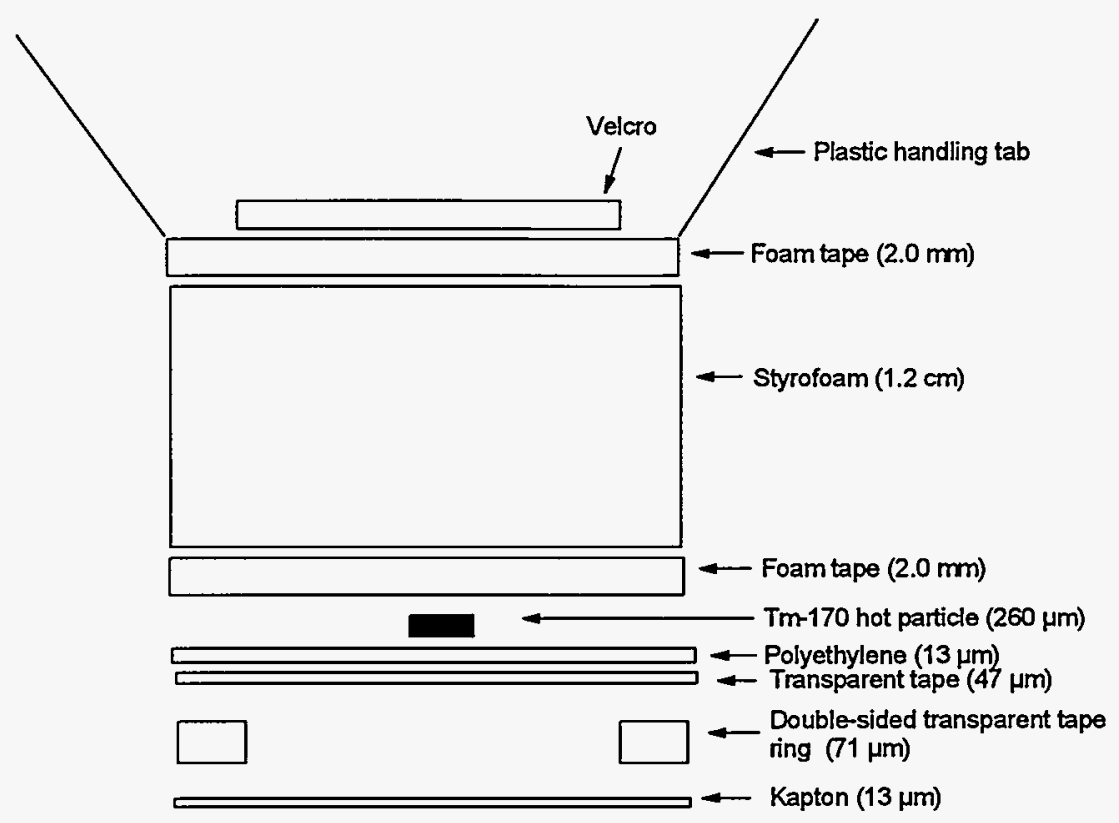

Figure 3.9 Tm-170 placement block for 160- and 470- $\mathrm{Tm}$ diameter $\mathrm{Tm}-170$ sources used for experiments 4 and 5. Only the 160- $\mu \mathrm{m}$ diameter particle was used for experiment 4.

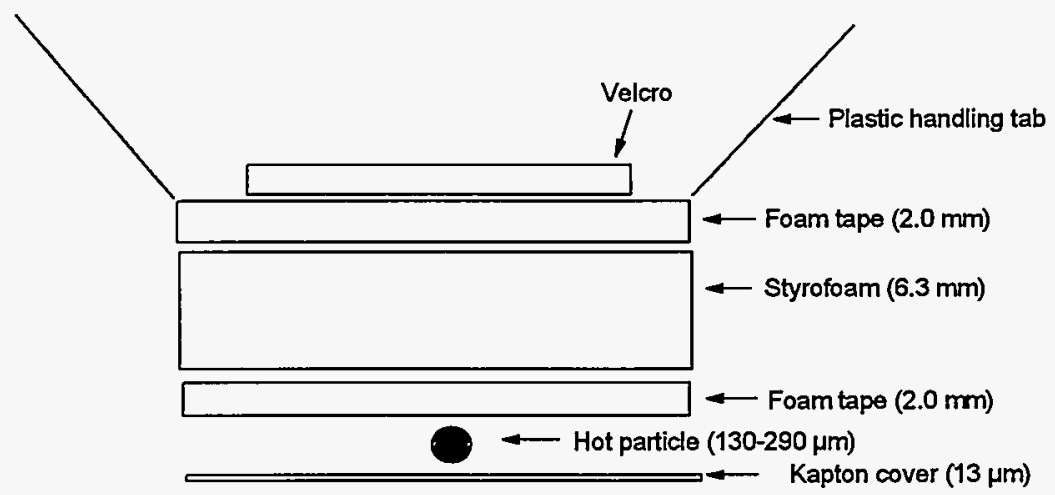

Figure 3.10 Source placement block used for $\mathrm{Tm}-170$ experiments 6 and 7; Yb-175 experiments 11, $12,13,15$, and 17; and $U C_{2}$ experiments 18 and 19. The Tm-170, $\mathrm{Yb}-175$, and $\mathrm{UC}_{2}$ particles were 260-, 130-, and 290- $\mu \mathrm{m}$ thick, respectively. 


\section{General Experimental Protocol}

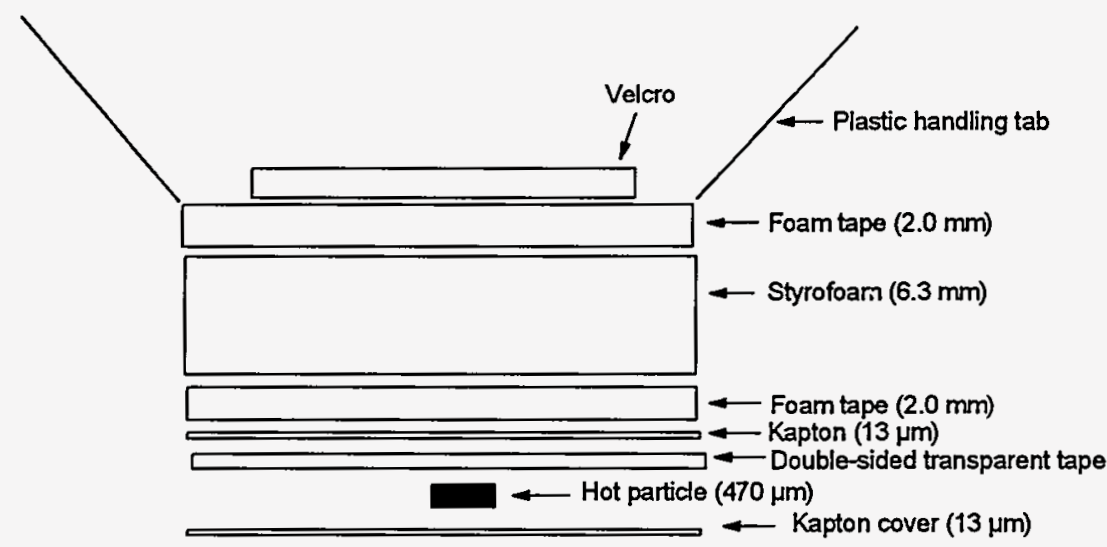

Figure $3.11 \mathrm{Tm}-170$ source placement block used for experiment 10. The Kapton and double-sided transparent tape were used to prevent source from sinking into foam tape several months later.

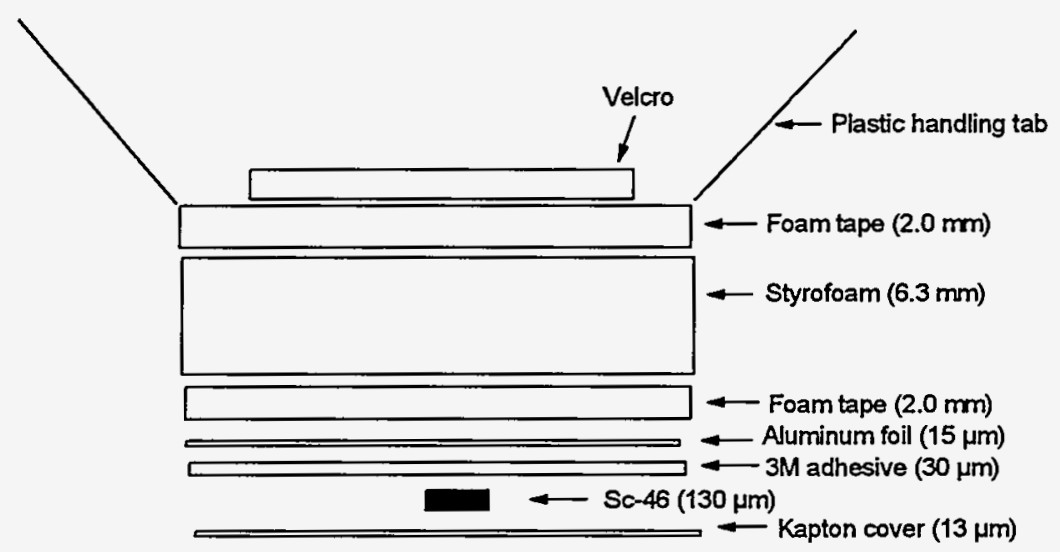

Figure 3.12 Sc-46 source placement block used for experiments 13,16 , and 17. 


\section{General Experimental Protocol}

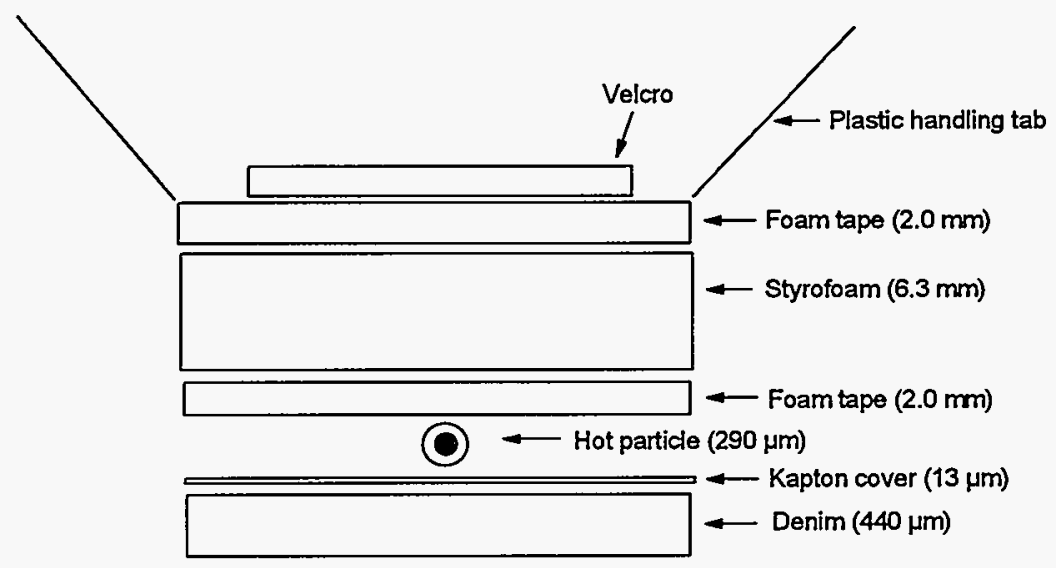

Figure 3.13 Off-skin $\mathrm{UC}_{2}$ source placement block used for experiments 18 and 19.

with a face area $2.54 \mathrm{~cm}$ by $2.54 \mathrm{~cm}$. The density of the Styrofoam was $0.15 \mathrm{~g} / \mathrm{cc}$. The thickness of the Styrofoam base was decreased to $0.63 \mathrm{~cm}$ after experiment 5 to eliminate the source's tendency to tip over. Double-sided foam tape with a thickness of about $2.0 \mathrm{~mm}$, width of $2.54 \mathrm{~cm}$, and a density of $9.8 \mathrm{mg} / \mathrm{cc}$ was used to fasten plastic tabs to the back of the source's mounting block. These tabs were needed to manipulate the source with tongs. Another layer of double-sided foam tape was placed over the central portion of the back of the Styrofoam base to secure a layer of Velcro $\otimes^{3}$ that was used to manipulate the source during dosimetry and pig irradiations when using the cone/rod source assembly (described later). A layer of double-sided foam tape was also placed on the Styrofoam face of the source-mounting block to mount the particle to the block. The low-density Styrofoam base and foam tape minimized backscatter and thereby better approximated a particle on the skin with air as a backscatter medium.

To ensure that the particle was in contact with the skin, a foam tape tip (double-sided foam tape, about $3 \mathrm{~mm}$ by $3 \mathrm{~mm}$ ) was placed in the center of the exposure block and the source was placed on this tip for some of the earlier irradiations (on-skin $\mathrm{UC}_{2}$, experiments 1 and 2; Tm-170 sources $\# 1$, \#3 for experiment 3). While there were no obvious differences in effect between tipped and non-tipped sources in the first Tm-170 pig exposure, the tip was abandoned because of concerns that skin anoxia was induced due to the pressure of the tip.

\subsubsection{Source Mounting and Geometry}

During these studies, a variety of source-mounting materials were employed as summarized in Table 3.8 and described in detail below.

${ }^{3}$ Velcro is a registered trademark of Velcro Industries. 
General Experimental Protocol

Table 3.8 Specifications for materials used for the hot particle source-mounting block

\begin{tabular}{|c|c|c|c|}
\hline Material & Thickness & Area dimensions & Density \\
\hline Styrofoam & $\begin{array}{l}1.3 \mathrm{~cm}(7 / 91-2 / 92) \\
6.3 \mathrm{~mm}(3 / 92-2 / 95)\end{array}$ & $2.5 \mathrm{~cm} \times 2.5 \mathrm{~cm}$ & $0.15 \mathrm{~g} / \mathrm{cc}$ \\
\hline Foam tape & $2.0 \mathrm{~mm}$ & $2.5 \mathrm{~cm} \times 2.5 \mathrm{~cm}$ & $9.8 \mathrm{mg} / \mathrm{cc}$ \\
\hline Foam tape-tip & $2.0 \mathrm{~mm}$ & $3 \mathrm{~mm} \times 3 \mathrm{~mm}$ & $9.8 \mathrm{mg} / \mathrm{cc}$ \\
\hline Kapton & $13 \mu \mathrm{m}$ & $2.5 \mathrm{~cm} \times 2.5 \mathrm{~cm}$ & $1.4 \mathrm{~g} / \mathrm{cc}$ \\
\hline Aluminum foil & $15 \mu \mathrm{m}$ & $2.5 \mathrm{~cm} \times 2.5 \mathrm{~cm}$ & $2.7 \mathrm{~g} / \mathrm{cc}$ \\
\hline $\begin{array}{l}\text { 3M acrylic adhesive } \\
966\end{array}$ & $30 \mu \mathrm{m}$ & $2.5 \mathrm{~cm} \times 2.5 \mathrm{~cm}$ & \\
\hline Polyethylene & $13 \mu \mathrm{m}$ & $2.5 \mathrm{~cm} \times 2.5 \mathrm{~cm}$ & $0.92 \mathrm{~g} / \mathrm{cc}$ \\
\hline Transparent tape & $47 \mu \mathrm{m}$ & $2.5 \mathrm{~cm} \times 2.5 \mathrm{~cm}$ & $1.2 \mathrm{~g} / \mathrm{cc}$ \\
\hline Denim & $440 \mu \mathrm{m}$ & $2.5 \mathrm{~cm} \times 2.5 \mathrm{~cm}$ & $0.58 \mathrm{~g} / \mathrm{cc}$ \\
\hline $\begin{array}{l}\text { Double-sided } \\
\text { transparent tape } \\
\text { perimeter }\end{array}$ & $71 \mu \mathrm{m}$ & $\begin{array}{c}\sim 3 \mathrm{~mm} \text { wide } \\
\text { around perimeter } \\
\text { of mounting block } \\
\text { face }\end{array}$ & \\
\hline $\begin{array}{l}\text { Foam material for } \\
\text { off-skin Tm-170 }\end{array}$ & $\begin{array}{c}830 \mu \mathrm{m} \\
\text { (120- and } 280-\mu \mathrm{m} \text { sources) } \\
1400 \mu \mathrm{m} \\
\text { (160- and } 470-\mu \mathrm{m} \text { sources) }\end{array}$ & $2.5 \mathrm{~cm} \times 2.5 \mathrm{~cm}$ & $\begin{array}{c}20 \mathrm{mg} / \mathrm{cc} \\
(230-\& 380-\mu \mathrm{m} \\
\text { sources }) \\
\\
12 \mathrm{mg} / \mathrm{cc} \\
(310-\& 448-\mu \mathrm{m} \\
\text { sources) }\end{array}$ \\
\hline
\end{tabular}

After one particle was separated from the other sources and quartz fragments, the sourcemounting block was placed face down on the particle. The particle adhered to the double-sided foam tape. The particle was centered by having fluorescent yellow-marker cross-hairs with the outline of the source-mounting block on a paper tray before pouring the sources from the ampule. The source was moved to the intersection of the cross-hairs, and then the source-mounting block could easily be positioned above its outline.

After attaching the source to the foam tape, it was covered with $13-\mu \mathrm{m}$ thick, low-density polyethylene $\left(0.93 \mathrm{~g} / \mathrm{cc}\right.$ ) for the early $\cup \mathrm{C}_{2}$ experiments 1 and 2 (Figure 3.3 ) and for the off-skin 


\section{General Experimental Protocol}

source geometry for experiment 2 (Figure 3.4). The thin layer of low-density plastic ensured minimal degradation of the beta energy spectrum to more closely approximate a particle on the skin. In addition to the plastic cover, the off-skin $U_{2}$ particle was also covered with a piece of $440-\mu \mathrm{m}$-thick denim cloth with a density of $0.58 \mathrm{~g} / \mathrm{cc}$. The denim strip had matching Velcro sewn onto its ends. This was wrapped around the source-mounting block and secured on the back with Velcro tabs.

The sources were invariably wiped to check for contamination before using for dosimetry or pig irradiations.

For the early Tm-170 irradiations, starting with experiment 3 , the Tm-170 sources were covered with polyethylene several days before irradiating the pig. On the day of irradiation, the sources were found to be contaminated from radiation damage, compromising the integrity of the polyethylene. The particles then were covered with $47-\mu \mathrm{m}$ thick transparent tape with a density of $1.2 \mathrm{~g} / \mathrm{cc}$ to further contain them. Four Tm-170 sources were used in this experiment; two had the Tm-170 particles on 2.0-mm thick foam tape tips (Figure 3.5), and two were mounted without tips (Figure 3.6).

Eight off-skin Tm-170 irradiations were carried out for experiment 3 by placing the mounted $\mathrm{Tm}-170$ particles described above on 1.4-mm-thick foam that was taped to the pig's flank. The foam had a density of $12 \mathrm{mg} / \mathrm{cc}$. Dosimetry results later showed that the particles mounted on foam-tape tips pressed into the foam, and thus, they were not as far off the skin as the Tm-170 sources that were not mounted on tips. The distances the particles were off the skin were calculated from measured centerline doses, assuming that the dose varied inversely as the square of distance from the particle's center. The effective particle center chosen by finding the $\mathrm{Tm}-170$ particle thickness that would deposit $50 \%$ of the dose of the whole particle for a $1 \mathrm{~cm}^{2}$ area at a distance of $1.4 \mathrm{~mm}$ off the surface of the dosimetry film based on calculations using VARSKIN MOD2 (Durham, 1991). The distances the particles were off the skin for the Tm-170 sources were 1.4 and $0.83 \mathrm{~mm}$ for the non-tipped and tipped sources, respectively.

In later Tm-170 pig irradiations for experiments 4 and 5, the particles used for experiment 3 were covered with 13- $\mu \mathrm{m}$-thick Kapton (a plastic resistant to radiation damage) with a density of $1.4 \mathrm{~g} / \mathrm{cc}$. The Kapton was secured to the edges of the Styrofoam block with double-sided transparent tape 71- $\mu \mathrm{m}$ thick (Figure 3.9). Kapton has a yellow tinge and is transparent.

The Tm-170 sources were remounted for irradiations on experiments 6 and 7 without the tape tips, using Kapton instead of polyethylene as a covering material (Figure 3.10). Unlike the polyethylene, the Kapton did not conform to the particle, and did not press it into the foam; rather, the Kapton remained as a flat layer covering the particle.

Before the Tm-170 pig irradiations for experiments 8,9 , and 10 , the sources had sunk into the double-sided foam tape since the last remounting. The Kapton over the particle also appeared to be indented into the foam, as if attached to the source. Therefore, the Tm-170 particle used for this experiment was remounted (Figure 3.11). A Kapton backing was used to minimize the chances of the particle sinking into the foam tape in possible future experiments. 
The $\mathrm{Yb}-175$ sources were mounted using the same protocol developed for the $\mathrm{Tm}-170$ sources (Figure 3.10) for experiments 11, 12, 13, 15, and 17.

For Sc-46, a layer of 15- $\mu$ m-thick aluminum was placed on the double-sided foam tape on the face of the source-mounting block. The aluminum then was covered with a 30- $\mu \mathrm{m}$-thick layer of $3 \mathrm{M}$ Corporation acrylic adhesive 966 . The Sc-46 particles were attached to the adhesive and covered with Kapton (Figure 3.12). The reason for this different protocol was to prevent the particles from sinking into the foam tape over the period of several months; this also minimized the dose to the experimenters who did not have to remount the sources for each experiment, and it saved time. The backscatter of the Sc- 46 beta particles for the Sc-46 source covered with $15-\mu \mathrm{m}$-thick aluminum mounted on a 1-mm-thick aluminum backing contributed to an $11 \%$ increase in dose averaged over $1 \mathrm{~cm}^{2}$ at a depth of 60-80 $\mu \mathrm{m}$ of water. ${ }^{4}$ This result agrees with a cruder calculation which took into account that the Sc-46 source is inordinately thick. In addition, the number of backscattered beta particles emitted from the edges of the Sc-46 particle were considered. The backscatter component from $15-\mu \mathrm{m}$-thick aluminum foil was assumed to be considerably less than from the 1-mm-thick aluminum backing.

The source geometry for the final $\mathrm{UC}_{2}$ pig irradiations for experiments 18 and 19 was similar to that developed for the Tm-170 and $\mathrm{Yb}-175$ sources used later, except that the off-skin source again was covered with $440-\mu \mathrm{m}$ - thick denim (Figures 3.10 and 3.13).

The Kapton covering on the hot particles tolerated a considerable dose without rupturing; it did rupture on one Sc-46 source after a dose greater than $240 \mathrm{MGy}$. However, another cover withstood a dose greater than $290 \mathrm{MGy}$ from a Sc-46 particle without rupturing. The Kapton cover for the later Sc-46 source underwent considerable mechanical stress during the irradiation of the flanks of seven pigs on four different days, as well as during a dosimetry intercomparison, before rupturing. The Kapton cover for one Tm-170 source was exposed to more than $2.1 \mathrm{GGy}$ (2.1 E9 Gy) before being remounted when the particle had slightly sunk into the foam tape base; however, the Kapton seemed to be physically adhered to the particle, and was still in contact with it before remounting. For another Tm-170 source, the Kapton cover withstood a dose greater than 450 MGy over more than two years before remounting. These doses were point doses measured at $4 \mu \mathrm{m}$ depth in dye film outside the Kapton cover; thus, the doses actually received by the Kapton were greater than the measured ones due to distance considerations, and to the absorption of low-energy beta particles and conversion electrons that were not energetic enough to penetrate the Kapton cover.

\subsection{Source Dosimetry}

Methods of measuring dose from hot particles result in values for an identical particle varying by up to factors of two for similar established dosimetry systems (Darley et al., 1991; Soares et al.,

${ }^{4}$ We thank Hsiao-Hua Hsu, Los Alamos National Laboratory, who carried out this calculation on July 27, 1994. 


\section{General Experimental Protocol}

1991). The present studies used GafChromic $\AA^{5}$ dye film (a radiochromic foil dosimeter) and a hand-held ion chamber. Dosimetry was carried out the same day as the irradiation for $\mathrm{UC}_{2}$, both before and after the irradiations; dosimetry for the other sources was carried out either the same day or within several days of the pig irradiation.

\subsubsection{GafChromic Dye Films}

\subsubsection{GafChromic Dye: Description}

The GafChromic dye film consists of a $6.5-\mu \mathrm{m}$-thick $(1.2 \mathrm{~g} / \mathrm{cc})$ dye layer mounted on a 99- $\mu \mathrm{m}-$ thick polyester polyethylene-terephthalate (PTP) base. A $0.75-\mu m$-thick protective coating $(1.2 \mathrm{~g} / \mathrm{cc})$ covers the film, and a 1- $\mu \mathrm{m}$-thick adhesive layer secures the dye to the base, as described by David Lewis, GAF Chemical Corporation, February 12, 1992 (Figure 3.14).

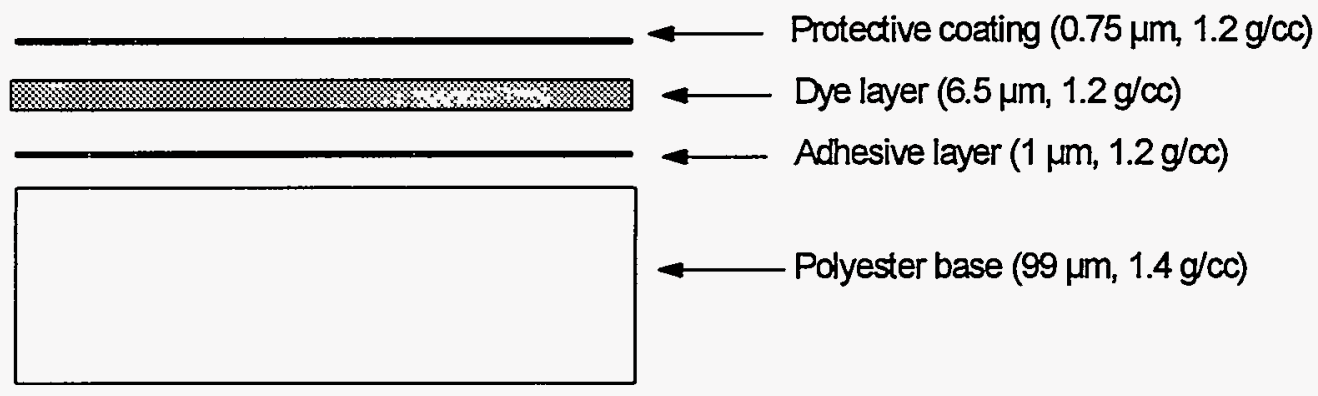

Figure 3.14 GafChromic dye film construction with manufacturerspecified dimensions except for the density of the polyester base, which was determined by measuring the film.

The measured thickness of the film was $107.25 \mu$ m (agreeing with the manufacturer's specifications), and the measured density was $1.38 \mathrm{~g} / \mathrm{cc}$. For calculations, the nominal density of the polyester base was taken to be $1.4 \mathrm{~g} / \mathrm{cc}$, rather than 1.33 as suggested by the manufacturer.

The film has an approximately linear response for doses between 30 and 1,000 Gy (Saylor et al., 1988), and also for high-energy photons (Co-60) and high-energy beta sources (Sr-Y-90).

Apparently, there is no dose-rate effect (Soares and McLaughlin, 1993). The image stabilizes after several weeks, and the delay time between reading the particle films and the calibration films was about the same in all cases, thereby compensating for changes with time.

${ }^{5}$ GafChromic is a registered trademark.

NUREG/CR-6531 
General Experimental Protocol

\subsubsection{GafChromic Dye: Exposure}

Films were cut from a 15-cm-wide GafChromic film roll. In experiments 1 to 16 , these were 2.5 $\mathrm{cm}$ by $2.5 \mathrm{~cm}$, but in experiments 17 to 19 , the sizes were $4 \mathrm{~cm}$ by $4 \mathrm{~cm}$. For all experiments, stacks of films were exposed to determine a depth-dose profile. Polyethylene spacers were used in the earlier experiments.

In the earlier experiments ( 1 to 16), the film stacks were secured to a Lucite base using transparent tape at the corners of the top film. For later experiments (17 to 19), the films were covered with aluminized Mylar ${ }^{\mathrm{MM}^{6}}$ windows, and the Mylar was taped to the Lucite base. The Mylar had a measured thickness of $9.8 \mu \mathrm{m}$ and a density of $1.4 \mathrm{~g} / \mathrm{cc}$.

The films were exposed by attaching Velcro on the back of the source-mounting block to Velcro on a polymethylmethacrylate (PMMA) rod placed in the dosimetry jig; the rod could be raised and lowered in the jig. The mounted film stack then was placed in the jig, and the source was lowered onto it. The weight of the rod ensured that the source was in contact with the film stack, and that the stack was flat. The source was raised and lowered by hand and timed with a stop watch. Timing errors were estimated to be less than $0.5 \mathrm{~s}$. Due to the high dose rates of some of the particles, the exposure times were as short as $4 \mathrm{~s}$. In these cases, an exposure several seconds longer also was made to identify any timing errors; none were noted.

The films were exposed under ambient fluorescent light; at all other times, they were shielded from light in opaque envelopes.

The films were exposed such that the centerline dose to the first or second film in the stack was about 100-200 Gy. Second, third, and sometimes fourth exposures were made using additional stacks of film, in which each subsequent exposure time was a factor of ten greater than the previous exposure. Multiple exposures allowed for the determination of dose to the peripheral and central areas by combining the unsaturated dose profile (in terms of dose at radial distance from the centerline) from each of the films (McWilliams et al., 1992). This procedure was used for experiments 11 to 19 . In the earlier experiments, the film exposures spanned doses of a factor of $2\left(\mathrm{UC}_{2}\right.$ for experiment 1$)$, a factor of $10\left(\mathrm{UC}_{2}\right.$ for experiment 2 and $\mathrm{Tm}-170$ for experiments 4-10), and a factor of 20 or 30 (Tm-170 for experiment 3 ). Sets of three film stacks were used to cover the range of exposures for the early experiments. Doses at the centerline and integrated over $1.1 \mathrm{~mm}^{2}$ and $1 \mathrm{~cm}^{2}$ for the films in each of the stacks, at the same film depth, were averaged together unless they showed saturation. Films showing nonlinearity due to saturation were not included in the average. The criterion for saturation was a dose $20 \%$ less than that for the shortest film exposure. In all cases, a minimum of two films were used for this averaging, and in some cases, four films were used (i.e., morning and evening $\mathrm{UC}_{2}$ dosimetry). For dose averaged over $1 \mathrm{~cm}^{2}$, the shortest film exposure was sometimes not used due to an under-response when compared with measured doses from films irradiated for longer periods.

${ }^{6}$ Mylar is a trademark for a thin, strong polyester film. 


\section{General Experimental Protocol}

\subsubsection{Film Calibration}

The GafChromic dosimeters were calibrated by exposing films from the same batch as that used for the dosimetry studies to selected doses from a Co-60 gamma source. The delay between exposing and reading the films was about two weeks, similar to the delay after exposing the films to the hot particles, thereby avoiding any need for corrections due to fading of the film.

\subsubsection{GafChromic Dye: Readout}

The irradiated films were read by Chris Soares at the National Institute of Standards and Technology in Gaithersburg, Maryland. Two-dimensional densitometry was carried out using a commercial scanning laser densitometer with a HeNe laser at $633 \mathrm{~nm}$ wavelength. The diameter of the laser spot was $100-\mu \mathrm{m}$ and it was moved in increments of 40 to $160 \mu \mathrm{m}$ in both the $\mathrm{x}$ and $\mathrm{y}$ directions, depending on the size of the image being scanned.

After scanning each film and adjusting for calibrations, data from all films exposed at the same depth for different exposure times were combined to obtain the dose profile at that depth (Figure 3.15). Doses averaged over different areas were determined using a curve-fitting software and a computer program written in BASIC that integrated the function (Soares et al., 1990; McWilliams et al, 1992).

\subsubsection{Dose and Beta Particle Emissions Determination from GafChromic Dye Measurements}

The dose measurements were used to obtain dose estimates at 1) 16- $\mu \mathrm{m}$ depth averaged over

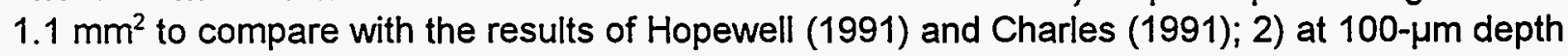
"point" dose to compare with the calculated values of Forbes and Mikhail (NCRP, 1989); 3) at $70-\mu \mathrm{m}$ depth averaged over $1 \mathrm{~cm}^{2}$, which is the dose criteria for skin contamination used by the NRC (1991) and was also the depth and area dose reported by Reece et al. (1994); and 4) and at 100- and 150- $\mu \mathrm{m}$ depth averaged over $1 \mathrm{~cm}^{2}$ corresponding to the range 100-150 $\mu \mathrm{m}$ which was suggested by the ICRP (1991a). Measurements were also used to obtain the number of beta particles emitted from the particle, as suggested by NCRP (1989). Since the dye film has a density $40 \%$ greater than tissue, doses to the areas of interest listed above were corrected using ratios obtained from the point-kernel computer code VARSKIN MOD2 (Durham, 1991, 1992), described below.

The ratio of the expected tissue dose averaged over area $A$ at some tissue depth $d_{t}$, and the film measured value averaged over area $A$ at film depth $d_{f}$ should be the same as the ratio calculated using VARSKIN MOD2 for tissue dose averaged over area $A$ at these depths. This ratio then can be used to estimate the expected tissue dose as shown in Equation 3.5. 


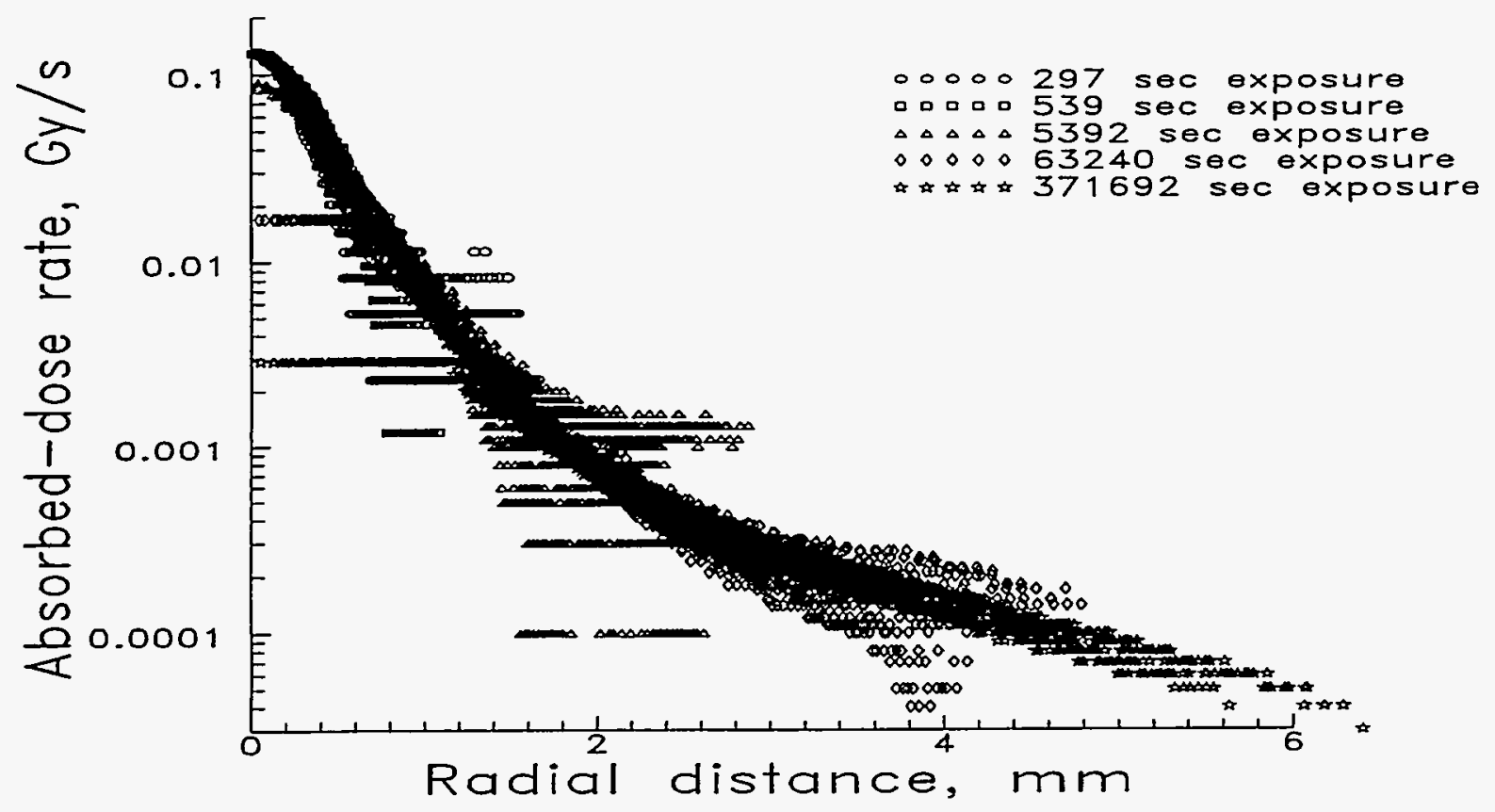

Figure 3.15 Radial dose profile for Tm-170 particle at a film density thickness of $1.8 \mathrm{mg} / \mathrm{cm}^{2}$. This is shown as an example to demonstrate the effect of combining films with different exposure times. 


\section{General Experimental Protocol}

$$
D\left(\begin{array}{c}
\text { area } A \text {, depth } d_{t} \\
\text { for tissue }
\end{array}\right)=D\left(\begin{array}{c}
\text { measured for film } \\
\text { at depth } d_{f} \\
\text { for area } A
\end{array}\right) \times \frac{D\left(\begin{array}{c}
\text { VARSKIN MOD2 } \\
\text { area } A \text {, depth } d_{t}
\end{array}\right)}{D\left(\begin{array}{c}
\text { VARSKIN MOD2 } \\
\text { Film depth } d_{t} \\
\text { area } A
\end{array}\right)}
$$

In the case in which the dose averaged over $1.1 \mathrm{~mm}^{2}$ at a depth of $16 \mu \mathrm{m}$ was used to compare with results of Hopewell (1991), the $16 \mu \mathrm{m}$ depth, $1.1 \mathrm{~mm}^{2}$ dose was derived from measurements using the first film in the stack of films. This value was usually within $10 \%$ of the $16 \mu \mathrm{m}$ depth, $1.1 \mathrm{~mm}^{2}$ dose determined using the second film in the stack. (For dose at deeper depths, the second film in the stack was used.)

The number of beta particles emitted from the particle per unit dose was not measured directly. Rather, VARSKIN MOD2 (Durham, 1991, 1992) was used to calculate the activity of a source (proportional, or equal, to the number of beta particles emitted in the source) required to produce a $1 \mathrm{~Gy}$ dose at $70 \mu \mathrm{m}$ depth averaged over $1 \mathrm{~cm}^{2}$ for the source geometry used. Next, the proportion of beta particles emitted in the source that penetrate the source and containment material was calculated in the following way. Dose was calculated using VARSKIN MOD2 at a depth of $1 \mu \mathrm{m}$ below the containment material. The area involved was equal to the average of the top and bottom of the particle for a source and containment material with the correct density, and also for a source and containment material with zero density. The ratio of these two doses is the transmission factor. Multiplying the transmission factor by the number of beta particles emitted in the source gives the number of beta particles emitted from the source, assuming that the dose was directly proportional to the number of beta particles. We note that the calculated number of beta particles has an accuracy limited to that of VARSKIN MOD2 and depends on the value of the transmission factor. As the transmission factor is reduced, the assumption that dose is proportional to the number of beta particles emitted from the source becomes less accurate due to the lower average energy of the beta particles. Durham $(1991,1992)$ and Darley et al. (1994) have discussed the accuracy of the VARSKIN MOD2 code.

For comparison to the above calculation, transmission factors for the number of beta particles emitted from the source and Kapton cover were calculated using a 1- $\mu \mathrm{m}$ depth and $1 \mathrm{~cm}^{2}$ area (Table 3.9). Note that the number of beta particles emitted from the particle and containment material per Gy using a transmission factor for the projected particle area immediately under the particle was $(1.8$ to 3.4$) \times 10^{9}$ for all particles. When transmission factors calculated using an area of $1 \mathrm{~cm}^{2}$ are used, the values increase with decreasing maximum beta-particle energy except for $\mathrm{Yb}-175$ and off-skin $\mathrm{UC}_{2}$. 
Table 3.9 Number of beta particles emitted from the source and containment material per unit dose for hot particles and geometries used in the study

\begin{tabular}{|c|c|c|}
\hline Hot particle & $\begin{array}{c}\text { Emitted betas per Gy using } \\
\text { particle's area transmission } \\
\text { factor }\end{array}$ & $\begin{array}{c}\text { Emitted betas per Gy using } \\
1 \mathbf{c m}^{2} \text { area transmission } \\
\text { factor }\end{array}$ \\
\hline \hline On-skin $\mathrm{UC}_{2}$ & $1.9 \mathrm{Eg}^{\mathrm{b}}$ & $1.8 \mathrm{E} 9$ \\
\hline Off-skin UC 2 & $2.8 \mathrm{E} 9$ & $3.0 \mathrm{E} 9$ \\
\hline Tm-170 & $2.5 \mathrm{E} 9$ & $1.8 \mathrm{E} 9$ \\
\hline Yb-175 & $2.0 \mathrm{E} 9$ & $2.4 \mathrm{E} 9$ \\
\hline $\begin{array}{c}\text { Sc-46 (with gamma } \\
\text { contribution) }\end{array}$ & $2.9 \mathrm{E} 9$ & $2.6 \mathrm{E} 9$ \\
\hline $\begin{array}{c}\text { Sc-46 (without gamma } \\
\text { contribution) }\end{array}$ & $3.4 \mathrm{E} 9$ & $2.9 \mathrm{E} 9$ \\
\hline
\end{tabular}

a. The second column is for a transmission factor calculated over the area of the particle's face, as described above. The third column is for a transmission factor calculated over $1 \mathrm{~cm}^{2}$. The calculated dose is at a depth of $70 \mu \mathrm{m}$ averaged over $1 \mathrm{~cm}^{2}$.

b. E9 is short for times $10^{9}$.

\subsubsection{Ionization Chamber}

During the source mounting and animal irradiations, a hand-held ionization chamber meter was used to estimate the activity of the sources, particularly for the Sc-46 sources. GafChromic film dose-rate measurements and exposure-rate measurements taken with a hand-held ionization chamber during previous experiments aided in estimating expected skin dose rates $( \pm 30 \%)$ from the particles for later experiments.

\subsubsection{Dosimetry Intercomparisons}

To validate the results of dye film dosimetry and provide information for better comparisons with previous studies, dosimetry measurements of four hot particles were made at different depths using five different methods (Kaurin et al., 1996). Details of these studies are presented in the Appendix of this document. The hot particles had maximum dimensions of $650 \mu \mathrm{m}$ and maximum beta-particle energies of $0.97,0.46,0.36$, and $0.32 \mathrm{MeV}$. Absorbers were used to 


\section{General Experimental Protocol}

obtain dose at different depths as measured with each dosimeter. Measurements were made using exoelectron dosimeters, an extrapolation chamber, NE Extremity Tape ${ }^{\mathrm{TM}}{ }^{7}$ dosimeters, Eberline RO-2 and RO-2A TM $8^{8}$ survey meters, and two sets of GafChromic dye film with each set read out at a different institution. Dose was averaged over $1 \mathrm{~cm}^{2}$ of tissue at $18,70,125$, and $400 \mu \mathrm{m}$ depth. The results of the intercomparisons were used to validate the dye film dosimetry employed in these studies.

\subsection{Pig Husbandry, Training, and Preparations}

\subsubsection{Experimental Animals}

The Hanford mini-pig strain was selected due to its history of use in other studies of radiation effects on the skin. Females (litter mates when possible) were obtained from Charles River Laboratories $^{9}$ which maintain a breeding facility in New Hampshire, approximately four weeks before their scheduled first use. Up to three animals were initially placed in the same pen allowing them to acclimate to their surroundings. After 3-5 days, they were separated into single pens which were temperature-controlled with a 12-hour light/dark light cycle and cleaned daily with a germicidal pressure-wash system. The animals were maintained, as per the recommendation of the breeder, on Purina Prolab Minipig Chow, ${ }^{10}$ the ration per day depending on the weight of the animal. Water was available ad libitum from a swine-watering device as used in the Charles River breeding facility. The health status of the animals was monitored daily at the time of feeding.

The weight of each animal at time of shipping was supplied by the vendor, with subsequent weighings when the animals were anesthetized for treatment.

The pigs' ages at the time of irradiation for the 1991-92 experiments varied from 3.3 to 15 months. The pigs' ages at the time of irradiation for the 1994-95 experiments was 2.8 to 4.4 months. The 2.8- to 4.4-month-old-pigs were preferred for the experiments to determine the doses to generate scabs with 10 and $50 \%$ incidence (Table 5.16). The 3- to 4-month-old pig was thought to have skin similar to that of humans, and the younger age is consistent with the pig's age used in the Hopewell (1991) studies.

\subsubsection{Animal Training}

Immediately after the pigs arrived, a caretaker or technician entered the animals' pens and placed feeding bowls containing the daily food ration for each animal. The person stayed with the animals during eating and thereafter for 20-60 minutes. After two to five days, the animals

\footnotetext{
${ }^{7}$ Trademark of NE Technology Inc., Monmouth Junction, NJ.

${ }^{8}$ Trademark of the Eberline Instruments Corporation.

${ }^{9}$ Charles River Laboratories, 251 Ballardvale Street, Wilmington, MA 01887.

${ }^{10}$ Obtained from Riverhead Agway, Riverhead, NY 11901.
} 
became accustomed to the person's presence and allowed touching. Subsequently, after the animals were separated into single pens, the feeding was done by progressively moving the bowl out of the pen, down the corridor, and up the entrance ramp into the observation cubicle. Within a few days, the animals became accustomed to the routine and when the pen door was opened, the animal would proceed down the hall and into the observation cubicle to eat. After several trials, the animals became accustomed to staying in the observation cubicle for the full eating period and would allow brushing, shaving, photographing, and close examination of each exposure area while eating.

\subsubsection{Animal Preparation}

Seven to ten days before irradiation the animals underwent the following procedures;

(1) They were weighed and anaesthetized for tattooing. Anesthesia was induced by intramuscular injection of ketamine at a dosage of approximately $20 \mathrm{mg} / \mathrm{kg}$ body weight, followed by isofluorine inhalation at $2.5 \%$ or "to effect" in air.

(2) The hair on their flanks then was clipped off with special care taken not to disturb the keratin layer.

(3) The animals were tattooed on both flanks using an electric tattooing tool. ${ }^{11}$ In early studies using larger animals, the pig flanks were divided into $3.8-\mathrm{cm}$ square grids marked by a tattooed dot at each corner. In later studies on smaller animals, $2.5-\mathrm{cm}$ grids were used to allow more irradiation areas. The columns of squares were labeled from one to ten and the rows alphabetically. In early studies where only one flank was irradiated on a day, the letters $A$ to $F$ were used on both flanks. For the final two animals, where both flanks were irradiated on the same day, one flank was lettered $A$ to $F$, and the opposite flank $G$ through $L$ to reduce the possibility of confusing exposure sites.

\subsection{Irradiation of Pigs}

Prior to each irradiation, exposure sites on the pig flank were selected for irradiation. Doses, including controls, were assigned to sites to give a uniform distribution of doses, i.e., high doses were given to sites over the entire animal flank with no high-dose site next to another high-dose site. This procedure was used to equalize variations in responses due to possible differences in pig skin over the animal flank.

For the range-finding experiments (described in section 4.2), no replicate doses were used. For the percent-scab incidence experiments (described in section 4.3), multiple sites were given the same dose. The purpose of the percent scab-incidence studies was to determine the dose which caused $10 \%$ scab induction. For this purpose, a large number of replicate exposures were made at lower doses.

${ }^{11}$ S\&W Tattooing, Inc., 137 Sunrise Highway, Amityville, NY 11701. 


\section{General Experimental Protocol}

The pigs were exposed on the same day that the sources were activated for the $\mathrm{UC}_{2}$ irradiations. For $\mathrm{Yb}-175$ irradiations, exposures were usually done on the day following activation. The long half-lives of Tm-170 and Sc-46 enabled the same sources to be used for multiple irradiations up to 8 months after activation. Since the Tm-170 sources sunk into the foam tape over the course of several months, these sources were remounted several days before irradiating the pigs. Table 3.10 summarizes the nineteen experiments carried out using animals identified by number, irradiation date, age, isotope and source size employed, dose range, number of exposures per dose, and comments related to the purposes of individual experiments. Reference to statistics near threshold implies a large enough number of exposures at a low dose such that if no lesions were produced, we could conclude with $95 \%$ confidence that the expected incidence was below $10 \%$, based upon binomial probabilities.

\subsubsection{Beta Shields During Irradiations}

The pigs were anesthetized (see section 3.4.3) and irradiated while lying on an operating table. To minimize dose to the researchers and animal caretakers, beta shields were constructed of $1-\mathrm{cm}$-thick transparent Lucite. During irradiations, a shield was placed at the head of the pig to protect the caretaker who monitored and adjusted the anesthesia. A 210-cm (7-foot) tall, 20-cm (4-foot) wide beta shield with arm slots for manipulating the source was placed along the length of the table. The researcher faced either the back or belly of the animal while working.

\subsubsection{Placement of Hot Particles on the Pigs}

\subsubsection{Denim Source-Holding Harness}

Immediately after the pig was shaved, a denim harness, which extended along the back and belly of the pig, was placed under the animal (Figure 3.16). The harness had Velcro strips sewn onto it parallel to the length of the animal at both the pig's back and belly positions. Matching Velcro was sewn onto the ends of elastic straps, approximately $20-\mathrm{cm}$ long (unstretched) and $1-\mathrm{cm}$ wide. The Velcro on the elastic straps was attached to the Velcro on the denim harness at the back and belly of the animal, so that the elastic strap was positioned in the middle of a column between tattoo marks on the animal's flank. One elastic strap was used for each column. Multiple parallel Velcro strips were sewn along the edge of the denim harness; this allowed adjustment of the effective size of the harness by folding over the excess denim to select the appropriate Velcro strip. It also permitted the use of various strips to provide the desired tension for pigs of different sizes.

Sources were placed on the pigs by first lifting the elastic strap with one pair of $46-\mathrm{cm}$-long tongs, placing the source under the elastic strap with another pair of tongs, and lowering both the elastic strap and source simultaneously. In this way, an exposure accuracy of about 1s was attained.

There was some concern about the pressure from the source block slightly deoxygenating the skin. Therefore, the pressure was measured during one experiment by inserting paper between a blank source-mounting and the pig's skin with the block positioned under an elastic strap. The elastic strap was pulled vertically using a hook attached to a spring. When the pressure on the 
Table 3.10 Details of each pig irradiation experiment

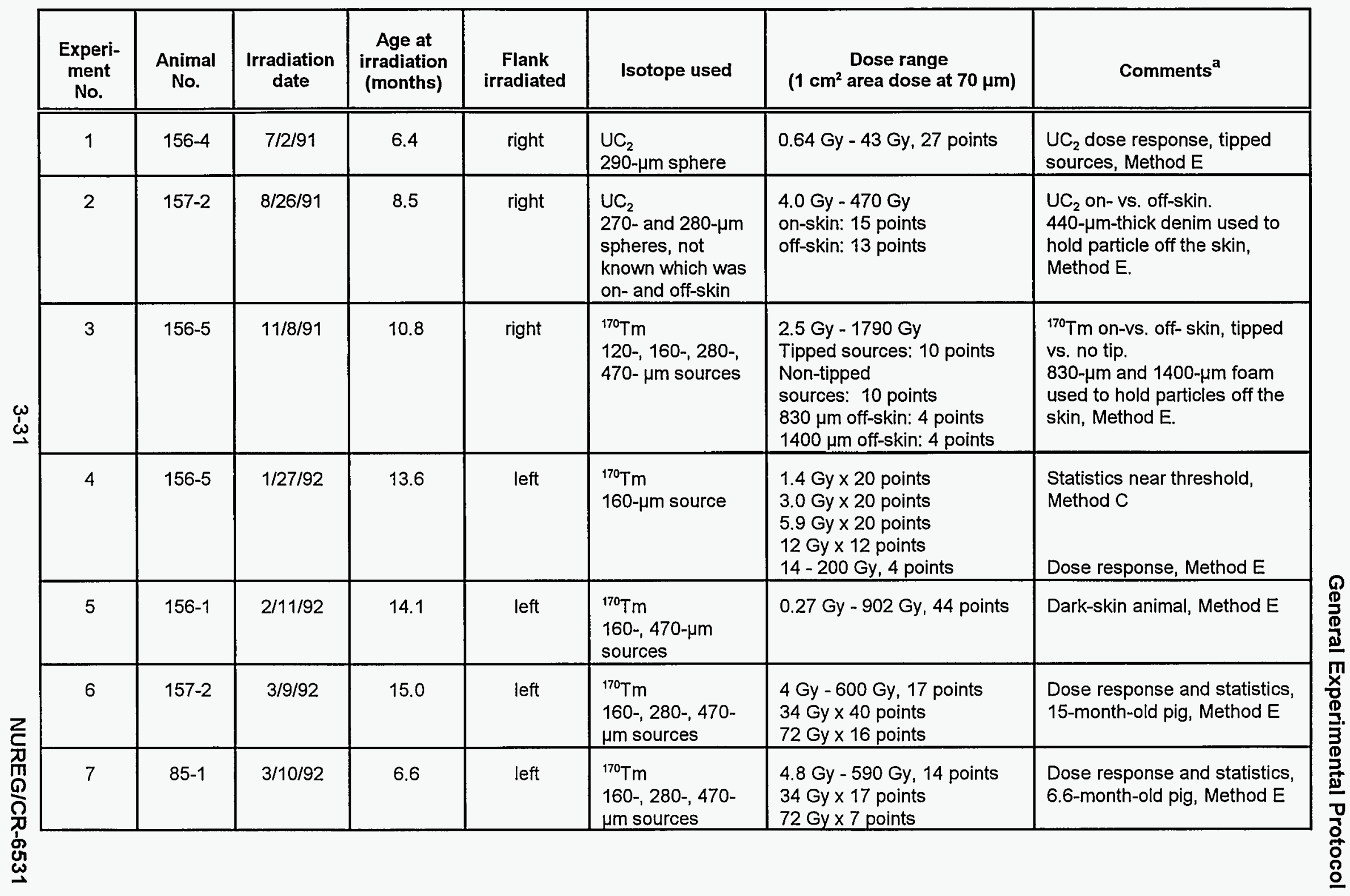


Table 3.10 (Cont.)

\begin{tabular}{|c|c|c|c|c|c|c|c|}
\hline $\begin{array}{l}\text { Experi- } \\
\text { ment } \\
\text { No. }\end{array}$ & $\begin{array}{l}\text { Animal } \\
\text { No. }\end{array}$ & $\begin{array}{l}\text { Irradiation } \\
\text { date }\end{array}$ & $\begin{array}{c}\text { Age at } \\
\text { irradiation } \\
\text { (months) }\end{array}$ & $\begin{array}{l}\text { Flank } \\
\text { Irradiated }\end{array}$ & Isotope used & $\begin{array}{c}\text { Dose range } \\
\left(1 \mathrm{~cm}^{2} \text { area dose at } 70 \mu \mathrm{m}\right)\end{array}$ & Comments $^{\mathrm{a}}$ \\
\hline 8 & $85-1$ & $6 / 8 / 92$ & 9.6 & right & $\begin{array}{l}{ }^{170} \mathrm{Tm} \\
470-\mu \mathrm{m} \text { source }\end{array}$ & $\begin{array}{l}\text { 3.0 Gy } \times 13 \text { points } \\
4.9 \text { Gy } \times 13 \text { points } \\
7.7 \text { Gy } \times 13 \text { points } \\
10 \text { Gy } \times 13 \text { points }\end{array}$ & $\begin{array}{l}\text { Statistics near threshold, } \\
\text { Method C }\end{array}$ \\
\hline 9 & $23-1$ & $6 / 8 / 92$ & 3.8 & both & $\begin{array}{l}{ }^{170} \mathrm{Tm} \\
470-\mu \mathrm{m} \text { source }\end{array}$ & $\begin{array}{l}3.0 \text { Gy } \times 22 \text { points } \\
4.9 \text { Gy } \times 22 \text { points } \\
7.7 \text { Gy } \times 23 \text { points } \\
10 \text { Gy } \times 22 \text { points } \\
\end{array}$ & $\begin{array}{l}\text { Statistics near threshold, } \\
\text { Methods } E, A \text {, and } C\end{array}$ \\
\hline 10 & $23-5$ & $6 / 8 / 92$ & 3.8 & both & $\begin{array}{l}{ }^{170} \mathrm{Tm} \\
470-\mu \mathrm{m} \text { source }\end{array}$ & $\begin{array}{l}3.0 \text { Gy } \times 19 \text { points } \\
4.9 \text { Gy } \times 20 \text { points } \\
7.7 \text { Gy } \times 20 \text { points } \\
10 \text { Gy } \times 19 \text { points } \\
\end{array}$ & $\begin{array}{l}\text { Statistics near threshold, } \\
\text { Methods } E, A, B \text {, and } C\end{array}$ \\
\hline 11 & $85-2$ & $7 / 31 / 92$ & 11.3 & left & $\begin{array}{l}{ }^{175} \mathrm{Yb} \\
270-, 320-, 510- \\
\mu \mathrm{m} \text { sources }\end{array}$ & $\begin{array}{l}0.50 \text { Gy }-53 \text { Gy, } 18 \text { points } \\
1.3 \text { Gy } \times 31 \text { points } \\
5.1 \text { Gy } \times 11 \text { points }\end{array}$ & $\begin{array}{l}{ }^{175} \mathrm{Yb} \text { dose response and test } \\
\text { of expected } 10 \text { and } 50 \% \text { ulcer } \\
\text { incidence, Method } \mathrm{E}\end{array}$ \\
\hline 12 & $38-2$ & $7 / 31 / 92$ & 3.3 & both & $\begin{array}{l}175 \mathrm{Yb} \\
270-, 320-, 510- \\
\mu \mathrm{m} \text { sources }\end{array}$ & $\begin{array}{l}0.50 \text { Gy }-53 \text { Gy, } 42 \text { points } \\
1.3 \text { Gy } \times 31 \text { points } \\
5.1 \text { Gy } \times 11 \text { points }\end{array}$ & $\begin{array}{l}{ }^{175} \mathrm{Yb} \text { dose response using } \\
\text { Method } \mathrm{E} \text {, and test of exp- } \\
\text { ected } 10 \text { and } 50 \% \text { ulcer } \\
\text { incidence using Method } \mathrm{E} \\
\text { and modified Method } \mathrm{E} \\
\text { (section 5.6) }\end{array}$ \\
\hline 13 & $37-1$ & $7 / 25 / 94$ & 3.0 & left & $\begin{array}{l}{ }^{175} Y b \\
460-\mu m \text { source }\end{array}$ & $\begin{array}{l}14 \text { Gy } \times 3 \text { points } \\
7.8 \text { Gy } \times 1 \text { point } \\
2.5 \text { Gy } \times 4 \text { points } \\
1.3 \text { Gy } \times 7 \text { points } \\
0.78 \text { Gy } \times 1 \text { point } \\
0.62 \text { Gy } \times 9 \text { points } \\
0.31 \text { Gy } \times 9 \text { points } \\
0 \text { Gy } \times 12 \text { points }\end{array}$ & $\begin{array}{l}\text { Statistics near threshold and } \\
\text { scabs for biopsy using } \\
\text { Methods } A, B \text {, and } C \text {, scab- } \\
\text { diameter response using } \\
\text { Method } B \text {. }\end{array}$ \\
\hline
\end{tabular}


Table 3.10 (Cont.)

\begin{tabular}{|c|c|c|c|c|c|c|c|}
\hline $\begin{array}{c}\text { Experi- } \\
\text { ment } \\
\text { No. }\end{array}$ & $\begin{array}{l}\text { Animal } \\
\text { No. }\end{array}$ & $\begin{array}{l}\text { Irradiation } \\
\text { date }\end{array}$ & $\begin{array}{c}\text { Age at } \\
\text { irradiation } \\
\text { (months) }\end{array}$ & $\begin{array}{c}\text { Flank } \\
\text { irradiated }\end{array}$ & Isotope used & $\begin{array}{c}\text { Dose range } \\
\left(1 \mathrm{~cm}^{2} \text { area dose at } 70 \mu \mathrm{m}\right)\end{array}$ & Comments $^{a}$ \\
\hline 14 & $37-1$ & $7 / 25 / 94$ & 3.0 & right & $\begin{array}{l}{ }^{46} \mathrm{Sc} \\
440-\mu \mathrm{m} \text { source }\end{array}$ & $\begin{array}{l}53 \text { Gy } \times 4 \text { points } \\
18 \text { Gy } \times 5 \text { points } \\
9.1 \text { Gy } \times 5 \text { points } \\
6.2 \text { Gy } \times 1 \text { point } \\
4.4 \text { Gy } \times 12 \text { points } \\
2.2 \text { Gy } \times 10 \text { points } \\
0.55 \text { Gy } \times 1 \text { point } \\
0 \text { Gy } \times 9 \text { points }\end{array}$ & $\begin{array}{l}\text { Statistics near threshold and } \\
\text { scabs for biopsy using } \\
\text { Methods } A, B \text {, and } C \text {, scab- } \\
\text { diameter response using } \\
\text { Method } B \text {. }\end{array}$ \\
\hline 15 & $39-3$ & $7 / 26 / 94$ & 2.8 & both & $\begin{array}{l}175 \mathrm{Yb} \\
460-\mu \mathrm{m} \text { source }\end{array}$ & $\begin{array}{l}14 \text { Gy } \times 7 \text { points } \\
7.8 \text { Gy } \times 2 \text { points } \\
2.5 \text { Gy } \times 10 \text { points } \\
1.2 \text { Gy } \times 12 \text { points } \\
0.78 \mathrm{~Gy} \times 2 \text { points } \\
0.62 \text { Gy } \times 19 \text { points } \\
0.31 \text { Gy } \times 19 \text { points } \\
0 \text { Gy } \times 16 \text { points }\end{array}$ & $\begin{array}{l}\text { Statistics near threshold and } \\
\text { scabs for biopsy using } \\
\text { Methods } A, B \text {, and } C \text {, scab- } \\
\text { diameter response using } \\
\text { Method } B \text {. }\end{array}$ \\
\hline 16 & $50-2$ & $9 / 1 / 94$ & 3.5 & both & $\begin{array}{l}{ }^{46} \mathrm{Sc} \\
440-\mu \mathrm{m} \text { source }\end{array}$ & $\begin{array}{l}53 \text { Gy } \times 12 \text { points } \\
18 \text { Gy } \times 10 \text { points } \\
9.1 \text { Gy } \times 11 \text { points } \\
5.7 \text { Gy } \times 2 \text { points } \\
4.4 \text { Gy } \times 16 \text { points } \\
2.2 \text { Gy } \times 18 \text { points } \\
0.56 \text { Gy } \times 2 \text { points } \\
0 \text { Gy } \times 13 \text { points }\end{array}$ & $\begin{array}{l}\text { Statistics near threshold and } \\
\text { scabs for biopsy using } \\
\text { Methods } A, B \text {, and } C \text {, scab- } \\
\text { diameter response using } \\
\text { Method } B \text {. }\end{array}$ \\
\hline 17 & $50-3$ & $9 / 29 / 94$ & 4.4 & both & $\begin{array}{l}{ }^{175} \mathrm{Yb} \text { and }{ }^{46} \mathrm{Sc} \\
440-\mu \mathrm{m} \text { sources }\end{array}$ & $\begin{array}{c}{ }^{46} \mathrm{Sc}: \quad 1.2 \mathrm{~Gy} \times 26 \text { points } \\
{ }^{175} \mathrm{Yb}: 3.7 \mathrm{~Gy} \times 13 \text { points } \\
0.78 \mathrm{~Gy} \times 6 \text { points } \\
0.55 \mathrm{~Gy} \times 26 \text { points } \\
\text { controls: } 0 \mathrm{~Gy} \times 8 \text { points }\end{array}$ & $\begin{array}{l}\text { Statistics near threshold and } \\
\text { scabs for biopsy using } \\
\text { Methods } A, B \text {, and } C \text {, scab- } \\
\text { diameter response using } \\
\text { Method } B \text {. }\end{array}$ \\
\hline
\end{tabular}




\begin{tabular}{|c|c|c|c|c|c|c|c|}
\hline $\begin{array}{c}\text { Experl- } \\
\text { ment } \\
\text { No. }\end{array}$ & $\begin{array}{c}\text { Animal } \\
\text { No. }\end{array}$ & $\begin{array}{l}\text { Irradiation } \\
\text { date }\end{array}$ & $\begin{array}{c}\text { Age at } \\
\text { Irradiation } \\
\text { (months) }\end{array}$ & $\begin{array}{c}\text { Flank } \\
\text { Irradiated }\end{array}$ & Isotope used & $\begin{array}{c}\text { Dose range } \\
\left(1 \mathrm{~cm}^{2} \text { area dose at } 70 \mu \mathrm{m}\right)\end{array}$ & Comments $^{a}$ \\
\hline 18 & $90-2$ & $2 / 7 / 95$ & $3-4$ & both & $\begin{array}{l}\text { fissioned } \cup_{2} \\
290 \mu \mathrm{m}\end{array}$ & $\begin{array}{c}\text { on-skin: } 51 \text { Gy } \times 6 \text { points } \\
29 \text { Gy } \times 4 \text { points } \\
22 \text { Gy } \times 10 \text { points } \\
8.7 \text { Gy } \times 15 \text { points } \\
3.8 \text { Gy } \times 14 \text { points } \\
3.1 \text { Gy } \times 2 \text { points } \\
2.2 \text { Gy } \times 10 \text { points } \\
\text { off-skin: } 64 \text { Gy } \times 5 \text { points } \\
29 \text { Gy } \times 11 \text { points } \\
12 \text { Gy } \times 16 \text { points } \\
\text { controls: } 0 \text { Gy } \times 16 \text { points }\end{array}$ & $\begin{array}{l}\text { Statistics near threshold and } \\
\text { scabs for biopsy using } \\
\text { Methods } A, B \text {, and } C \text {, scab- } \\
\text { diameter response using } \\
\text { Method B. }\end{array}$ \\
\hline 19 & $90-3$ & $2 / 7 / 95$ & $3-4$ & both & $\begin{array}{l}\text { fissioned } \cup_{2} \\
290 \mu \mathrm{m}\end{array}$ & $\begin{array}{c}\text { on-skin: } 51 \text { Gy } \times 8 \text { points } \\
22 \text { Gy } \times 9 \text { points } \\
12 \mathrm{~Gy} \times 4 \text { points } \\
8.7 \mathrm{~Gy} \times 11 \text { points } \\
3.8 \mathrm{~Gy} \times 15 \text { points } \\
2.2 \mathrm{~Gy} \times 9 \text { points } \\
\text { off-skin: } 64 \mathrm{~Gy} \times 7 \text { points } \\
29 \mathrm{~Gy} \times 9 \text { points } \\
12 \mathrm{~Gy} \times 14 \text { points } \\
\text { controls: } 0 \mathrm{~Gy} \times 15 \text { points }\end{array}$ & $\begin{array}{l}\text { Statistics near threshold and } \\
\text { scabs for biopsy using } \\
\text { Methods } A, B \text {, and } C \text {, scab- } \\
\text { diameter response using } \\
\text { Method } B \text {. }\end{array}$ \\
\hline
\end{tabular}

a. Methods $E, A, B$, and $C$ refer to scab-scoring procedures described in Section 4.1. 


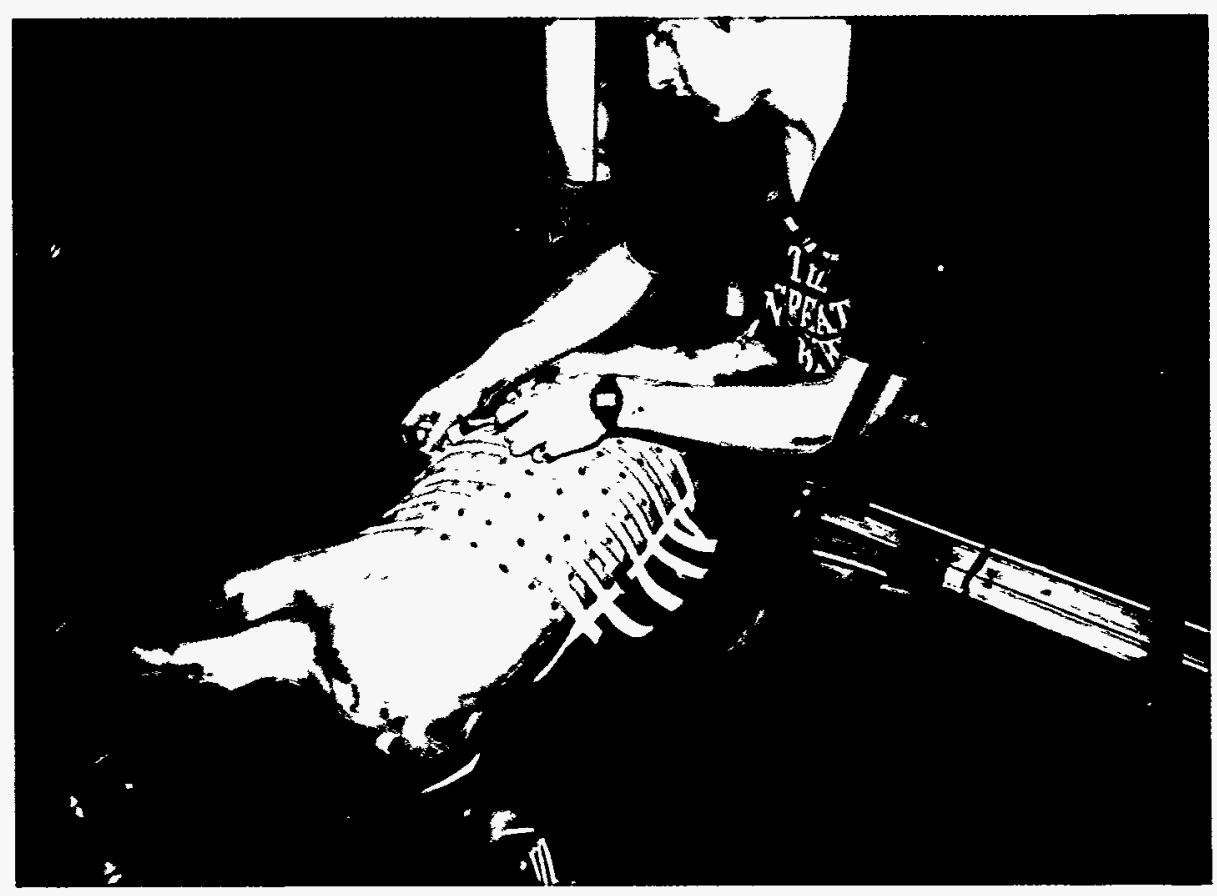

Figure 3.16 Denim source-holding harness

paper decreased to a level that it could easily be pulled free, the deflection of the spring was measured. The average pressure was $200 \pm 60 \mathrm{~Pa}(0.030 \pm 0.0090 \mathrm{psi})$, which was considered negligible.

\subsubsection{Cone/Rod for Placing the Source}

The cone/rod consisted of a Styrofoam cone with an apex diameter of $2.5 \mathrm{~cm}$, a base diameter of about $5.5 \mathrm{~cm}$, and a height of $7.5 \mathrm{~cm}$. Velcro on the back of the source-mounting block was attached to Velcro secured to the apex of the cone. A circular beta shield, 1-cm-thick PMMA with a diameter of $34 \mathrm{~cm}$, was secured to the base of the cone to minimize the dose to the hand and forearm of the person manipulating the source. A PMMA rod $22-\mathrm{cm}-10 \mathrm{ng}$ and $1.9 \mathrm{~cm}$ in diameter was inserted through a hole in the beta shield and into the base of the cone, penetrating about $4 \mathrm{~cm}$ into the cone (Figure 3.17).

Skin exposures were made by gripping the rod portion of the cone/rod and holding the source on the animal within the desired grid area. To minimize arm fatigue, the operator's elbow was supported on a small three-legged table. The operator held the cone/rod so that the source firmly contacted the skin, but did not exert extreme pressure on the skin to avoid deoxygenating it. Since these exposures lasted less than 45 seconds, it is believed that skin was not anoxic. The elastic straps were taken off or moved for exposures using the cone/rod. 


\section{General Experimental Protocol}

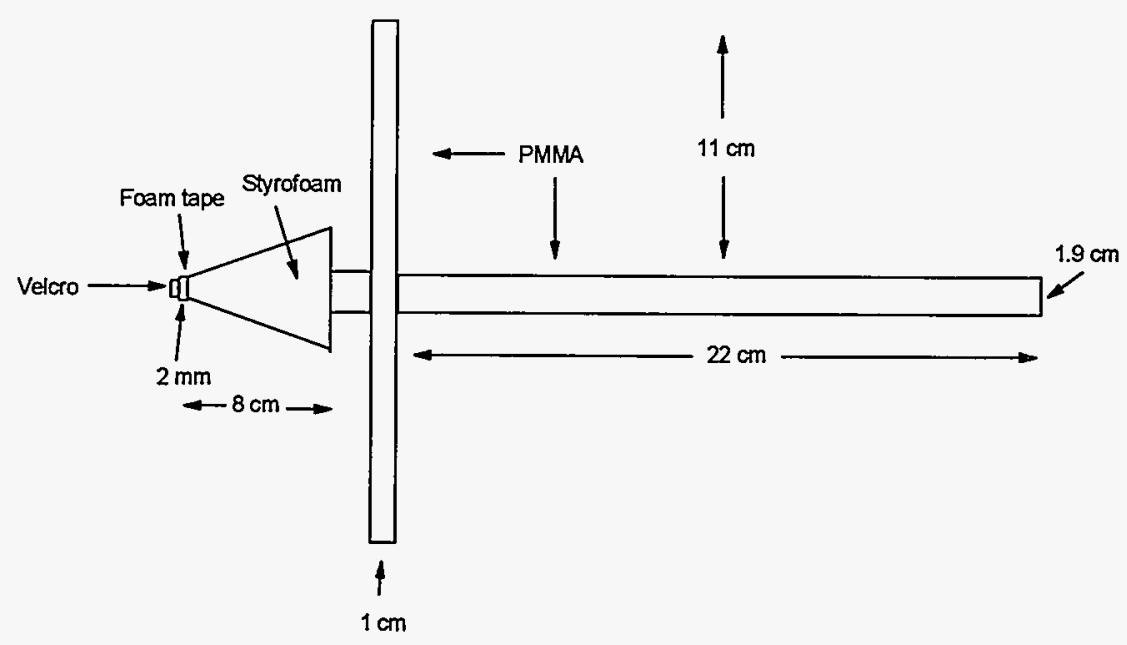

Figure 3.17 Cone-rod assembly used to hold the source mounting-blocks (Figures 3.3 to 3.13 ) on the pig for irradiations lasting less than $\mathbf{4 5}$ seconds.

Timing errors associated with placing and removing the cone/rod were estimated to be about $0.5 \mathrm{~s}$.

\subsubsection{Video Documentation of the Pig Irradiation}

A remote-controlled video camcorder was mounted above the pig during all irradiations. This proved to be valuable in verifying/correcting the location of the source and irradiation times.

For the last series of irradiations, the camcorder was connected to a remote monitor so that the source placements could be verified by observers in real time, and errors made in placing the particles could be immediately noted. This also was valuable in allowing remote monitoring of the pig's breathing patterns under anesthesia.

\subsubsection{Source Placement Protocol}

The placement of the source was timed by one or two observers, using pre-set countdown timers. The primary timer was in the same room as the source operator and the countdown would start as the operator placed the source on the pig. An observer would note the source's placement position, beginning placement time, total placement time, and make notes about the exposure (e.g., not well centered). Another individual would verify the source's placement and recorded notes. 
The majority of pigs were irradiated using two or three sources simultaneously. The protocol required planning and estimating the source's placement position and timing before irradiation, since only one source could be under any individual elastic strap at once. Placing a second source under the same elastic strap would risk altering the position of the first one.

\subsubsection{Treatment of Control Sites}

In the 1994-95 studies, a large number of sites were deliberately not irradiated. These sites were selected prior to the irradiation to serve as controls. While it was not thought necessary to shamirradiate these sites, observers scoring the pigs (section 3.6) had no knowledge as to which sites were irradiated and which sites were controls.

\subsection{Observation of Lesions and Scoring Procedure}

\subsubsection{Observation Cubicle}

The observation cubicle consisted of a rectangular box $112-\mathrm{cm}$ long (44 inches), $76-\mathrm{cm}$ wide (30 inches), and $60-\mathrm{cm}$ (24 inches) high, supported $60 \mathrm{~cm}$ (24 inches) above the floor on legs at each corner. The two long sides consisted of $0.64-\mathrm{cm}$ ( $1 / 4$ inch) thick Lucite sheets. These fit in grooves and could be raised or lowered to allow researchers better access to the animals. The two end panels were constructed of $1.3-\mathrm{cm}(1 / 2$ inch) thick plywood measuring $45 \times 60 \mathrm{~cm}$ ( $18 \times 24$ inches) hinged at the top giving an opening for the pigs to enter.

A wooden chute, attached to the cubicle floor at one end of the apparatus, served as a ramp for the animals to enter the observation area. The ramp had a ridged floor to prevent them from slipping. At the opposite end of the observation chamber was a 20.3-cm ( 8 inch) high platform measuring 45.7-cm (18 inches) long and 40.6- $\mathrm{cm}$ (16 inches) wide with an off-center hole to accommodate a stainless-steel feeding bowl. The off-center hole caused the pig to stand near one side of the cubicle, which facilitated observation and photographing the opposite flank. The bowl platform could be lifted out and reversed for observing either flank of the pig.

\subsubsection{Observation Procedure}

At least two observers took part in each observation, but the observations were made and recorded independently. Each person examined each grid area across one row and recorded his/her observations. Before proceeding to the next row, the observers would compare their findings to ensure that the data were properly recorded. Agreement among the observers was not necessary. Most times, a third person was available to consider any differences between the two observers. For any unresolved discrepancies, additional detailed comments and notations were included on the observation sheet. Descriptive statements were made, as well as actual measurements of skin changes. Although not marked on the pig's skin, in all studies carried out after $7 / 25 / 94$ (these involved $\mathrm{Yb}-175, \mathrm{Sc}-46$ and the second series of fissioned $\mathrm{UC}_{2}$ exposures) each grid square was conceptually divided into nine sectors numbered from one to nine, beginning in the upper left-hand corner. The position of each lesion was thus noted, so lesions 


\section{General Experimental Protocol}

beginning in the upper left-hand corner. The position of each lesion was thus noted, so lesions could be tracked to ensure that if an early-appearing lesion disappeared and later reappeared, that it was indeed the same lesion.

\subsubsection{Photo Documentation}

Any lesion that appeared was photographed using a 35-mm Dine Auto Frame Closeup Fixed Focus Camera ${ }^{12}$ with an in-picture data line containing a $20-\mathrm{mm}$ scale, the animal's number, flank, location, the date, and days post-irradiation (DPI). All lesions were photographed when first observed and at least once a week throughout the observation period.

\subsubsection{Histological Determinations and Histopathological Evaluation}

The following paragraphs describe the primary purposes, and the methodology used, for histological and histopathological studies of the pigs' skin.

\subsubsection{Thickness of Keratin Layer}

The thickness of the keratinous layer was examined to evaluate dose at depth and to interpret the results. Variations in thickness with age, the site on the animal, and between strains have been reported. Van Den Aardweg et al. (1990) demonstrated that while epidermal thickness in the large white pig was 60-90 $\mu \mathrm{m}$ with very little keratin layer, another strain of minipigs, the Gottinger, had an epidermal thickness of only $40 \mu \mathrm{m}$, but a keratin layer of $70 \mu \mathrm{m}$, leading to an effective depth of $110 \mu \mathrm{m}$ for the basal cells. For low-energy beta particles, this difference in depth leads to a significant difference in dose to the basal cells, and thus, can markedly effect the induction of skin ulcers. Because of this, 3- to 4-month-old pigs, which were used in the later BNL studies, were preferred; they have a keratin layer which is similar in thickness to that of adult humans (Hall, 1988). The general morphology of the skin of 3- to 4- and 9-month-old pigs are comparable.

To further understand the results from the exposures, it was most important to know the thickness of the keratin layer at the time of exposure. Not only was there a possible strain difference, but also the treatment (such as shaving) of the animals before placing the sources can reduce the thickness of the keratin layer. Hence, biopsy samples were taken from several skin areas of each animal 7-10 days before irradiation. Clipping the hair did not significantly reduce the keratin. At the time of irradiation, additional samples were taken immediately after the pig again was closely shaved. Close shaving removed some of the keratin, especially on older pigs. Therefore, these samples gave a measure of remaining thickness of the keratin at the time of irradiation. These samples also provided additional information on variability among areas on a single animal and variations among animals.

${ }^{12}$ Lester A. Dine Inc., 351 Hiatt Drive, Palm Beach Gardens, FL 33418. 


\section{General Experimental Protocol}

\subsubsection{Depth of Basal Cells}

The depth of the basal cells, which are prime targets for some types of radiation damage, was measured to establish whether this parameter was similar in the pigs used in this study to those used in other laboratories. The depth of these cells also is of particular importance for betaparticle irradiations since beta penetration is highly energy-dependent and varies among isotopes.

\subsubsection{Methodology for Histological and Histopathological Studies}

To determine the thickness of the keratin layer and the depth of the basal cells, three biopsies were taken on each flank of the animals in a diagonal line, so that when viewing the animal from one side, a biopsy site would be near the upper-front, a second near the middle, and a third near the lower-rear. Using the same procedure on the reverse flank gave six biopsies, with one sample from near the four corners of the grid area and two near the middle. These biopsies were not taken in specifically designated grid sites, but in the general areas noted above, to sample different positions on the animal's flanks. Each biopsy was designated with a single letter code, the relative position of which was recorded on a diagram of each animal.

The biopsies were taken using a 6-mm biopsy punch, and placed immediately in $10 \%$ buffered formalin. In most cases there was very little bleeding; however, if bleeding occurred, it was stopped by compression with sterile gauze. The wounds then were sprinkled with neomycin/bacitracin antibiotic powder.

Except in cases where special care was taken not to disturb the keratin layer, the biopsy areas first were cleaned with $70 \%$ ethanol and allowed to dry.

All biopsies were carried out under surgical anesthesia. All animals were observed daily throughout the experiment, and in no case did a biopsy site become infected; all sites healed with little or no scarring.

On the day of irradiation, animals again were weighed, anaesthetized, and closely shaved to remove any hair stubble which had grown since the previous shaving and which might prevent close contact of the particle and the skin.

Immediately after irradiation, two or more additional biopsies were taken on each flank to determine the thickness of the keratin layer and the depth of the basal cells at the time of irradiation. These biopsies were treated identically to the pre-exposure biopsies.

The circular "punch" biopsies were subsequently cut longitudinally (perpendicular to the plane of the epidermis) in as nearly equal halves as possible. For histopathological evaluation of irradiated areas, each section was cut through any visible lesion, or if there was no lesion, the cut was made through the center of the biopsy. 


\section{General Experimental Protocol}

At the end of the experiment, several additional biopsies were taken of areas with either unhealed or healed lesions. The slides were first scanned by Drs. H. Atkins and A. Carsten at $B N L$, and then sent to Dr. John Archambeau ${ }^{13}$ for further evaluation.

Biopsy samples were sent to American Histolabs ${ }^{14}$ for processing. The two halves of each biopsy were mounted to section through both pieces, and at least three sections per slide were mounted. Sections were cut 5 microns thick and stained with hematoxylin and eosin.

Three areas were selected for measuring keratin thickness and basal cell depth from each histological section. From each, five areas of interest were photographed using an Olympus Universal Vanox Microscope system with a 35-mm Photomicrographic System Camera model PM-10-A. Photomicrographs also were taken at the same magnification of a 2-mm ruler with 10-micrometer subdivisions.

The resultant tissue and micrometer photographs were equally enlarged to facilitate the measurements. For this, the micrometer photograph was overlaid on the tissue photographs and the distances were read off.

\subsubsection{Characterization of Skin Changes}

Skin changes were scored as a) erythema - a reddening of the skin that can be caused by heat, drugs, ultraviolet radiation, or ionizing radiation; b) dark scabs - scabs that are generally thought to result from effects deep enough to cause release of red dermal blood cells; or c) white scabs scabs that are very superficial and apparently do not contain blood cells. Each lesion was measured for diameter and recorded to the nearest millimeter.

Although funding limitations did not allow an in-depth study of the time-course and severity of lesion development, the study did include 1) examining the early-appearing (less than 2 weeks) and the later (greater than 40 days) lesions, and 2) taking biopsies of areas exposed to Sc-46 $\left(E_{\max } 0.36 \mathrm{MeV}\right)$ and $\mathrm{Yb}-175\left(E_{\max } 0.47 \mathrm{MeV}\right)$ at two different doses (those expected to induce approximately $30 \%$ and $100 \%$ lesion incidence).

${ }^{13}$ Loma Linda Medical Center, Department of Radiation Medicine, Room 121, 11234 Anderson Street, Loma Linda, CA 92354.

${ }^{14}$ American Histolabs, Inc., 7605-F Airpark Road, Gaithersburg, MD 20879. 


\section{METHODS OF DATA ANALYSIS}

Two basic approaches to data analysis were employed. One assumes a deterministic or threshold response and is based on the scab-diameter criterion and analysis. This is the approach employed by the NCRP Committee (NCRP, 1989) in Report 106. The second approach is based on the incidence of effects and observed lesions compared to the number of exposed areas. Data analyses are based on fitting data to cumulative normal probability functions, which imply stochastic processes are dominant. The lesions observed for this criteria were erythema, dark scabs, and white scabs. In this analysis, the diameter of lesion is not evaluated -- the lesion is either detected or not detected.

\subsection{Criteria for Lesion Assessment}

An endpoint considered undesirable was a break in the skin. It was assumed that the observation of a scab indicated that there had been a break in the skin. At doses corresponding to a low percent incidence, these small scabs were difficult to see, and the determination was considered somewhat subjective. While this was later found not to be the case, several methods were used to determine scab incidence. These methods are described next.

\subsubsection{Scab Criteria for Method "E"}

The scoring method first used for the 1991-92 studies was termed Method E for Early method. Lesions were scored three times per week for three weeks, then twice per week. A scab was considered radiation-induced if it was seen by both observers any three times during the scoring period in question, i.e., 28,48 , or $71 \mathrm{DPI}$. This method was effective for most of the 1991-92 studies, since the doses were large and the scabs were very persistent. The resulting scab diameter had a high degree of correlation with dose for $U_{2}$ as in the Forbes and Mikhail data set (NCRP, 1989) and percent scab incidence (PSI) values were consistent with the method used by Hopewell et al. (1986) for Tm-170 exposures (section 5.7.5). The method was not used after 1992 , and some of the data on percent scab incidence using Method $E$ were reevaluated using the following scoring criteria.

\subsubsection{Scab Criteria for Method "A"}

For later determinations, another scoring criterion was used, termed Method " $A$," which detected the most scabs. It is a modified Hopewell et al. (1986) method, in which pigs were scored twice per week for 28 days by two or, in some cases, three observers. In Hopewell's method, if a lesion was seen by all observers for two consecutive scoring periods, the lesion was considered radiation-induced. Half-lesion points were assigned if a lesion was recorded by two of three observers. To model this scoring criterion, we eliminated data from one of the three weekly observation periods for the first $21 \mathrm{DPI}$. The day eliminated corresponded to an observation every third and fourth day in a 1-week period. After $21 \mathrm{DPI}, \mathrm{BNL}$ observers made only two observations per week, which was similar to the Hopewell scoring schedule. The following were BNL's scab-scoring criteria (Method A). If two observers scored an area as a scab on the same 
Methods

day, but neither did on the next observation day, or if two observers scored the area as a scab on one observation day but only one observer scored it as a scab the next observation day, or vise versa, the area received a score of one-half of a scab. If two observers scored the area as a scab on two consecutive observation days, then the lesion was considered to be a full scab.

\subsubsection{Scab Criteria for Method "B"}

This next method used, termed Method "B" or "4-of-6/4-of-4," scored fewer scabs than Method $A$. For the first three weeks in which the pigs were scored three times per week, a scab was considered to be radiation-induced if two independent observers each scored an area as a scab a minimum of twice in one week. This was called 4-out-of-6, since there were two observers and three observation periods, giving six possible outcomes; four sightings were required out of the six, with each observer seeing the scab at least twice. After the first 21 days, the pigs were scored twice per week, and a scab was considered to be radiation-induced if two observers each scored a scab on two consecutive observation days -- which was called 4-out-of-4.

\subsubsection{Scab Criteria for Method "C"}

The final method termed Method " $C$," or "6-of-8/5-of-6," was the most restrictive technique used, and it was designed to minimize spurious apparent background. A scab was considered radiation-induced if two observers scored an area as a scab three times each, out of four consecutive scoring periods for the first three weeks. After three weeks, when the pigs were only scored twice per week, a scab was considered radiation-induced if one observer scored an area as a scab a minimum of twice and another observer scored the area as a scab a minimum of three times in three consecutive scoring periods.

\subsection{Scab Diameter Regression Analyses}

The linear regression methodology was used in NCRP 106 (1989) in which the observed scab diameter was plotted as a function of the natural logarithm of the number of beta particles emitted from $\mathrm{UC}_{2}$ particles. The relationship appeared to be a straight line. The fitted line was extrapolated to the $x$-axis intercept, and the corresponding dose was then considered the "threshold" dose, i.e., below which no observable ulceration was expected. The NCRP reduced the estimated threshold dose by a factor of about three to estimate a threshold for a point source

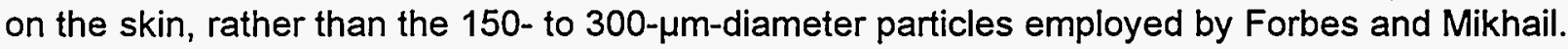
The mathematics used to determine this threshold and its standard deviation are given in Appendix A of Baum et al. (1992), and were used to analyze some of the data reported here.

\subsubsection{Scab Diameter: Experimental Description}

For this approach, a range of doses is required which will induce scabs with significantly different diameters. This method is most efficient if doses are equally spaced logarithmically (each dose 
is a constant factor greater than the previous one) and several of the exposures cause no scabs. Including the exposed sites that did not result in scabs, plotted as zero diameter, at very low doses in the regression will incorrectly bias the apparent threshold toward low values. For this reason, data in the regression included all exposed sites with doses greater than the lowest dose which produced a scab and the next lower dose that did not result in a scab. The inclusion of the "zero diameter" scab with a dose just less than the lowest dose which resulted in a scab was not thought to bias the data significantly to lower doses. Note that all exposed sites not resulting in scabs with doses greater than the lowest dose which induced a scab are included in the regression (scored as a zero diameter scab). For the BNL experiments, the sizes of scabs were recorded during each observation, and the maximum diameter of each was used for the regression.

In addition to the number of beta particles emitted from the source, the dose averaged over $1 \mathrm{~cm}^{2}$ at $70 \mu \mathrm{m}$ was used as an independent parameter. For a given geometry, this dose is directly proportional to the number of beta particles emitted.

\subsubsection{Advantages of the Scab-Size Method of Analysis}

Correlating scab size with dose has several advantages. Scab size tends to be a function of dose, as is most evident for the higher energy beta-particle emitters. Scab size is a measure of the non-stochastic damage caused by hot particles, and the dose delivered can be very crudely estimated from scab diameter for the higher energy (e.g., $0.97 \mathrm{MeV}$ ) beta-particle emitters.

Another advantage is that a large number of data points are not required to determine the approximate threshold. For example, Forbes and Mikhail's (NCRP, 1989) data-set included only nineteen hot-particle exposures. Thus, this approach proved very useful in preliminary BNL studies in estimating the dose that would be needed for $10 \%$ incidence. This estimate then was used to plan more extensive dose-response studies.

Additional data, such as scab persistence and erythema size, can also be related to dose, as illustrated in the Results section of this report.

\subsubsection{Disadvantages of the Scab-Size Method of Analysis}

The scab-diameter method is best used in a range-finding study, or a study to determine ulceration with $100 \%$ incidence. Even though ulcers are normally considered deterministic effects, there are stochastic aspects of the induction and observation processes. The scab diameter method of analysis is not reliable enough to quantify the stochastic region (probability of low percent scab incidences) of the ulcer-induction response from hot-particle exposures.

The method also is not useful for lower energy beta particle emitters, as was noted for $\mathrm{Yb}-175$ which has a maximum beta particle energy of $0.47 \mathrm{MeV}$, with a maximum range of about $1.5 \mathrm{~mm}$ in tissue. For a $\mathrm{Yb}-175$ particle on the skin, the maximum expected scab diameter, therefore, is $3 \mathrm{~mm}$ plus the diameter of the particle (the lesion might become larger if it becomes infected or is 


\section{Methods}

scratched). Also, inaccuracies in observing the lesions, and the non-circular shape of some lesions did not allow distinctions of size increments less than about $1 \mathrm{~mm}$. Thus, the uncertainty in scab size is a greater percentage of the effect for these small lesions than it is for larger lesions produced by higher energy beta particle emitters. Regressions of scab diameter as a function of dose for Yb-175 gave thresholds near zero, which is illogically small, presumably due to statistical, background, and scab-size limitations.

\subsection{Dose-response Analysis of Percent Scab Incidence}

The Percent-Scab Incidence (PSI) methodology was used in Hopewell's particle studies (Hopewell et al., 1986, Hopewell, 1991). Replicate exposures were made at different doses to determine the number of ulcers induced per number of exposures, or the PSI for each exposure. The entire dose response can then be plotted to give the PSI as a function of dose. The PSI as a function of the log of the dose is well fitted by a sigmoidal curve and a cumulative normal (Gaussian) distribution was assumed. The curve can be analyzed using probit statistical procedures (Finney, 1964) (described in section 4.3.2) to calculate expected ulcer incidence at any dose with the related confidence intervals.

\subsubsection{PSI: Experimental Description}

Replicate exposures were made for doses that are approximately logarithmically spaced. Since many replicates must be made at each dose, some prior knowledge of the dose response was necessary so that dose points are not wasted on $0 \%$ or $100 \%$ incidence exposure-levels. The dose range for the BNL PSIs was determined from the results of the previous experiments on scab-size regression. These PSI experiments relate to a binomial response, i.e., there either is or is not a scab for each exposure point. While the size of the scab was noted for other purposes, it was not used in the PSI dose-response analyses, the purpose of which was to determine a $10 \%$ incidence and a lower $95 \%$ confidence band on dose. The experimental plan required sufficient exposures so that the lower $95 \%$ limit would be reasonable, i.e., within a factor of 2 or 3 .

Larger uncertainties are associated with low-frequency events. This uncertainty was reduced by increasing the number of replicate exposures to 26 or 28 at the lower doses.

\subsubsection{Probit Analysis Method}

Finney (1964) discussed the probit analysis method. Briefly, the percent response of a cumulative normal distribution is transformed into the number of standard deviations, or probits, from the mean. If the function is cumulative normal, the result is a straight line. Normal linear-regression techniques or a maximum likelihood function are then employed to obtain the best-fit to this line.

Inverse confidence limits (95\%) of dose were calculated for each predicted response. These limits are to be distinguished from those of standard linear regression in which confidence limits 
for the dependent variable are calculated. The inverse confidence limits are calculated using fiducial probability, and are also called fiducial limits (Finney, 1964). As an example, assume the $E D_{50}$ value for scab induction is 8.5 Gy with $95 \%$ inverse confidence limits (or fiducial limits) of 5.7 to $9.8 \mathrm{~Gy}$. This means that if a scab incidence of $50 \%$ is observed, it is $95 \%$ probable that the dose causing this response is between 5.7 and $9.8 \mathrm{~Gy}$, with a mean value of $8.5 \mathrm{~Gy}$. For the sake of brevity, "confidence limit(s)" will refer to the inverse confidence limits(s) or the fiducial limit(s) throughout the remainder of the report. These confidence limits are displayed graphically in many plots in the following sections and must not be mistaken for uncertainty of scab incidence for a given dose; they are the uncertainty of dose for a given scab incidence.

The probit procedure was also used to test scoring Methods $A, B$, and $C$ to determine which yielded the best fit to a Gaussian distribution. The SAS/STAT probit computer software (1989) was used for probit analysis of the PSI data.

\subsubsection{Advantages of the PSI Experiment}

The PSI experiments quantify the stochastic nature of skin lesions caused by hot particles. The results reflect the many variables of the skin, such as its morphology, variation in depth of the target cells, variations in the thickness of the keratin layer, and proximity of the source to a hair follicle.

\subsubsection{Disadvantages of the PSI Experiment}

Many more exposures are needed for these experiments than for the scab-size experiments because of the large number of replicates required at each dose. To optimize the exposures, some knowledge of the dose response was required beforehand. For this purpose, a rangefinding experiment was done investigating scab diameter as a function of dose.

\subsection{Binomial Statistics on $10 \%$ Incidence}

Originally, it was believed that the dose-response curve may not be normally distributed at lowfrequency events due to numerous variables in skin response. If the dose response was not Gaussian at low doses, then the probit procedure could not be used to predict incidence at low doses. To ensure that a dose could be identified that would yield $s 10 \%$ incidence with $95 \%$ confidence, a simple statistical axiom was employed.

Using binomial statistics, if twenty-eight spots are exposed, all to the same dose, and none produce lesions, it is $95 \%$ probable that the $10 \%$ incidence value occurs at a greater dose (see binomial tables in Natrella, 1963). Twenty-eight replicate particle irradiations were therefore carried out at two or more low doses, and the highest dose that yielded no scabs gave the desired $<10 \%$ incidence dose value. 
Methods

\subsection{Analyses of Scab Persistence and Erythema Results}

\subsubsection{Percent-Scab-Days (PSD) Methodology}

The lesions generated from particles are superficial for the most part. One method to quantify the potential harm or psychological distress to humans associated with these may be to measure the persistence of the scab. There is a logical trade-off between the risks of one or more scabs for one or more weeks vs. a low probability of stochastic risks of a more serious nature.

The PSD criterion is a measure of the fraction of days in the observation period that scabs were observed on the pigs for each dose. Rather than relying on the "4-of-6" scored criterion for the lesion to be considered radiation-induced, as described in section 4.1, PSD is simply 100 times the ratio of the number of times a scab is seen (summed over all observers) divided by the total number of observations (summed over all observers) for a certain dose. Scab days can then be analyzed as the PSDs over a specific period, e.g., to give the probability of seeing a scab from a certain dose during the 28 days (or more) after the exposure. The PSD can also be calculated over a period, e.g., to give the probability of seeing a scab from a certain dose between 7 and 14 days after the exposure.

\subsubsection{Advantages of the PSD Methodology}

The PSD methodology can be used in conjunction with the percent-scab-incidence experiments. The methodology is a quantitative measurement of scab persistence. As a measure of detriment, it may be a useful quantity in determining the acceptable amount of non-stochastic damage to the human skin from particles.

\subsubsection{Disadvantages of the PSD Methodology}

The PSD criterion may not adequately reflect the importance of larger lesions. Although larger lesions tend to persist longer, the detriment may better be related to scab's area and depth, and these factors may not be linearly reflected in its persistence.

\subsection{Evaluation of Histology Measurements}

Possible histological differences (between animals and between areas on the same animal) and histopathological radiation effects were evaluated by examining biopsies taken pre- and postirradiation as described in section 3.6.4.3.

Five measurements were made of the basal-layer depth and the keratin-layer thickness for each of the three pictures taken of different areas of each prepared slide from the biopsies. These fifteen measurements were used in statistical evaluations. Also, keratin thickness was compared before and after close shaving. 
The measurements of the basal and keratin layer were made to ensure that the responses, e.g., the $E D_{10}$ and $E D_{50}$ values, were not influenced by these parameters. This was important since comparisons were made for different beta particle energy emitters; e.g., if the basal cell depth for all the pigs irradiated with $\mathrm{Yb}-175$ was shallower than that of the other pigs irradiated with other isotopes, then one can not exclude skin differences from confounding the response.

To investigate these differences, a three-stage nested design was used in the analysis of variance (Hicks 1993). In the design, the pig's flanks (left and right) were nested within each pig, and the biopsies were nested within each flank. All variables were considered fixed, rather than random, since the biopsy sites were chosen, and the measurement of the biopsies was also selected to be representative. Only the pigs used in the 1994-95 studies were compared (experiments 13 to 19 in Table 3.10 for $\mathrm{UC}_{2}, \mathrm{Yb}-175$, and Sc-46), as the data were not available for the earlier studies. The calculations were carried out using the "proc glm" procedure of the SAS/STAT computer software (1989).

If differences were found, comparisons of least-squares means were used to identify which pigs were different. Least-squares means were necessary, since the number of biopsies on the pigs differed in some cases. This was carried out using the least-squares means option in the "proc $\mathrm{g} / \mathrm{m} "$ procedure of the SAS/STAT computer software (1989). A Bonferroni Multiple Comparisons Test, an option in the procedure listed above, was also used to compare with the results of the least-square means comparison.

Statistical t-tests were used to determine if changes in keratin thickness before and after close shaving were significant (see Section 5.18). 



\section{EXPERIMENTAL RESULTS}

This report covers experimental work done during the 1991-92 and 1994-95 periods. To provide a clear and complete record, the results and early analyses for specific studies are first summarized approximately chronologically; it highlights the implementation of minor changes in experimental or analytical protocols.

A general summary of results for the preferred scoring method (usually Method $E$ or $C$ ) for each experiment is given in Table 5.1.

Table 5.1 Results for each of the experiments listed in Table 3.10. See the following text for further details.

\begin{tabular}{|c|c|c|c|}
\hline $\begin{array}{l}\text { Experi- } \\
\text { ment No. } \\
\text { (Source) }\end{array}$ & $\begin{array}{l}\text { Animal } \\
\text { No. }\end{array}$ & $\begin{array}{l}\text { Irradia- } \\
\text { tion } \\
\text { date }\end{array}$ & $\begin{array}{l}\text { Findings } \\
\text { (dose averaged over } 1 \mathrm{~cm}^{2} \text { at } 70 \mu \mathrm{m} \text { depth) }\end{array}$ \\
\hline $\begin{array}{c}1 \\
\left(\mathrm{UC}_{2}\right)\end{array}$ & $156-4$ & $7 / 2 / 91$ & $\begin{array}{l}\text { aScab diameter vs. dose regression threshold of } 4.4 \pm 1.6 \mathrm{~Gy} \text {. This } \\
\text { threshold is } 1 / 4 \text { th that of Forbes and Mikhail. }\end{array}$ \\
\hline$\stackrel{2}{\left(\mathrm{UC}_{2}\right)}$ & $157-2$ & $8 / 26 / 91$ & $\begin{array}{l}\text { Scab diameter vs. dose regression thresholds of } 9.1 \pm 2.2 \text { and } \\
9.9 \pm 2.7 \mathrm{~Gy} \text { for on- and off-skin sources, respectively. The on-skin } \\
\text { source yielded a threshold one-half that of Forbes and Mikhail. }\end{array}$ \\
\hline $\begin{array}{c}3 \\
(\mathrm{Tm}-170)\end{array}$ & $156-5$ & $11 / 8 / 91$ & $\begin{array}{l}\text { Scab diameter vs. dose regression thresholds of } 4.7 \pm 2 \mathrm{~Gy} \\
\text { and } 30 \pm 10 \mathrm{~Gy} \text { for on- and combined off-the-skin particles, } \\
\text { respectively. }\end{array}$ \\
\hline $\begin{array}{c}4 \\
(\mathrm{Tm}-170) \\
\end{array}$ & $156-5$ & $1 / 27 / 92$ & $\begin{array}{l}\text { Scab diameter vs. dose regression threshold of } 5.7 \pm 0.58 \mathrm{~Gy} \text {, } \\
\mathrm{ED}_{5}=5.9 \mathrm{~Gy}, \mathrm{ED}_{50}=12 \mathrm{~Gy} \text {. }\end{array}$ \\
\hline $\begin{array}{c}5 \\
(T m-170)\end{array}$ & $156-1$ & $2 / 11 / 92$ & $\begin{array}{l}\text { Scab diameter vs. dose regression threshold of } 2.5 \pm 1.9 \mathrm{~Gy} \text { for } \\
160 \text { and } 470-\mu \mathrm{m} \text { sources. All scabs produced a persistent, } \\
\text { depigmented area. }\end{array}$ \\
\hline $\begin{array}{c}6 \\
(T m-170) \\
\end{array}$ & $157-2$ & $3 / 9 / 92$ & $\begin{array}{l}\text { Scab diameter vs. dose regression threshold considered } \\
\text { inappropriate. }\end{array}$ \\
\hline $\begin{array}{c}7 \\
(T m-170)\end{array}$ & $85-1$ & $3 / 10 / 92$ & $\begin{array}{l}\text { Scab diameter vs. dose regression threshold considered } \\
\text { inappropriate. }\end{array}$ \\
\hline $\begin{array}{c}8 \\
(T m-170) \\
\end{array}$ & $85-1$ & $6 / 8 / 92$ & $\begin{array}{l}\text { Inconclusive due to few sites exposed and erratic data (see Figure } \\
5.29 \text { ). }\end{array}$ \\
\hline $\begin{array}{c}9 \\
(\mathrm{Tm}-170) \\
\end{array}$ & $23-1$ & $6 / 8 / 92$ & $\begin{array}{l}\text { Results combined for pigs } 23-1 \text { and } 23-5: \mathrm{ED}_{10}: 2.8 \mathrm{~Gy}(1.9-3.5) \text {, } \\
\mathrm{ED}_{50}: 5.9 \mathrm{~Gy}(5.1-6.7) \text {. }\end{array}$ \\
\hline $\begin{array}{c}10 \\
(\mathrm{Tm}-170)\end{array}$ & $23-5$ & $6 / 8 / 92$ & See results for pig $23-1$ \\
\hline
\end{tabular}


Experimental Results

Table 5.1 (Cont.)

\begin{tabular}{|c|c|c|c|}
\hline $\begin{array}{l}\text { Experi- } \\
\text { ment No. } \\
\text { (Source) }\end{array}$ & $\begin{array}{l}\text { Animal } \\
\text { No. }\end{array}$ & $\begin{array}{l}\text { Irradia- } \\
\text { tion } \\
\text { date }\end{array}$ & $\begin{array}{l}\text { Findings } \\
\text { (dose averaged over } 1 \mathrm{~cm}^{2} \text { at } 70 \mu \mathrm{m} \text { depth) }\end{array}$ \\
\hline $\begin{array}{c}11 \\
(\mathrm{Yb}-175)\end{array}$ & $85-2$ & $7 / 31 / 92$ & $\begin{array}{l}\text { Scab diameter vs. dose regression threshold considered } \\
\text { inappropriate. Doses of } 1.3 \mathrm{~Gy} \text { and } 5.1 \mathrm{~Gy} \text { yielded } 68 \text { and } 82 \% \\
\text { scab incidence. }\end{array}$ \\
\hline $\begin{array}{c}12 \\
(Y b-175)\end{array}$ & $38-2$ & $7 / 31 / 92$ & $\begin{array}{l}\text { Scab diameter vs. dose regression threshold considered } \\
\text { inappropriate. Doses of } 1.3 \mathrm{~Gy} \text { and } 5.1 \mathrm{~Gy} \text { yielded } 13 \text { and } 25 \% \\
\text { scab incidence using scoring methodology discussed in Section } \\
5.6 \text {. }\end{array}$ \\
\hline $\begin{array}{c}13 \\
(\mathrm{Yb}-175)\end{array}$ & $37-1$ & $7 / 25 / 94$ & Results are combined with those from pigs $39-3$ and $50-3$ below. \\
\hline $\begin{array}{c}14 \\
(\mathrm{Sc}-46)\end{array}$ & $37-1$ & $7 / 25 / 94$ & Results are combined with those from pigs $50-2$ and $50-3$ below. \\
\hline $\begin{array}{c}15 \\
(\mathrm{Yb}-175)\end{array}$ & $39-3$ & $7 / 26 / 94$ & $\begin{array}{l}\text { Results are combined with pigs } 37-1,38-2, \text { and } 50-3 . E_{10}=1.3 \\
(0.89-1.8) \mathrm{Gy} ; \mathrm{ED}_{50}=6.0(4.3-9.7) \mathrm{Gy} \text {. }\end{array}$ \\
\hline $\begin{array}{c}16 \\
(\mathrm{Sc}-46)\end{array}$ & $50-2$ & $9 / 1 / 94$ & $\begin{array}{l}E D_{10}=5.1(2.7-7.2) G y ; E D_{50}=12(8.8-17) \text { Gy, results of pigs } \\
37-1,50-2 \text {, and } 50-3 \text { combined. }\end{array}$ \\
\hline $\begin{array}{c}17 \\
(\mathrm{Yb}-175)\end{array}$ & $50-3$ & $9 / 29 / 94$ & See results for pigs $39-3$ and $50-2$ above. \\
\hline $\begin{array}{l}18 \\
\left(\mathrm{UC}_{2}\right)\end{array}$ & $90-2$ & $2 / 7 / 95$ & $\begin{array}{l}\text { On-skin } \mathrm{ED}_{10}=8.5(5.7-9.8) \mathrm{Gy} ; \mathrm{ED}_{50}=11(9.9-19) \mathrm{Gy} \text {. Off-skin } \\
\mathrm{ED}_{10}=4.5(0.90-7.0) \mathrm{Gy} ; \mathrm{ED}_{50}=11(6.2-14) \mathrm{Gy} \text {. Results } \\
\text { combined with pig } 90-3 \text { below. }\end{array}$ \\
\hline $\begin{array}{c}19 \\
\left(\mathrm{UC}_{2}\right)\end{array}$ & $90-3$ & $2 / 7 / 95$ & Results combined with pig $90-2$ above. \\
\hline
\end{tabular}

a. Scab diameter vs. dose regression thresholds are the dose axis intercept, which is similar to the methodology used in NCRP 106 (1989).

Section 6 includes additional data analyses that include tests of the sensitivity of results to the different scoring protocols described earlier, combining data from individual experiments to increase the statistical power and the reliability of conclusions, and comparing the results with those of other researchers. 
Experimental Results

\subsection{On-Skin $\mathrm{UC}_{2}$ Results}

\subsubsection{Scab Occurrences}

On-skin $U_{2}$ experiments were conducted in experiments 1 and 2 . The particles were placed on a foam-tape tip to ensure that they did not move and were in firm contact with the skin (Figure 3.3). Regressing the natural log of the number of beta particles against the diameter of the resultant scabs, as described in NCRP 106 (1989), gave formation thresholds of $(7.8 \pm 2.8) \times 10^{9}$ and $(1.6 \pm 0.87) \times 10^{10}$ for experiments 1 and 2 irradiations, respectively (Figures 5.1 and 5.2). Similar plots are given in Figures 5.3 and 5.4 where the dose rather than the number of beta particles is expressed as the independent variable (thresholds of $4.4 \pm 1.6 \mathrm{~Gy}$ and $9.1 \pm 1.6 \mathrm{~Gy}$ ). Plots similar to Figures 5.3 and 5.4 are termed dose-response curves. The regressions included all points on the graph to the right of, and including, the data point representing the lowest dose that produced a detectable scab and the dose point to the immediate left of the first scab. The deduced "thresholds," expressed as the number of beta particles emitted from the source, were one-fourth and one-half below the results of Forbes and Mikhail (NCRP, 1989) for BNL's on-skin exposures of experiments 1 and 2, respectively.

The BNL doses spanned the doses used by Forbes and Mikhail and included ones which produced no ulcers; this could account for the differences because no zero-diameter ulcers were obtained in Forbes and Mikhail's studies. This methodology is best for providing an estimate for a low probability of detecting a barely visible scab, as illustrated in the results described below.

\subsubsection{Comparisons of Erythema and Scab Occurrences}

Although induction of erythema has generally not been considered a serious or dose-limiting effect, its occurrence was measured in these studies. It is of interest partly because it may be an early indication of hot-particle exposure, or may be of some value in separating the effects of hot particles from other causes of skin lesions.

The diameter of erythema was measured in exposed sites at the same time and on the same schedule as scabs were recorded. Figures 5.5 to 5.12 show correlations between erythema and scab diameters vs. days post-irradiation for exposures to activated $\mathrm{UC}_{2}$ particles (experiment 2) for doses from 0 to $470 \mathrm{~Gy}$ averaged over $1 \mathrm{~cm}^{2}$ at $70 \mu \mathrm{m}$ depth $\left(0\right.$ to $8.2 \times 10^{11}$ beta particles emitted from the source). Each exposure is identified by a letter and a number (indicating row and column on the pig's flank, respectively), e.g., A-5, C-3. Negative bars indicate days in which the pigs were not observed. Figures 5.5 to 5.8 include the results for on-skin exposures that produced both erythema and scabs; Figures 5.9 to 5.11 show the off-skin exposures that produced both erythema and scabs; Figure 5.12 gives the results for both on-skin and off-skin exposures that only produced erythema. Erythema diameters are shown in the panels on the left, and scab diameters for the corresponding exposures are shown in the panels on the right. Erythema generally preceded the detection of scabs and the maximum diameters for erythema were larger than for the corresponding scabs. One unexposed site (A-5, top of Figure 5.5) had occasional indications of erythema and a 1-mm-diameter scab was noted three times on 8,12 , 


\section{Experimental Results}

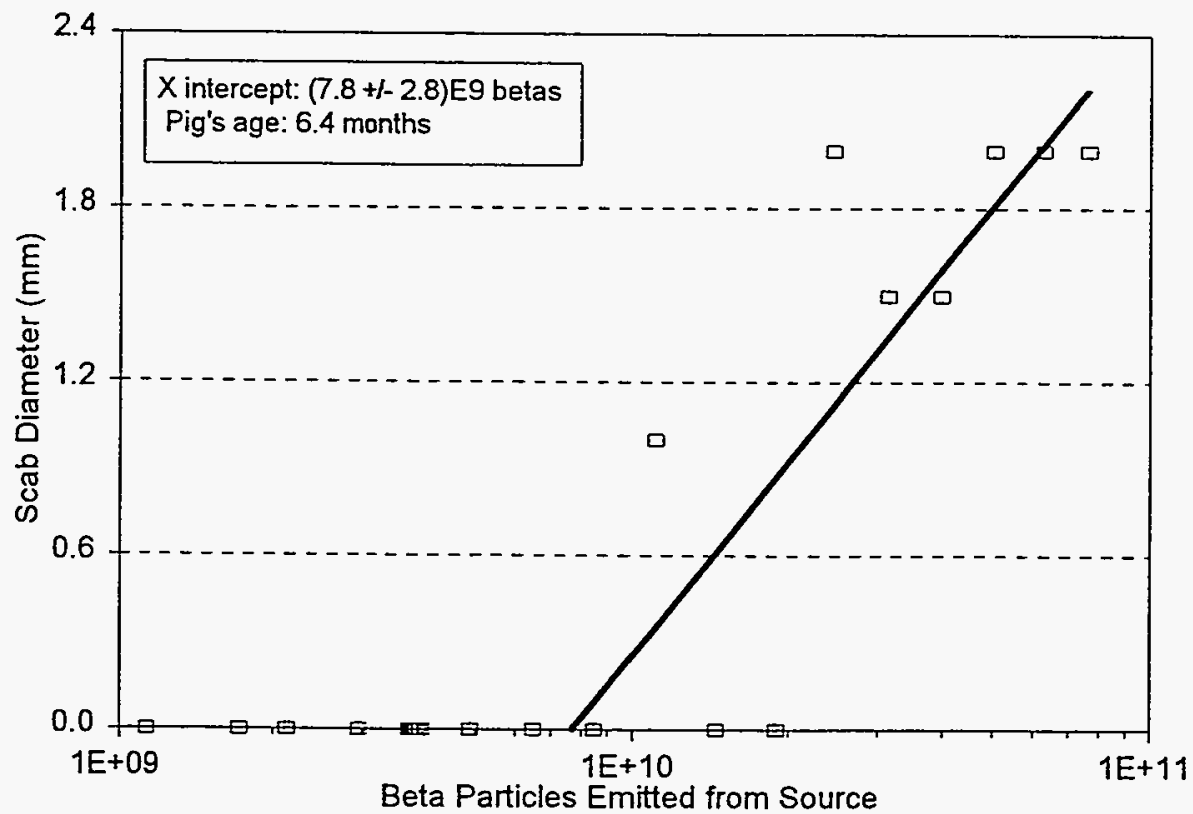

Figure 5.1 Scab diameters resulting from on-skin $\mathrm{UC}_{2}$ exposures as a function of the number of beta particles emitted from source for experiment 1 .

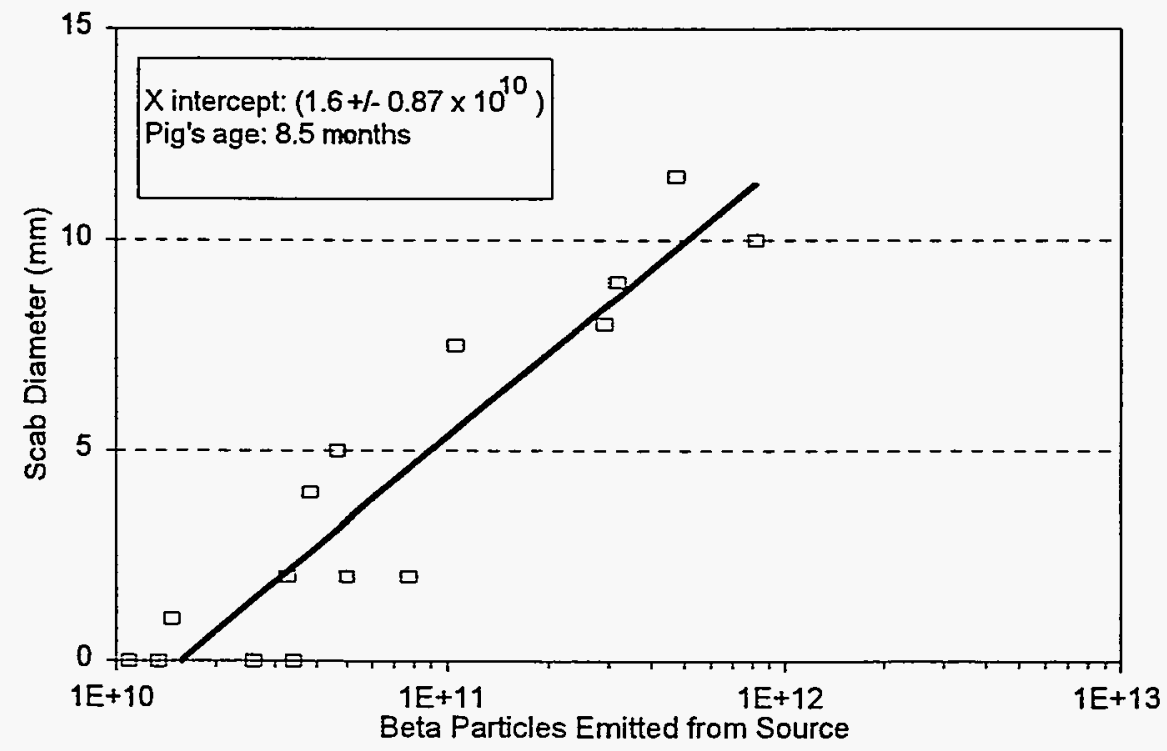

Figure 5.2 Scab diameters from on-skin $\mathrm{UC}_{2}$ exposures as a function of the number of beta particles emitted from source for experiment 2. 


\section{Experimental Results}

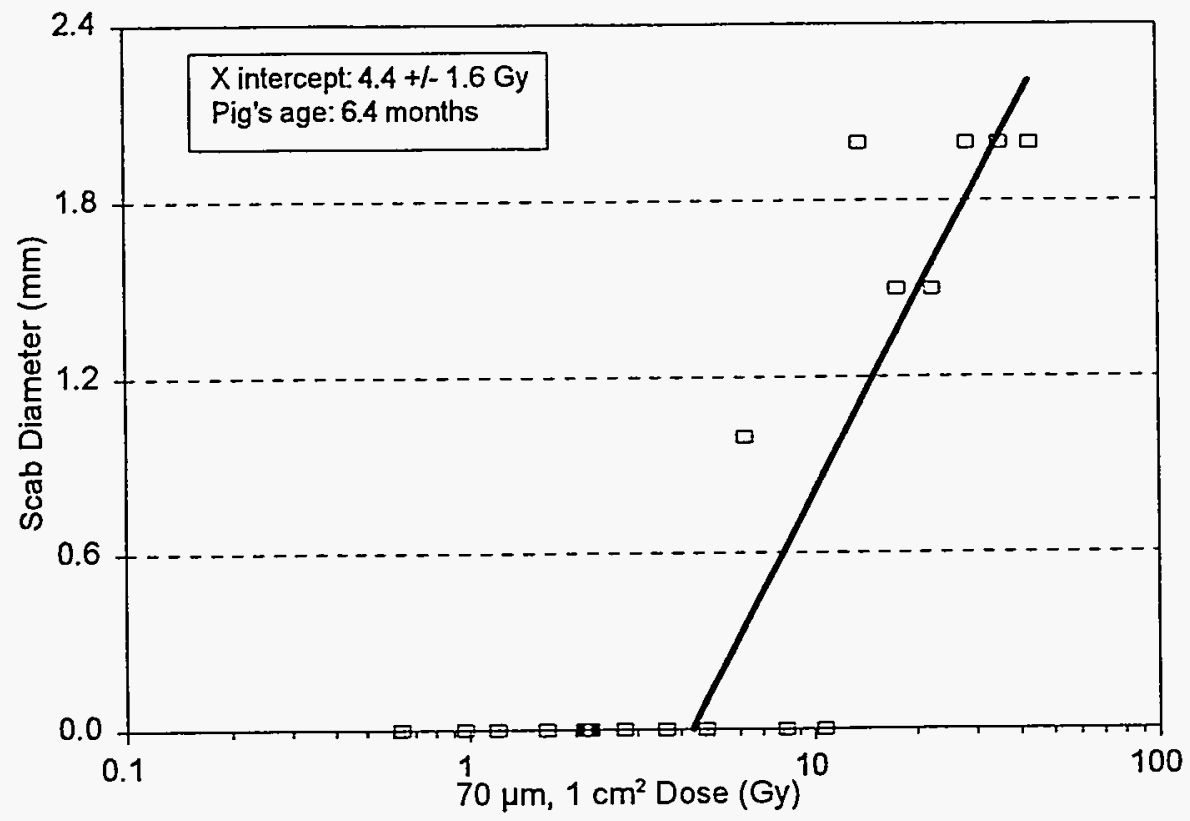

Figure 5.3 Scab diameters resulting from an on-skin $U_{2}$ exposures as a function of dose for experiment 1.

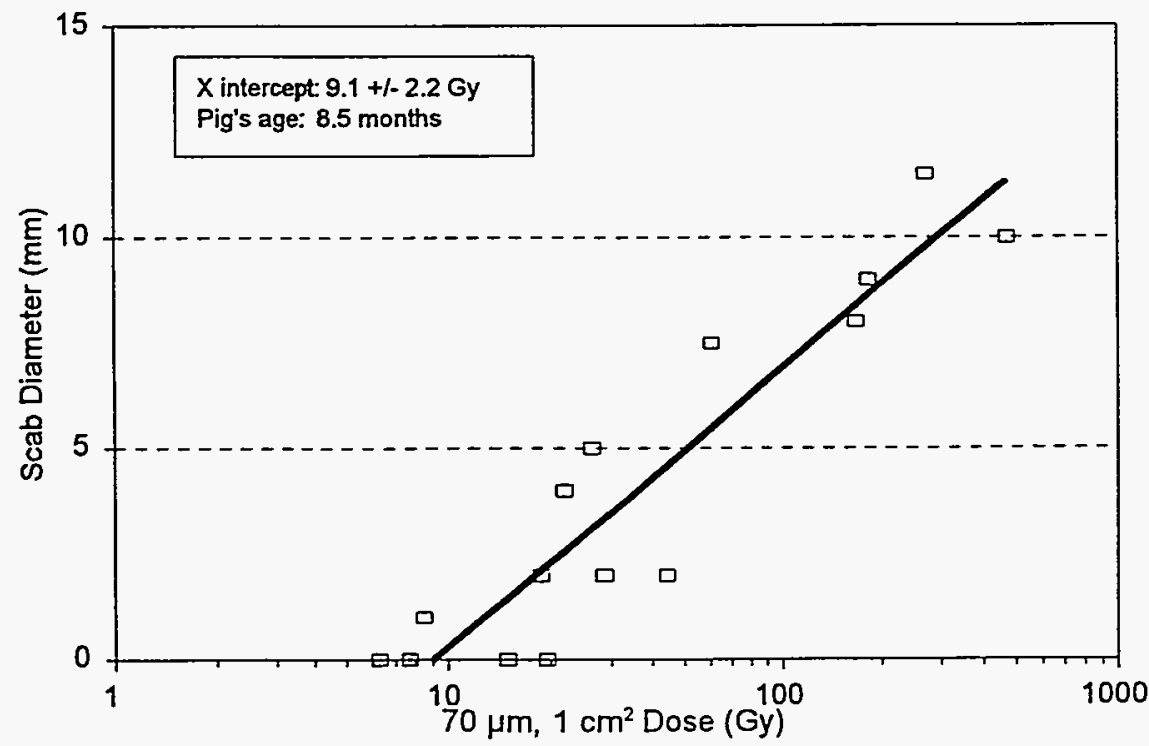

Figure 5.4 Scab diameters resulting from on-skin $\mathrm{UC}_{2}$ exposures as a function of dose for experiment 2. 

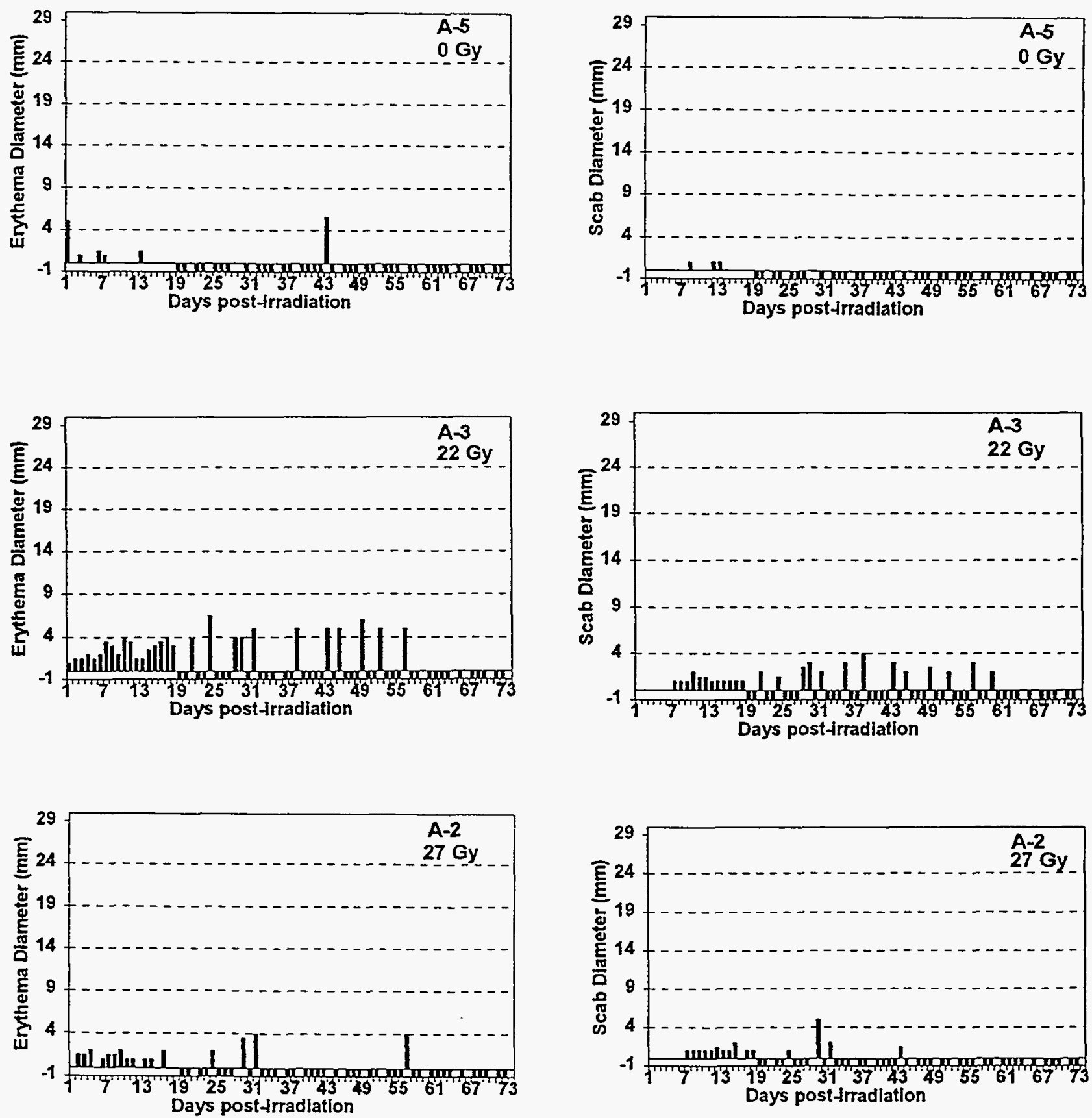

Figure 5.5 Histograms of erythema and scab results for $\mathrm{UC}_{2}$ on-skin exposures for experiment 2 (scaled to maximal occurrence). 

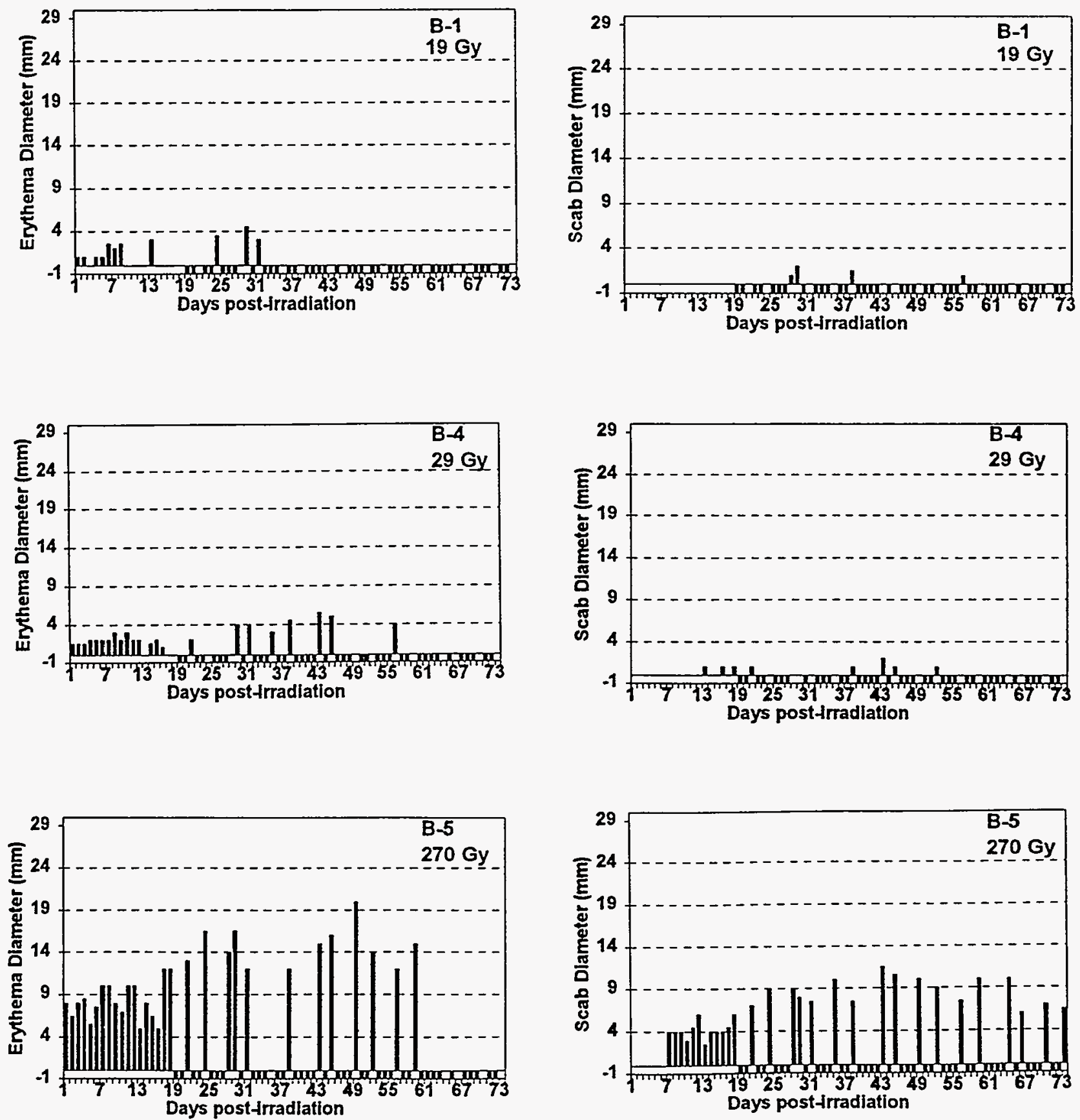

Figure 5.6 Histograms of erythema and scab results for $\mathrm{UC}_{2}$ on-skin exposures for experiment 2 (scaled to maximal occurrence). 


\section{Experimental Results}

Erythema
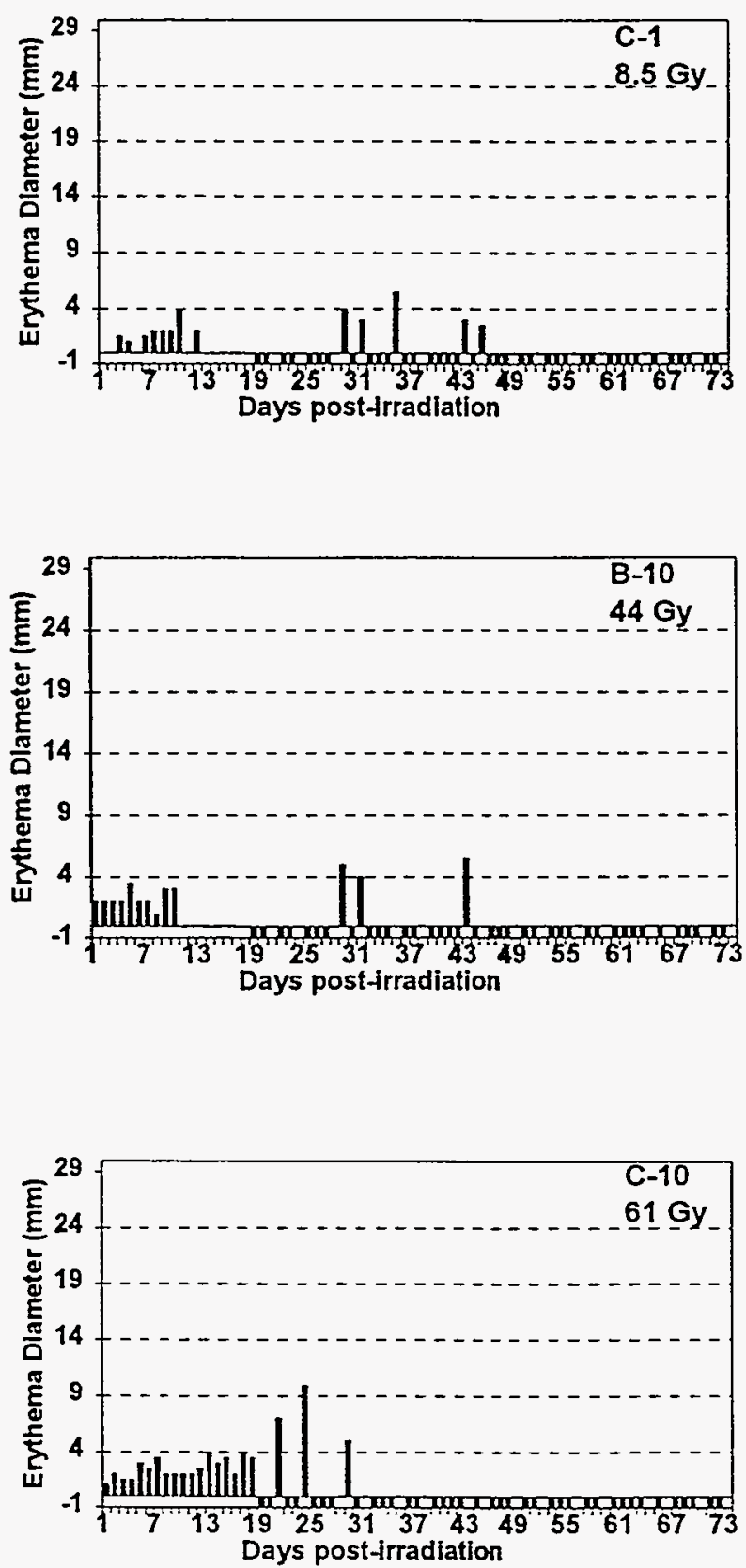

Scabs
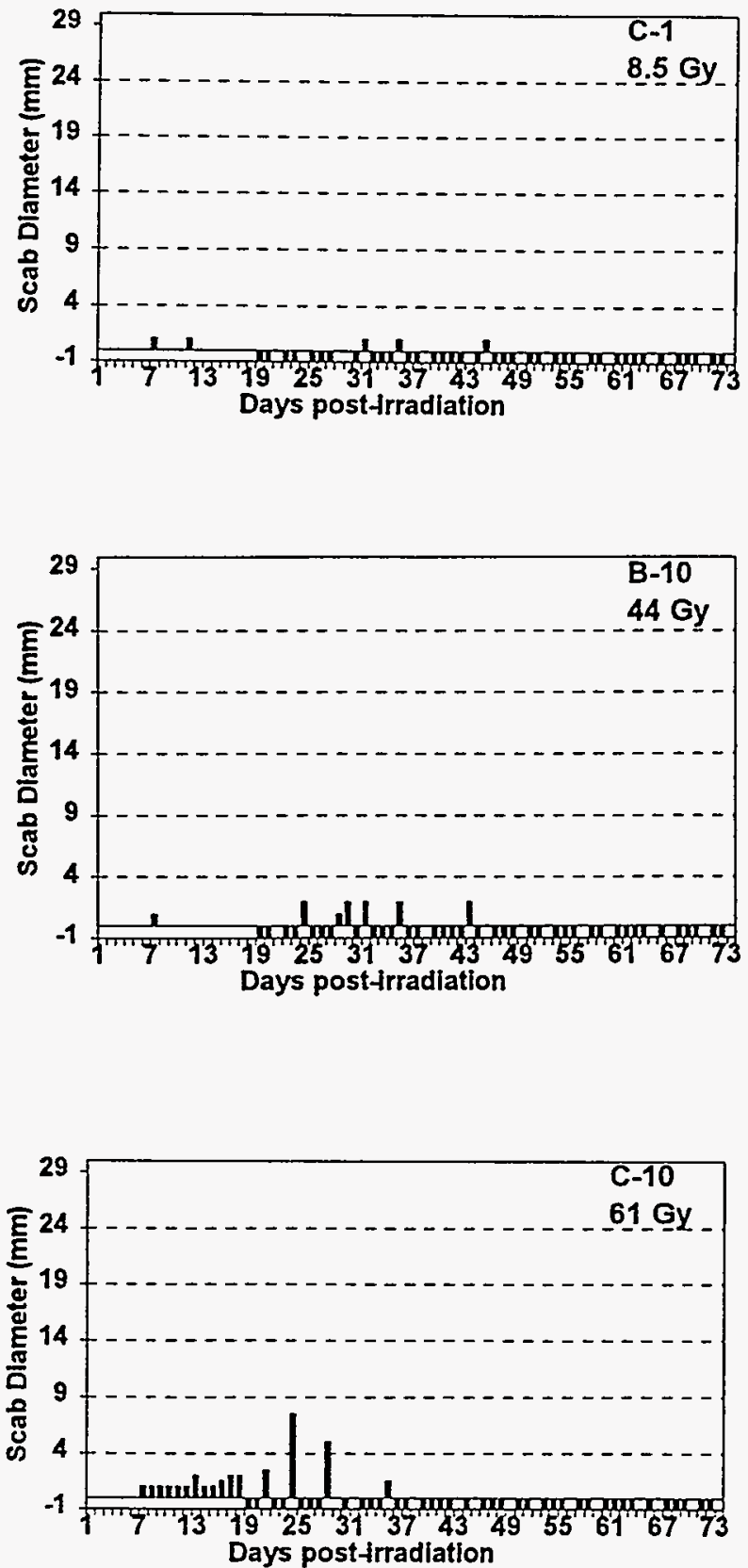

Figure 5.7 Histograms of erythema and scab results for $\mathrm{UC}_{2}$ on-skin exposures for experiment 2 (scaled to maximal occurrence). 

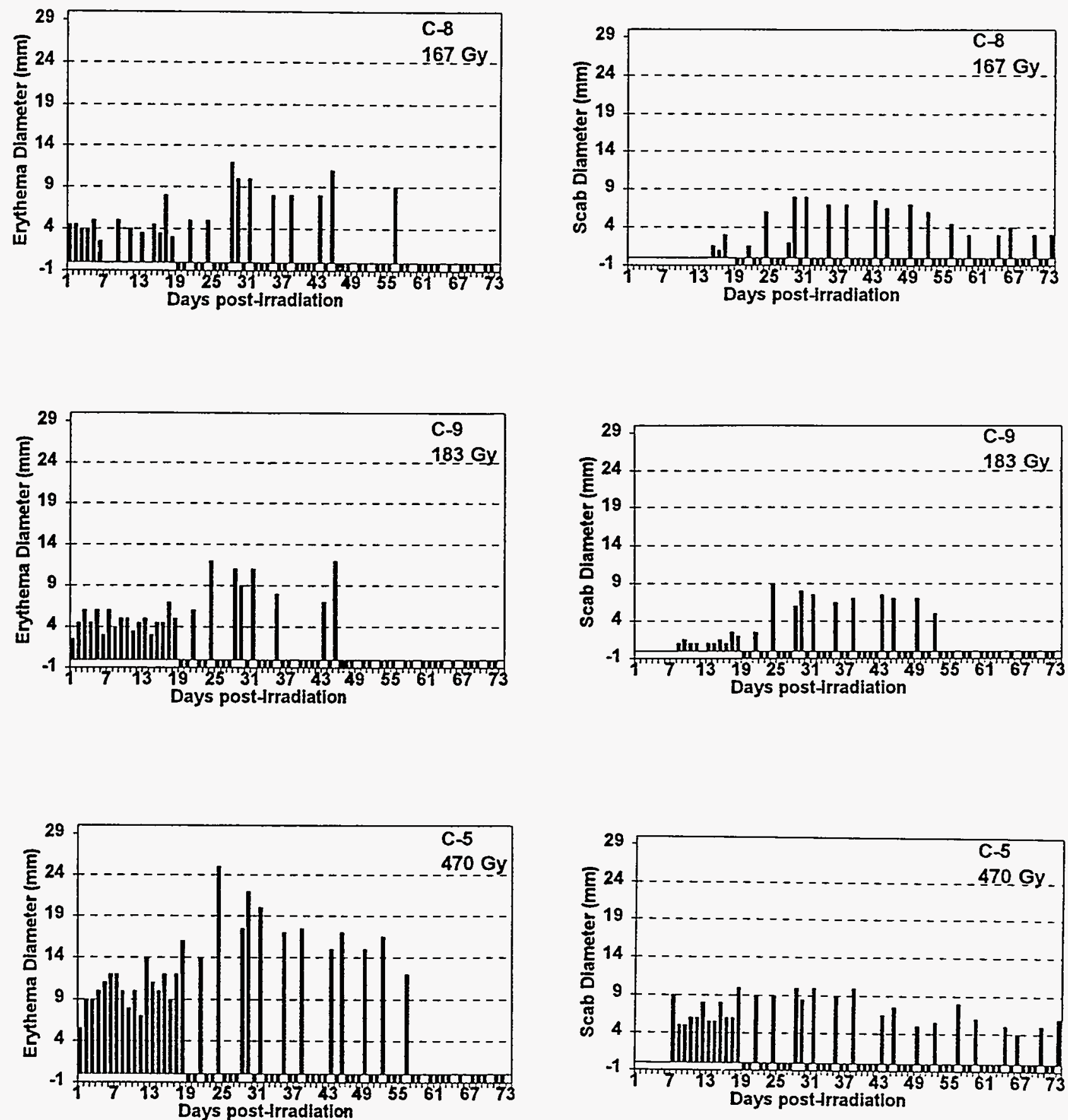

Figure 5.8 Histograms of erythema and scab results for $U_{2}$ on-skin exposures for experiment 2 (scaled to maximal occurrence). 

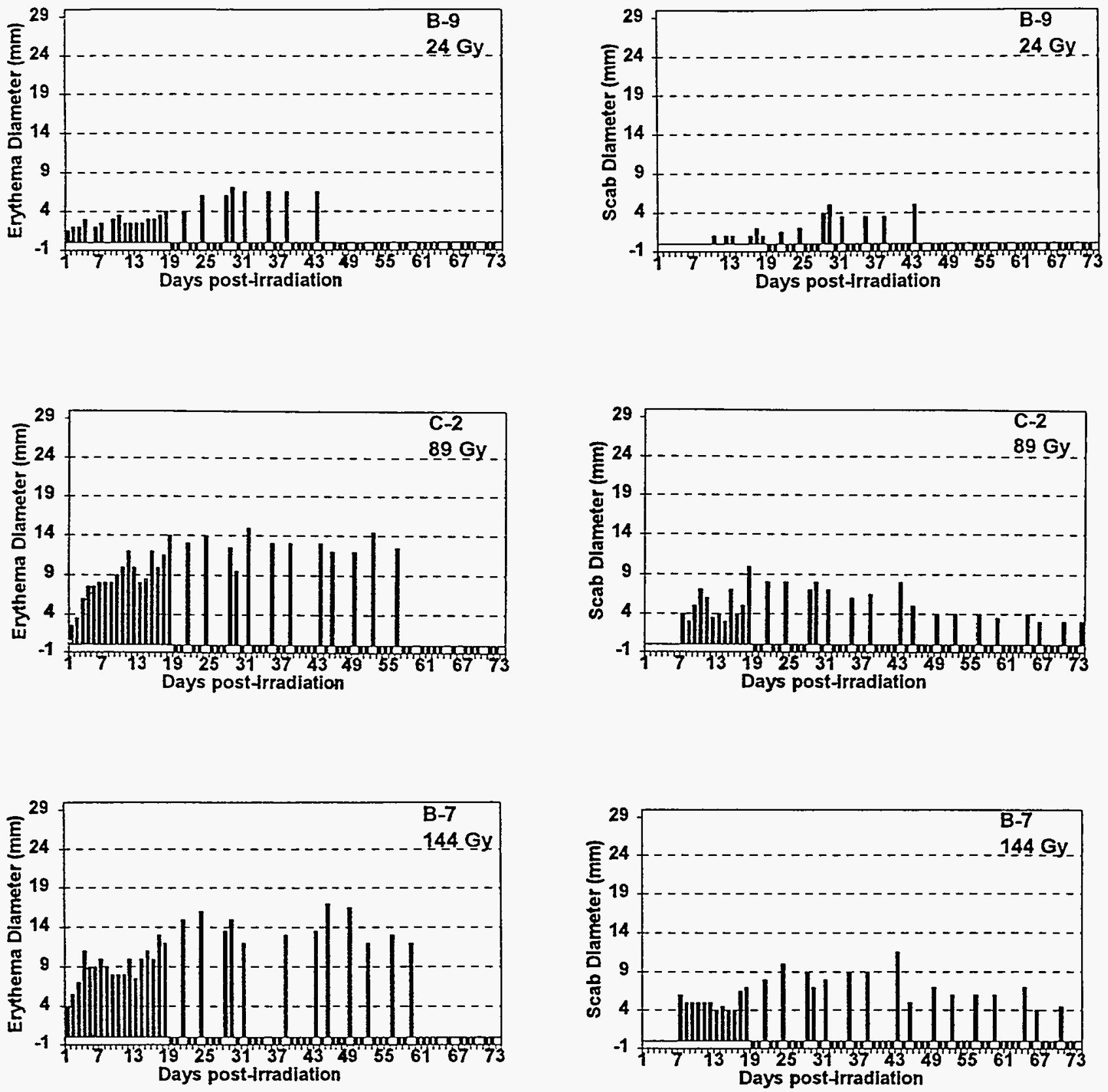

Figure 5.9 Histograms of erythema and scab results for $\mathrm{UC}_{2}$ off-skin exposures for experiment 2 (scaled to maximal occurrence). 
Erythema
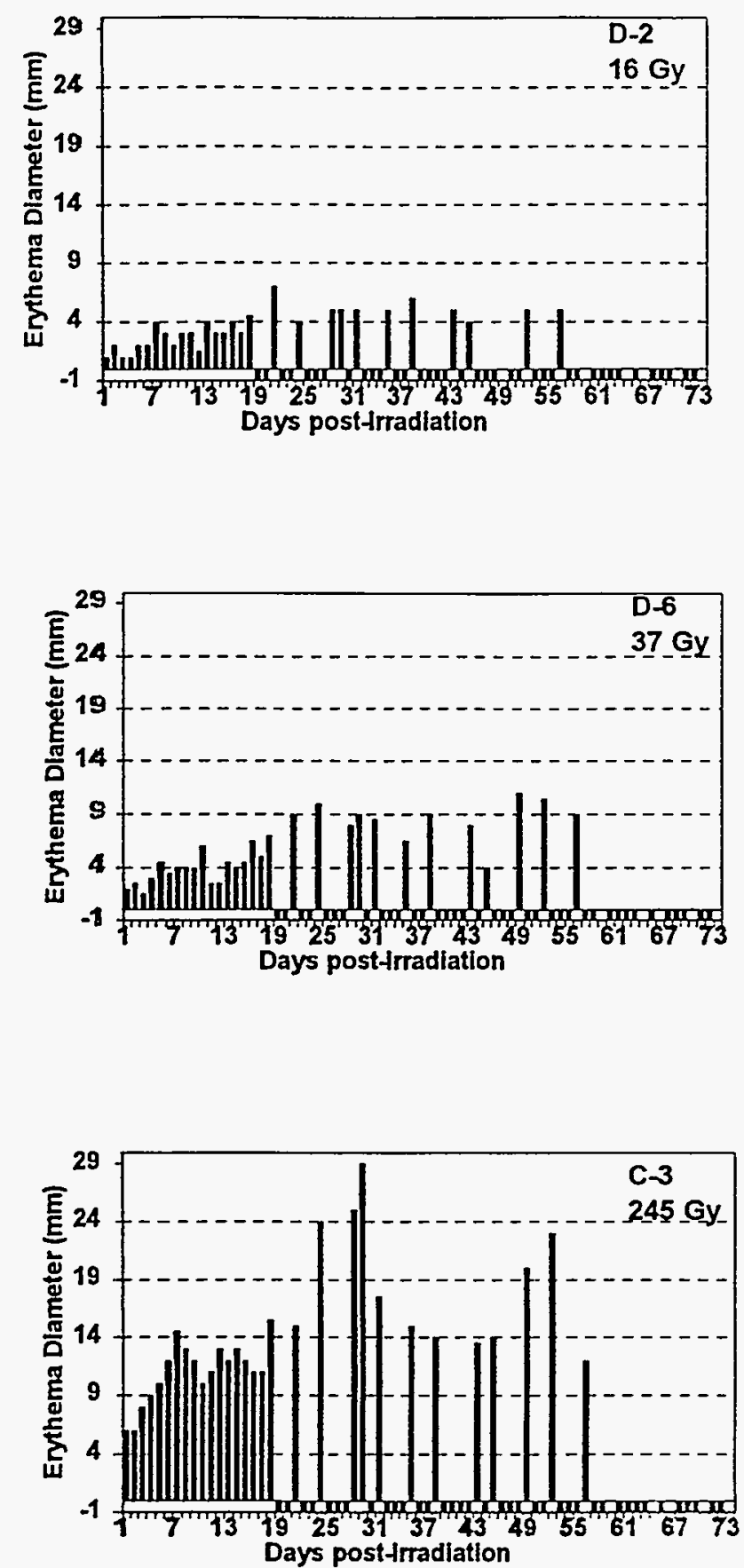

Scabs
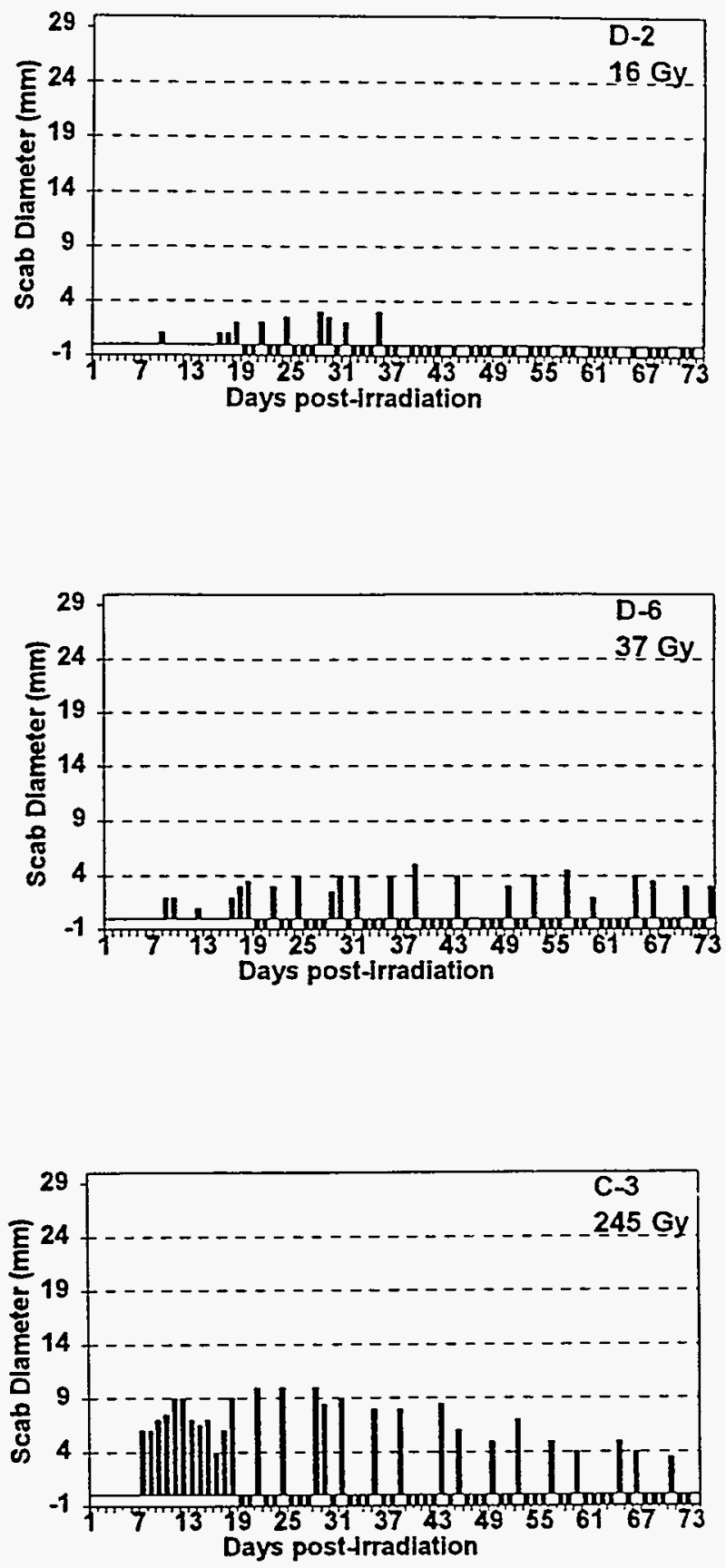

Figure 5.10 Histograms of erythema and scab results for $\mathrm{UC}_{2}$ off-skin exposures for experiment 2 (scaled to maximal occurrence). 

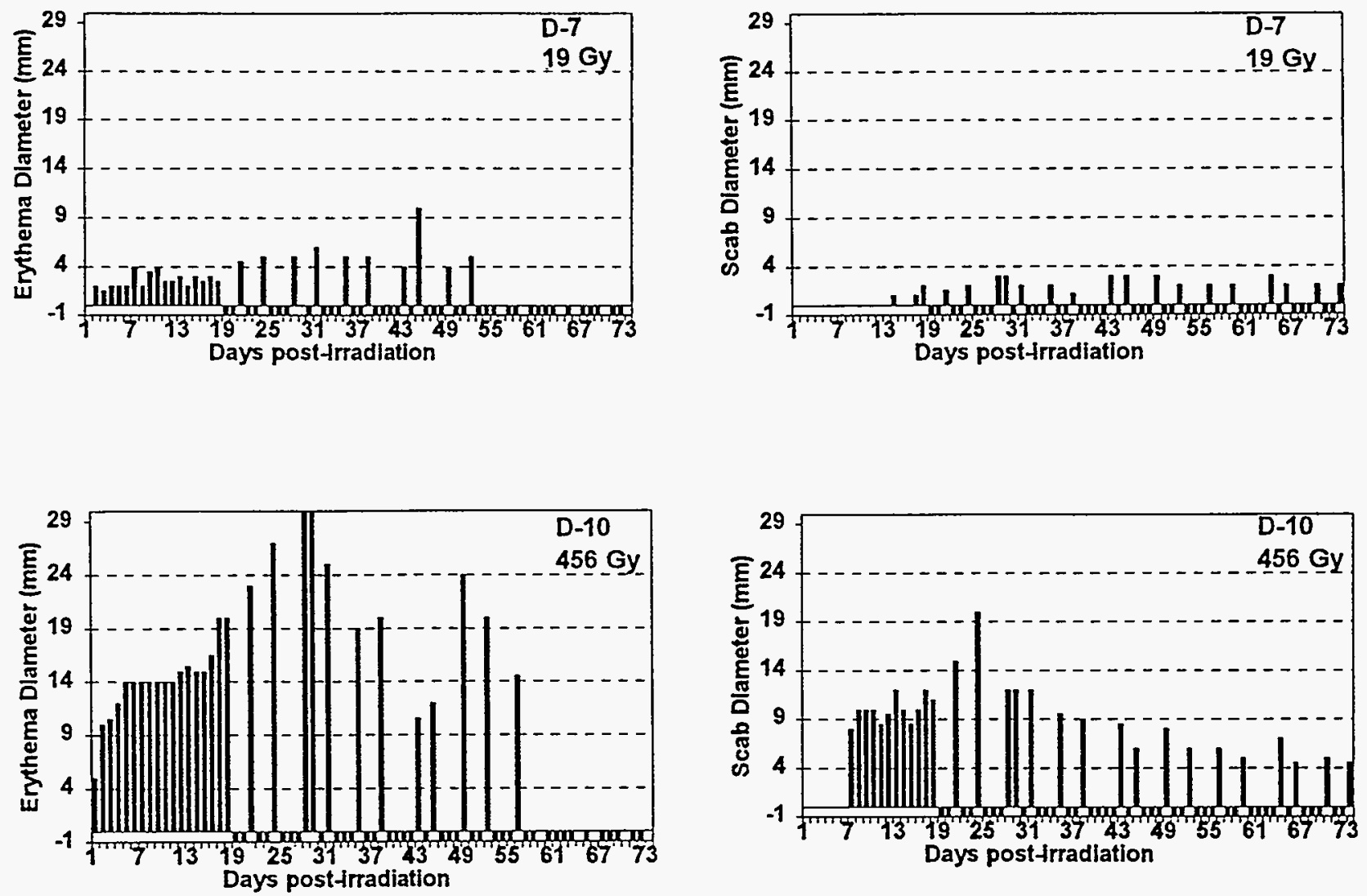

Figure 5.11 Histograms of erythema and scab results for $\mathrm{UC}_{2}$ off-skin exposures for experiment 2 (scaled to maximal occurrence). 
Erythema
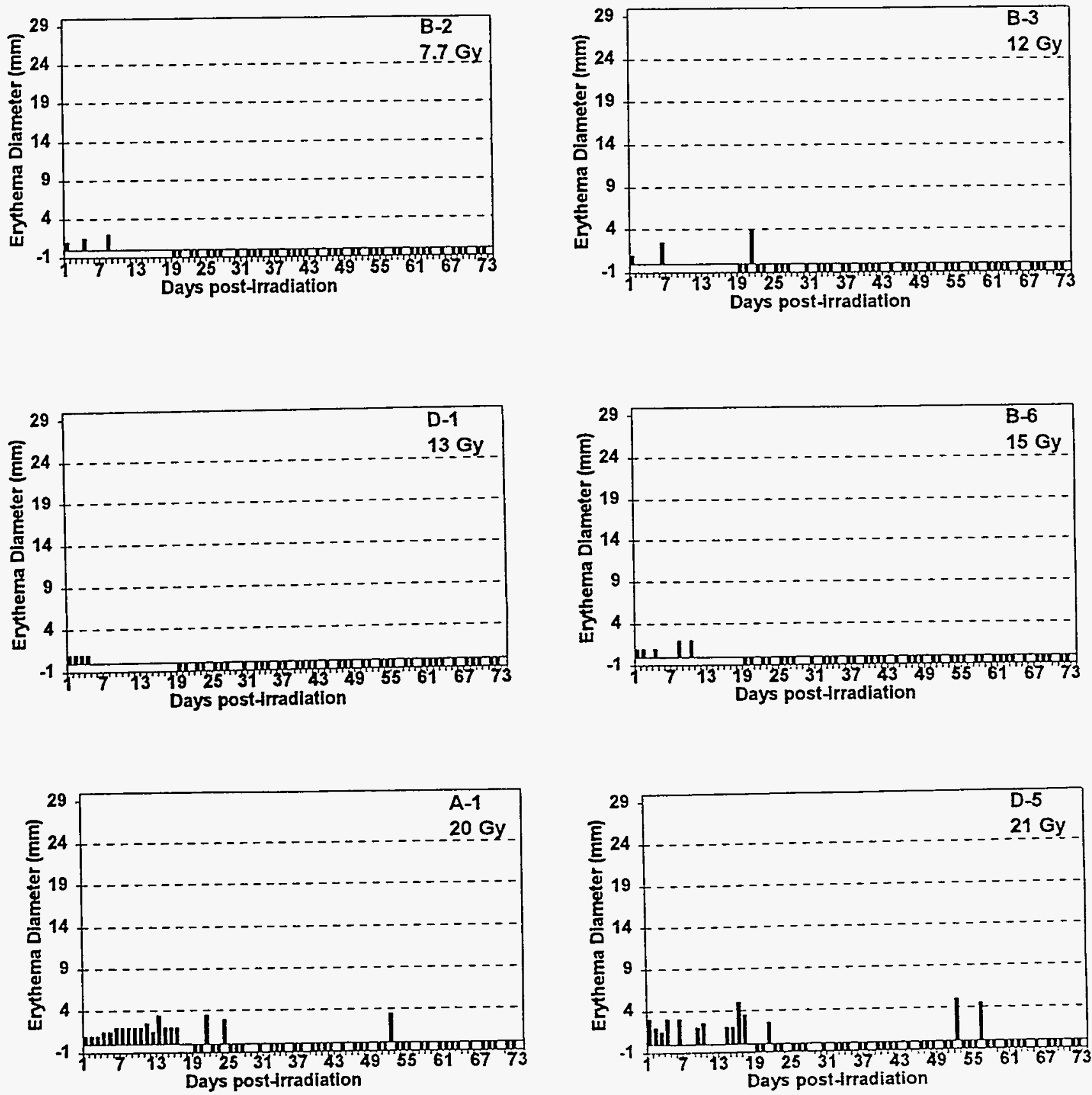

Figure 5.12 Histograms of erythema results for $U C_{2}$ on- and off-skin exposures that only produced erythema in experiment 2 (scaled to maximal occurrence). The "-1" bar indicates days the pig was not observed. 


\section{Experimental Results}

and $13 \mathrm{DPI}$ (pigs were observed daily for the first portion of this experiment). Evidence of scab and erythema in this exposure site A-5 was the only false-positive (Method E) result observed for zero dose. Scratches from the pig's activity, insect bites, and infections in the sites of the lesion where hair shafts penetrated the scabs were conditions susceptible to mis-scoring. These abnormalities were normally identifiable by the abrupt appearance or dissipation of an effect.

For site D-5, which received a 21 Gy off-skin exposure, an extremely late and atypical erythema (noted between 52 and $56 \mathrm{DPI}$ ), in Figure 5.12, was not consistent with a radiation effect. In general, the incidence of erythema was observed to progress, escalating to a maximal size within 21 to $29 \mathrm{DPI}$. For on- and off-the-skin sites which received the lowest doses, the erythema disappeared after reaching maximal diameters of 1 to $2 \mathrm{~mm}$. Biphasic erythema cycles were noticed in sites B-10 and C-1 (Figure 5.7), two on-skin sites which received above-threshold doses for erythema incidence; this agrees with the skin reactions observed in Hopewell et al.'s experiment (1986). Between 35 and 43 DPI, dry desquamation with depigmented scabs were observed. Once this condition was noted, any effect surrounding a lesion was no longer considered erythema. Thus, the actual erythema cycle lasted approximately 45 days for both sites. No incidence of moist desquamation was observed in any of the irradiated fields, with the exception of moist areas that accompanied scab retraction after 21 days, agreeing with Hopewell's observations (1991).

Regression intercepts for erythema zero-diameter effect were less than that for scabs by approximately one and two scab-diameter standard deviations for on- and off-skin, respectively (Figures 5.13 and 5.14). Both on- and off-the-skin placement of particles resulted in scab formation as early as one week after the exposures. The scabs reached maximal sizes approximately 29 to $45 \mathrm{DPI}$. The longest uiceration period was for several off-the-skin exposures which were evident after $144 \mathrm{DPI}$, when the experiment was terminated (see Section 5.14 and Figure 5.71).

From the photographic documentation, we reached some qualitative conclusions. Characteristic biological responses were seen in the on- and off-skin exposure sites which received the greatest doses. One noticeable difference between the scabs induced by on-the-skin placement was that they sometimes developed with asymmetrical geometries, whereas those induced by off-the-skin placement more frequently developed into flat, circular scabs.

For the same number of beta particles emitted, it was noted that the off-skin response in B-7 (Figure 5.9) scabbed at the same time and was only slightly larger than that of the on-skin radiation-induced ulcer in B-5 (Figure 5.6). Hair shafts penetrated the sides of the off-skin lesion, which seemed to develop more quickly than the on-skin one. Overall, the lesions' progressions were very similar; however, the on-skin radiation-induced scab was characterized by its thick, raised, and well-organized appearance in contrast to the off-skin scab, which was flat and superficial. A white depigmented ring appeared around both scabs on the forty-third day. In addition, the response for the on-skin site included the typical retraction that accompanies the process of tissue repair. The off-skin scab sloughed off by day 73 , but the on-skin scab still persisted at 85 DPI. However, the off-skin hot-particle-induced scab was noted again at 


\section{Experimental Results}

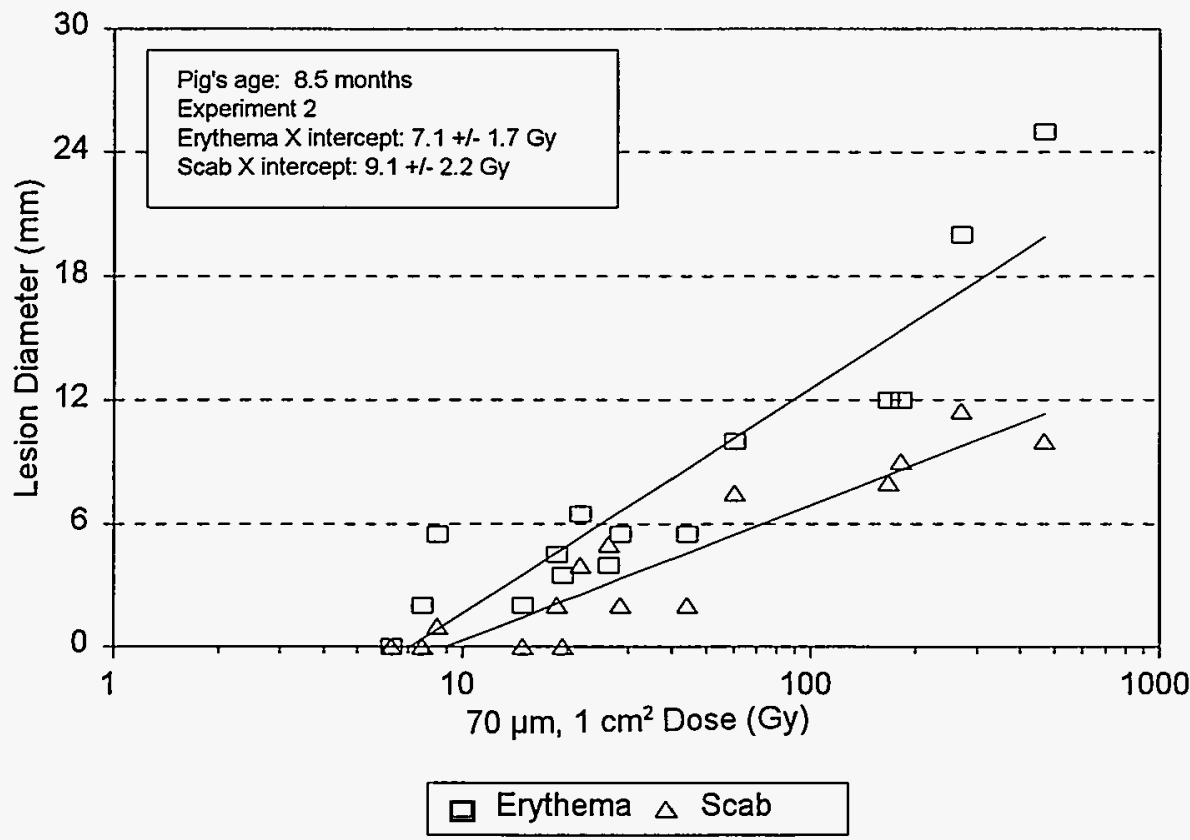

Figure 5.13 Comparison of on-skin $\mathrm{UC}_{2}$ scab and erythema diameters

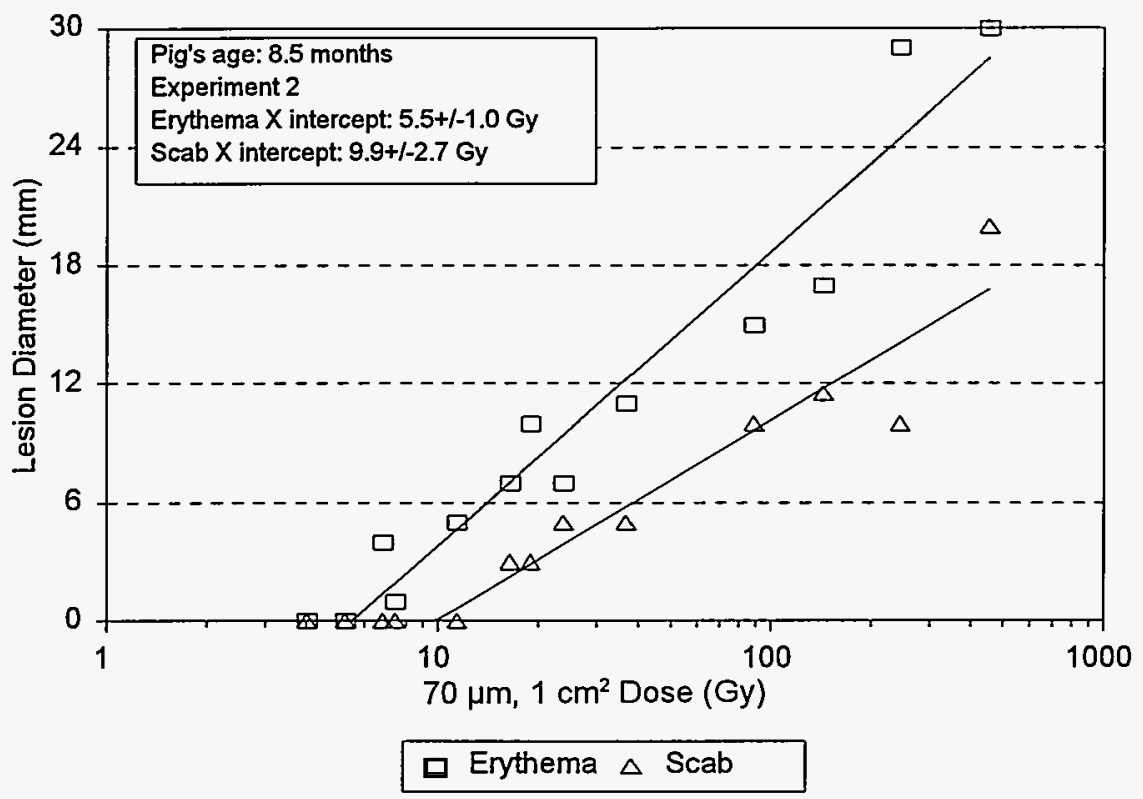

Figure 5.14 Comparison of off-skin $\mathrm{UC}_{2}$ scab and erythema diameters 


\section{Experimental Results}

$144 \mathrm{DPI}$, whereas the on-skin scab was not. The same progression of effects was observed in C-3 and C-5, another off- and on-skin pair under equivalent beta-particle exposures.

\subsection{Off-skin $\mathrm{UC}_{2}$ Results}

An off-skin $U_{2}$ pig exposure was carried out for experiment 2 to investigate the possibility of there being a lower threshold from particles not directly on the skin. Such a lower threshold could, conceivably, occur by delivering a lethal amount of beta radiation to a larger number of cells, by reducing the overkill phenomenon that occurs for cells close to an on-skin hot particle. In addition, a smaller dose from on-skin hot particles is given to peripheral cells due to the absorption of beta particles in tissue.

Regression analyses using the natural log of the number of beta particles emitted from the source versus scab diameter gave a threshold of $(2.9 \pm 0.78) \times 10^{10}$ (Figure 5.15). A threshold of

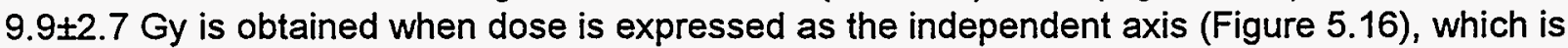
similar to that for an on-skin particle. This finding indicates that an off-skin particle does not have a significantly lower threshold for inducing scabs than an on-skin particle, when the threshold is expressed as dose averaged over $1 \mathrm{~cm}^{2}$ at $70 \mu \mathrm{m}$ depth in skin.

Progression of erythema and scab lesions is summarized on Figures 5.9 through 5.12 .

\subsection{On-skin Tm-170 Results}

To verify experiments performed by Hopewell (1991), BNL conducted several Tm-170 particle on-skin irradiations. Both the scab-diameter regression and percent-incidence analysis methods were used.

\subsubsection{Experiment 3 using $\mathrm{Tm}-170$}

To determine whether there were anoxia effects due to compression of the skin by the foam tape-tips used in the $\mathrm{UC}_{2}$ irradiations, two Tm-170 particles were placed on $3 \mathrm{~mm} \times 3 \mathrm{~mm}$ foam tape-tips, and two $\mathrm{Tm}-170$ particles were placed on a $2.5 \mathrm{~cm} \times 2.5 \mathrm{~cm}$ area of foam tape (Figures 3.5 and 3.6$)$.

Figure 5.17 shows the dose-response for experiment 3. Regressions using the natural log of dose deposited versus scab diameter for tipped versus non-tipped sources showed no significant difference; therefore, the two were combined for analysis (Figure 5.17).

\subsubsection{Experiment 4 using $\mathrm{Tm}-170$}

It was assumed that the transparent tape covering the particles would be compromised by radiation damage, so before irradiating the pig for experiment 4, a 13- $\mu \mathrm{m}$-thick layer of Kapton, a radiation-resistant plastic, was placed on top of the previous containment layers. The Kapton was 


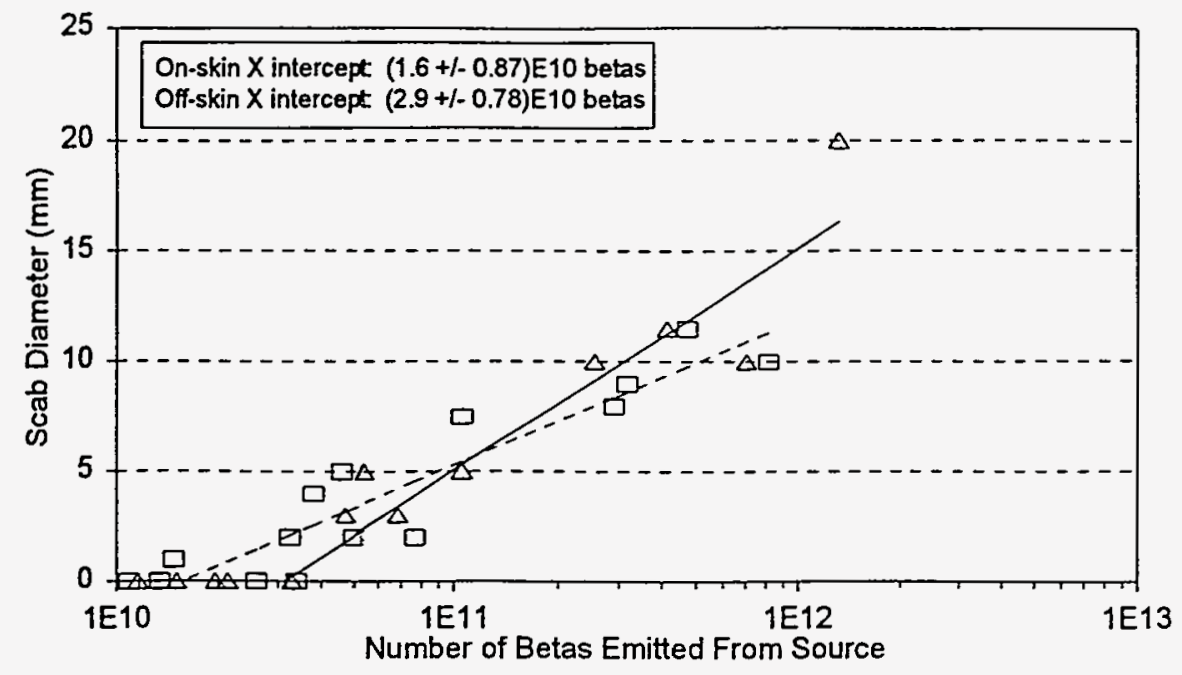

$\square$ On-Skin -.... $\Delta$ Off-Skin _ _

Figure 5.15 Scab diameters for pig irradiated with off-skin $\mathrm{UC}_{2}$ particles as a function of the numbers of beta particles emitted from the source. On-skin response is shown for comparison. The

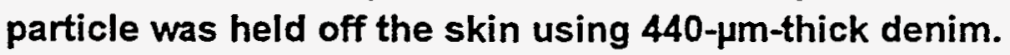

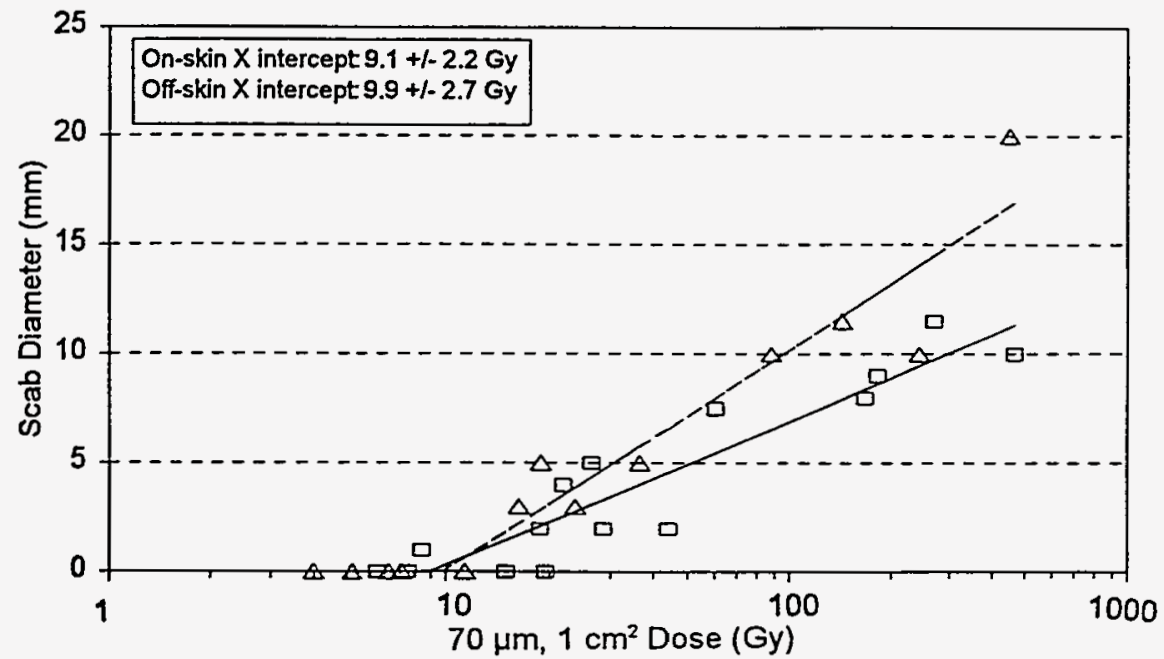

으-Skin -.... $\triangle$ Off-Skin -

Figure 5.16 Scab diameters for pig irradiated with off-skin $\mathrm{UC}_{2}$ particles as a function of dose. On-skin response is shown for comparison. The particle was held off the skin using $440-\mu m$-thick denim. 


\section{Experimental Results}

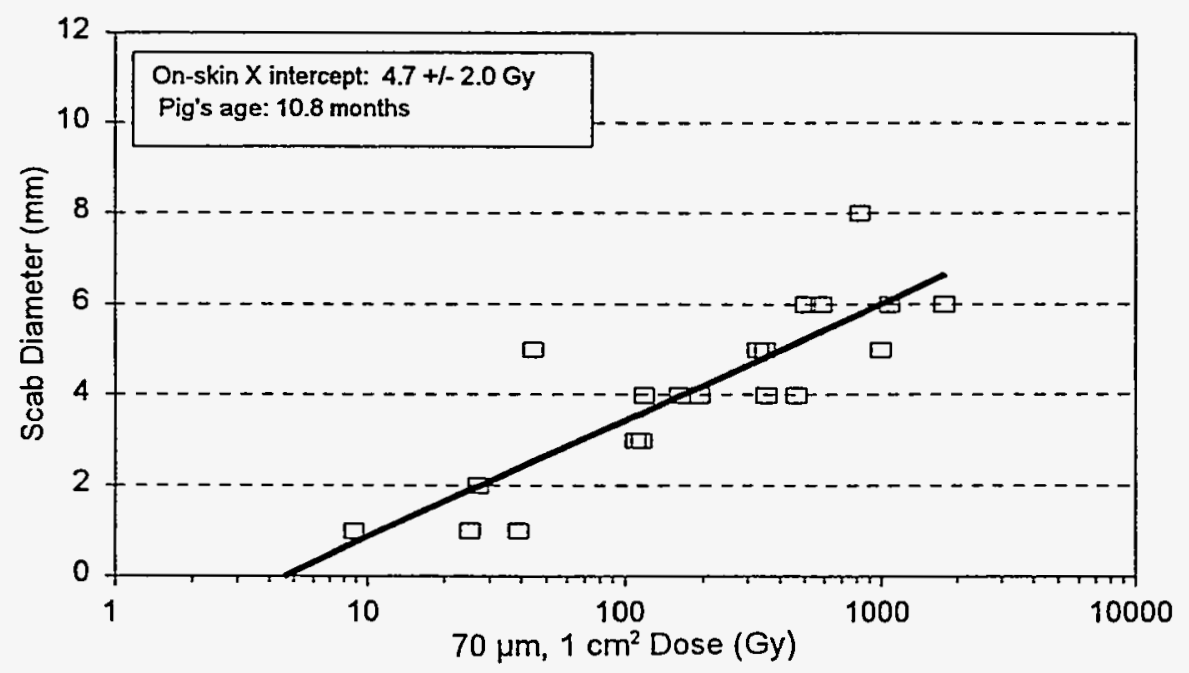

Figure 5.17 Scab diameters for on-skin Tm-170 irradiation as a function of dose for experiment 3.

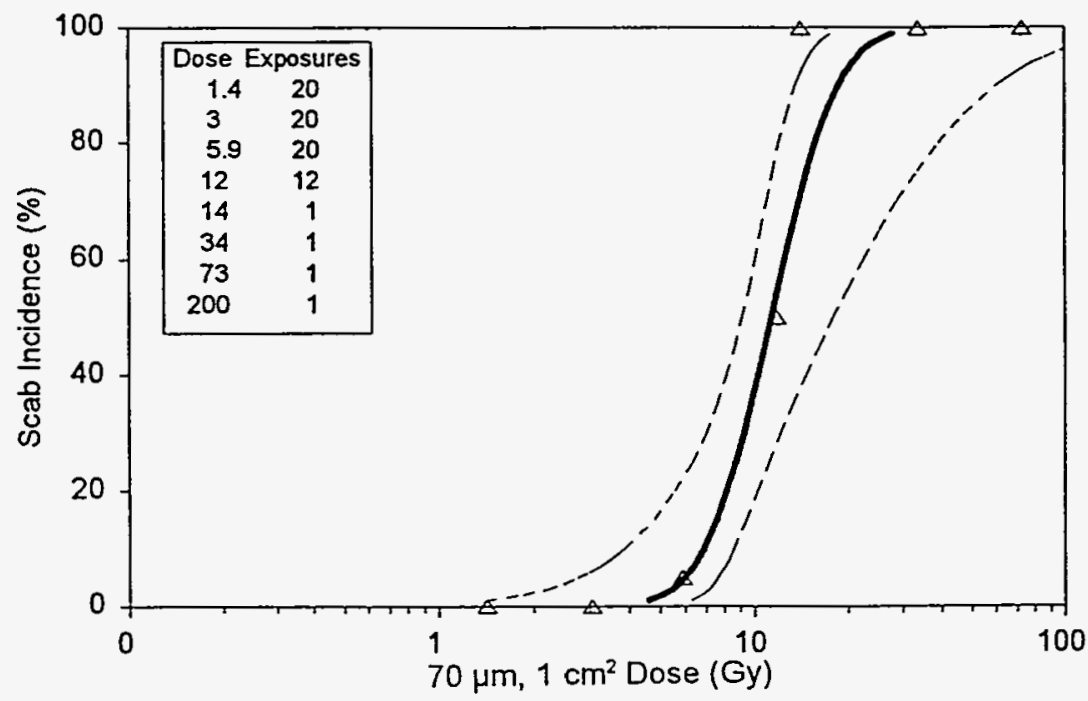

$\triangle$ Scab Incidence _- Probit Regression - . 95\% Confidence

Figure 5.18 Scab incidence for 13.6-month-old pig irradiated with Tm-170 in experiment 4. 
secured to the Styrofoam exposure block face using 71- $\mu$ m-thick double-sided transparent tape (Figure 3.9).

A Hopewell-type scab incidence versus dose experiment was performed (Figure 5.18). Using scoring Method $\mathrm{C}$, the dose needed to produce 10 and $50 \%$ scab incidence was 6.9 (3.9-8.6 $95 \%$ CLS) and $11\left(9.2-1895 \%\right.$ CLS) Gy. These values, the $E D_{10}$ and $E D_{50}$, were factors of 3.6 and 2.4 greater, respectively, than that reported by Hopewell (1991).

A dose-response regression, using the natural log of dose versus scab diameter, for the same irradiation gave a dose axis intercept of $5.7 \pm 0.58$ Gy (Figure 5.19).

\subsubsection{Experiment 5 using $\mathrm{Tm}-170$}

Some of the pigs used in Forbes and Mikhail's experiment were pigmented. Forbes informed the BNL researchers in September 1991 that the hot particles produced a white area closest to the hot particle's irradiation site where the melanocytes were killed, and a hyperpigmented halo outside this depigmented area where the melanocytes were stimulated.

One of BNL's pigs became pigmented following puberty. This pig was exposed to Tm-170 particles for experiment 5 using the source geometry shown in Figure 3.9. A scab-diameter regression for this animal gave an $x$-axis intercept of $2.5 \pm 1.9$ Gy (Figure 5.20 ). Note that there were seven sites exposed to doses higher than this threshold that did not produce scabs. Depigmentation and hyper-pigmentation were similar to that described by Forbes.

\subsubsection{Experiments 6 and 7 using $\mathrm{Tm}-170$}

For experiments 6 and 7, three of the four Tm-170 particles were remounted on new Styrofoam exposure blocks and covered with Kapton (Figure 3.10); this minimized the amount of material between the Tm-170 particles and the pig's skin. The smallest Tm-170 particle $(120 \mu \mathrm{m})$ fractured during handling and was not used further.

Two pigs of different ages were irradiated during experiments 6 and 7 for both a scab-diameter experiment and a PSI experiment. The irradiations were intended to further determine the PSI for different doses but all produced scabs (i.e., 100\% incidence) and therefore could not be used to predict a range of percent-ulcer incidences. However, the results were included in the scabdiameter regressions.

Scab-diameter regressions gave $x$-axis intercepts of $1.3 \pm 0.60$ Gy averaged over $1 \mathrm{~cm}^{2}$ at $70 \mu \mathrm{m}$ depth for the 15-month-old pig, and $0.71 \pm 0.48$ Gy for the 6.6-month-old pig (Figures 5.21 and 5.22). These intercepts imply a threshold at a much lower dose than supported by the low-dose data points. This illustrates that this approach is not appropriate for deducing thresholds for scab induction. 


\section{Experimental Results}

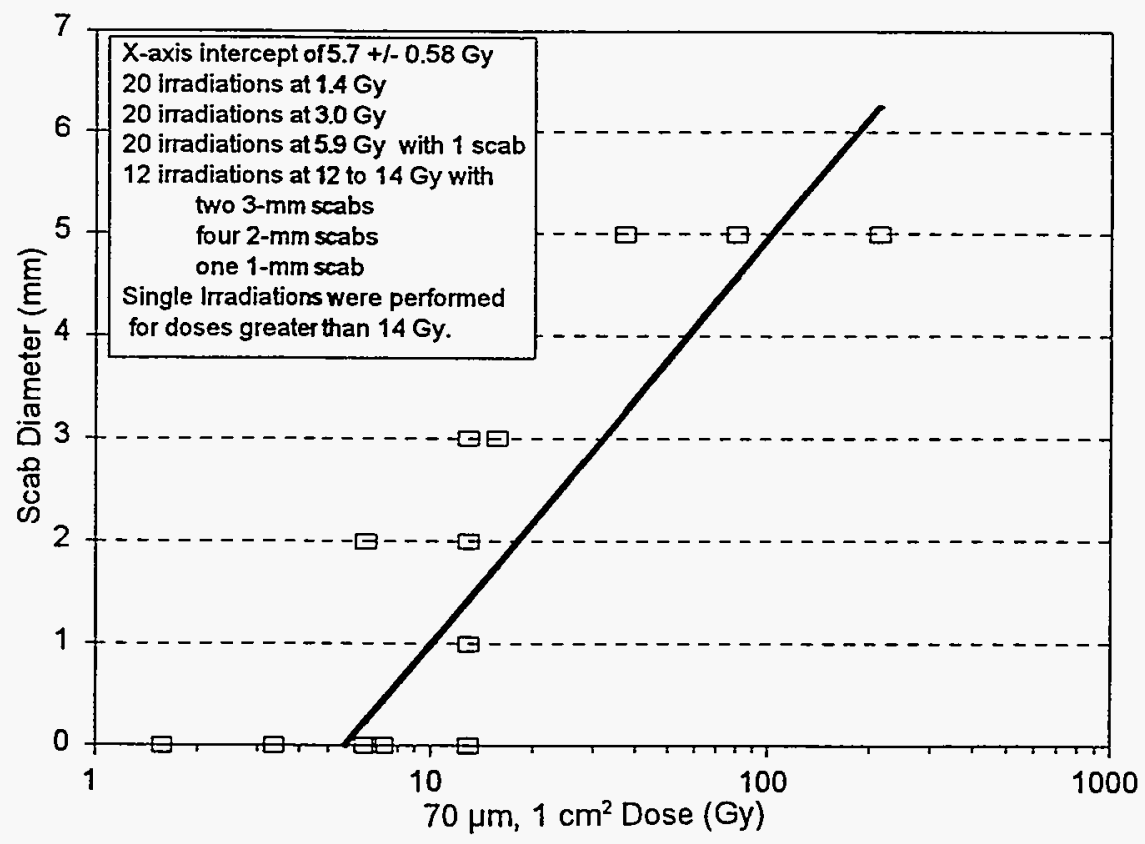

Figure 5.19 Scab diameters for pig irradiated with $\mathrm{Tm}-170$ in experiment 4.

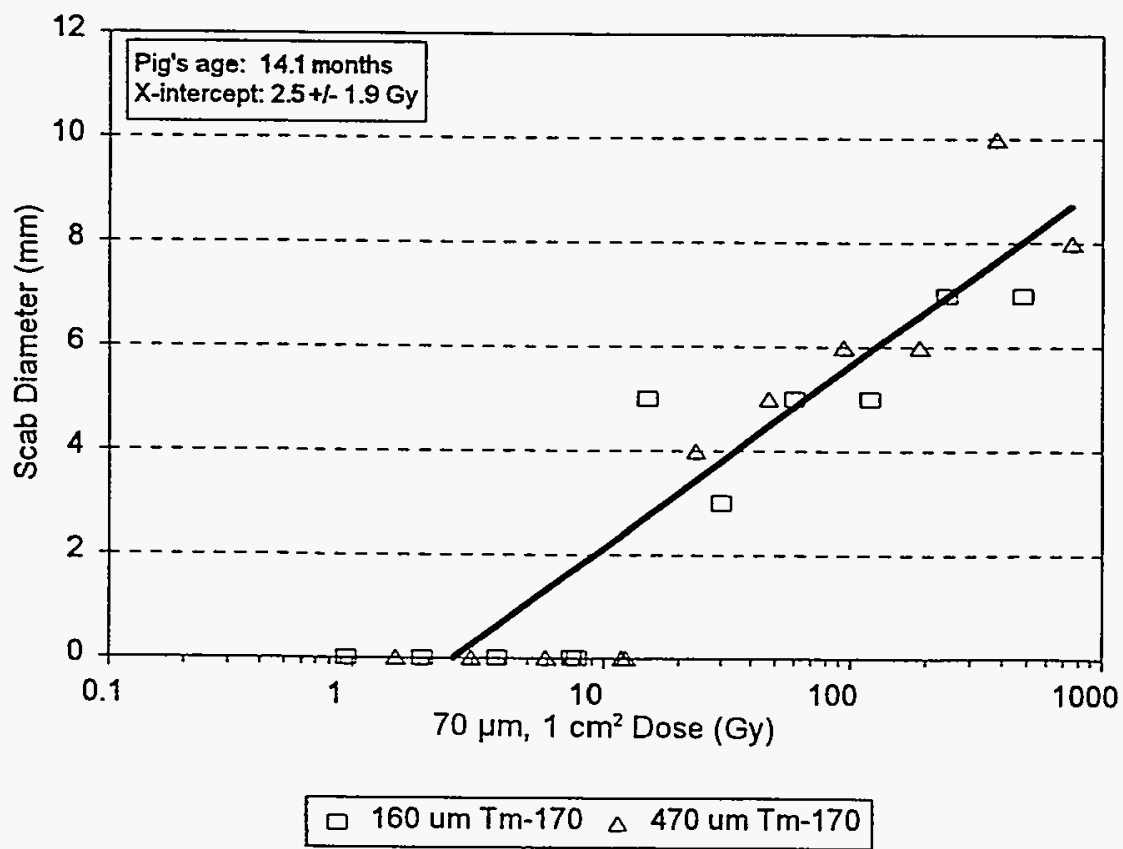

Figure 5.20 Scab diameters for pig irradiated with $\mathrm{Tm}-170$ in experiment 5. 


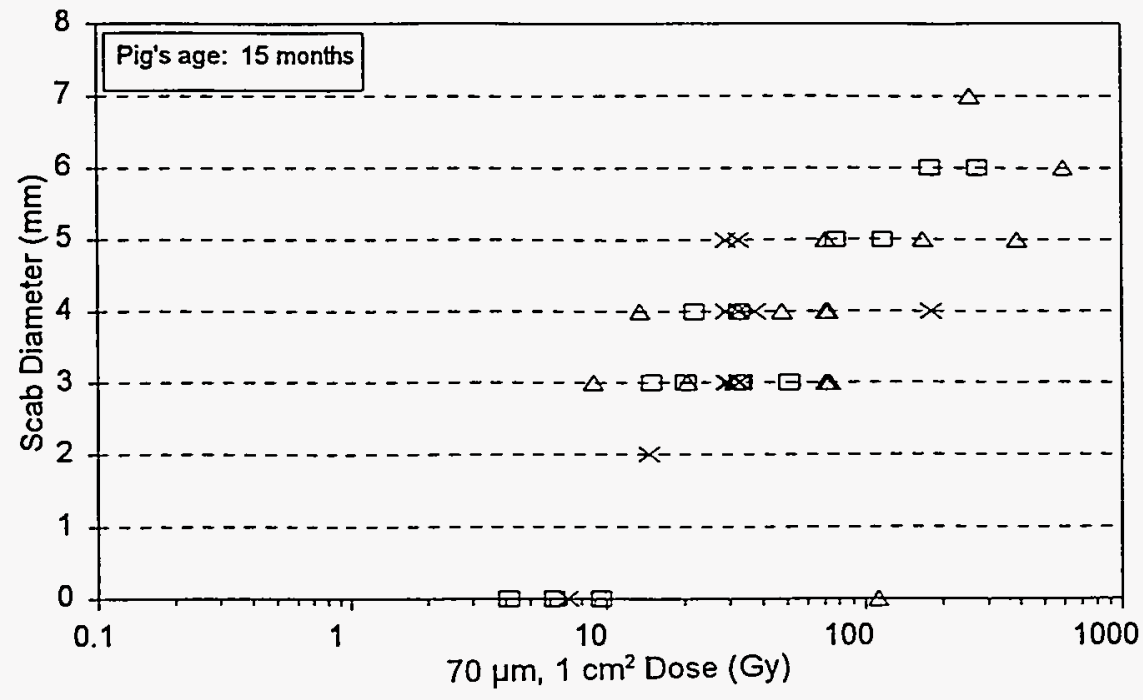

口 $160 \mathrm{um} \mathrm{Tm}-170 \times 280 \mathrm{um}$ Tm-170 $\triangle 470 \mathrm{um} \mathrm{Tm}-170$

Figure 5.21 Scab diameters for pig irradiated with Tm-170 in experiment 6.

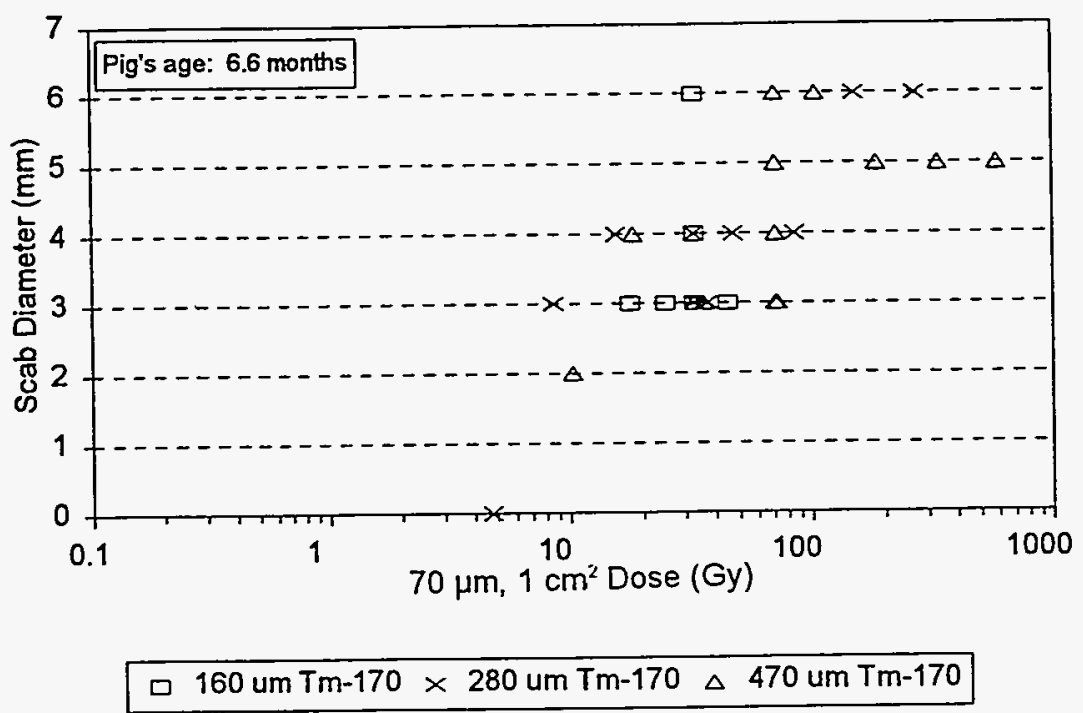

Figure 5.22 Scab diameters for pig irradiated with $\mathrm{Tm}-170$ in experiment 7. 


\section{Experimental Results}

\subsubsection{Experiments 8, 9, and 10 using $\mathrm{Tm}-170$}

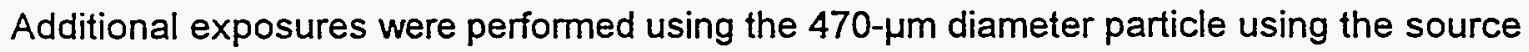
geometry shown in Figure 3.11 to expand on the percent scab incidence versus dose data from experiment 4. Three pigs were used: two 3.8-month-old litter mates in experiments 9 and 10 , and one 9.6-month-old in experiment 8 (Figure 5.23). The results are similar to those found by Hopewell (1991) but not to those from the 13.6-month-old pig irradiated for experiment 4. However, these similarities did not reflect an important difference which was noted when our scoring period was extended from 28 to 48 or 71 days and the scoring criteria were modified slightly, as discussed below.

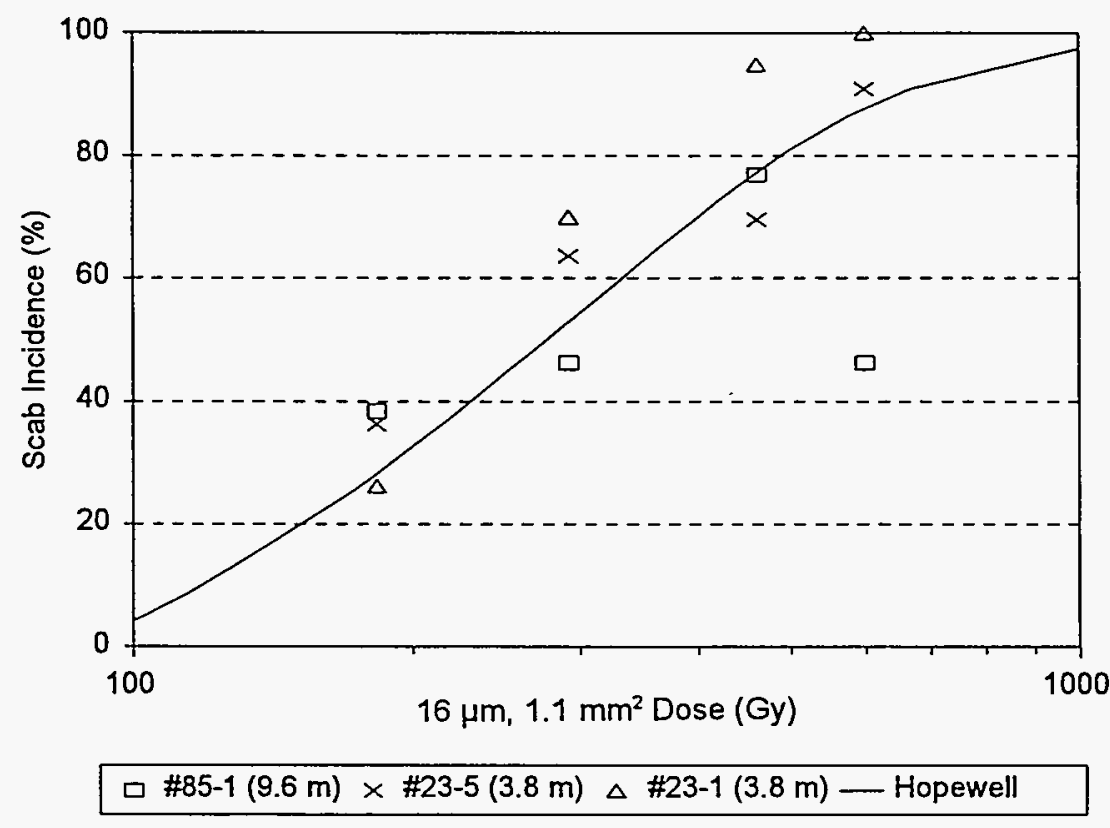

Figure 5.23 Scab incidence from a $470 \mu \mathrm{m}$ Tm-170 particle for scoring Method $E$ for experiments 8,9 , and 10 . Each BNL data point has a scab incidence error of $9-20 \%$. Data used to generate the solid line were taken from Figure 10 of Hopewell (1991) and have an uncertainty of $\pm 15-20 \%$ at the $E D_{50}$.

Hopewell scored animals for 28 days after exposure. BNL observations were continued to 71 DPI. Also, at the time, Hopewell's criterion for scoring an ulcer as radiation-induced was that two successive observations were needed by two observers, scoring animals twice weekly. For these early studies, BNL scored a lesion as a radiation-induced lesion if a scab was observed three times (not necessarily consecutive) during the observation period that continued to 48 to 71 DPI (see Sections 4.1 and 5.9 for more recent scoring methods and results). Observations were normally made every other day for the first 21 days, and twice a week thereafter. 
The BNL Tm-170 data for experiments 8, 9, and 10 were compared using both the Hopewell scoring criteria and the BNL scoring criteria. Data collected by BNL for periods of 28,48 , and 71 days were used to estimate the apparent threshold for Tm-170. The results are summarized in Table 5.2 and Figures 5.24 to 5.25 for 3.8-month-old pigs exposed to Tm-170, and in Figures 5.26 and 5.27 for a 9.6-month-old pig. The $5 \%$ scab incidence results were obtained using probit regression analyses.

Table 5.2 Effects of scoring technique and observation periods on $5 \%$ scab incidence estimates for 3.8-month-old pigs exposed to $\mathrm{Tm}-170$

\begin{tabular}{|l|c|c|c|c|}
\hline \multicolumn{1}{|c|}{ Data set } & $\begin{array}{c}\text { Scoring } \\
\text { technique }\end{array}$ & $\begin{array}{c}\text { Number of } \\
\text { observation } \\
\text { days }\end{array}$ & $\begin{array}{c}\text { ED dose } \\
\text { averaged over } \\
1.1 \mathrm{~mm}^{2} \text { at } \\
16 \mu \mathrm{m}(\mathrm{Gy})\end{array}$ & $\begin{array}{c}\text { ED }_{5} \text { dose } \\
\text { averaged over } \\
1 \mathrm{~cm}^{2} \text { at } \\
70 \mu \mathrm{m}(\mathrm{Gy})\end{array}$ \\
\hline \hline Hopewell & Hopewell & 28 & 90 & $1.5^{\mathrm{a}}$ \\
\hline Experiments 9 \& 10 & Method E & 28 & 130 & 2.2 \\
\hline Experiments 9 \& 10 & Method E & 48 & 52 & 0.87 \\
\hline Experiments 9 \& 10 & Method E & 71 & 28 & 0.47 \\
\hline Experiments 9 \& 10 & Hopewell & 28 & 130 & 2.2 \\
\hline Experiments 9 \& 10 & Hopewell & 48 & 50 & 0.83 \\
\hline Experiments 9 \& 10 & Hopewell & 71 & 30 & 0.50 \\
\hline
\end{tabular}

a. Dose averaged over $1.1 \mathrm{~mm}^{2}$ at $16 \mu$ m divided by 60 to obtain $1 \mathrm{~cm}^{2}$ dose at $70 \mu \mathrm{m}$ determined by BNL measurements and calculations using VARSKIN MOD 2.

The $\mathrm{ED}_{5}$ values ranged from 2.2 Gy for 28 -day observations to $0.5 \mathrm{~Gy}$ for 71 -day observations for 3-month-old pigs. Similar estimates of threshold values were obtained from regressions using data from either the Hopewell or the BNL scoring criteria; thus, the differences noted were primarily due to the length of the scoring period. Although not expected, based on previously reported results (Hopewell, 1991), we found an increase in scab incidence by factors of about 5 to 2 after $28 \mathrm{DPI}$ for the range of doses administered for the young pigs (Figures 5.24 and 5.25). 


\section{Experimental Results}

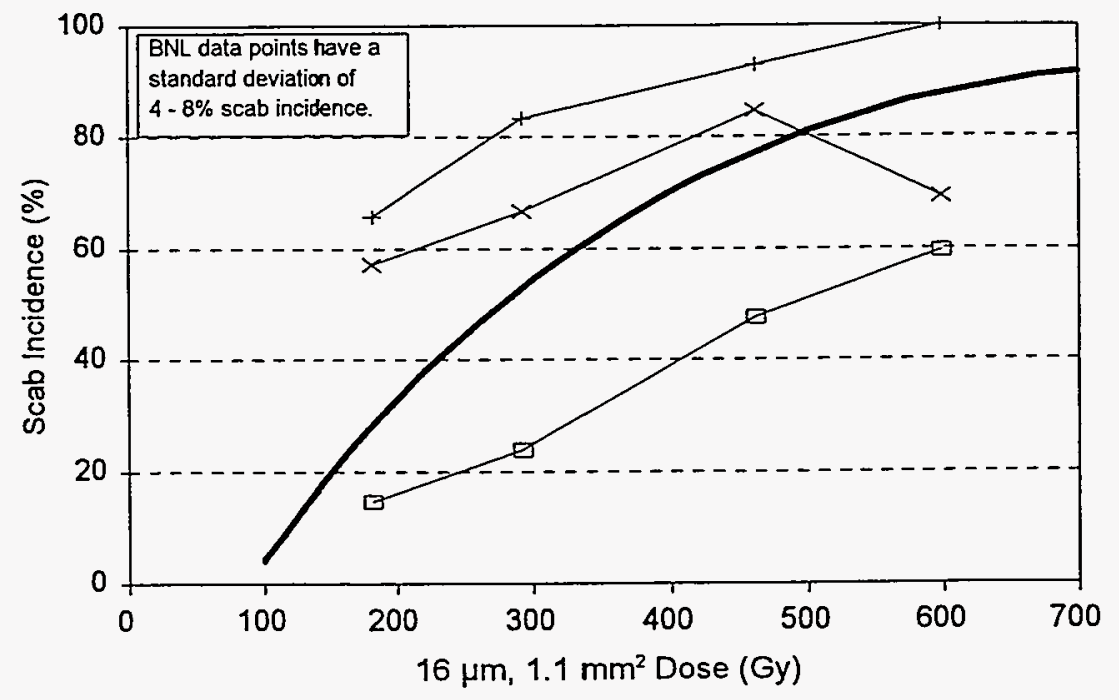

\begin{tabular}{|c|c|}
\hline $8 \mathrm{mo}, 28 \mathrm{dpi}$ & $\nrightarrow 3.8 \mathrm{mo}, 48 \mathrm{dpi}$ \\
\hline
\end{tabular}

Figure 5.24 Scab incidence data from Tm-170 experiments 9 and 10 for 3.8-month-old pig using BNL Method E scoring technique compared with Hopewell's (1991) results.

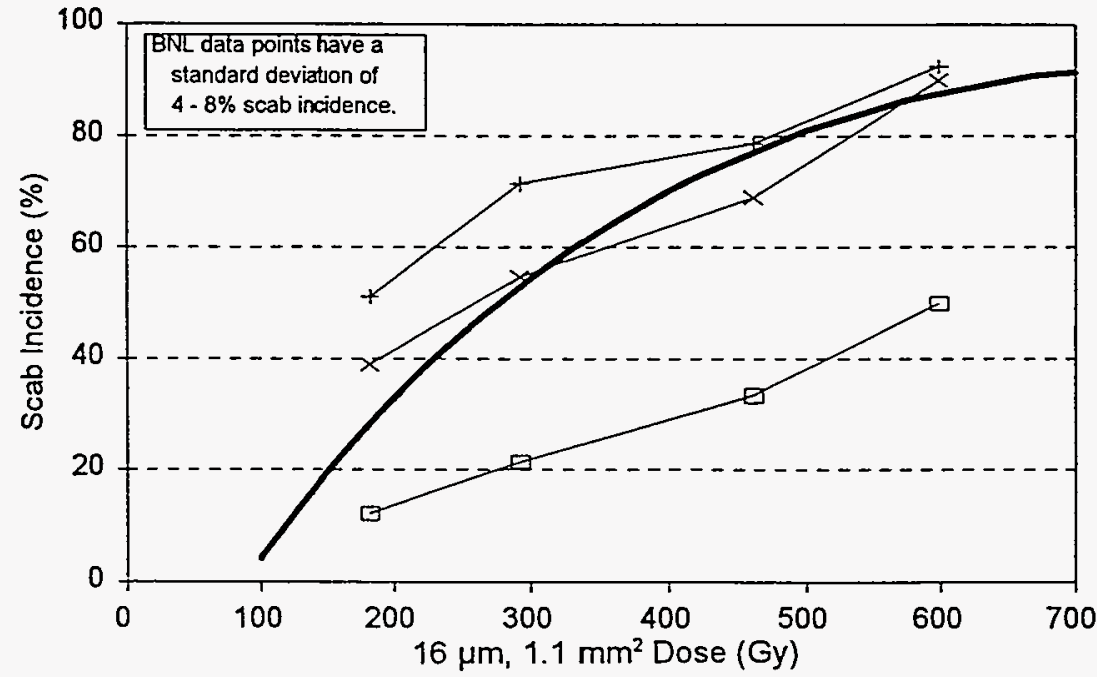

$$
\begin{array}{ll}
\leftarrow 3.8 \mathrm{mo}, 28 \mathrm{dpi} & -3.8 \mathrm{mo}, 48 \mathrm{dpi} \\
+3.8 \mathrm{mo}, 71 \mathrm{dpi} & - \text { Hopewell Tm-170 } \\
\hline
\end{array}
$$

Figure 5.25 Scab incidence data from Tm-170 experiments 9 and 10 for 3.8-month-old pig using Hopewell scoring technique compared with Hopewell's (1991) results. 


\section{Experimental Results}

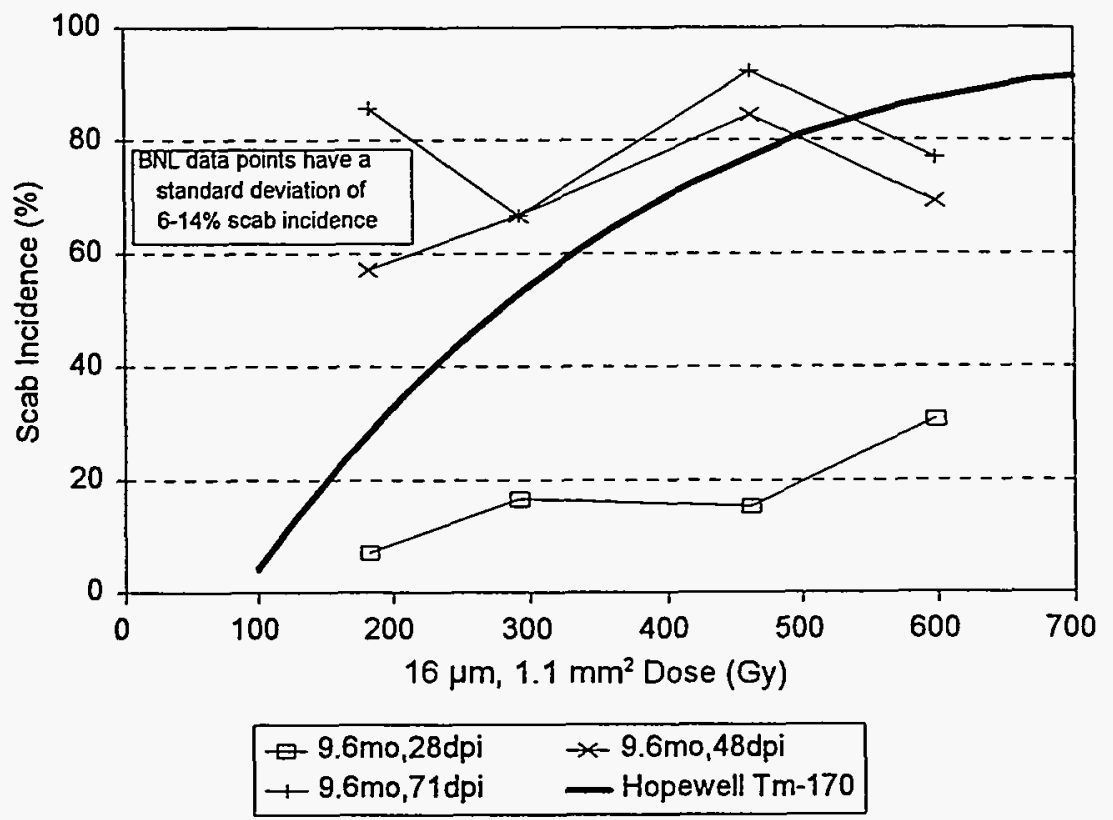

Figure 5.26 Scab incidence from Tm-170 for 9.6-month-old pig using BNL Method E scoring technique compared with Hopewell's (1991) results.

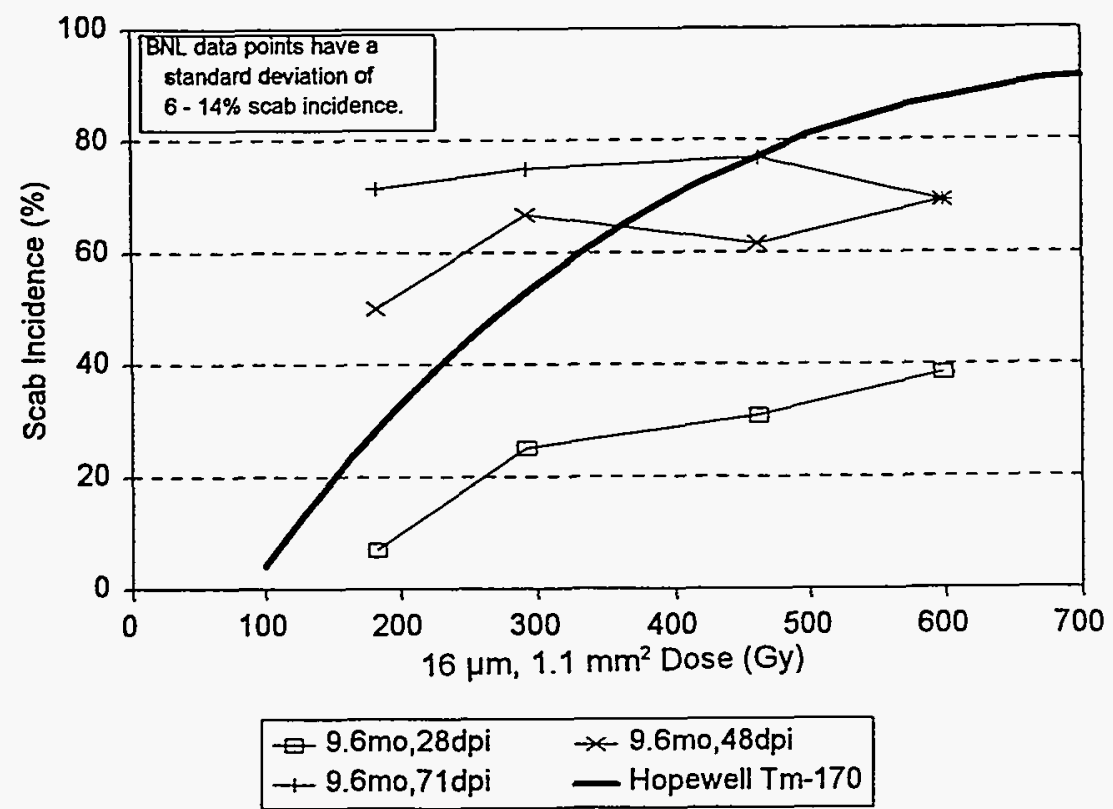

Figure 5.27 Scab incidence from Tm-170 for 9.6-month-old pig using Hopewell scoring technique compared with Hopewell's (1991) results. 


\section{Experimental Results}

A more recent analysis was made of the Tm-170 irradiation using scoring Method $C$ for 71 days of observation to determine $E D_{10}$ and $E D_{50}$ values (Figure 5.28). Since no control sites were used for this experiment, a background of $3.2 \%$ similar to that of the $1995 \mathrm{UC}_{2}$ experiment was assumed (see Section 5.8), which is close to the $2.8 \%$ for all control sites for all experiments in 1994-95. The $E D_{10}$ and $E D_{50}$ were 2.8 and $5.9 \mathrm{~Gy}$, respectively.

Using scoring Method $C$, the response of the 9.6-month-old pig irradiated with Tm-170 was more erratic than that of the younger pigs (Figure 5.29). This may have been due to the number of exposures, since there were about 40 replicate exposures at each dose for the younger pigs but only 13 at each dose point for the older pig. Confidence intervals could not be calculated due to this erratic data. The older pig seemed to be less sensitive than the younger pigs to higher doses as shown when comparing Figure 5.18 with Figure 5.28.

\subsection{Off-skin Tm-170 Results}

Off-skin irradiations were performed using Tm-170 for experiment 3. The hot particle's geometry is shown in Figures 3.7 and 3.8. To simulate a particle held off the skin by hair or cloth, the compression of the off-skin foam by the tipped source blocks compared to the non-tipped sources gave an off-skin distance of 830 and $1,400 \mu \mathrm{m}$, respectively, as described in section 3.2.5. The dose response from all particles ( 8 total exposures) was not sufficiently different to warrant separating the tipped and non-tipped data for dose-response regression analyses; therefore, data were combined for analysis (Figure 5.30). The off-skin X-axis intercept $(30 \pm 10 \mathrm{~Gy})$ is six times greater than that of the on-skin $X$-axis intercept $(4.7 \pm 2.0 \mathrm{~Gy})$.

\subsection{Initial Yb-175 Results}

For experiments 11 and 12, a 11.3-month-old pig and a 3.3-month-old pig were exposed to $\mathrm{Yb}$ 175 particles with maximum dimensions of 270 to $510 \mu \mathrm{m}$. These animals each received 31 exposures at a dose (1.3 Gy averaged over $1 \mathrm{~cm}^{2}$ at $70-\mu \mathrm{m}$ depth) intended to yield $10 \%$ incidence of scabs, and 11 exposures at a dose $(5.1 \mathrm{~Gy})$ intended to yield $50 \%$ incidence of scabs. In addition, the older animal was exposed at 18 additional sites and the younger animal at 42 additional sites in the range-finding to doses from 0.5 to $53 \mathrm{~Gy}$. This study had to be considered preliminary as only one observer was available after $20 \mathrm{DPI}$. Table 5.3 and Figures 5.31 and 5.32 summarize the results.

Data for 28-37 DPIs on the right flank of the 3.3-month-old animal were lost because the tape used for dictating results was inaudible. Thus, two observations at a critical time for scabs becoming evident were lost. 
Experimental Results

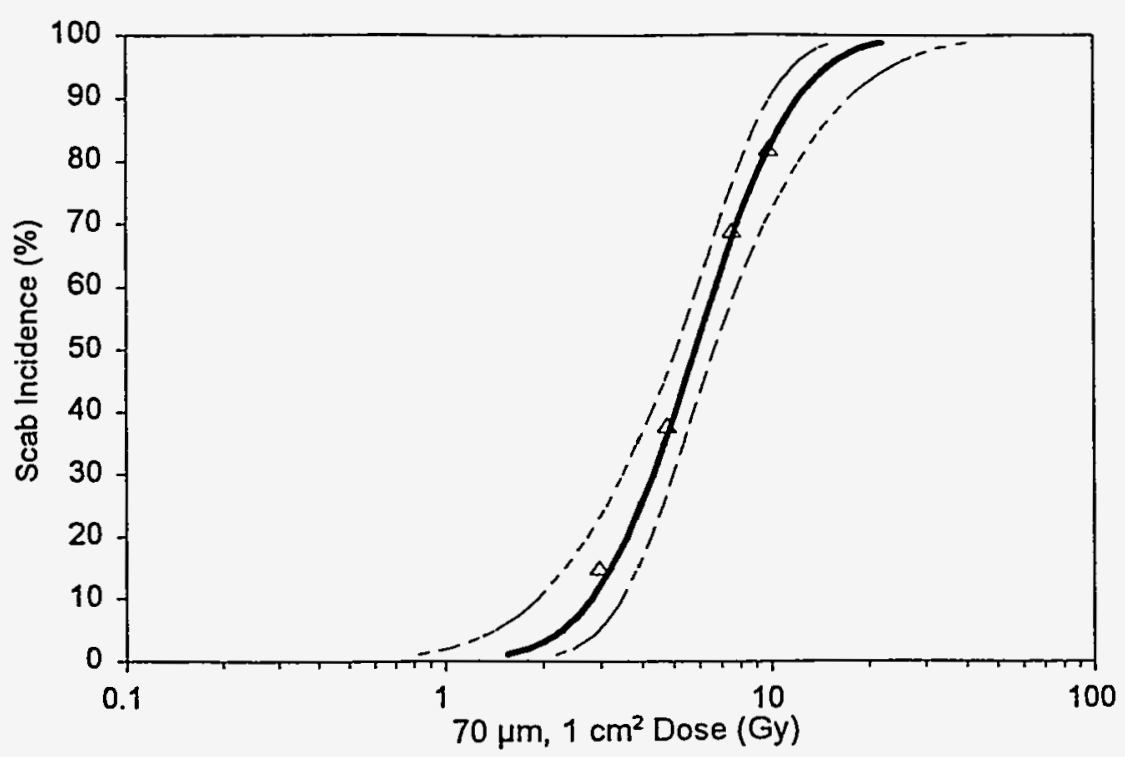

$\triangle$ Scab Incidence $\quad$ Probit Regression - - .95\% CLs

Figure 5.28 Scab incidence data from Tm-170 experiments 9 and 10 for 3.8-month-old pig using BNL scoring Method C.

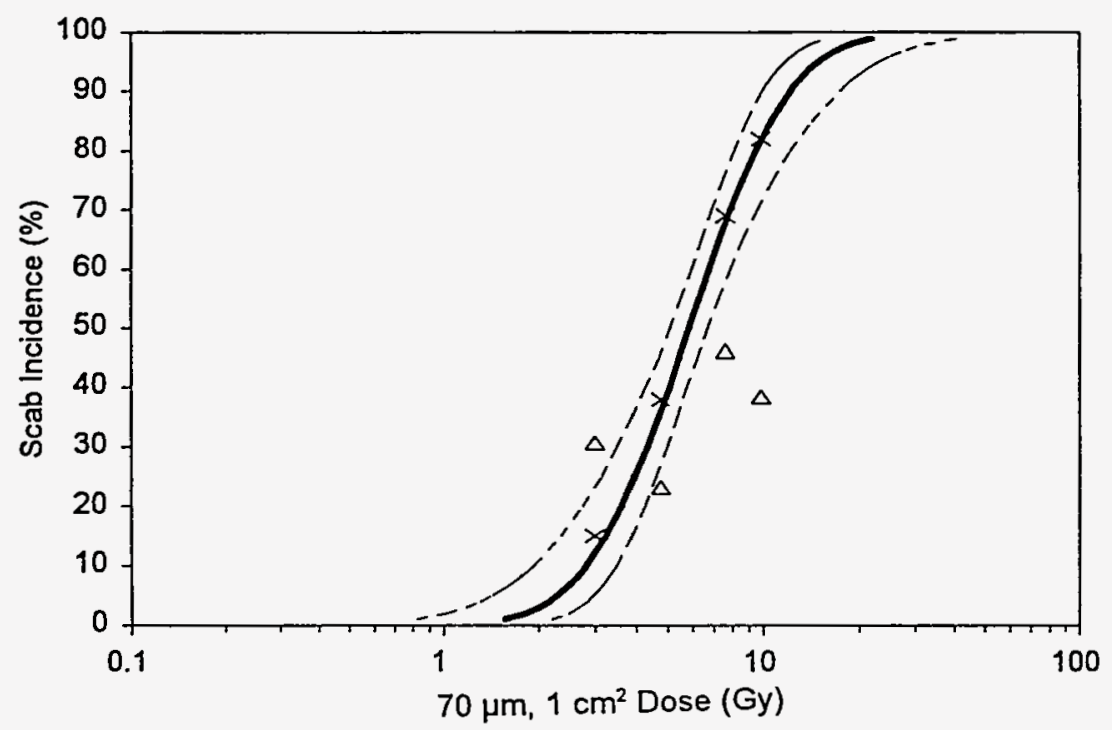

$\triangle 9.6$ mo. old

$\times 3.8 \mathrm{mo}$. old

Regress $3.8 \mathrm{mo} . \quad \ldots 95 \% \mathrm{CLs} 3.8 \mathrm{mo}$

Figure 5.29 Comparison of scab incidence data from Tm-170 experiments for 3.8-and 9.6-month-old pigs using BNL scoring Method C. 


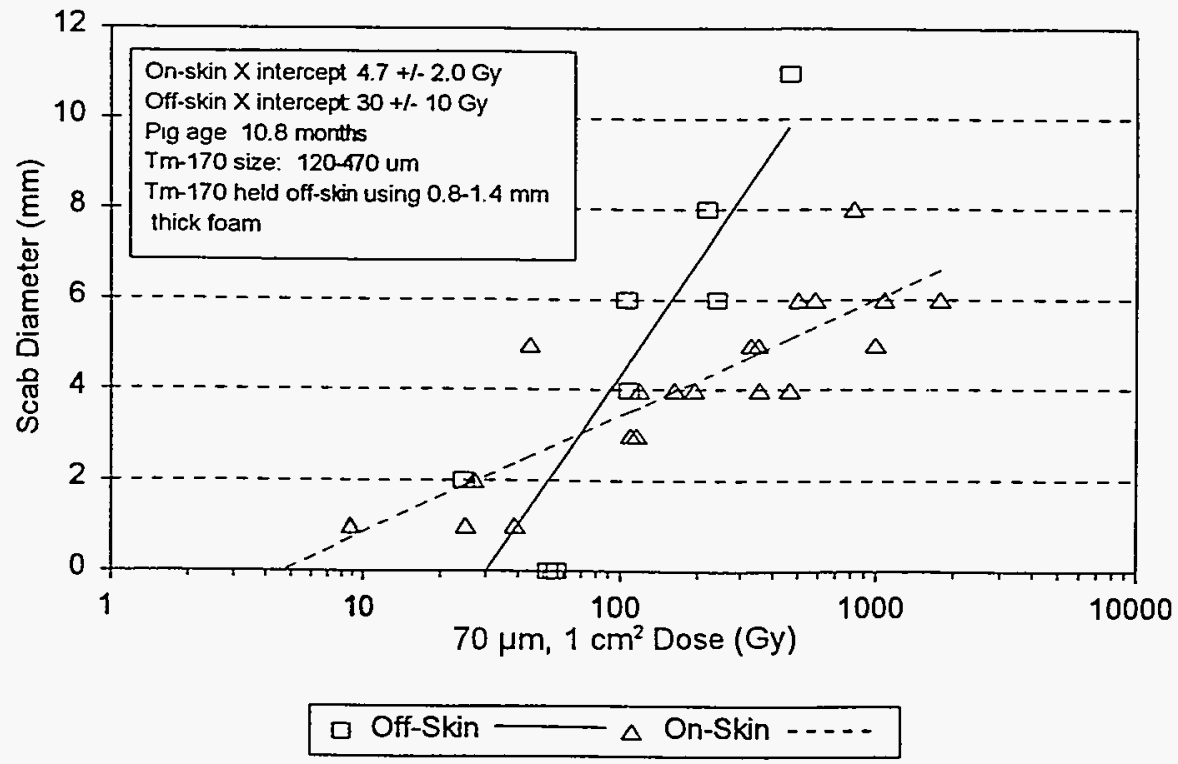

Figure 5.30 Scab diameters from on- and off-skin Tm-170 particles for pig irradiated in experiment 3.

Table 5.3 Summary of scab incidence using $\mathrm{Yb}-175$ for experiments 11 and 12

\begin{tabular}{|c|c|c|c|c|c|}
\hline \multirow{2}{*}{ Expieriment } & \multicolumn{2}{|c|}{ Dose (Gy) } & \multirow{2}{*}{$\begin{array}{l}\text { Number of } \\
\text { exposures }\end{array}$} & \multirow{2}{*}{$\begin{array}{c}\text { Number of } \\
\text { scabs }\end{array}$} & \multirow{2}{*}{$\begin{array}{c}\text { Scab } \\
\text { incidence } \\
\%\end{array}$} \\
\hline & $\begin{array}{c}1.1 \mathrm{~mm}^{2} \\
16 \mu \mathrm{m}\end{array}$ & $\begin{array}{l}1 \mathrm{~cm}^{2} \\
70 \mu \mathrm{m}\end{array}$ & & & \\
\hline $\begin{array}{c}12 \\
\text { Left flank } \\
\text { (3.3-month-old) }\end{array}$ & $\begin{array}{l}147 \\
564\end{array}$ & $\begin{array}{l}1.3 \\
5.1\end{array}$ & $\begin{array}{c}15 \\
5\end{array}$ & $\begin{array}{l}9 \\
3\end{array}$ & $\begin{array}{l}60 \pm 13 \\
60 \pm 22\end{array}$ \\
\hline $\begin{array}{c}12 \\
\text { Left \& right flank } \\
\text { (3.3-month-old) }\end{array}$ & $\begin{array}{l}147 \\
564\end{array}$ & $\begin{array}{l}1.3 \\
5.1\end{array}$ & $\begin{array}{l}31 \\
12\end{array}$ & $\begin{array}{c}13 \\
7\end{array}$ & $\begin{array}{l}42 \pm 8.9 \\
58 \pm 14\end{array}$ \\
\hline $\begin{array}{c}11 \\
\text { Left flank } \\
\text { (11.3-month-old) }\end{array}$ & $\begin{array}{l}147 \\
564\end{array}$ & $\begin{array}{l}1.3 \\
5.1\end{array}$ & $\begin{array}{l}31 \\
11\end{array}$ & $\begin{array}{c}21 \\
9\end{array}$ & $\begin{array}{l}68 \pm 8.4 \\
82 \pm 12\end{array}$ \\
\hline
\end{tabular}

a. The standard deviation is for a simple binomial distribution, $\sigma=(n p q)^{1 / 2}$ where $n, p$, and $q$ are the number of trials, probability of a scab, and probability of no scab, respectively.

b. Two observations for the right flank are missing as described in the following text. 


\section{Experimental Results}

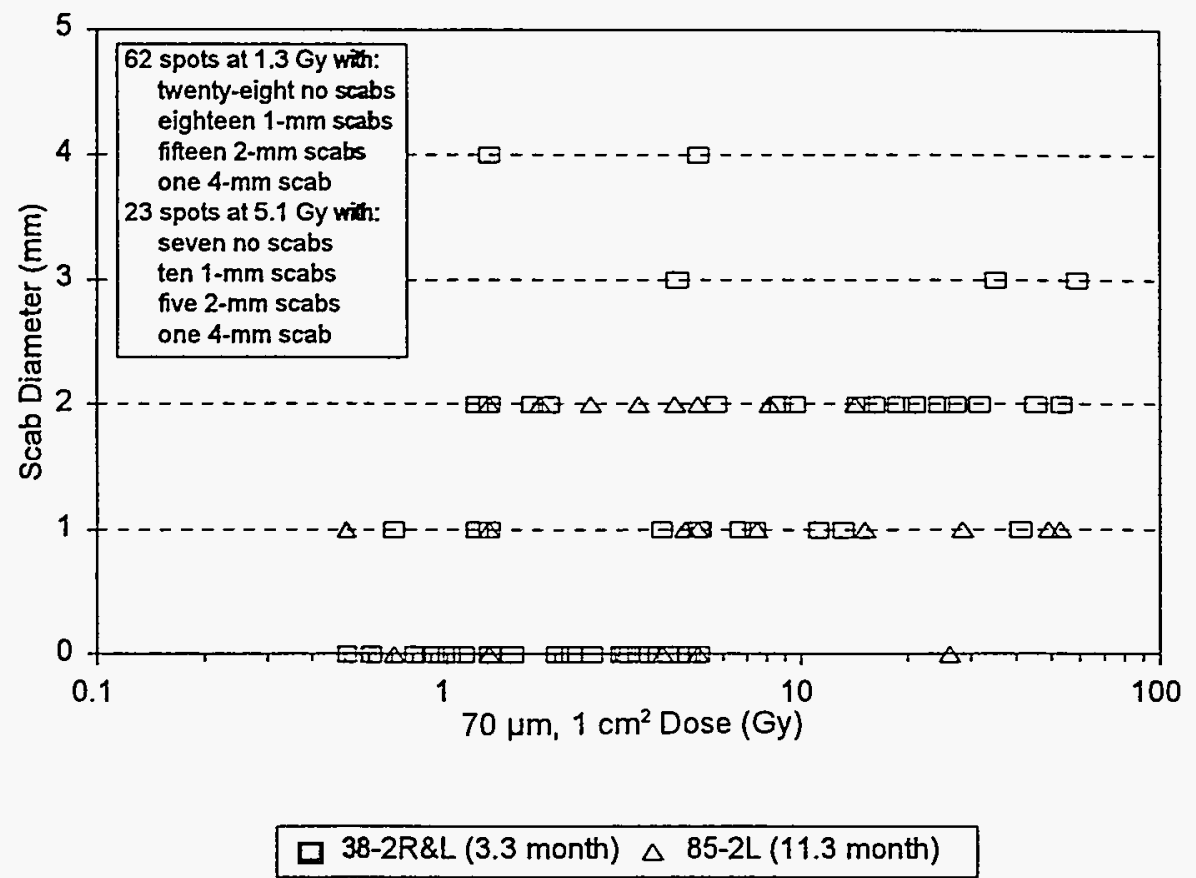

Figure 5.31 Scab diameter using scoring Method E for 3.3- and 11.3-month-old pigs exposed to $\mathrm{Yb}-175$ in experiments 11 and 12 .

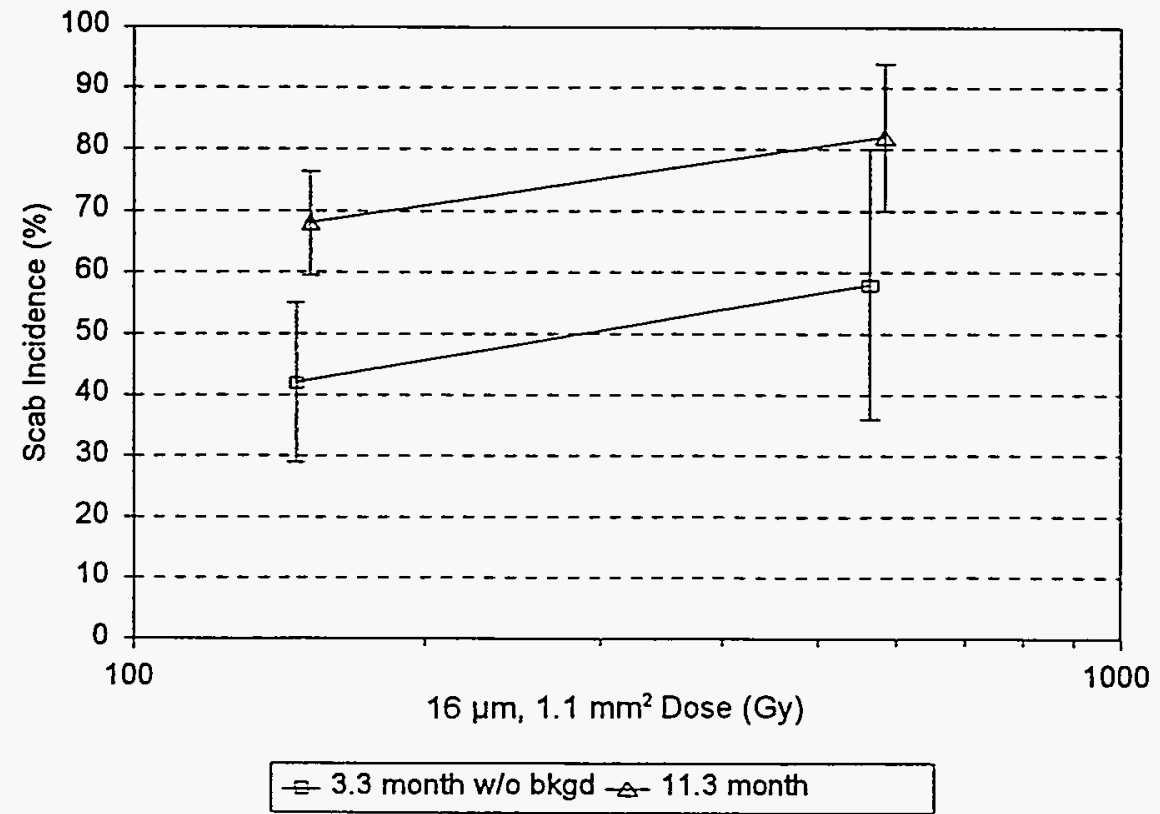

Figure 5.32 Scab incidence using scoring Method E for 3.3- and 11.3-month-old pigs exposed to $\mathrm{Yb}-175$ in experiments 11 and 12. 


\section{Experimental Results}

As shown in Table 5.3 and in Figure 5.32, the scab incidences were nearly independent of dose for the 1.3 and $5.1 \mathrm{~Gy}$ exposures for both animals and ranged from 42 to $82 \%$. There is no significant difference between the incidence for the two animals even though their ages were different when considering only the left flank of pig 38-2 with 85-2. Data for the older pig was not included in subsequent analysis. Younger pigs were preferred, as discussed in Section 3.6.4.1.

It is interesting that there was a 2.3-fold increase in the number of scabs for the left flank of the 3.3-month-old animal at a dose of $1.3 \mathrm{~Gy}$ (averaged over $1 \mathrm{~cm}^{2}$ at $70 \mu \mathrm{m}$ depth) compared with the right flank. This is most likely due to the number of observations for the left flank being 21 and that for the right flank being 16 . While the number of exposures was much smaller for the 5.1 Gy exposure, the response for both flanks was the similar $3 / 5(60 \%)$ for the left flank and $4 / 7$ $(57 \%)$ for the right flank.

There were four grid locations on the left flank of the 3.3-month-old pig that were not irradiated, but were observed. Observers may have known prior to the experiment that several of these sites were not going to be irradiated due to the positions in skin folds near the front and rear legs. Only one of these sites could be classified as a scab using scab scoring Method E. Two of the four unexposed sites were scored as scabs and on two consecutive observation periods by a single observer, which would have been classified as scabs under scab scoring Method $A$ if only one observer is considered. Erythema was noted about $25 \%$ of the time during the entire scoring period for all the unexposed areas.

There were three grid locations on the right flank of the 3.3-month-old pig that were also not irradiated. None of these sites would have been classified as scabs using either the Method $E$ or A scoring criteria. Erythema was scored on $23 \%$ of the total observations, which is similar to that of the left flank. The lower scab background as compared to the left flank may again be due to the right flank having five fewer observation periods. Combining the left and right flanks gave a background of 1 out of $7(14 \%)$ for the Method E criteria.

The unexposed areas can be used as a crude measure of background scab incidence. Subtracting this background gives a net scab incidence of 28 and $44 \%$ for the 1.3 and 5.1 Gy areas for the left and right flanks combined (Table 5.4). These net scab incidence values are about two-thirds and three-fourths of the gross values given in Table 5.3.

Two grid locations on the 11.3-month-old animal were not irradiated; however, it was agreed prior to the experiment with the observers that these areas were not to be exposed due to the positions in skin folds near the front and rear legs. Nevertheless, these areas were scored. Erythema was scored for one of these areas on four scoring periods after $26 \mathrm{DPI}$, and for six scoring periods for the other area beginning on the first DPI. Since neither of these two areas were classified as scabs, the results given in Table 5.3 are not changed.

This preliminary experiment demonstrated that for the protocol used in these low-dose experiments, a sufficient number of control sites were needed for proper understanding of the background incidence rate, as well as several independent observers to increase quality assurance in future experiments. 
Table 5.4 Net scab incidence with background subtracted for the 3.3-month-old pig exposed to $\mathrm{Yb}-175$ in an initial experiment

\begin{tabular}{|c|c|c|c|c|c|}
\hline \multirow{2}{*}{ Pig } & \multicolumn{2}{|c|}{ Dose (Gy) } & \multirow{2}{*}{$\begin{array}{l}\text { Number of } \\
\text { exposures }\end{array}$} & \multirow{2}{*}{$\begin{array}{l}\text { Number of } \\
\text { scabs }\end{array}$} & \multirow{2}{*}{$\begin{array}{c}\text { Net } \\
\text { scab } \\
\text { incidence } \\
\%\end{array}$} \\
\hline & $\begin{array}{c}1.1 \mathrm{~mm}^{2} \\
16 \mu \mathrm{m}\end{array}$ & $\begin{array}{l}1 \mathrm{~cm}^{2} \\
70 \mu \mathrm{m} \\
\end{array}$ & & & \\
\hline $\begin{array}{c}\text { 38-2 } \\
\text { Left flank }\end{array}$ & $\begin{array}{c}0 \\
147 \\
564\end{array}$ & $\begin{array}{c}0 \\
1.3 \\
5.1\end{array}$ & $\begin{array}{c}4 \\
15 \\
5\end{array}$ & $\begin{array}{l}1 \\
9 \\
3\end{array}$ & $\begin{array}{l}35 \pm 32 \\
35 \pm 43\end{array}$ \\
\hline $\begin{array}{c}38-2 \\
\text { Left \& right flank }\end{array}$ & $\begin{array}{c}0 \\
147 \\
564\end{array}$ & $\begin{array}{c}0 \\
1.3 \\
5.1\end{array}$ & $\begin{array}{c}7 \\
31 \\
12\end{array}$ & $\begin{array}{c}1 \\
21 \\
9\end{array}$ & $\begin{array}{l}28 \pm 18 \\
44 \pm 26\end{array}$ \\
\hline
\end{tabular}

a. Standard deviation, $s$, calculated using Poisson statistics where $s=\left(n_{s} /\left(n_{e}\right)^{2} \mid b_{s} /\left(b_{e}\right)^{2}\right)^{1 / 2}$ where $n_{s}, n_{e}, b_{s}$, and $b_{e}$ are the number of scabs, number of exposures, background number of scabs, and background number of exposures, respectively.

Data on scab diameters are summarized for the two pig exposures in Figure 5.31. The standard deviation of the $X$-axis intercept value was as large as the $X$-axis intercept value. For this reason, a meaningful intercept cannot be deduced from this data.

The dose response shows that there were very few scabs of 3- and 4-mm diameter. This is due to the maximum range of $\mathrm{Yb}-175$ beta particles which is about $1.4 \mathrm{~mm}$, with $95 \%$ of the beta particle's energy absorbed in approximately $0.63 \mathrm{~mm}$ of tissue. One scab occurred from a dose below $1 \mathrm{~Gy}$ for the 11-month-old pig (85-2), seeming to indicate that $\mathrm{Yb}-175$ was more effective than $\mathrm{Tm}-170$ or $\mathrm{UC}_{2}$ in producing scabs. For this reason, a more complete study of $\mathrm{Yb}-175 \mathrm{scab}$ incidence was planned.

\subsection{Additional Yb-175 Studies}

As indicated in Table 3.10, a second series of animals were exposed to $\mathrm{Yb}-175$ in 1994 and are detailed in rows for experiment numbers 13,15 , and 17. The hot-particle geometry is shown in Figure 3.10 and described in Section 3.2.5. Since the 1992 results described above yielded a dose response that was very flat (little slope), 36 sites were reserved to determine the possible frequencies of "background" or "control" incidence that would need to be subtracted from induced effects to give more accurate values. Biopsy samples were also taken from irradiated and unirradiated sites on these animals and analyzed as previously described (Section 3.6.4.3) . 


\section{Experimental Results}

The results of regression analysis for scab incidence for $71 \mathrm{DPI}$ are shown in Figure 5.33 for scoring Method $\mathrm{C}$, which gave a zero background incidence as described in Section 4.1.4. (The results for other scoring methods are given in Section 5.11 , below.)

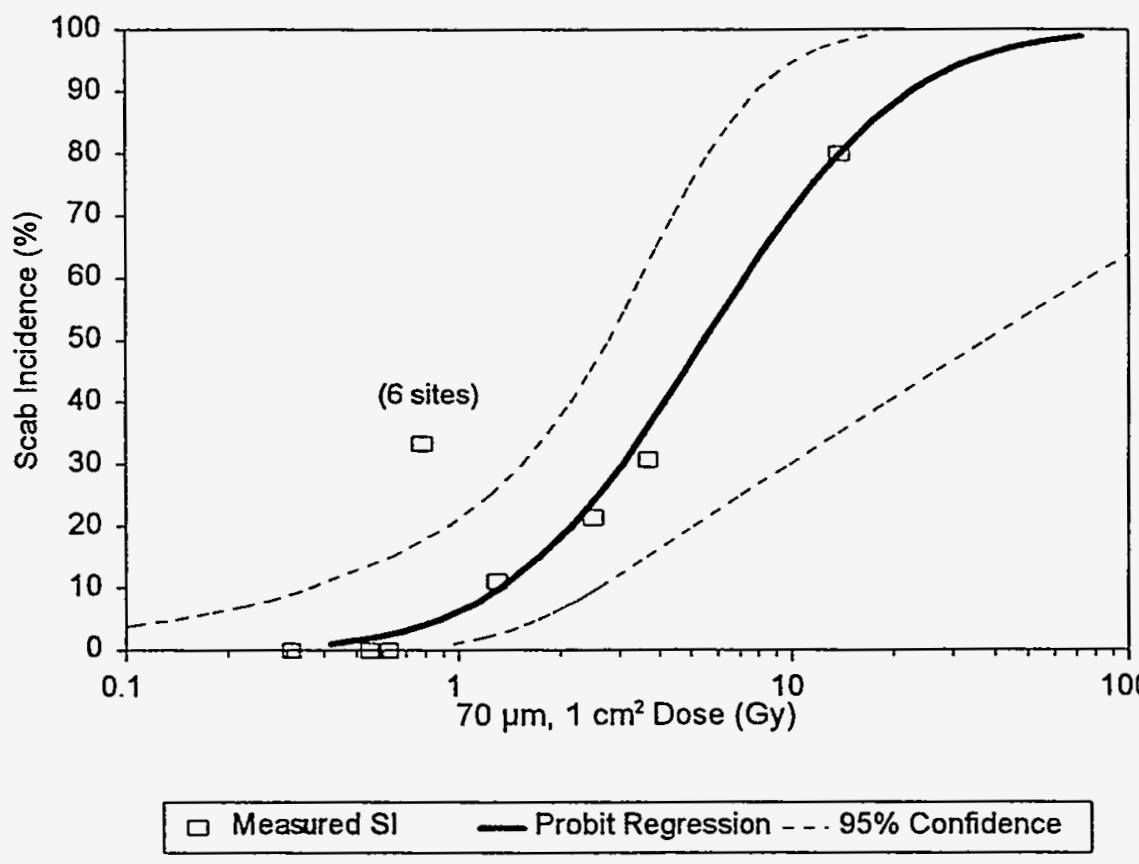

Figure 5.33 Scab incidence for scoring Method $C$ and pigs exposed to Yb-175 particles in experiments 13,15 , and 17 . Only 6 sites were exposed to $0.78 \mathrm{~Gy}$.

The point plotted at 0.78 Gy resulted from scabs at two of only six sites exposed at this dose and therefore has a large statistical uncertainty. The $E D_{10}$ and $E D_{50}$ values for the three animals combined were 1.3 and $5.5 \mathrm{~Gy}$, respectively, for dark plus white scabs. The $E D_{50}$ value is consistent with the 58 and $60 \%$ values obtained at $5.1 \mathrm{~Gy}$ in the 1992 work described above for the 3.3-month-old pig (Table 5.3). The $1.3 \mathrm{~Gy}$ value for the $E D_{10}$ is more in keeping with the general responses found in these studies and indicates that the $E D_{10}$ values found in the 1992 work were probably erroneous. This is addressed in the following paragraphs.

The large uncertainties for the plots of percent scab incidence for higher doses were due to our greater concern to clearly establish an $E D_{10}$ value with small confidence limits, as $Y b-175$ was the most efficient at producing skin ulcers at lower doses. For this reason, there were few exposures at doses greater than $14 \mathrm{~Gy}$ (averaged over $1 \mathrm{~cm}^{2}$ at $70 \mu \mathrm{m}$ depth) in the 1994 experiments. In the preliminary $\mathrm{Yb}-175$ experiment with the 3.3-month-old pig in 1992, 12 exposures were made at doses of greater than $14 \mathrm{~Gy}$. All of these irradiations resulted in scabs 


\section{Experimental Results}

when using the Method E scab criterion of requiring a scab to be seen by the majority of observers for three different scoring periods. Since the 1992 data was available to us, and would add considerable additional information to the 1994 data, a method for reconciling the two data sets was developed, as described below.

For the $1992 \mathrm{Yb}-175$ data set, there were three observers for the first week of observations, two for the following two weeks of observations, and one observer thereafter until 62 DPI. There were 16 observations of the right flank and 21 of the left flank.

The scab selection criteria, A, B, and C discussed in Section 4.1 could not be applied because there was only one observer for two-thirds of the observation period. Therefore, a modified version of Method $E$ was used. Scabs were considered to be radiation-induced if seen on five different days for the left flank of the 3.3-month-old pig and four different days for its right flank. The different required number of sightings reflects the fewer scoring periods for the right flank. Using this criterion, none of the seven unexposed sites were scored as having scabs. Thus, this modified Method E criteria minimizes false-positive scabs. The percentage of 1.3 Gy scabs was reduced from $42 \%$ (Table 5.3) to $13 \%$ (Table 5.5). This value is similar to the 1994 results which had $11 \%$ scab incidence for this dose. The percentage of $5.1 \mathrm{~Gy}$-induced scabs was reduced from 58 (Table 5.3) to 25 (Table 5.5). While the latter value for $5.1 \mathrm{~Gy}$ exposures (Table 5.5) did not agree well with the 1994 results in which 3.7 Gy gave $31 \pm 13 \%$ and 14 Gy gave $80 \pm 13 \%$ scab incidence, when the uncertainties ( 1 standard deviation) were taken into consideration, the result is not unreasonable. With this scab-selection criterion, 11 of the 12 high-dose sites (doses greater than $14 \mathrm{~Gy}$ ) resulted in scabs (Table 5.5).

The probit regression algorithm uses a maximum likelihood function, which accommodates individual data points ( 1 or $0 \mathrm{scab}(\mathrm{s})$ out of 1 exposure) as well as group exposures at a single dose, with each exposure site receiving equal weight. Thus, this high-dose data could be included with the 1994 data without the potential biases introduced when unequal doses are averaged together in conventional probit analysis. Combining only the high-dose irradiations (greater than $14 \mathrm{~Gy}$ ) with the $1994 \mathrm{PSI}$ probit regression gives much smaller confidence levels (compare Figure 5.33 with Figure 5.34). Including the 1.3, 5.1 Gy, and the high-dose 1992 results (from Table 5.5) with the 1994 data does not change the $E D_{10}$ and $E D_{50}$ values appreciably (Table 5.6 and Figure 5.35). As an example, the upper $95 \%$ confidence interval for the $E D_{50}$ is increased by about $1 \mathrm{~Gy}$, due to the lower incidence of the $5.1 \mathrm{~Gy}$ sites exposed in 1992. The preferred data set for the $\mathrm{Yb}-175$ exposures is the 1994 data set combined with the replicate and high dose data from the 1992 experiment, as shown in Figure 5.35 (last row of Table 5.6). While the confidence limits for the $E D_{50}$ for this data set are larger than those given for the 1994 data set, combined with the doses greater than 14 Gy of the 1992 data set (Figure 5.34) (middle row of Table 5.6), it was difficult to justify inclusion of only one portion of the data.

The upper and lower confidence intervals about the $\mathrm{ED}_{10}$ given in Table 5.6 decreased substantially when the 1992 high-dose data was included with the 1994 data because there was greater certainty that the merged data covering a larger dose-range was more normally distributed. Hence, the t-test statistic was reduced to 1.96 , which is the test statistic value for normal distributions. The t-test statistic was used in the calculating confidence intervals. 


\section{Experimental Results}

Table 5.5 Reanalysis of Yb-175 data listed in Table 5.3 using four scab sightings on the right flank and five scab sightings on the left flank and modified Method $E$ scoring criteria

\begin{tabular}{|c|c|c|c|c|c|}
\hline \multirow{2}{*}{$\begin{array}{l}\text { Pig } \\
38-2\end{array}$} & \multicolumn{2}{|c|}{ Dose $(G y)^{a}$} & \multirow{2}{*}{$\begin{array}{l}\text { Number of } \\
\text { exposures }\end{array}$} & \multirow{2}{*}{$\begin{array}{c}\text { Number of } \\
\text { scabs }\end{array}$} & \multirow{2}{*}{$\begin{array}{c}\text { Net } \\
\text { incidence } \\
\%\end{array}$} \\
\hline & $\begin{array}{c}1.1 \mathrm{~mm}^{2} \\
16 \mu \mathrm{m}\end{array}$ & $\begin{array}{r}1 \mathrm{~cm}^{2} \\
70 \mu \mathrm{m} \\
\end{array}$ & & & \\
\hline Left flank & $\begin{array}{c}0 \\
147 \\
564\end{array}$ & $\begin{array}{c}0 \\
1.3 \\
5.1\end{array}$ & $\begin{array}{c}4 \\
15 \\
5\end{array}$ & $\begin{array}{l}0 \\
2 \\
0\end{array}$ & $\begin{array}{c}13 \pm 9 \\
0\end{array}$ \\
\hline $\begin{array}{l}\text { Left and right } \\
\text { flanks }\end{array}$ & $\begin{array}{c}0 \\
147 \\
564\end{array}$ & $\begin{array}{c}0 \\
1.3 \\
5.1\end{array}$ & $\begin{array}{c}7 \\
31 \\
12\end{array}$ & $\begin{array}{l}0 \\
4 \\
3\end{array}$ & $\begin{array}{c}13 \pm 6 \\
25 \pm 13\end{array}$ \\
\hline $\begin{array}{l}\text { Left and right } \\
\text { flanks }\end{array}$ & $\begin{array}{l}2.0 E+03 \\
1.7 E+03 \\
2.6 E+03 \\
2.2 E+03 \\
3.3 E+03 \\
2.9 E+03 \\
4.3 E+03 \\
3.7 E+03 \\
5.5 E+03 \\
4.7 E+03 \\
7.2 E+03 \\
6.2 E+03\end{array}$ & $\begin{array}{l}15 \\
16 \\
19 \\
21 \\
24 \\
27 \\
32 \\
35 \\
41 \\
45 \\
53 \\
59\end{array}$ & $\begin{array}{l}1 \\
1 \\
1 \\
1 \\
1 \\
1 \\
1 \\
1 \\
1 \\
1 \\
1 \\
1\end{array}$ & $\begin{array}{l}0 \\
1 \\
1 \\
1 \\
1 \\
1 \\
1 \\
1 \\
1 \\
1 \\
1 \\
1\end{array}$ & $\begin{array}{c}0 \\
100 \\
100 \\
100 \\
100 \\
100 \\
100 \\
100 \\
100 \\
100 \\
100 \\
100\end{array}$ \\
\hline
\end{tabular}

a. The ratio of doses in columns 2 and 3 vary from 104 to 137, depending on the particle size employed.

b. Standard deviation calculated using binomial statistics (see footnote under Table 5.3 for description) which gives values within $10 \%$ for Poisson statistics (see footnote under Table 5.4 for a description).

Note that the $E D_{50}$ values in Table 5.6 for $Y b-175$ are within $10 \%$ of the value for $T m-170$. The uncertainties for the $\mathrm{Yb}-175 \mathrm{ED}_{50}$ value are larger than those for the $\mathrm{Tm}-170$ source, so it is not clear which, if either, hot particle produces ulcers more efficiently $50 \%$ of the time.

The scab diameters were also recorded for the 1994 experiments. The largest scabs for doses less than 20 Gy (highest Yb-175 exposure for 1994 experiment) were $4 \mathrm{~mm}$ (Figure 5.36 and Table 5.7). The correlation coefficient was only 0.5 , thus, no regression line or intercept are given. 


\section{Experimental Results}

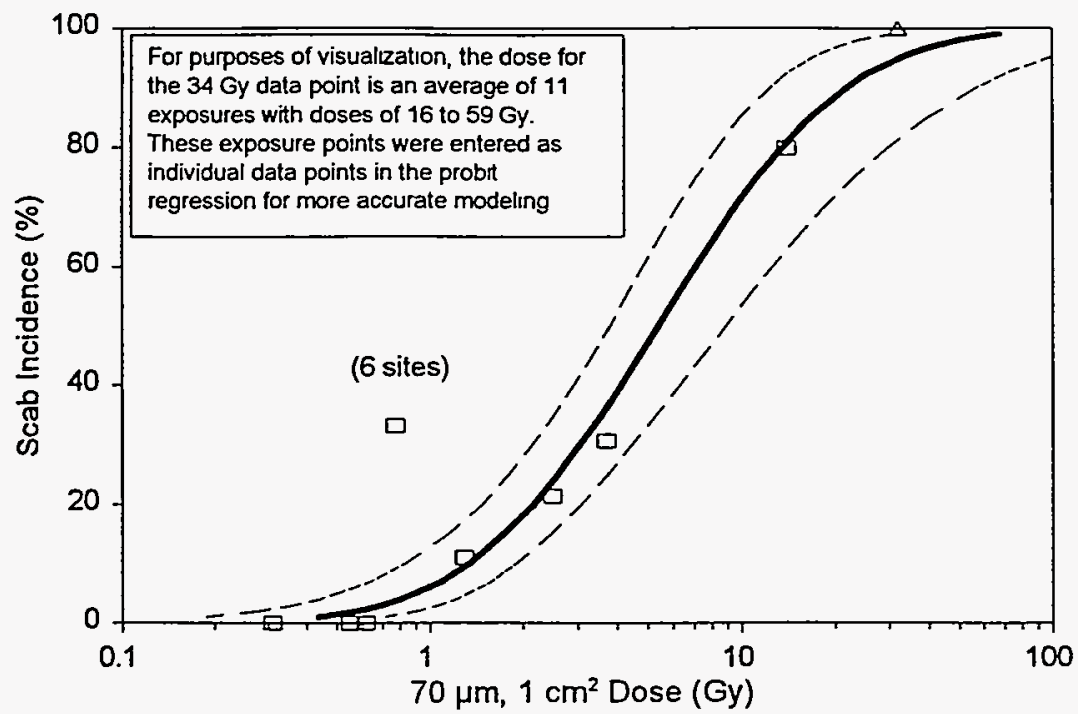
Probit Regress - - 95\% CLs

Figure 5.34 Scab incidence for pigs exposed to Yb-175 in 1994 (scabscoring Method C, $71 \mathrm{DPI}$ ), and for 12 areas exposed to doses greater than $14 \mathrm{~Gy}$ in 1991 (scab-scoring Method modified E, $62 \mathrm{DPI})$.

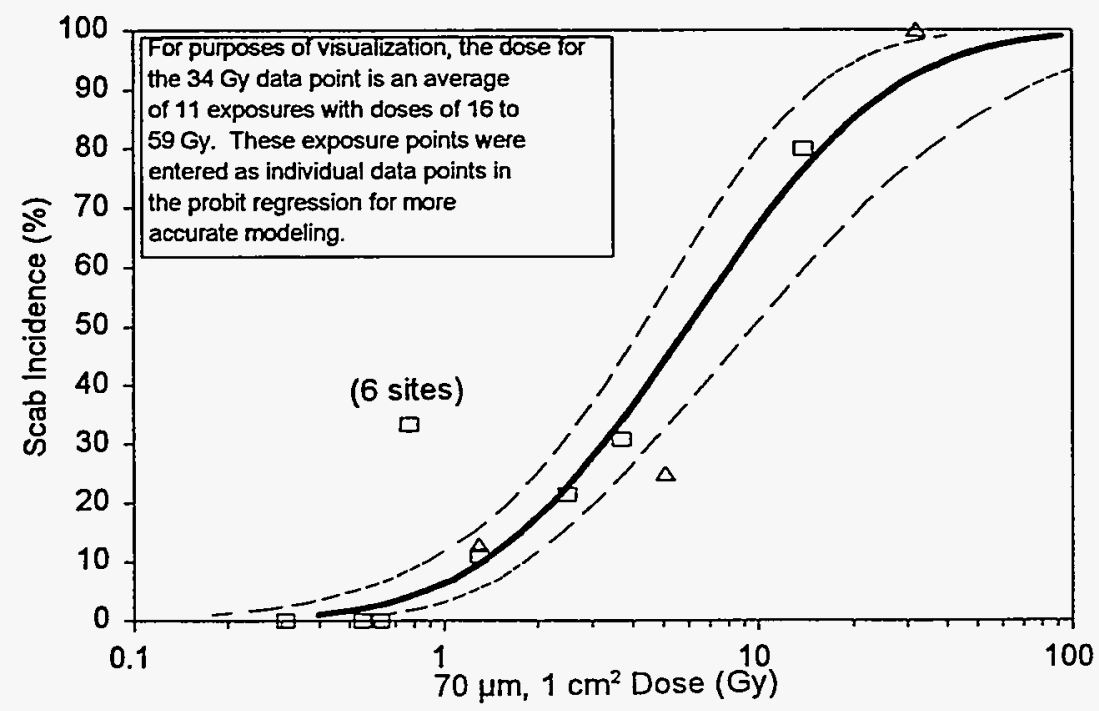

\begin{tabular}{|lll|}
\hline 口 1994 & $\Delta 1992 \quad$ Probit Regress - - 95\% CLs \\
\hline
\end{tabular}

Figure 5.35 Scab incidence for pigs exposed to $\mathrm{Yb}-175$ in 1994, including all 1992 exposures. 


\section{Experimental Results}

Table 5.6 Probit regression results for $1994 \mathrm{Yb}-175$ data combined with the 1992 preliminary data ${ }^{2}$

\begin{tabular}{|l|c|c|c|c|}
\hline \multicolumn{1}{|c|}{ Data used } & $\begin{array}{c}\mathrm{ED}_{10} \\
(\mathrm{~Gy})^{\mathrm{b}}\end{array}$ & $\begin{array}{c}\mathrm{ED}_{10} \\
95 \% \text { confidence } \\
\text { interval }(\mathrm{Gy})\end{array}$ & $\begin{array}{c}\mathrm{ED}_{50} \\
(\mathrm{~Gy})^{\mathrm{b}}\end{array}$ & $\begin{array}{c}\mathrm{ED}_{50} \\
\text { 95\% confidence } \\
\text { interval (Gy) }\end{array}$ \\
\hline \hline 1994 & 1.3 & 0.36 to 2.6 & 5.5 & 2.8 to 38 \\
\hline 1994 and 1992 doses > 14 Gy & 1.3 & 0.84 to 1.9 & 5.4 & 3.8 to 8.9 \\
\hline $\begin{array}{l}1994 \text { and 1992 doses 1.3, 5.1 } \\
\text { and }>14 \text { Gy (preferred data } \\
\text { set) }\end{array}$ & 1.3 & 0.89 to 1.8 & 6.0 & 4.3 to 9.7 \\
\hline
\end{tabular}

a. The scoring method used for the 1994 data was Method $C$ for 71 days of obsenvation. The scoring method for the 1992 data was the modified Method E, discussed above, for 62 days. Data from the 1992 experiment used in the probit analysis are listed in Table 5.5. Scab occurrences from both the left and right flanks of the 1992 animal were included in the results.

b. Dose is averaged over $1 \mathrm{~cm}^{2}$ at a depth of $70 \mu \mathrm{m}$.

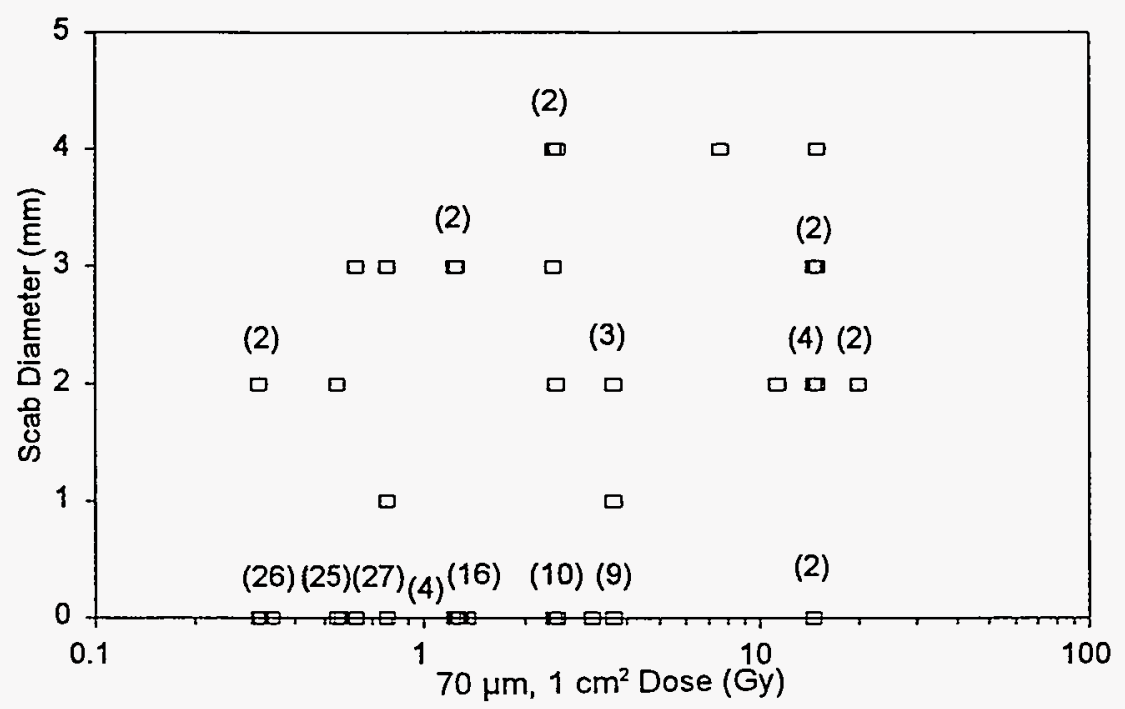

Figure 5.36 Scab diameter for Yb-175 for 1994 experiments 13, 15, and 17. The numbers above data points indicate multiple number of sites with the measured response. See Table 5.7 for further details. 
Table 5.7 Number of scabs, by diameter, for given doses from $\mathrm{Yb}-175$ particles using scoring Method B

\begin{tabular}{|c|c|c|c|c|c|}
\hline \multirow{2}{*}{$\begin{array}{c}\text { Dose } \\
1 \mathrm{~cm}^{2} \\
70 \mu \mathrm{m}(\mathrm{Gy})\end{array}$} & \multicolumn{5}{|c|}{ Number of scabs (by diameter) } \\
\hline & No scab & $1 \mathrm{~mm}$ & $2 \mathrm{~mm}$ & $3 \mathrm{~mm}$ & $4 \mathrm{~mm}$ \\
\hline 0.31 & 26 & 0 & 2 & 0 & 0 \\
\hline 0.55 & 25 & 0 & 1 & 0 & 0 \\
\hline 0.62 & 27 & 0 & 0 & 1 & 0 \\
\hline 0.78 & 4 & 1 & 0 & 1 & 0 \\
\hline 1.3 & 16 & 0 & 0 & 2 & 0 \\
\hline 2.5 & 10 & 0 & 1 & 1 & 2 \\
\hline 3.7 & 9 & 1 & 3 & 0 & 0 \\
\hline 7.8 & 0 & 0 & 0 & 0 & 1 \\
\hline 14 & 2 & 0 & 5 & 2 & 1 \\
\hline 20 & 0 & 0 & 2 & 0 & 0 \\
\hline
\end{tabular}

\subsection{Sc-46 Studies and Results}

Details for the hot particle geometry used for the Sc-46 irradiation are shown in Figure 3.12 and described in sections 3.1.4 and 3.2.5. Information pertaining to the pigs' age, doses, and number of sites irradiated are given in Table 3.10 for experiments number 14, 16, and 17.

Figure 5.37 shows the results for regression analyses of scab incidence vs. dose. The $E D_{10}$ and $E D_{50}$ values for the combined data using scoring Method $C$ were 5.1 and 12 Gy, respectively, after 71 days of observations. The background scab incidence for the Sc-46 exposures was $11 \%(3 \div 28)$. This was higher than for either the $\mathrm{Yb}-175$ and $\mathrm{UC}_{2}$ irradiations carried out in 1994-95. No scabs were seen for the two lowest dose regimens of 1.2 and 2.2 Gy (26 and 28 sites, respectively) for scoring Method $C$. Additional analyses of these data are given in the comparisons section of this report.

Regression of the diameter of the scabs induced by Sc-46 hot particles gave a dose-axis intercept value of $2.2 \pm 0.36 \mathrm{~Gy}$ (averaged over $1 \mathrm{~cm}^{2}$ at $70 \mu \mathrm{m}$ depth), when the minimum dose used for the regression was 2.2 Gy (Figure 5.38 ) (correlation coefficient $=0.70$ ). 


\section{Experimental Results}

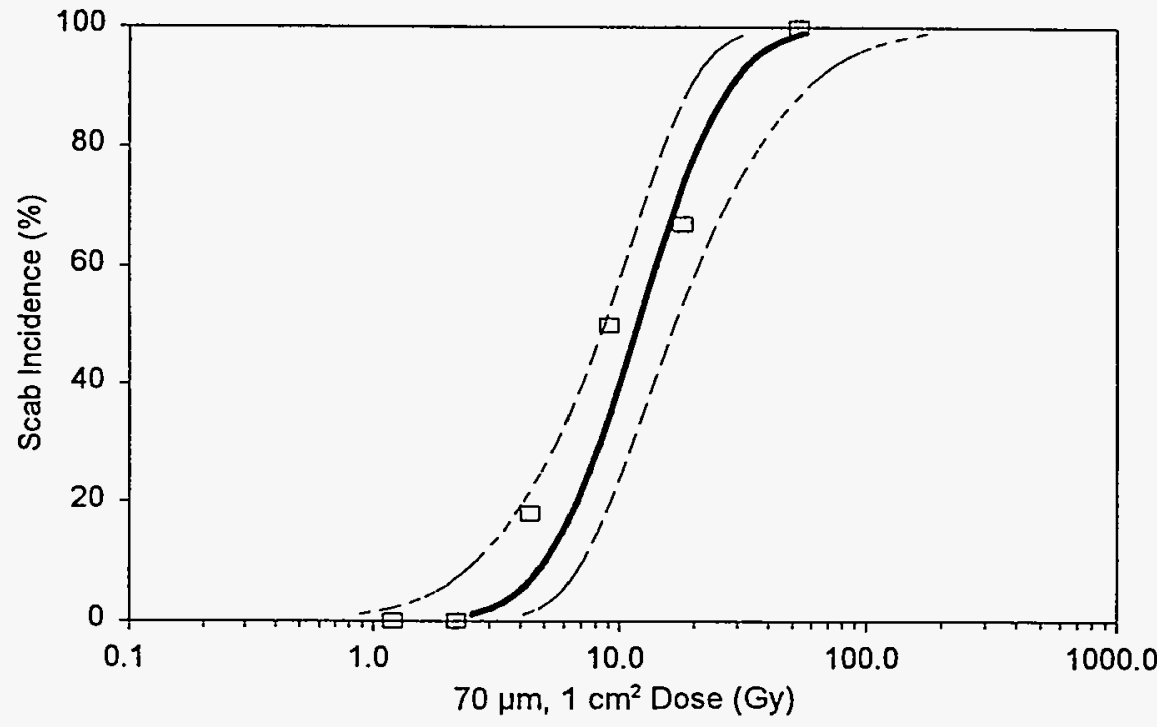

$\square$ Scab Incidence —Probit Regression - -.95\% Confidence

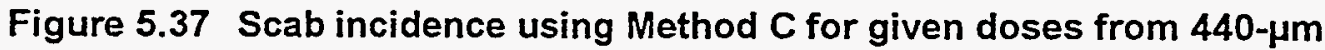
diameter Sc-46 hot particles.

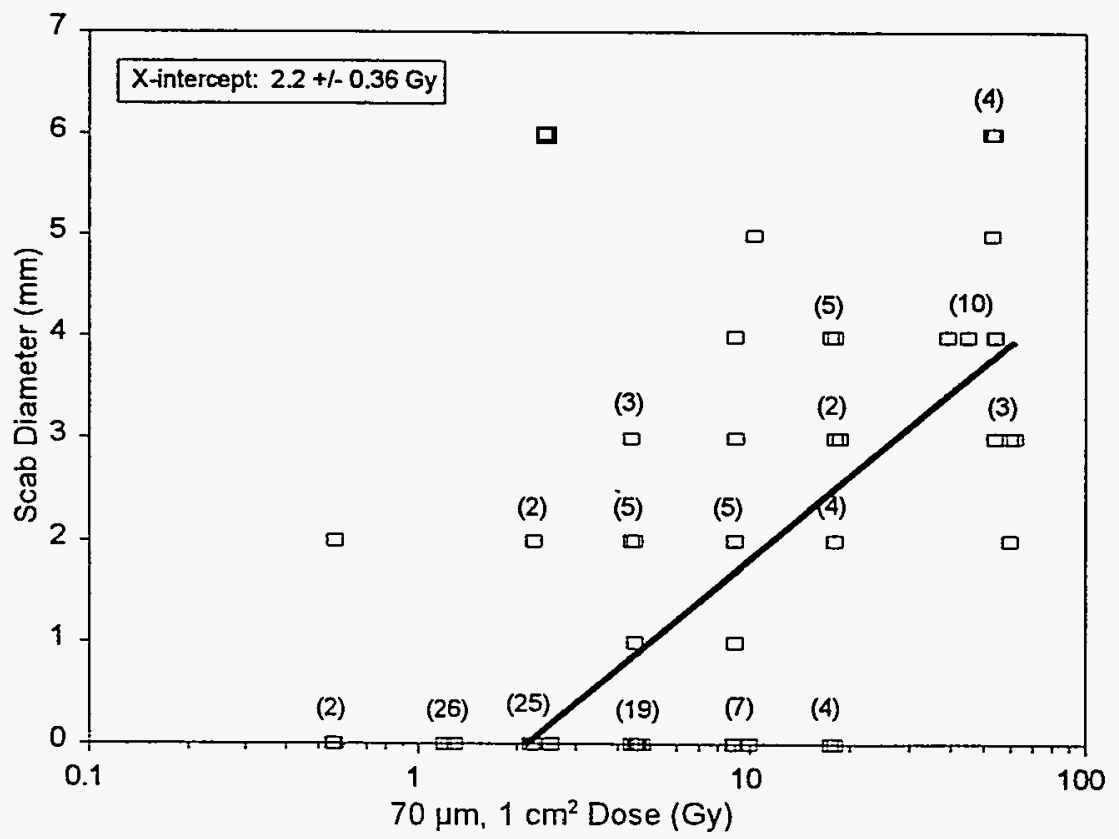

Figure 5.38 Scab diameters in experiments 14, 16, and 17 using scoring Method B for pigs irradiated with Sc-46 hot particles. The regression used doses greater than or equal to $2.2 \mathrm{~Gy}$. See Table 5.8 for the number of scabs of each size at each dose. The numeral above the data points refers to the number of sites with similar doses showing the same scab diameter if greater than 1. 


\section{Experimental Results}

The value for a zero-diameter scab was $1.5 \pm 0.22$ Gy when all data were used (correlation coefficient $=0.72$ ). This demonstrates the small influence of the $0.55 \mathrm{~Gy}$ data and the zerodiameter data for the $1.2 \mathrm{~Gy}$ exposure (Table 5.8). Some of the scab diameters are larger than the range of the maximum energy beta particles $(0.36 \mathrm{MeV})$. The increased size may be due to dose deposition from photons, infection, or physiological stress in the skin outside the radiationdamaged site.

Table 5.8 Number of scabs, by diameter, for given doses from Sc-46 particles using scoring Method $B$

\begin{tabular}{|c|c|c|c|c|c|c|c|}
\hline $\begin{array}{c}\text { Dose } \\
1 \mathrm{~cm}^{2} \\
70 \mu \mathrm{m} \\
(\mathrm{Gy})\end{array}$ & \multicolumn{7}{|c|}{ Number of scabs (diameter) } \\
\cline { 2 - 8 } & No scab & $1 \mathrm{~mm}$ & $2 \mathrm{~mm}$ & $3 \mathrm{~mm}$ & $4 \mathrm{~mm}$ & $5 \mathrm{~mm}$ & $6 \mathrm{~mm}$ \\
\hline \hline 0.55 & 2 & 0 & 1 & 0 & 0 & 0 & 0 \\
\hline 1.2 & 26 & 0 & 0 & 0 & 0 & 0 & 0 \\
\hline 2.2 & 25 & 0 & 2 & 0 & 0 & 0 & 1 \\
\hline 4.4 & 19 & 1 & 5 & 3 & 0 & 0 & 0 \\
\hline 9.1 & 7 & 1 & 5 & 1 & 1 & 1 & 0 \\
\hline 18 & 4 & 0 & 4 & 2 & 5 & 0 & 0 \\
\hline 53 & 0 & 0 & 1 & 3 & 10 & 1 & 4 \\
\hline
\end{tabular}

\subsection{Additional $\mathrm{UC}_{2}$ Studies}

Probit analysis was carried out on the $1991 \mathrm{UC}_{2}$ data. The uncertainties were large since there were few replicate doses in 1991 data. To improve the percent scab incidence data set, two additional animals were irradiated in 1995 as detailed in Table 3.10 in rows for experiment numbers 18 and 19. On-skin doses ranged from 2.2 to $51 \mathrm{~Gy}$ and off-skin doses ranged from 12 to $64 \mathrm{~Gy}$. The latter were made using $0.44-\mathrm{mm}$-thick denim, as in the 1991 exposures. A total of 31 sites were unirradiated controls.

To obtain additional data for the on-skin $\mathrm{UC}_{2}$ analysis, eleven exposed sites at a dose of 2 Gy in the $1991 \mathrm{UC}_{2}$ experiment were combined with seventeen 2 Gy exposures in the 1995 experiment. The pig used for the 1991 experiment was 6.4 months old. None of the 31 sites of the two 3- to 4-month-old pigs exposed to $3.8 \mathrm{~Gy}$ in 1995 developed scabs, and none of the 


\section{Experimental Results}

three sites of the 6.4-month-old pig exposed to 4.8 to 2.8 Gy developed scabs, it is reasonable to conclude that pigs of both ages respond similarly to a 2 Gy irradiation from $U_{2}$.

It was initially expected that the off-skin scab incidence would be less than that of the on-skin scab incidence for similar doses, based on similar comparisons of the $1991 \mathrm{UC}_{2}$ data, and the $\mathrm{Tm}-170$ data (experiments 2 and 3 ). Therefore, the on-skin $\mathrm{UC}_{2}$ data were considered more critical, and only three replicate dose-points were chosen for the off-skin $\mathrm{UC}_{2}$ experiment.

For scoring Method C using $56 \mathrm{DPl}$ observations, the lower confidence intervals of the off-skin $\mathrm{UC}_{2} \mathrm{ED}_{10}$ for the probit regression were unreasonably low. Four single doses from the 1991 offskin $U_{2}$ hot particle exposures were lower than the replicate doses given in the 1995 study. None of these low-dose sites $(4.0,5.2,6.8,7.4 \mathrm{~Gy})$ gave a scab by any scoring method. The pig used for the 1991 experiment was 8.5 months old. A single dose of $11.4 \mathrm{~Gy}$ for this pig did not result in a scab, whereas a single dose of $16 \mathrm{~Gy}$ did cause a scab. These results were not incompatible with those of the 1995 study in which 11.8 Gy resulted in $62 \%$ scab incidence. Thus, these four low dose sites exposed in 1991 were combined with the 1995 results. The uncertainties in the predicted response, while still very large, were much improved (Figure 5.40).

Probit regression analyses results for these studies using scoring Method $C$ yielded $E D_{10}$ and $E D_{50}$ values of 8.5 and $11 \mathrm{~Gy}$ after 56 days of observation for on-skin exposures (Figure 5.39). For off-skin exposures, $\mathrm{ED}_{10}$ and $\mathrm{ED}_{50}$ values were 4.5 and $10.6 \mathrm{~Gy}$, respectively (Figure 5.40); the uncertainties in these latter values were large. Thus, we cannot conclude, at $95 \%$ confidence, that there is a difference between results from on-skin or off-skin exposures to activated $U C_{2}$ particles. This is true at both $E D_{10}$ and $E D_{50}$.

Comparison of the on- and off-skin response indicates that lower doses of the off-skin $U_{2}$ particle may be needed to produce low (e.g., 10\%) PSI events, based on analysis of the two responses (Figure 5.41), however, the $95 \%$ confidence bands overlap so conclusions are not definite.

Figure 5.42 shows results of regression analyses of scab diameter for exposures to $\mathrm{UC}_{2}$ particles for the 1995 study. Zero-scab diameter intercepts on the dose-axis occur at doses of $2.0 \pm 1.2$ Gy for off-skin exposures and at $4.1 \pm 0.46$ and $5.8 \pm 0.95$ Gy for on-skin exposures using only exposures $\geq 3.7$ or $8.2 \mathrm{~Gy}$, respectively. The analysis of doses $\geq 3.7 \mathrm{~Gy}$ includes 51 exposures that yielded no scabs, whereas the analysis using doses $\geq 8.2$ Gy includes only 21 exposures that produced no scabs. 


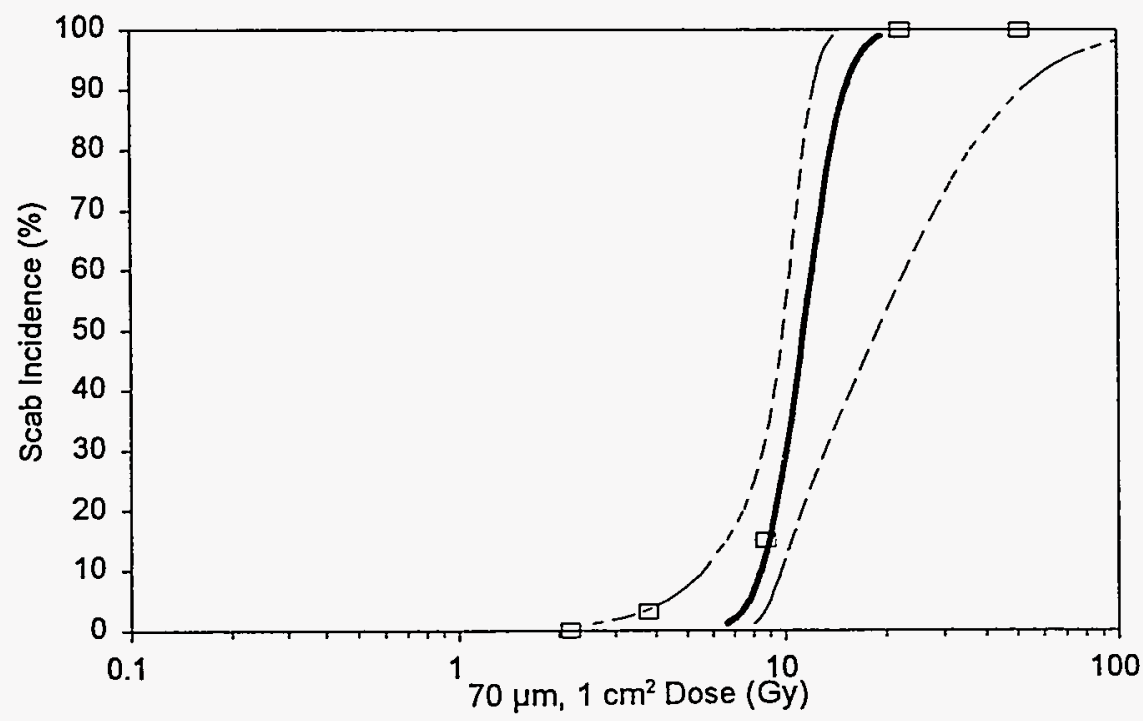

$\square$ Scab Incidence —Probit Regression - . .95\% Confidence

Figure 5.39 Scab incidence using Method $\mathrm{C}$ for $56 \mathrm{DPI}$ data for on-skin $\mathrm{UC}_{2}$ exposures in experiments 18 and 19.

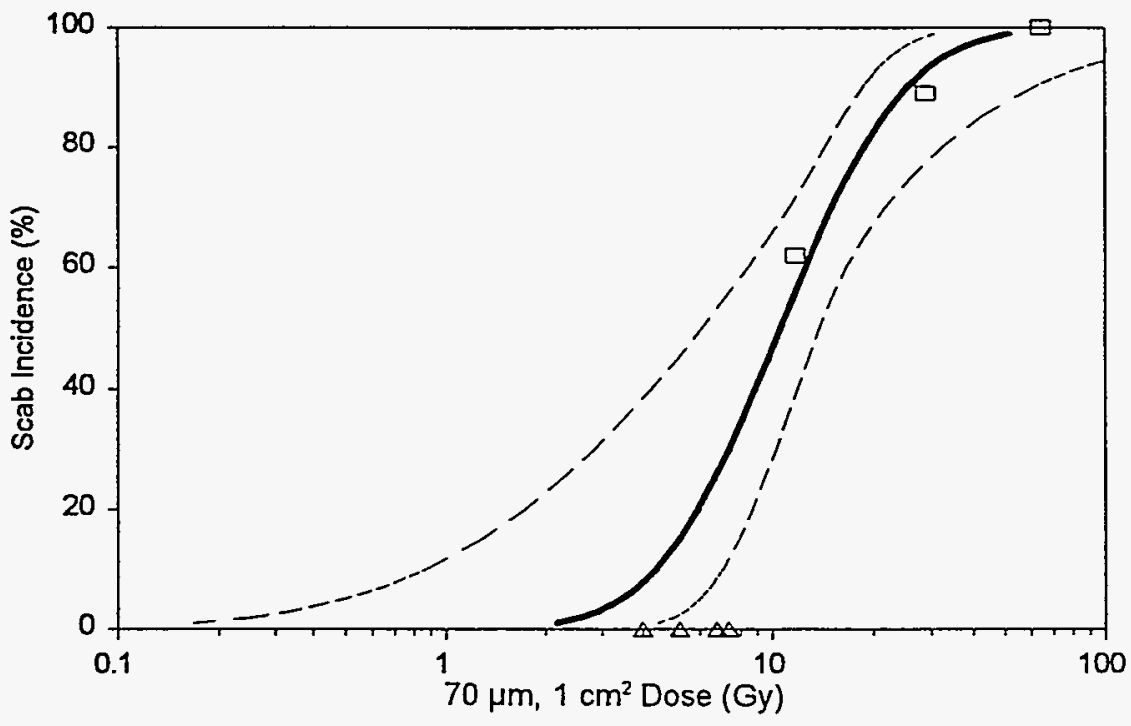

$\square$ Multiple exposures $\triangle$ Single exposures - Probit Regress $\quad-95 \%$ CLs

Figure 5.40 Scab incidence using scoring Method C for 56 DPI data for offskin $\mathrm{UC}_{2}$. The particle size was $290 \mu \mathrm{m}$. The particle was held off the skin using $0.44-\mathrm{mm}$-thick denim; only three replicate doses were made for this experiment. Four sites with low doses of 4.0 to $7.4 \mathrm{~Gy}$ which did not result in scabs from experiment 2 were included to decrease the $95 \%$ confidence limits, as described in the text. 
Experimental Results

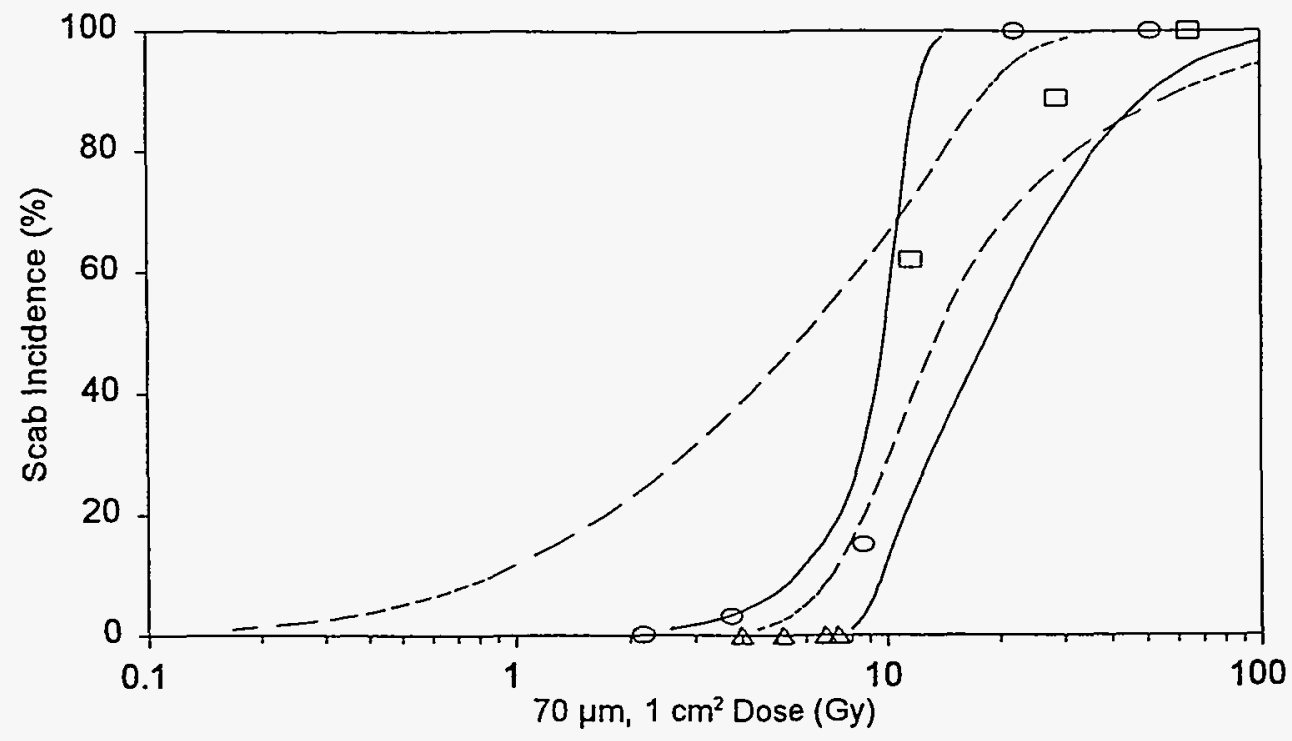

$\square$ Off-Skin

- - Off-Skin $95 \%$ CLS

$\triangle$ Off-Skin, single exposures

o On-Skin

— On-Skin 95\% CLs

Figure 5.41 Comparison of confidence limits for scab incidence from exposure to on- and off-skin $\mathrm{UC}_{2}$ hot particles. Only measured scab incidence and $95 \%$ confidence intervals are shown to clarify the differences in responses. Four sites exposed to offskin sources with doses of 4.0 to $7.4 \mathrm{~Gy}$ which did not result in scabs from experiment 2 were included to decrease the $95 \%$ confidence limits, as described in the text. 
Experimental Results

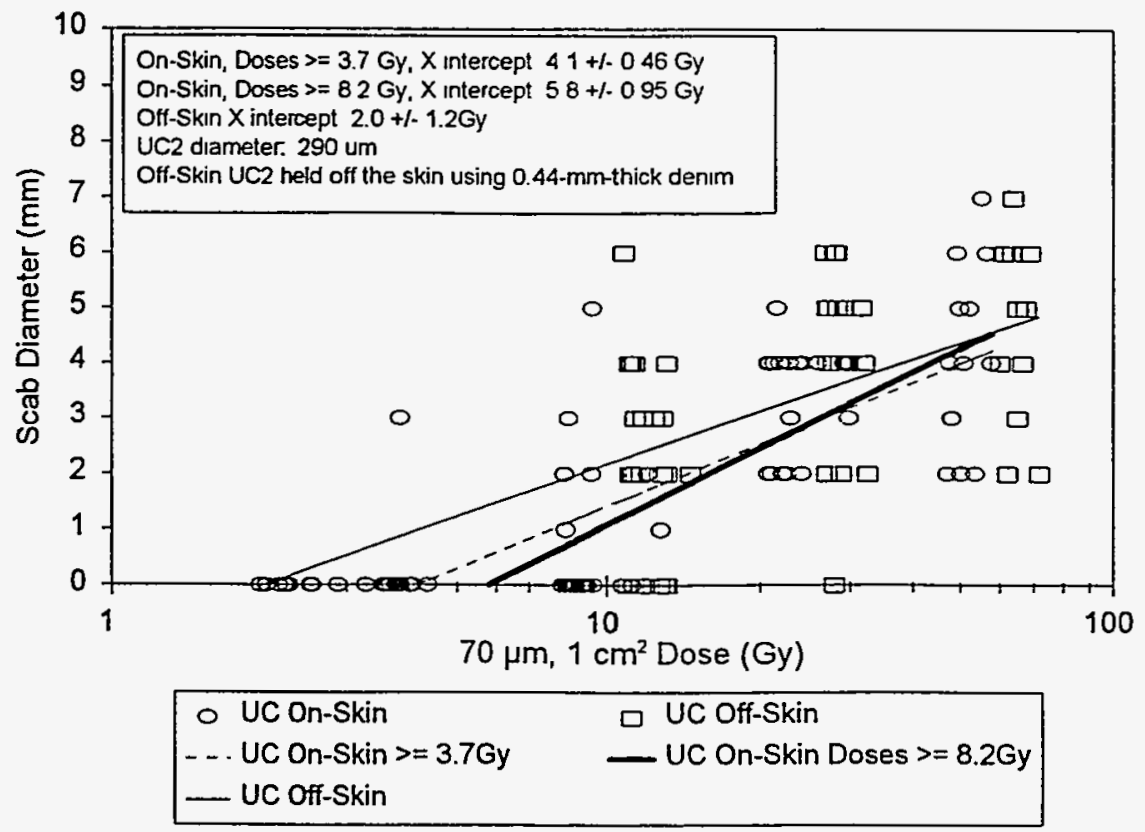

Figure 5.42 $\mathrm{BNL} \mathrm{UC}_{2}$ on- and off-skin, 1995, scab diameter results using scoring Method B.

\subsection{Evaluation of Scab Diameter Regression Analysis}

To better quantify the adequacy of using a linear regression of the scab size versus the natural logarithm of dose to obtain a threshold from the $x$-axis intercept (section 4.2), coefficients of linear correlation were calculated for each experiment (Table 5.9). The correlation coefficient was also calculated for the Forbes and Mikhail results, which was the data-set used by the NCRP committee (1989) in developing the methodology.

The correlation coefficient for the Forbes and Mikhail fissioned $U_{2}$ data was 0.98 . This was an exceptionally high correlation. The correlation coefficients for the $B N L U_{2}$ data were somewhat lower, varying from 0.81 to 0.95 for Experiments 1 and 2 for on- and off-skin particles. The correlation coefficients for combined $\mathrm{UC}_{2}$ data from Experiments 18 and 19 were 0.78 and 0.48 for on- and off-skin particles, respectively.

The correlation coefficient may be influenced by the dose range used in the analysis. If the slope of the regression line is greater than zero, the correlation coefficient tends to be lower if a smaller dose range is used (Neter et al., 1996). Thus, the lower correlation coefficients for Experiments 18 and 19 compared with Experiments 1 and 2 were not surprising, since the dose ranges of the former were considerably smaller than those of the latter (Table 5.9). As an example, the doses used for the off-skin $U C_{2}$ particle regression for Experiment 2 ranged from 11-460 Gy and gave a correlation coefficient of 0.95 , as compared with the doses used for Experiments 18 and 19 for the off-skin $U_{2}$ particle regression which ranged from 12 to $64 \mathrm{~Gy}$ and gave a correlation coefficient of 0.48 . 


\section{Experimental Results}

Table 5.9 Coefficients of linear correlation for scab-diameter regressions

\begin{tabular}{|c|c|c|c|c|}
\hline Hot particle & $\begin{array}{c}\text { Experiment } \\
\text { No. }\end{array}$ & $\begin{array}{l}\text { On- or } \\
\text { off-skin }\end{array}$ & $\begin{array}{c}\text { Dose range } \\
(\mathrm{Gy}) \\
\end{array}$ & $\begin{array}{l}\text { Correlation } \\
\text { coefficient }\end{array}$ \\
\hline \multirow{4}{*}{$\mathrm{UC}_{2}$} & Forbes-Mikhail & on-skin & $15-480$ & 0.98 \\
\hline & 1 & on-skin & $11-43$ & 0.81 \\
\hline & 2 & $\begin{array}{l}\text { on-skin } \\
\text { off-skin }\end{array}$ & $\begin{array}{c}7.7-470 \\
11-460\end{array}$ & $\begin{array}{l}0.92 \\
0.95\end{array}$ \\
\hline & 18,19 & $\begin{array}{l}\text { on-skin } \\
\text { off-skin }\end{array}$ & $\begin{array}{l}3.8-51 \\
12-64\end{array}$ & $\begin{array}{l}0.78^{b} \\
0.48\end{array}$ \\
\hline \multirow{6}{*}{$\mathrm{Tm}-170$} & 3 & $\begin{array}{l}\text { on-skin } \\
\text { off-skin }\end{array}$ & $\begin{array}{l}9-1790 \\
25-470\end{array}$ & $\begin{array}{l}0.85 \\
0.88\end{array}$ \\
\hline & 4 & on-skin & $6.5-215$ & 0.84 \\
\hline & 5 & on-skin & $15-900$ & 0.84 \\
\hline & 6 & on-skin & $6.3-600$ & 0.66 \\
\hline & 7 & on-skin & $4.8-590$ & 0.70 \\
\hline & $8,9,10$ & on-skin & c & c \\
\hline \multirow{3}{*}{ Yb-175 } & 11 & on-skin & $0.50-53$ & 0.14 \\
\hline & 12 & on-skin & $0.50-53$ & 0.47 \\
\hline & $13,15,17$ & on-skin & $0.62-20$ & 0.49 \\
\hline Sc-46 & $14,16,17$ & on-skin & $2.2-60$ & 0.71 \\
\hline
\end{tabular}

a. The dose range (averaged over $1 \mathrm{~cm}^{2}$ at $70 \mu \mathrm{m}$ depth) used in the scab-diameter regression may be less than the range of doses delivered to the pig (section 4.2.1).

b. Computed for doses greater than $3.8 \mathrm{~Gy}$, correlation coefficient $=0.71$ for doses greater than $8.0 \mathrm{~Gy}$.

c. Scab-diameter data were not analyzed.

The correlation coefficients for Tm-170 experiments 3 through 7 were 0.66 to 0.88 . The dose ranges used in these experiments were generally greater than those for the $U_{2}$ experiments. Correlation coefficients for $\mathrm{UC}_{2}$ experiments that had dose ranges of at least a factor of ten between the highest and lowest exposures (i.e., experiments 2, 18, and 19) with comparable 


\section{Experimental Results}

Tm-170 experiments (experiments 3 through 7), shows that coefficients for $\mathrm{UC}_{2}$ are somewhat larger $(0.78-0.95)$ than for $\mathrm{Tm}-170(0.7-0.88)$.

The correlation coefficients for $\mathrm{Yb}-175$ Experiments 11 and 12 were 0.14 and 0.47 . The dose ranges for experiments 11 and 12 were 0.50 to $53 \mathrm{~Gy}$, which were larger that for $\mathrm{UC}_{2}$ Experiment 1 , which was 11 to $43 \mathrm{~Gy}$ and had a correlation coefficient of 0.81 . Thus, the correlation coefficient for the $\mathrm{Yb}-175$ data was much less than that for the $\mathrm{UC}_{2}$ data.

The correlation coefficient was 0.71 for the combined data from Sc-46 Experiments 14,16 , and 17. This value is much larger than that for the $\mathrm{Yb}-175$ experiments, which encompassed dose ranges that were either equivalent or larger.

One-sided statistical tests for the correlation coefficient were carried out. The experiments, except for number 11, had correlation coefficients significantly greater than zero. The correlation coefficient for experiment 11 was not greater than zero $(p<0.05$, i.e., the slope of the regression line was not significantly greater than zero). Correlation coefficients significantly greater than zero were to be expected, i.e., as the dose increases, a larger portion of exposed sites will form scabs.

The correlation coefficient appears to be large for higher energy beta particles $\left(\mathrm{UC}_{2}\right.$ and $\left.\mathrm{Tm}-170\right)$ and decreases for lower energy beta particles (Yb-175). This is most likely due to the smaller relative error associated with observing large scabs compared with small scabs. The largest scabs produced by $\mathrm{Yb}-175$ were $4 \mathrm{~mm}$ in diameter. The relative error associated with correctly measuring a 4-mm scab is quite large, i.e., a $1-\mathrm{mm}$ error for a $4-\mathrm{mm}$ scab is $25 \%$. The largest scabs produced by on-skin $\mathrm{UC}_{2}$ were $12 \mathrm{~mm}$, which would have a correspondingly smaller relative measurement error, i.e., a $1-\mathrm{mm}$ error for a $12-\mathrm{mm}$ scab would have a relative error of $8 \%$. This may also be the cause of the greater variability of the data from sources that emit lower energy beta particles.

The largest scab diameters for the Sc-46 data were larger than the maximum range of the beta particles emitted by the source. This was most likely due to the effects caused by the gammaray dose. Since the scab diameters were larger, the associated relative error in observing the scab diameter was smaller, and the correlation coefficient was greater than that for $\mathrm{Yb}-175$ induced scabs.

It is also of interest to compare the correlation coefficients with the slopes of the PSI curves. The maximum slope (at the $E D_{50}$ ) of the $P S I$ curve for $U C_{2}$ was much greater than that for $Y b-175$ (compare Figure 5.35 with Figure 5.39). The maximum PSI slope for Tm-70 was less than that of $\mathrm{UC}_{2}$ and greater than that of $\mathrm{Yb}-175$ (compare Figure 5.28 with Figures 5.35 and 5.39). The maximum PSI slope for the Sc-46 data was greater than that for $\mathrm{Yb}-175$ and less than that for $\mathrm{Tm}-170$ (compare Figure 5.37 with Figures 5.28 and 5.35). The relative values of these slopes correspond with the relative values of the correlation coefficients.

This discussion illustrates some of the inadequacies of the scab-diameter regression technique. The first inadequacy was that for low-energy beta-particle emitters, correlation coefficients were 


\section{Experimental Results}

small, and the $x$-axis intercepts had large uncertainties. Secondly, the largest scab size measured appears to be a function of the maximum range of the beta particles; thus, at high doses, the fitted scab diameter will cease to be linear with logarithm of the dose. Thirdly, there was some subjectivity for including exposed sites that did not result in scabs. An example of this can be seen in Figure 5.36 which shows two scabs at the lowest dose regimen, $0.31 \mathrm{~Gy}$, using scoring Method B. The lowest dose used in this regression was $0.62 \mathrm{~Gy}$, which did not include the two scabs with a dose of $0.31 \mathrm{~Gy}$ and the 26 other sites at this same dose that resulted in no scabs. Including the $0.31 \mathrm{~Gy}$ exposures would incorrectly bias the $x$-axis intercept to a lower value (see Section 4.2.3 for further details). Finally, the scab diameter regressions used with the BNL data included exposed sites greater than the cutoff dose (Section 4.2.1) which did not result in scabs as having zero diameter. Thus, the regression contains both a binomial response, scab or no scab, mixed with a continuous response, which was the scab diameter.

For these reasons, the probit regression analysis (PSI) better quantified the scab induction response. The measured response was binomial, either a scab is present or it is not, which was less subject to error than measuring scab diameters. The subjectivity of excluding some data was less than that for the scab-diameter methodology. And finally, the data were well predicted by the cumulative normal function (as measured with the chi-squared statistical test for normality).

Nevertheless, the scab-diameter regression methodology was helpful in establishing the dose range for later PSI experiments. Scab size could also be used as a measure of detriment.

\subsection{Comparability of Results for Different Observers}

During a Hot Particle Workshop at BNL, March 19-20, 1992, experienced and inexperienced observers, together with two trained BNL personnel, examined skin lesions on pigs at $10 \mathrm{DPI}$. The experienced observers were John $W$. Hopewell (radiobiologist whose data was used extensively in ICRP 60 (1991b) to derive the $0.5 \mathrm{~Gy} / \mathrm{cm}^{2}$ hot-particle deterministic dose limit), James S. Durham (dosimetrist and principal investigator for hot-particle research sponsored by the Electric Power Research Institute (EPRI) with results published by Reece et al. (1992)), and $P$. Donald Forbes (biologist for the hot particle data used extensively in NCRP 106 (1989)). Two inexperienced observers (non-BNL) examined the same lesions. In the first trial there was good scoring agreement among the BNL and experienced observers; however, one inexperienced observer reported significantly fewer scabs.

After the first trial, the scoring results were discussed, as well as definitions of end points to be avoided. When a second pig was observed the following day, all observers reported a total number of scabs within $10 \%$ of the mean number for all observers, thus demonstrating that the visual endpoints to be scored are not subjective and can be agreed upon.

It should be noted that scabs observed during the Hot Particle Workshop were induced by relatively high doses, which resulted in $100 \%$ scab induction after three or four weeks. Lower dose scabs are somewhat more difficult to observe as the resultant maximum scab sizes are smaller (less than $2 \mathrm{~mm}$ ) and are sometimes difficult to distinguish from fecal spots, scratches, or 
other trauma. Because of these compounding problems, scoring smaller scabs induced at lower doses or with lower energy beta-particle emitters may be a more observer-dependent process. Therefore, scoring such small lesions must undergo more stringent quality control to assure that it is accurate and objective.

At a second workshop held September 15-16, 1994, observer's responses for lower dose and lower energy beta particle exposures were investigated. The observers were the same experienced individuals as before. The pigs were exposed to Sc-46 (14 DPI and $52 \mathrm{DPI}$ ) and $\mathrm{Yb}-175$ (50 DPI and $52 \mathrm{DPI}$ ). Again, there was good agreement between the BNL and other observers, indicating that skin scabs caused by low dose and low beta energy emitters were readily distinguishable by both trained and experienced observers.

\subsection{Evaluation of Scoring Methods}

The scabs observed in these hot particle studies generally were very small. The smallest scabs reported by Forbes and Mikhail (in NCRP, 1989) were $0.5 \mathrm{~mm}$ in diameter. Since it was difficult to reliably distinguish between 0.5 - and $1-\mathrm{mm}$-diameter lesions, $1 \mathrm{~mm}$ was the smallest recorded diameter in the BNL studies. All lesions were then scored as being of size equal to the nearest whole value in millimeters. The width and length of scabs were averaged to obtain the reported value.

The final decision on whether an observed lesion should be accepted as real was made using various criteria, such as its shade (dark or white), frequency of observation, scab position in the exposure site, and the number of observers who scored it. To test the sensitivity of results to some of these choices, data for each isotope were evaluated using the three methods, $A, B$, and $C$, described in Section 4.1. Data were then processed to deduce $E D_{10}$ and $E D_{50}$ values and $95 \%$ confidence limits for data scored for $28,48,56$, and $71 \mathrm{DPI}$.

The results from these exposures are summarized in Tables 5.10 to 5.14 and Figures 5.43 to 5.52. More detailed information of Figures 5.43 to 5.52 is contained in Table 5.15. In Figures 5.43 to 5.52 , the doses for $10 \%$ incidence and $50 \%$ incidence are shown as horizontal ticks along the left and right side, respectively, of the vertical lines, which reflect the $95 \%$ confidence limits. The top line of each vertical line reflects the upper $95 \%$ confidence on the $50 \%$ incidence value, and the bottom line of each vertical line represents the lower $95 \%$ confidence on the $10 \%$ incidence value, as shown in the key (legend appears to left to Figure 5.43). The labels on the abscissa reflect DPI and method of scoring $(A, B$, or $C)$. Thus, 28A means scoring for $28 D P I$ using scoring Method $\mathrm{A}, 48 \mathrm{~B}$ means scoring for $48 \mathrm{DPI}$ with Method $\mathrm{B}$, and so forth. The variability in confidence limits seen in Figures 5.43 to 5.52 is noticeable, but there is no apparent trend in variability for the various methods. There is a trend in $E D_{10}$ and $E D_{50}$ values for $28 \mathrm{DPI}$ compared to 48 and $71 \mathrm{DPI}$. This is more apparent in the tabulated values shown in Table 5.15, and the plots for various beta particle energies shown in Figures 5.53 to 5.56, as discussed in the following paragraphs. 
Experimental Results

Experimental Results

Table 5.12 Percent scab incidence (PSI) for on-skin Tm-170 scabs. All exposures were made using the cone/rod which minimized timing errors in source placement.

\begin{tabular}{|c|c|c|c|c|c|c|c|c|}
\hline \multirow{2}{*}{$\begin{array}{c}\text { Dose } \\
70 \mu \mathrm{m} \\
1 \mathrm{~cm}^{2} \\
\text { (Gy) }\end{array}$} & \multirow{2}{*}{$\begin{array}{l}\text { No. of } \\
\text { exposed } \\
\text { sites }\end{array}$} & \multirow{2}{*}{$\begin{array}{l}\text { Days } \\
\text { post- } \\
\text { irradiation }\end{array}$} & \multicolumn{3}{|c|}{ Dark Scab PSI (\%) } & \multicolumn{3}{|c|}{ Dark and White Scab PSI (\%) } \\
\hline & & & $\begin{array}{c}\text { Method } \\
\text { A }\end{array}$ & $\begin{array}{c}\text { Method } \\
\text { B }\end{array}$ & $\begin{array}{c}\text { Method } \\
\text { C }\end{array}$ & $\begin{array}{c}\text { Method } \\
\text { A }\end{array}$ & $\begin{array}{c}\text { Method } \\
\text { B }\end{array}$ & $\begin{array}{c}\text { Method } \\
\text { C }\end{array}$ \\
\hline $\begin{array}{c}0 \\
\text { (control) }\end{array}$ & 0 & $\begin{array}{l}28 \\
48 \\
71\end{array}$ & & & & & & \\
\hline 3.0 & 41 & $\begin{array}{l}28 \\
48 \\
71\end{array}$ & $\begin{array}{l}10 \\
17 \\
20\end{array}$ & $\begin{array}{l}4.9 \\
12 \\
12\end{array}$ & $\begin{array}{c}2.4 \\
4.9 \\
10\end{array}$ & $\begin{array}{l}16 \\
44 \\
50\end{array}$ & $\begin{array}{l}10 \\
20 \\
22\end{array}$ & $\begin{array}{l}4.9 \\
7.3 \\
15\end{array}$ \\
\hline 4.8 & 42 & $\begin{array}{l}28 \\
48 \\
71\end{array}$ & $\begin{array}{l}7.1 \\
29 \\
29\end{array}$ & $\begin{array}{l}7.1 \\
24 \\
24\end{array}$ & $\begin{array}{l}4.8 \\
24 \\
24\end{array}$ & $\begin{array}{l}18 \\
52 \\
63\end{array}$ & $\begin{array}{l}12 \\
36 \\
43\end{array}$ & $\begin{array}{l}4.8 \\
33 \\
38\end{array}$ \\
\hline 7.6 & 42 & $\begin{array}{l}28 \\
48 \\
71\end{array}$ & $\begin{array}{l}19 \\
49 \\
49\end{array}$ & $\begin{array}{l}14 \\
43 \\
43\end{array}$ & $\begin{array}{l}14 \\
50 \\
50\end{array}$ & $\begin{array}{l}35 \\
67 \\
74\end{array}$ & $\begin{array}{l}21 \\
57 \\
62\end{array}$ & $\begin{array}{l}21 \\
67 \\
69\end{array}$ \\
\hline 9.9 & 39 & $\begin{array}{l}28 \\
48 \\
71\end{array}$ & $\begin{array}{l}38 \\
59 \\
59\end{array}$ & $\begin{array}{l}49 \\
62 \\
62\end{array}$ & $\begin{array}{l}36 \\
56 \\
56\end{array}$ & $\begin{array}{l}46 \\
94 \\
96\end{array}$ & $\begin{array}{l}64 \\
92 \\
92\end{array}$ & $\begin{array}{l}49 \\
82 \\
82\end{array}$ \\
\hline
\end{tabular}


Experimental Results

Table 5.13 Percent scab incidence (PSI) for on-skin Yb-175 scabs. Note that this table does not include the 1992 preliminary data (Table 5.5).

\begin{tabular}{|c|c|c|c|c|c|c|c|c|}
\hline \multirow{2}{*}{$\begin{array}{c}\text { Dose } \\
70 \mu \mathrm{m} \\
1 \mathrm{~cm}^{2} \\
(G y)\end{array}$} & \multirow{2}{*}{$\begin{array}{l}\text { No. of } \\
\text { exposed } \\
\text { sites }\end{array}$} & \multirow{2}{*}{$\begin{array}{c}\text { Days } \\
\text { post- } \\
\text { irradia- } \\
\text { tion }\end{array}$} & \multicolumn{3}{|c|}{ Dark scab PSI (\%) } & \multicolumn{3}{|c|}{ Dark and white scab PSI (\%) } \\
\hline & & & $\begin{array}{c}\text { Method } \\
\text { A }\end{array}$ & $\begin{array}{c}\text { Method } \\
\text { B }\end{array}$ & $\begin{array}{l}\text { Method } \\
\text { C }\end{array}$ & $\begin{array}{c}\text { Method } \\
\text { A }\end{array}$ & $\begin{array}{c}\text { Method } \\
\text { B }\end{array}$ & $\begin{array}{l}\text { Method } \\
\text { C }\end{array}$ \\
\hline $\begin{array}{c}0 \\
\text { (control) }\end{array}$ & 36 & $\begin{array}{l}28 \\
48 \\
71\end{array}$ & $\begin{array}{l}5.6 \\
5.6 \\
8.3\end{array}$ & $\begin{array}{l}2.8 \\
2.8 \\
2.8\end{array}$ & $\begin{array}{l}0 \\
0 \\
0\end{array}$ & $\begin{array}{l}5.6 \\
8.3 \\
14\end{array}$ & $\begin{array}{l}2.8 \\
2.8 \\
2.8\end{array}$ & $\begin{array}{l}0 \\
0 \\
0\end{array}$ \\
\hline $0.31 \pm 0.0$ & 28 & $\begin{array}{l}28 \\
48 \\
71\end{array}$ & $\begin{array}{c}0 \\
1.8 \\
8.9\end{array}$ & $\begin{array}{l}3.6 \\
3.6 \\
7.1\end{array}$ & $\begin{array}{l}0 \\
0 \\
0\end{array}$ & $\begin{array}{l}1.8 \\
8.9 \\
20\end{array}$ & $\begin{array}{l}3.6 \\
3.6 \\
7.1\end{array}$ & $\begin{array}{l}0 \\
0 \\
0\end{array}$ \\
\hline $0.55 \pm 0.0$ & 26 & $\begin{array}{l}28 \\
48 \\
71\end{array}$ & $\begin{array}{c}0 \\
1.9 \\
5.8\end{array}$ & $\begin{array}{c}0 \\
0 \\
3.8\end{array}$ & $\begin{array}{l}0 \\
0 \\
0\end{array}$ & $\begin{array}{c}0 \\
3.8 \\
10\end{array}$ & $\begin{array}{c}0 \\
0 \\
3.8\end{array}$ & $\begin{array}{l}0 \\
0 \\
0\end{array}$ \\
\hline $0.62 \pm 0.01$ & 28 & $\begin{array}{l}28 \\
48 \\
71\end{array}$ & $\begin{array}{l}1.8 \\
11 \\
11\end{array}$ & $\begin{array}{c}0 \\
3.6 \\
3.6\end{array}$ & $\begin{array}{l}0 \\
0 \\
0\end{array}$ & $\begin{array}{l}1.8 \\
14 \\
16\end{array}$ & $\begin{array}{c}0 \\
3.6 \\
3.6\end{array}$ & $\begin{array}{l}0 \\
0 \\
0\end{array}$ \\
\hline $0.78 \pm 0.00$ & 6 & $\begin{array}{l}28 \\
48 \\
71\end{array}$ & $\begin{array}{l}14 \\
43 \\
43\end{array}$ & $\begin{array}{c}0 \\
33 \\
33\end{array}$ & $\begin{array}{c}0 \\
17 \\
33\end{array}$ & $\begin{array}{l}14 \\
43 \\
43\end{array}$ & $\begin{array}{c}0 \\
33 \\
33\end{array}$ & $\begin{array}{c}0 \\
17 \\
33\end{array}$ \\
\hline $1.3 \pm 0.03$ & 18 & $\begin{array}{l}28 \\
48 \\
71\end{array}$ & $\begin{array}{l}2.8 \\
17 \\
17\end{array}$ & $\begin{array}{l}5.6 \\
11 \\
11\end{array}$ & $\begin{array}{c}0 \\
0 \\
11\end{array}$ & $\begin{array}{l}2.8 \\
17 \\
19\end{array}$ & $\begin{array}{l}5.6 \\
11 \\
11\end{array}$ & $\begin{array}{c}0 \\
0 \\
11\end{array}$ \\
\hline $2.5 \pm 0.04$ & 14 & $\begin{array}{l}28 \\
48 \\
71\end{array}$ & $\begin{array}{l}14 \\
25 \\
32\end{array}$ & $\begin{array}{l}14 \\
21 \\
29\end{array}$ & $\begin{array}{l}14 \\
14 \\
21\end{array}$ & $\begin{array}{l}14 \\
32 \\
39\end{array}$ & $\begin{array}{l}14 \\
21 \\
29\end{array}$ & $\begin{array}{l}14 \\
14 \\
21\end{array}$ \\
\hline $3.7 \pm 0.00$ & 13 & $\begin{array}{l}28 \\
48 \\
71\end{array}$ & $\begin{array}{l}7.7 \\
27 \\
35\end{array}$ & $\begin{array}{c}0 \\
23 \\
31\end{array}$ & $\begin{array}{c}0 \\
23 \\
31\end{array}$ & $\begin{array}{l}7.7 \\
31 \\
35\end{array}$ & $\begin{array}{c}0 \\
23 \\
31\end{array}$ & $\begin{array}{c}0 \\
23 \\
31\end{array}$ \\
\hline 7.8 & 1 & $\begin{array}{l}28 \\
48 \\
71\end{array}$ & $\begin{array}{l}100 \\
100 \\
100\end{array}$ & $\begin{array}{l}100 \\
100 \\
100\end{array}$ & a & $\begin{array}{l}100 \\
100 \\
100\end{array}$ & $\begin{array}{l}100 \\
100 \\
100\end{array}$ & a \\
\hline $14 \pm 1.2$ & 10 & $\begin{array}{l}28 \\
48 \\
71\end{array}$ & $\begin{array}{l}50 \\
85 \\
85\end{array}$ & $\begin{array}{l}40 \\
80 \\
80\end{array}$ & $\begin{array}{l}40 \\
80 \\
80\end{array}$ & $\begin{array}{l}50 \\
85 \\
85\end{array}$ & $\begin{array}{l}40 \\
80 \\
80\end{array}$ & $\begin{array}{l}40 \\
80 \\
80\end{array}$ \\
\hline $20 \pm 0.0$ & 2 & $\begin{array}{l}28 \\
48 \\
71\end{array}$ & $\begin{array}{l}50 \\
50 \\
50\end{array}$ & $\begin{array}{l}50 \\
50 \\
50\end{array}$ & $\begin{array}{c}50 \\
100^{\mathrm{b}} \\
100^{\mathrm{b}}\end{array}$ & $\begin{array}{l}100 \\
100 \\
100\end{array}$ & $\begin{array}{l}100 \\
100 \\
100\end{array}$ & $\begin{array}{c}50 \\
100^{b} \\
100^{b}\end{array}$ \\
\hline
\end{tabular}

a. Biopsied after scored as scab using Method B, time not given for subsequent development to a Method C scab.

b. One of the scabs was biopsied after it became a Method B scab; time not given for subsequent development to a Method C scab. 
Experimental Results

Table 5.14 Percent scab incidence (PSI) for Sc-46 scabs

\begin{tabular}{|c|c|c|c|c|c|c|c|c|}
\hline \multirow{2}{*}{$\begin{array}{c}\text { Dose } \\
70 \mu \mathrm{m} \\
1 \mathrm{~cm}^{2} \\
(\mathrm{~Gy})\end{array}$} & \multirow{2}{*}{$\begin{array}{l}\text { No. of } \\
\text { exposed } \\
\text { sites }\end{array}$} & \multirow{2}{*}{$\begin{array}{l}\text { Days } \\
\text { post- } \\
\text { irradia- } \\
\text { tion }\end{array}$} & \multicolumn{3}{|c|}{ Dark scab PSI (\%) } & \multicolumn{3}{|c|}{ Dark and white scab PSI (\%) } \\
\hline & & & $\begin{array}{c}\text { Method } \\
\text { A }\end{array}$ & $\begin{array}{c}\text { Method } \\
\text { B }\end{array}$ & $\begin{array}{c}\text { Method } \\
\text { C }\end{array}$ & $\begin{array}{c}\text { Method } \\
\text { A }\end{array}$ & $\begin{array}{c}\text { Method } \\
\text { B }\end{array}$ & $\begin{array}{l}\text { Method } \\
\text { C }\end{array}$ \\
\hline $\begin{array}{c}0 \\
\text { (control) }\end{array}$ & 28 & $\begin{array}{l}28 \\
48 \\
71\end{array}$ & $\begin{array}{l}18 \\
21 \\
23\end{array}$ & $\begin{array}{l}11 \\
11 \\
11\end{array}$ & $\begin{array}{l}11 \\
11 \\
11\end{array}$ & $\begin{array}{l}18 \\
21 \\
23\end{array}$ & $\begin{array}{l}11 \\
11 \\
11\end{array}$ & $\begin{array}{l}11 \\
11 \\
11\end{array}$ \\
\hline $\begin{array}{c}0.55 \pm \\
0.00\end{array}$ & 3 & $\begin{array}{l}28 \\
48 \\
71\end{array}$ & $\begin{array}{c}0 \\
33 \\
33\end{array}$ & $\begin{array}{c}0 \\
33 \\
33\end{array}$ & $\begin{array}{l}0 \\
0 \\
0\end{array}$ & $\begin{array}{c}0 \\
33 \\
33\end{array}$ & $\begin{array}{c}0 \\
33 \\
33\end{array}$ & $\begin{array}{l}0 \\
0 \\
0\end{array}$ \\
\hline $1.2 \pm 0.0$ & 26 & $\begin{array}{l}28 \\
48 \\
71\end{array}$ & $\begin{array}{l}1.9 \\
3.9 \\
3.9\end{array}$ & $\begin{array}{l}0 \\
0 \\
0\end{array}$ & $\begin{array}{l}0 \\
0 \\
0\end{array}$ & $\begin{array}{l}1.9 \\
3.9 \\
3.9\end{array}$ & $\begin{array}{l}0 \\
0 \\
0\end{array}$ & $\begin{array}{l}0 \\
0 \\
0\end{array}$ \\
\hline $2.2 \pm 0.07$ & 28 & $\begin{array}{l}28 \\
48 \\
71\end{array}$ & $\begin{array}{l}5.4 \\
13 \\
21\end{array}$ & $\begin{array}{l}3.6 \\
7.1 \\
7.1\end{array}$ & $\begin{array}{l}0 \\
0 \\
0\end{array}$ & $\begin{array}{l}7.1 \\
18 \\
27\end{array}$ & $\begin{array}{l}3.6 \\
11 \\
11\end{array}$ & $\begin{array}{l}0 \\
0 \\
0\end{array}$ \\
\hline $4.4 \pm 0.08$ & 28 & $\begin{array}{l}28 \\
48 \\
71\end{array}$ & $\begin{array}{l}16 \\
38 \\
38\end{array}$ & $\begin{array}{l}14 \\
32 \\
32\end{array}$ & $\begin{array}{c}7 \\
14 \\
18\end{array}$ & $\begin{array}{l}20 \\
41 \\
43\end{array}$ & $\begin{array}{l}14 \\
32 \\
32\end{array}$ & $\begin{array}{c}7 \\
14 \\
18\end{array}$ \\
\hline $9.1 \pm 0.39$ & 16 & $\begin{array}{l}28 \\
48 \\
71\end{array}$ & $\begin{array}{l}53 \\
66 \\
66\end{array}$ & $\begin{array}{l}44 \\
56 \\
56\end{array}$ & $\begin{array}{l}38 \\
50 \\
50\end{array}$ & $\begin{array}{l}53 \\
66 \\
69\end{array}$ & $\begin{array}{l}44 \\
56 \\
56\end{array}$ & $\begin{array}{l}38 \\
50 \\
50\end{array}$ \\
\hline $18.0 \pm 0.3$ & 15 & $\begin{array}{l}28 \\
48 \\
71\end{array}$ & $\begin{array}{l}60 \\
80 \\
80\end{array}$ & $\begin{array}{l}53 \\
73 \\
73\end{array}$ & $\begin{array}{l}47 \\
60 \\
67\end{array}$ & $\begin{array}{l}67 \\
87 \\
87\end{array}$ & $\begin{array}{l}53 \\
73 \\
73\end{array}$ & $\begin{array}{l}47 \\
60 \\
67\end{array}$ \\
\hline $53.0 \pm 5.2$ & 19 & $\begin{array}{l}28 \\
48 \\
71\end{array}$ & $\begin{array}{l}95 \\
95 \\
95\end{array}$ & $\begin{array}{l}95 \\
95 \\
95\end{array}$ & $\begin{array}{l}95 \\
95 \\
95\end{array}$ & $\begin{array}{l}100 \\
100 \\
100\end{array}$ & $\begin{array}{l}100 \\
100 \\
100\end{array}$ & $\begin{array}{l}100 \\
100 \\
100\end{array}$ \\
\hline
\end{tabular}




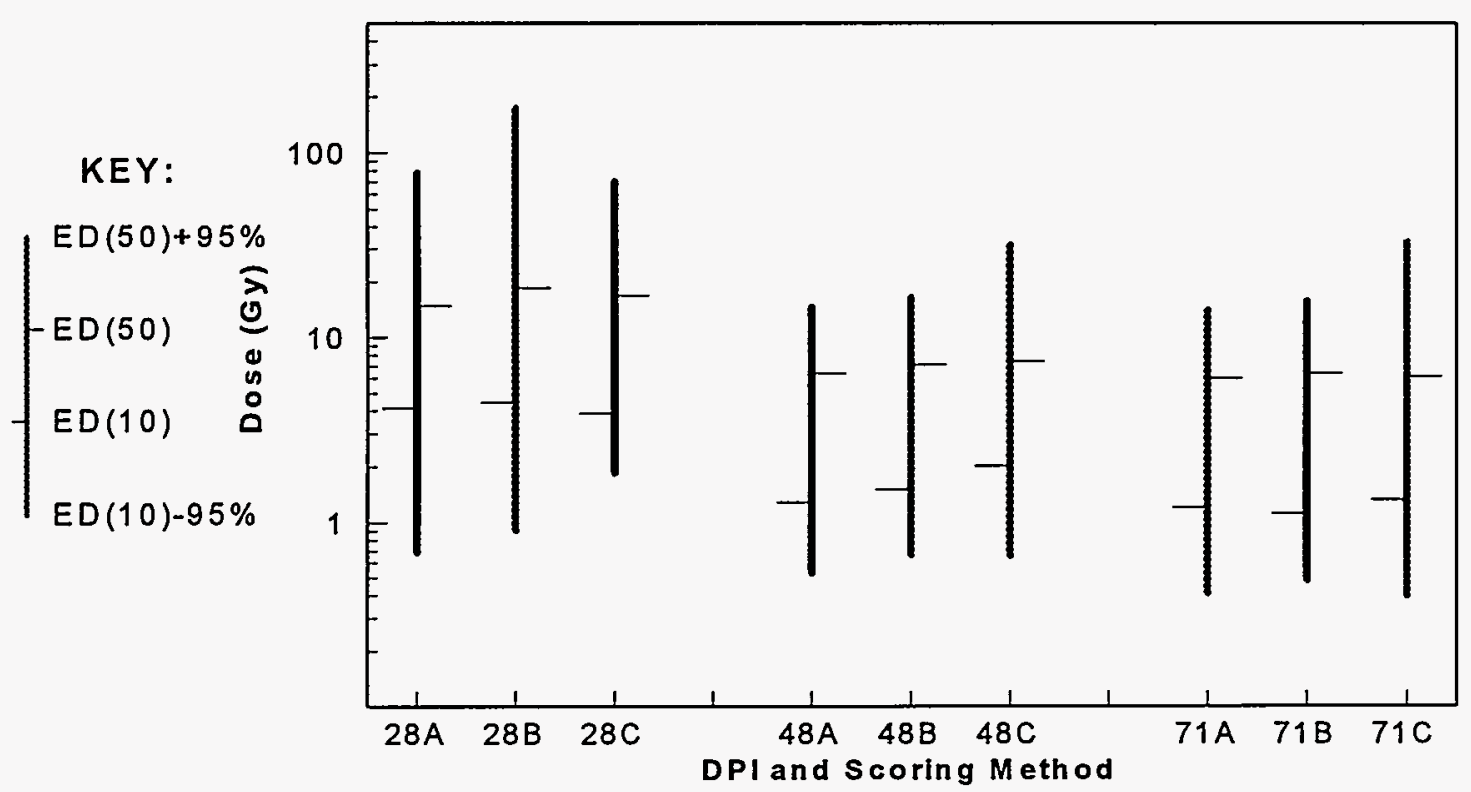

Figure $5.43 E D_{10}, E D_{50}$, and $95 \%$ confidence limits for dark scabs induced by $\mathrm{Yb}-175$ on skin.

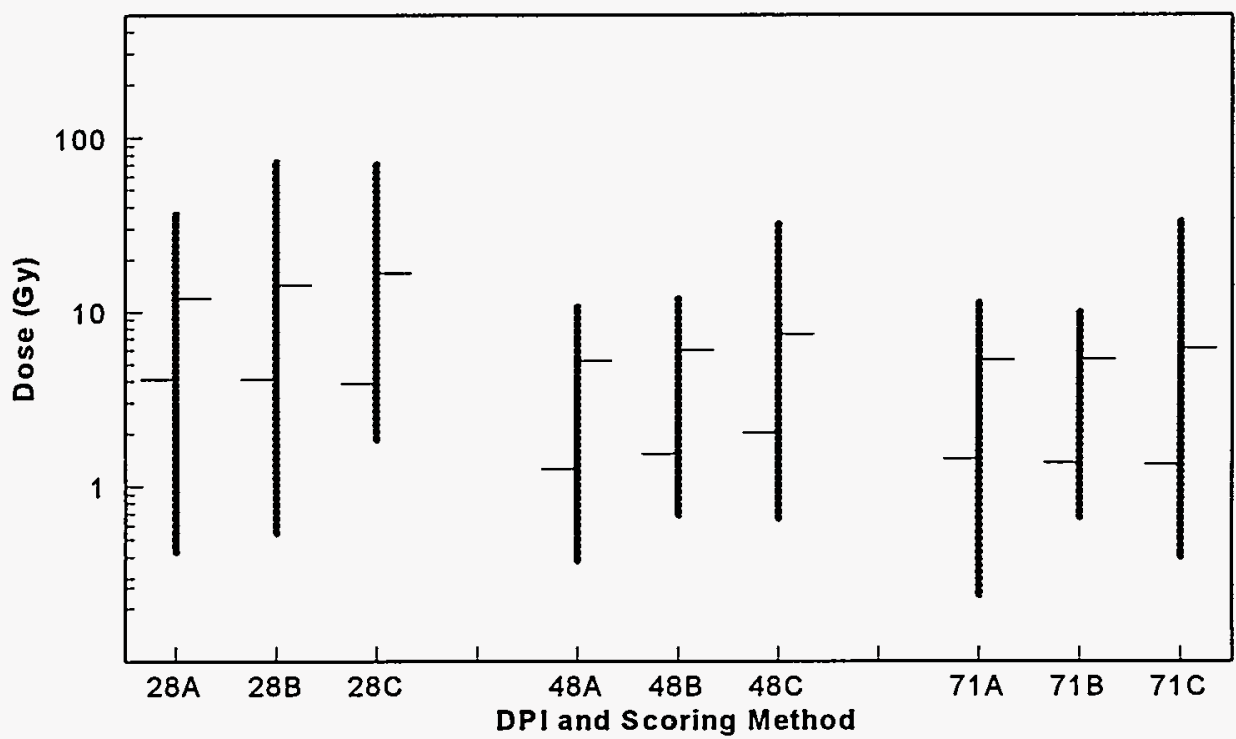

Figure 5.44 $E D_{10}, E D_{50}$, and $95 \%$ confidence limits for combined white and dark scabs induced by $\mathrm{Yb}-175$ on skin. 


\section{Experimental Results}

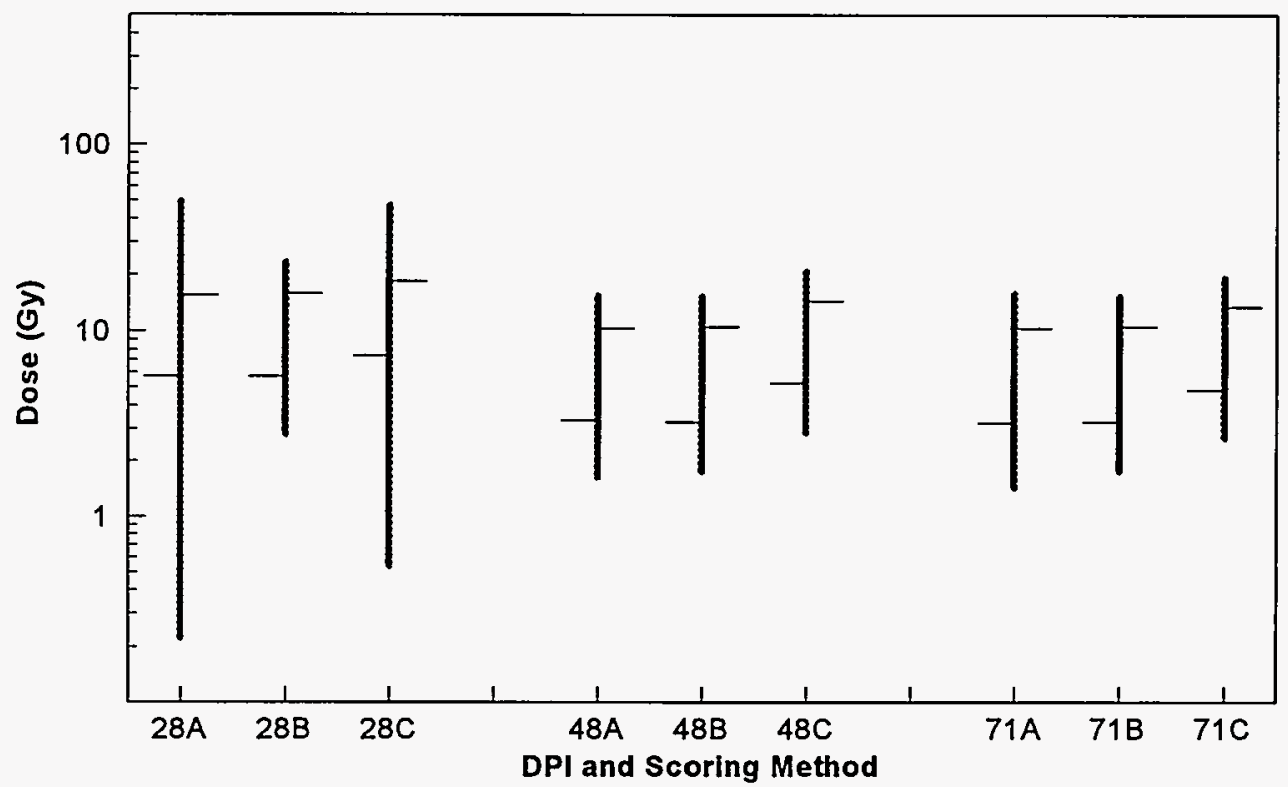

Figure $5.45 E D_{10}, E D_{50}$, and $95 \%$ confidence limits for dark scabs induced by Sc-46 on skin.

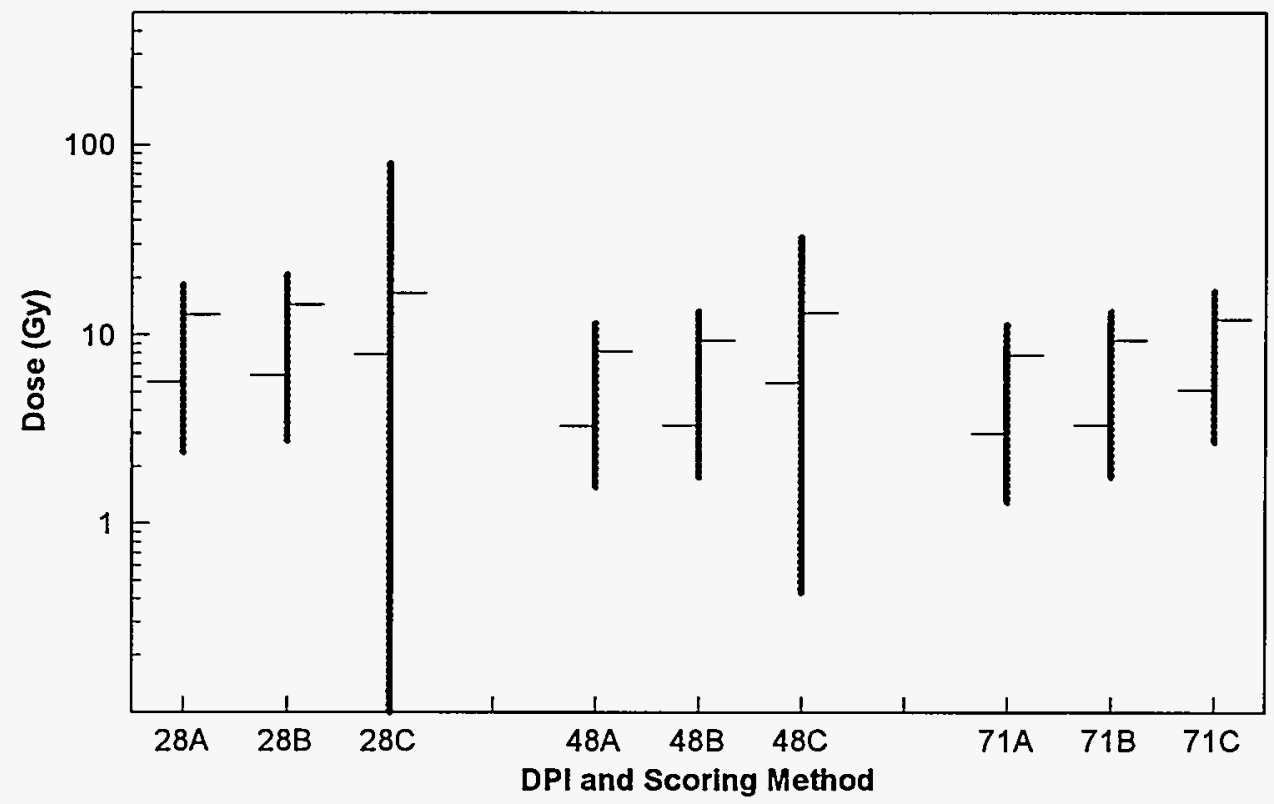

Figure $5.46 E D_{10}, E D_{50}$, and $95 \%$ confidence limits for combined white and dark scabs induced by Sc-46 on skin. 


\section{Experimental Results}

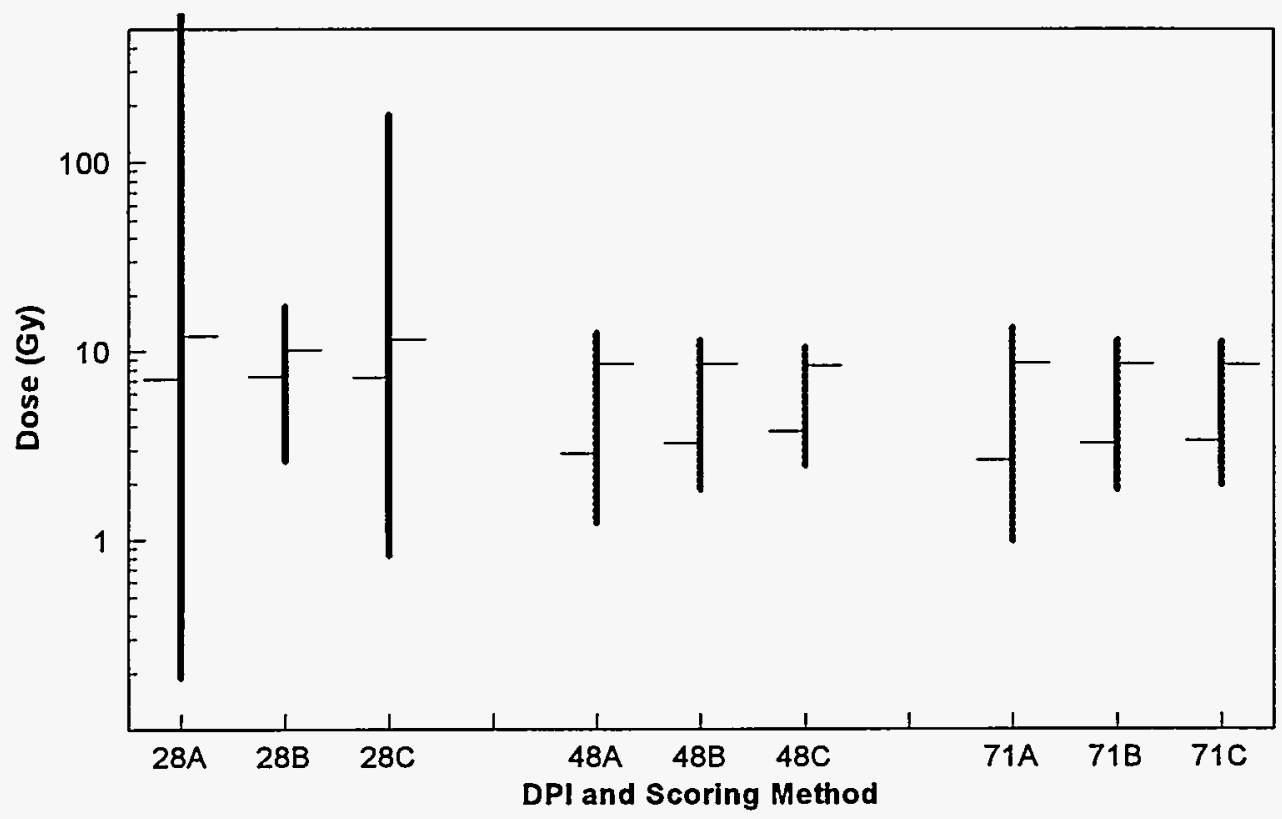

Figure 5.47 $\mathrm{ED}_{10}, \mathrm{ED}_{50}$, and $95 \%$ confidence limits for dark scabs induced by $\mathrm{Tm}-170$ on skin.

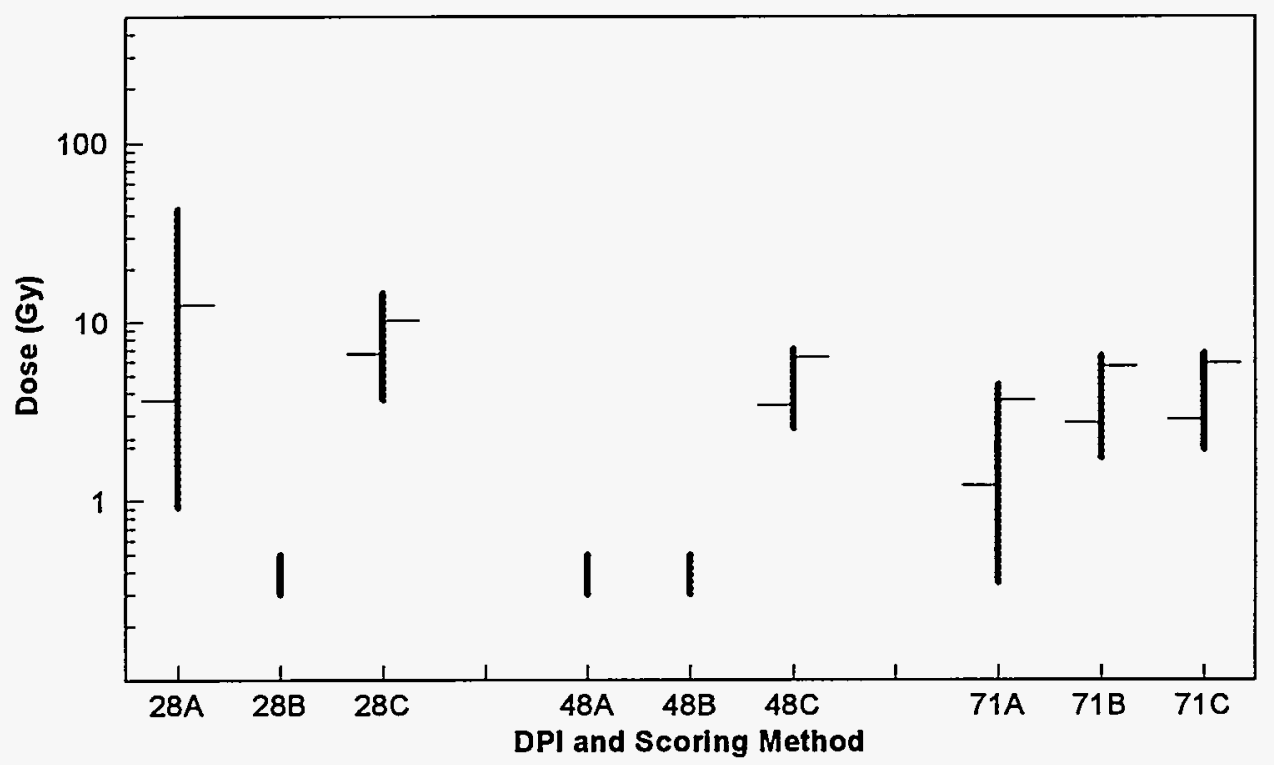

Figure 5.48 $\mathrm{ED}_{10}, \mathrm{ED}_{50}$, and $95 \%$ confidence limits for combined white and dark scabs induced by Tm-170 on skin. The SASISTAT probit fitting routine failed to converge for $28 \mathrm{~B}, 28 \mathrm{C}, 48 \mathrm{~A}$, and 48B data. 


\section{Experimental Results}

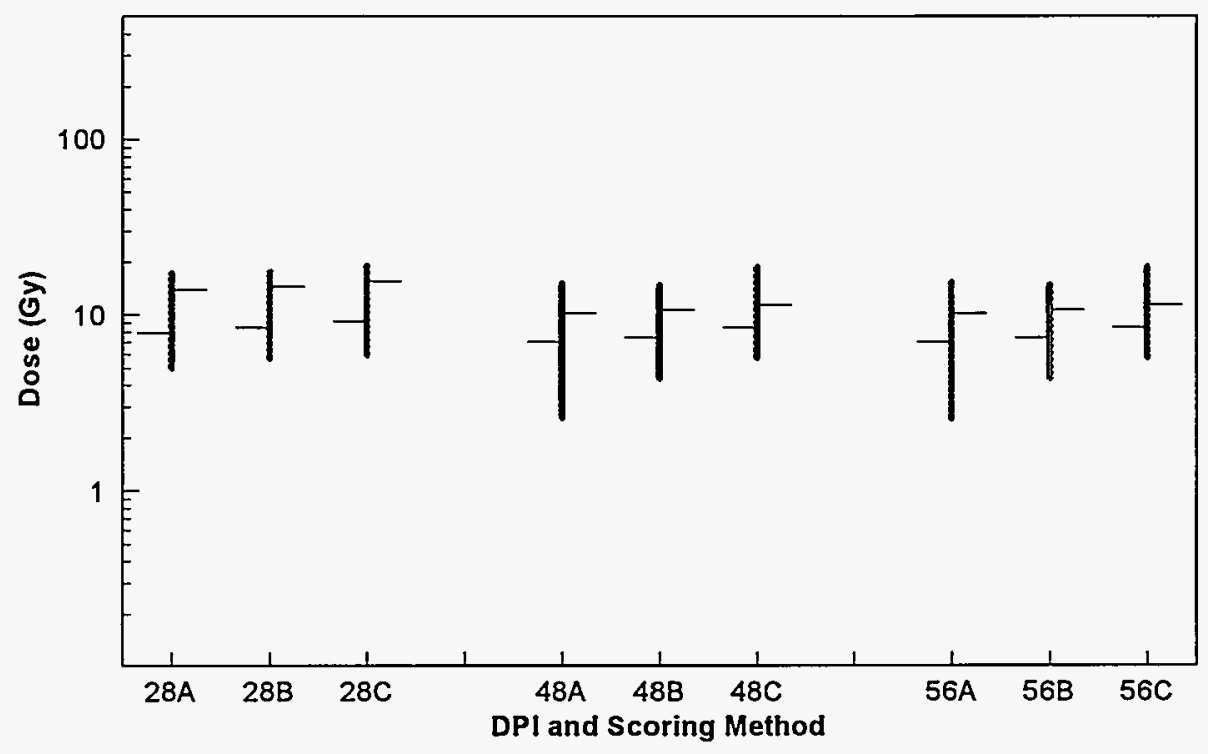

Figure $5.49 E D_{10}, E D_{50}$, and $95 \%$ confidence limits for dark scabs induced by $\mathrm{UC}_{2}$ on skin.

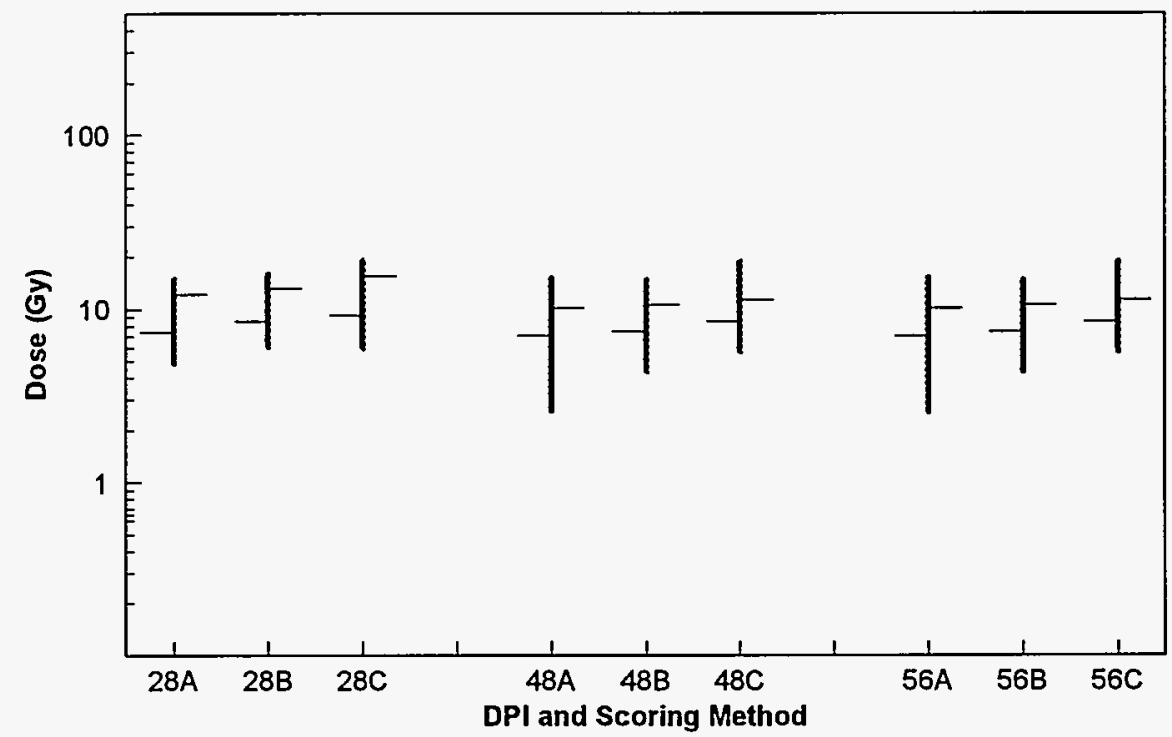

Figure 5.50 $E D_{10}, E D_{50}$, and $95 \%$ confidence limits for combined white and dark scabs induced by $\mathrm{UC}_{2}$ on skin. 


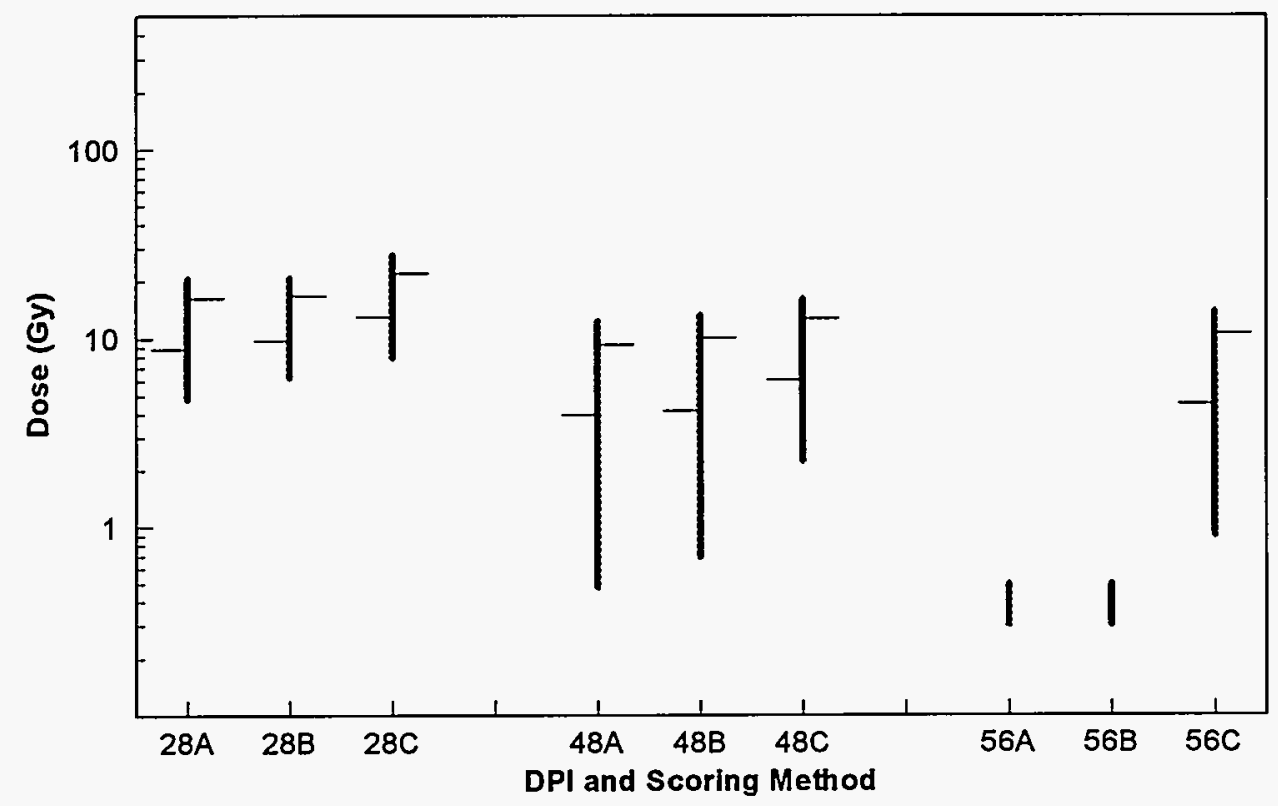

Figure 5.51 $E D_{10}, E D_{50}$, and $95 \%$ confidence limits for combined white and dark scabs induced by $\mathrm{UC}_{2}$ off skin. The SAS/STAT probit fitting routine failed to converge for $56 \mathrm{~A}$ and $56 \mathrm{~B}$ data.

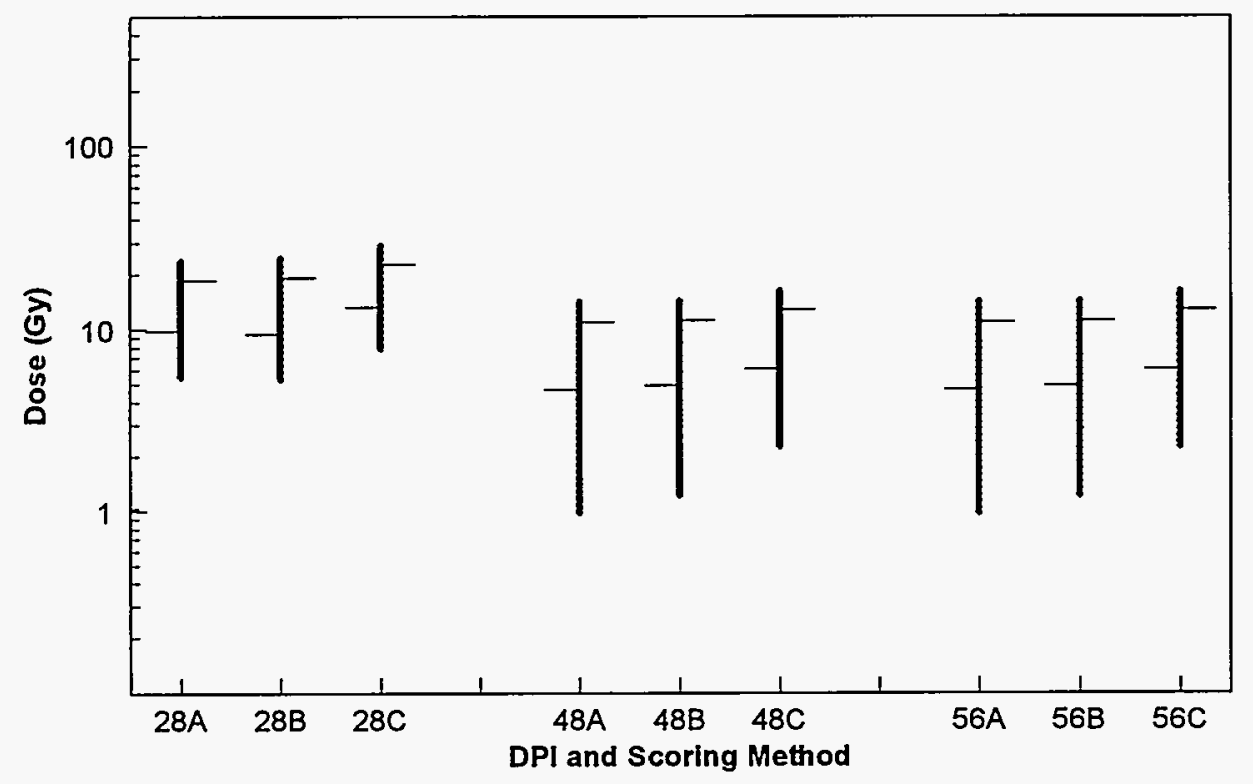

Figure $5.52 \mathrm{ED}_{10}, \mathrm{ED}_{50}$, and $95 \%$ confidence limits for dark scabs induced by $\mathrm{UC}_{2}$ off skin. 


\begin{tabular}{|c|c|c|c|c|c|c|c|c|c|c|c|c|c|c|c|c|c|c|c|c|}
\hline \multirow{6}{*}{ 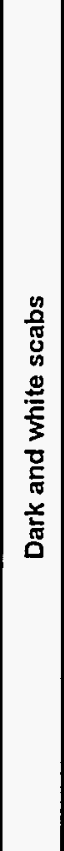 } & 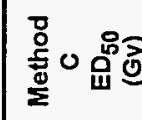 & & $\begin{array}{l}\mathscr{I} \\
\stackrel{\mathrm{I}}{ }\end{array}$ & $\begin{array}{l}\stackrel{6}{ } \\
\stackrel{\leftrightarrow}{\sigma}\end{array}$ & 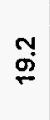 & $\underset{\sigma}{\sigma}$ & $\stackrel{\rightleftarrows}{\rightleftarrows}$ & 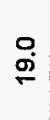 & চே. & 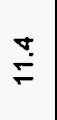 & $\stackrel{\circ}{\circ}$ & $\stackrel{\mathscr{R}}{\stackrel{5}{f}}$ & $\frac{Q}{\dot{N}}$ & $\stackrel{! n}{N}$ & $\overline{\check{~}}$ & 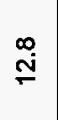 & 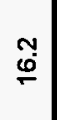 & $\frac{\bar{\sigma}}{6}$ & $\stackrel{\leftrightarrow}{\circ}$ & 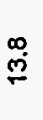 \\
\hline & 홍 & & $\begin{array}{l}\text { 另 } \\
\text { in }\end{array}$ & $\underset{\sigma}{\text { స్ }}$ & $\stackrel{\mathscr{\varphi}}{=}$ & $\underset{\text { in }}{R}$ & $\underset{\infty}{\stackrel{9}{0}}$ & 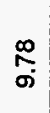 & $\underset{i \infty}{\stackrel{P}{0}}$ & $\underset{\infty}{\stackrel{g}{0}}$ & $\stackrel{\infty}{\stackrel{\infty}{\sigma}}$ & $\stackrel{\text { ㅁ }}{\sim}$ & $\stackrel{\circ}{\stackrel{g}{g}}$ & $\underset{\phi}{\ddot{\phi}}$ & $\stackrel{\mathscr{N}}{\text { N }}$ & $\underset{0}{8}$ & $\begin{array}{l}\mathscr{0} \\
\stackrel{\infty}{0}\end{array}$ & 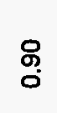 & 品 & న্ণ \\
\hline & 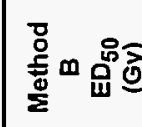 & & $\stackrel{\circ}{\circ}$ & $\overline{\stackrel{m}{r}}$ & $\bar{\varphi}$ & 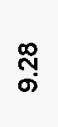 & $\hat{\circ}$ & $\stackrel{\mathscr{\rho}}{\dot{\Psi}}$ & 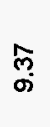 & 品 & 占 & $\stackrel{\stackrel{\infty}{\dddot{g}}}{\stackrel{2}{2}}$ & $\begin{array}{l}\infty \\
\stackrel{\infty}{\circ}\end{array}$ & $\begin{array}{l}0 \\
\dot{\sim}\end{array}$ & 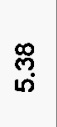 & $\bar{o}$ & $\stackrel{m}{\stackrel{m}{m}}$ & & & \\
\hline & 总四 웁오 & & $\frac{O}{6}$ & 岕 & $\stackrel{m}{\circ}$ & $\widehat{\widehat{m}}$ & $\stackrel{\mathscr{Q}}{\stackrel{2}{\sim}}$ & $\underset{\infty}{\bar{\infty}}$ & 蜼 & $\stackrel{8}{\stackrel{8}{\circ}}$ & $\stackrel{\text { s. }}{\circ}$ & ্ֻণ & $\underset{\infty}{\stackrel{R}{0}}$ & $\stackrel{\mathbb{N}}{\underset{\Upsilon}{\sim}}$ & : & $\frac{⿱ 亠}{\dot{*}}$ & 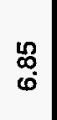 & & & \\
\hline & 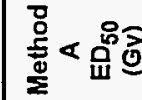 & & Бे. & $\overline{\mathrm{N}}$ & 吊 & $\stackrel{0}{\infty}$ & $\begin{array}{l}\vec{\Xi} \\
\infty \\
\infty\end{array}$ & $\stackrel{n}{\stackrel{m}{m}}$ & 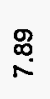 & $\stackrel{\leftrightarrow}{\circ}$ & $\stackrel{\mathscr{0}}{\stackrel{i}{\sim}}$ & 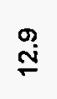 & $\stackrel{\mathscr{m}}{\oplus}$ & $\begin{array}{l}\infty \\
\stackrel{\text { ș }}{2}\end{array}$ & $\stackrel{\bar{m}}{\dot{q}}$ & 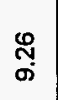 & $\stackrel{m}{\stackrel{m}{\dddot{N}}}$ & & & \\
\hline & 总 & & \& & 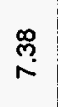 & $\frac{m}{\sigma}$ & $\stackrel{\text { Si }}{\text { i }}$ & $\begin{array}{l}8 \\
0\end{array}$ & $\underset{\infty}{\Delta}$ & $\bar{N}$ & $\begin{array}{l}\bar{f} \\
6\end{array}$ & 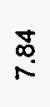 & $\underset{\sim}{\mathscr{\sigma}}$ & $\underset{\infty}{\stackrel{0}{\infty}}$ & 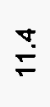 & ֻ̊ợ & $\begin{array}{l}\text { लू } \\
\text { ले }\end{array}$ & \begin{tabular}{l}
$\mathscr{0}$ \\
\hdashline
\end{tabular} & & & \\
\hline \multirow{6}{*}{ 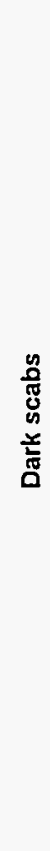 } & 总。品甬 & & 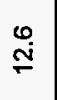 & $\begin{array}{l}\stackrel{0}{\mathscr{H}} \\
\stackrel{\leftrightarrow}{\circ}\end{array}$ & $\underset{\sigma}{\sigma}$ & চু & $\stackrel{\square}{\rightleftarrows}$ & $\stackrel{\circ}{\stackrel{\circ}{Q}}$ & চু & 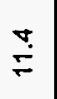 & $\stackrel{\circ}{\stackrel{\circ}{\circ}}$ & $\underset{\infty}{\mathscr{\infty}}$ & 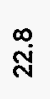 & $\overline{\mathrm{S}}$ & $\overline{\check{\sigma}}$ & $\stackrel{\infty}{\mathrm{N}}$ & ઼ָ & స్ & 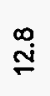 & $\underset{ٍ ్}{N}$ \\
\hline & 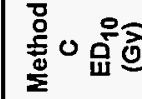 & & $\begin{array}{l}\text { 只 } \\
\text { 足 }\end{array}$ & 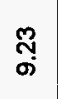 & $\stackrel{\mathscr{C}}{\rightleftarrows}$ & $\underset{\text { in }}{\stackrel{R}{0}}$ & $\underset{\infty}{\stackrel{9}{+}}$ & $\underset{\substack{\infty \\
\underset{\sigma}{0}}}{ }$ & $\underset{\text { is }}{\stackrel{P}{2}}$ & $\underset{\infty}{\stackrel{g}{0}}$ & $\underset{\sigma}{\stackrel{\infty}{\sigma}}$ & $\stackrel{\Re}{N}$ & $\stackrel{N}{\stackrel{N}{m}}$ & 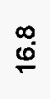 & $\underset{\sim}{\stackrel{\text { N }}{N}}$ & $\underset{\oplus}{\stackrel{8}{0}}$ & $\begin{array}{l}\mathscr{L} \\
\infty \\
\infty \\
\infty\end{array}$ & $\stackrel{\stackrel{N}{N}}{\text { N }}$ & $\underset{0}{\circ}$ & $\underset{\substack{\infty \\
\stackrel{\infty}{\infty}}}{ }$ \\
\hline & 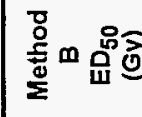 & & $\stackrel{\infty}{\leftarrow}$ & $\stackrel{\mathscr{R}}{+}$ & $\stackrel{\infty}{\stackrel{\infty}{\sim}}$ & $\begin{array}{l}\stackrel{\infty}{ָ} \\
\sigma\end{array}$ & $\hat{\circ}$ & 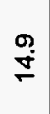 & 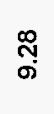 & 요 & $\stackrel{g}{\dot{I}}$ & $\stackrel{\square}{\underline{n}}$ & กั & $\begin{array}{l}\mathscr{0} \\
\dot{v}\end{array}$ & 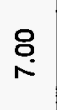 & $\stackrel{\stackrel{N}{\rightleftarrows}}{=}$ & 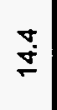 & ب & $\stackrel{\mathscr{Y}}{=}$ & $\underset{\dot{J}}{\stackrel{\nabla}{*}}$ \\
\hline & 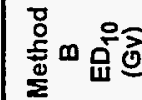 & & $\begin{array}{l}\hat{6} \\
\dot{0}\end{array}$ & 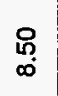 & ஜ̊ & ڤ్ & 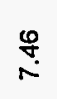 & $\underset{\infty}{\bar{\infty}}$ & مु & $\stackrel{\mathscr{V}}{\mathfrak{r}}$ & $\underset{\infty}{\pi}$ & $\underset{\text { ஸึ }}{\text { సิ }}$ & $\underset{\sigma}{\stackrel{7}{\circ}}$ & $\stackrel{\mathscr{L}}{\stackrel{\sim}{\sim}}$ & $\underset{ָ ָ}{~}$ & $\underset{\mathscr{g}}{\stackrel{g}{\sim}}$ & 员 & 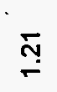 & $\underset{\stackrel{\mathscr{O}}{\circ}}{\stackrel{8}{*}}$ & 员 \\
\hline & $\begin{array}{l}\text { D } \\
\text { 总 } \\
\text { 总 }\end{array}$ & & 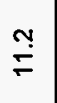 & $\stackrel{\circ}{\dot{+}}$ & $\stackrel{\check{\sim}}{\stackrel{5}{*}}$ & $\underset{\infty}{\stackrel{R}{0}}$ & 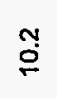 & 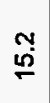 & $\underset{\infty}{R}$ & $\stackrel{\text { ִㅜ }}{\stackrel{0}{0}}$ & $\stackrel{m}{\stackrel{m}{p}}$ & $\hat{\dot{j}}$ & $\underset{\infty}{\stackrel{\infty}{\infty}}$ & $\underset{\dot{\vec{J}}}{\dot{\sim}}$ & ฟै & $\stackrel{\circ}{\circ}$ & $\underset{\sim}{\mathbb{Z}}$ & $\underset{0}{\widetilde{V}}$ & $\stackrel{\circ}{\circ}$ & 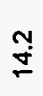 \\
\hline & 몷 & & $\begin{array}{l}\stackrel{\infty}{\%} \\
\stackrel{\sim}{*}\end{array}$ & $\stackrel{\text { ֻ }}{\sim}$ & $\check{\Phi}$ & $\underset{\text { i }}{\bar{j}}$ & مِ & $\underset{\substack{\infty \\
\infty \\
\infty}}{ }$ & i⿱ & ํㅜㅇ & 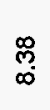 & $\underset{\stackrel{\infty}{*}}{\stackrel{\infty}{i}}$ & 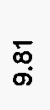 & 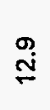 & ఫั่ & 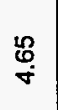 & 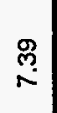 & $\begin{array}{l}\hat{\sigma} \\
\text { o }\end{array}$ & $\begin{array}{l}\stackrel{\leftrightarrow}{0} \\
\underset{\sim}{*}\end{array}$ & $\stackrel{\text { g }}{\sim}$ \\
\hline & 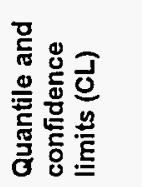 & & 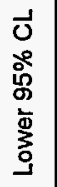 & 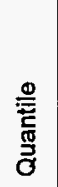 & 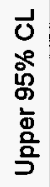 & 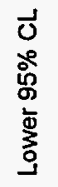 & 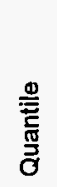 & 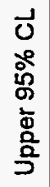 & 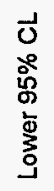 & 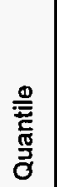 & 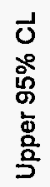 & 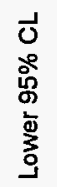 & 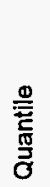 & 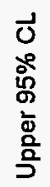 & 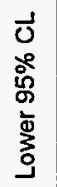 & 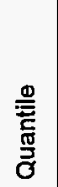 & 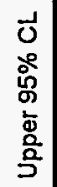 & 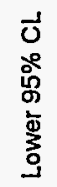 & 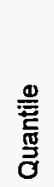 & 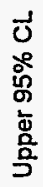 \\
\hline & $\overline{\mathrm{a}}$ & & & $\stackrel{\mathscr{N}}{ }$ & & & \& & & & $\stackrel{\circ}{\circ}$ & & & $\stackrel{\infty}{\sim}$ & & & $\stackrel{\infty}{+}$ & & & 吊 & \\
\hline & $\begin{array}{l}\text { 음 } \\
\stackrel{0}{0} \\
\stackrel{0}{0}\end{array}$ & لِ & & & & & 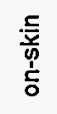 & & & & & & & & & 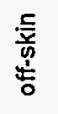 & & & & \\
\hline
\end{tabular}


Table 5.15 (Cont.)

\begin{tabular}{|c|c|c|c|c|c|c|c|c|c|c|c|c|c|c|}
\hline \multirow[b]{2}{*}{ Isotope } & \multirow[b]{2}{*}{ DPI } & \multirow[b]{2}{*}{$\begin{array}{l}\text { Quantile and } \\
\text { confidence } \\
\text { limits (CL) }\end{array}$} & \multicolumn{6}{|c|}{ Dark scabs } & \multicolumn{6}{|c|}{ Dark and white scabs } \\
\hline & & & $\begin{array}{c}\text { Method } \\
A \\
E_{10} \\
(G y)\end{array}$ & $\begin{array}{c}\text { Method } \\
A \\
E D_{50} \\
(G y) \\
\end{array}$ & $\begin{array}{c}\text { Method } \\
\text { B } \\
E_{10} \\
(G y) \\
\end{array}$ & $\begin{array}{c}\text { Method } \\
B \\
E D_{50} \\
(G y) \\
\end{array}$ & $\begin{array}{c}\text { Method } \\
C \\
E D_{10} \\
(G y) \\
\end{array}$ & $\begin{array}{c}\text { Method } \\
C \\
E_{50} \\
(G y) \\
\end{array}$ & $\begin{array}{c}\text { Method } \\
A \\
E_{10} \\
(G y) \\
\end{array}$ & $\begin{array}{c}\text { Method } \\
A \\
E D_{50} \\
(G y) \\
\end{array}$ & $\begin{array}{c}\text { Method } \\
\text { B } \\
E D_{10} \\
(G y) \\
\end{array}$ & $\begin{array}{c}\text { Method } \\
\text { B } \\
\text { ED }_{50} \\
(G y) \\
\end{array}$ & $\begin{array}{c}\text { Method } \\
C \\
E D_{10} \\
(G y) \\
\end{array}$ & $\begin{array}{c}\text { Method } \\
C \\
E D_{50} \\
(G y) \\
\end{array}$ \\
\hline \multicolumn{15}{|c|}{ Tm-170 } \\
\hline \multirow{9}{*}{ on-skin } & \multirow{3}{*}{28} & Lower 95\% CL & 0.19 & 9.82 & 2.63 & 9.31 & 0.82 & 9.92 & 0.92 & 9.16 & & & 3.61 & 9.14 \\
\hline & & Quantile & 7.13 & 12.0 & 7.37 & 10.1 & 7.28 & 11.6 & 3.64 & 12.5 & & & 6.60 & 10.2 \\
\hline & & Upper 95\% CL & 8.28 & 713 & 8.26 & 17.5 & 8.35 & 178 & 5.04 & 43.2 & & & 7.59 & 14.6 \\
\hline & \multirow{3}{*}{48} & Lower 95\% CL & 1.23 & 7.04 & 1.83 & 7.19 & 2.47 & 7.27 & & & & & 2.52 & 5.59 \\
\hline & & Quantile & 2.89 & 8.60 & 3.27 & 8.56 & 3.77 & 8.43 & & & & & 3.41 & 6.30 \\
\hline & & Upper $95 \% \mathrm{CL}$ & 3.97 & 12.6 & 4.23 & 11.5 & 4.65 & 10.5 & & & & & 4.06 & 7.08 \\
\hline & \multirow{3}{*}{71} & Lower 95\% CL & 0.98 & 6.98 & 1.83 & 7.19 & 1.95 & 7.17 & 0.35 & 2.43 & 1.74 & 4.84 & 1.93 & 5.12 \\
\hline & & Quantile & 2.67 & 8.65 & 3.27 & 8.56 & 3.35 & 8.48 & 1.21 & 3.63 & 2.71 & 5.64 & 2.83 & 5.88 \\
\hline & & Upper $95 \% \mathrm{CL}$ & 3.78 & 13.3 & 4.23 & 11.5 & 4.28 & 11.2 & 1.96 & 4.47 & 3.42 & 6.46 & 3.50 & 6.71 \\
\hline \multicolumn{15}{|c|}{ Yb-175 } \\
\hline \multirow{9}{*}{ on-skin } & \multirow{3}{*}{28} & Lower $95 \% \mathrm{CL}$ & 0.69 & 8.24 & 0.92 & 9.55 & 1.85 & 9.18 & 0.43 & 6.89 & 0.55 & 8.18 & 1.85 & 9.18 \\
\hline & & Quantile & 4.11 & 14.9 & 4.24 & 18.6 & 3.87 & 16.8 & 4.11 & 12.0 & 4.11 & 14.3 & 3.87 & 16.8 \\
\hline & & Upper $95 \% \mathrm{CL}$ & 7.45 & 78.2 & 8.08 & 174 & 6.64 & 70.7 & 7.10 & 36.7 & 7.26 & 73.2 & 6.64 & 70.7 \\
\hline & \multirow{3}{*}{48} & Lower 95\% CL & 0.53 & 3.91 & 0.67 & 4.44 & 0.66 & 3.98 & 0.38 & 3.27 & 0.69 & 3.94 & 0.66 & 3.98 \\
\hline & & Quantile & 1.28 & 6.40 & 1.51 & 7.16 & 2.02 & 7.42 & 1.27 & 5.20 & 1.54 & 6.03 & 2.02 & 7.42 \\
\hline & & Upper $95 \% \mathrm{CL}$ & 2.12 & 14.7 & 2.41 & 16.6 & 3.76 & 31.9 & 2.15 & 10.8 & 2.41 & 12.0 & 3.76 & 31.9 \\
\hline & \multirow{3}{*}{71} & Lower $95 \% \mathrm{CL}$ & 0.41 & 3.64 & 0.48 & 3.92 & 0.40 & 3.12 & 0.24 & 3.13 & 0.67 & 3.55 & 0.40 & 3.12 \\
\hline & & Quantile & 1.20 & 6.00 & 1.12 & 6.42 & 1.33 & 6.12 & 1.44 & 5.29 & 1.36 & 5.32 & 1.33 & 6.12 \\
\hline & & Upper $95 \% \mathrm{CL}$ & 2.05 & 14.1 & 1.81 & 15.8 & 2.54 & 33.1 & 2.56 & 11.4 & 2.06 & 10.0 & 2.54 & 33.1 \\
\hline
\end{tabular}


Table 5.15 (Cont.)

\begin{tabular}{|c|c|c|c|c|c|c|c|c|c|c|c|c|c|c|}
\hline \multirow[b]{2}{*}{ Isotope } & \multirow[b]{2}{*}{ DPI } & \multirow[b]{2}{*}{$\begin{array}{l}\text { Quantile and } \\
\text { confidence } \\
\text { limits (CL) }\end{array}$} & \multicolumn{6}{|c|}{ Dark scabs } & \multicolumn{6}{|c|}{ Dark and white scabs } \\
\hline & & & $\begin{array}{c}\text { Method } \\
A \\
E D_{10} \\
(G y) \\
\end{array}$ & $\begin{array}{c}\text { Method } \\
A \\
E_{50} \\
(G y) \\
\end{array}$ & $\begin{array}{c}\text { Method } \\
\text { B } \\
\text { ED }_{10} \\
(G y)\end{array}$ & $\begin{array}{c}\text { Method } \\
B \\
E D_{50} \\
(G y) \\
\end{array}$ & $\begin{array}{c}\text { Method } \\
\text { C } \\
\text { ED }_{10} \\
(\mathrm{~Gy}) \\
\end{array}$ & $\begin{array}{c}\text { Method } \\
\text { C } \\
E D_{50} \\
(G y) \\
\end{array}$ & $\begin{array}{c}\text { Method } \\
A \\
E D_{10} \\
(G y) \\
\end{array}$ & $\begin{array}{c}\text { Method } \\
A \\
E D_{50} \\
(G y) \\
\end{array}$ & $\begin{array}{c}\text { Method } \\
\text { B } \\
E_{10} \\
(G y) \\
\end{array}$ & $\begin{array}{c}\text { Method } \\
B \\
E D_{50} \\
(G y) \\
\end{array}$ & $\begin{array}{c}\text { Method } \\
C \\
E D_{10} \\
(G y)\end{array}$ & $\begin{array}{c}\text { Method } \\
C \\
E D_{50} \\
(G y) \\
\end{array}$ \\
\hline \multicolumn{15}{|l|}{ Sc -46} \\
\hline \multirow{9}{*}{ on-skin } & \multirow{3}{*}{28} & Lower $95 \% \mathrm{CL}$ & 0.22 & 5.77 & 2.77 & 11.1 & 0.54 & 7.98 & 2.38 & 8.83 & 2.73 & 10.2 & 0.00 & 3.80 \\
\hline & & Quantile & 5.74 & 15.5 & 5.71 & 15.8 & 7.40 & 18.3 & 5.63 & 12.8 & 6.12 & 14.5 & 7.87 & 16.7 \\
\hline & & Upper $95 \% \mathrm{CL}$ & 11.7 & 49.7 & 8.51 & 23.3 & 13.8 & 47.3 & 8.29 & 18.5 & 8.94 & 20.7 & 14.4 & 79.8 \\
\hline & \multirow{3}{*}{48} & Lower $95 \% \mathrm{CL}$ & 1.63 & 7.07 & 1.75 & 7.52 & 2.83 & 10.3 & 1.55 & 5.77 & 1.76 & 6.83 & 0.43 & 6.12 \\
\hline & & Quantile & 3.32 & 10.3 & 3.26 & 10.5 & 5.25 & 14.4 & 3.29 & 8.15 & 3.34 & 9.37 & 5.57 & 13.0 \\
\hline & & Upper $95 \% \mathrm{CL}$ & 5.05 & 15.5 & 4.77 & 15.3 & 7.60 & 20.9 & 4.82 & 11.6 & 4.82 & 13.3 & 9.89 & 32.9 \\
\hline & \multirow{3}{*}{71} & Lower $95 \% \mathrm{CL}$ & 1.43 & 6.91 & 1.75 & 7.52 & 2.63 & 9.56 & 1.30 & 5.39 & 1.76 & 6.83 & 2.68 & 8.77 \\
\hline & & Quantile & 3.20 & 10.3 & 3.26 & 10.5 & 4.79 & 13.3 & 2.99 & 7.81 & 3.34 & 9.37 & 5.11 & 12.0 \\
\hline & & Upper $95 \% \mathrm{CL}$ & 5.03 & 15.8 & 4.77 & 15.3 & 6.91 & 19.2 & 4.50 & 11.3 & 4.82 & 13.3 & 7.22 & 16.9 \\
\hline
\end{tabular}

a. Open boxes indicate where the fitting routine failed to converge. 


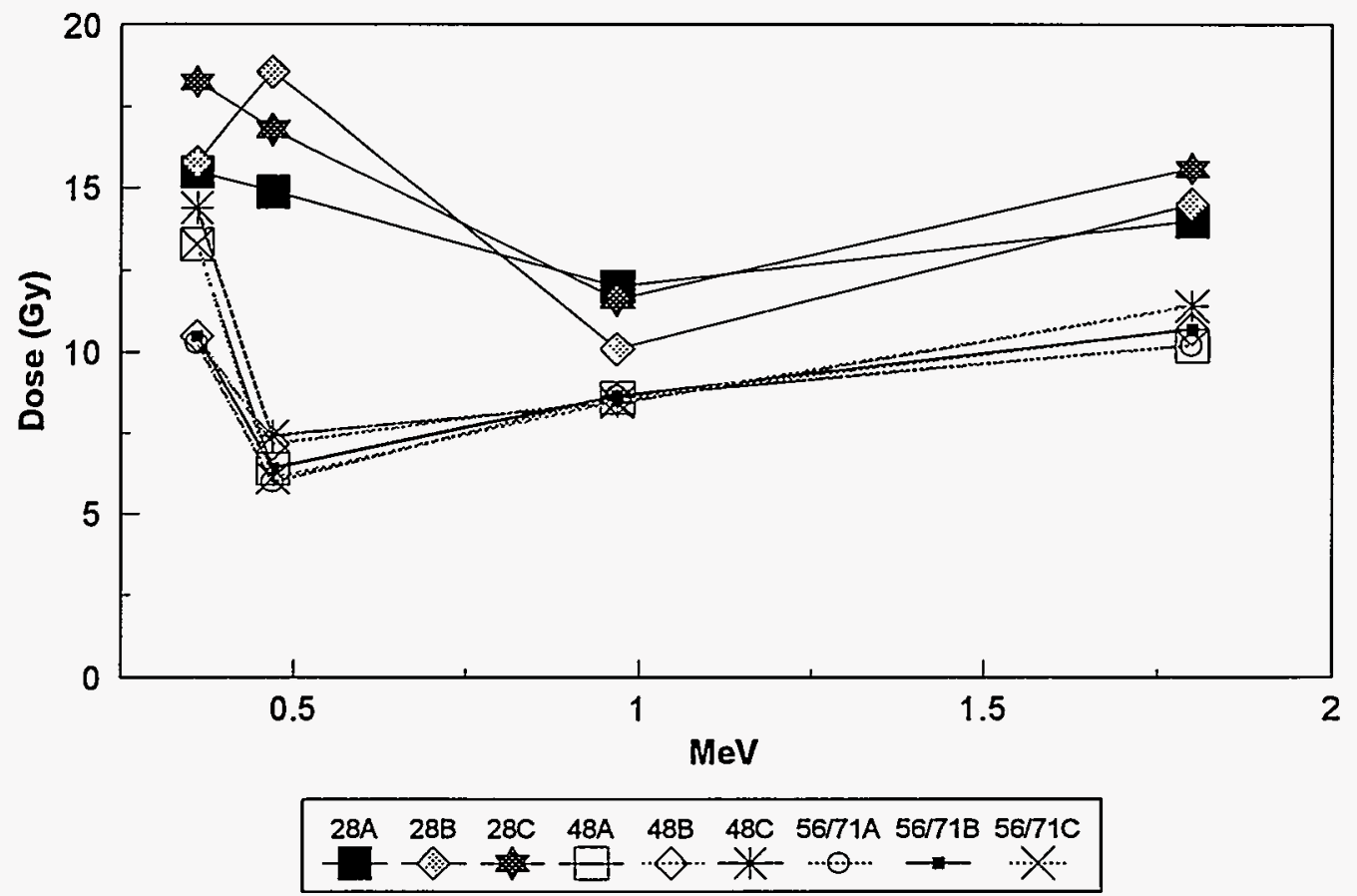

Figure 5.53 $E D_{50}$ values versus maximum beta particle energy for production of dark scabs for various scoring periods and methods.

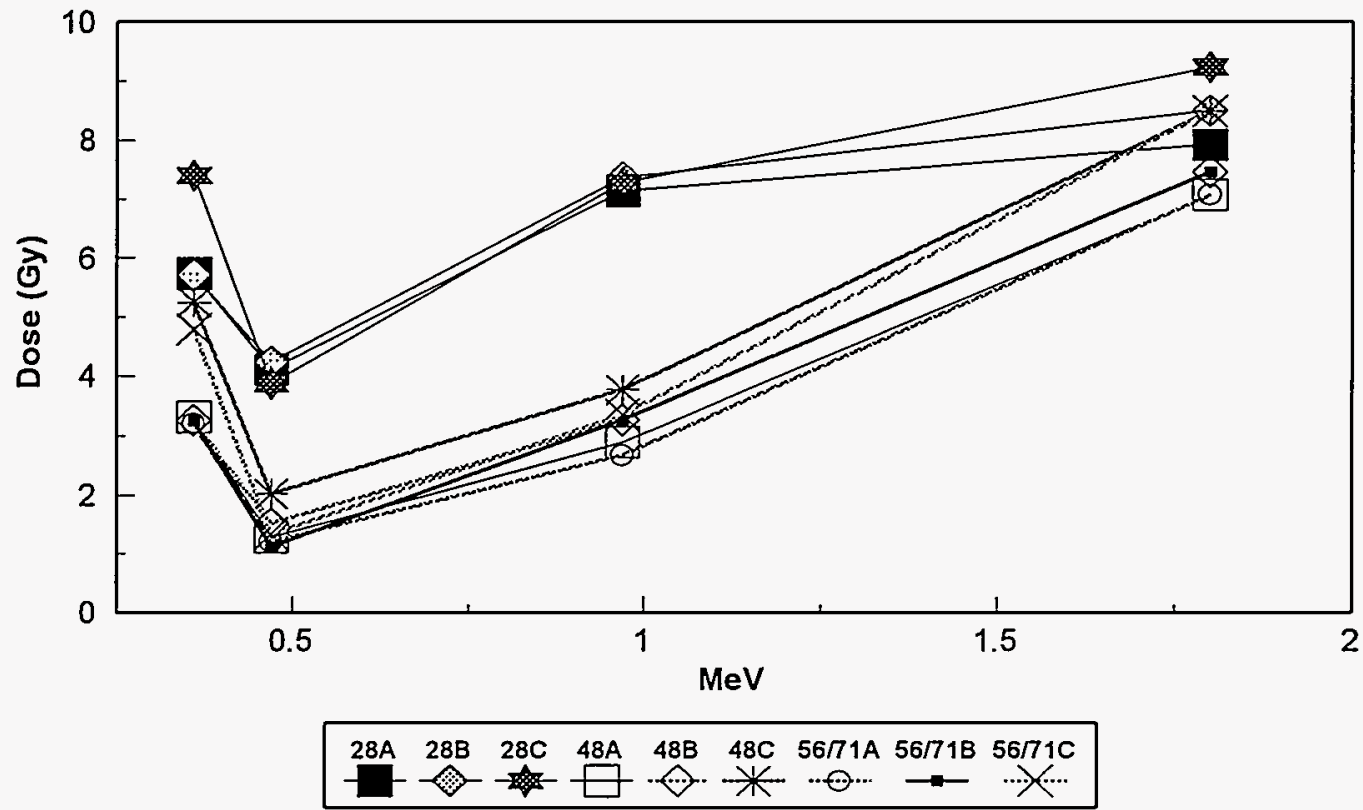

Figure 5.54 $E D_{10}$ values versus maximum particle energy for production of dark scabs for various scoring periods and methods. 


\section{Experimental Results}

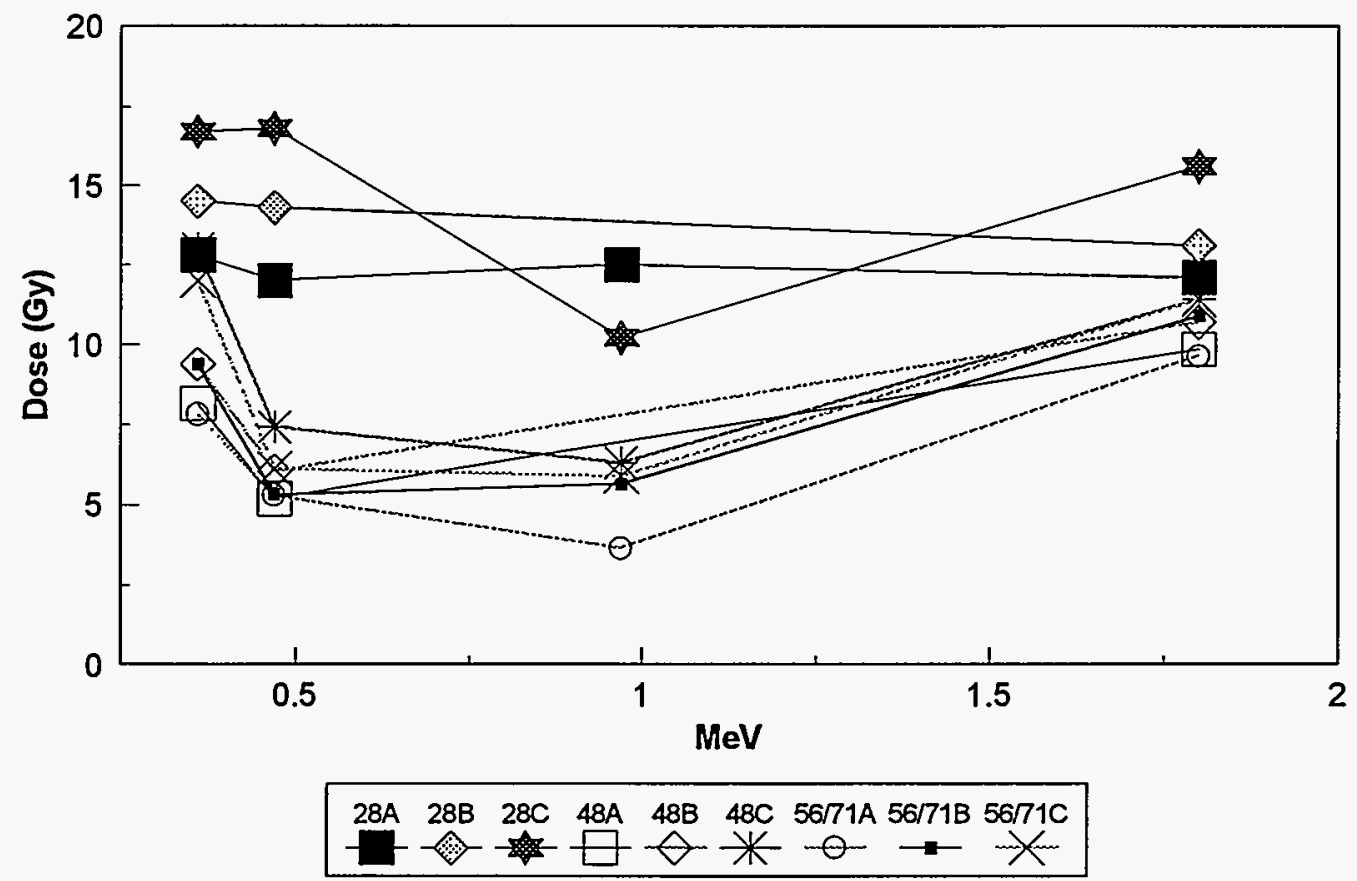

Figure 5.55 $E D_{50}$ values versus maximum beta particle energy for production of combined white and dark scabs for various scoring periods and methods.

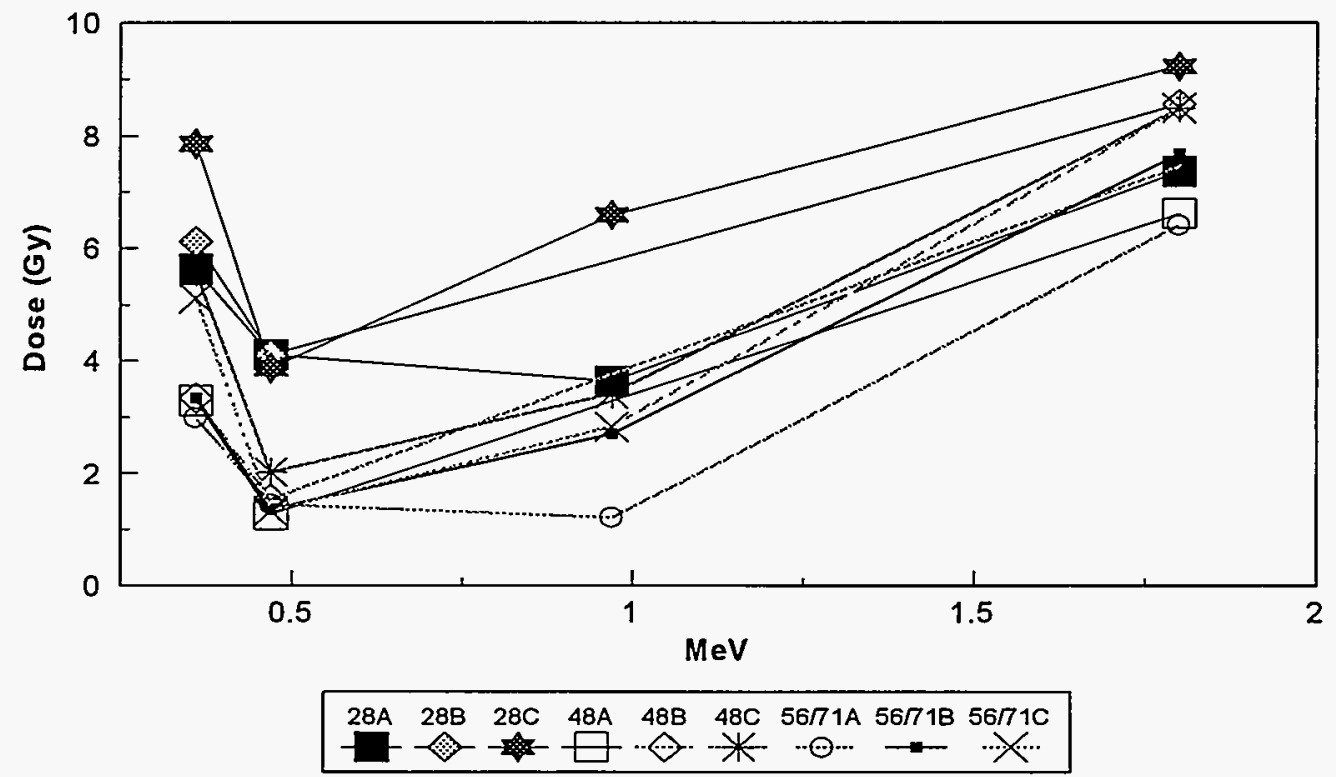

Figure 5.56 $E D_{10}$ values versus maximum beta particle energy for production of combined white and dark scabs for various scoring periods and methods. 
Experimental Results

The results shown in Figures 5.43 to 5.52 , with a few exceptions, show similar ranges for statistical uncertainties and similar values for $E D_{10}$ and $E D_{50}$, provided that the observations are evaluated over 48 days or more. For the 28-day observation, larger $E D_{10}$ and $E D_{50}$ values are obtained, as can be seen more readily in Figures 5.53 to 5.56 , where results for the 48,56 , and $71 \mathrm{DPI}$ generally clump together at lower dose values than those for the 28 -day results.

The results show that scab criteria methods $B$ and $C$ yield minimum $E D_{10}$ and $E D_{50}$ values for $0.47 \mathrm{MeV}(\mathrm{Yb}-175)$, whereas the minimum occurs at $1 \mathrm{MeV}(\mathrm{Tm}-170)$ for Method A with white and dark scabs combined. However, the statistical uncertainties are large compared to the differences in $E D_{50}$ values for $\mathrm{Yb}-175$ compared with $\mathrm{Tm}-170$.

A careful review of magnitudes of uncertainties shown in Table 5.15 indicate that Method $C$ is the most reliable in giving small error bars and yielding results which converge in the probit analysis routines. There are blanks in Table 5.15 in several locations reflecting a lack of convergence in the statistical analysis, which indicates the data are not suitable for the probit routine which is based on the assumption that data are normally distributed. Hence, Method $C$ is considered most appropriate for analyzing these data.

The $E D_{10}$ and $E D_{50}$ results for scoring Method $C$ and the sum of white and dark scabs are summarized in Figures 5.57 and 5.58 , along with $95 \%$ confidence limits. For dose averaged over $1 \mathrm{~cm}^{2}, \mathrm{Yb}-175$ particles, which emit $0.47 \mathrm{MeV}$ maximum energy beta particles are more effective than the other energies at the $10 \%$ incidence level. However, at $50 \%$ incidence, there is no significant difference in effectiveness for maximum beta energies of 0.47 and $0.97 \mathrm{MeV}$. For dose averaged over $1.1 \mathrm{~mm}^{2}$ at $70-\mu \mathrm{m}$ depth, the $95 \%$ confidence limits for the $\mathrm{Yb}-175$ and $\mathrm{Tm}-170 \mathrm{ED}_{10}$ are similar (Figure 5.58 and Table 5.16). Also, for dose averaged over $1.1 \mathrm{~mm}^{2}$ at 70- $\mu \mathrm{m}$ depth, the $T \mathrm{~m}-170 \mathrm{ED}_{50}$ is significantly lower than for the other hot particles used in these studies.

Table 5.16 gives the tabular values of $E D_{10}$ and $E D_{50}$ for scoring Method $C$ for all isotopes used in the BNL studies. The values are given for point dose at $100 \mu \mathrm{m}$ depth (given in some of the work of Forbes and Mikhail in Baum et al., 1992), $1.1 \mathrm{~mm}^{2}$ at $16 \mu \mathrm{m}$ depth (given for Hopewell's (1991) results), $1.1 \mathrm{~mm}^{2}$ at $70 \mu \mathrm{m}$ depth (which was initially thought to be a dose criteria less dependent on beta-particle energy), $1 \mathrm{~cm}^{2}$ at $70 \mu \mathrm{m}$ depth (area and depth given for dose of skin contamination (NRC, 1991a)), $1 \mathrm{~cm}^{2}$ at $100 \mu \mathrm{m}$ depth (suggested to be of interest by the ICRP59 committee (1991a)), and $1 \mathrm{~cm}^{2}$ at $150 \mu \mathrm{m}$ depth (suggested to be of interest by the ICRP-59 committee (1991a)), number of beta particles emitted from the source (given in the analysis of the Forbes and Mikhail's data set (NCRP, 1989)), and source activity in units of GBqs and $\mu \mathrm{Ci}$-hr (suggested by NCRP (1989)).

Conversion factors were also included in Table 5.16 to facilitate dose comparisons. Most of the figures listed have dose averaged over $1 \mathrm{~cm}^{2}$ at $70-\mu \mathrm{m}$ depth in tissue as the independent axis; thus, this was the reference point for the conversion factor. As a first example, to convert an onskin $U C_{2}$ dose averaged over $1 \mathrm{~cm}^{2}$ at $70-\mu \mathrm{m}$ depth in tissue to $1 \mathrm{~cm}^{2}$ at $150-\mu \mathrm{m}$ depth, multiply the dose averaged over $1 \mathrm{~cm}^{2}$ at $70-\mu \mathrm{m}$ depth by 0.91 . As a second example, to obtain dose averaged over $1.1 \mathrm{~mm}^{2}$ at a depth of $16 \mu \mathrm{m}$ from $1 \mathrm{~cm}^{2}$ dose at $70 \mu \mathrm{m}$ for the on-skin Tm-170 


\section{Experimental Results}

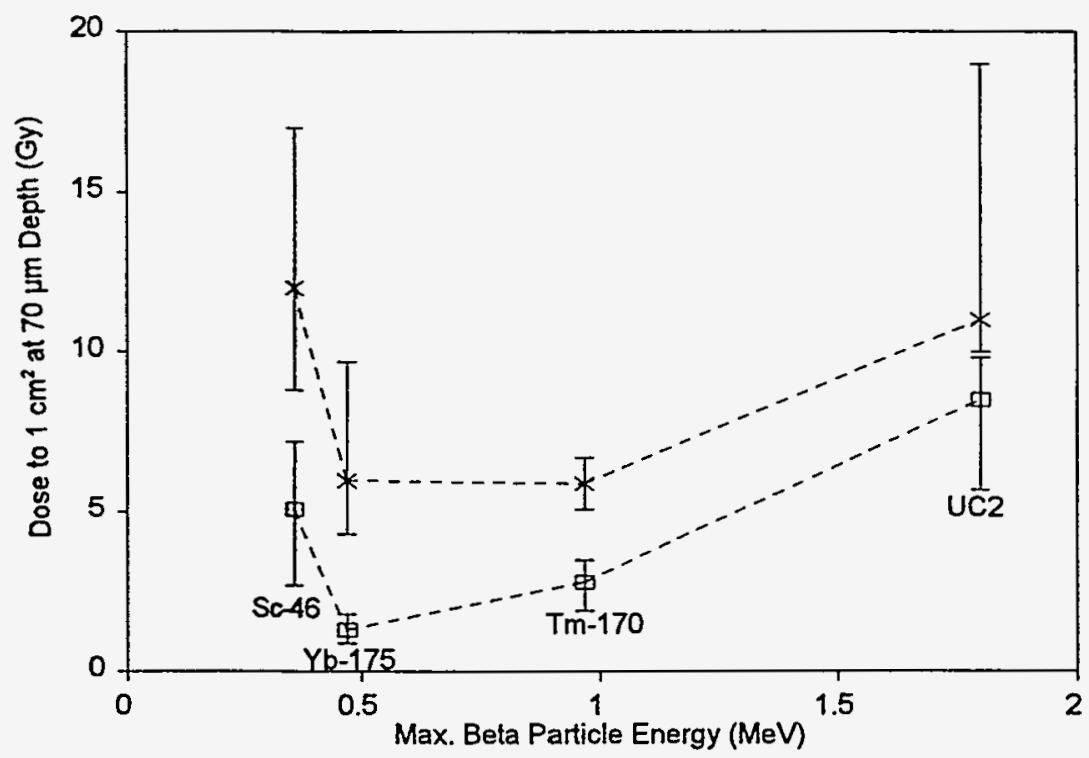

- - $10 \%$ Incidence $-x \cdot 50 \%$ Incidence

Figure 5.57 Doses averaged over $1 \mathrm{~cm} 2$ at $70 \mu \mathrm{m}$ depth required to induce scabs with 10 and $50 \%$ incidence using scoring Method $\mathrm{C}$ for $71 \mathrm{DPI}$ data (Tm-170, Yb-175, Sc-46) or $56 \mathrm{DPI}$ data $\left(\mathrm{UC}_{2}\right)$ for on-skin hot particles. Error bars represent $95 \%$ confidence levels.

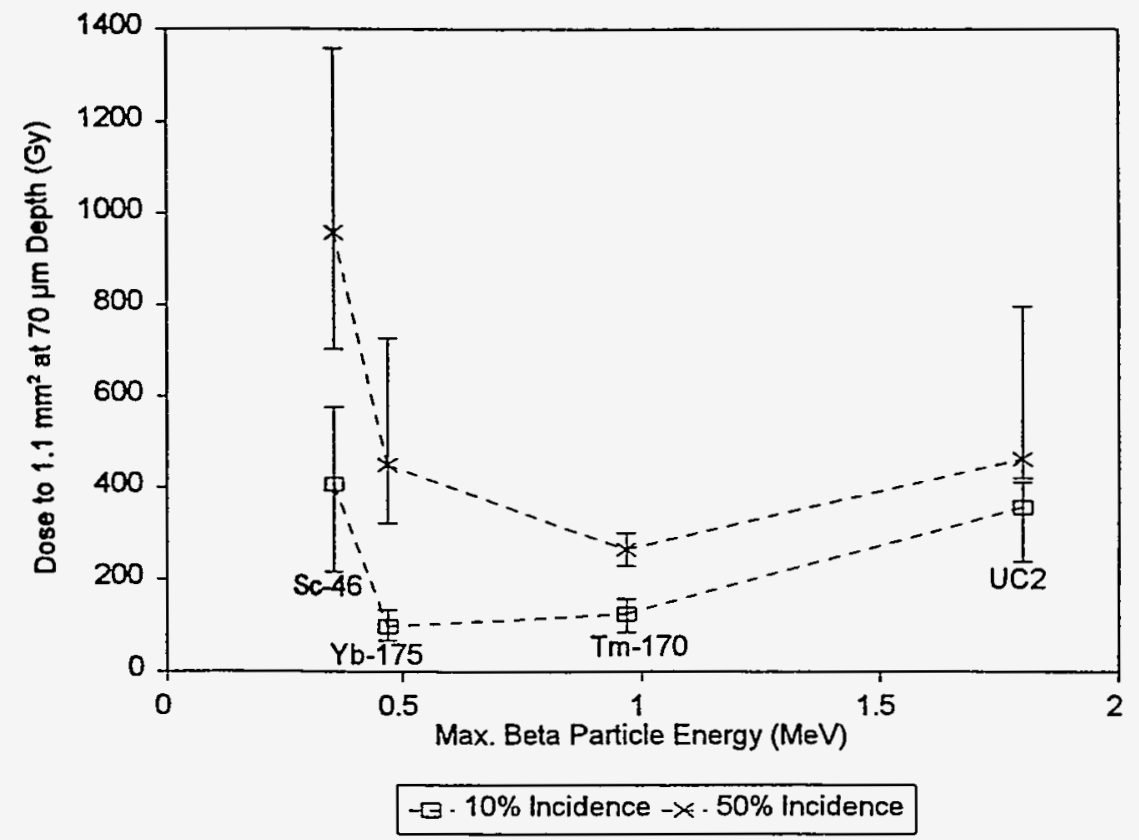

Figure 5.58 Doses averaged over $1.1 \mathrm{~mm}^{2}$ at $70 \mu \mathrm{m}$ depth required to induce on-skin scabs with 10 and $50 \%$ incidence using scoring Method C for 71 DPI data (Tm-170, Yb-175, Sc-46) or 56 DPI data $\left(U C_{2}\right)$. Error bars represent $95 \%$ confidence levels. 
Table 5.16 Values of $E D_{10}$ and $E D_{50}$ for doses averaged over selected areas and at selected depths. Scoring Method $C$ was used in all cases, with the modified scoring procedure for the $1992 \mathrm{Yb}-175$ data described in Section 5.6. The scoring period was $71 \mathrm{DPI}$ for Tm-170, Yb-175, and Sc-46; and $56 \mathrm{DPI}$ for on- and off-skin $\mathrm{UC}_{2}$.

\begin{tabular}{|c|c|c|c|c|c|c|c|c|c|c|}
\hline $\begin{array}{l}\text { Hot particle } \\
\text { (experiment } \\
\text { number) }\end{array}$ & & $\begin{array}{c}\text { Point } \\
100 \mu m \\
(G y)\end{array}$ & $\begin{array}{c}1.1 \mathrm{~mm}^{2} \\
16 \mu \mathrm{m} \\
(\mathrm{Gy})\end{array}$ & $\begin{array}{c}1.1 \mathrm{~mm}^{2} \\
70 \mu \mathrm{m} \\
(\mathrm{Gy})\end{array}$ & $\begin{array}{c}1 \mathrm{~cm}^{2} \\
70 \mu \mathrm{m} \\
(\mathrm{Gy})\end{array}$ & $\begin{array}{c}1 \mathrm{~cm}^{2} \\
100 \mu \mathrm{m} \\
(\mathrm{Gy})\end{array}$ & $\begin{array}{c}1 \mathrm{~cm}^{2} \\
150 \mu \mathrm{m} \\
(\mathrm{Gy})\end{array}$ & $\begin{array}{c}\text { No. beta } \\
\text { particles } \\
\text { emitted } \\
\text { from } \\
\text { source }^{\mathrm{a}} \\
\left(10^{9}\right)\end{array}$ & $\begin{array}{l}\text { No. beta } \\
\text { particles } \\
\text { emitted in } \\
\text { source } \\
\text { (GBq s) }\end{array}$ & $\begin{array}{c}\text { No. beta } \\
\text { particles } \\
\text { emitted in } \\
\text { source } \\
\text { ( } \mu \text { Ci-hr) }\end{array}$ \\
\hline $\begin{array}{l}\text { Off-skin } \\
\text { fissioned } \cup C_{2} \\
\text { (experiments } 2 \text {, } \\
18 \text {, and 19) }\end{array}$ & $\begin{array}{l}\text { ED }_{10} \\
\text { Lower } 95 \% \mathrm{CL} \\
\text { Upper } 95 \% \mathrm{CL} \\
\text { ED }_{50} \\
\text { Lower } 95 \% \mathrm{CL} \\
\text { Upper } 95 \% \mathrm{CL} \\
\text { Conversion }^{c}\end{array}$ & $\begin{array}{c}65 \\
13 \\
104 \\
\\
153 \\
89 \\
199 \\
\\
14\end{array}$ & $\begin{array}{c}59 \\
12 \\
94 \\
\\
139 \\
81 \\
181 \\
\\
13\end{array}$ & $\begin{array}{c}56 \\
11 \\
90 \\
\\
132 \\
77 \\
172 \\
\\
12\end{array}$ & $\begin{array}{c}4.5 \\
0.90 \\
7.2 \\
11 \\
6.2 \\
14 \\
1.0\end{array}$ & $\begin{array}{c}4.2 \\
0.84 \\
6.7 \\
\\
9.9 \\
5.8 \\
13 \\
\\
0.93\end{array}$ & $\begin{array}{c}3.8 \\
0.8 \\
6.2 \\
\\
9.1 \\
5.3 \\
12 \\
\\
0.86\end{array}$ & $\begin{array}{l}13 \\
2.6 \\
20 \\
\\
3.0 \\
18 \\
39 \\
\\
2.8\end{array}$ & $\begin{array}{l}14 \\
2.8 \\
23 \\
\\
33 \\
19 \\
43 \\
\\
3.2\end{array}$ & $\begin{array}{c}110 \\
21 \\
170 \\
\\
250 \\
150 \\
330 \\
\\
\\
24\end{array}$ \\
\hline $\begin{array}{l}\text { On-skin } \\
\text { fissioned } \cup C_{2} \\
\text { (experiments } 1 \text {, } \\
18 \text {, and 19) }\end{array}$ & $\begin{array}{l}\text { ED }_{10} \\
\text { Lower } 95 \% \mathrm{CL} \\
\text { Upper } 95 \% \mathrm{CL} \\
\text { ED }_{50} \\
\text { Lower } 95 \% \mathrm{CL} \\
\text { Upper } 95 \% \mathrm{CL} \\
\text { Conversionc }\end{array}$ & $\begin{array}{c}970 \\
651 \\
1118 \\
\\
1303 \\
1132 \\
2171 \\
\\
114\end{array}$ & $\begin{array}{c}490 \\
329 \\
565 \\
\\
658 \\
572 \\
1097 \\
58\end{array}$ & $\begin{array}{l}357 \\
240 \\
412 \\
\\
480 \\
417 \\
800 \\
\\
42\end{array}$ & $\begin{array}{l}8.5 \\
5.7 \\
9.8 \\
\\
11 \\
9.9 \\
19 \\
\\
1.0\end{array}$ & $\begin{array}{l}8.2 \\
5.5 \\
9.4 \\
\\
11 \\
10 \\
18 \\
\\
\\
0.97\end{array}$ & $\begin{array}{c}7.7 \\
5.2 \\
8.9 \\
\\
10 \\
9.0 \\
17 \\
\\
0.91\end{array}$ & $\begin{array}{l}15 \\
10 \\
18 \\
\\
21 \\
18 \\
34 \\
\\
\\
1.8\end{array}$ & $\begin{array}{l}16.6 \\
11.1 \\
19.1 \\
\\
22.3 \\
19.4 \\
37.1 \\
\\
2.0\end{array}$ & $\begin{array}{c}130 \\
84 \\
140 \\
\\
170 \\
150 \\
280 \\
\\
15\end{array}$ \\
\hline $\begin{array}{l}\text { On-skin } \\
\text { Tm-170 } \\
\text { (Experiments } 9 \\
\text { and 10) }\end{array}$ & $\begin{array}{l}\text { ED }_{10} \\
\text { Lower } 95 \% \mathrm{CL} \\
\text { Upper } 95 \% \mathrm{CL} \\
\text { ED }_{50} \\
\text { Lower } 95 \% \mathrm{CL} \\
\text { Upper } 95 \% \mathrm{CL} \\
\text { Conversion }\end{array}$ & $\begin{array}{l}305 \\
208 \\
377 \\
\\
634 \\
552 \\
724 \\
\\
108\end{array}$ & $\begin{array}{l}164 \\
112 \\
203 \\
\\
341 \\
297 \\
390 \\
\\
58\end{array}$ & $\begin{array}{c}129 \\
88 \\
159 \\
\\
267 \\
233 \\
305 \\
\\
\\
45\end{array}$ & $\begin{array}{l}2.8 \\
1.9 \\
3.5 \\
\\
5.9 \\
5.1 \\
6.7 \\
\\
1.0\end{array}$ & $\begin{array}{l}2.5 \\
1.7 \\
3.1 \\
\\
5.3 \\
4.6 \\
6.0 \\
\\
0.90\end{array}$ & $\begin{array}{l}2.3 \\
1.5 \\
2.8 \\
\\
4.7 \\
4.1 \\
5.4\end{array}$ & $\begin{array}{l}7.1 \\
4.8 \\
8.7 \\
\\
15 \\
13 \\
17\end{array}$ & $\begin{array}{l}17 \\
12 \\
21 \\
\\
36 \\
31 \\
41\end{array}$ & $\begin{array}{c}130 \\
88 \\
160 \\
\\
270 \\
230 \\
310 \\
\\
45\end{array}$ \\
\hline
\end{tabular}




\begin{tabular}{|c|c|c|c|c|c|c|c|c|c|c|}
\hline $\begin{array}{c}\text { Hot particle } \\
\text { (experiment } \\
\text { number) }\end{array}$ & & $\begin{array}{l}\text { Point } \\
100 \mu \mathrm{m} \\
\text { (Gy) }\end{array}$ & $\begin{array}{c}1.1 \mathrm{~mm}^{2} \\
16 \mu \mathrm{m} \\
(\mathrm{Gy})\end{array}$ & $\begin{array}{c}1.1 \mathrm{~mm}^{2} \\
70 \mu \mathrm{m} \\
(\mathrm{Gy})\end{array}$ & $\begin{array}{c}1 \mathrm{~cm}^{2} \\
70 \mu \mathrm{m} \\
(\mathrm{Gy})\end{array}$ & $\begin{array}{c}1 \mathrm{~cm}^{2} \\
100 \mu \mathrm{m} \\
(\mathrm{Gy})\end{array}$ & $\begin{array}{c}1 \mathrm{~cm}^{2} \\
150 \mu \mathrm{m} \\
(\mathrm{Gy})\end{array}$ & $\begin{array}{l}\text { No. beta } \\
\text { particles } \\
\text { emitted } \\
\text { from } \\
\text { source } \\
\left(10^{9}\right) \\
\end{array}$ & $\begin{array}{l}\text { No. beta } \\
\text { particles } \\
\text { emitted in } \\
\text { source }^{b} \\
\text { (GBq s) }\end{array}$ & $\begin{array}{l}\text { No. beta } \\
\text { particles } \\
\text { emitted in } \\
\text { source }{ }^{b} \\
\text { ( } \mu \text { Ci.hr) }\end{array}$ \\
\hline $\begin{array}{l}\text { On-skin } \\
\text { Yb-175 } \\
\text { (Experiments } \\
12,13,15 \text {, and } \\
17)\end{array}$ & $\begin{array}{l}\text { ED }_{10} \\
\text { Lower } 95 \% \mathrm{CL} \\
\text { Upper } 95 \% \mathrm{CL} \\
\text { ED }_{50} \\
\text { Lower } 95 \% \mathrm{CL} \\
\text { Upper } 95 \% \mathrm{CL} \\
\text { Conversion }^{\circ}\end{array}$ & $\begin{array}{c}229 \\
156 \\
316 \\
\\
1055 \\
756 \\
1705 \\
176\end{array}$ & $\begin{array}{c}148 \\
101 \\
204 \\
\\
682 \\
489 \\
1102 \\
114\end{array}$ & $\begin{array}{c}98 \\
67 \\
136 \\
\\
453 \\
325 \\
732 \\
\\
75\end{array}$ & $\begin{array}{l}1.3 \\
0.89 \\
1.8 \\
\\
6.0 \\
4.3 \\
9.7 \\
1.0\end{array}$ & $\begin{array}{l}1.0 \\
0.71 \\
1.4 \\
4.8 \\
3.4 \\
7.8 \\
\\
0.80\end{array}$ & $\begin{array}{l}0.72 \\
0.49 \\
1.00 \\
\\
3.3 \\
2.4 \\
5.4 \\
\\
0.55\end{array}$ & $\begin{array}{l}2.6 \\
1.7 \\
3.5 \\
\\
12 \\
8.4 \\
19 \\
\\
\\
2.0\end{array}$ & $\begin{array}{c}20 \\
14 \\
28 \\
\\
93 \\
66 \\
150 \\
15\end{array}$ & $\begin{array}{c}150 \\
100 \\
210 \\
700 \\
500 \\
1100 \\
120\end{array}$ \\
\hline $\begin{array}{l}\text { On-skin } \\
\text { Sc-46 } \\
\text { (Experiments } \\
14,16 \text {, and 17) }\end{array}$ & $\begin{array}{l}\text { ED }_{10} \\
\text { Lower } 95 \% \mathrm{CL} \\
\text { Upper } 95 \% \mathrm{CL} \\
\text { ED }_{50} \\
\text { Lower } 95 \% \mathrm{CL} \\
\text { Upper } 95 \% \mathrm{CL} \\
\text { Conversion }\end{array}$ & $\begin{array}{c}969 \\
508 \\
1369 \\
\\
2276 \\
1663 \\
3205 \\
\\
190\end{array}$ & $\begin{array}{l}689 \\
361 \\
973 \\
\\
1617 \\
1182 \\
2278 \\
\\
135\end{array}$ & $\begin{array}{c}411 \\
216 \\
581 \\
\\
965 \\
705 \\
1359 \\
\\
80\end{array}$ & $\begin{array}{l}5.1 \\
2.7 \\
7.2 \\
\\
12 \\
8.8 \\
17 \\
\\
1.0\end{array}$ & $\begin{array}{l}4.1 \\
2.1 \\
5.8 \\
10 \\
7.0 \\
13 \\
\\
0.80\end{array}$ & $\begin{array}{l}2.7 \\
1.4 \\
3.8 \\
\\
6.4 \\
4.7 \\
9.0 \\
\\
0.53\end{array}$ & $\begin{array}{l}15^{\mathrm{d}} \\
7.9^{\mathrm{d}} \\
21^{\mathrm{d}} \\
35^{\mathrm{d}} \\
26^{\mathrm{d}} \\
50^{\mathrm{d}} \\
2.9^{\mathrm{d}}\end{array}$ & $\begin{array}{c}48 \\
25 \\
68 \\
\\
110 \\
83 \\
160 \\
\\
9.4\end{array}$ & $\begin{array}{c}360 \\
190 \\
510 \\
\\
850 \\
620 \\
1200 \\
71\end{array}$ \\
\hline
\end{tabular}

a. Number of beta particles emitted from particle calculated from dose measurements and values given in Table 3.9 for particle area transmission factors.

b. The activity of the source is based on calculations using VARSKIN MOD2 (Durham 1991, 1992).

c. Multiply dose averaged over $1 \mathrm{~cm}^{2}$ at $70 \mu \mathrm{m}$ depth by the conversion factor indicated to obtain dose over areas and at depth of interest.

d. Number of beta particles emitted from the Sc-46 particle includes adjustments for dose due to secondary electron contribution from gamma rays. 
particle, multiply the dose averaged over $1 \mathrm{~cm}^{2}$ at $70-\mu \mathrm{m}$ depth by 58 . The conversion factors were calculated using equation 3.5.

The conversion factors given for the $\mathrm{UC}_{2}$ experiments can be used for all $B N L \mathrm{UC}_{2}$ experiments since the particle sizes and beta particle energies were similar. The conversion factor given for the Tm-170 hot particle data was only for the $470-\mu \mathrm{m}$ source.

The conversion factor given for the $\mathrm{Yb}-175$ source was for the preferred data set shown in Table 5.6. The $\mathrm{Yb}-175$ data set included data from experiment 12 in which the $510-\mu \mathrm{m}$ hot particle was used for the groups exposed to 1.3 and $5.1 \mathrm{~Gy}$, and 270 - and $320-\mu \mathrm{m}$ sources were used for twelve exposed sites receiving doses greater than $14 \mathrm{~Gy}$ ( 6 exposures each). The $\mathrm{Yb}-175$ hot particle sizes for experiments 13,15 , and 17 were 440 and $460 \mu \mathrm{m}$. The $\mathrm{Yb}-175$ conversion factor given in Table 5.16 was calculated using a weighted average from the different hot particle sizes, with the weights proportional to the number of sites exposed for each hot particle. Since the number of exposures from the 270 - and $320-\mu m$ hot particles was small, the contribution to the weighted average was very small, so the conversion factor can be effectively used for 440 to $510 \mu \mathrm{m}$ BNL Yb-175 hot particles.

The conversion factor for the Sc-46 hot particles was for $440-\mu \mathrm{m}$ sources.

\subsection{Scab-Days and Erythema Criteria for Detriment}

To better understand the severity of scabs or the detriment caused by different sources of hot particles, the quantity percent-scab-days (PSDs) and percent-effect-days were calculated. This was carried out for data accumulated in 1994-95 for $56\left(\mathrm{UC}_{2}\right)$ or $71 \mathrm{DPI}, \mathrm{Yb}-175$ and Sc-46 data sets and for $1992 \mathrm{Tm}-170$ data for experiments 9 and 10. The term PSD is 100 times the ratio of the number of observation days on which a particular exposed site was scored as a scab to the total number of days on which the site was observed. PSDs were averaged for replicate doses. The PSDs increase with increasing dose. Except for $\mathrm{UC}_{2}$ exposures for doses greater than $20 \mathrm{~Gy}, \mathrm{PSDs}$ generally increase with time until the lesion has healed and then decrease (see Figures 5-61a through 5.64h). The same trends are true for erythema. When both erythema and scab data are plotted on the same figure, the term percent-effect-days is used. The Yb-175 exposed sites had greater PSDs than either on-skin or off-skin $U_{2}$ exposures for doses less than $14 \mathrm{~Gy}$. The Tm-170 exposed sites yielded slightly elevated PSDs compared to $\mathrm{Yb}-175$ exposed sites for 3.0 to 7.6 Gy doses, with a $50 \%$ greater value at $10 \mathrm{~Gy}$.

Peak or maximum values of PSDs versus dose are plotted in Figures 5.59 and 5.60 for Sc-46 and $Y-175$, respectively. In these studies, 56 unexposed sites were scored (Table 3.10) and yielded a background correction of 2.8 PSDs for each type of particle (these corrections are shown on the figures).

The results for both erythema and scabs are further illustrated as a function of days postirradiation in Figures 5.61a-f for Sc-46, Figures 5.62a-h for Yb-175, Figures 5.63a-d for Tm-170, and Figures $5.64 a-h$ for $U C_{2}$, respectively, where scab data are plotted as dark scabs, white scabs, and total scabs and compared to PSDs for erythema which was also routinely scored during these studies. (The ordinates have different scales in the various illustrations.) 


\section{Experimental Results}

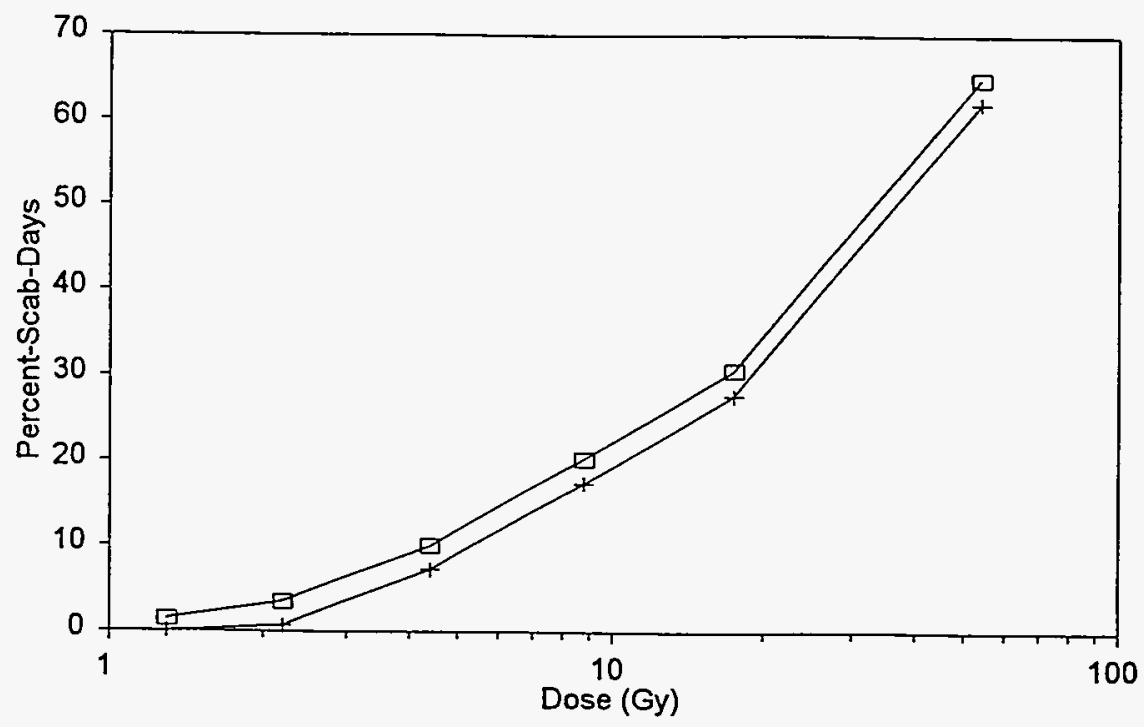

$\Xi$ Uncorrrected + Bkg Removed

Figure 5.59 Percent-scab-days (dark plus white) for doses from $440 \mu \mathrm{m}$ Sc-46 hot particles.

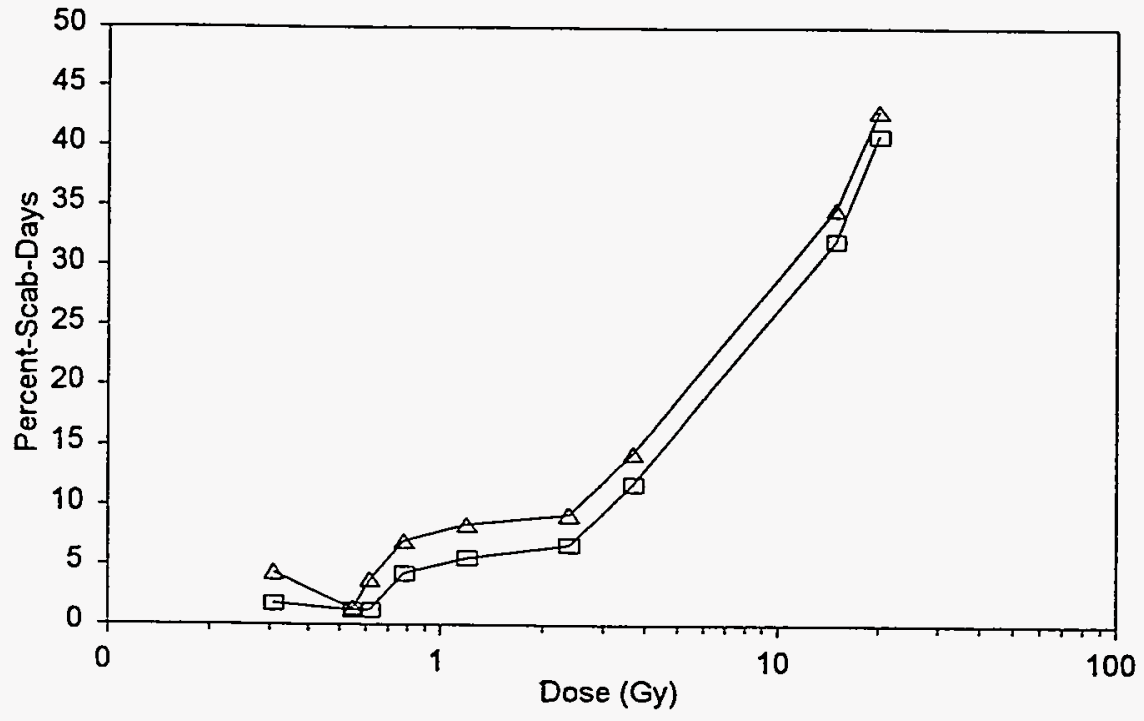

$\triangle$ Uncorrected $\quad$ Bkg Removed

Figure 5.60 Percent-scab-days (dark plus white) for doses from 440 to $460 \mu \mathrm{m}$ Yb-175 hot particles. 


\section{Experimental Results}

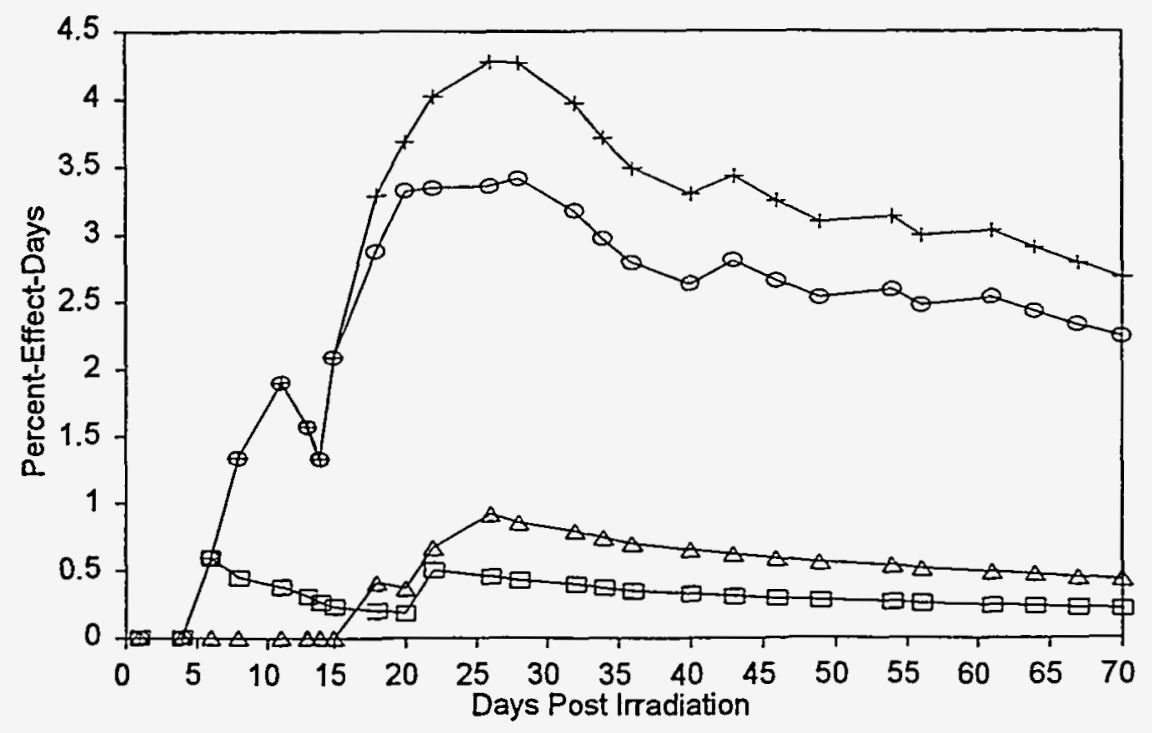

$\bigoplus$ Erythema $\odot$ Dark Scabs $\triangle$ - White Scabs + All Scabs

Figure 5.61a Percent-effect-days for Sc-46 control (0 Gy) exposures.

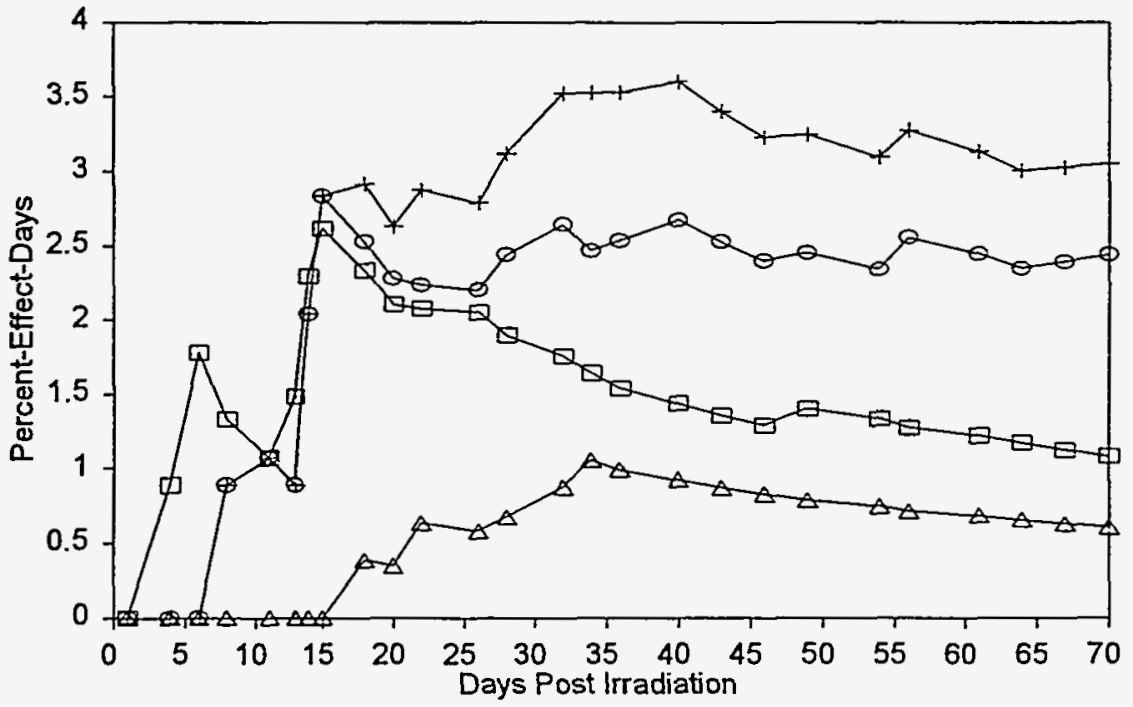

$Ð$ Erythema $\rightarrow$ Dark Scabs $₫$ White Scabs + All Scabs

Figure 5.61b Cumulative percent-effect-days for Sc-46 exposures (range 2.2-2.5 Gy). 


\section{Experimental Results}

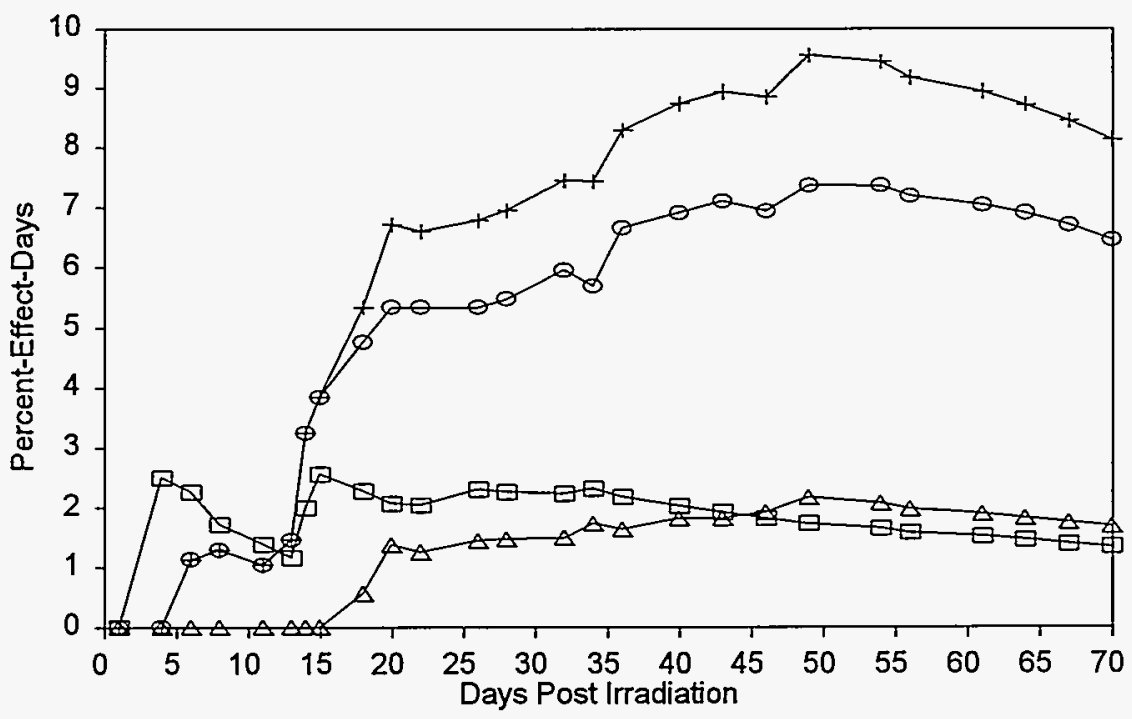

$\sqsubset$ Erythema $\oslash$ Dark Scabs $\triangle$ White Scabs + All Scabs

Figure 5.61c Cumulative percent-effect-days for Sc-46 exposures (range 4.4-4.7 Gy).

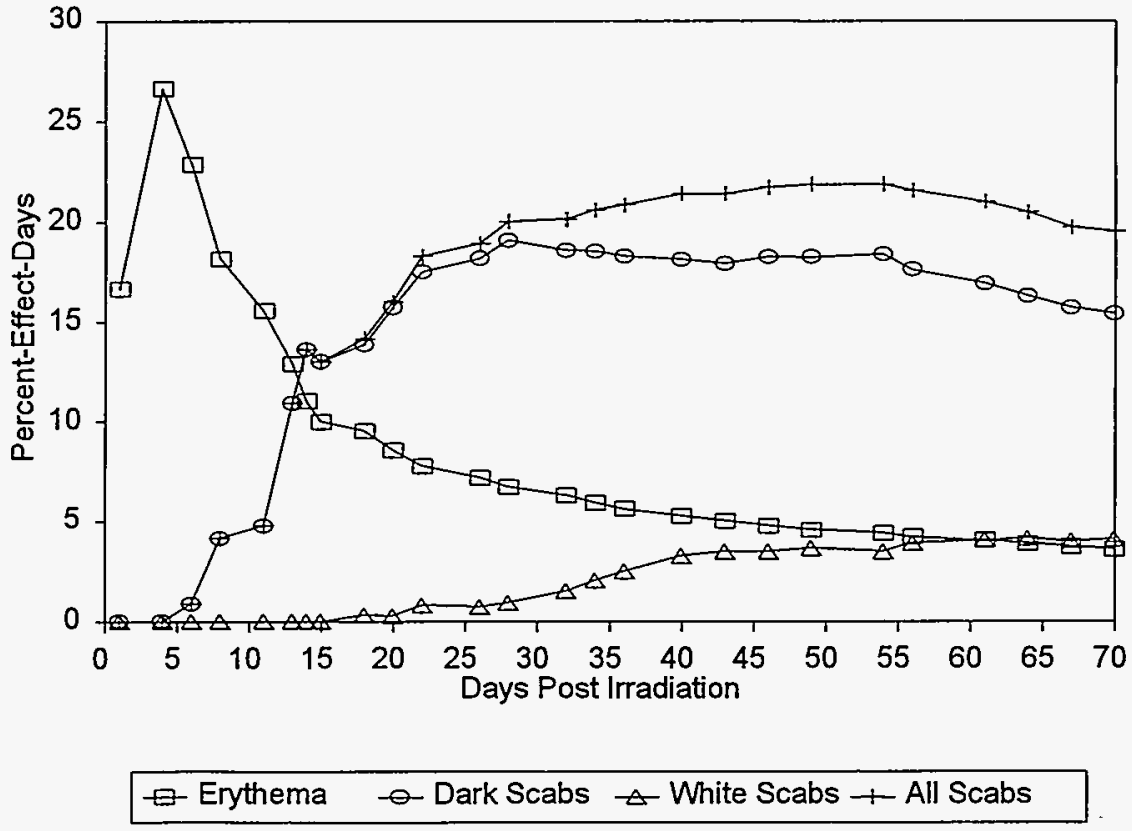

Figure 5.61d Cumulative percent-effect-days for Sc-46 exposures (range 8.8-10.2 Gy). 


\section{Experimental Results}

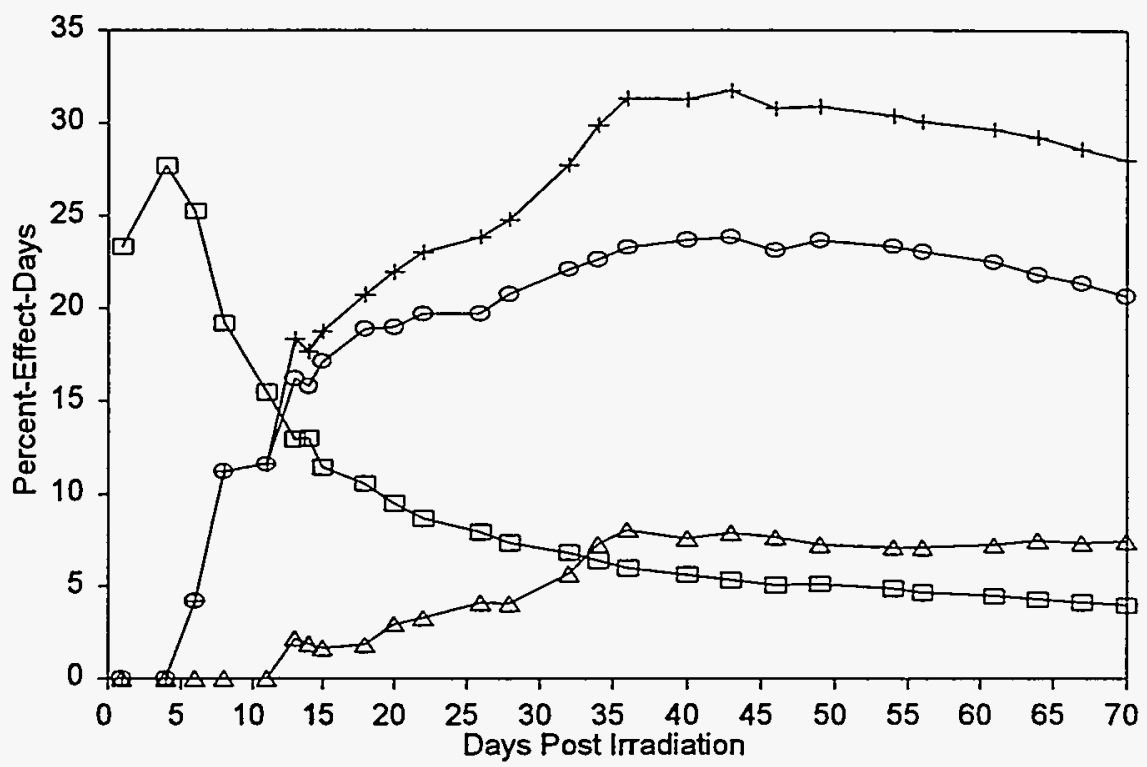

Erythema $\rightarrow$ Dark Scabs $\triangle$ White Scabs + All Scabs

Figure 5.61e Cumulative percent-effect-days for Sc-46 exposures (range 17.5-18.6 Gy).

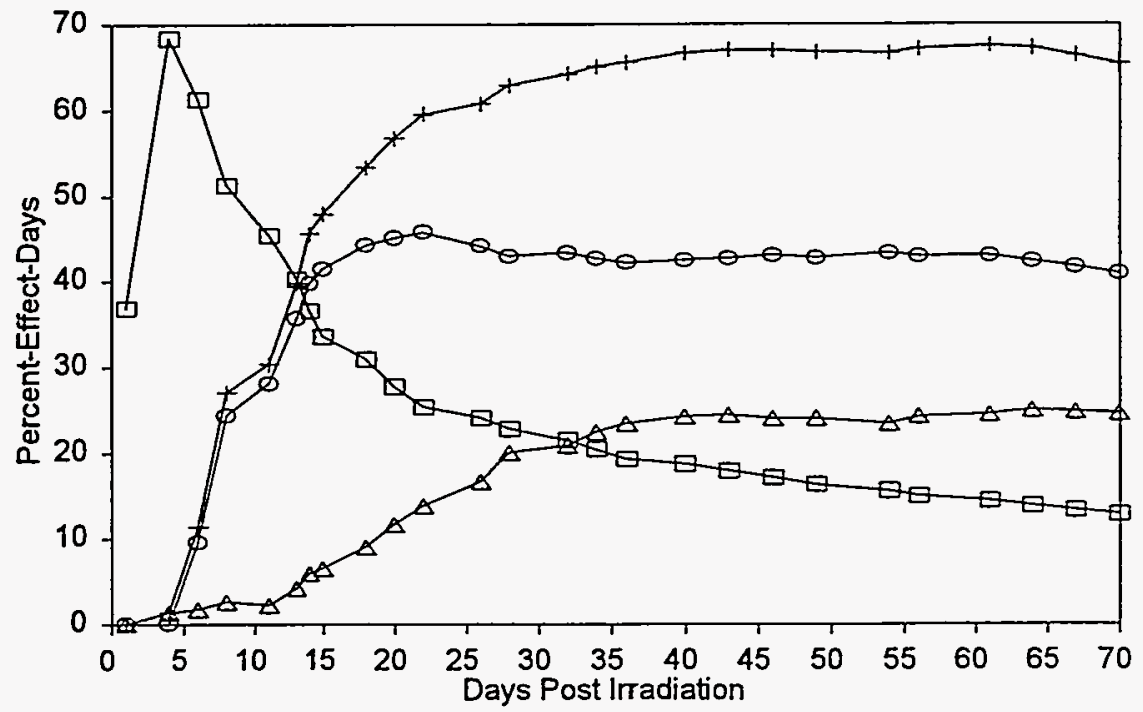

$\square$ Erythema $\multimap$ Dark Scabs $\triangle$ White Scabs + All Scabs

Figure 5.61f Cumulative percent-effect-days for Sc-46 exposures (range 39.0-61.6 Gy). 


\section{Experimental Results}

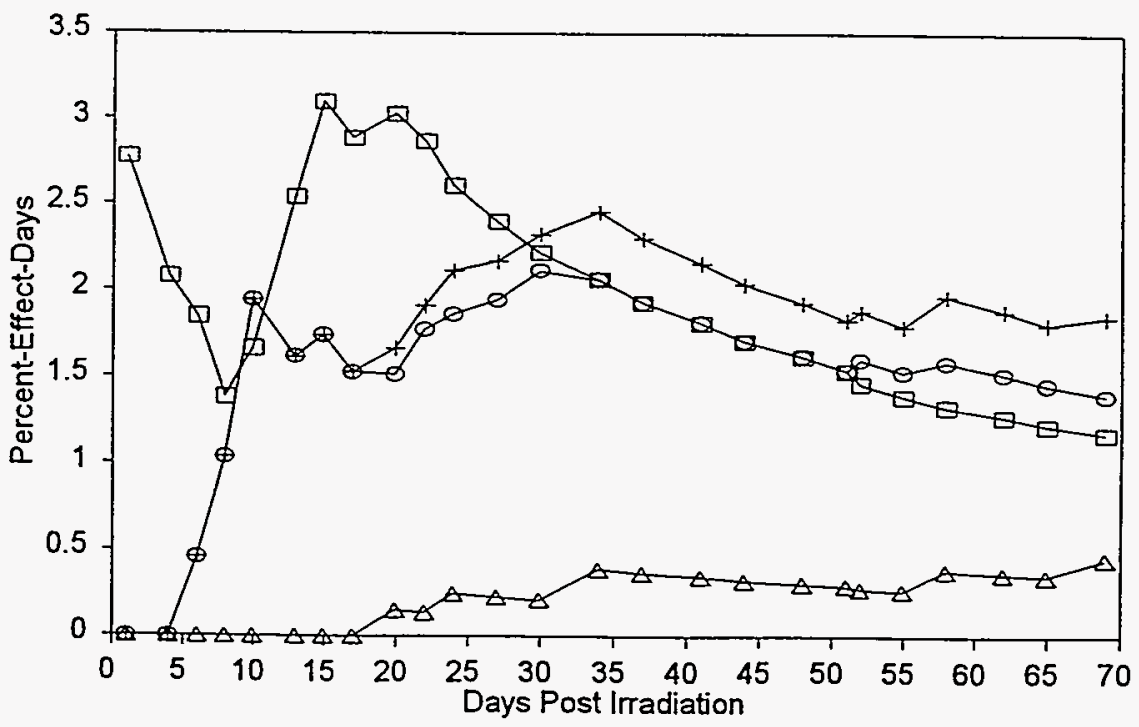

$\square$ Erythema $\odot$ Dark Scabs $\triangle$ White Scabs + - All Scabs

Figure 5.62a Cumulative percent-effect-days for Yb-175 control (zero dose) exposures.

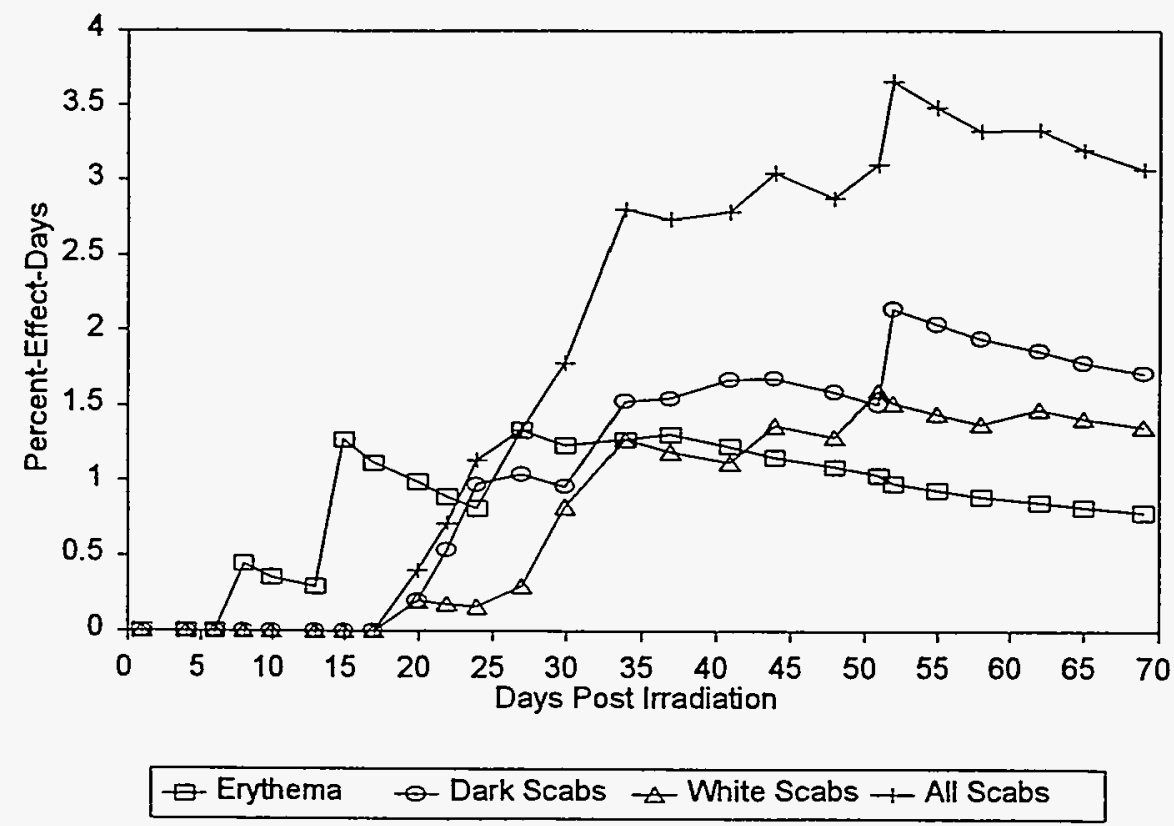

Figure 5.62b Cumulative percent-effect-days for $\mathrm{Yb}-1750.31 \mathrm{~Gy}$ exposures. 


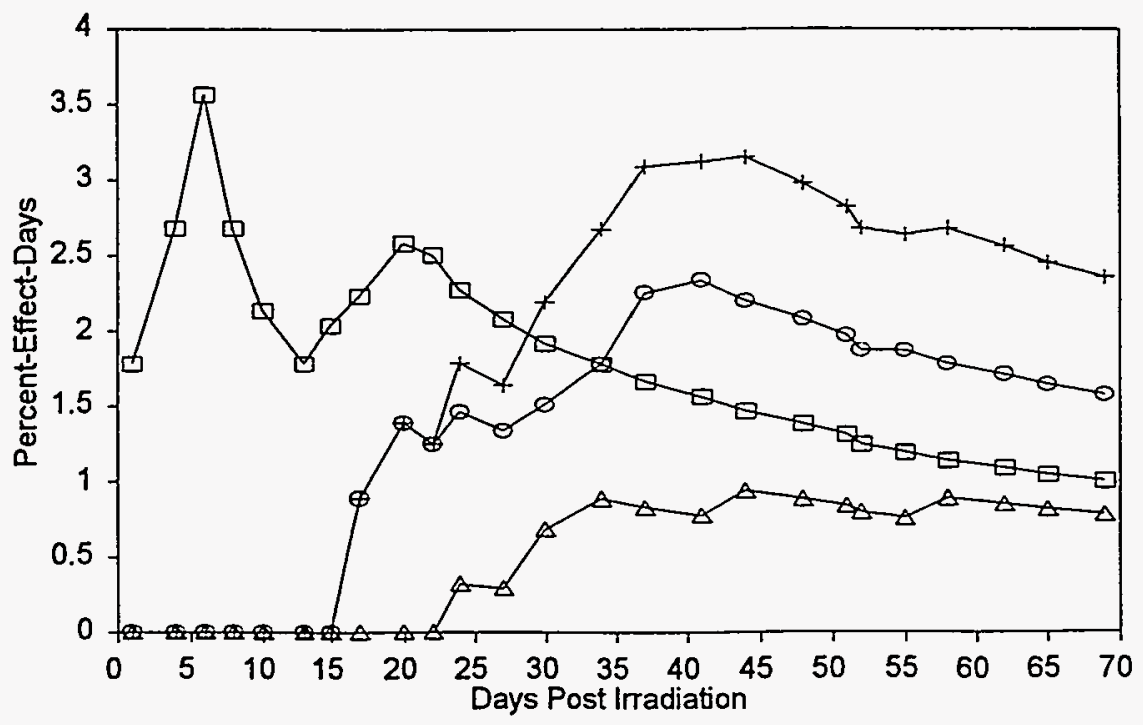

$\oplus$ - Erythema $\odot$ Dark Scabs $\triangle$ White Scabs + All Scabs

Figure 5.62c Cumulative percent-effect-days for $\mathrm{Yb}-175$ exposures (0.60-0.63 Gy).

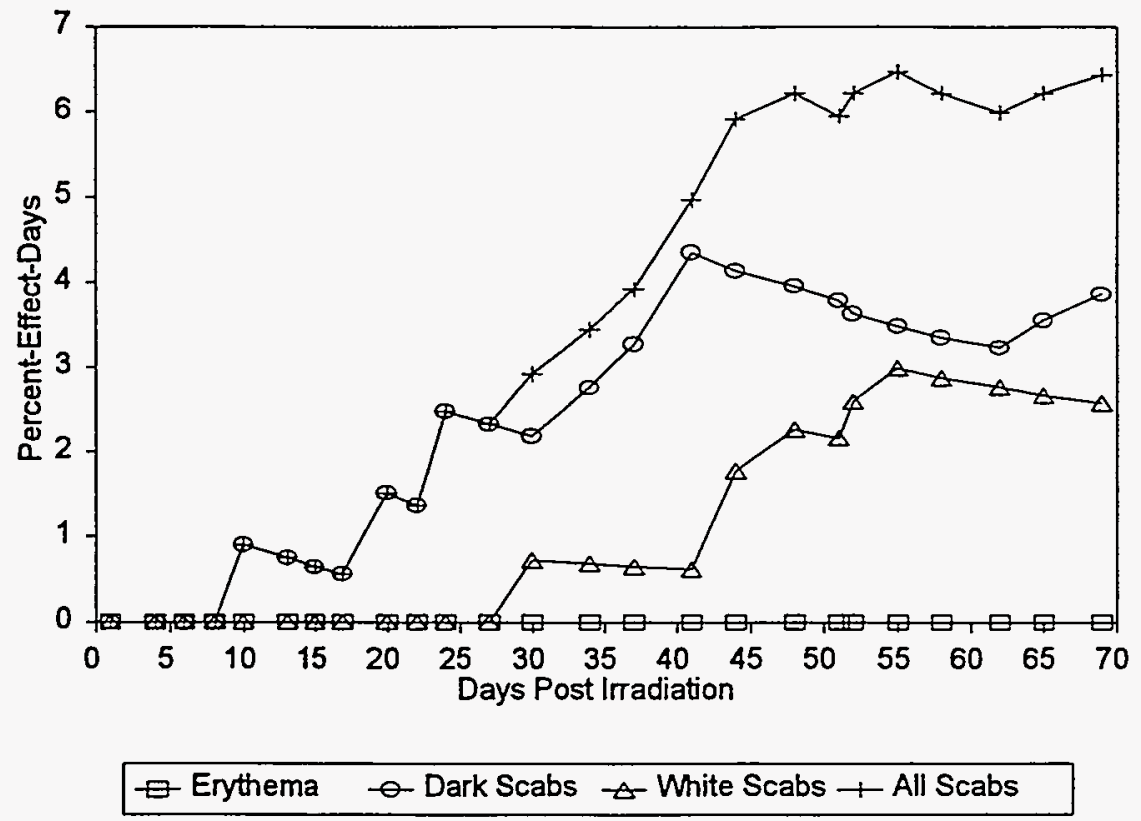

Figure 5.62d Cumulative percent-effect-days for $\mathrm{Yb}-175$ exposures (0.78 Gy). 


\section{Experimental Results}

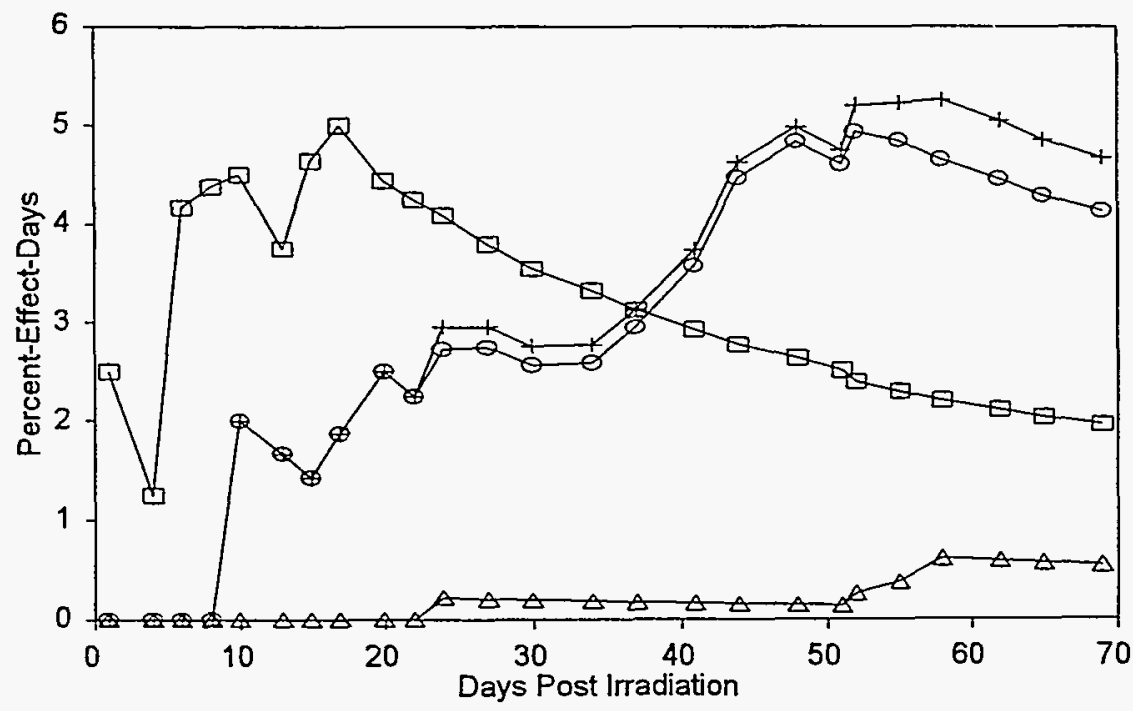

$\triangle$ Erythema $\odot$ - Dark Scabs $\triangle$ White Scabs + All Scabs

Figure 5.62e Cumulative percent-effect-days for $\mathrm{Yb}-175$ exposures (range 1.2-1.4 Gy).

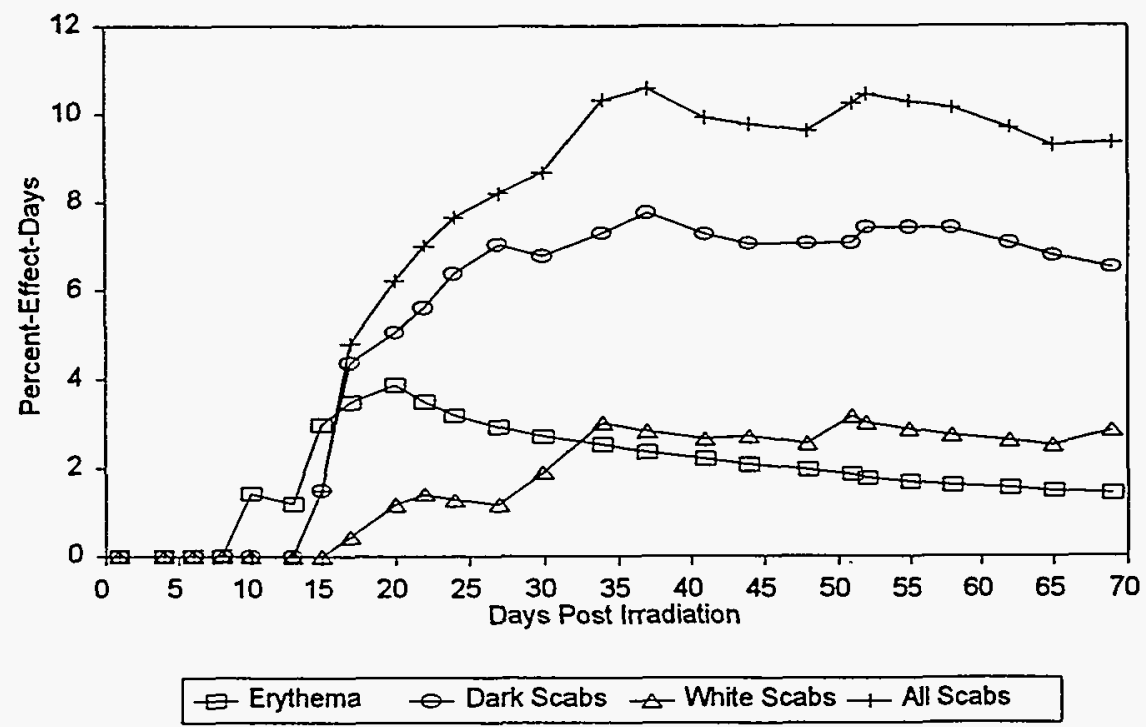

Figure 5.62f Cumulative percent-effect-days for $\mathrm{Yb}-175$ exposures (2.4-2.5 Gy). 


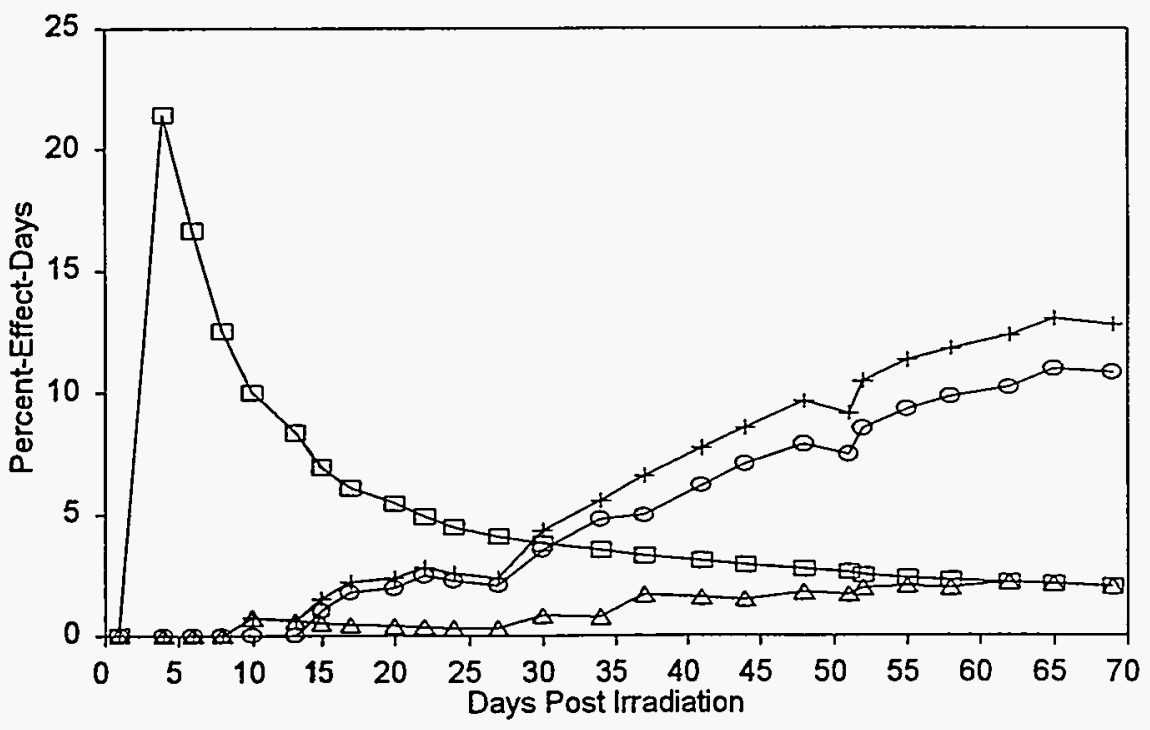

๑ Erythema $\oslash$ - Dark Scabs $\triangle$-White Scabs + All Scabs

Figure 5.62g Cumulative percent-effect-days for $\mathrm{Yb}-175$ exposures (3.7 Gy).

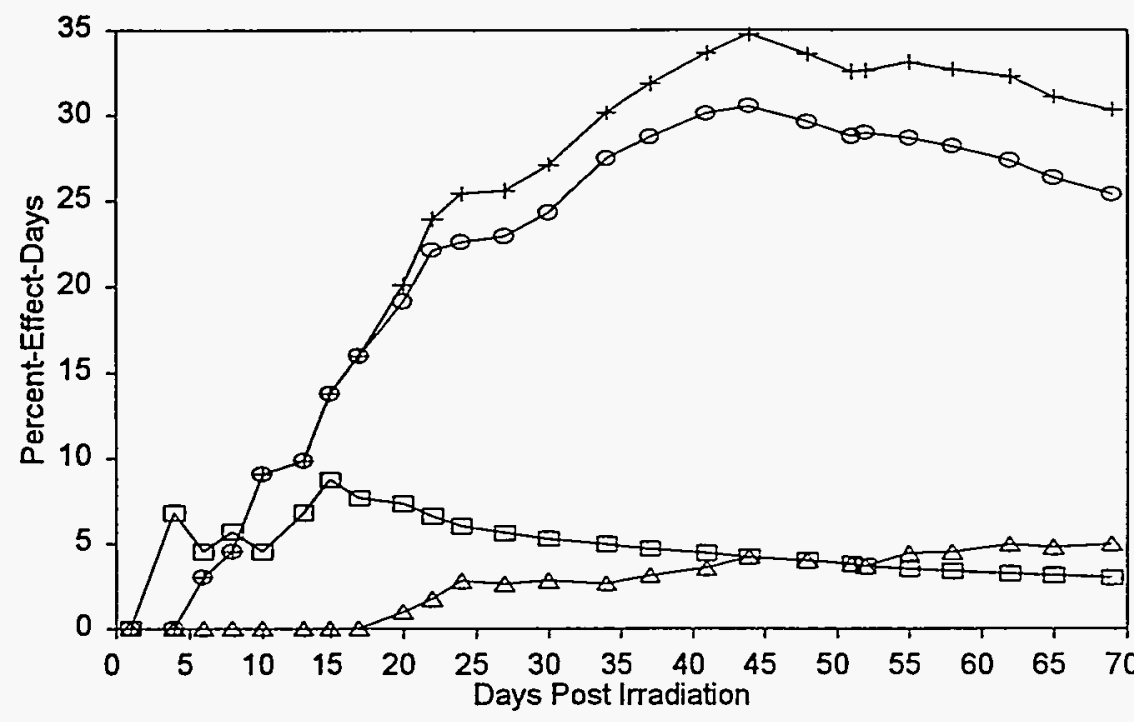

$Ð$ - Erythema $\ominus$ Dark Scabs $\triangle$-White Scabs +- All Scabs

Figure 5.62h Cumulative percent-effect-days for $\mathrm{Yb}-175$ exposures (14.5$14.9 \mathrm{~Gy})$. 


\section{Experimental Results}

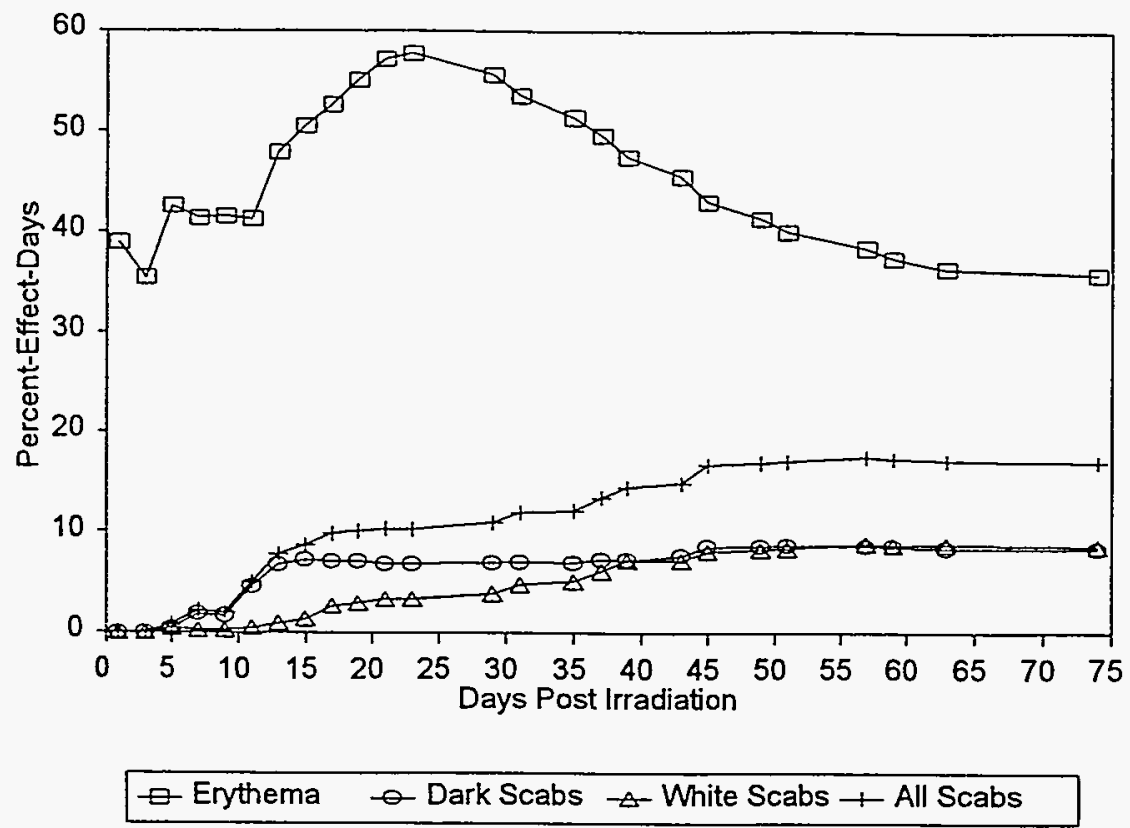

Figure 5.63a Cumulative percent-effect-days for $\mathrm{Tm}-170$ exposures (3 Gy).

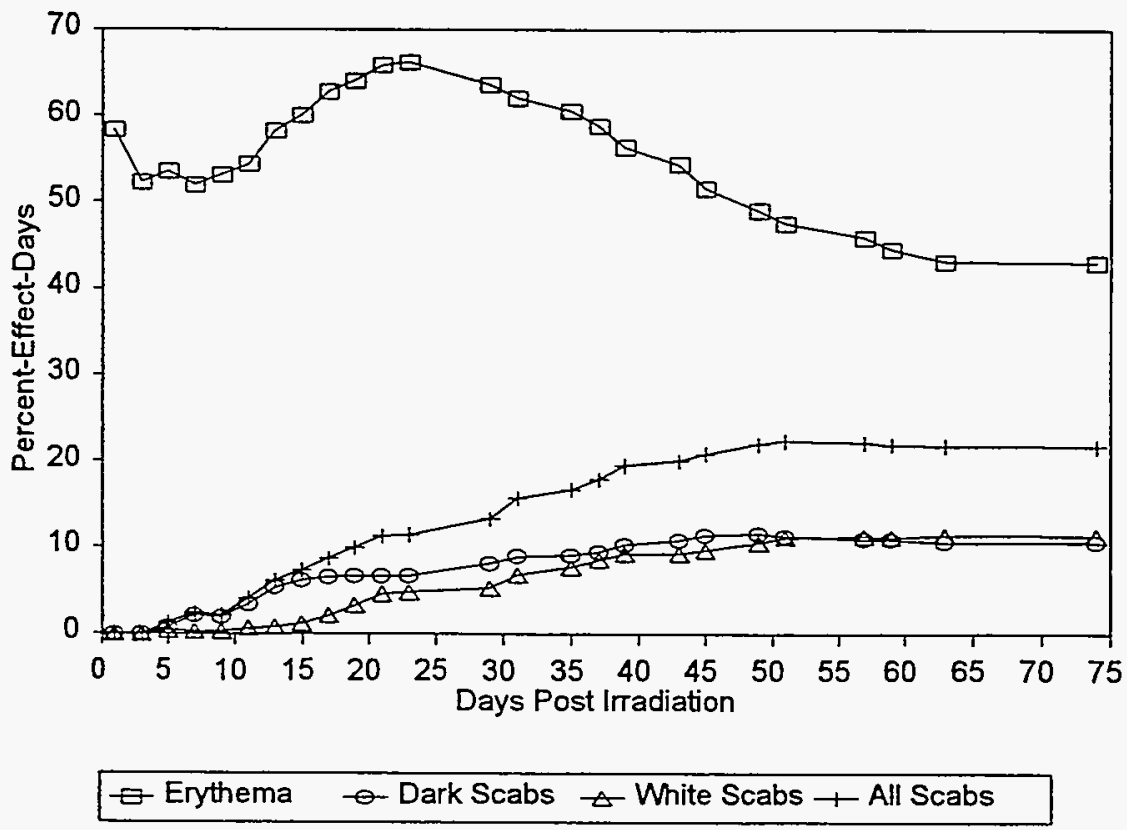

Figure 5.63b Cumulative percent-effect-days for Tm-170 exposures (4.8 Gy). 


\section{Experimental Results}

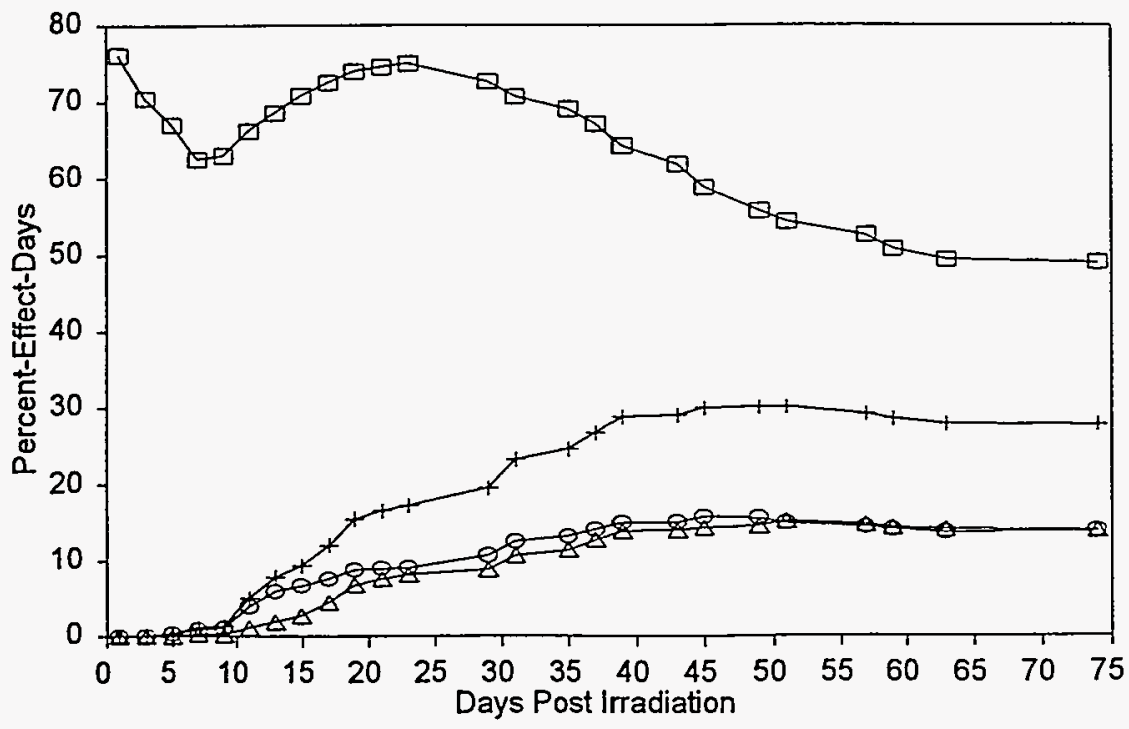

$\sqsubset$ Erythema $\curvearrowleft$ Dark Scabs $\triangle$ White Scabs + All Scabs

Figure 5.63c Cumulative percent-effect-days for $\mathrm{Tm}-170$ exposures (7.7 Gy).

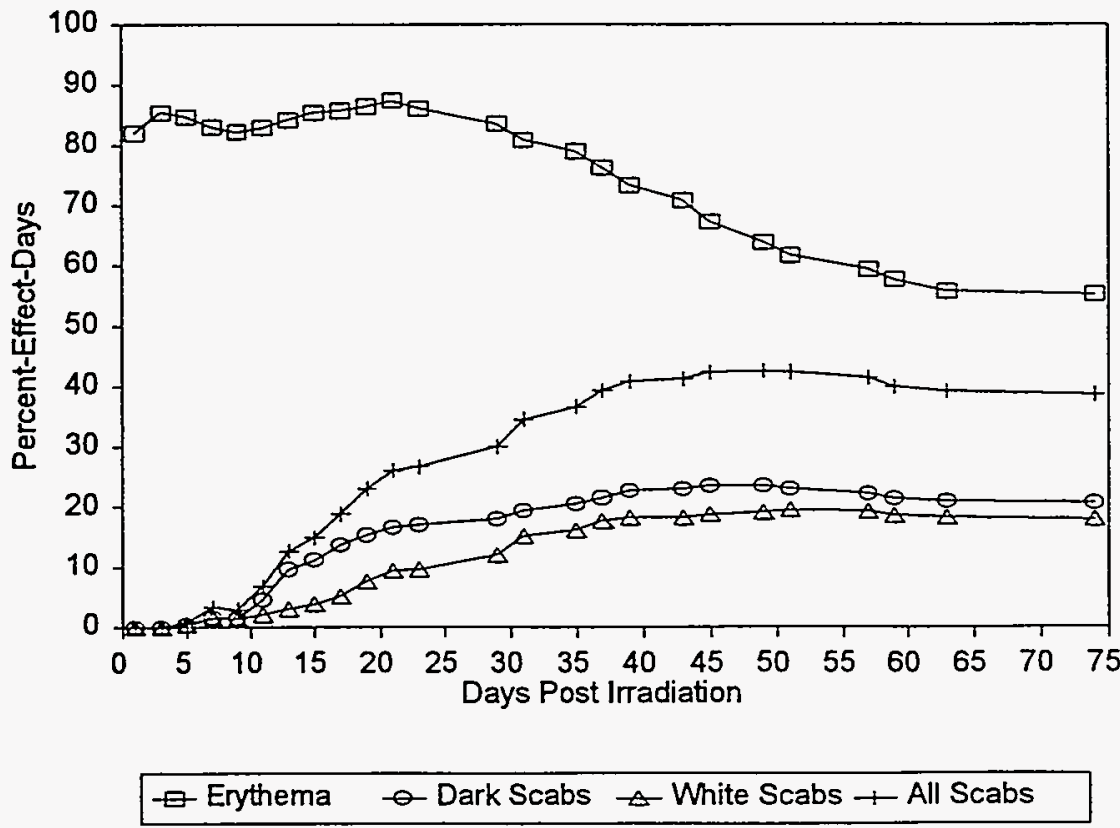

Figure 5.63d Cumulative percent-effect-days for $\mathrm{Tm}-170$ exposures (9.9 Gy). 


\section{Experimental Results}

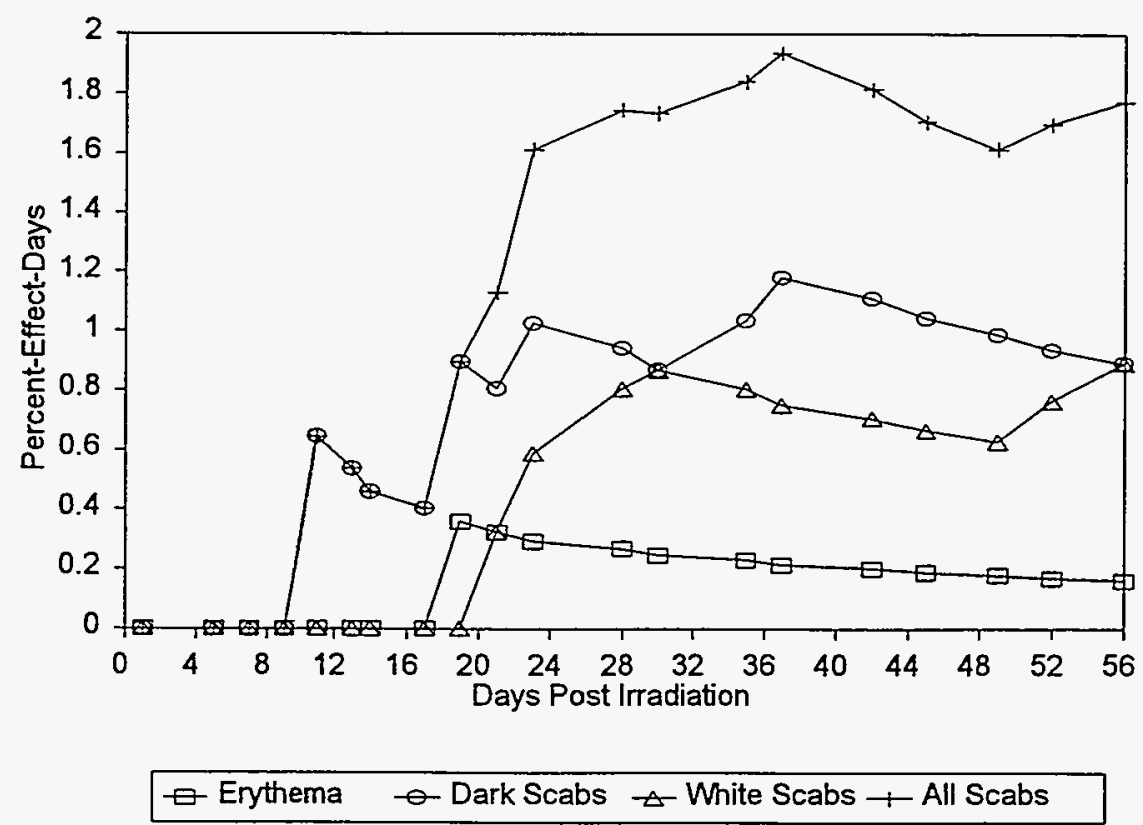

Figure 5.64a $\mathrm{UC}_{2}$ controls ( 0 dose). Cumulative percent effect observed.

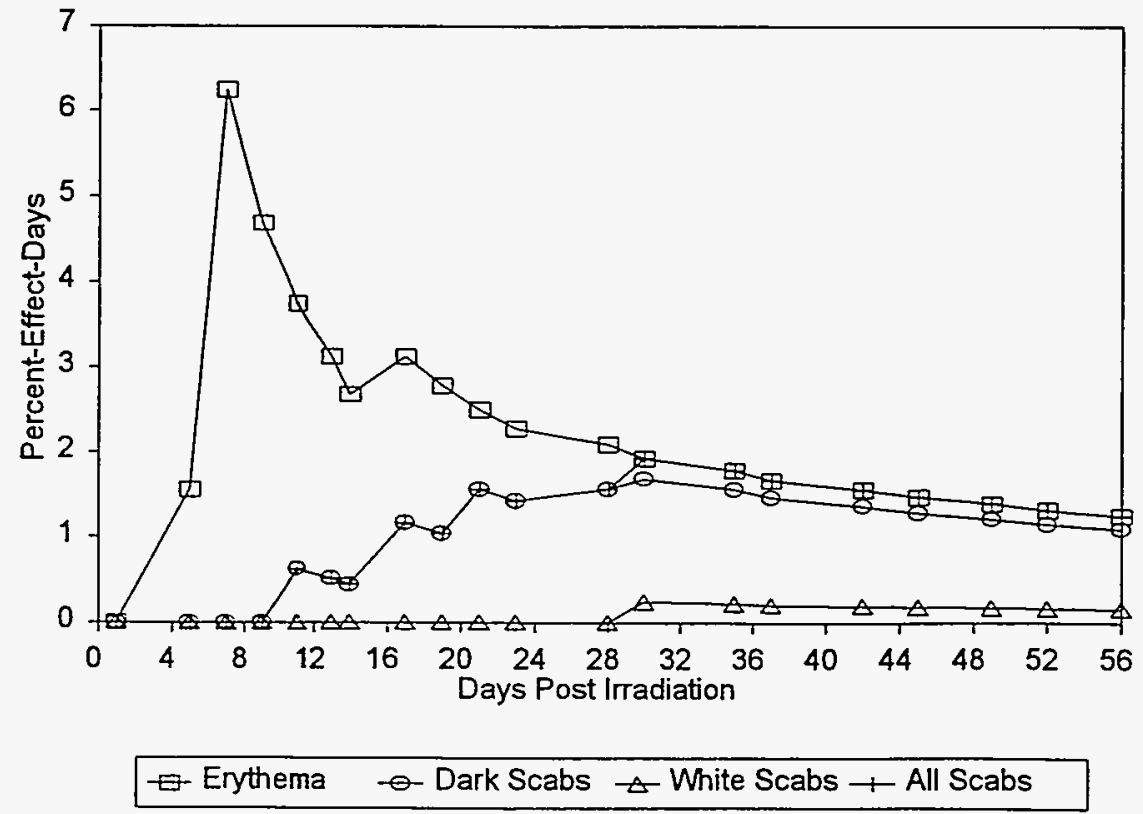

Figure 5.64b $\mathrm{UC}_{2}$ on-skin exposures (avg. $2.21 \mathrm{~Gy}$ ). Cumulative percent effect observed. 


\section{Experimental Results}

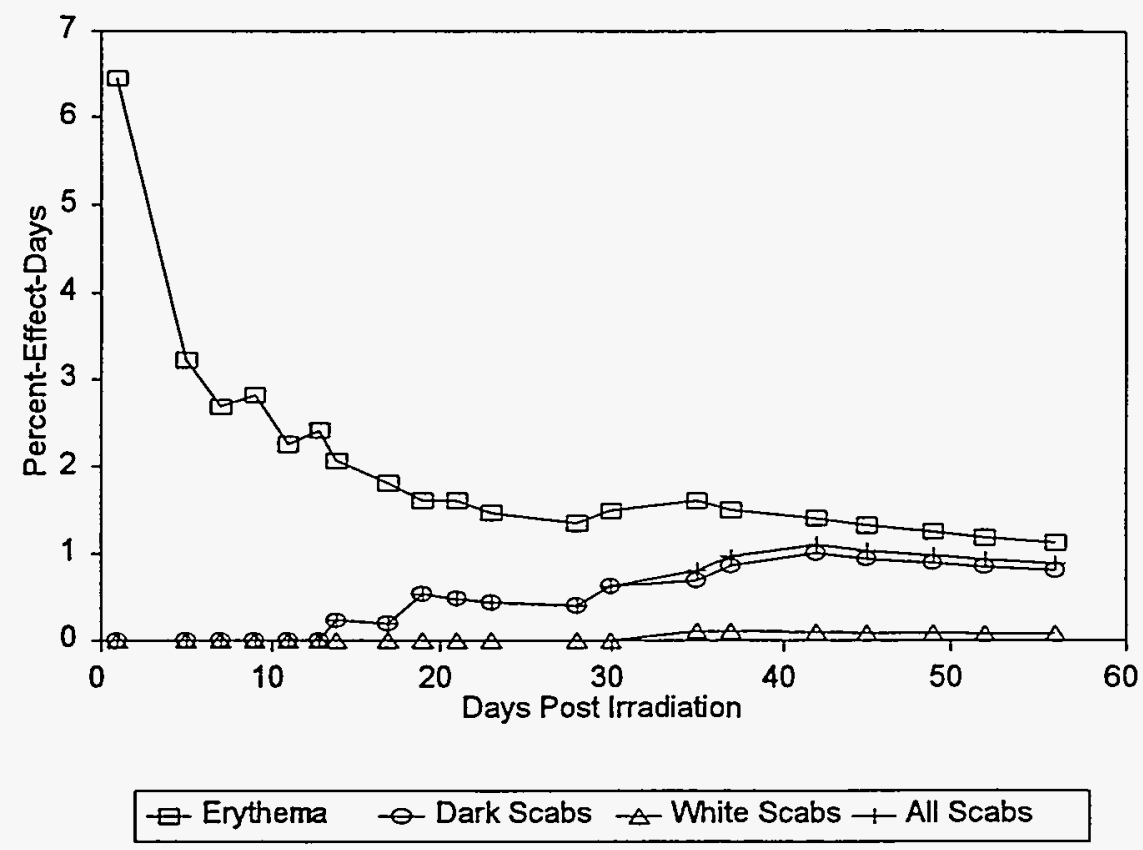

Figure 5.64c Cumulative percent-effect-days for $\mathrm{UC}_{2}$ on-skin exposures (avg. $3.78 \mathrm{~Gy}$ ).

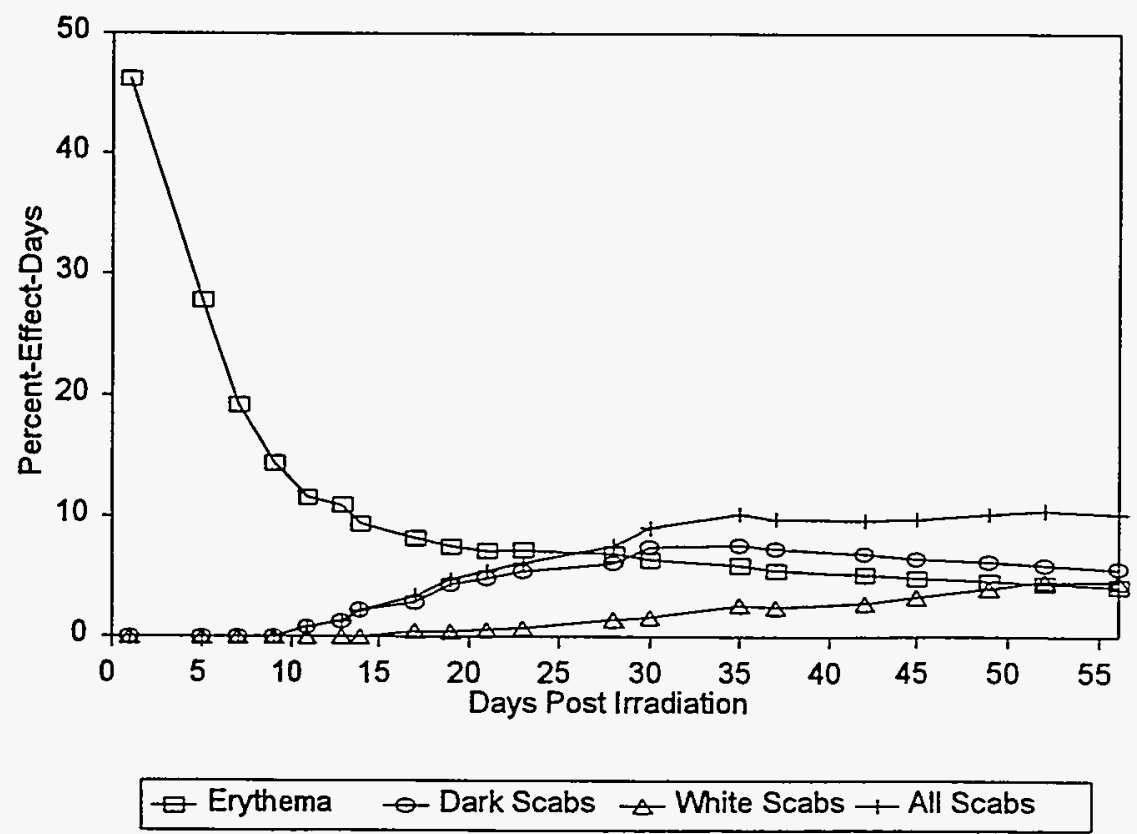

Figure 5.64d Cumulative percent-effect-days for $\mathrm{UC}_{2}$ on-skin exposures (avg. 8.7 Gy). 


\section{Experimental Results}

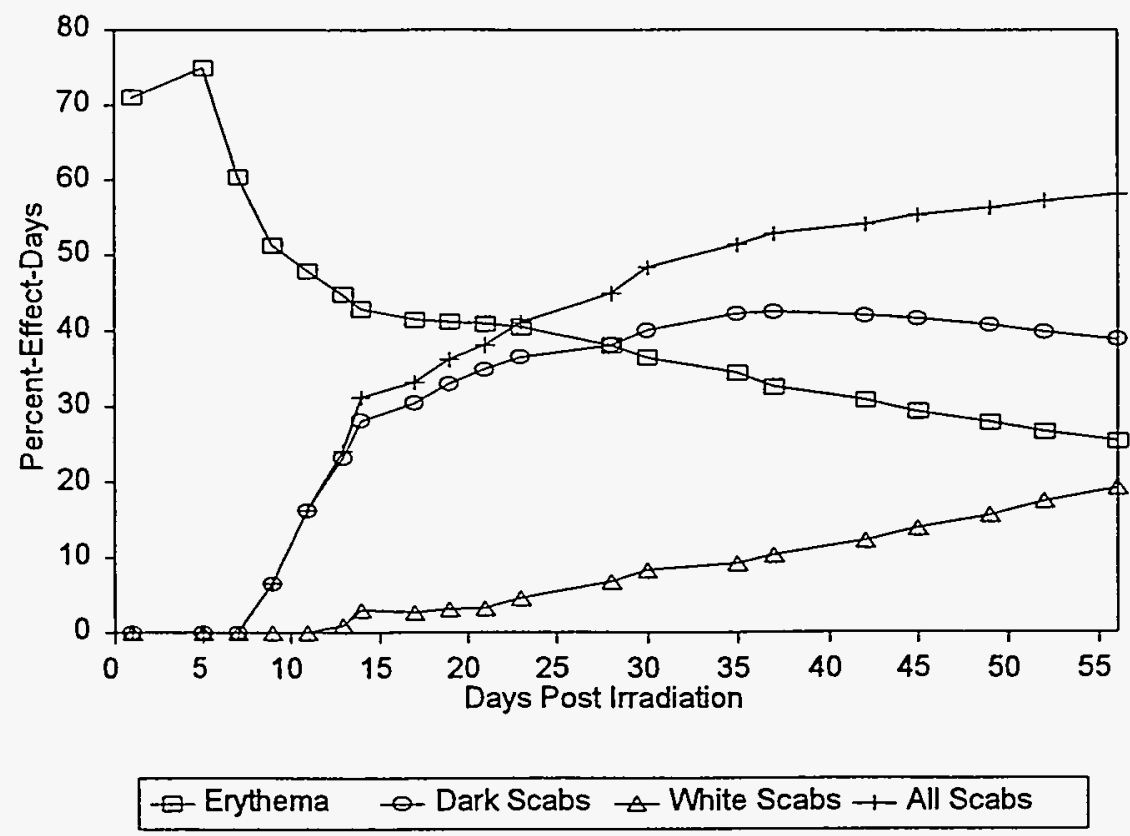

Figure 5.64e Cumulative percent-effect-days for $\mathrm{UC}_{2}$ on-skin exposures (avg. 22.25 Gy).

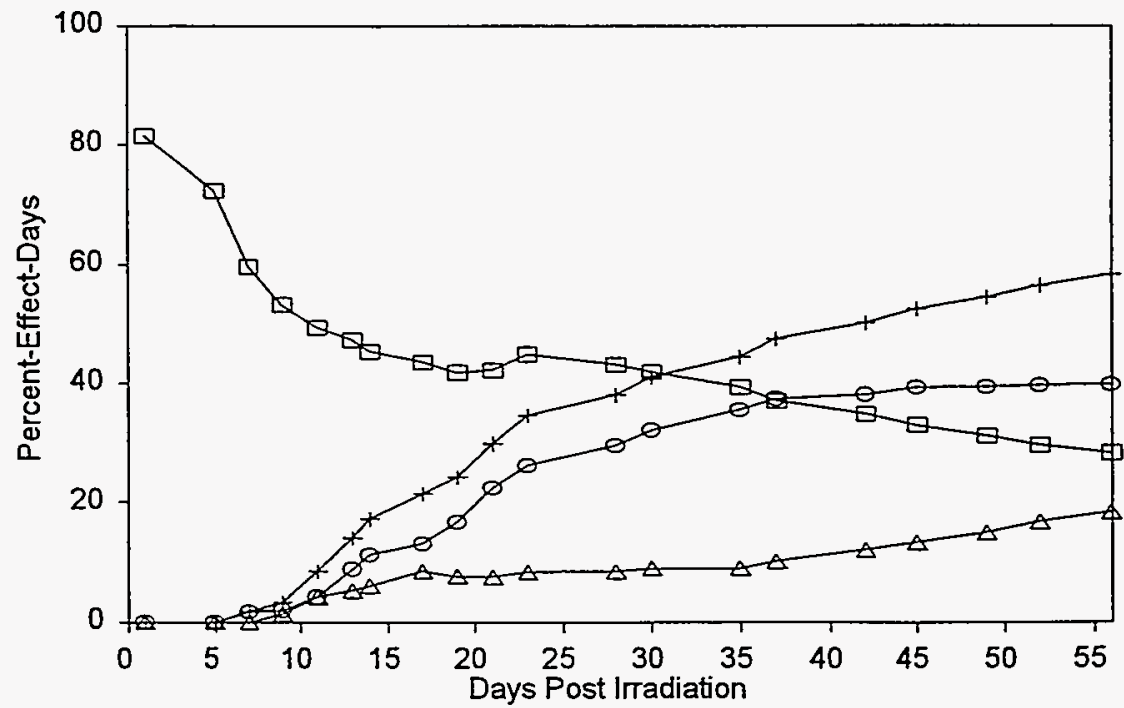

- Erythema $\ominus$ - Dark Scabs $\triangle$-White Scabs $\rightarrow$ All Scabs

Figure 5.64f Cumulative percent-effect-days for $\mathrm{UC}_{2}$ off-skin exposures (avg. 28.82 Gy). 


\section{Experimental Results}

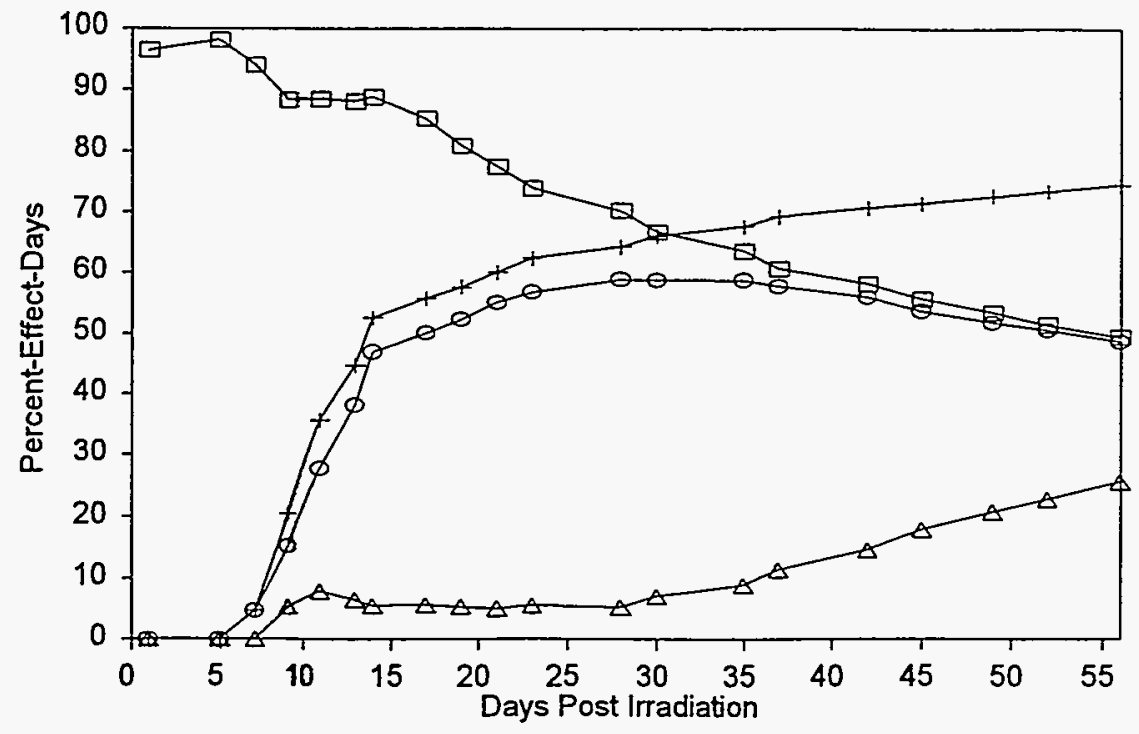

$Ð$ Erythema $\theta$ - Dark Scabs $\triangle$-White Scabs + All Scabs

Figure $5.64 \mathrm{~g}$ Cumulative percent-effect-days for $\mathrm{UC}_{2}$ on-skin exposures (avg. $51.28 \mathrm{~Gy}$ ).

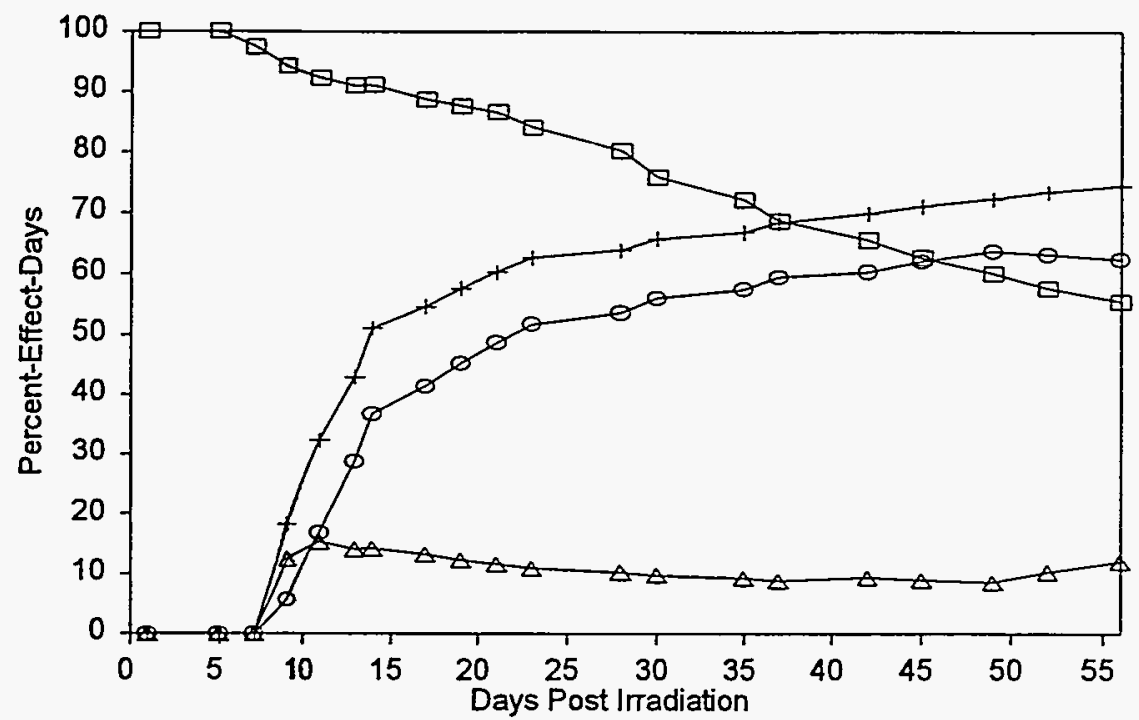

$\square$-Erythema - - Dark Scabs $\triangle$ White Scabs + All Scabs

Figure 5.64h Cumulative percent-effect-days for $\mathrm{UC}_{2}$ off-skin exposures (avg. 64.4 Gy). 


\section{Experimental Results}

The results are plotted as cumulative percent-effect-days as defined above, not percent effect observed on any one day. The values can be thought of as a moving average with days postirradiation.

These data show that erythema usually precedes the detection of scabs; however, due to its relatively short persistence, its effect, measured in percent-effect-days, is less than that for scabs for all exposures except for $\mathrm{Tm}-170$, which consistently showed much larger percenteffect-days for erythema than dark, white, or total scabs (Figure 5.63a-d).

The average frequency of the erythemic response during the entire observation period for the sites exposed to $\mathrm{Tm}-170$ in 1992 was $34,41,46$, and $52 \%$ for the 3.0, 4.8, 7.7, and $9.9 \mathrm{~Gy}$ exposures, respectively; these values are all greater than the $25 \%$ erythema response noted by the same observers for the 7 unirradiated sites on the 3.3-month-old pig irradiated with $\mathrm{Yb}-175$, discussed in Section 5.5. Since this Tm-170 experiment was conducted before we understood the need for background areas, the background response for the $\mathrm{Yb}-175$ pig could be used as a less-than-ideal, but perhaps representative, adjustment factor for the erythemic observations.

A comparison between erythema induced by hot particles and external X-ray exposure can be made. The Tm-170 erythemic response exhibiting a gradual increase and gradual decrease is similar to that seen in pigs for acute X-ray doses in the range of $17.5 \mathrm{~Gy}$ (Fowler et al., 1963, in Hall, 1988). The Tm-170 response also indicates a secondary wave of erythema beginning on $13,13,9$, and $11 \mathrm{DPI}$ for $3.0,4.8,7.6$, and 9.9 Gy exposures, respectively. The erythemic response in pig skin for $X$ rays is not evident for acute 17.5 Gy exposures until about $11 \mathrm{DPI}$ with a secondary response around 35 DPI (Fowler et al., 1963, in Hall, 1988).

While erythema may always precede observation of a scab, the observation frequencies employed in these studies were not sufficient to demonstrate this, presumably because erythema may be very transient and easily missed, especially at low doses.

\subsection{Intercomparison of BNL Studies}

Comparisons between scab-diameter regression thresholds and scab incidence $E D_{10} s$ were made for $\mathrm{UC}_{2}$ and Tm-170 data as a function of the pig's age (Figure 5.65). The error bars for the scab-diameter regressions are for one standard deviation, and the error bars for $E D_{10}$ values are for two standard deviations ( $95 \%$ confidence). For experiments in which both scab-diameter regressions and probit scab-incidence regressions were carried out, the uncertainty for the scabdiameter and scab-incidence regressions are to the right and left of the data point, respectively.

The scab diameter thresholds for $\mathrm{UC}_{2}$ and $\mathrm{Tm}-170$ ranged from 4.4 to 9.1 and 0.89 to $5.6 \mathrm{~Gy}$, respectively, with substantial uncertainty in the estimates. Also, there is no apparent dependence on the animal's age for the scab-diameter regression thresholds. In experiments 1 and 2 using $\mathrm{UC}_{2}$, a 13- $\mu$ m-thick polyethylene cover was used on the sources. In both experiments 6 and 7 using Tm-170, a particle cover of only 13- $\mu m$-thick Kapton was used. For experiment 3 , the $\mathrm{Tm}-170$ particles were covered with $13 \mu \mathrm{m}$ of polyethylene and $47 \mu \mathrm{m}$ of 


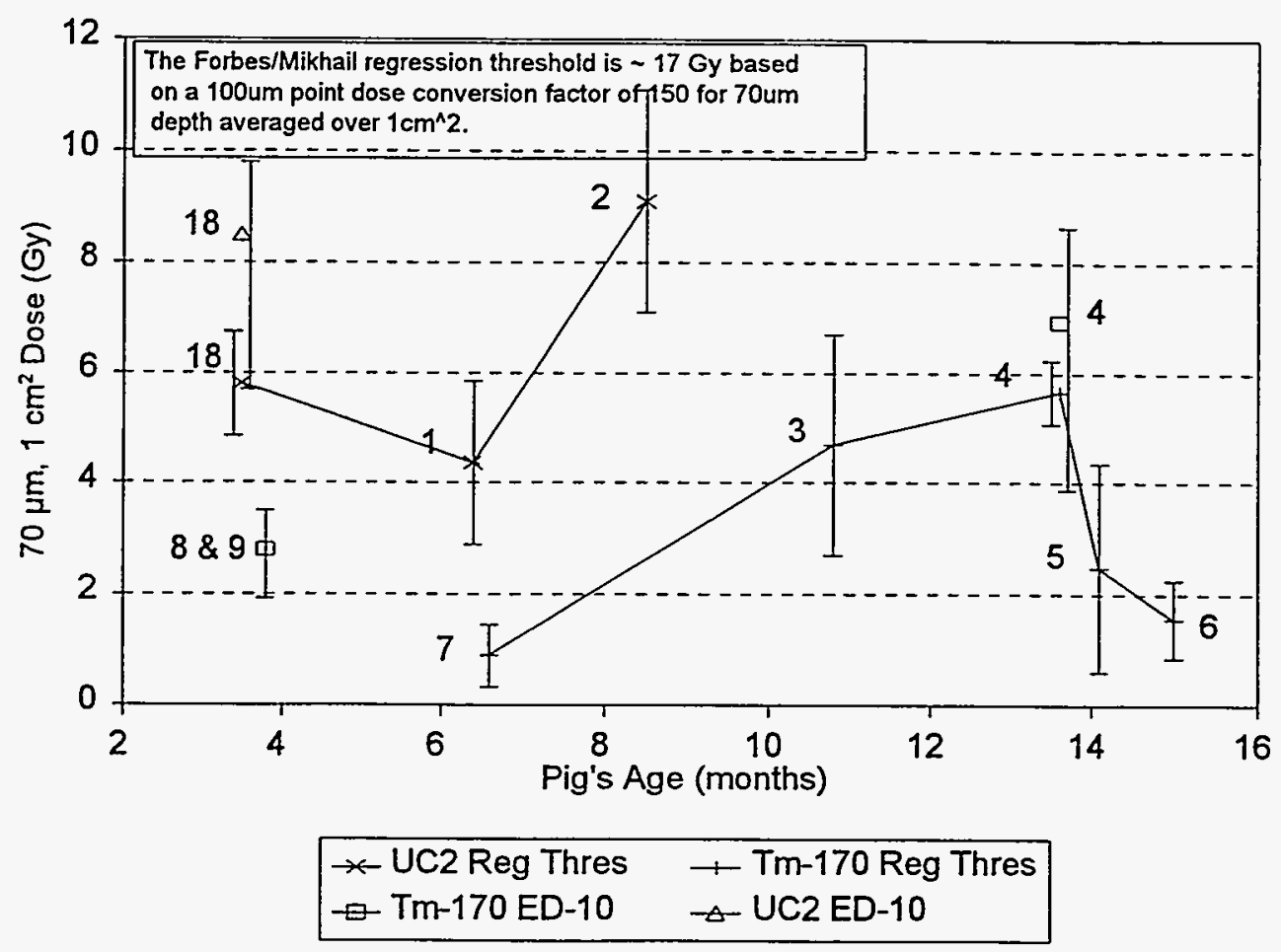

Figure 5.65 Scab-diameter regression thresholds and $E D_{10}$ values for $U C_{2}$ and $\mathrm{Tm}-170$ as a function of pig's age. Experiment numbers are indicated beside data points. The error bars for the scabdiameter regressions (passing through the value or to the left of the value) are for 1 sigma (multiplying by a factor of two would give approximately $95 \%$ confidence). The error bars for the $E D_{10}$ values (passing through the value or to the right of the value) are for $95 \%$ confidence. The $\mathrm{ED}_{10}$ value for a 9.6 month-old pig exposed to $\mathrm{Tm}-170$ is highly uncertain (Figure 5.29) and therefore is not plotted.

transparent tape. For experiments 4 and 5, the Tm-170 particles were covered with $13 \mu \mathrm{m}$ of polyethylene, $47 \mu \mathrm{m}$ of transparent tape, and $13 \mu \mathrm{m}$ of Kapton.

The $E D_{10}$ incidence data for $\mathrm{Tm}-170$ provides a somewhat more coherent data set than the scab-diameter regressions (Figure 5.65). Both 3.8-month-old pigs yielded an $E D_{10}$ at $3.8 \mathrm{~Gy}$ and an $\mathrm{ED}_{50}$ at about $5.9 \mathrm{~Gy}$ averaged over $1 \mathrm{~cm}^{2}$ at a depth of $70 \mu \mathrm{m}$ (comparison not shown). The 9.6-month-old pig had an $\mathrm{ED}_{50} \mathrm{scab}$ incidence between 7.6 and $21 \mathrm{~Gy}$ (Figure 5.29). The 13.6month-old pig irradiated for experiment 4 had an $E_{10}$ at $6.9 \mathrm{~Gy}$ and an $\mathrm{ED}_{50}$ at $11 \mathrm{~Gy}$, twice the doses needed for the 3.8-month-old pig. 


\section{Experimental Results}

The Tm-170 ED 10 value for the older pig is significantly different from the young pigs (95\% confidence intervals do not overlap) (Figure 5.65). The greater $E D_{10}$ and $E D_{50}$ values may be due to either an animal-to-animal difference or to the additional containment covers of $13 \mu \mathrm{m}$ polyethylene and $47 \mu \mathrm{m}$ transparent tape discussed in the regression dose response, above.

The effects of off-skin irradiations had a regression threshold greater than, or equal to, the regression threshold of on-skin particles (Figures 5.16 and 5.30). This result and those presented previously (Section 5.8) are somewhat ambiguous as to off-skin $U_{2}$ particles having a lower $E D_{10}$ than on-skin $U_{2}$ particles.

A plot similar to Figure 5.65 for Sc-46 and $\mathrm{Yb}-175$ could not be made because only one older pig was irradiated with $\mathrm{Yb}-175$ irradiation; all the other pigs used were 3- to 4-months old. Most of the exposures for the Tm-170 and $\mathrm{UC}_{2}$ scab-diameter threshold given in Figure 5.65 were also for $100 \%$ incidence. The $\mathrm{Yb}-175$ and $\mathrm{Sc}-46$ exposures were primarily designed to determine the incidence rather than the diameter of scabs. Thus, multiple sites were given the same dose. The $\mathrm{X}$-axis intercept for a scab-diameter regression determined from this type of data is heavily influenced by the lowest dose used in the regression (Section 4.2.1) and introduces significant bias into the determination of the scab-threshold (see Table 6.1 for the $U_{2} C_{2}$ intercepts for experiments 18 and 19 using doses greater than 3.8 and $8.0 \mathrm{~Gy}$ ). This fact also implies that the thresholds for scab-diameter regression given in Figure 5.65 for the irradiations carried out for experiment 4 using Tm-170 and for experiment 18 and 19 using $\mathrm{UC}_{2}$ should be cautiously interpreted when compared with thresholds from other $100 \%$ scab-incidence experiments.

\subsection{Scab Onset and Persistence}

One measure of unacceptable damage caused by a hot particle is persistence of the scab. If the scab only persists for a few days, it is less likely to become infected and would be less objectionable cosmetically. The persistence and time of first appearance of the scab may also indicate the degree of damage. Preliminary analyses were made for both parameters.

The time-of-onset of the scab was noted by the first DPI of scab occurrence and is given in Figures 5.66 to 5.70 for on- and ofi-skin $U_{2}, T m-170, Y b-175$, and Sc-46. The first DPI of scab occurrence is the first observation day on which the scab was seen, with the observation on the next observation day resulting in the scab being considered radiation-induced by Method $B$. Time-of-onset decreased with increase in dose, as is supported by the late occurring scabs seen for the lower dose data.

The persistence of the scab also was measured, as the number of days between time-of-onset and the last day it was observed. This was investigated from the 1991-92 data sets. For these analyses, scabs were scored as radiation-induced if they were observed by two observers on at least three observations in the entire observation period (Method E).

Scabs produced by higher dose on-skin particles, $U_{2}$ in particular, persist less than those caused by off-skin $U_{2}$ hot particles (Figure 5.71). (The latter were held $0.44 \mathrm{~mm}$ off the skin 


\section{Experimental Results}

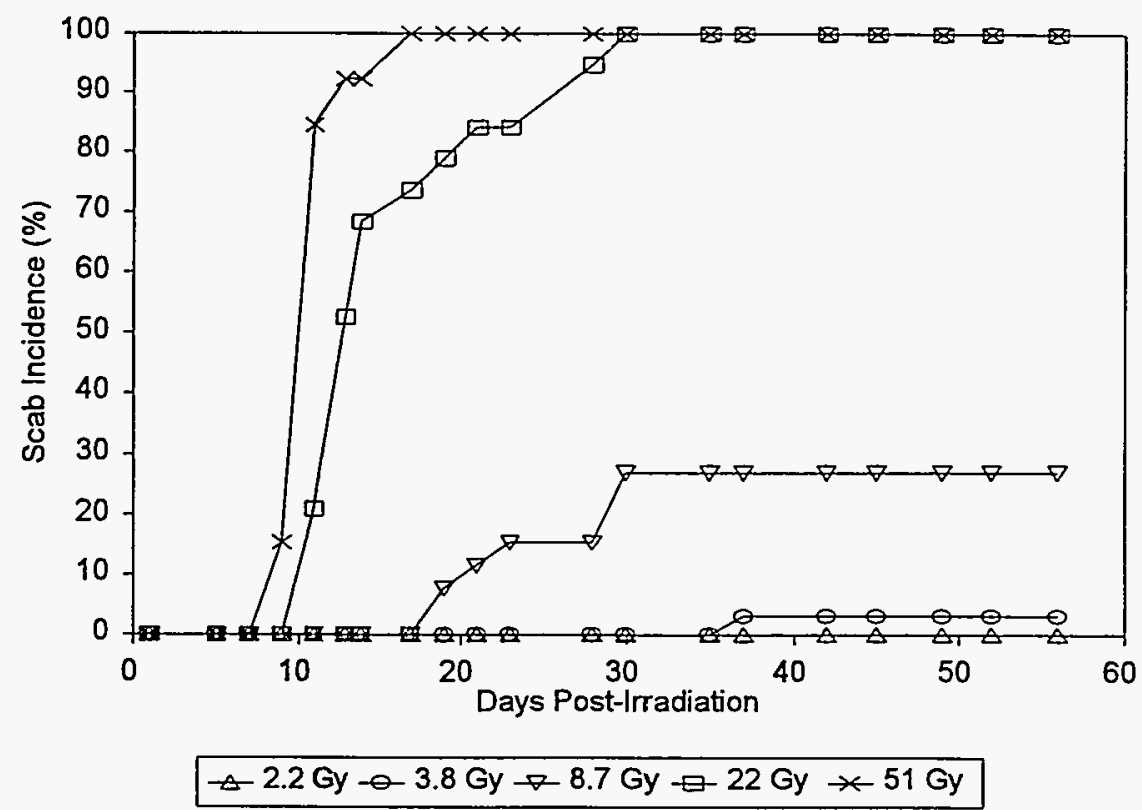

Figure 5.66 Time-of-onset of scabs using scoring Method B for replicate exposures at selected doses from on-skin $\mathrm{UC}_{2}$ hot particles.

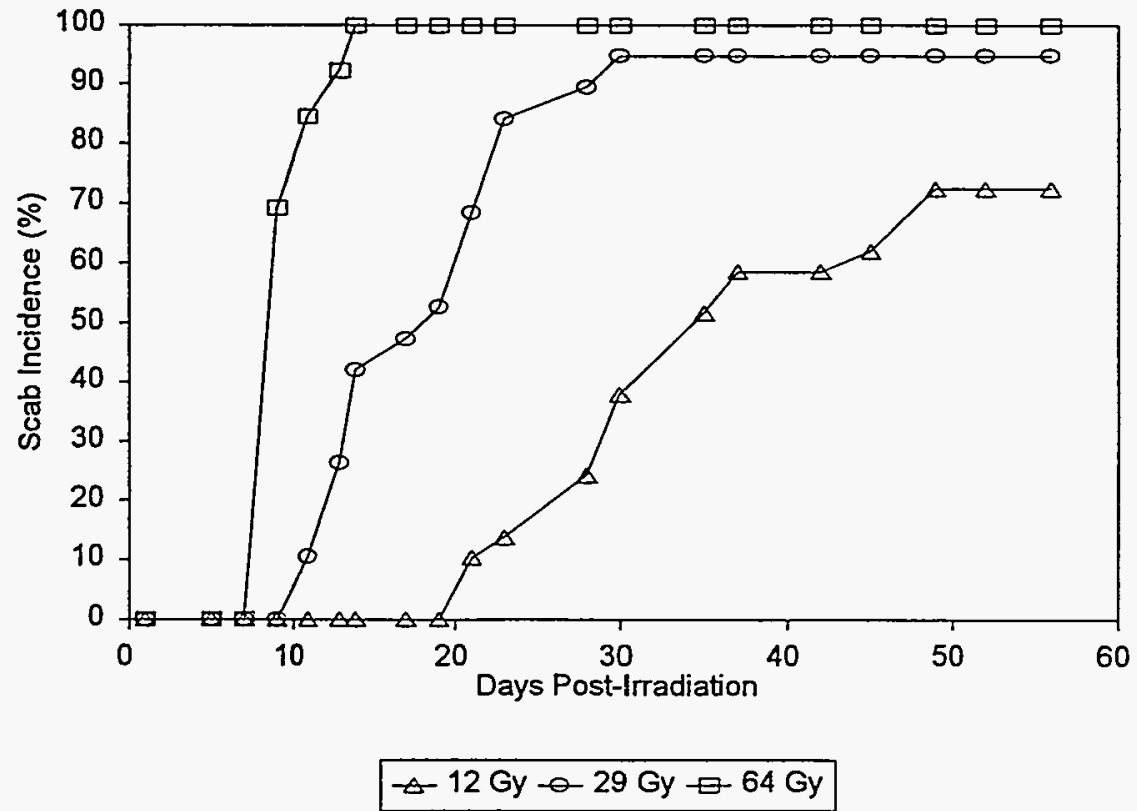

Figure 5.67 Time-of-onset of scabs using scoring Method B for replicate exposures at selected doses from off-skin $U_{C_{2}}$ hot particles. 


\section{Experimental Results}

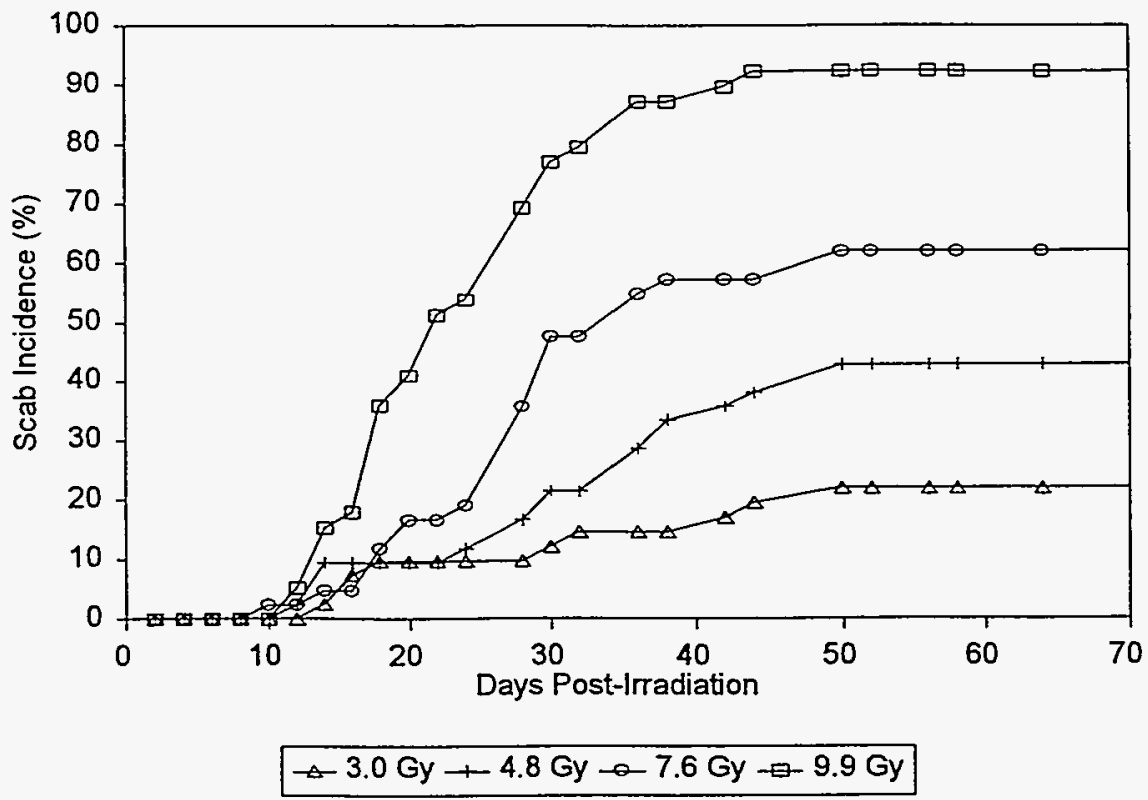

Figure 5.68 Time-of-onset of scabs using scoring Method B for replicate exposures at selected doses from on-skin Tm-170 hot particles.

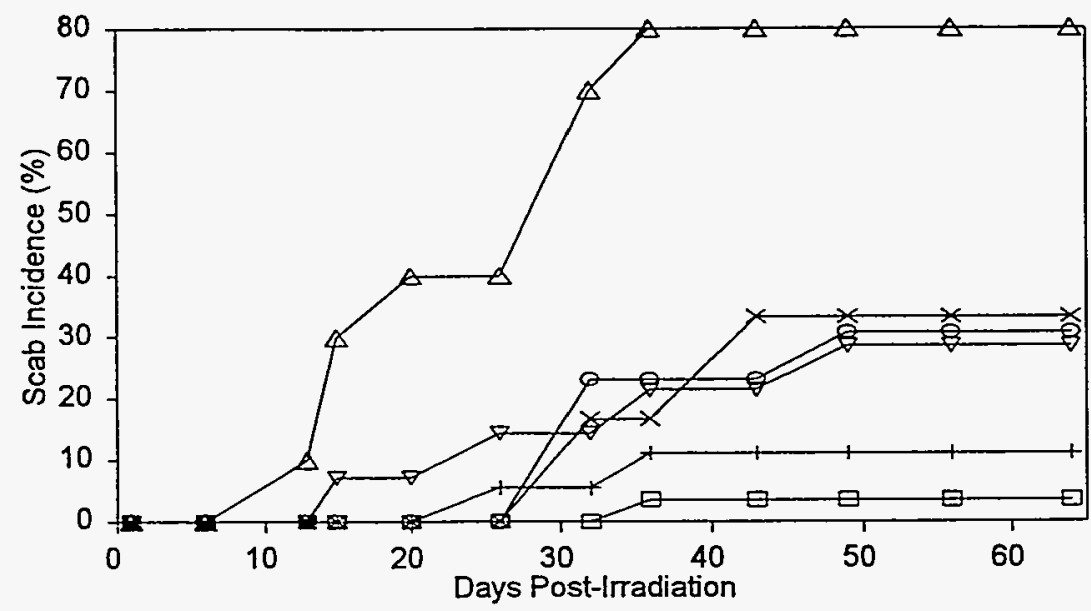

$\because 0.63 \mathrm{~Gy} * 0.78 \mathrm{~Gy}+1.2 \mathrm{~Gy} \rightarrow 2.4 \mathrm{~Gy} \rightarrow 3.7 \mathrm{~Gy} \triangle 14 \mathrm{~Gy}$

Figure 5.69 Time-of-onset of scabs using scoring Method B for replicate exposures at selected doses from on-skin $\mathrm{Yb}-175$ particles. 
Experimental Results

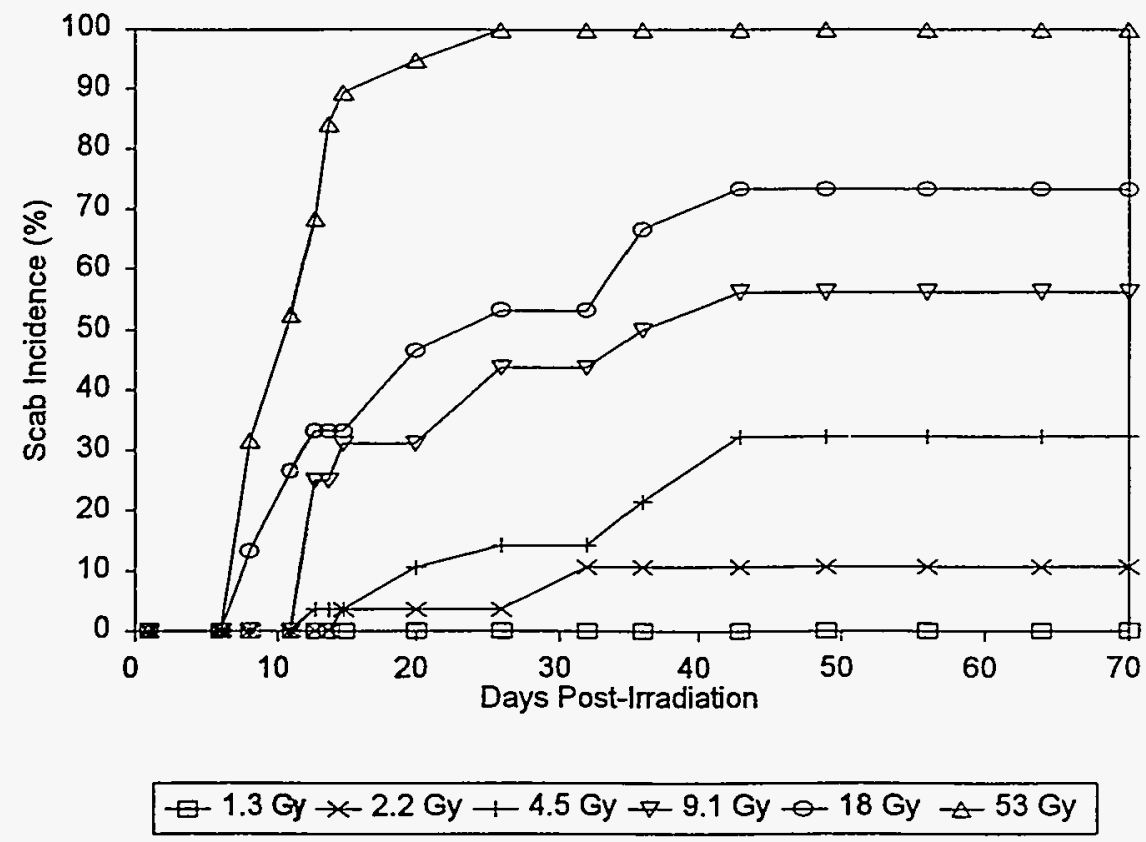

Figure 5.70 Time-of-onset of scabs using scoring Method B for replicate exposures at selected doses from on-skin Sc-46 hot particle.

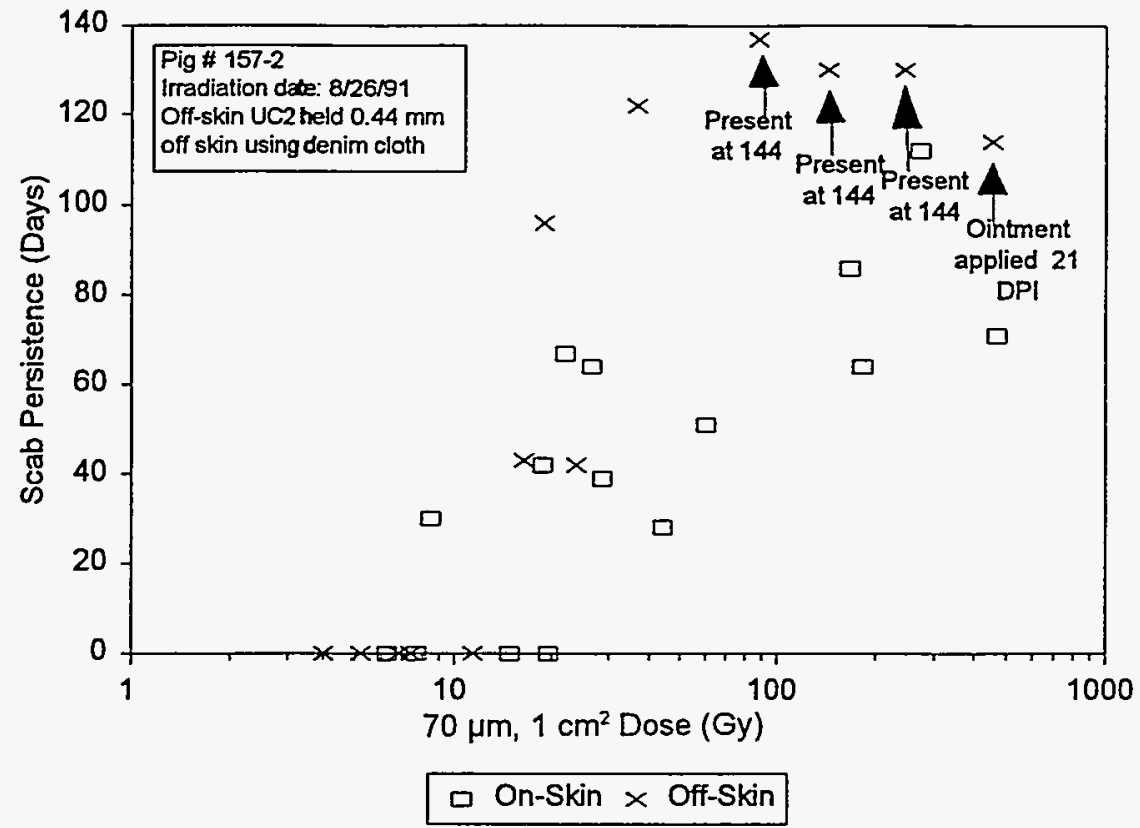

Figure 5.71 Scab persistence for on- and off-skin $U_{2}$ irradiations in experiment 2. Three scabs were still present at $144 \mathrm{DPl}$ when observations were discontinued. Persistence covers the time between the first and last sighting of the scab. 


\section{Experimental Results}

using denim cloth.) On-skin $U \mathrm{C}_{2}$ radiation-induced scabs for doses between 8.5 and $44 \mathrm{~Gy}$ ( 1 $\mathrm{cm}^{2}$ averaged over $70 \mu \mathrm{m}$ depth) persisted $45 \pm 17$ days, while doses between 61 and $470 \mathrm{~Gy}$ induced scabs that persisted $77 \pm 23$ days. Scabs induced by off-skin $\mathrm{UC}_{2}$ hot-particle doses between 16 and 37 Gy persisted for $76 \pm 40$ days. Scabs induced by off-skin UC $\mathrm{U}_{2}$ hot-particle doses between 89 and 460 Gy persisted for more than $130 \pm 9.7$ days with three of the six scabs still present at $144 \mathrm{DPI}$, when observations were discontinued. One off-skin $\mathrm{UC}_{2}$-induced scab caused by 450 Gy showed localized infection and was treated daily for 5 days beginning at 21 DPI with anti-bacterial ointment.

Scabs produced by low dose (3-10 Gy averaged over $1 \mathrm{~cm}^{2}$ at $70 \mu \mathrm{m}$ depth) on-skin Tm-170 irradiations showed a wide variability in persistence; the average persistence was approximately $36 \pm 13$ days. Despite this large variability, the average is consistent with two on-skin $U_{2}$ hot particle-induced scabs caused by 8.5 and 19 Gy which persisted approximately 40 days.

Scabs produced by higher doses (20 to $780 \mathrm{~Gy}$ ) from on-skin Tm-170 particles persisted for greater than 35 days ( $70 \%$ of 53 days) on one pig (Figure 5.72 ). Observations were discontinued at $53 \mathrm{DPI}$, when most of the scabs were still present. This indicates that scabs induced by $\mathrm{Tm}-170$ hot particles may not persist for less than those induced by $\mathrm{UC}_{2}$ particles.

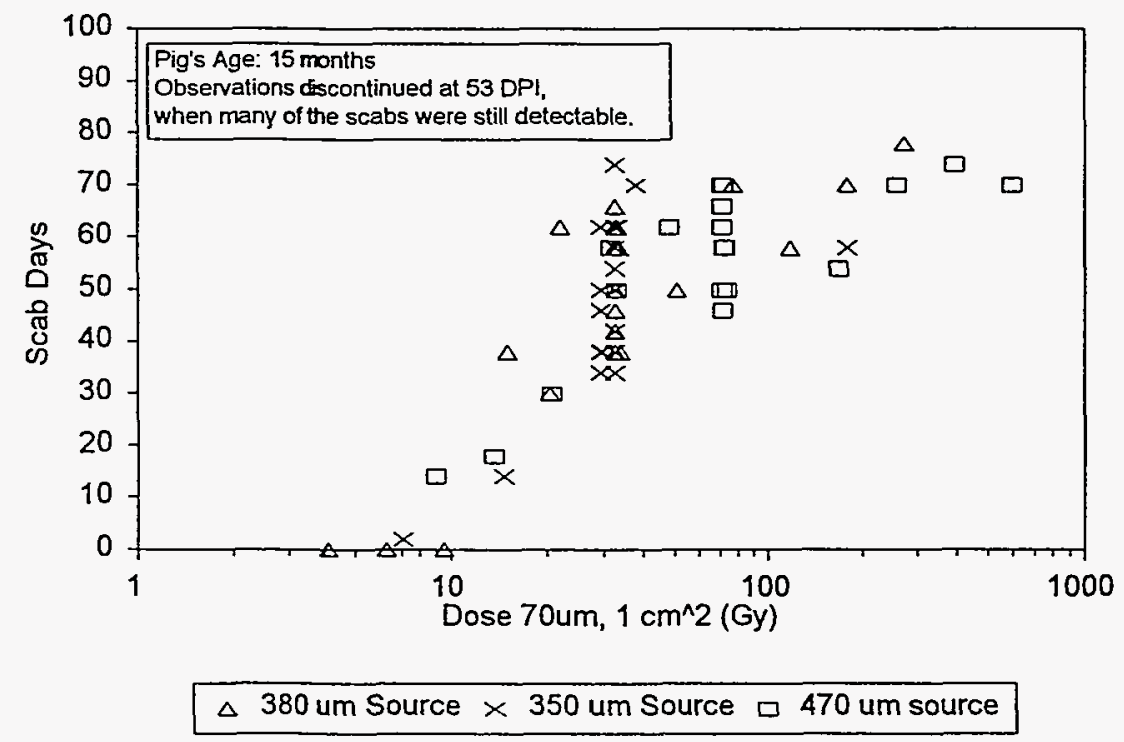

Figure 5.72 On-skin Tm-170 induced scab days, where "percent-scabdays" scab days is 100 times the number of days the scab was seen divided by the number of observation days. 
Experimental Results

\subsection{Backscatter Experiments}

There was some concern about dose due to backscattered beta particles. Monte Carlo calculations show that $1 \mathrm{~cm}^{2}$ tissue dose at a depth of $70 \mu \mathrm{m}$ from a point source on-skin with air as the backscatter medium is $30 \%$ less than dose deposited using the same parameters for an energetic point source in an infinite water medium (Cross et al., 1992). This difference is due to the lack of beta particles backscattered from air to tissue for the semi-infinite medium. This was of interest in these studies as the computer code VARSKIN MOD 2 (Durham, 1991, 1992) was used to extend data from measurements and calculate doses at specific depths and sites of interest. This widely used code uses the point kernel method of calculating doses in an infinite medium (Berger, 1971). In the case of hot particles on the skin, an infinite medium is an inappropriate model, which overestimates doses for the semi-infinite medium case. VARSKIN MOD 2 is based on an assumption that backscattered beta particles from finite size sources compensate for the lack of backscatter from tissue surrounding the particle (assumed in the point-kernel calculations) (Durham, 1991).

Monte Carlo calculations were performed by James Liu (of the Stanford Linear Accelerator Center on 12/8/92) for a 100- $\mathrm{mm}$ cube of Tm-170 using the EGS4 beta dosimetry code (Nelson et al., 1985) for both air and tissue backscatter. The results showed a $15 \%$ greater dose with backscatter from tissue. This difference would be difficult to measure using radiochromic dye films which have a measurement error of approximately $15 \%$ for hot particles. For the larger source sizes used in the BNL studies, an even smaller correction would be needed. As a result, no backscatter corrections were applied to the data.

\subsection{Dosimetry Intercomparison Results}

Dosimetry intercomparisons (see Appendix) were made using Co-60, Sc-46, Yb-175, and Tm170 sources. Comparisons between two sets of GafChromic dye film indicated differences as large as a factor of two for point dose measurements at a film density thickness of $1.8 \mathrm{mg} / \mathrm{cm}^{2}$. This difference was most likely due to the different spot sizes used to measure the optical density ( $25 \mu \mathrm{m}$ compared to $100 \mu \mathrm{m}$ diameter). Differences between the two systems were factors of $1.03 \pm 0.14$ and $1.13 \pm 0.22$ greater for the system used for BNL films than that of the system used by M.W. Charles for $1.0 \mathrm{~mm}^{2}$ and $1 \mathrm{~cm}^{2}$ areas, respectively, for all depths compared.

Comparisons of tissue dose averaged over $1 \mathrm{~cm}^{2}$ for $18,70,125$, and $400 \mu \mathrm{m}$ depth based on interpolated measured values were within a factor of $1.07 \pm 0.17$ of the mean for the GafChromic dye film (used by M.W. Charles), extrapolation chamber, NE Extremity Tape dosimeters, and Eberline RO-2 and $2 \mathrm{~A}$ survey meters excluding the $400 \mu \mathrm{m}$ estimate obtained from the NE Extremity Tape for the Co-60 and Sc-46 particle, and the $70 \mu \mathrm{m}$ estimate obtained by M.W. Charles GafChromic measurements for the Yb-175 source. The NE Extremity Tape dosimeters under-responded by about a factor of two compared with the GafChromic dye films at a density thickness of $40 \mathrm{mg} / \mathrm{cm}^{2}$ for two hot particles with maximum beta particle energies of 0.32 and $0.36 \mathrm{MeV}$ which each emitted two 1-MeV photons per disintegration. The GafChromic film used by M.W. Charles for the $70 \mu \mathrm{m}$ Yb-175 hot particle was internally inconsistent, which was not 


\section{Experimental Results}

understood. Better agreement was attained for the 18- and 70- $\mu \mathrm{m}$ tissue depths, in which BNL values were factors of $0.97 \pm 0.094$ and $0.96 \pm 0.085$ of the other systems, respectively, for the four hot particle types with the exclusions noted in Table 26 of the Appendix to this report. Tissue doses determined using exoelectron dosimeters were a factor of 2-12 less than those determined with other dosimeters, possibly due to faulty equipment during these experiments. Additional information is given in separate reports (Kaurin et al., 1996, and Appendix).

\subsection{Keratin Thickness and Basal Cell Depth}

As previously noted, the overall study was not designed to investigate in detail variations in skin characteristics among animals, nor the histopathology of developing lesions. Rather, a series of biopsy measurements was taken on animals involved primarily in the later phase of the study to determine whether there was great variation in skin structure among animals, which may result in different degrees of response not attributable to the dose or energy of radiation exposures. Most measurements were taken during the final phase of the program and mostly involved animals aged from 2.8 to 4 months. Limited data are available from older animals.

The measuring techniques are described in Section 3.6.4. Table 5.17 summarizes the results for the means, standard deviations, and ranges of thickness for the keratin layer and the depth for basal cell layer. The standard deviation in keratin thickness (10) was usually between 10 and $20 \%$, and while the standard deviation of the thickness in basal depth was about $10 \%$. The range in values was typically a factor of two above and below the mean (from 15 measurements of each biopsy with the number of biopsies indicated as "positions sampled"). Mean values vs. age in months are plotted in Figure 5.73 for keratin thickness and Figure 5.74 for basal layer depth. Both show considerable variability $( \pm 30)$ for pigs of 3 to 4 months age. The 15-month-old pig had a significantly thicker keratin layer $(49 \mu \mathrm{m})$ and basal cell depth $(100 \mu \mathrm{m})$ than the average for all other ages.

Statistical analysis of the biopsy data indicated for all pigs that there were no differences in keratin or basal layer thickness between the right and left flanks of the same pig $(p=0.49$ and $p=0.09$, respectively). Significant differences were found in both thickness of the keratin and basal layers for the different pigs. The t-test for the least-squared-means comparisons for keratin thickness showed that pigs used for the $\mathrm{Yb}-175$ and Sc-46 irradiations (experiment numbers $13,14,15,16$ and 17 in Table 3.10) were significantly different from the pigs used in the $U C_{2}$ irradiations (experiment numbers 18 and 19 in Table 3.10) $(p<0.05)$. There was no statistical difference between the pigs irradiated with $\mathrm{UC}_{2}(p<0.87)$.

The t-test on the least squared means for basal thickness showed that a single pig (experiment numbers 13 and 14 in Table 3.10) was significantly different than the other pigs used in the 199495 experiments. A Bonferroni Multiple Comparisons test gave the same results. This pig had one flank irradiated with Sc-46 and the other flank irradiated with Yb-175. This result was interesting, because the basal thickness includes the keratin thickness. Thus, one might also expect the pigs irradiated using $\mathrm{UC}_{2}$ would have a basal thickness significantly different from the other pigs, as the previously described keratin thickness for these pigs was significantly different. The mean basal cell depth for the pig which was statistically different was $75 \mu \mathrm{m}$, which was $17 \%$ 


\section{Experimental Results}

Table 5.17 Keratin thickness and basal cell depth for pig skin sites used for hot particle placements

\begin{tabular}{|c|c|c|c|c|c|c|c|c|c|}
\hline \multirow{2}{*}{ Isotope } & \multirow{2}{*}{ Animal } & \multirow{2}{*}{$\begin{array}{c}\text { Animal's } \\
\text { age } \\
\text { (months) }\end{array}$} & \multirow{2}{*}{$\begin{array}{l}\text { Positions } \\
\text { sampled }^{2}\end{array}$} & \multicolumn{3}{|c|}{ Keratin thickness ( $\mu \mathrm{m})$} & \multicolumn{3}{|c|}{ Basal cell depth ( $\mu \mathrm{m})$} \\
\hline & & & & Mean & $\begin{array}{l}\text { SD of } \\
\text { mean }\end{array}$ & Range & Mean & $\begin{array}{l}\text { SD of } \\
\text { mean }\end{array}$ & Range \\
\hline \multirow{4}{*}{$\mathrm{UC}_{2}$} & $90-2 \mathrm{~L}$ & 4.0 & 8 & 29 & 7.5 & $10-89$ & 77 & 14 & $35-190$ \\
\hline & $90-2 R$ & 4.0 & 8 & 36 & 17 & $4-140$ & 84 & 24 & $38-300$ \\
\hline & 90-3L & 4.0 & 8 & 33 & 8.2 & $10-110$ & 74 & 28 & $39-180$ \\
\hline & $90-3 R$ & 4.0 & 8 & 36 & 12 & $9-90$ & 85 & 20 & $31-70$ \\
\hline \multirow{4}{*}{ Tm-170 } & $23-1$ & 3.8 & 3 & 22 & 2.4 & $9-54$ & 64 & 1.0 & $29-120$ \\
\hline & $23-5$ & 3.8 & 2 & 18 & 5.1 & $8-49$ & 56 & 0.09 & $32-88$ \\
\hline & $85-1 L$ & 6.6 & 1 & 30 & 16 & $9-60$ & 61 & 16 & $39-91$ \\
\hline & 157-2L & 15.0 & 8 & 49 & 7.0 & $10-130$ & 100 & 9.8 & $42-220$ \\
\hline \multirow{4}{*}{$Y b-175$} & $37-1 \mathrm{~L}$ & 3.0 & 6 & 27 & 6.3 & $10-83$ & 78 & 5.7 & $48-140$ \\
\hline & 39-3L & 2.8 & 6 & 30 & 5.4 & $10-98$ & 82 & 6.8 & $44-200$ \\
\hline & $39-3 R$ & 2.8 & 6 & 32 & 7.6 & $12-99$ & 86 & 9.2 & $43-160$ \\
\hline & $85-2 L$ & 11.3 & 7 & 19 & 2.8 & $2-52$ & 61 & 7.2 & $30-110$ \\
\hline \multirow{5}{*}{ Sc-46 } & $37-1 R$ & 3.0 & 6 & 27 & 4.5 & $10-76$ & 73 & 3.5 & $40-140$ \\
\hline & $\begin{array}{c}37-2 L \\
\text { (pig died } \\
21 \mathrm{DPI})\end{array}$ & 3.0 & 3 & 21 & 5.5 & $9-68$ & 62 & 3.6 & $40-130$ \\
\hline & $\begin{array}{c}37-2 R \\
\text { (pig died } \\
21 \mathrm{DPI} \text { ) }\end{array}$ & 3.0 & 3 & 24 & 9.9 & $6-79$ & 64 & 12 & $38-110$ \\
\hline & $50-2 L$ & 3.5 & 6 & 29 & 6.7 & $9-75$ & 80 & 8.8 & $47-150$ \\
\hline & $50-2 R$ & 3.5 & 2 & 26 & 1.6 & $10-59$ & 79 & 7.5 & $51-140$ \\
\hline \multirow{2}{*}{ pig died } & 39-4L & 2.8 & 3 & 31 & 0.94 & $13-57$ & 75 & 5.6 & $48-120$ \\
\hline & $39-4 R$ & 2.8 & 3 & 37 & 3.2 & $16-83$ & 88 & 8.9 & $58-160$ \\
\hline \multirow{2}{*}{$\begin{array}{c}\text { Yb-175 } \\
\text { and } \\
46-S c\end{array}$} & $50-3 L$ & 4.4 & 3 & 32 & 7.9 & $10-79$ & 91 & 4.2 & $61-170$ \\
\hline & $50-3 R$ & 4.4 & 5 & 33 & 8.4 & $12-91$ & 83 & 8.5 & $47-160$ \\
\hline
\end{tabular}

a. Fifteen measurements were taken on each sample at each position as described in the text. 


\section{Experimental Results}

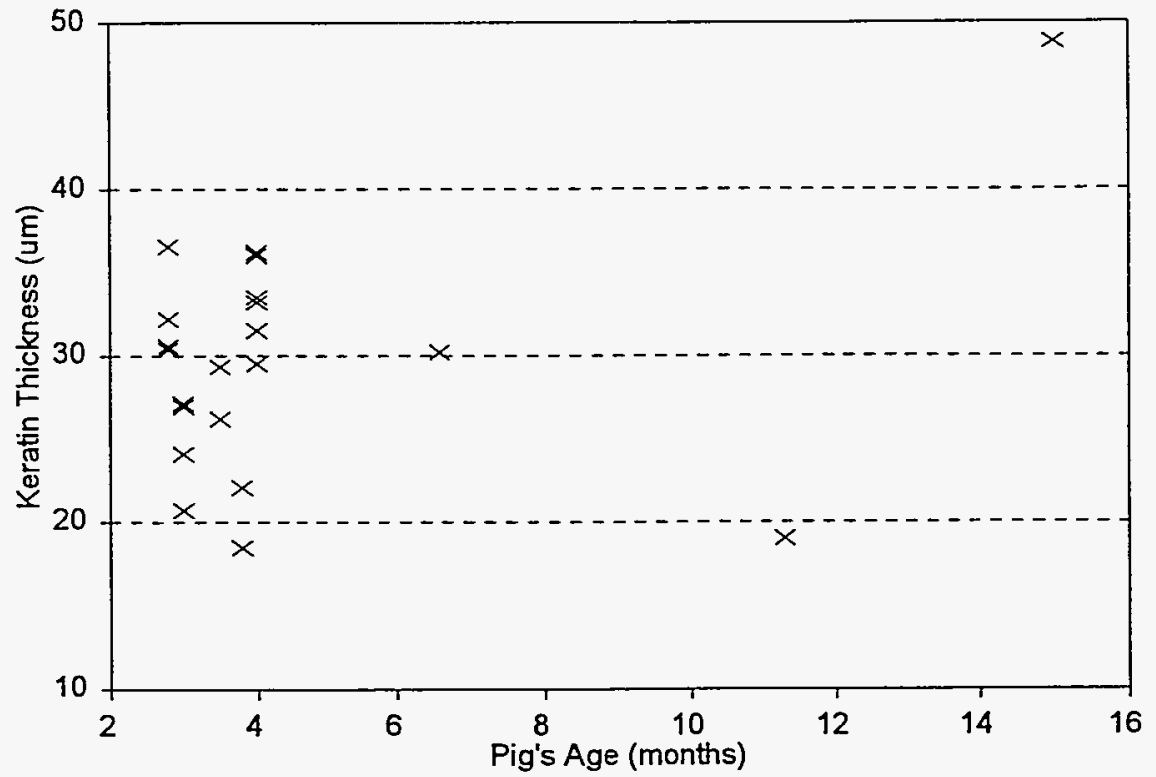

Figure 5.73 Mean keratin thickness for skin areas used for hot particle exposures as a function of pig's age.

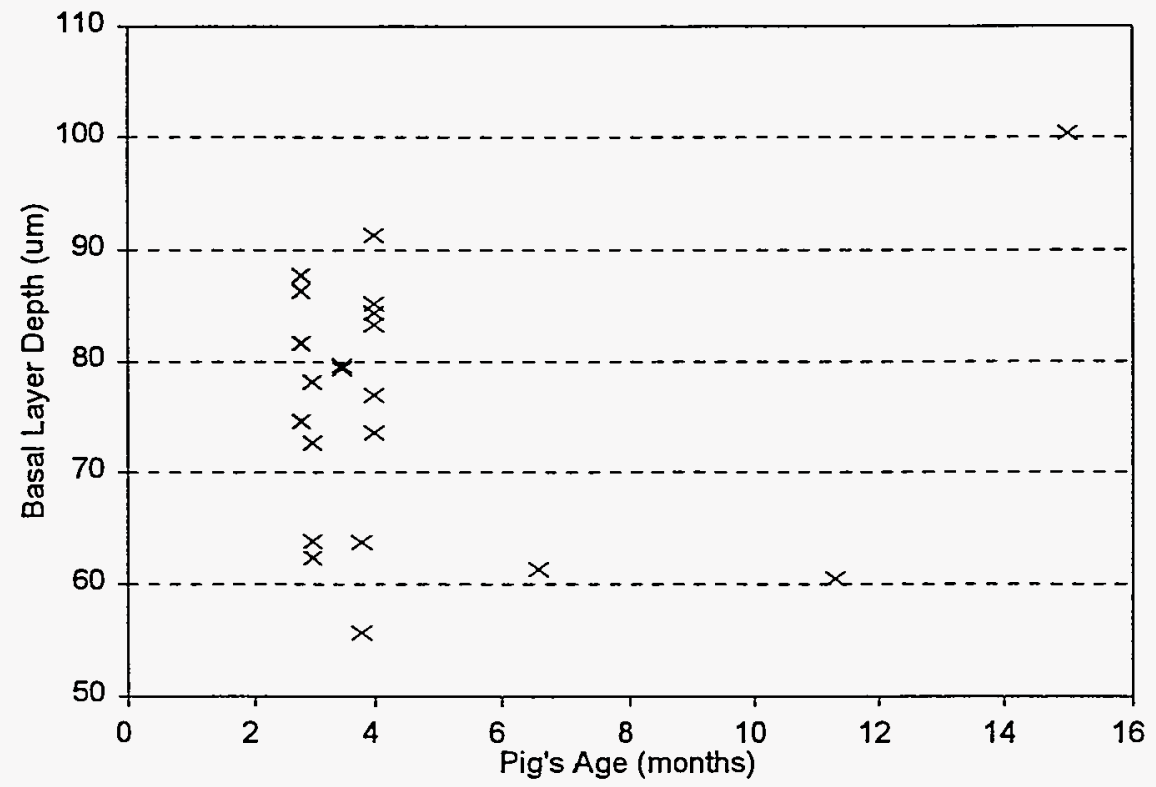

Figure 5.74 Mean basal layer depth for skin areas used for hot particle exposure as a function of pig's age. The basal cell depth includes the keratin layer. 
less than that for the pig with the thickest basal cell layer. While this measured difference was statistically significant, a difference of $12 \mu \mathrm{m}$ in terms of beta-energy penetration at this depth is not significant. The percentage of beta particles attenuated for $\mathrm{Co}-60$ beta particles, which are slightly less energetic than Sc-46 beta particles between 75 and $87 \mu \mathrm{m}$ is about $5 \%$ (Berger, 1971). This value of $5 \%$ includes considerations for the Kapton layer. Attenuation for higher energy beta-particles would be less. From this analysis, it is assumed that the differences in pig response to the different isotopes for the $Y \mathrm{~b}-175, \mathrm{Sc}-46$, and $\mathrm{UC}_{2} \mathrm{PSI}$ experiments is independent of the particular pig.

From Table 5.17, it appears that the keratin and basal layer thickness for the 3.8-month-old Tm170 pigs was thinner than that of the other 3- to 4-month-old pigs (this analysis excludes the pigs in Table 5.17 that died). The percentage of Co- 60 beta particles that would be attenuated between $56 \mu \mathrm{m}$ (the minimum of the two 3.8-month-old pigs irradiated with $\mathrm{Tm}-170$ ) and $87 \mu \mathrm{m}$ is about $10 \%$. This difference is not thought to substantially influence scab response comparisons between the different hot particle types.

\subsection{Effects of Close Shaving}

To test the hypothesis that shaving does not affect the mean thickness of the keratin layer, three biopsies were taken from animal 37-1 and two from animal 90-3 before and after close shaving. These were processed as indicated in section 3.6.4 and 15 measurements of keratin layer thickness were made on each sample. Student's t-test evaluations of the means and variances were made comparing samples taken at nearby sites on the same animal before and after shaving. Five comparisons are summarized in Table 5.18. The results were accepted as having equal means at the $95 \%$ confidence level ( $t$ between \pm 2.05 with 28 degrees of freedom). It was concluded that close shaving of these 3- to 4-month-old pigs did not significantly affect the thickness of the keratin layer.

Table 5.18 Keratin thickness before and after close shave

\begin{tabular}{|c|c|c|c|c|c|c|c|c|}
\hline $\begin{array}{l}\text { Pig } \\
\text { No. }\end{array}$ & $\begin{array}{c}\text { Number } \\
\text { before }\end{array}$ & $\begin{array}{l}\text { Number } \\
\text { after }\end{array}$ & $\begin{array}{c}\text { Standard } \\
\text { deviation } \\
\text { before }^{\mathbf{b}}\end{array}$ & $\begin{array}{c}\text { Standard } \\
\text { deviation } \\
\text { after }\end{array}$ & $\begin{array}{c}\text { Standard } \\
\text { deviation } \\
\text { pooled d }^{\mathbf{d}}\end{array}$ & $\begin{array}{l}\text { Mean } \\
\text { before }\end{array}$ & $\begin{array}{l}\text { Mean } \\
\text { after }\end{array}$ & Statistic ${ }^{0}$ \\
\hline \multirow[t]{3}{*}{$37-1 L$} & 15 & 15 & 7.3 & 8.9 & 12 & 28 & 21 & 1.7 \\
\hline & 15 & 15 & 7.5 & 8.7 & 12 & 28 & 22 & 1.4 \\
\hline & 15 & 15 & 5.8 & 23 & 23 & 25 & 38 & -1.6 \\
\hline \multirow[t]{2}{*}{ 90-3L } & 15 & 15 & 29 & 12 & 31 & 45 & 33 & 1.0 \\
\hline & 15 & 15 & 14 & 15 & 20 & 41 & 34 & 1.0 \\
\hline
\end{tabular}

a. Number of measurements made for each biopsy.

b. Standard deviation for mean keratin thickness before close shaving.

c. Standard deviation for mean keratin thickness after close shaving.

d. Pooled standard deviation of mean keratin thickness before and after close shaving.

e. Mean keratin thickness before close shaving.

f. Mean keratin thickness after close shaving.

g. Calculated student's t-test value. 


\section{Experimental Results}

\subsection{Histopathology Analysis}

No effort was made to trace the development or etiology of lesions, since this would have required using additional animals to obtain sufficient samples for each isotope at various doses and times post-irradiation. Instead, typical lesions were described, taken from different animals receiving different radiation doses from different isotopes.

Approximately 300 biopsies were obtained from control and irradiated sites to document the histology of the gross changes observed in time following exposure to the different radionuclides. The schedule of biopsies is listed in Table 5.19. The timing can be related to the phases identified for the scab-formation model outlined in Table 5.20. However, not all sites for each radioactive particle were sampled at the same time interval; the dose spread is inclusive. As a consequence of the selection, samples of the early (day 14) changes for $\mathrm{Yb}-175$ cannot be documented. Similarly, the healing phase for $\mathrm{UC}_{2}$ cannot be documented.

Table 5.19 Summary of biopsy schedule for histologic orientation

\begin{tabular}{|c|c|c|c|c|c|c|c|c|c|c|c|}
\hline \multirow{2}{*}{ Nuclide } & \multicolumn{11}{|c|}{ Day of biopsy } \\
\hline & 14 & 19 & 24 & 25 & 28 & 32 & 64 & 68 & 77 & 78 & 96 \\
\hline$Y b-175$ & & & & & & & & & & $\%$ & \\
\hline Sc-46 & & & & & & & & & & & \\
\hline $\mathrm{UC}_{2}$ & & & & & & & & & & & \\
\hline
\end{tabular}

Table 5.20 Time related events in evolution of scabs and healing

\begin{tabular}{|l|l|l|l|l|}
\hline Phase & Degenerative & Regenerative & Hyperplastic & Remodeling \\
\hline \hline Time & $1-23$ days & 23-32 days & $28-36$ days & $\begin{array}{l}36-96 \text { days and } \\
\text { beyond }\end{array}$ \\
\hline $\begin{array}{l}\text { Surface } \\
\text { events }\end{array}$ & Erythema & $\begin{array}{l}\text { Erythema, } \\
\text { persistence of } \\
\text { crust }\end{array}$ & $\begin{array}{l}\text { Dark scab, } \\
\text { persistence and } \\
\text { formation of white } \\
\text { scab }\end{array}$ & Loss of scabs \\
\hline
\end{tabular}




\section{Experimental Results}

Table 5.20 (Cont.)

\begin{tabular}{|c|c|c|c|c|}
\hline Phase & Degenerative & Regenerative & Hyperplastic & Remodeling \\
\hline Epidermis & $\begin{array}{l}\text { Linear cell loss } \\
\text { from basal and } \\
\text { prickle cell } \\
\text { layers of } \\
\text { epidermis. } \\
\text { Terminates in a } \\
\text { cellular } \\
\text { remnant, } \\
\text { ulceration, } \\
\text { serum leakage, } \\
\text { and crust } \\
\text { formation (dark } \\
\text { scab) (Figure } \\
5.77 \text { ) }\end{array}$ & $\begin{array}{l}\text { Exponential basal } \\
\text { and prickle cell } \\
\text { repopulation } \\
\text { (Figure } 5.78 \text { ). }\end{array}$ & $\begin{array}{l}\text { Continued epidermal } \\
\text { repopulation. Keratin } \\
\text { layer thickening. } \\
\text { Persistence of scab. } \\
\text { (Figures } 5.79,5.81 \text {, } \\
5.82 \text {, and } 5.84 \text { ) }\end{array}$ & $\begin{array}{l}\text { Keratin layer and } \\
\text { epidermal layer } \\
\text { thickening } \\
\text { persists (Figure } \\
5.83 \text { ) }\end{array}$ \\
\hline Dermis & & $\begin{array}{l}\text { Edema, } \\
\text { inflammatory } \\
\text { infiltration }\end{array}$ & Loss of microvessels & $\begin{array}{l}\text { Fibrosis, loss of } \\
\text { microvessels } \cup_{2}\end{array}$ \\
\hline
\end{tabular}

\subsubsection{Orientation Model from Preclinical Studies on Pig Skin}

The evolution of a radiation skin lesion that forms a crust and heals occurs in four phases:

1) the degenerative phase from 1-23 days following irradiation, 2) the regenerative or healing phase that occurs from 23-32 days, 3) the hyperplastic phase extending from 28-36 days, and 4) a second response phase that occurs from 36-96 days and beyond. The degenerative phase is characterized by a progressive, linear loss of basal and prickle cells and manifesting little basal cell proliferation. These irradiated cells progress through a maturation, functional, and senescent stage and are lost. Without cell replacement there is a loss of cell cover, with the effect that serum leaks onto the surface and dries forming a crust or dark scab. The dark scab is used as a parameter to indicate skin ulceration and damage. This crust remains attached to the epidermal and keratin remnants.

Erythema occurs in two phases. There may be an initial phase occurring at 0 to 3-4 days following irradiation and a subsequent phase occurring at 10 to 14 days, or more, before crust formation. Erythema is considered to reflect microvessel dilatation rather than being associated with endothelial cell loss. If a scab is not formed, erythema may persist to 28 days and beyond.

About 23 days following irradiation, surviving basal cells begin proliferating and exponentially replace the lost basal and prickle cells by 32 days. This is referred to as the regenerative phase. This rapid cell replacement produces a thickened, hyperplastic epidermis which persists from 32-36 days to 49 days, forming the hyperplastic phase. In the large fields used in preclinical 


\section{Experimental Results}

studies (Archambeau et al., 1995, Archambeau, 1987) all fields irradiated with single dose fractions as high as $45 \mathrm{~Gy}$ reformed the basal layer by 32 days. However, all fields receiving single-dose fractions larger than 27 Gy broke down a second time in the period from 32-70 days and beyond as a result of progressive microvascular loss. This is referred to in this study as the second response phase.

The sequence of changes produced, the time of occurrence, and the histologic changes identified from published data are listed as a model in Table 5.20. The first line indicates the chronology of the observed gross change produced. The second line indicates the period of onset, and the expected duration. The gross changes typical for the period are listed in the third line. The histologic changes are listed in the fourth and fifth lines. The numbers beneath the described change indicates the photomicrograph that illustrates the change. The radionuclide and dose used are listed in the captions of the photomicrographs.

A comparison of the observed lesion parameters for $10-\mathrm{cm}$ diameter fields from $250 \mathrm{kVp}$ X-rays and the $\sim 350-\mu \mathrm{m}$ particles evaluated in this study is shown in Table 5.21.

Table 5.21 Comparison of hot particle skin reactions with those produced by $10-\mathrm{cm}$ diameter preclinical field exposures

\begin{tabular}{|c|c|c|}
\hline Time following exposure & $\begin{array}{l}\text { Preclinical field } \\
10-\mathrm{cm} \text { in diameter }\end{array}$ & $\begin{array}{l}\text { Hot particle } \\
\sim 350 \mu \mathrm{m}\end{array}$ \\
\hline $1-23$ days & $\begin{array}{l}\text { Erythema, epidermis cell } \\
\text { loss, crust formation }\end{array}$ & Erythema scab formation \\
\hline$E D_{50}$ for scab formation & (Not scored) & $\sim 10 \mathrm{~Gy}$ \\
\hline $23-36$ days & Fields healed & Scab persistence \\
\hline$E D_{50}$ for skin healing & $23.6 \mathrm{~Gy}$ & Scab persistence \\
\hline $36-49$ days & $\begin{array}{c}\text { Some fields had a second } \\
\text { breakdown }\end{array}$ & $\begin{array}{c}\text { White scab formation, scab } \\
\text { persistence }\end{array}$ \\
\hline 50-96 days and beyond & Necrosis & Loss of scabs \\
\hline
\end{tabular}

The gross skin changes of erythema, scab (crust) formation, dry desquamation (loss of epidermal cells without crust formation), moist desquamation (loss of epidermal cells with crust formation), and necrosis (loss of epidermal cell and microvessels), produced following irradiation reflect a reproducible and dose-dependent sequence of population changes occurring in component tissues. Histologic study reveals that the initial ulceration (loss of epidermal cells and crust formation or moist desquamation) covered with a dark scab was healed by 32 days, and following this period all fields sampled at all exposures were healed (had an intact epidermis) beneath the crust (scab). As a consequence, the presence of a persistent dark scab does not 
indicate an unhealed epidermis or radiation ulcer. The persistence of the crust for periods longer than the expected 36 days is explained by the retention of the nucleated epidermal cells and the regenerating keratin layer covered with purulent material. A white scab is seen as a retained hyperplastic, parakeratotic (retained nuclei) keratin layer which remains adherent to the epidermis.

The hyperplastic changes producing a thickened keratin layer and epidermis are dose- and timedependent. The thickness of the keratin layer and the depth of the basal layer were measured following high total doses, the $E D_{50}$ dose for scab formation and a low total dose. The measurements were compared to control samples. These results are shown in Table 5.22. Basal cell depth increased significantly $(P<0.05)$ due to increased cell divisions (hyperplasia) after an $E_{50}$ for $U C_{2}$ or Sc-46 exposures but not after $Y b-175$ exposures. Keratin thickness increased significantly $(P<0.05)$ after $E D_{50}$ exposures from $U C_{2}$ or $S c-46$, but not after $Y b-175$ exposures.

Table 5.22 Keratin thickness and basal layer depth for sites exposed to $\mathrm{UC}_{2}, \mathrm{Sc}-46$, and $\mathrm{Yb}-175$ particles

\begin{tabular}{|c|c|c|c|c|}
\hline Nuclide & Dose (Gy) & $\begin{array}{l}\text { Day post- } \\
\text { irradiation }\end{array}$ & $\begin{array}{l}\text { Keratin thickness } \\
\pm S D(\mu \mathrm{m})\end{array}$ & $\begin{array}{c}\text { Basal layer depth } \\
\pm S D(\mu \mathrm{m})\end{array}$ \\
\hline \multirow[t]{4}{*}{$\mathrm{UC}_{2}$} & 0 & 0 & $33.8 \pm 3.1$ & $80.1 \pm 5.6$ \\
\hline & $58,61.2,65$ & 64 & $\begin{array}{c}153.8 \pm 93 \\
p=0.03^{\mathrm{a}}\end{array}$ & $\begin{array}{c}275.9 \pm 122.5 \\
p=0.01\end{array}$ \\
\hline & $\begin{array}{l}E D_{50} \\
\sim 10\end{array}$ & 64 & $\begin{array}{c}185.5 \pm 76.1 \\
p=0.0025\end{array}$ & $\begin{array}{c}239.0 \pm 79 \\
p=0.002\end{array}$ \\
\hline & $2.2,3.6,3.9$ & 64 & $\begin{array}{c}22.67 \pm 8.8 \\
p=0.03\end{array}$ & $\begin{array}{c}66.5 \pm 13.2 \\
p=0.08\end{array}$ \\
\hline \multirow[t]{4}{*}{ Sc-46 } & 0 & 0 & $25.4 \pm 3.3$ & $71.6 \pm 8.3$ \\
\hline & 54 & 96 & $\begin{array}{c}61.5 \pm 33 \\
p=0.03\end{array}$ & $\begin{array}{c}135.8 \pm 91.7 \\
p=0.15\end{array}$ \\
\hline & $\begin{array}{l}E D_{50} \\
9,10.2\end{array}$ & 77,96 & $\begin{array}{l}38.9 \pm 8.4 \\
p=0.008\end{array}$ & $\begin{array}{c}111.8 \pm 24.9 \\
p=0.008\end{array}$ \\
\hline & $1.2,1.3,4.5$ & $77,77,96$ & $\begin{array}{c}43.8 \pm 20.7 \\
p=0.08\end{array}$ & $\begin{array}{c}98.5 \pm 32.2 \\
p=0.1\end{array}$ \\
\hline \multirow[t]{4}{*}{$Y b-175$} & 0 & 0 & $27.2 \pm 5.8$ & $76.7 \pm 11.3$ \\
\hline & 14.5 & 77 & $\begin{array}{c}49.8 \pm 17.2 \\
p=0.03\end{array}$ & $\begin{array}{c}104.9 \pm 32 \\
p=0.12\end{array}$ \\
\hline & $\begin{array}{l}E D_{50} \\
\sim 5.5\end{array}$ & 68 & $\begin{array}{c}32.3 \pm 7.7 \\
p=0.26\end{array}$ & $\begin{array}{c}81.3 \pm 17.5 \\
p=0.64\end{array}$ \\
\hline & 0.78 & 68,77 & $\begin{array}{c}4.19 \pm 20.0 \\
p=0.18\end{array}$ & $\begin{array}{c}99.3 \pm 27.8 \\
p=0.15\end{array}$ \\
\hline
\end{tabular}

a. $p$ values less than 0.05 indicate significant differences between exposed and control samples. $\mathrm{p}$ values were obtained using a one way analysis of variance. 


\section{Experimental Results}

\subsubsection{Histologic Sampling}

Baseline photomicrographs showing histologic features, and then the changes occurring in time following the hot particle irradiation are shown in Figures 5.75 to 5.84 . The nuclide employed, the dose calculated at a depth of $70 \mu \mathrm{m}$ over a $1 \mathrm{~cm}^{2}$ area, and the time following irradiation and specific comments are included in the caption. The photomicrographs were selected to document the evolution of the histologic changes associated with the gross changes observed. A first emphasis was to illustrate the histologic change and time correspondence of these events with preclinical models and to point out the marked hyperplastic changes found in this study.

The degenerative and regenerative phases and their length correspond to the preclinical study model. The hyperplastic phase exists longer and is more marked especially following $\mathrm{UC}_{2}$ irradiation. Possible discrepancies for the length of adherence of scabs and scab diameters reflect the dose distribution and method of dose assignment. Clearly, over the $1 \mathrm{~cm}^{2}$ area that the dose was integrated, there is a rapid dose fall-off across the diameter and vertically along the axis. The dose distribution permits the size of the ulcer to increase with total dose and, similarly, the maximum beta particle ranges determine the site-limit where regenerating cells occur.

The scab parameter reflects the histologic events occurring in the epidermis. The dark scab is a crust beneath which repopulation of the epidermis occurs. As noted above, the size reflects the dose distribution. At lower dose, the crust is small and is adherent to about 30 to 40 days. The hyperplastic phase in these fields is less marked. At higher doses, the crust is larger, the adherence or persistence is longer, and the hyperplasia is more marked. These changes have been measured and listed in Tables 5.20 and 5.21 .

\subsubsection{General Comments}

There did not appear to be any nonhealing lesions among those examined histologically (doses $\leq$ $65 \mathrm{~Gy}$ ). There were, however, several examples of lesions that still retained histologically apparent crusts as long as 64 days post-irradiation with $\mathrm{UC}_{2}$. In general, the $\mathrm{UC}_{2}$ lesions appeared to be more severe.

At high doses, which could inactivate epidermal cells in small volumes, healing appears to have occurred from the edge of the exposed site as noted by Hopewell (1991). Fragmentation or edema occurred in the papillary dermis following higher doses, but there were no epidermal changes to indicate loss of microvessel nutrition during the periods examined. $U_{2}$ exposures resulted in hyperkeratosis, epidermal thickening, presence of keratin plugs around hair follicles, and scarring. 


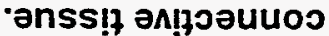

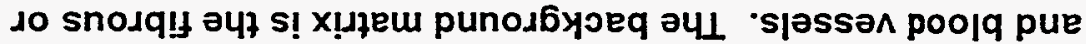

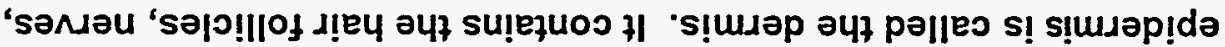

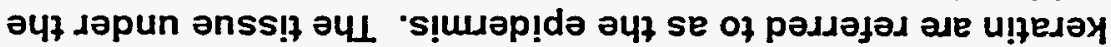

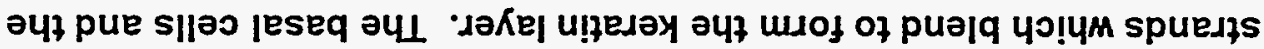

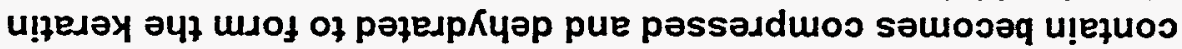

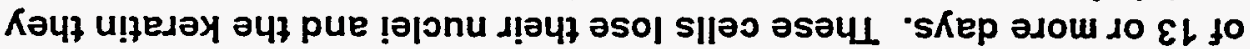

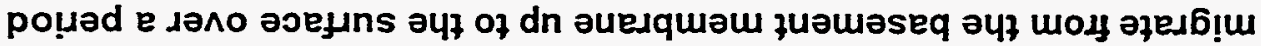

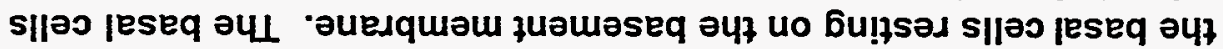

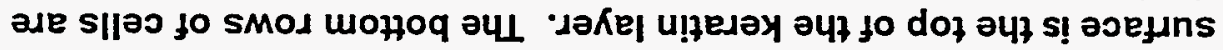

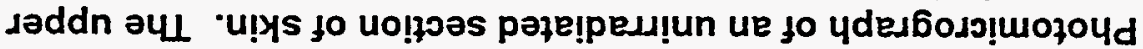

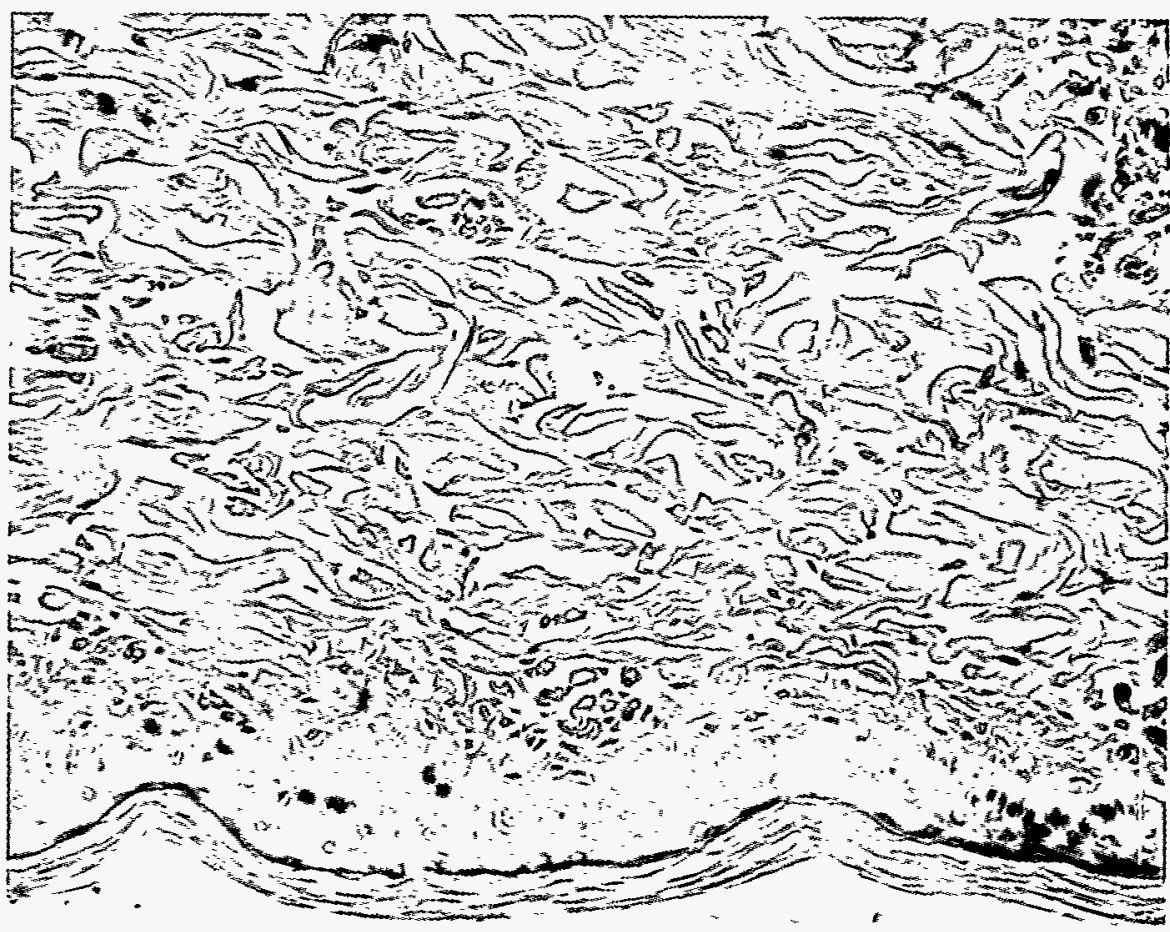


Experimental Results

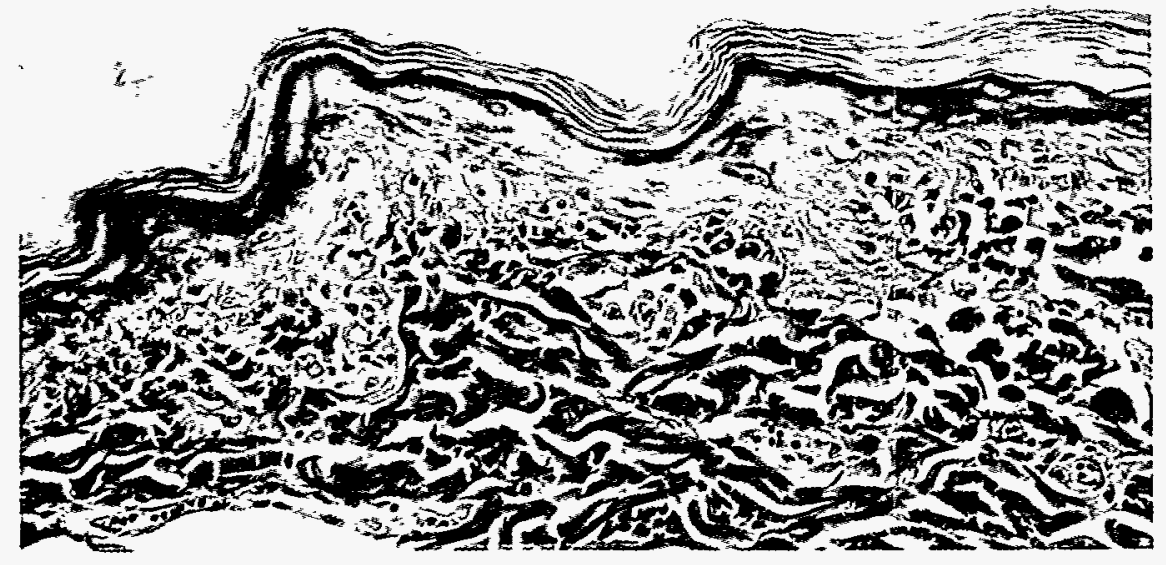

Figure 5.76 A photomicrograph (X200) 19 days following a 53 Gy Sc-46 exposure to pig 37-2L. The epidermis is an atrophic remnant containing no basal cells and scattered large prickle cell nuclei. There is no evidence of proliferation. The papillary dermis shows edema with microvessel dilatation. 
Experimental Results

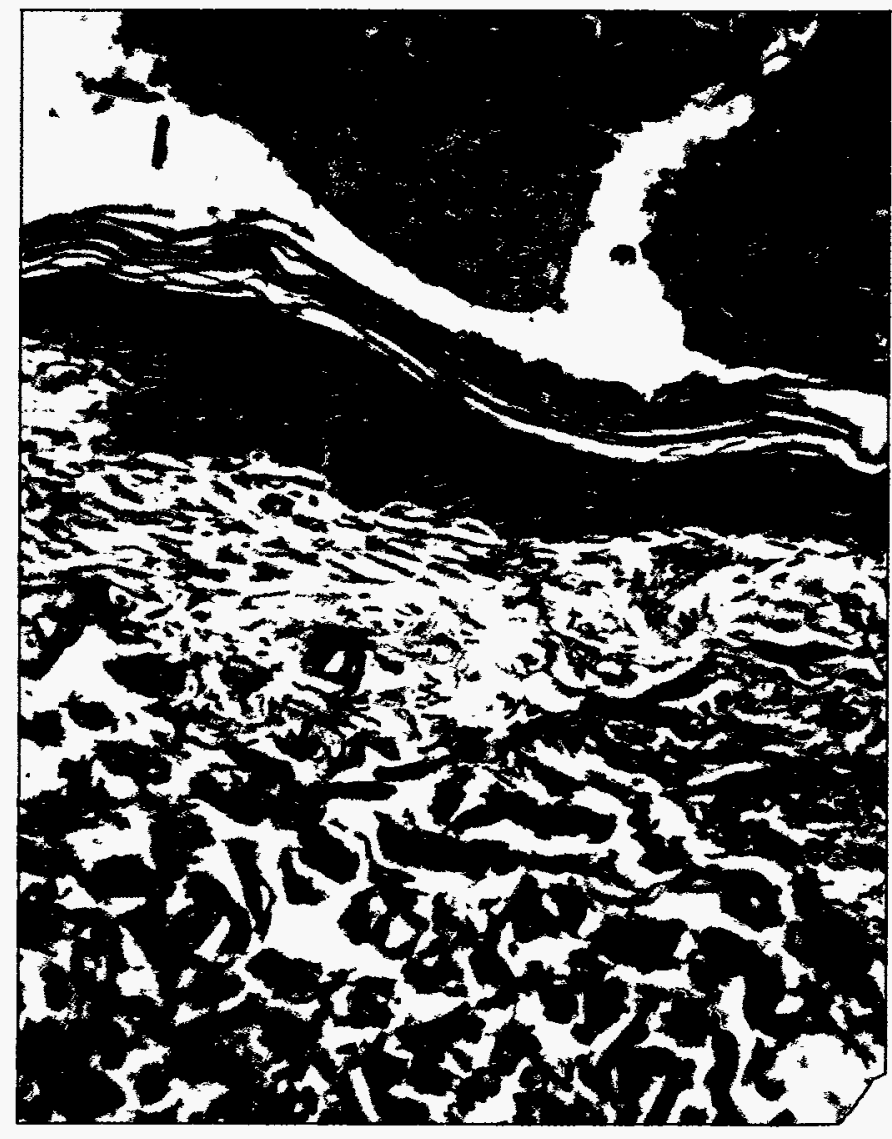

Figure 5.77 A photomicrograph (X100) 28 days following a $20 \mathrm{~Gy}$ Yb-175 exposure to pig 50-3R. A thick crust "scab" overlies the epidermis in the upper portion of the photomicrograph. This indicates that the epidermis has regenerated beneath the crust or scab. The epidermis is hyperplastic. The papillary dermis is intact with some microvessel dilatation. 
Experimental Results

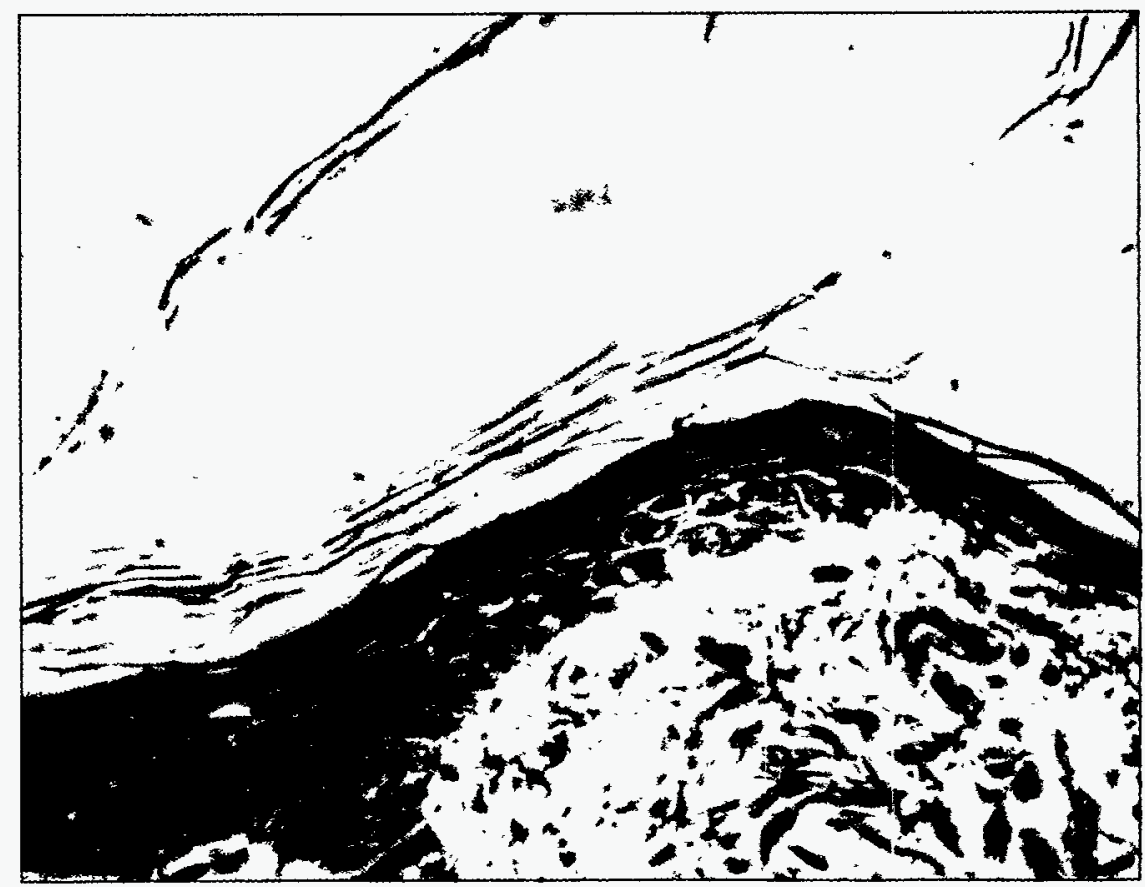

Figure 5.78 A photomicrograph (X100) 28 days following a $20 \mathrm{~Gy}$ Yb-175 exposure to pig 50-3L. At the right, the epidermal remnant consists of keratin and a few giant cells containing large nuclei. Centrally, the epidermal layer is proliferative and is migrating beneath an atrophic remnant of epidermis. A mitotic epidermal basal cell (large cell to the right of center with two vertical appearing bars) is seen. 


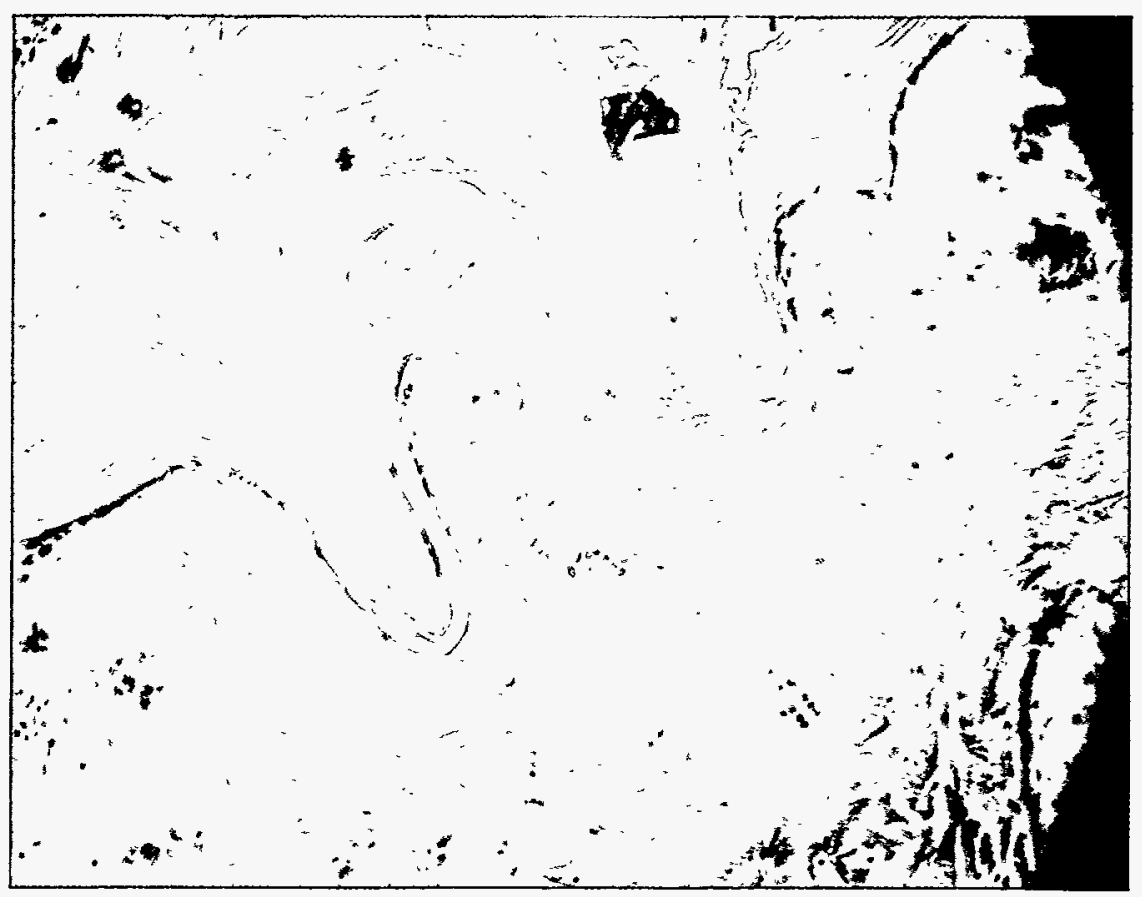

Figure 5.79 A photomicrograph (X100) 64 days following a $22 \mathrm{~Gy} \mathrm{UC}_{2}$ "on-skin" exposure to pig 90-2R. Follicular (hair follicle) plugging (central projections into the epidermis), hyperkeratosis, epidermal hyperplasia, and dermal scarring containing a reduced microvasculature are present. 
Experimental Results

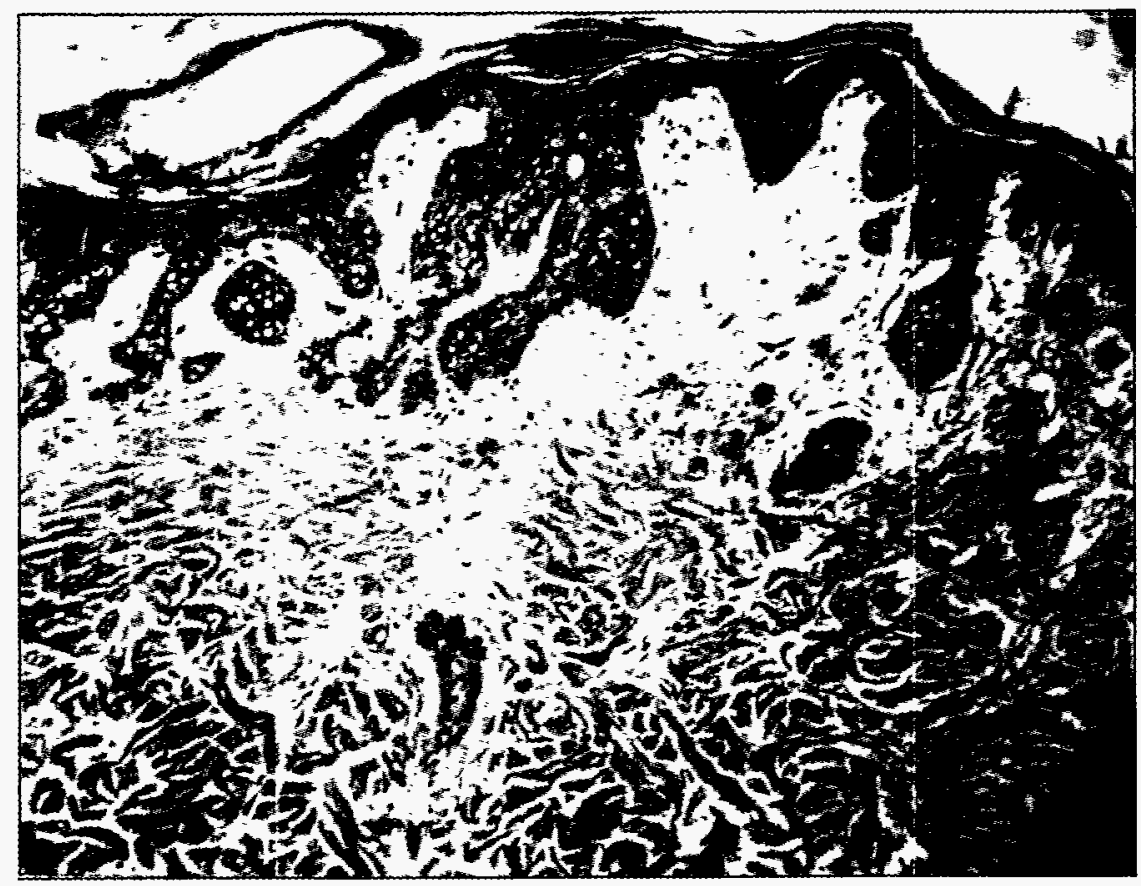

Figure 5.80 A photomicrograph (X100) 64 days following an off-skin 62 Gy $\mathrm{UC}_{2}$ exposure of pig $90-2 R$. There is epidermal and marked rete peg (projections of the epidermis into the dermis) hyperplasia. The papillary dermis is edematous, with decreased density of microvessels. 
Experimental Results

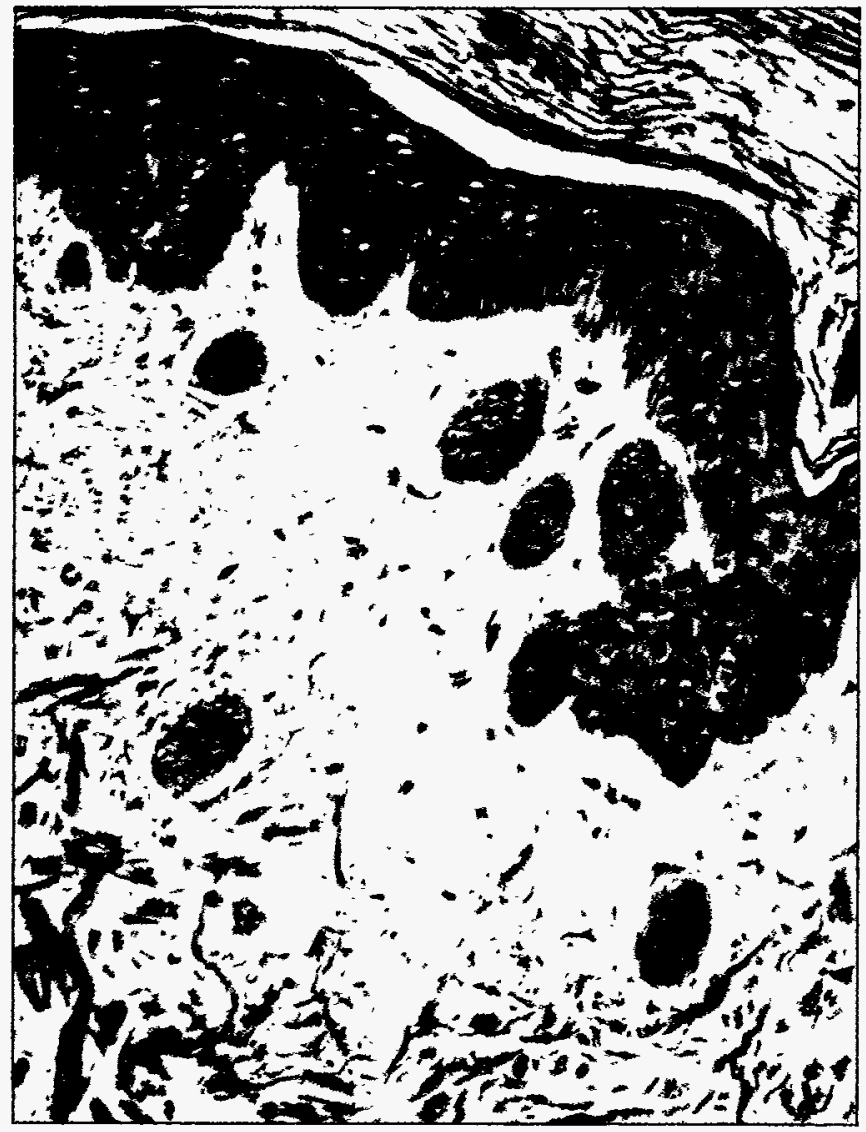

Figure 5.81 A photomicrograph (X200) 64 days following an off-skin 62 Gy $\mathrm{UC}_{2}$ exposure to pig $\mathbf{9 0 - 2 R}$. The corneal layer is hyperkeratotic, the intact epidermis is hyperplastic. What appears to be circular "remnants" of rete pegs are present in the edematous dermis. These appear to be proliferative pegs that exist independently in adjacent sections. 


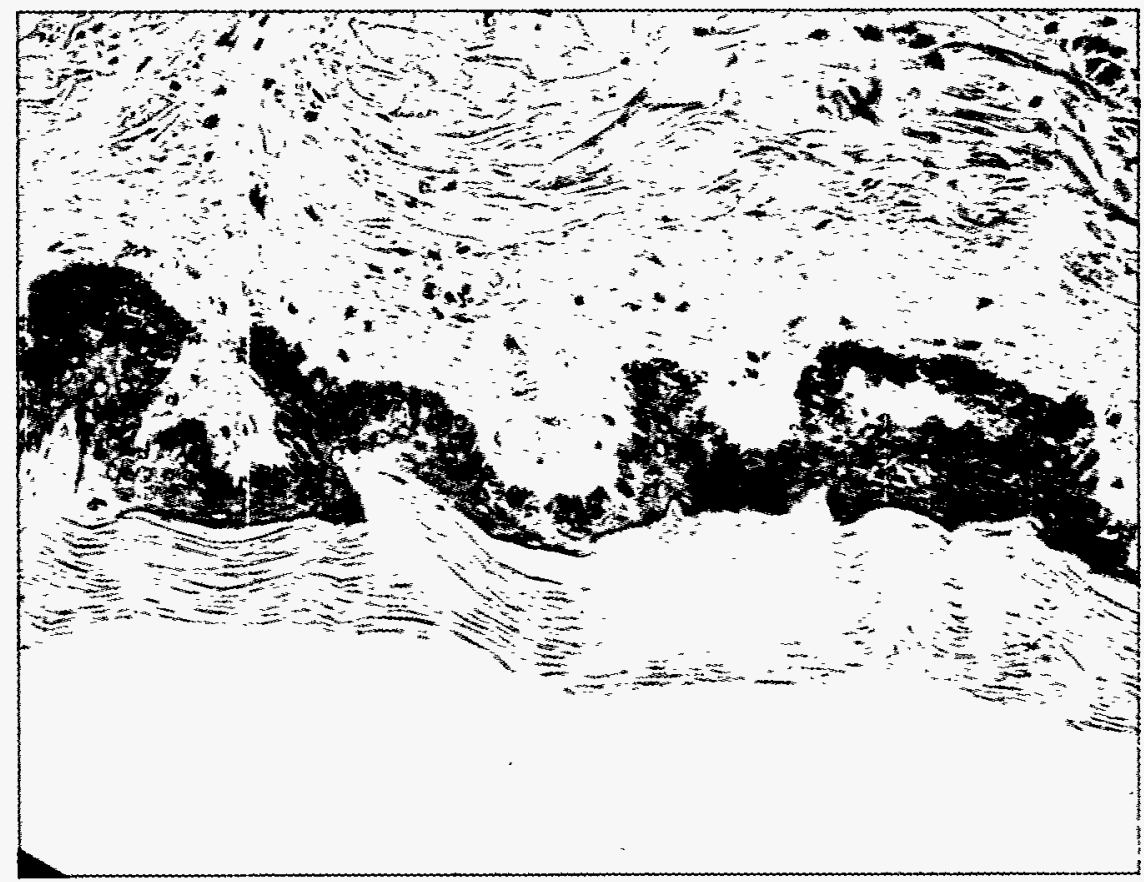


Experimental Results

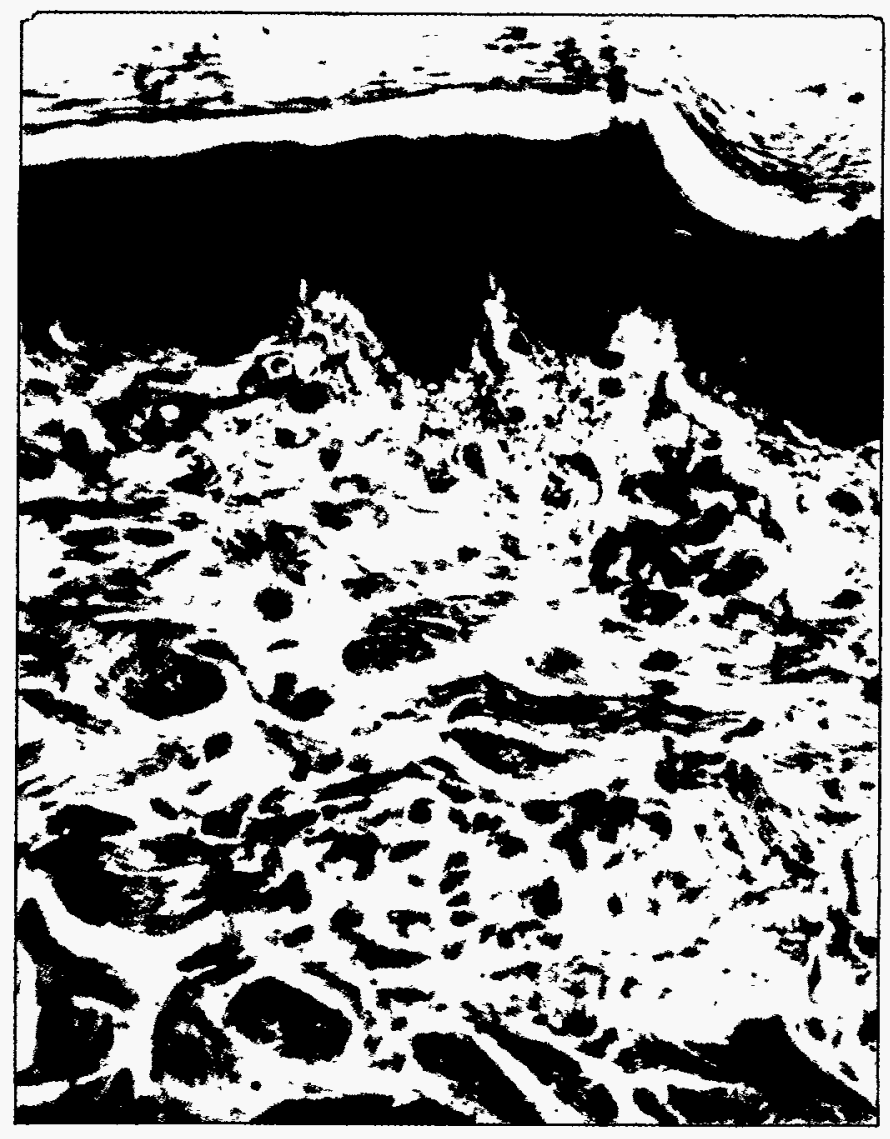

Figure 5.83 A photomicrograph $(X 400)$ from another area of Figure 5.8296 days following $53 \mathrm{~Gy} \mathrm{Sc-46}$ exposure to pig $50-2 \mathrm{R}$. There is hyperkeratosis (top of photomicrograph) and a moderately thickened epidermis. There is some thickening of the papillary dermis with vessel wall thickening. 
Experimental Results

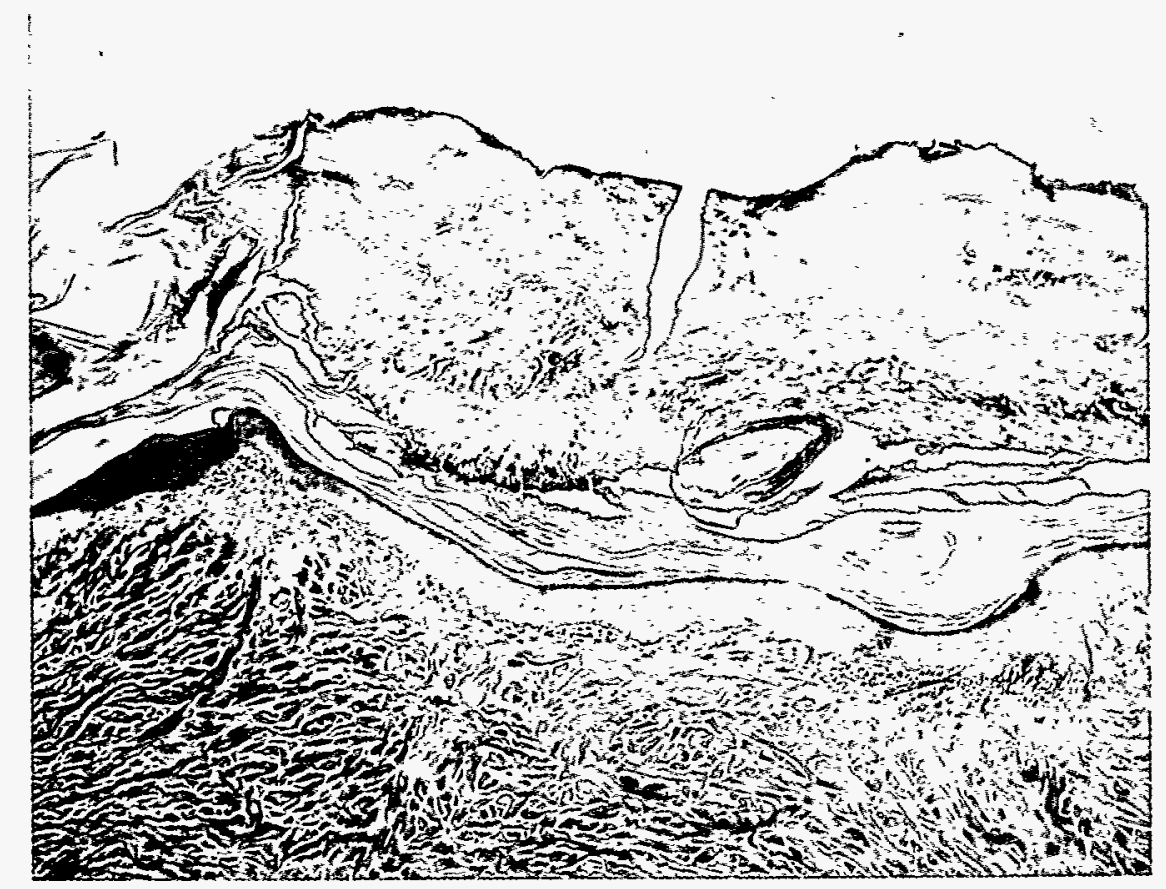

Figure 5.84 A photomicrograph (X100) of a white scab 2.4-mm long and 1-mm thick over a field 64 days following $60 \mathrm{~Gy} \mathrm{UC}_{2}$ exposure to pig 90-2. The hyperplastic epidermis is seen just below mid-picture. In the mid-picture there is a thickened keratin layer, a broken space with attached keratin and crust. 
Experimental Results

\subsection{Uncertainties, Background Studies, and Sensitivity Studies}

During the first twelve experimental studies in 1991 and 1992 (see Table 5.1), no specific sites were designated as "controls" and left unexposed because this would have increased the costs of the studies both for a larger number of animals and for scoring a larger number of sites. Also, the natural occurrence of scabs was not expected to be a significant problem. However, the results from the 1992 scoping study using Yb-175 (Section 5.5) yielded nearly the same scab incidence (about $60 \%$ ) at $1.3 \mathrm{~Gy}$ as at $5.1 \mathrm{~Gy}$. This seemed likely to have resulted from a large and unusual background incidence of scabs since all other studies showed much steeper doseresponses, tending toward zero incidence as dose was reduced a factor of two or three below the $50 \%$ incidence value. More recent analysis of data from this pig shows a background response on several areas that were not exposed (Section 5.5).

For this reason, each animal flank exposed during the 1994-95 experiments included 4 to 16 unexposed areas, scored as controls to determine background rates. These provided background data for the Sc-46, $\mathrm{Yb}-175$, and $\mathrm{UC}_{2}$ studies summarized above. The total number of background areas for these experiments was 28-36 per type of hot particle (95 in total). The following is a summary of the results and methods used to analyze the Sc-46 and Yb- 175 data taken in 1994 , covering pigs $37-1,39-3,50-2$, and $50-3$.

\subsubsection{Scoring Scab Incidence During 71 DPI}

During the 1994-95 experiments, one animal (50-3) exposed to $\mathrm{Yb}-175$ had five brown spots at low doses that were centrally located in five adjacent areas near the rear flank. These spots are reflected in the results shown in parentheses in Table 5.23. These brown spots were not open ulcers, but appeared to be blisters which formed in the dermis, leaving behind a slightly dark area. These pockets of dead cells then migrated towards the skin surface where they slowly flaked off. The hallmark characteristic of these lesions was their early appearance. Four of the five spots were induced by $1.3 \mathrm{~Gy}$ or less, and one by $3.7 \mathrm{~Gy}$. If they had been typical radiationinduced scabs for low doses, they would have appeared nearer to 30 days, but four appeared 18 $\mathrm{DPI}$, and the fifth brown spot at $26 \mathrm{DPI}$. This early appearance is characteristic of scabs resulting from much higher doses.

A series of probit analyses was made to test (a) the effects of scoring or not scoring these brown spots as scabs in PSI analyses, (b) the effect of scoring them in the analysis of scab days (see below), and (c) the sensitivity of both criteria (PSI and PSD) to corrections for possible background rates. These results for PSI are summarized in Tables 5.24 and 5.25. The analysis for scab incidence was performed using combinations of three natural background values with the $\mathrm{Yb}-175$ and Sc-46 sets of scab data. The analysis was carried out both excluding the brown spots (top three rows of Tables 5.24 and 5.25) and including the brown spots as scabs (bottom three rows of Tables 5.24 and 5.25). Since the background rates are very low, i.e., 0 to $11 \%$ for $\mathrm{PSI}$ analysis, their values are difficult to measure precisely. That is, relative statistical uncertainties of background are 100 to $200 \%$ in the studies performed here; therefore, it is important to estimate how these uncertainties may reflect on final results. 
Experimental Results

Table 5.23 The 71 DPI scoring results for Sc-46 and Yb-175 using scoring Method B for animals $37-1$ ( $L \& R$ ), 39-3, 50-2, and 50-3. The fractions indicate the number of scabs per sites irradiated.

\begin{tabular}{|c|c|c|c|c|c|c|}
\hline \multicolumn{3}{|c|}{ Yb-175 } & \multicolumn{4}{|c|}{$S c-46$} \\
\hline $\begin{array}{l}\text { Dose } \\
\text { (Gy) }\end{array}$ & $\begin{array}{r}39-3 \\
37-1 L\end{array}$ & $50-3^{a}$ & $\begin{array}{l}\text { Dose } \\
\text { (Gy) }\end{array}$ & $37-1 R$ & $50-2$ & $50-3^{a}$ \\
\hline 20 & $b$ & $2 / 2$ & 60 & $b$ & b & $2 / 2$ \\
\hline 14 & $7 / 8$ & $b$ & 53 & $4 / 4$ & $13 / 13$ & b \\
\hline 3.7 & b & $4 / 14(5 / 14)$ & 18 & $5 / 5$ & $8 / 10$ & b \\
\hline 2.5 & $4 / 15$ & b & 8.8 & $3 / 6$ & $7 / 11$ & b \\
\hline 1.3 & $3 / 17$ & b & 4.4 & $5 / 12$ & $4 / 16$ & b \\
\hline 0.78 & $b$ & $2 / 9(4 / 9)$ & 2.2 & $1 / 10$ & $2 / 18$ & b \\
\hline 0.62 & $1 / 29$ & b & 1.3 & $b$ & b & $0 / 26(1 / 26)$ \\
\hline 0.55 & $b$ & $1 / 25(2 / 25)$ & & & & \\
\hline 0.31 & $1 / 28$ & b & & & & \\
\hline \multicolumn{3}{|c|}{ Total sites Yb-175: 146} & \multicolumn{4}{|c|}{ Total sites Sc-46: 133} \\
\hline
\end{tabular}

a. Numbers in parentheses are proportions if brown spots are included.

b. No exposures were made at this dose.

Table 5.24 Probit results for Sc-46 with and without brown spots using scoring Method B for 71 DPI data listed in Table $\mathbf{5 . 2 3}$ for selected background percentages

\begin{tabular}{|c|c|c|c|}
\hline$E_{10}(\mathrm{~Gy})$ & Brown spots & Background (\%) & 95\% C.L. (Gy) \\
\hline $2.4 \mathrm{~Gy}$ & No & 0 & $1.6-3.2$ \\
\hline $2.8 \mathrm{~Gy}$ & No & 5 & $1.7-3.8$ \\
\hline $3.3 \mathrm{~Gy}$ & No & 11 & $1.9-4.6$ \\
\hline $2.1 \mathrm{~Gy}$ & Yes & 0 & $1.4-2.9$ \\
\hline $2.7 \mathrm{~Gy}$ & Yes & 5 & $1.5-3.8$ \\
\hline $3.3 \mathrm{~Gy}$ & Yes & 11 & $1.8-4.6$ \\
\hline
\end{tabular}


Experimental Results

Table 5.25 Probit results for Yb-175 with and without brown spots using scoring Method B for 71 DPI data listed in Table 5.23 for selected background percentages

\begin{tabular}{|c|c|c|c|c|}
\hline$E D_{10}(G y)$ & $E D_{50}(G y)$ & Brown spots & Background \% & 95\% C.L. on $E_{10}(G y)$ \\
\hline \hline 0.95 & 4.9 & No & 0 & $0.57-1.4$ \\
\hline 1.3 & 5.8 & No & 2.8 & $0.65-1.9$ \\
\hline 1.5 & 5.4 & No & 5 & $0.69-2.3$ \\
\hline 0.74 & 4.4 & Yes & 0 & $0.20-1.4$ \\
\hline 0.95 & 4.6 & Yes & 2.8 & $0.16-1.9$ \\
\hline 1.1 & 4.9 & Yes & 5 & $0.12-2.3$ \\
\hline
\end{tabular}

\subsubsection{Scoring Scabs as a Percentage of Total Observations (Scab Days)}

The second method of analysis consisted of considering the scabs on a scab-days basis (Section 4.5.1), which enables generation of an $E D_{10}$ based on total time of appearance during the scoring period. For the sensitivity analysis, the number of scab-days was first calculated for each dose for Sc-46, both including and excluding the brown spots (Table 5.26). The number of scab-days for the control areas on each of the pigs used in the Sc-46 study was then calculated (Table 5.27). The sensitivity of applying a flank-specific background correction versus an average background correction was tested with results for Sc-46 displayed in Table 5.28. A similar procedure was carried out for Yb-175 (Tables 5.29 to 5.31).

Table 5.26 Scab days analysis of Sc-46 71 DPI data

\begin{tabular}{|c|c|c|c|}
\hline $\begin{array}{c}\text { Dose } \\
\text { (sites exposed) }\end{array}$ & Observation days & Scab days & PSD \\
\hline \hline 60 Gy $(2 \mathrm{pts})^{\mathrm{a}}$ & 44 & 26 & 59 \\
\hline $53 \mathrm{~Gy}(17 \mathrm{pts})$ & 860 & 559 & 65 \\
\hline $18 \mathrm{~Gy}(15 \mathrm{pts})$ & 785 & 240 & 31 \\
\hline $9.1 \mathrm{~Gy}(17 \mathrm{pts})$ & 862 & 175 & 20 \\
\hline $4.4 \mathrm{~Gy}(28 \mathrm{pts})$ & 1472 & 148 & 10 \\
\hline $2.2 \mathrm{~Gy}(28 \mathrm{pts})$ & 1467 & 51 & 3.5 \\
\hline 1.2 Gy $(26 \mathrm{pts})$ & 1196 & $17(48)^{\mathrm{b}}$ & $1.4(4)^{\mathrm{b}}$ \\
\hline
\end{tabular}

a. Both points biopsied $26 \mathrm{DPI}$.

b. Values in parentheses reflect inclusion of the brown spots discussed above. 


\section{Experimental Results}

The values of PSD increase with increasing dose. Results listed in Tables 5.28 and 5.31, using the Method 1 background subtraction and excluding the brown spots, were further analyzed using probit regression to determine $E D_{10}$ values. These $E D_{10}$ values were approximately $100 \%$ higher than those based on scoring percentage scab-incidence because the shallower probit regression is based on lower percentages for all doses than the probit regression for scab incidence. As an example, a 20 Gy dose from $\mathrm{Yb}-175$ will produce $100 \%$ incidence for scabs; however, due to the limited persistence and the time delay before a scab appears, the percentage of scab days will be less than $100 \%$. These results are contrasted in Figures 5.85 and 5.86 for Sc-46 and $\mathrm{Yb}-175$, respectively.

Table 5.27 Analysis of scab days for Sc-46 control sites

\begin{tabular}{|c|c|c|c|c|}
\hline Pig Number & No. of controls & Observation days & Scab days & PSD \\
\hline \hline $50-3$ & 8 & 368 & 5 & 1.4 \\
\hline $37-1 R$ & 8 & 432 & 8 & 1.9 \\
\hline $50-2$ & 12 & 624 & 28 & 4.5 \\
\hline Average & 28 & 1424 & 41 & 2.9 \\
\hline
\end{tabular}

Table 5.28 Analysis of Sc-46 PSD data with corrections for background

\begin{tabular}{|c|c|c|c|}
\hline Dose (Gy) & Uncorrected PSD & Method 1 PSD & Method 2 PSD $^{\mathrm{b}}$ \\
\hline \hline 60 & 59 & 57 & 57 \\
\hline 53 & 65 & 62 & 62 \\
\hline 18 & 31 & 28 & 27 \\
\hline 9.1 & 20 & 17 & 17 \\
\hline 4.4 & 10 & 7 & 7 \\
\hline 2.2 & 3.5 & 0.6 & 0.3 \\
\hline 1.2 & 1.4 & 0 & 0.1 \\
\hline
\end{tabular}

a. Method 1: Apply avg. 2.9\% background subtraction (from Table 5.27).

b. Method 2: Apply $1.4 \%, 1.9 \%$, and $4.5 \%$ background subtraction to respective flanks (from Table 5.27). 
Table 5.29 PSD analysis of $\mathrm{Yb}-175$ for $71 \mathrm{DPI}$ data

\begin{tabular}{|c|c|c|c|}
\hline $\begin{array}{c}\text { Dose } \\
\text { (sites exposed) }\end{array}$ & Observation days & Scab days & PSD \\
\hline \hline 20 Gy (2 pts) & 44 & 19 & 43 \\
\hline 14 Gy (8 pts) & 399 & 139 & 35 \\
\hline 3.7 Gy (14 pts) & 644 & $93(120)^{\mathrm{b}}$ & $14(19)^{\mathrm{b}}$ \\
\hline 2.5 Gy (15 pts) & 750 & 70 & 9.3 \\
\hline 1.3 Gy (17 pts) & 850 & 71 & 8.4 \\
\hline 0.78 Gy (9 pts) & 414 & $29(82)^{\mathrm{b}}$ & $7(29)^{\mathrm{b}}$ \\
\hline 0.62 Gy (29 pts) & 1439 & 55 & 3.8 \\
\hline 0.55 Gy (25 pts) & 1150 & $16(45)^{\mathrm{b}}$ & $1.4(3.9)^{\mathrm{b}}$ \\
\hline 0.31 Gy (28 pts) & 1400 & 62 & 4.4 \\
\hline
\end{tabular}

a. Both 20 Gy spots biopsied 26 DPI.

b. Values in parentheses reflect inclusion of the brown spots discussed above.

Table 5.30 Analysis of scab days for Yb-175 control sites (36) for 71 DPI data.

\begin{tabular}{|c|c|c|c|}
\hline $\begin{array}{c}\text { Pig } \\
\text { number }\end{array}$ & $\begin{array}{c}\text { Observation } \\
\text { days }\end{array}$ & $\begin{array}{c}\text { Scab } \\
\text { days }\end{array}$ & PSD \\
\hline \hline $50-3$ & 368 & 5 & 1.4 \\
\hline $39-3$ & 1395 & 42 & 3.0 \\
$37-1 \mathrm{~L}$ & 1763 & 47 & 2.7 \\
\hline Totals & & & \\
\hline
\end{tabular}


Experimental Results

Table 5.31 Analysis of Yb-175 PSD with corrections for natural background

\begin{tabular}{|c|c|c|c|}
\hline Dose (Gy) & Uncorrected PSD & Method $1^{\mathrm{a}}$ PSD & Method ${ }^{\mathrm{b}}$ PSD \\
\hline 20 & 43 & 41 & 41 \\
\hline 14 & 35 & 32 & 32 \\
\hline 3.7 & 14 & 12 & 13 \\
\hline 2.5 & 9.3 & 6.7 & 6.3 \\
\hline 1.3 & 8.4 & 5.6 & 5.3 \\
\hline 0.78 & 7.0 & 4.3 & 5.6 \\
\hline 0.62 & 3.8 & 1.2 & 0.8 \\
\hline 0.55 & 1.4 & 0 & 0 \\
\hline 0.31 & 4.4 & 1.8 & 1.4 \\
\hline
\end{tabular}

a. Method 1: Apply avg. 2.7\% background subtraction (from Table 5.30).

b. Method 2: Apply $3.0 \%$ and $1.4 \%$ background subtraction to the respective flanks (from Table 5.30 ).

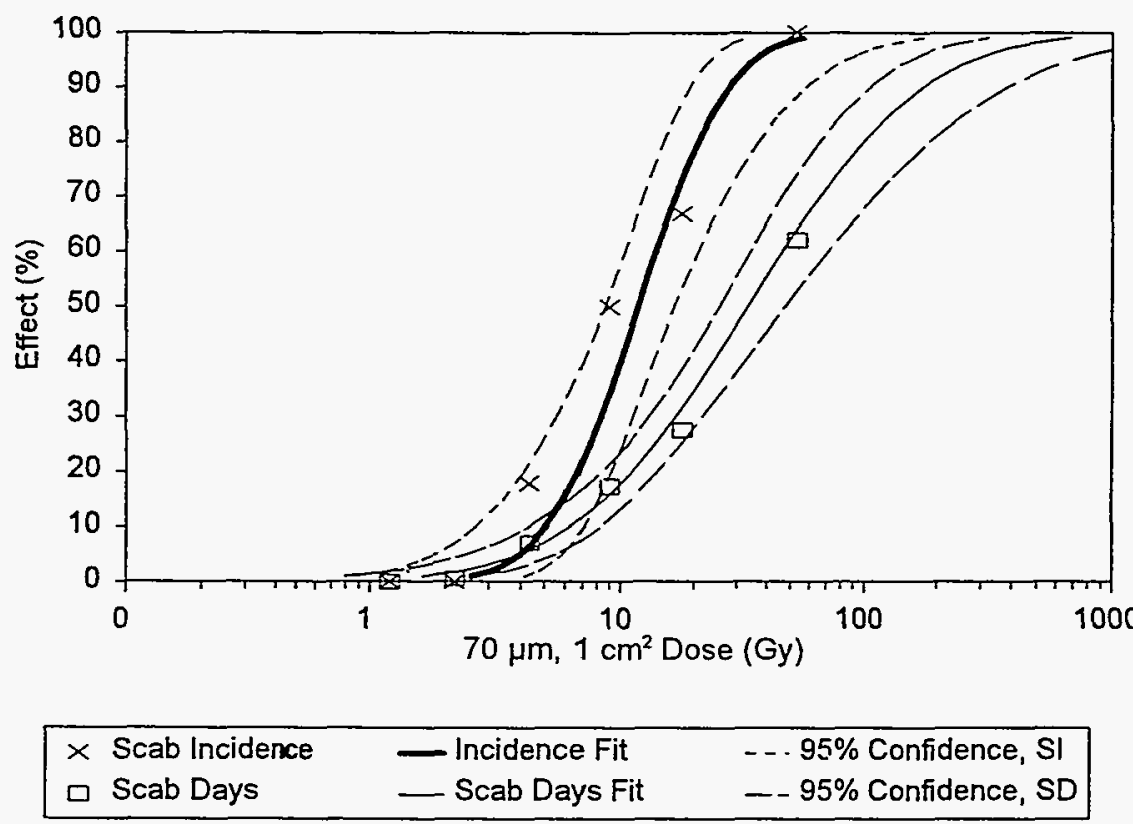

Figure 5.85 Comparison of percent scab incidence and scab days for 71 DPI Sc-46-induced scabs. (Scab incidence was determined using Method C.) Scab days had a $2.88 \%$ background correction (Method I). The brown spots noted in the text were not included. 


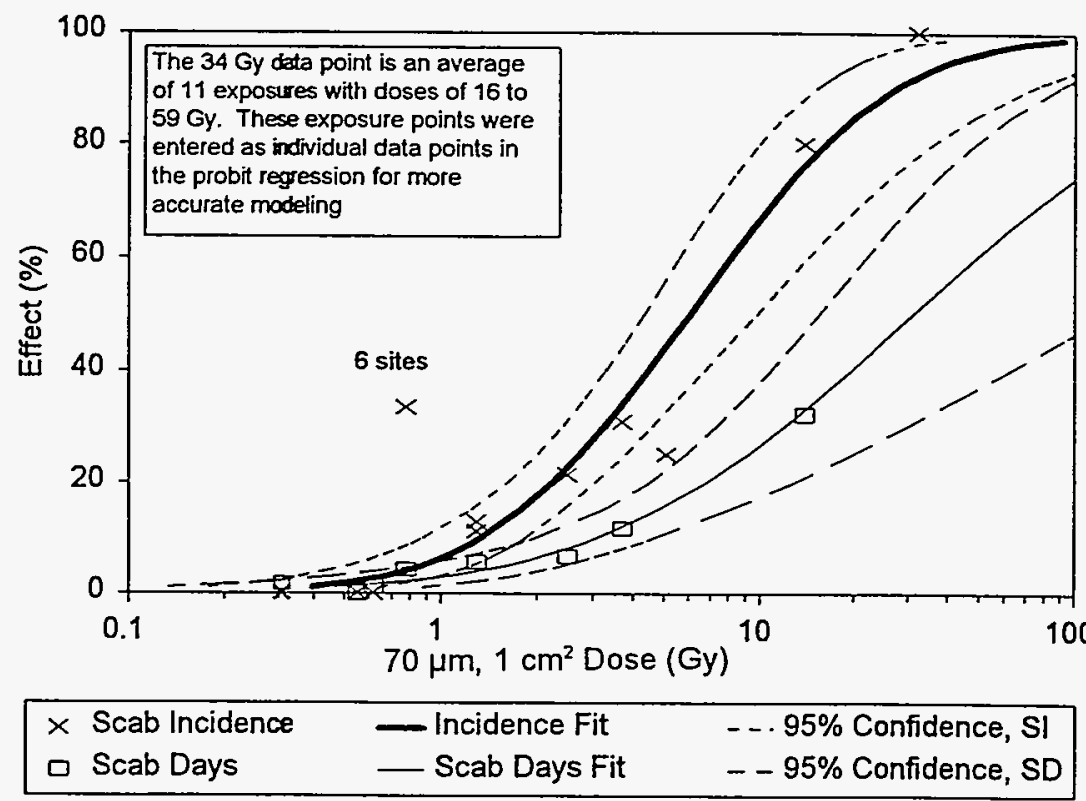

Figure 5.86 Comparison of percent scab incidence and scab days for 71 DPI Yb-175-induced lesions. Scab incidence was determined using Method C for the 1994 data (Table 5.5), and a modified scoring procedure discussed for the 1992 data (Table 5.13). Scab days had a $2.66 \%$ background correction factor (Method I) and only 1994 data were used. No brown spots were included.

\subsubsection{Control Data}

The control data were similarly analyzed to determine if there was a significant difference between the natural backgrounds computed by the PSI and PSD methods. The control data were also analyzed by flank to compare pig-to-pig and flank-to-flank variabilities which might justify using a smaller overall level for natural background.

Fifty-six control areas were included in the $\mathrm{Yb}-175$ and Sc-46. Of these, 36 were on flanks exposed to $\mathrm{Yb}-175$, and 28 were on flanks exposed to Sc-46. Eight controls were on flanks exposed to both so that they were counted twice separately in determining the natural background for each type of hot particle. Table 5.32 shows a breakdown by flank for both scoring methods.

There was minimal variability between the background lesions for studies using Sc-46 and Yb175 when assessed by the scab-days technique. This is because every false positive gets an equal weighting; for example, using the 71 days scoring period, each observation would result in $1 / 71$ value, as does each person-observation day. This technique also takes into account the random occurrence of false positives. Scoring on a consecutive-days criterion places no weight on false positives which are not grouped, but which, nevertheless, may contribute to the scoring 
Experimental Results

Table 5.32 Background results for scab scoring Method B. Fractions in the incidence column indicate the number of scabs per control sites.

\begin{tabular}{|c|c|c|c|}
\hline Flank & Incidence method & Scab days \% & Hot particle \\
\hline \hline $37-1 \mathrm{~L}$ & $0 / 12$ & 3.6 & $\mathrm{Yb}$ \\
\hline $37-1 \mathrm{R}$ & $0 / 8$ & 1.9 & $\mathrm{Sc}$ \\
\hline $39-3 \mathrm{~L}$ & $0 / 7$ & 3.9 & $\mathrm{Yb}$ \\
\hline $39-3 \mathrm{R}$ & $0 / 9$ & 0.1 & $\mathrm{Yb}$ \\
\hline $50-2 \mathrm{~L}$ & $1 / 7$ & 4.7 & $\mathrm{Sc}$ \\
\hline $50-2 \mathrm{R}$ & $1 / 5$ & 4.3 & $\mathrm{Sc}$ \\
\hline $50-3 \mathrm{~L}$ & $1 / 4$ & 2.7 & $\mathrm{Sc} / \mathrm{Yb}$ \\
\hline $50-3 \mathrm{R}$ & $0 / 4$ & 0.0 & $\mathrm{Sc} / \mathrm{Yb}$ \\
\hline Avg. (total) & $3 / 56(5.4 \%)$ & 2.8 & \\
\hline Avg. (Yb-175) & $1 / 36(2.8 \%)$ & 2.7 & \\
\hline Avg. (Sc-46) & $3 / 28(11 \%)$ & 2.9 & \\
\hline
\end{tabular}

of a transient lesion in terms of scab-days. In the scab-days method, averages included all pig flanks thus lessening the effect of one pig consistently being dirtier than the others.

The sensitivity of $E D_{10}$ results to background incidence rates from 0 to $11 \%$ are illustrated for Sc-46 and Yb-175 in Figures 5.87 and 5.88, respectively. The effects of background corrections on PSDs results are illustrated for Sc-46 and $Y b-175$ in Figures 5.59 and 5.60, respectively. 


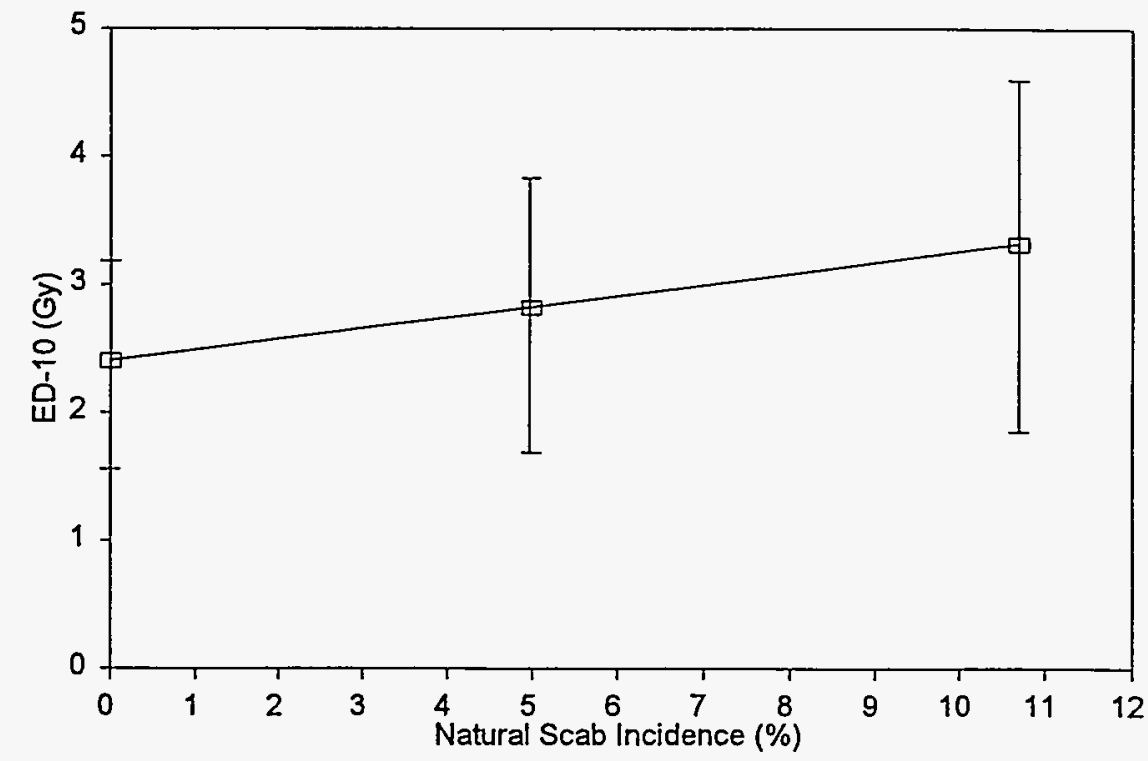

Figure 5.87 $E D_{10}$ for Sc-46 at $71 \mathrm{DPl}$ (without brown spots) as a function of background scab incidence for scab scoring Method B.

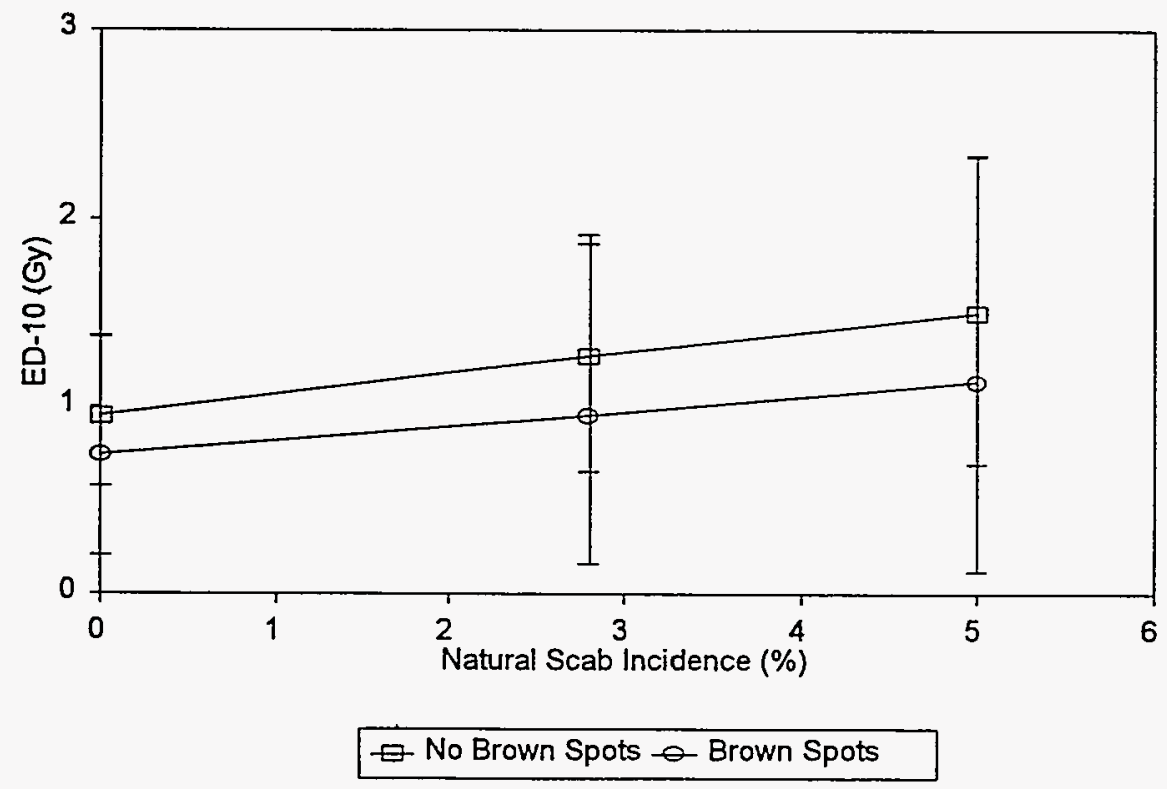

Figure 5.88 $E D_{10}$ for $\mathrm{Yb}-175$ at $71 \mathrm{DPI}$ (without brown spots) as a function of background scab incidence for scab scoring Method B. 


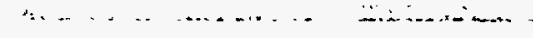




\section{COMPARISONS WITH OTHER STUDIES AND UNCERTAINTIES}

\subsection{Fissioned U-235 Comparisons with Other Studies}

\subsubsection{Comparisons with Forbes and Mikhail's Results with $\mathrm{UC}_{2}$}

Table 6.1 summarizes the results of the $B N L$ studies for $U_{2}$ particles both on-skin exposures and off-skin exposures, along with Forbes and Mikhail's data for on-skin exposures. These results were expressed in terms of the dose intercepts (dose at the apparent threshold) and standard deviations for regressions of scab diameter vs. dose. These apparent threshold doses were expressed in four ways: (1) point dose at $100 \mu \mathrm{m}$ depth in tissue, (2) dose averaged over 1 $\mathrm{cm}^{2}$ at $70 \mu \mathrm{m}$ depth in tissue, (3) dose averaged over $1.1 \mathrm{~mm}^{2}$ at $16 \mu \mathrm{m}$ depth in tissue, and (4) number of beta particles emitted from the surface of the sources. The slopes of the regression curves, scab diameter per unit dose, are given in units of $\mathrm{mm} / \mathrm{Gy}$ (dose averaged over $1 \mathrm{~cm}^{2}$ at $70 \mu \mathrm{m}$ ) or $\mathrm{mm} / \mathrm{beta}$.

Intercepts (apparent thresholds) for on-skin exposure range from about 4 to 9 Gy for dose averaged over $1 \mathrm{~cm}^{2}$ at $70 \mu \mathrm{m}$ depth in tissue. Differences from experiment to experiment, as shown in Table 6.1, were about a factor of two for BNL on-skin hot-particle-induced scabs. The Forbes and Mikhail results were about a factor of two greater than values from the BNL study. The latter yielded an intercept at about $17 \mathrm{~Gy}$ using the BNL conversion factor $1.8 \times 10^{9}$ beta particles per Gy (see Section 3.3.1.5). The two off-skin ( $440-\mu m$ denim) studies yielded intercepts at about 2 and $10 \mathrm{~Gy}$.

For doses expressed as number of beta particles emitted from the sources, the intercepts occurred at approximately $(0.8$ to 1.6$) \times 10^{10}$ beta particles for on-skin exposures, whereas Forbes and Mikhail's data yielded an intercept at approximately $3 \times 10^{10}$ beta particles.

The off-skin results gave intercepts between $(0.6$ and 3$) \times 10^{10}$ beta particles. These results and those above indicate that $U_{2}$ particles $440 \mu \mathrm{m}$ off-skin yield thresholds for scab induction similar to those for particles on-skin.

The scab diameters for 1991 and 1995 off-skin and on-skin exposures are compared with Forbes and Mikhail's data in Figures 6.1 and 6.2, respectively. The 1991 data show significant differences in scab size at higher doses for off-skin exposures, as might be expected since the dose tends to be spread over a somewhat larger areas. Data from the 1995 study do not show this, probably due to the limited dose range employed.

The sizes of the induced scabs given in the Forbes and Mikhail data (NCRP, 1989) were previously thought to differ for the 150 and $300 \mu \mathrm{m}$ diameter $\mathrm{UC}_{2}$ sources (Baum and Kaurin, 1991; Charles, 1991; Baum et al., 1992). This apparent difference was due to the scab diameters for each of the particle sizes following a separate regression line when the data were 
Table 6.1 Dose (or number of beta particles emitted from the particle) axis intercepts for zero scab diameter from linear regressions of the logarithm of the dose (independent axis) and scab diameter (dependent axis)

\begin{tabular}{|c|c|c|c|c|c|c|c|c|c|c|c|}
\hline \multirow[b]{2}{*}{$\begin{array}{l}\text { Experiment } \\
\text { data set }\end{array}$} & \multirow[b]{2}{*}{$\begin{array}{c}\mathrm{UC}_{2} \\
\text { exposure }\end{array}$} & \multicolumn{2}{|c|}{ Slope } & \multicolumn{8}{|c|}{ X-intercept } \\
\hline & & $\begin{array}{c}\text { Slope } \\
\text { (mm/Gy or } \\
\text { mm/ttbeta) }\end{array}$ & $\begin{array}{l}\text { SD }^{a} \text { slope } \\
\text { (mm/Gy or } \\
\text { mm/\#beta) }\end{array}$ & $\begin{array}{l}\text { Dose } \\
\text { point @ } \\
100 \mu \mathrm{m} \\
(\mathrm{Gy})\end{array}$ & $\begin{array}{c}S^{a} \text { dose } \\
\text { point @ } \\
100 \mu \mathrm{m} \\
(\mathrm{Gy})\end{array}$ & $\begin{array}{c}\text { Dose avg } \\
\text { over } 1 \mathrm{~cm}^{2} \\
@ 70 \mu \mathrm{m} \\
\text { (Gy) }\end{array}$ & $\begin{array}{c}S D^{a} \\
\text { dose } \\
\text { avg over } \\
1 \mathrm{~cm}^{2} @ \\
70 \mu \mathrm{m} \\
\text { (Gy) }\end{array}$ & $\begin{array}{c}\text { Dose avg } \\
\text { over } 1.1 \\
\mathrm{~mm}^{2} \text { at } 16 \\
\mu \mathrm{m} \text { (Gy) }\end{array}$ & $\begin{array}{c}\mathrm{SD}^{\mathrm{a}} \text { dose } \\
\text { avg over } \\
1.1 \mathrm{~mm}^{2} \\
@ 16 \mu \mathrm{m} \\
\text { (Gy) }\end{array}$ & $\begin{array}{l}\text { \# betas } \\
\text { emitted } \\
\text { from } \\
\text { encapsul } \\
\text { surface }\end{array}$ & $\begin{array}{c}\mathrm{SD}^{\mathrm{a}} \# \\
\text { betas } \\
\text { emitted } \\
\text { from } \\
\text { encapsul } \\
\text { surface }\end{array}$ \\
\hline Experiment 1 & On-skin & 1.0 & 0.25 & 630 & 230 & 4.4 & 1.6 & 310 & 120 & $7.7 E+09$ & $2.8 \mathrm{E}+09$ \\
\hline Experiment 2 & On-skin & 2.9 & 0.35 & 1400 & 340 & 9.1 & 2.2 & 700 & 170 & $1.6 \mathrm{E}+10$ & $3.8 E+09$ \\
\hline Experiment 2 & Off-skin & 4.4 & 0.56 & 340 & 92 & 9.9 & 2.7 & 310 & 83 & $2.9 E+10$ & $7.7 E+09$ \\
\hline${ }_{2}^{\text {Experiments } 1 \&}$ & On-skin & 2.6 & 0.25 & 1300 & 200 & 8.3 & 1.3 & 630 & 100 & $1.5 \mathrm{E}+10$ & $2.3 E+09$ \\
\hline $\begin{array}{l}\text { Experiments } 18 \\
\& 19\end{array}$ & Off-skin & 1.4 & 0.32 & 28 & 16 & 2.0 & 1.2 & 27 & 15 & $5.8 E+09$ & $3.4 E+09$ \\
\hline $\begin{array}{l}\text { Experiments } 18 \\
\& 19\end{array}$ & On-skin & 1.6 & 0.13 & 470 & 52 & 4.1 & 0.46 & 240 & 26 & $7.5 E+09$ & $8.3 E+08$ \\
\hline $\begin{array}{l}\text { Experiments } 18 \\
\& 19\end{array}$ & On-skin & 2.0 & 0.25 & 660 & 110 & 5.8 & 0.95 & 340 & 55 & $1.1 E+10$ & $1.7 \mathrm{E}+09$ \\
\hline Forbes/Mikhail & On-skin & $2.4^{\mathrm{c}}$ & 0.17 & 2800 & 330 & & & & & & \\
\hline Forbes/Mikhail & On-skin & $1.7^{\mathrm{e}}$ & 0.083 & & & $17.0^{d}$ & 2.1 & $1000^{d}$ & 120 & $3.1+10$ & $3.7 E+09$ \\
\hline
\end{tabular}

a. $S D=$ standard deviation.

b. Regression analysis indicated that there were no differences between the on-skin experiments 1 and 2 scab diameters for similar doses.

c. The slope calculated using the reported number of beta particles differs from that using the reported dose.

d. The thresholds for the Forbes/Mikhail data for dose averaged over $1 \mathrm{~cm}^{2}$ at $70 \mu \mathrm{m}$ depth and over $1.1 \mathrm{~mm}^{2}$ at $16 \mu \mathrm{m}$ depth are calculated using $\mathrm{BNL}$ conversion factors and the listed number of beta particles emitted from the Forbes/Mikhail particles. 


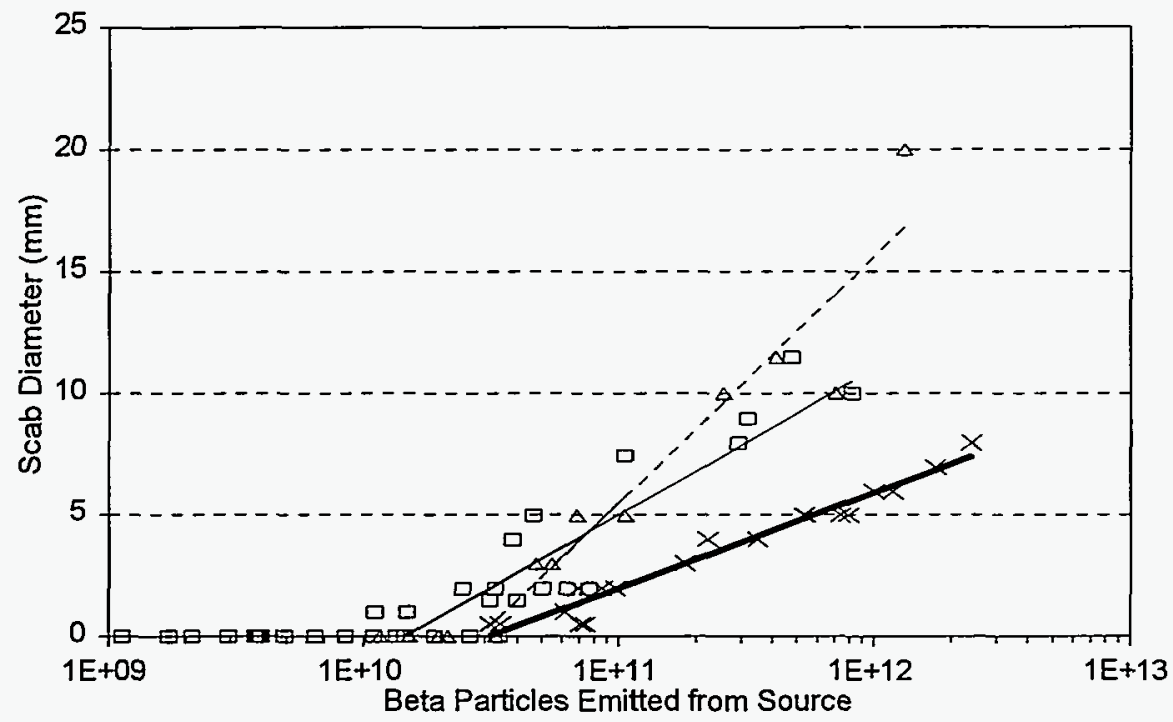

$$
\begin{aligned}
& \text { 口 On-Skin } 1991 \Delta \text { Off-Skin } 1991 \times \text { Forbes/Mikhail } \\
& \text { On-skin Regress - - . Off-skin Regress _ F/M Regress }
\end{aligned}
$$

Figure 6.1 On- and off-skin $\mathrm{UC}_{2}$ data from BNL results for 1991 compared with those of Forbes and Mikhail. The BNL hot particles were about $\mathbf{2 8 0} \mu \mathrm{m}$ in diameter, while those for the Forbes and Mikhail data set were about $150 \mu \mathrm{m}$ (10 lower dose points) and $300 \mathrm{\mu m}$ ( 9 higher dose points) in diameter. The BNL off-skin particle was covered with $440-\mu m$-thick denim. 


\section{Comparisons}

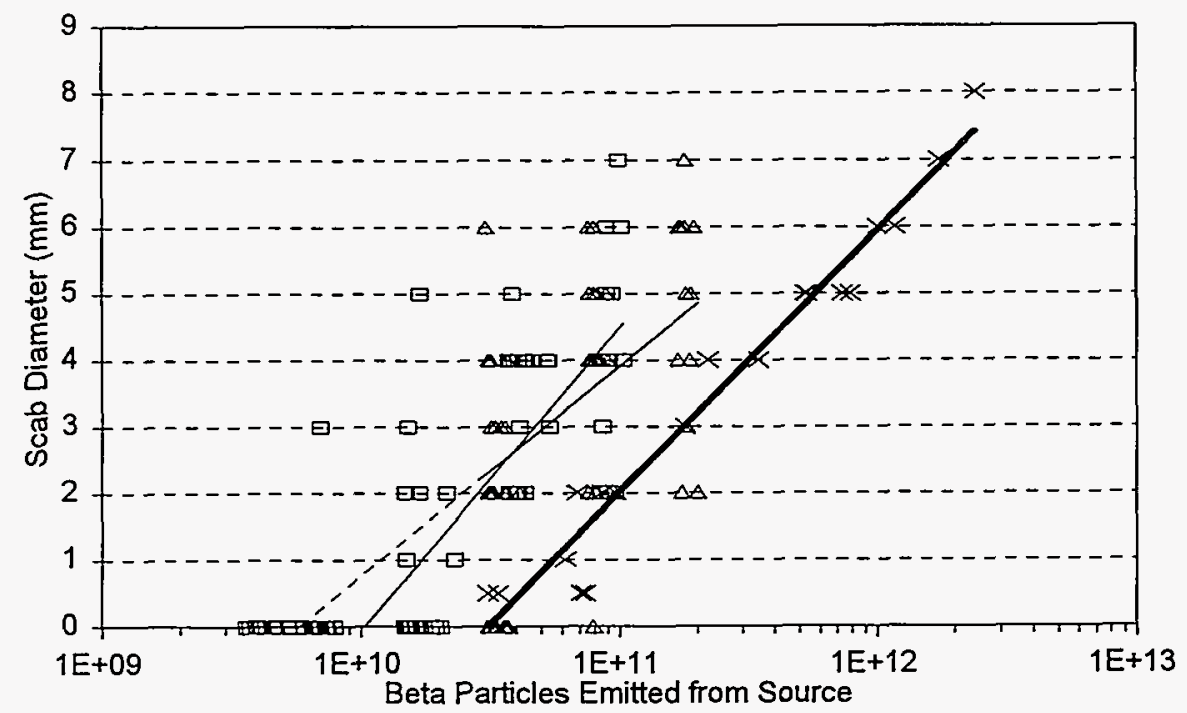

On-Skin $1995 \Delta$ Off-Skin $1995 \times$ Forbes/Mikhail

On-skin regress - - . Off-skin Regress _ F/M Regress

Figure 6.2 On- and off-skin $\mathrm{UC}_{2}$ data from BNL results for 1995 compared with those of Forbes and Mikhail. The BNL particles were $290 \mu \mathrm{m}$ in diameter, while the Forbes and Mikhail particles were about $150 \mu \mathrm{m}$ (10 lower dose points) and $300 \mu \mathrm{m}$ ( 9 higher dose points) in diameter. The BNL off-skin particle was covered with 440- $\mu$ m-thick denim. 


\section{Comparisons}

plotted as a linear-linear scale of scab diameter and number of beta particles (Figure 6.3). More recent analyses of scab size data carried out by BNL show this interpretation may be incorrect, and result from a lack of overlapping data for the two source sizes.

The linear plots of the BNL data (Figure 6.4) for scab diameter versus dose have a similar shape to that of the Forbes and Mikhail data (Figure 6.3); however, a single source was used for each BNL off- and on-skin exposure. Since the off-skin particle tends to distribute dose more like a larger on-skin particle, these data suggest that scab diameter for sources of this size and beta energy were more a function of dose and the finite range of the beta particles, rather than particle size. The apparent curvature is thought to be due to the non-linear attenuation of the beta particles with distance from the source. Thus, the radius at $70 \mu \mathrm{m}$ depth in skin at which dose reaches $10 \mathrm{~Gy}$ increases approximately as the square root of dose. This effect was also evident with the Tm-170 experiment number 3 (Figure 6.5).

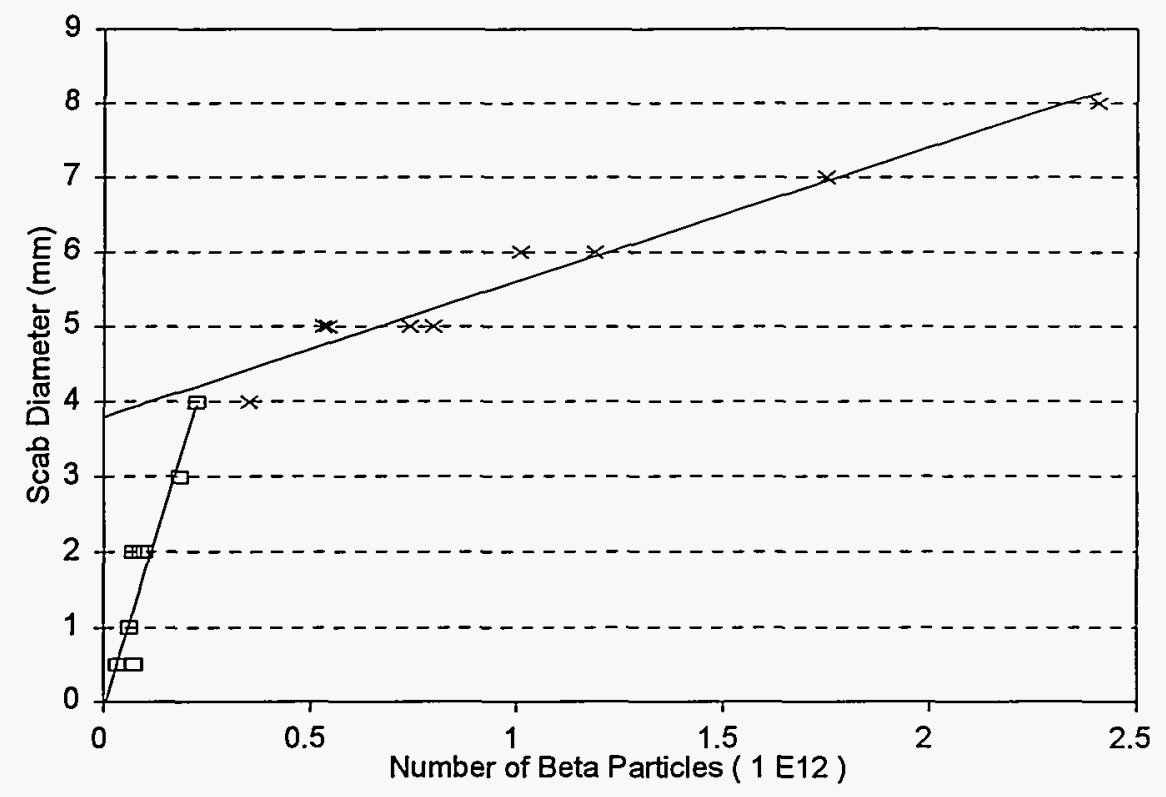

Figure 6.3 Scab size from the Forbes and Mikhail data set (1971). The open squares and "X"s represent the number of beta particles

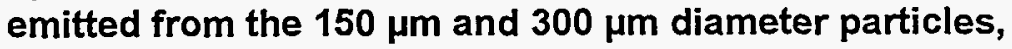
respectively. 


\section{Comparisons}

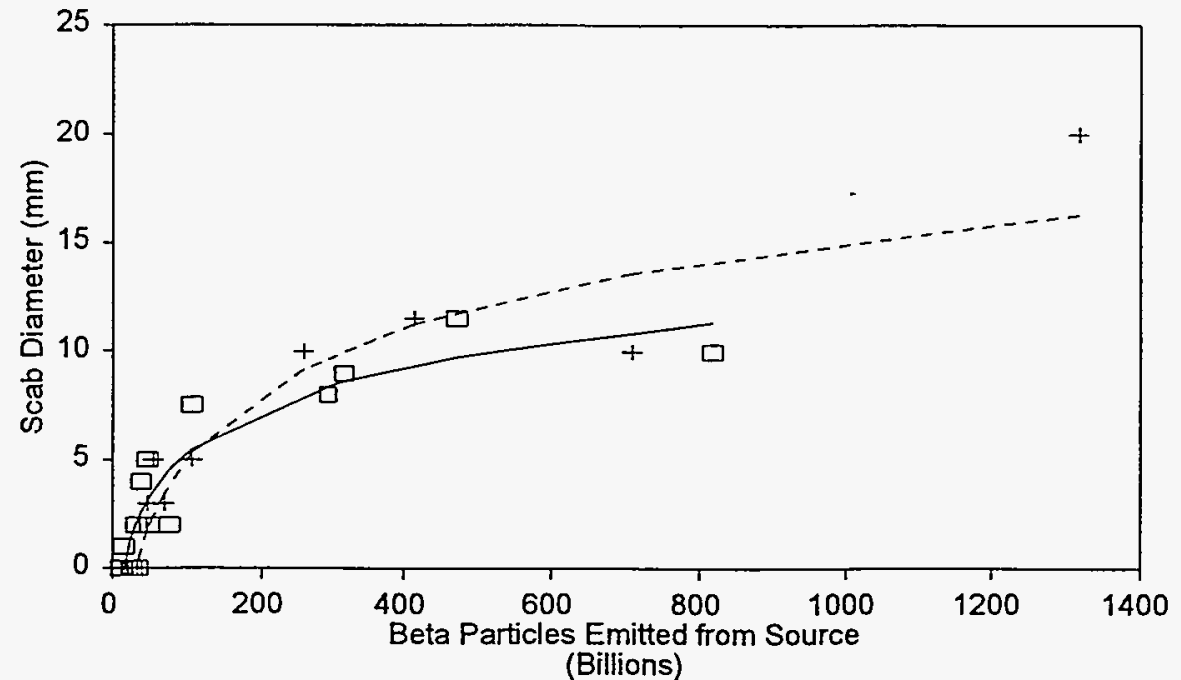

$\square$ On-Skin + Off-Skin - On-Skin Regress. - - . Off-Skin Regress.

Figure 6.4 Scab sizes for the $\mathrm{BNL} \mathrm{UC}_{2}$ experiment 2. The off-skin exposures were made by placing $440-\mu m$-thick denim between the source and the skin.

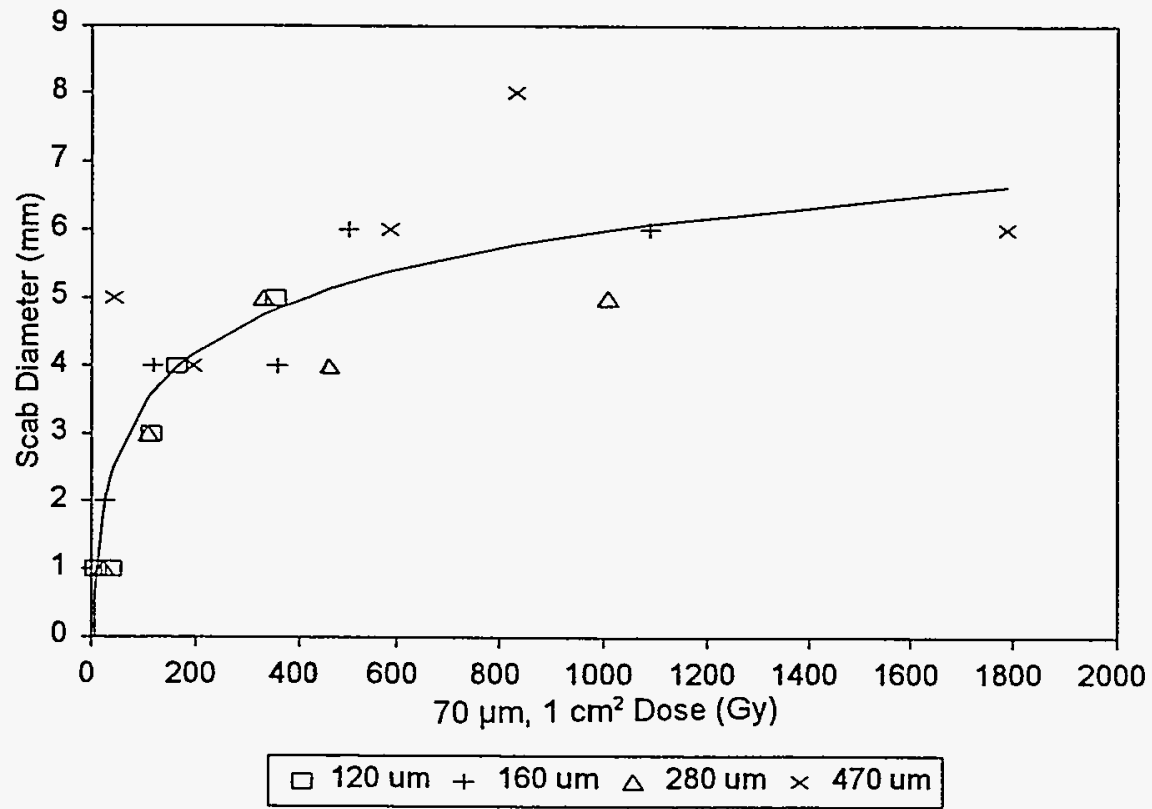

Figure 6.5 Scab sizes for different size $\mathrm{Tm}-170$ particles carried out for experiment 3 . 


\subsubsection{Comparisons of Reece et al.'s and BNL's Results for Activated U Exposures}

\subsubsection{On-skin Activated U Results}

Reece et al. (1994) studied skin injuries from hot particles having maximum energies from about $0.2 \mathrm{MeV}$ to about $3 \mathrm{MeV}$ including 32 exposures to $1-\mathrm{mm}$ diameter activated $\mathrm{UO}_{2}$ particles and 10 exposures to $0.3-\mathrm{mm}$ diameter $\mathrm{UO}_{2}$ particles. The animals' ages were not specified.

Animals were scored by three observers daily for the first 14 days, and twice weekly for the following 18 weeks with a final set of observations at week 20.

The lesions in these studies were reported as open sores, scabs, or scars. To compare Reece et al.'s results with BNL's results, their results for 0.3- and 1-mm-diameter particles were combined, grouping the data as shown in Table 6.2. Reece et al.'s data was grouped to generate adequate numbers of exposed sites for graphing and analysis. In the summary table in the Reece et al. report, a new criterion is used to reflect what is termed "skin injuries," which are open sores and/or scabs that persisted 20 weeks post-exposure. These results are listed in the last column of Table 6.2.

The percent scab incidence and percent skin injuries (both for Reece et al.'s combined data) are plotted in Figure 6.6 for comparison with BNL results obtained using 0.29-mm-diameter $\mathrm{UC}_{2}$ particles. The results from the two studies are significantly different. $E D_{50}$ values are about 11 Gy for BNL's scab data, about 33 Gy for Reece et al.'s scab data, and about 50 Gy for Reece et al.'s skin injury data. The large differences between BNL's scab results and Reece et al.'s skin injury criterion are not surprising since many BNL-detected scabs did not persist for 56 days. However, the large difference between the two for the scab incidence was not expected and we can only speculate about it. The Reece et al. scoring criteria were not stated in sufficient detail to know if a lesion was considered an open sore or scab, when one, two, or three of the observers scored it, nor if observers compared their observations and together agreed on how to score an observation, or if they scored separately to avoid biases. Since BNL observers did not compare results until scoring was completed, they did not always score a specific area the same. As described in Section 5.11, the results are somewhat dependent on scoring criteria with two observers, and would likely be even more so if all three were required to score an exposed areas as a scab for it to be counted as such. Especially at low doses, where lesions are very small, the requirement for three observers to score a barely detectable lesion would result in fewer positive results than for only two. Since the age of the animals was not given by Reece et al., the effect of age of the animals on the comparative result could not be judged. 


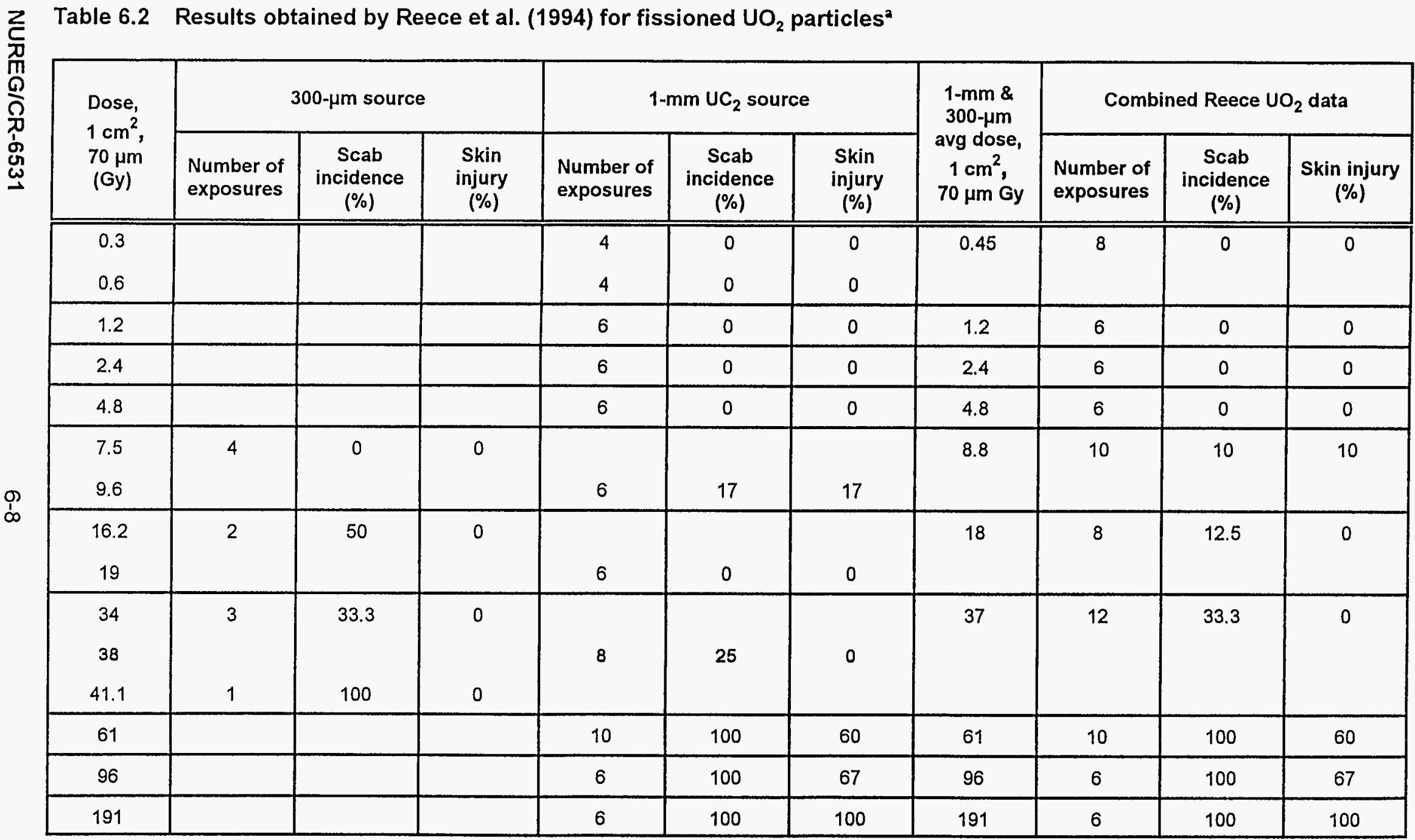

a. Their data for the 1.0- and 0.3-mm sources were combined in the last four columns to generate Figure 6.6. 


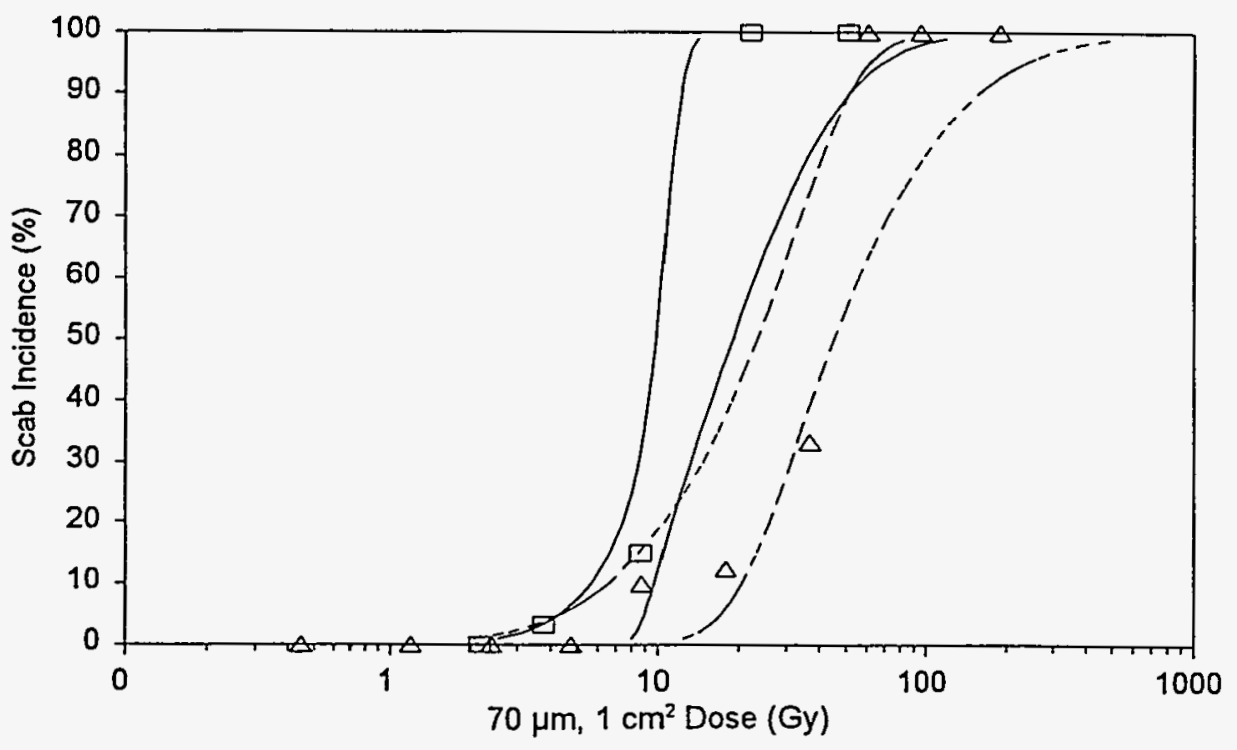

$\square$ BNL, $0.29 \mathrm{~mm} \triangle \mathrm{Reece}, 18.3 \mathrm{~mm}-\mathrm{BNL} 95 \% \mathrm{CLs}$ - . Reece $95 \%$ CLs

Figure 6.6 Comparison of 95\% confidence limits for BNL's on-skin 0.29$\mathrm{mm} \mathrm{UC}_{2}$ hot particle with results of Reece et al. (1994) for onskin 0.3-and 1.0-mm UO $\mathrm{mot}_{2}$ particles. Probit analysis on the Reece data set was carried out by BNL.

The estimated average maximum beta energy of the fissioned $\mathrm{UO}_{2}$ sources used by Reece et al. was less than $1.1 \mathrm{MeV}$. The estimated average beta particle energy of the fissioned $\mathrm{UO}_{2}$ was less than $0.4 \mathrm{MeV}$; this figure is based on interpolating values given for a 10-minute irradiation of U-235 and a 4-day cooling period (Ulberg and Kochendorfer, 1966). This energy was somewhat lower than that of BNL's fissioned $\mathrm{UC}_{2}$, which had average maximum beta-particle energy of 1.8 $\mathrm{MeV}$, and an average beta-particle energy of $0.71 \mathrm{MeV}$, based on similar interpolations. The particles used by Reece et al. also were covered with 70- $\mu$ m-thick Mylar. Only one significant digit was reported for the density of the Mylar $(1 \mathrm{~g} / \mathrm{cc}$ ), but Mylar density is usually approximately $1.3 \mathrm{~g} / \mathrm{cc}$, which would give a density thickness of $9.1 \mathrm{mg} / \mathrm{cm}^{2}$. The density thickness for the BNL Kapton cover was $1.8 \mathrm{mg} / \mathrm{cm}^{2}$. This greater value for Reece et al.'s cover may have degraded the beta-energy spectrum more than the covering material used by BNL. Thus, both the cover's greater density thickness and the lower beta-particle energy may have contributed to the differences. However, the lower beta-particle energy of the Reece et al.'s sources should be more effective in producing scabs, based on BNL's results for Tm-170 particles.

In Reece et al.'s pig exposures, six areas received doses of 19 Gy from the $1-\mathrm{mm} \mathrm{UO}_{2}$ source. The only effect noted was erythema for four of the sites after the second day. The erythema 


\section{Comparisons}

persisted for 9 to $24 \mathrm{DPI}$. These results are compared to BNL's results for nineteen areas exposed to $22 \mathrm{~Gy}$ from an on-skin 290- $\mu \mathrm{m} \mathrm{UC}_{2}$ source (Figure 6.7). BNL's results show erythema on $70 \%$ of the areas on the first day after the irradiation, persisting for about $30 \mathrm{DPI}$. This is somewhat similar to the Reece results. However, scabs began appearing on the ninth day after the exposure, and all the sites developed scabs for all BNL's scab-scoring criteria.

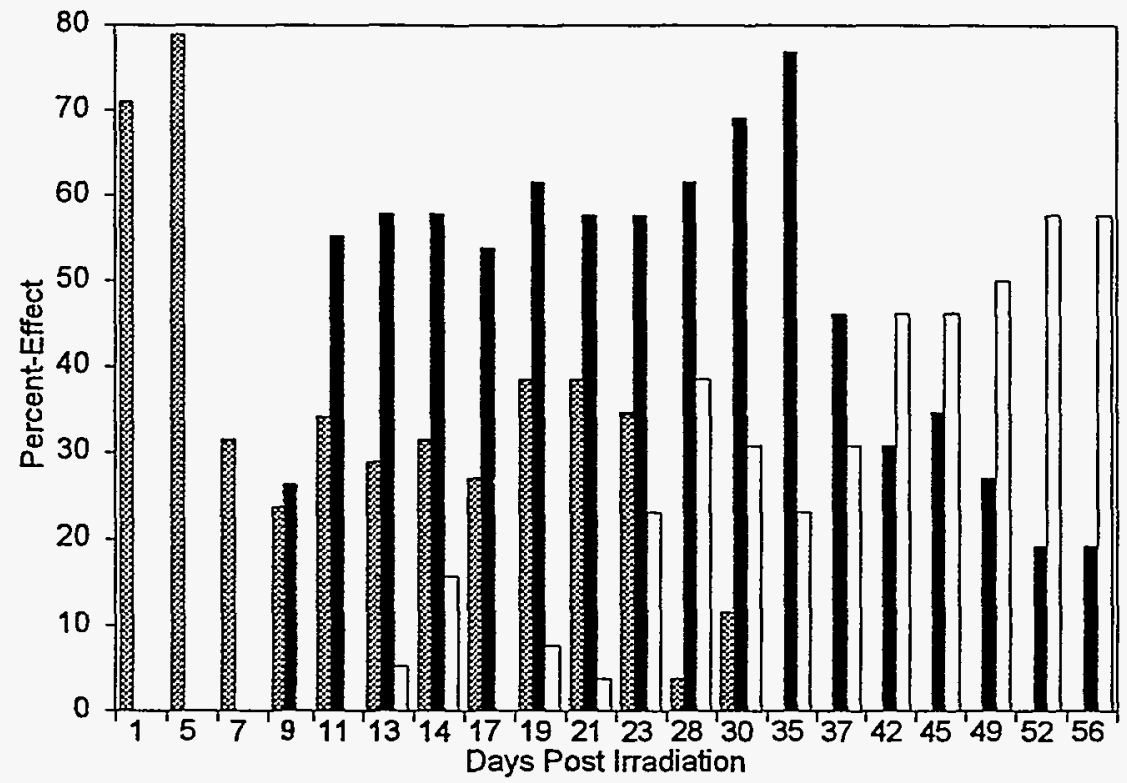

Erythema Dark Scabs $\square$ White Scabs

Figure 6.7 Percenteffect for days on which sites were scored for 19 areas receiving a dose of $22 \mathrm{~Gy}$ from $\mathrm{BNL}$ on-skin $\mathrm{UC}_{2}$ exposures.

\subsubsection{Off-Skin Activated U Results}

Reece et al. (1994) also carried out several off-skin $U_{2}$ pig irradiations. Four exposures of 4 to 6 Gy were made with the $1-\mathrm{mm} \mathrm{UO}_{2}$ source with $1.2 \mathrm{~cm}$ of air between the source and the skin. Six exposures also were made with a 0.2-mm-thick piece of shoe cover over the source. Doses of 18,28 , and 29 Gy were given to two different sites for each dose. The stated density of the cover was $0.6 \mathrm{~g} / \mathrm{cc}$, which gave a density thickness of $120 \mathrm{mg} / \mathrm{cm}^{2}$. The denim used in the BNL experiments was $440-\mu \mathrm{m}$ thick and had a density of $0.58 \mathrm{~g} / \mathrm{cc}$, which gave a density thickness of $260 \mathrm{mg} / \mathrm{cm}^{2}$, about twice that of the Reece et al. studies. 
None of the Reece et al. exposed sites developed into scabs. By contrast, the BNL studies, Method C, gave $62 \%$ incidence at $12 \mathrm{~Gy}$ and $89 \%$ incidence at $29 \mathrm{~Gy}$ (the background incidence of $3.2 \%$ was not subtracted from these values).

\subsection{Tm-170 Comparisons with Other Studies}

\subsubsection{BNL Tm-170 Results Compared with Those of Hopewell (1991)}

As shown in Section 5.3.5, BNL's Tm-170 results agreed well with those of Hopewell for observations to 28 DPI using scoring Method E and one similar to that used by Hopewell (1991). However, when observations were extended to $71 \mathrm{DPI}$, additional scabs were observed in BNL studies which lowered the $E D_{10}$ and $E D_{50}$ values. Other scoring methods (Sections 4.1 and 5.9) yielded somewhat higher $E D_{10}$ results for BNL's results compared to Hopewell, as shown in Table 6.5 below.

The statistical packages used for the probit regressions by Hopewell and BNL employed different procedures for determining the regression fit and the confidence limits. To better compare the two data sets, BNL carried out probit regressions for both the Hopewell and BNL Tm-170 data sets using BNL software (Tm-170 data kindly provided by Dr. M.W. Charles). The doses for this comparison are averaged over $1.1 \mathrm{~mm}^{2}$ at a depth of $16 \mu \mathrm{m}$, as reported by Hopewell (1991).

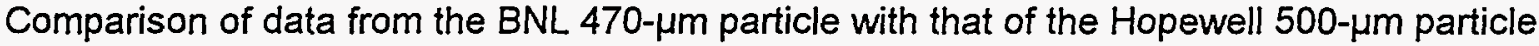
indicate that, while the slope of the Hopewell regression is steeper than that of the BNL regression (Figure 6.8), there is substantial overlap of the $95 \%$ confidence limits (Figure 6.9). Scoring Method $\mathrm{C}$ was used for scoring of the BNL scabs, and the background correction used was $3.2 \%$, which was actually observed for the $1995{\cup C_{2}}_{2}$ exposures. The observation period for the BNL data was 71 days. The scoring method used by Hopewell is as described in Section 4.1.2. The data are surprisingly similar, especially when the different observation periods ( 28 versus 71 days) are considered. The Hopewell data deviate from the predicted line more than do the BNL data due to fewer exposures made at each dose in the former (Figure 6.8). However, the Hopewell data cover a wider dose range with more dose regimens than the BNL data; consequently, the width of the confidence limits is comparable to the BNL data (Figure 6.9).

Hopewell (1991) also averaged the $\mathrm{ED}_{50}$ values for $0.1-, 0.5-, 1-$, and $2-\mathrm{mm}$ sources due to the similarity of the responses. BNL data are plotted with the Hopewell data on Figure 6.10. The t-test statistic for the regression analysis of these data was slightly larger than 1.96, which indicates that the Tm-170 combined particle data may not be from the same response population. Since the $E D_{50}$ value for results from Hopewell's $0.5-\mathrm{mm} \mathrm{Tm}-170$ particle is about $40 \%$ greater than the mean value for the other three particles, this result is not surprising.

\subsubsection{BNL On-skin Tm-170 Results Compared with Those of Reece et al. (1994)}

Figure 6.11 compares the results reported by Reece et al. (1994) using 1-mm-diameter disks of $\mathrm{Tm}-170$ with those obtained at BNL using a $0.47-\mathrm{mm}$ source. ED $\mathrm{ED}_{50}$ values of about 5.9 Gy and 


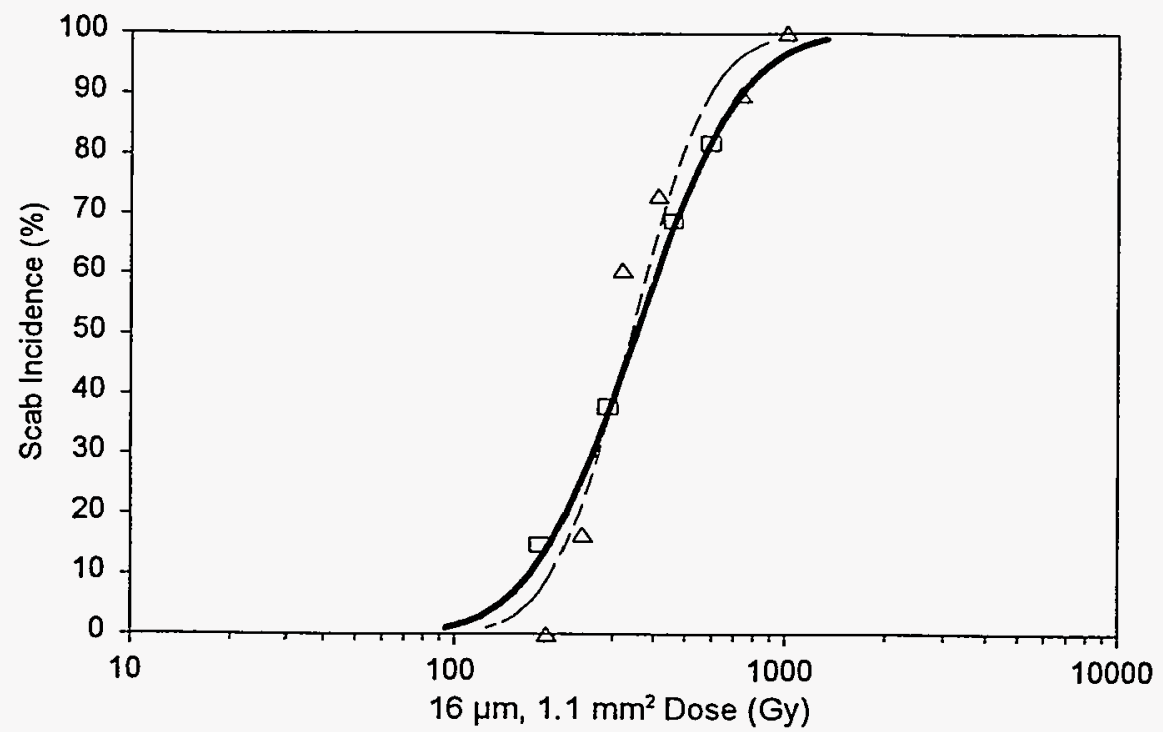

$\begin{array}{ll}\square \text { BNL } & - \text { BNL Regress } \\ \triangle \text { Hopewell } & -- \text { Hopewell Regress }\end{array}$

Figure 6.8 Comparison of probit regressions for Hopewell's (1991) data

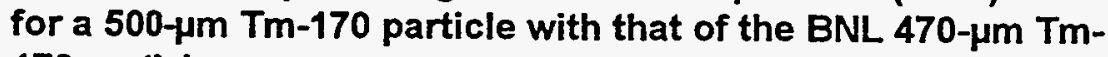
170 particle.

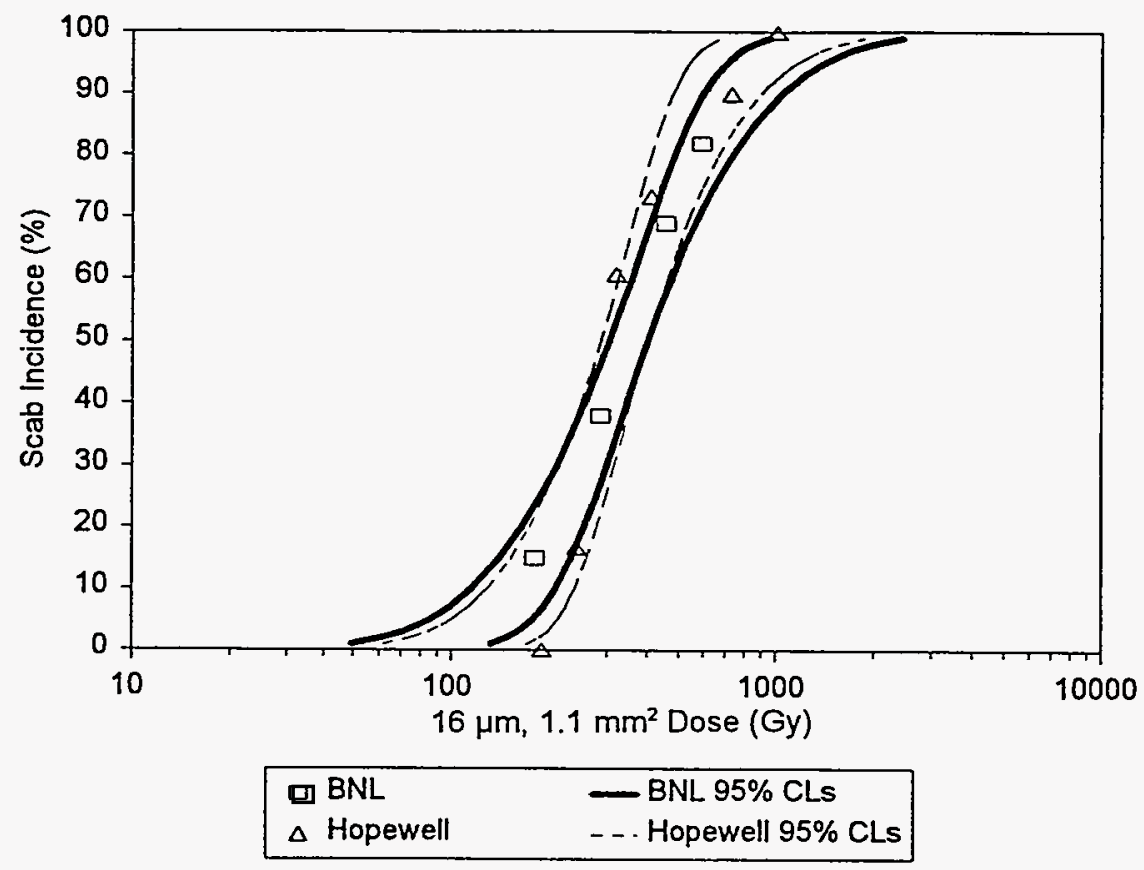

Figure 6.9 Comparison of 95\% confidence intervals for Hopewell's (1991)

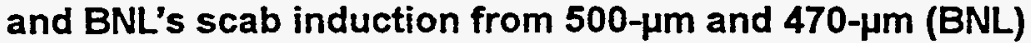
Tm-170 particles, respectively. 
Comparisons

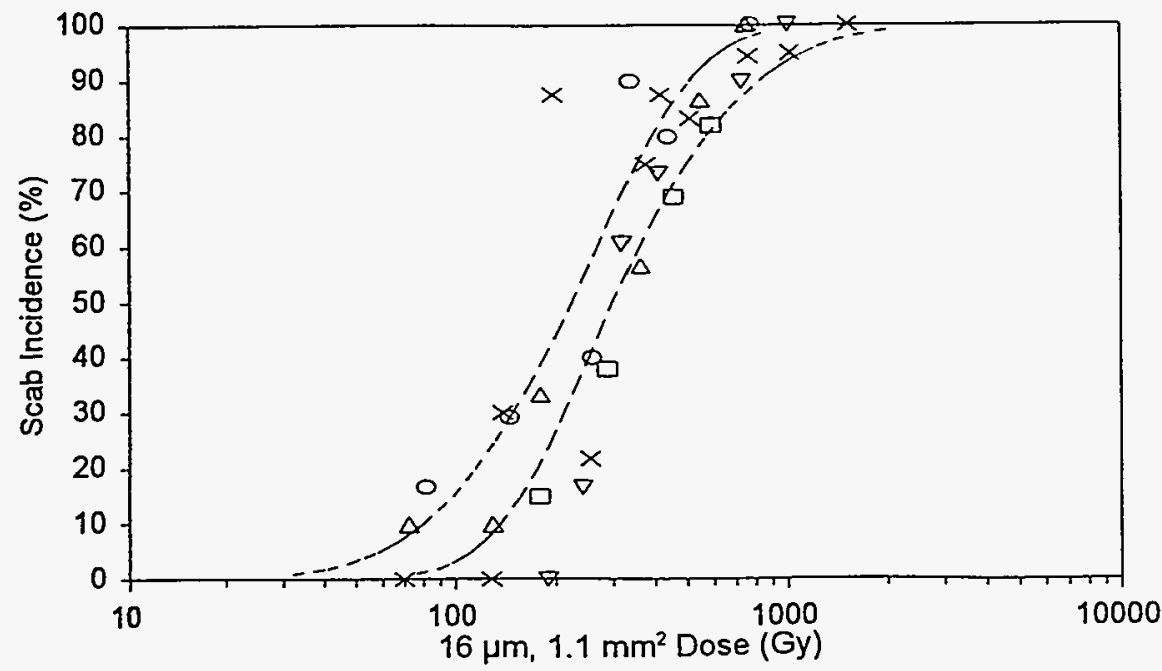

口 BNL -.. Hopewell $95 \%$ CLs $\nabla$ Hopewell $0.5 \mathrm{~mm}$

○ Hopewell $0.1 \mathrm{~mm} \triangle$ Hopewell $1 \mathrm{~mm} \times$ Hopewell $2 \mathrm{~mm}$

Figure 6.10 Comparison of probit regression for Hopewell's combined

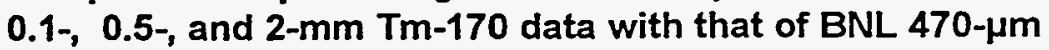
diameter $\mathrm{Tm}-170$ data.

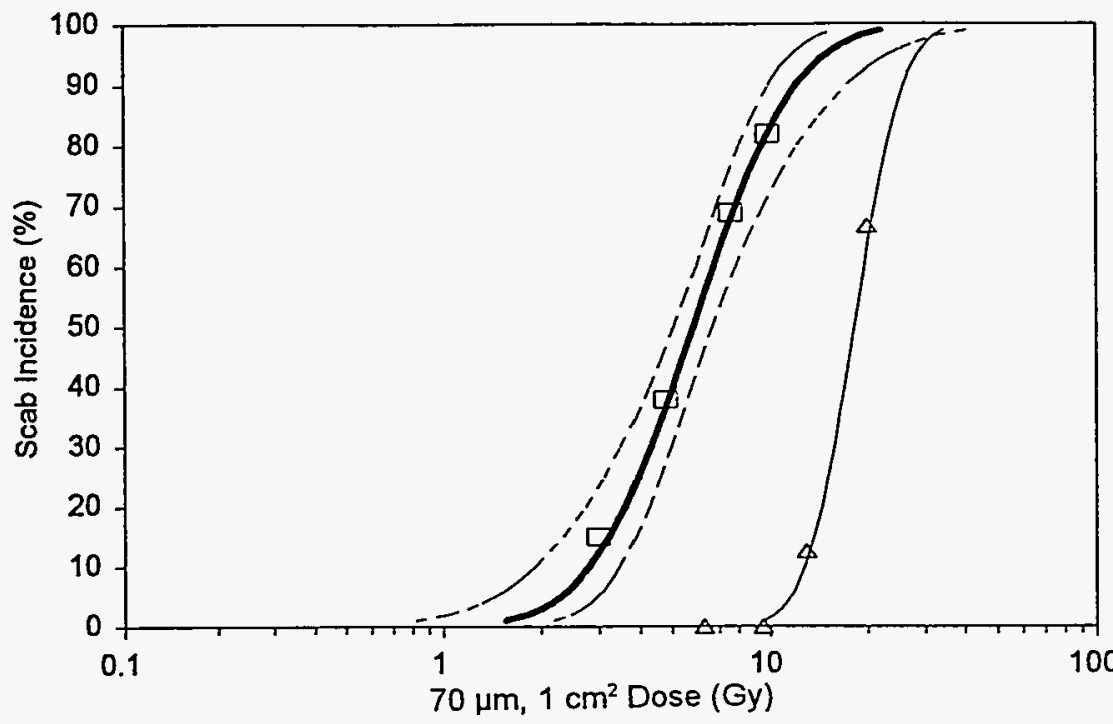

$\square$ BNL $\quad$ BNL Regress BNL 95\% CLs

$\triangle$ Reece 1-mm Tm-170 — Reece Regress

Figure 6.11 Comparison of scabs induced by Reece et al.'s (1994) 1-mm on-skin Tm-170 particle with that of BNL $0.47-\mathrm{mm}$ on-skin Tm170 particle. The few exposures in the Reece study gave insufficient information to determine reasonable confidence limits. 


\section{Comparisons}

18 Gy were obtained for BNL and Reece et al.'s results, respectively. Thus, a ratio of about three or four to one is obtained both for these $E D_{50}$ values and those obtained above for the $U C_{2}$ comparison. The uncertainties on the Reece et al.'s $E_{50}$ value are large since only 1 of 8 exposures yielded a scab at $13.1 \mathrm{~Gy}$, and 2 of 3 exposures yielded scabs at $20.1 \mathrm{~Gy}$ (Table 6.3) Again, the differences could have been due to greater beta-particle energy loss in the source and the thicker cover, different scoring criteria, or possibly, the pigs may have been of a different age.

Table 6.3 Doses given to pig skin for on-skin 1-mm Tm-170 sources during the Reece et al. (1994) study. The "average dose" and "\% scab incidence" columns show data used for graphic presentation (Figure 6.11).

\begin{tabular}{|c|c|c|c|c|}
\hline $\begin{array}{c}\text { Dose } \\
(\mathrm{Gy})\end{array}$ & $\begin{array}{c}\text { Number of } \\
\text { exposures }\end{array}$ & $\begin{array}{c}\text { Number of } \\
\text { scabs }\end{array}$ & $\begin{array}{c}\text { Average dose } \\
(\mathrm{Gy})\end{array}$ & $\begin{array}{c}\text { \% Scab } \\
\text { incidence }\end{array}$ \\
\hline 4.7 & 1 & 0 & 6.3 & 0 \\
7.8 & 1 & 0 & 9.5 & 0 \\
\hline 9.3 & 2 & 0 & & \\
9.6 & 2 & 0 & 13 & \\
\hline 11.7 & 4 & 0 & & \\
14.1 & 1 & 0 & & \\
14.4 & 1 & 0 & 20 & \\
\hline 14.8 & 2 & 1 & & \\
\hline 17.6 & 1 & 0 & 1 & \\
21.1 & 1 & 0 & & \\
21.7 & 1 & & & \\
\hline
\end{tabular}

\subsubsection{Off-Skin Tm-170 Results Compared with those of Reece et al. (1994)}

Reece et al. (1994) exposed animals to $1-\mathrm{mm}$ diameter $\mathrm{Tm}-170$ particles that were separated from the skin by $0.8,1.6,2.4,3.2$, and $4.0 \mathrm{~mm}$. BNL made several exposures that were separated from the skin by 0.8 and $1.4 \mathrm{~mm}$. BNL's data and Reece et al.'s data for 0.8 and 1.6 $\mathrm{mm}$ are summarized in Table 6.4 for dose at $70 \mu \mathrm{m}$ depths.

The BNL data set consisted of only eight data points, four for each height off the skin. The data are insufficient to draw meaningful conclusions but are not in obvious conflict with Reece et al.'s data (1994) (Figure 6.12). The $E D_{10}$ and $E D_{50}$ values calculated for the combined Reece data is 9.8 and $18 \mathrm{~Gy}$. These values are similar to Reece's on-skin Tm-170 data. 
Table 6.4 Tm-170 particle off-skin results. Reece et al.'s 1-mm hot particle data (1994) are compared with BNL's 0.12 - to $0.47-\mathrm{mm}$ hot particle findings for scab induction from Tm-170 particles that were 0.8 and $1.4 \mathrm{~mm}$ off-skin. The BNL 1.4-mm off-skin particle and Reece et al.'s 1.6-mm off-skin are grouped together.

\begin{tabular}{|c|c|c|c|c|c|c|}
\hline \multirow{3}{*}{$\begin{array}{l}\text { Dose } 1 \mathrm{~cm}^{2} \\
70 \mu \mathrm{m}(\mathrm{Gy})\end{array}$} & \multicolumn{3}{|c|}{$0.8 \mathrm{~mm}$} & \multicolumn{3}{|c|}{$1.6 \mathrm{~mm}$ (Reece) and $1.4 \mathrm{~mm}$ (BNL) } \\
\hline & \multirow{2}{*}{$\begin{array}{l}\text { Number of } \\
\text { exposures }\end{array}$} & \multicolumn{2}{|c|}{ Number of scabs } & \multirow{2}{*}{$\begin{array}{l}\text { Number of } \\
\text { exposures }\end{array}$} & \multicolumn{2}{|c|}{ Number of scabs } \\
\hline & & Reece & BNL & & Reece (1.6) & BNL (1.4) \\
\hline 7.6 & & & & 1 & 0 & \\
\hline 8.3 & 1 & 0 & & & & \\
\hline 8.7 & 2 & 0 & & & & \\
\hline 11 & 4 & 0 & & & & \\
\hline 11 & & & & 1 & 0 & \\
\hline 12 & & & & 3 & 0 & \\
\hline 12 & 2 & 0 & & & & \\
\hline 13 & 2 & 1 & & & & \\
\hline 14 & 2 & 2 & & & & \\
\hline 14 & & & & 1 & 1 & \\
\hline 16 & & & & 1 & 0 & \\
\hline 17 & 4 & 3 & & & & \\
\hline 20 & 1 & 0 & & & & \\
\hline 21 & 2 & 1 & & & & \\
\hline 25 & 1 & & 1 & & & \\
\hline 25 & 2 & 1 & & & & \\
\hline 26 & 1 & 1 & & & & \\
\hline 26 & & & & 2 & 1 & \\
\hline 35 & 1 & 1 & & & & \\
\hline 52 & & & & 1 & & 0 \\
\hline 56 & 1 & & 0 & & & \\
\hline 106 & 1 & & 1 & & & \\
\hline 108 & & & & 1 & & 1 \\
\hline 221 & & & & 1 & & 1 \\
\hline 243 & 1 & & 1 & & & \\
\hline 467 & & & & 1 & & 1 \\
\hline
\end{tabular}




\section{Comparisons}

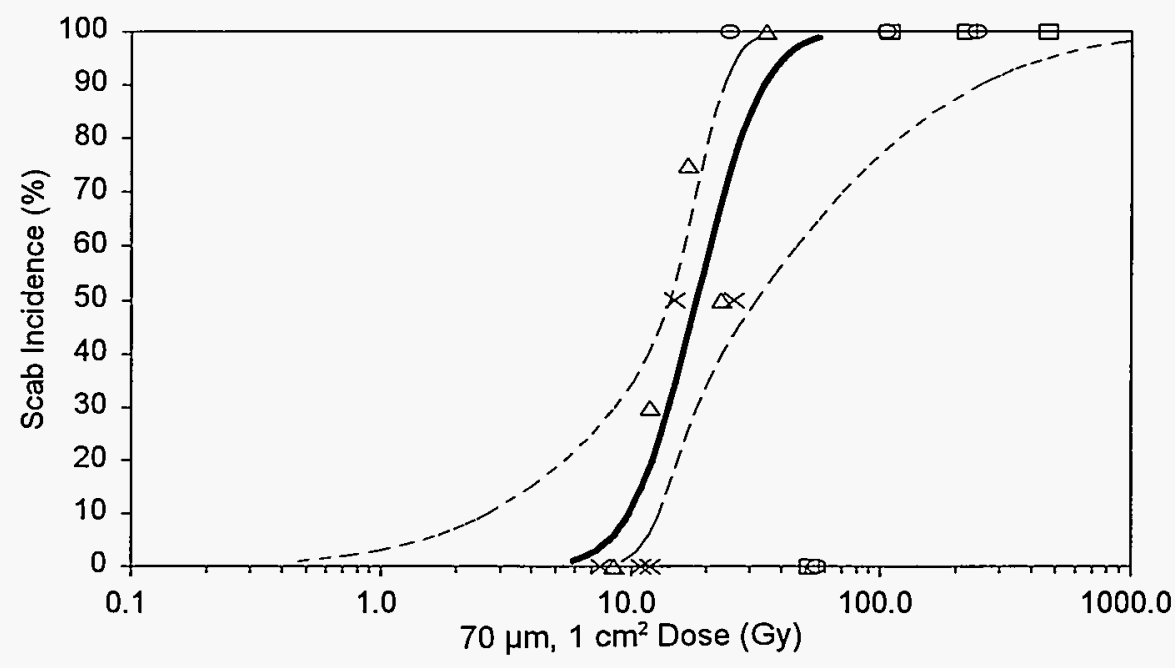

$\triangle$ Reece $0.8 \mathrm{~mm}$ off $\times$ Reece $1.6 \mathrm{~mm}$ off $\bigcirc$ BNL $0.8 \mathrm{~mm}$ off BNL $1.4 \mathrm{~mm}$ off — Reece Regression - - Reece $95 \%$ CLs

Figure 6.12 Probit analysis of Reece et al.'s (1994) 0.8-mm and 1.6-mm offskin $\mathrm{Tm}-170$ results. Only single exposures were carried out by BNL at selected doses for $\mathrm{Tm}-170$ particles $0.8-\mathrm{mm}$ and 1.4-mm off-skin.

\subsection{Sc-46/Co-60 Comparisons}

Reece et al. (1994) exposed 82 spots to a Co-60 particle of about $1 \mathrm{~mm}$ in its largest dimension, and 18 spots to a $1-\mathrm{mm}$-long, $200-\mu \mathrm{m}$-diameter cobalt wire containing Co-60. The doses ranged from $1.8 \mathrm{~Gy}$ to $58 \mathrm{~Gy}$. Only two doses gave scabs; $29 \mathrm{~Gy}$ (1 of 6 exposures) induced a $17 \%$ scab incidence, which rose to $100 \%$ after 58 Gy (3 of 3 exposures). The results are plotted in Figure 6.13 and compared with BNL's results for Sc-46 exposures of approximately the same $\beta$ and $Y$ energies. $E D_{50}$ values of about 12 and $34 \mathrm{~Gy}$, respectively, were obtained based on BNL probit analyses of both data sets. While the number of exposures carried out by Reece et al. (1994) were quite large, confidence intervals could not be calculated due to the paucity of scabs induced.

The ratio of these values is again about 3 to 1 . This ratio may be influenced somewhat by the greater $\beta / Y$ ratio for BNL's Sc-46 doses compared to Reece et al.'s Co-60 doses. Only four Reece et al. exposures produced scabs -- 1 of 6 exposures at $28.8 \mathrm{~Gy}$, and 3 of 3 exposures at $58 \mathrm{~Gy}$. These were all due to exposures to the larger particle which Reece et al. estimated had approximately equal $\beta$ and $\gamma$ doses at the surface of the skin, but would have had much larger $\gamma$ than $\beta$ particle doses at $70 \mu \mathrm{m}$ depth in tissue. 


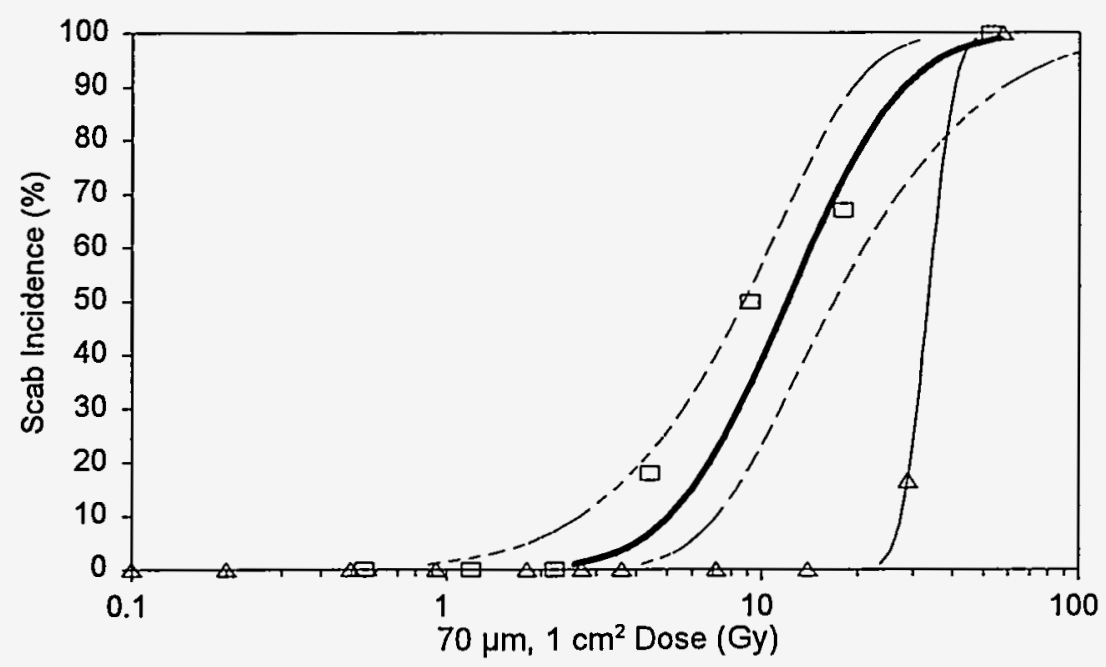

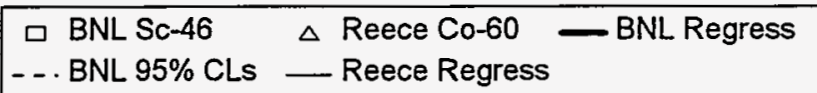

Figure 6.13 Comparison of Reece et al.'s (1994) 1- $\mathrm{mm} \times 1-\mathrm{mm} \times 0.4-\mathrm{mm}$ Co-60 source and 1-mm long, 200- $\mu \mathrm{m}$ thick Co-60 wire with BNL's $0.44-\mathrm{mm}$ Sc-46 particle. Insufficient scabs resulted from the Co-60 exposures to generate $95 \%$ confidence limits.

\subsection{Comparisons with Results of Hopewell (1986) for Pm-147, Tm- 170 , and $\mathrm{Sr} / \mathrm{Y}-90$}

Hopewell et al. (1986) employed 2-mm-diameter disks of Pm-147 having $0.22 \mathrm{MeV}$ maximum beta-particle energy, Tm-170 foils of 0.1 to $2 \mathrm{~mm}$ diameter with $0.97 \mathrm{MeV}$ maximum beta-particle energy, and a 1-mm-diameter $\mathrm{Sr} / \mathrm{Y}-90$ bead (in a somewhat collimated holder) with an average maximum beta particle energy of $1.4 \mathrm{MeV}$ (average of $\mathrm{Sr}-90$ and $\mathrm{Y}-90$ maximum energies). Their $E D_{10}$ and $E D_{50}$ results were reported for doses measured at $16 \mu \mathrm{m}$ depth in tissue and averaged over $1.1 \mathrm{~mm}^{2}$. To compare their results with those of BNL and Reece et al. expressed as dose averaged over $1 \mathrm{~cm}^{2}$ at $70 \mu \mathrm{m}$ depth in tissue, reported results were divided by the ratios of doses at these depths and areas calculated using the VARSKIN MOD2 code (Durham, 1991). These ratios were 124 for Pm-147, 59 for Tm-170 (measured at $16 \mu \mathrm{m}$ depth for a $0.5-\mathrm{mm}$ size source), and 44 for $\mathrm{Sr} / \mathrm{Y}-90$. The results are summarized in Table 6.5. Only ED $\mathrm{D}_{50}$ values are listed in Table 6.5 for Reece et al. data because the number of spots exposed did not yield sufficient lesions to reliably estimate incidence at the $10 \%$ level. The data from Table 6.5 are plotted in Figures 6.14 and 6.15 for average and maximum beta-particle energies. These energies do not reflect energy losses within the sources or their containers. These losses may be important, especially for the Pm, Co, and Sc sources. Also, the Sr/Y-90 source employed by Hopewell was somewhat collimated. 
Comparisons

Table 6.5 Comparison of Hopewell et al.'s (1986), BNL's, and Reece et al.'s (1994) results

\begin{tabular}{|c|c|c|c|c|c|c|c|}
\hline \multirow{2}{*}{ Isotope } & \multirow{2}{*}{$\begin{array}{c}E_{\max } \\
(\mathrm{MeV})\end{array}$} & \multirow{2}{*}{$\begin{array}{c}E_{\text {avg }} \\
(\mathrm{MeV})\end{array}$} & \multicolumn{2}{|c|}{ Hopewell } & \multicolumn{2}{|c|}{$\mathrm{BNL}^{\mathrm{d}}$} & \multirow{2}{*}{$\begin{array}{c}\text { Reece } \\
\mathrm{ED}_{50} \\
(\mathrm{~Gy})\end{array}$} \\
\hline & & & $\begin{array}{l}E D_{10} \\
(G y)\end{array}$ & $\begin{array}{l}E D_{50} \\
\text { (Gy) }\end{array}$ & $\begin{array}{l}E D_{10} \\
\text { (Gy) }\end{array}$ & $\begin{array}{l}E D_{50} \\
(G y)\end{array}$ & \\
\hline Pm-147 & 0.22 & 0.062 & 2.7 & 3.9 & & & \\
\hline Co-60 & 0.32 & 0.096 & & & & & 40 \\
\hline Sc-46 & 0.36 & 0.11 & & & $\begin{array}{c}5.1 \\
(2.7-7.2)\end{array}$ & $\begin{array}{c}12.0 \\
(8.8-17)\end{array}$ & \\
\hline Yb-175 & 0.47 & 0.12 & & & $\begin{array}{c}1.3 \\
(0.9-1.8)\end{array}$ & $\begin{array}{c}6.0 \\
(4.3-9.7)\end{array}$ & \\
\hline Tm-170 & 0.97 & 0.29 & 1.9 & 4.5 & $\begin{array}{c}2.8 \\
(1.9-3.5)\end{array}$ & $\begin{array}{c}5.9 \\
(5.1-6.7)\end{array}$ & $18^{e}$ \\
\hline $\mathrm{Sr} / \mathrm{Y}-90$ & $1.4^{b}$ & 0.55 & 3.4 & 8.4 & & & \\
\hline$U(\text { on-skin })^{c}$ & & 79 , 19 & & & $\begin{array}{c}8.5 \\
(5.7-9.8)\end{array}$ & $\begin{array}{c}11.4 \\
(10-19)\end{array}$ & 40 \\
\hline$U$ (off-skin) & & & & & $\begin{array}{c}4.5 \\
(0.9-7.2)\end{array}$ & $\begin{array}{c}10.6 \\
(6.2-14)\end{array}$ & \\
\hline
\end{tabular}

a. Dose averaged over $1 \mathrm{~cm}^{2}$ at $70 \mu \mathrm{m}$ depth (Gy).

b. Average of the maximum and average energies emitted by the isotopes in the source. The values for fissioned U-235 were determined from Ulberg and Kochendorfer (1966) for a 10-minute activation. Values in parentheses are estimated values for the Reece et al. (1994) studies.

c. BNL used $\mathrm{UC}_{2} ;$ Reece et al. used $\mathrm{UO}_{2}$.

d. Values in parentheses are $95 \%$ confidence limits.

e. The same value was obtained for particles 0.8 or $1.6 \mathrm{~mm}$ off the skin.

The shallow response curve and the lower $E D_{10}$ value for the $\mathrm{Yb}-175$ source is somewhat perplexing (Figure 6.16). Scab incidence for the $\mathrm{Yb}-175$ sources was consistently higher than the other isotopes for doses less than $3.7 \mathrm{~Gy}$ (Figure 6.17). The ED $1095 \%$ confidence limits for the $\mathrm{Yb}-175$ source, including the 1992 data, do not overlap with the $E D_{10} 95 \%$ confidence limits of the Sc-46 or the Tm-170 induced response (see sixth column in Table 5.16 and Figure 5.57). 


\section{BNL Results}

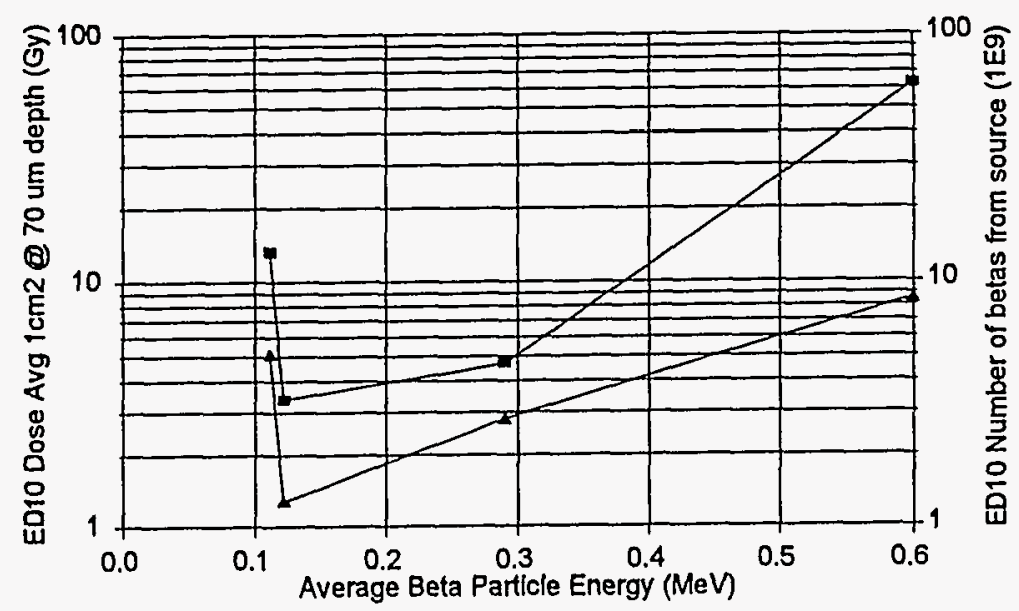

$\rightarrow$ ED10 $\rightarrow$ 1E9 Betas

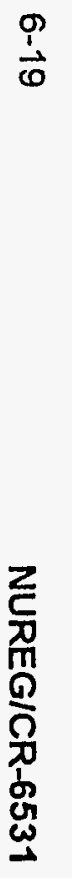

Hopewell Results

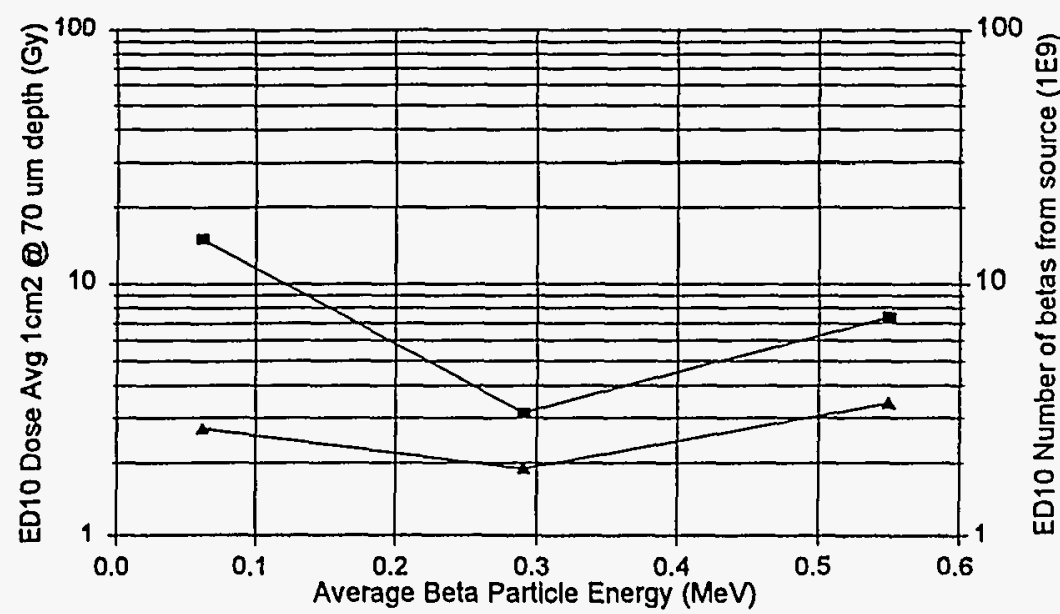

$\rightarrow$ ED10 $\rightarrow$ 1E9 Betas

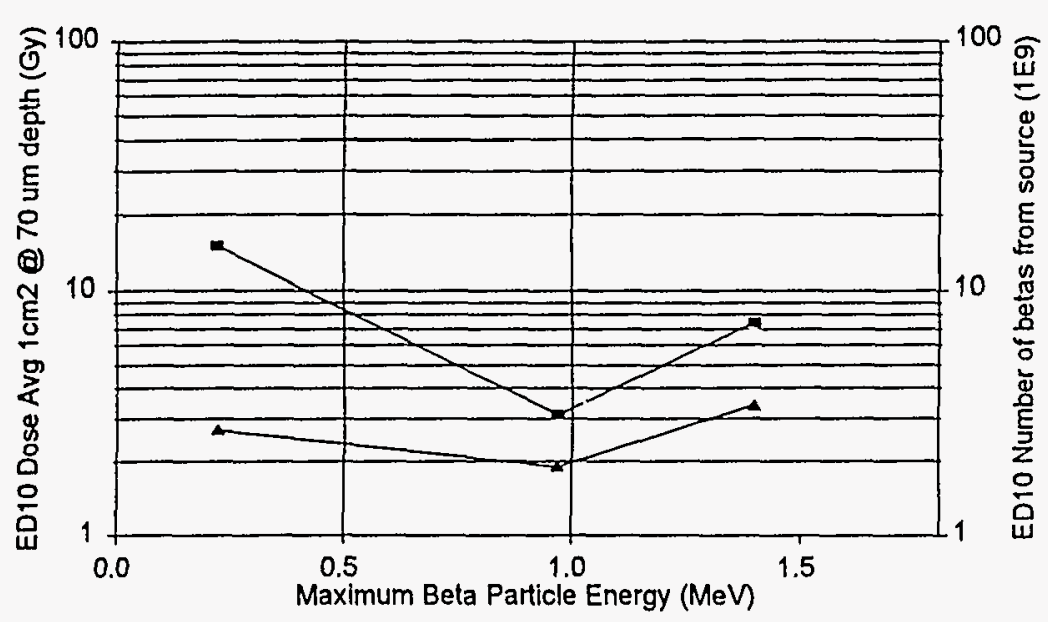

$\rightarrow-$ ED10 $\quad-1$ E9 Betas

Figure 6.14 Comparison of $\mathrm{BNL}$ and Hopewell $\mathrm{ED}_{10}$ with average and maximum beta particle energies 

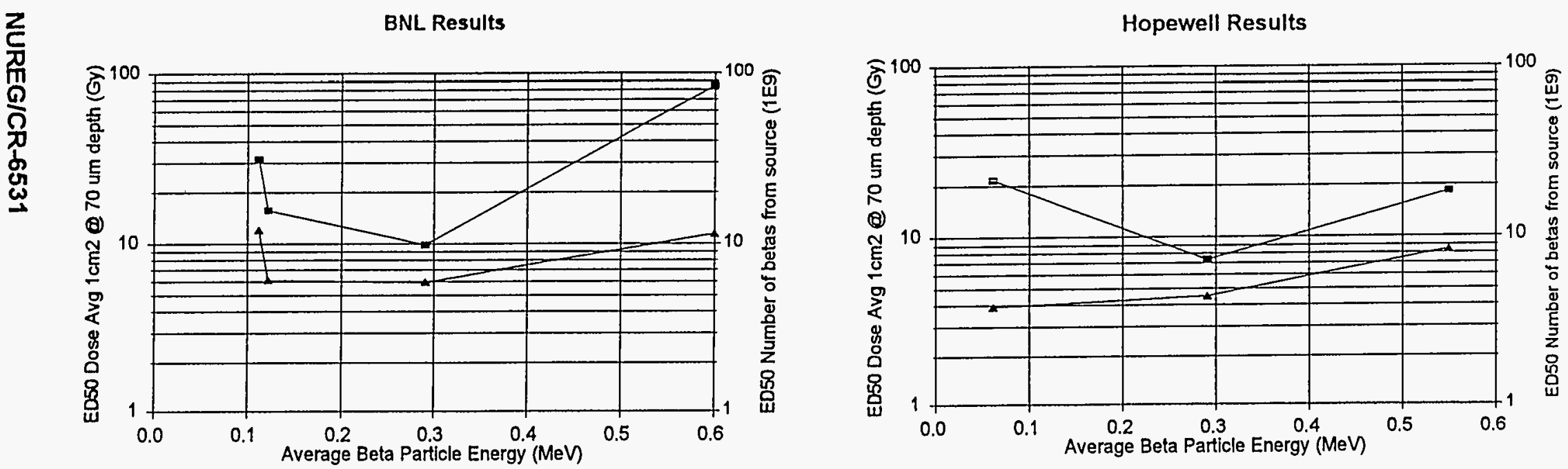

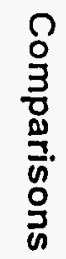

离

$$
\rightarrow \text { ED50 } \rightarrow \text { 1E9 Betas }
$$
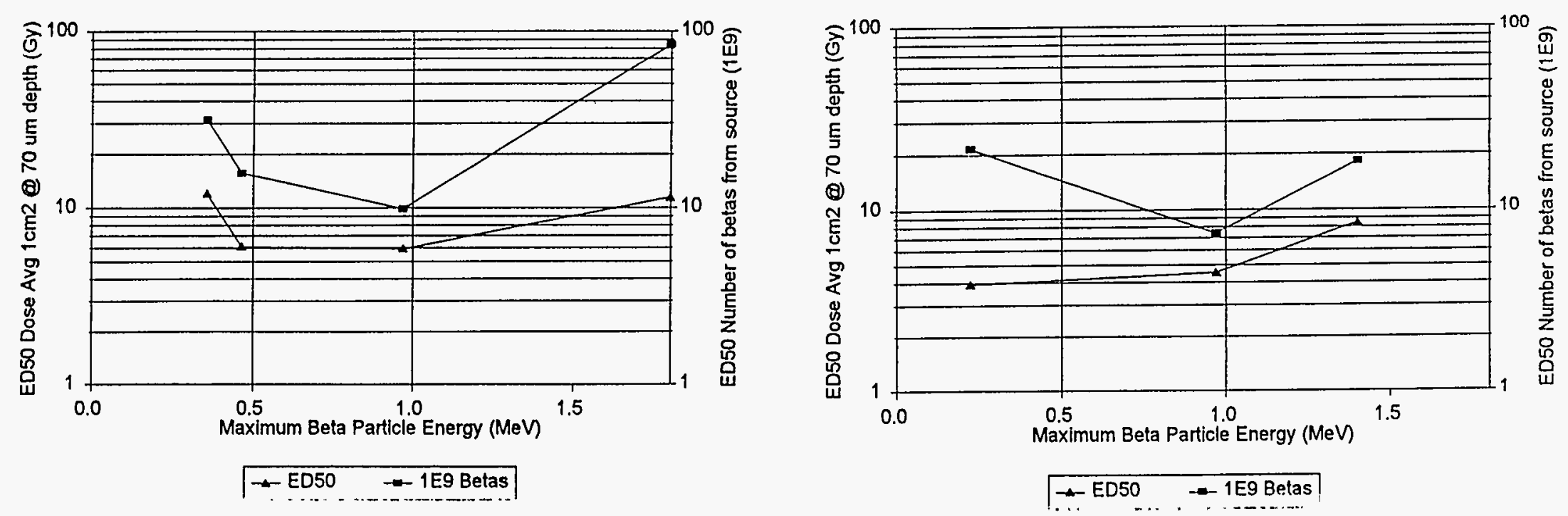

Figure 6.15 Comparison of $B N L$ and Hopewell $\mathrm{ED}_{50}$ with average and maximum beta particle energies 


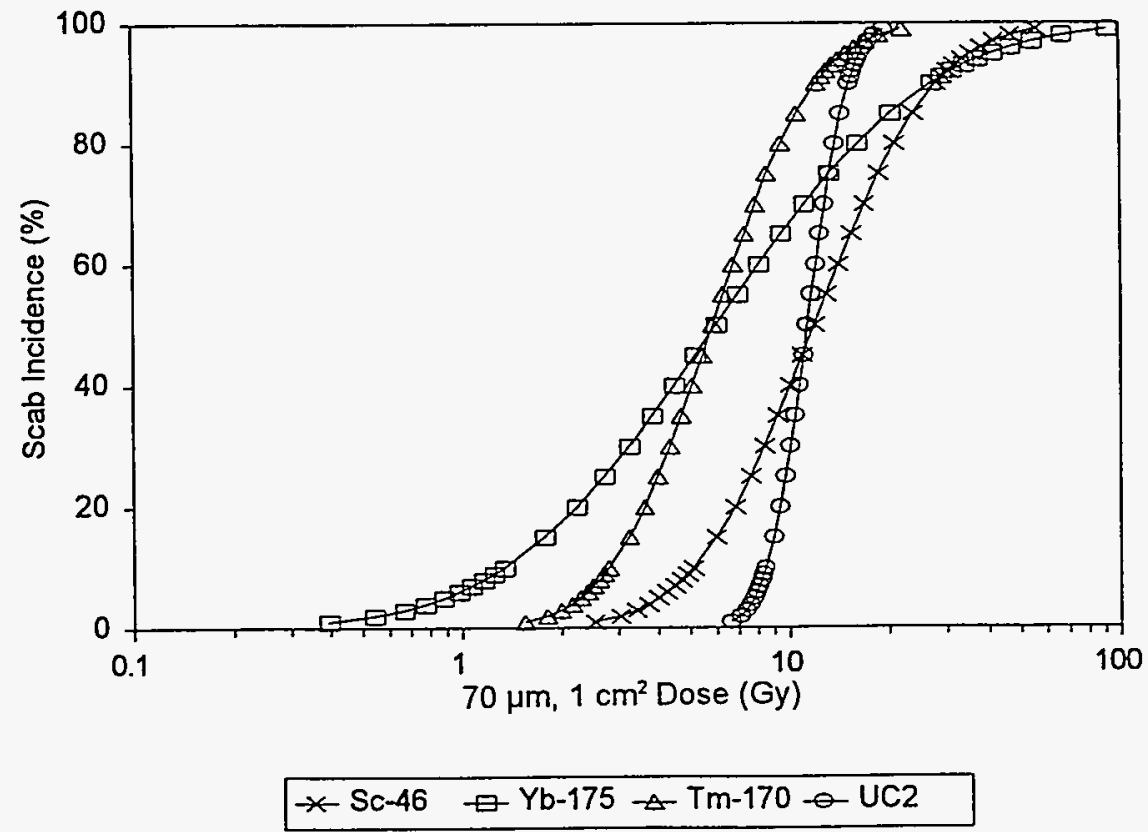

Figure 6.16 Probit regression results for all BNL's on-skin hot-particle data on scab incidence. Symbols on the regression lines are not data points, but aids to distinguish between the different responses.

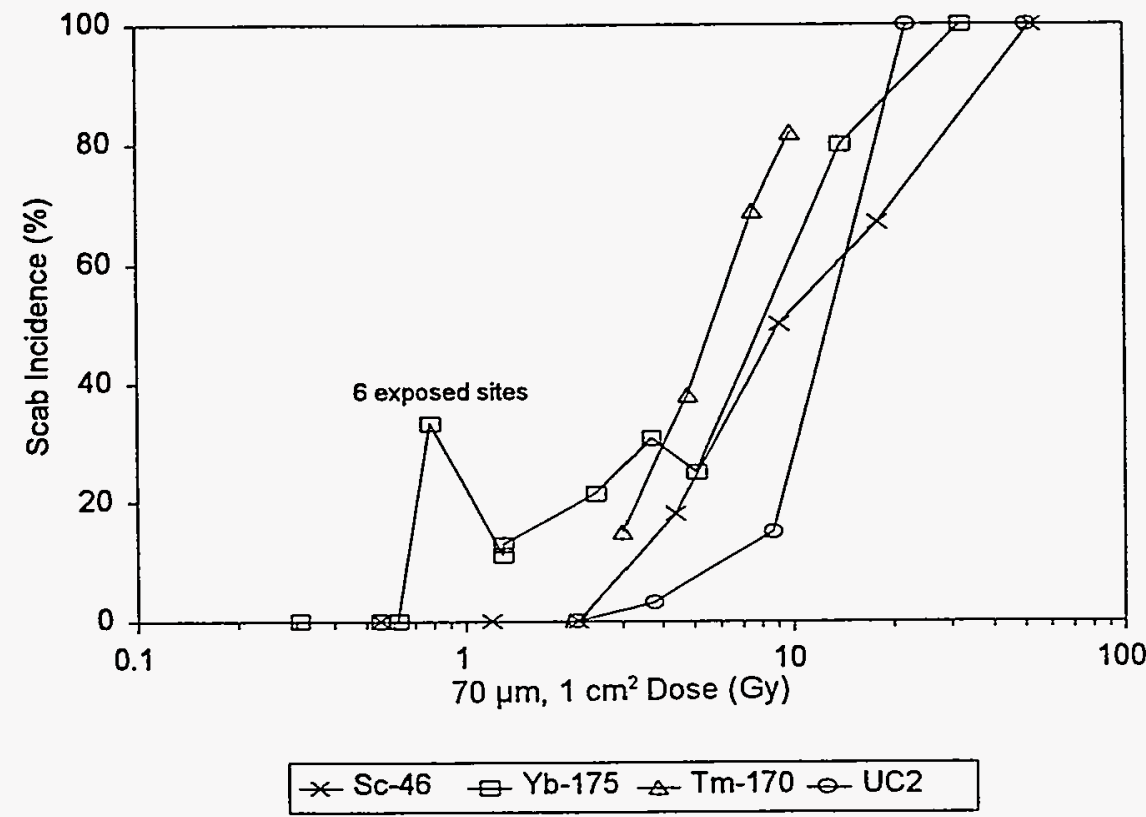

Figure 6.17 Scab incidence results for all BNL on-skin hot particles. Lines connect each data point to aid the eye. 


\section{SUMMARY, DISCUSSION, AND CONCLUSIONS}

Pig skin is very similar to human skin. Therefore, to establish a scientific data base that could be used to set acceptable exposure levels for humans, the induction of lesions in pig skin by exposure to radioactive particles of less than $1 \mathrm{~mm}$ in largest dimension was studied. More than 1,100 locations on the pigs were exposed, using particles ranging in maximum beta-particle energy from $0.3 \mathrm{MeV}$ (Sc-46) to about 2-3 MeV (mixed fission product sources). The betaparticle sources that induced small scabs with greatest efficiency at low doses were $\mathrm{Yb}-175$ (maximum energy at $0.47 \mathrm{MeV}$ ) and Tm-170 (maximum energy at $0.97 \mathrm{MeV}$ ). These sources produced detectable scabs with $50 \%$ incidence after doses of about 6 Gy averaged over $1 \mathrm{~cm}^{2}$ at $70-\mu \mathrm{m}$ depth in tissue. This result compares favorably with the $10^{10}$ beta-particle limit recommended by the NCRP (1989) to avoid deep ulceration.

The dose required for $10 \%$ incidence was generally about half of the $E D_{50}$ dose; however, for $\mathrm{Yb}-175$, this dose was unusually low, about $1.3 \mathrm{~Gy}$, with $95 \%$ confidence limits of 0.89 and $1.8 \mathrm{~Gy}$. This result is consistent with the $1 \mathrm{~Gy}$ limit recommended by the ICRP 59 task group (1991a).

$\mathrm{Tm}-170$ and $\mathrm{UC}_{2}$ particles held slightly off the skin $(0.4$ to $1 \mathrm{~mm})$ were approximately equally likely to produce lesions for doses averaged over $1 \mathrm{~cm}^{2}$ at $70-\mu \mathrm{m}$ depth when compared to on the skin. However, for doses in the range of $50 \%$ incidence, the scabs tended to be larger for sources off the skin than for those on the skin; this is attributed to a more uniform spread of dose for off-skin particles (less wasting of energy in the central portion of the lesion).

Scab incidence is a function of beta particle energy as well as dose, when dose is averaged over $1 \mathrm{~cm}^{2}$ area at a depth of $70 \mu \mathrm{m}$. Scabs are induced at lower doses for beta-particle emitters with maximum energies between 0.5 and $1.0 \mathrm{MeV}$, with scab-induction dose increasing for lower and higher maximum beta-energy emitters. The $E D_{10}$ for $0.5 \mathrm{MeV}$ maximum energy beta emitters was significantly less than that for other hot particles. The $E D_{50}$ values for the $\mathrm{Yb}-175$ and $\mathrm{Tm}-170$ hot particles were similar, $6.0(4.3-9.795 \% \mathrm{Cls})$ and 5.9 (5.1-6.7 95\% Cls) Gy, respectively.

Comparisons with other studies showed only fair agreement with those of Forbes and Mikhail (1969, in NCRP, 1989, and in Charles and Wells, 1980) for $U_{2}$ exposures (mixed fission products) differing by factors of 2 to 4 . These differences are likely due in part to differences in scoring criteria. Forbes and Mikhail scored lesions as ulcers or dry desquamation (Charles and Wells, 1980), whereas BNL scored lesions as scabs. Our scabs may include some lesions Forbes and Mikhail classified as dry desquamation. These differences were not analyzed further due to the qualitative nature of the scab or ulcer diameter analyses. Agreement with data of Hopewell (1991) was within a factor of 1.5 for $\mathrm{Tm}-170$ exposures $(0.97 \mathrm{MeV}$ maximum beta energy). However, BNL doses were factors of 3 to 4 lower for scab induction than the doses for induction of "skin injuries" (scabs plus open sores) in the Reece et al. (1994) UO $\mathrm{O}_{2} \mathrm{Tm}-170$, and Co-60 studies. These latter differences are thought to result from differences in criteria for scoring lesions since none of the lesions observed in the BNL studies appeared as open sores -the scabs formed too quickly for lesions to be seen as open sores. 


\section{Summary, Discussion, and Conclusions}

Uncertainty and sensitivity studies performed included observations of unexposed areas and evaluations of different scoring criteria. Reece et al. (1994) reported using 19 control areas. Hopewell (1991) did not report using any control areas. The background effects and different scoring criteria can each affect results by factors of 0.5 to 1.5 . Also, about half of the scabs observed in these studies occurred after the 28-day scoring period employed by Hopewell. Thus, factors of two to three overall differences in results between laboratories using similar scoring procedures but different observation periods may be expected.

The lesions scored in this type of study at low doses are small (e.g., about 1- to 2-mm diameter), and transient (e.g., 1-4 weeks). These lesions are not open, festering wounds, but rather, barely noticeable scabs. This raises the question of how this detriment should be weighted in comparison with the debilitating effects normally being avoided in setting limits for deterministic and stochastic risks.

In these studies, more than 1,100 individual spots were exposed to hot particles. About 560 of these developed detectable scabs which were assumed to result from a break in the integrity of the skin, and therefore, might become infected. Only two of the exposed sites became infected -these after exposures near $500 \mathrm{~Gy}$. One was treated topically with antibiotic ointment for five days and the other, being somewhat more severe, was treated topically and systemically with an antibiotic. Both lesions healed. 


\section{REFERENCES}

Archambeau, J.O., "Relative radiation sensitivity of the integumentary system dose response of the epidermal, microvascular and dermal populations," in Advances in Radiation Biology, Vol. 12, J. Lett and K. Altman (Eds.), Academic Press, San Diego, 147-203, 1987.

Archambeau, J.O. and G.W. Bennett, "Quantification of morphologic, cytologic and kinetic parameters of unirradiated swine skin: A histological model," Rad. Res., 98, 254-273 (1984).

Archambeau, J.O. and G.R Matheiu, "Comparison of the observed results of irradiation on the skin with those expected from an idealized model," Radiat. Res., 40 (2), 285 (1969).

Archambeau, J.O. and R.M. Shymko, "Tissue population configuration as a modifier of organ dose response," Int. J. Radiat. Oncol. Biol. Phys., 15, 727-734 (1988).

Archambeau, J.O., D. Hauser and R.M. Shymko, "Swine basal cell proliferation during a course of daily irradiation, five days a week, for six weeks (6000 Rad)," Int. J. Radiat. Oncol. Biol. Phys., 15, 1383-1388 (1988).

Archambeau, J.O., A. Ines and L.F. Fajardo, "Response of swine skin microvasculature to acute single exposures of x-rays: Quantification of endothelial changes," Rad. Res. 98, 37-51 (1984).

Archambeau, J.O., A. Ines and L.F. Fajardo, "Correlation of the dermal microvasculature morphology with the epidermal and the endothelial population changes produced by single $X$-ray fractions of 1649, 2231 and 2619 rad in swine," Int. J. Radiat. Oncol. Biol. Phys., 11, 1639-1646 (1985).

Archambeau, J.O., R. Pezner and T. Wasserman, "Pathophysiology of irradiated skin and breast," Int. J. Radiat. Oncol. Biol. Phys., 31 (5), 1171-1185 (1995).

Archambeau, J.O., G.W. Bennett, J.J. Abata and H.J. Brenneis, "Response of swine skin to acute single exposures of X-rays: Quantification of the epidermal cell changes," Radiat. Res. 79, 298-337 (1979).

Baum, J.W. and D.G. Kaurin, "Reassessment of data used in setting exposure limits for hot particles," Radiat. Prot. Dosim., 39, 49-54 (1991).

Baum, J.W., D.G. Kaurin, M. Waligorski, R. Bird and L.C. Sun, "Progress Report on Hot Particle Studies," NUREG/CR-5725, U.S. Nuclear Regulatory Commission, Washington, DC, 1992.

Berger, M.J, "Distribution of absorbed dose around point sources of electrons and beta particles in water and other media," J. Nuc. Med., Medical Internal Radiation Dose Committee, Supp. 5 (12), Pamphlet \# 7, 1971. 


\section{References}

Boice, J., Jr., N.E. Day, A. Andersen, et al., "Second cancers following radiation treatment for cervical cancer. An international collaboration among cancer registries," J. Natl. Cancer Inst. 74 (5), 955 (1985).

Cember, H. Introduction to Health Physics, Second Edition, Pergamon Press, Inc., New York, 1983.

Charles, M.W., "The hot particle problem," Radiat. Prot. Dosim., 39 (1-3), 39-47 (1991).

Charles, M.W. and J. Wells, "The development of criteria for limiting the non-stochastic effects of non-uniform skin exposure," in Proceedings of the 5th International Congress of the International Radiation Protection Association, Vol. I, Pergamon Press, NY, pp. 113-117, 1980.

Charles, M.W., J.P. Williams, and J.E. Coggle, "Skin carcinogenesis following uniform and nonuniform beta irradiation," Health Phys., 55 (2), 399-406 (1988).

Cross, W.G., N.O Freedman and P.Y. Wong, "Beta ray dose distributions from skin contamination," Radiat. Prot. Dosim., 40 (3), 149-168 (1992).

Darley, P.J., M.W. Charles and C.D. Hart, "Validation of theoretical models for calculating doses from hot particles," in Proceedings of the IRPA Regional Congress on Radiological Protection, Nuclear Technology Publishing, pp. 153-156, 1994.

Darley, P.J., M.W. Charles, C.D. Hart, J. Wells and M.S.E. Coleby, "Dosimetry of planar and punctiform beta sources using an automated extrapolation chamber and radiochromic dye films". Radiat. Prot. Dosim., 39 (1-3), 61-66 (1991).

Davis, F., J. Boice, J. Kelsey and R. Monson, "Cancer mortality after multiple fluoroscopic examinations of the chest," J. Natl. Cancer Inst., 78, 645 (1987).

Dean, P.N. and W.H. Langham, "Tumorigenicity of small highly radioactive particles," Health Phys., 16, 79 (1969).

Dean, P.N., J. Langham and L.M. Holland, "Skin response to a point source of fissioned Uranium-235 carbide," Health Phys., 19 (3), 3-7 (1970).

Dionne, B.J and J.W. Baum, "Discrete radioactive particles at nuclear power plants: prevention, mitigation and control". Radiat. Prot. Mang., 8 (5), 65-79 (1991).

Dunn, J., E. Levin, G. Linden and L. Harzfeld, "Skin cancer as a cause of death," Calif. Med., 102, 361 (1965).

Durham, J.S., "Hot particle dose calculations using the computer code VARSKIN MOD2," Radiat. Prot. Dosim., 39 (1-3), 75-78 (1991). 
Durham, J.S., "VARSKIN MOD2 and SADDE MOD2: computer codes for assessing skin dose from skin contamination," NUREG/CR-5873, U.S. Nuclear Regulatory Commission, Washington, D.C., 1992.

Eckerman, K.F., R.J. Westfall, J.C. Ryman and M.Cristy, "Availability of nuclear decay data in electronic form, including beta spectra not previously published," Health Phys., 67 (4), 338-345 (1994).

Epstein, E., N. Epstein, K. Bragg and G. Linden, "Metastases from squamous cell carcinomas of the skin," Archiv. Dermatol. 97, 245 (1968).

Finney, D.J., Probit Analysis, Second Edition, University Press, Cambridge, 1964.

Forbes, P.D., "Vascular Supply of the Skin and Hair in Swine," Chapter XXVII in Advances in Biology of Skin, Vol. IX, Hair Growth, Montagna, W. and R.L. Dobson (Eds.), Pergamon Press, Oxford, 419-432, 1969.

Forbes, P.D. and S.Z. Mikhail, "Acute lesions in skin produced by radioactive microspheres," presented at the Annual Meeting of the Radiation Research Society, 1970, abstract in Radiat. Res. 39, 493 (1969).

Fowler, J.F., R.L. Morgan, J.A. Silvester, D.K. Bewley and B.A. Turner, "Experiments with fractionated $X$-ray treatment of the skin of pigs. 1 - Fractionation up to 28 days," Br. J. Radiol. $36,188-196,1963$.

George, L.A. and L.K. Bustad, "Comparative effects of beta irradiation of swine, sheep and rabbit skin," in Swine in Biomedical Research, Bustad, L.K. and R.O. McClellan (Eds.), Battelle Memorial Institute, Richland, WA, p. 491, 1966.

Giles, G., R. Marks and P. Foley, "Incidence of non-melanocytic skin cancer treated in Australia," Brit. Med. J., 296, 13 (1988).

Hall, E.J., Radiobiology for the Radiologist, Third Edition, J.B. Lippincott Company, Philadelphia, 1988.

Hay, J., W. Duncan and G. Ker, "Subsequent malignancies in patients irradiated for testicular tumours," Brit. J. Radiol., 57, 59 (1984).

Hicks, C.R., Fundamental Concepts in the Design of Experiments, Fourth Edition, Oxford University Press, NY, 1993.

Hildreth, N., R. Shore, L. Hemplemann and M. Rosenstein, "Risk of extrathyroid tumors following radiation treatment in infancy for thymic enlargement," Radiat. Res., 102, 378 (1985). 


\section{References}

Hopewell, J.W., "Radiation effects on vascular tissue," in Cytotoxic Insult to Tissue: Effects on Cell Lineages, Potten C.S. and J.H. Hendry (Eds.), Edinburgh: Churchill Livingstone, pp. 228257, 1983.

Hopewell, J.W., "Mechanisms of the action of radiation on skin and underlying tissues," Brit. J. Radiol. Supp., 19, 39-51 (1986).

Hopewell, J.W., "The skin: its structure and response to ionizing radiation," Int. J. Radiat. Biol, 57 (4), 751-773 (1990)

Hopewell, J.W, "Biological effects of irradiation on skin and recommended dose limits," Radiat. Prot. Dosim., 39 (1/3), 11-24 (1991).

Hopewell, J.W. and G.J.M.J. Van den Aardweg, "Radiobiological studies with pig skin," Int. J. Radiat. Oncol., Biol., Phys., 14, 1047-1050 (1986).

Hopewell, J.W. and G.J.M.J. Van den Aardweg, "Studies of dose-fractionation on early and late responses in pig skin: A reappraisal of the important of the overall treatment time and its effects on radiosensitization and incomplete repair," Int. J. Radiat. Oncol. Biol. Phys., 21, 1441-1450, 1991.

Hopewell, J.W. and C.M.A. Young, "The effects of field size on the reaction of pig skin to single doses of X-rays," Brit. J. Radiol., 55, 356-361 (1982).

Hopewell, J.W., J.E. Coggle, J. Wells, R. Hamlet, J.P. Williams and M.W. Charles, "The Acute effects of different energy beta emitters on pig and mouse skin," Brit. J. Radiol. Suppl., 19, 47-51 (1986).

Hopewell, J.W., J.L. Foster, C.M.A. Young and G. Wiernik, "Late radiation damage to pig skin: effects of overall treatment time and fraction number," Radiology, 130, 783-788 (1979).

Hopewell, J.W., J.L. Foster, Y. Gunn, W.F. Moustafa, T.J.S. Patterson, G. Wiernik and C.M.A. Young, "Role of vascular damage in the development of late radiation effects in pig skin," in Late Effects of lonizing Radiation, IAEA: Vienna, Vol. 1, pp. 483-492, 1978.

Hrubec, Z., J. Boice, R. Monson and M. Rosenstein, "Breast cancer after multiple chest fluoroscopies: Second follow-up of Massachusetts women with tuberculosis," Cancer Res. 49, 229 (1989).

International Commission on Radiological Protection, "Report of the Task Group on Reference Man," ICRP Publication 23, Annals of the ICRP, Pergamon Press, Inc., New York, 1975.

International Commission on Radiological Protection, "Biological Basis for Dose Limitation in the Skin," ICRP Publication 59, Annals of the ICRP, Vol. 22, No. 2, Pergamon Press Inc., New York, $1991 a$. 
International Commission on Radiological Protection, "Recommendations of the International Commission on Radiation Protection," ICRP Publication 60, Annals of the ICRP, Pergamon Press Inc., New York, 1991b.

James, D.W., "Problem Assessment of Discrete Radioactive Particles," EPRI NP-5969 (Electric Power Research Institute, Palo Alto, CA), August 1988.

Jarvis, N.S., A. Birchall, A.C. James, M.R. Bailey and M.-D. Dorrian, "LUDEP 2.0, Personal Computer Program for Calculating Internal Doses Using the ICRP Publication 66 Respiratory Tract Model," NRPB-SR287 (National Radiological Protection Board, Chilton, Didcot, Oxon, United Kingdom), 1996.

Kaurin, D.G.L., J.W. Baum, M.W. Charles, D.P.J. Darley, J.S. Durham, M.J. Scannell and C.G., Soares, "Hot Particle Intercomparison Dosimetry Measurements," Proceedings of Ninth International Congress of the International Radiation Protection Association, Vol. 3, pp. 3-28 to 320, Vienna, Austria, April 14-19, 1996 (IRPA, c/o Austrian Research Center Seibersdorf, A-2444 Seibersdorf, Austria).

Kelly, J.J. and S. Gustafson, "Industry Experience with Discrete Radioactive Particles," EPRI TR104125 (Electric Power Research Institute, Palo Alto, CA), July 1994.

Lacassagne, A and G. Gricouroff, Action des radiations ionisants su l'organisme, Paris: Masson, 1956.

Likhtariov, I.A., V.S. Repin, O.A. Bondarenko and S. Ju. Nechaev, "Radiological effects after inhalation of highly radioactive fuel particles produced by the Chernobyl accident," Radiat. Prot. Dosim., 59, 4, 247-254 (1995).

Mandjukov, I.G., B.V. Mandjúkova, A. Alexiev and Ts. Andreev, "High activity hot particles in Kozloduy Nuclear Power Plant -- status of the investigations," Radiat. Prot. Dosim. 54 (2), 133138 (1994).

Marcarian, H.Z. and M.L. Calhoun, "Microscopic anatomy of the integument of adult swine," Am. J. Vet. Res. 27, 765-772 (1966).

McWilliams, F.F., M.J. Scannell, C.G. Soares, B.M. Coursey and G.E. Chabot, "Hot Particle dosimetry using Co-60 spheres," Radiat. Prot. Dosim., 40 (4), 223-234 (1992).

Moritz, A.R. and F.W. Henrique, "Effects of beta rays on the skin as function of the energy, intensity and duration of irradiation, II," Laboratory Investigation, 1, 167-185 (1952).

Morris, G.M., "Epidermal Cell Kinetics in Normal and X-irradiated Pig Skin," Ph.D. Thesis, University of London, 1987. 


\section{References}

Morris, G.M. and J.W. Hopewell, "Pig epidermis: a cell kinetic study," Cell and Tissue Kinetics 18, 407-415 (1985).

Morris, G.M. and J.W. Hopewell, "Changes in the cell kinetics of pig epidermis after repeated daily doses of X-rays," in Radiation Damage to Skin, Brit. J. Radiol. Suppl. 19 (London: British Institute of Radiology), pp. 34-38., 1986.

Morris, G.M. and J.W. Hopewell, "The cell kinetics of pig epidermis: further studies," Cell and Tissue Kinetics, 20, 161-169 (1987).

Morris, G.M. and J.W. Hopewell, "Changes in the cell kinetics of pig epidermis after single doses of X-rays," British J. Radiol. 61, 205-211 (1988).

Morris, G.M. and J.W. Hopewell, "Cell kinetic changes in the follicular epithelium of pig skin after irradiation with single and fractionated doses of X-rays," Brit. J. Radiol. 62, 41-47 (1989).

Morris, G.M., M. Rezvani, J.W. Hopewell, H. Franke and M. Loeffler, "Epidermal cell kinetics in pig skin," Epithelia, 1, 231-242 (1987).

National Council on Radiation Protection and Measurements, "Limit for Exposure to 'Hot Particles' on the Skin," NCRP Report 106, National Council on Radiation Protection and Measurements, Bethesda, MD, 1989.

Natrella, M.G., "Experimental Statistics," United States Department of Commerce National Bureau of Standards Handbook 91, August 1, 1963 (reprinted October 1966).

Nelson, W.R., H. Hirayama and D.W.O. Rogers, "The EGS4 Code Systems," SLAC Report 265, Stanford University, Stanford, CT, December 1985.

Neter, J., M.H. Kutner, C.J. Nachtsheim and W. Wasserman, Applied Linear Regression Models, Third Edition, Richard D. Irwin, Inc., Chicago, 1996.

Nuclear Regulatory Commission, "Excessive skin exposures due to contamination with hot particles," NRC Information Notice 86-23 (U.S. Nuclear Regulatory Commission, Washington, DC), April 9, 1986.

Nuclear Regulatory Commission, "Control of hot particle contamination at nuclear power plants," NRC Information Notice 87-39 (U.S. Nuclear Regulatory Commission, Washington, DC), August 21,1987

Nuclear Regulatory Commission, "Enforcement policy for hot particle exposures," NRC Information Notice 90-48 (U.S. Nuclear Regulatory Commission, Washington, DC), August 2, 1990. 
Nuclear Regulatory Commission, Standards for Protection Against Radiation, 10 CFR Parts 2, $19,20,30,31,32,34,35,39,40,50,61$ and 70, Federal Register, 56 (98), 23390-23470 (1991).

Peel, D.M., J.W. Hopewell, J. Wells and M.W. Charles, "Late nonstochastic changes in pig skin after $\beta$ irradiation," Radiat. Res., 101, 491-496 (1985).

Pöllänen, R. and H. Toivonen, "Skin doses from large uranium fuel particles: application to the Chernobyl accident," Radiat. Prot. Dosim. 54 (2), 127-132 (1994).

Reece, W.D., "Experiences and problems of skin irradiation due to hot particles at workplaces in the United States," Radiat. Prot. Dosim. 39 (1/3), 165-171 (1991).

Reece, W.D., J.S. Durham, S.E. Merwin and M.P. Moeller, "Threshold Levels for Nonstochastic Skin Effects from Low-Energy Discrete Radioactive Particles," EPRI TR-10048 (Electric Power Research Institute, Palo Alto, CA), April 1992.

Reece, W.D., J.S. Durham, S.E. Merwin and M.P. Moeller, "Nonstochastic Skin Effects from Discrete Radioactive Particles Emitting High-energy Spectra Beta Rays," EPRI TR-102658 (Electric Power Research Institute, Palo Alto, CA), October 1993.

Reece, W.D., J.W. Poston, Sr. and D.L. McFarlane, "Skin Injuries from Discrete Radioactive Particles," EPRI TR-104781 (Electric Power Research Institute, Palo Alto, CA), December 1994.

Ron, E., B. Modan and J. Boice, "Mortality after radiotherapy for ringworm of the scalp," Amer. J. Epidemiol., 127, 713 (1988).

Rubin, P. and G.W. Casarett, Clinical Radiation Pathology, Vol. 1, W.B. Saunders, Philadelphia, 62-119, 1968.

SAS Institute, Inc., SAS/STAT® User's Guide, Version 6, Fourth Edition, Vol. 1 and 2, SAS Institute, Cary, NC., 1989.

Saylor, M.C., T.T. Tamargo, W.L. McLaughlin, H.M. Khan, D.F. Lewis, and R.D. Schenfele, "A thin film recording medium for use in food irradiations," Radiat. Phys. Chem., 31 (4-6), 529-536, 1988.

Schneider, A., E. Shore-Freedman and R. Weinstein, "Radiation-induced thyroid and other head and neck tumors: Occurrence of multiple tumors and analysis of risk factors," J. Clin. Endocrinol. Metabol., 63, 10 (1986).

Sevcova, M., J. Sevc and J. Thomas, "Alpha irradiation of the skin and the possibility of late effects," Health Phys., 35, 803 (1978). 


\section{References}

Sevcova, M., J. Sevc, J. Augustinova, J. Dragon and J. Kordacova, "Incidence of skin basalioma in miner and non-miner groups, Comparison of epidemiological studies," Ceskoslovenska

Dermatologie, 59, 1 (1984).

Shore, R., R. Albert, M. Reed, N. Harley and B. Pasaternack, "Skin cancer incidence among children irradiated for ringworm of the scalp," Radiat. Res., 100, 192 (1984).

Shore, R., N. Hildreth, E. Woodard, P. Dvoretsky, L. Hempelmann and B. Pasternack, "Breast cancer among women given $\mathrm{X}$-ray therapy for acute postpartum mastitis," J. Natl. Cancer Inst., 77,689 (1986).

Smith, J.L. and M.L. Calhoun, "The microscopic anatomy of the integument of newborn swine," Am. J. Vet. Res. 25, 165-173, 1964.

Soares, C.G., B.M. Coursey, F.F. McWilliams and M.J. Scannell, "Dose mapping of radioactive hot particles using radiochromic film," Radioactivity and Radiochemistry, 14-16 (1990).

Soares, C.G., P.J. Darley, M.W. Charles and J.W. Baum, "Hot particle dosimetry using extrapolation chambers and radiochromic foils," Radiat. Prot. Dosim., 39 (1-3), 55-59 (1991).

Soares, C.G. and W.L. McLaughlin, "Measurement of radial dose distributions around small beta particle emitters using high resolution radiochromic foil dosimetry," Radiat. Prot. Dosim., 47 (14), 367-372 (1993).

Streilein, J.W., "Skin-associated lymphoid tissues (SALT): origins and functions," J. Invest. Dermatol., 80 (Suppl.), 12-16 (1983).

Ulberg, J.C. and D.B. Kochendorfer, "Model for Estimating Beta Dose to Tissue from Particle Debris in Aerospace Nuclear Applications," USNRDL-TR-1107, Springfield, VA, 1966.

Van Dahl, W., B. Goslings, J. Hermans et al., "Radiation-induced head and neck tumours: Is the skin as sensitive as the thyroid gland?" Eur. J. Cancer Clin. Oncol., 19, 1081 (1983).

Van Den Aardweg, G.J.M.J., M. Arnold and J.W. Hopewell, "A comparison of the radiation response of the epidermis in two strains of pig," Radiat. Res., (124), 283-287(1990).

Van Vloten, W., J. Hermans and W. Van Daal, "Radiation-induced skin cancer and radiodermatitis of the head and neck," Cancer, 59, 411 (1987).

Warnock, R.V., L.G. Bray, T.L. Cooper et al., "A health physics program for operation with failed nuclear fuel," Radiat. Prot. Mang. 4, 4, 21-30 (1987).

Weast, R.C. (Ed.), CRC Handbook of Chemistry and Physics, CRC Press, Inc., Cleveland, Ohio, 1976. 
References

Weber, D.A., K.F. Eckerman, L.T. Dillman and J.C. Ryman, "MIRD: Radionuclide Data and Decay Schemes," The Society of Nuclear Medicine, New York, 1989. 
. 


\section{GLOSSARY}

Area dose - dose averaged over a given area (e.g., $1 \mathrm{~cm}^{2}$ )

Basal layer - the cells forming the base of the epidermis (stem cells)

Becquerel (Bq) - the special name for the SI unit of activity. The becquerel is that quantity of radioactive material in which one atom is transformed per second, $1 \mathrm{~Bq}=1 \mathrm{tps}$.

Confidence limits (CLs) - inverse confidence limits of dose for a given percent scab incidence

Control area (or site) - an unexposed area scored for determination of background incidence of effects

Correlation coefficient - a measure of the independence of two random variables that ranges in value from -1 to +1 , indicating perfect negative correlation at -1 , absence of correlation at 0 , and perfect positive correlation at +1

Cumulative percent effect - one hundred times the sum of positive (determined by method of scoring) observed effects divided by the number of days on which observations were made

Dark scab - scabs which probably result from effects deep enough to cause release of red dermal blood cells

Degenerative - characterized by degeneration or a retrogressive pathologic change in cells or tissue in consequence of which the functions may be inhibited or destroyed in such a manner that necrosis may occur

Dermis - the layer of skin beneath the epithelium, having nerve endings, sweat glands, and blood and lymph vessels

Deterministic - effects which increase in severity with dose and normally have a threshold

Detriment - harm or injury

Dose - a general term denoting the quantity of radiation or energy absorbed per mass of tissue. For special purposes it must be appropriately qualified. If unqualified, it refers to absorbed dose. The SI unit of absorbed dose is the gray $(1 \mathrm{~Gy}=1 \mathrm{~J} / \mathrm{kg}=100 \mathrm{rad})$. Unless otherwise qualified, doses in this report are given in units of Gy averaged over $1 \mathrm{~cm}^{2}$ at a depth of $70 \mu \mathrm{m}$ in tissue.

Dry desquamation - dry scaling or pealing of the skin

Dye film - special plastic film coated with a thin layer of dye which turns blue upon exposure to ionizing radiation

$E_{\text {avg }}$ - average of the beta particle energies emitted by a source 


\section{Glossary}

Edema - excessive accumulation of serous fluid in cells, tissues, or serous cavities

Edematous - having properties of edema

Effective dose - the sum of the weighted equivalent doses in all the tissues and organs of the body

$E_{\max }$ - the maximum energy of beta particles emitted by a source

Epidermis - the protective, outer, nonvascular layer of the skin

Erythema - a reddening of the skin that can be caused by heat, drugs, ultraviolet radiation and ionizing radiation

Etiology - all of the causes of a disease or abnormal condition.

Exoelectron dosimeter - a dosimeter which when heated emits electrons from its surface after it has been exposed to radiation

Extrapolation chamber - a thin window parallel-plate ionization chamber with a movable electrode that permits estimation of dose to a surface, often used as a standard or reference measurement for that purpose

F-test - a statistical test used to compare the variances of two sample populations to determine if they are significantly different

Skin functional unit (FU) - defined as the smallest unit of skin that retains all the characteristics of skin; it consists of a micro vessel with associated epidermis and dermis

GafChromic Film - a commercial dye film employed for dosimetry in these studies

Gray (Gy) - the SI unit of absorbed dose $\left(1 \mathrm{~Gy}=1 \mathrm{~J} \mathrm{~kg}^{-1}=100 \mathrm{rad}\right)$

Hair follicle - a small cavity in the skin in which a hair grows

Histology - Anatomical study of the microscopic structure of animal and plant tissues

Histopathology - a branch of pathology concerned with the tissue changes characteristic of disease

Hot particle - a discrete particle, arbitrarily defined for this report as less than $1 \mathrm{~mm}$ in largest dimension that is sufficiently radioactive to present a risk of overexposure (approximately $10^{9} / 3.1 \times 10^{7}=32 \mathrm{~Bq}$ for a particle fixed on skin the whole year)

Hyperkeratosis - excessive growth of the keratin (horny) layer of tissue (skin)

NUREG/CR-6531

G-2 
Hyperplasia - a nontumorous increase in the number of cells in an organ or tissue with consequent enlargement of the affected part

Hyperplastic - relating to hyperplasia - an increase in number of cells in a tissue or organ, excluding tumor formation, whereby the bulk of the part or organ is increased

Hypertrophic - a nontumorous increase in the size of an organ or part without an increase in the number of constituent cells

Incidence - the frequency of occurrence of an effect based on the ratio of the number of effects observed compared to the number of areas exposed

Kapton - a commercial radiation resistant, plastic sheet

Keratin - the horny outer layer of skin

Lesion - a visually detectable effect -- in these studies, erythema or scab formation

Mitosis - the process of cellular replication and differentiation

Moist desquamation - shedding or peeling of cells with noticeable moisture present

Monte Carlo calculations - a technique which obtains a probabilistic approximation to the solution of a problem by using statistical sampling techniques

mrem - one-thousandth of a rem (0.01 mSv)

NE Extremity Tape dosimeter - a commercial dosimeter containing a thin layer of LiF thermoluminescent material

Off-skin exposure - an exposure made with the particle held slightly off the skin to simulate a particle on clothing or hair

On-skin exposure - an exposure in which the particle is held on the skin at a fixed location

Papillary dermis - the portion of the dermis containing small nipple-like eminences

Percent-effect-days - one hundred times the ratio of the number of times a specific effect is observed (summed over all observers) divided by the total number of observations (summed over all observers). The effect is either erythema, white scabs, dark scabs, or total scabs.

Percent-effect-observed - effects observed expressed as percent of areas exposed

Point kernel method - a calculational method in which one assumes the source is a point source 


\section{Glossary}

Point dose - dose predicted for a small point at some specific depth in tissue

Prickle cell - a cell provided with delicate radiating processes which contact with similar cells; found chiefly in the stratified pavement epithelium

Probit regression - a statistical treatment of the cumulative normal (sigmoid response) curve

Percent scab incidence (PSI) - obtained from experiments in which replicate exposures are made at each dose and regression analysis is employed to derive a dose-response function or curve

Range finding - an experiment done to determine a range of doses (with few or limited replicate exposures at each dose) that would be most useful in subsequent, larger experiments

Regeneration - reproduction or restoration of a lost or injured part

Remodeling - the replacement of structure with a change in characteristics or structure

Rete pegs - prolongations of the rete mucosum, which is the deepest of the epidermal layers, into the derma

Scab days - the product of percent-scab days (defined above) and days post-irradiation

Sievert (Sv) - the name for the SI unit of equivalent dose and effective dose: $1 \mathrm{~Sv}=1 \mathrm{~J} \mathrm{~kg}^{-1}$

t-test - a statistical test involving means of normal populations with estimated standard deviations, used for testing differences between means

Ulcer - localized interruption of the continuity of an epithial surface, with an inflamed base

VARSKIN MOD2 - the computer code used in these studies to calculate dose at various depths and radii in tissue due to hot particle exposures

Velcro - commercial pair of cloth tapes with protrusions on one tape which cling to plastic fuzz on the opposing tape, used to fasten objects together in an easily reversible fashion

White scab - a scab which is very superficial and apparently does not contain blood cells 
Appendix

\title{
APPENDIX
}

\section{HOT PARTICLE DOSIMETRY: INTERCOMPARISONS}

\author{
D.G.L. Kaurin", J. W. Baum;, M.W. Charles", P.J. Darley*, \\ J.S. Durham ${ }^{\dagger}$ and M.J. Scannell \\ "Brookhaven National Laboratory \\ Upton, NY 11973 \\ "University of Birmingham \\ Edgebaston, Birmingham \\ B15 2 TT, UK \\ tPacific Northwest Laboratory \\ P.O. Box 999 \\ Richland, WA 99352 \\ $\mp$ Yankee Atomic Electric Company \\ 580 Main St. \\ Bolton, MA 01740
}

${ }^{1}$ This work was performed under the auspices of the U.S. Nuclear Regulatory Commission. 


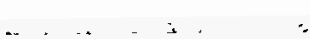


Appendix

\section{EXECUTIVE SUMMARY}

A workshop on Hot Particle Dosimetry Intercomparisons was held at Brookhaven National Laboratory (BNL) in September 1994. Groups from BNL, the University of Birmingham (UB) in the United Kingdom, Pacific Northwest Laboratory (PNL), and Yankee Atomic Electric Company (YAEC) participated in using a variety of techniques.

Dosimetry measurements of four "hot particles" were made at different depths using five different methods. The hot particles had maximum dimensions of $650 \mu \mathrm{m}$ and maximum beta particle energies of $0.97,0.46,0.36$, and $0.32 \mathrm{MeV}$. Absorbers were used to obtain dose at different depths for each dosimeter. Measurements were made using exoelectron dosimeters; an extrapolation chamber; thin, flexible thermoluminescent dosimeters; ionization chamber survey instruments; and radiochromic dye film.

All irradiations were conducted during the workshop and read out at each institution. The sources used were Tm-170, Yb-175, Sc-46, and Co-60. The exoelectron dosimeter measurements were made by the PNL group using their own equipment. The extrapolation chamber measurements were made by the YAEC group using the YAEC extrapolation chamber system. The radiochromic dye film, GafChromic, used by both BNL and UB groups, was manufactured by GAF Chemicals Corporation. The thermoluminescent dosimeter (TLD) and ionization survey measurements were both made by the YAEC group using NE Extremity Tape dosimeters, and Eberline RO-2 and RO-2A survey meters. Results were used to calculate dose averaged over 1 $\mathrm{cm}^{2}$ of tissue at $18,70,125$, and $400 \mu \mathrm{m}$ depth.

Comparisons between the BNL and UB sets of GafChromic dye film indicated differences as large as a factor of two for point-dose measurements at a film density thickness of $1.8 \mathrm{mg} / \mathrm{cm}^{2}$. Differences between the two improved to less than $20 \%$ when the dose was averaged over areas greater than $0.5 \mathrm{~mm}^{2}$ and for point-dose measurements at greater depths. These differences are most likely due to differences in the minimum spot size used for optical density measurements.

Additional comparisons of raw measurement data showed that the extrapolation chamber and NE Extremity Tape dosimeter under-responded relative to the GafChromic film at density thicknesses greater than $50 \mathrm{mg} / \mathrm{cm}^{2}$ for 0.36 and 0.32 maximum energy beta-particle emitters.

Interpolated tissue dose-rates averaged over $1 \mathrm{~cm}^{2}$ from measured values showed good agreement. The standard deviation of the estimated tissue doses normalized to the mean value at each depth was $11,9.1,12,23 \%$ for the $18,70,125$, and $400 \mu \mathrm{m}$ tissue depths, respectively (excluding the exoelectron dosimeter). Excluding values that were internally inconsistent or that were based on single measurements with large uncertainties decreased the standard deviation for the 18 and $70 \mu \mathrm{m}$ tissue depths to 6.6 and $7.5 \%$, respectively, with negligible effect for the deeper depths (again, excluding the exoelectron dosimeter). The under-response of the exoelectron dosimeters by factors of 2 to 12 was not understood and may have been due to equipment failures. 


\section{Appendix}

These results demonstrate that available techniques and instruments can be used to determine tissue dose from hot particles averaged over $1 \mathrm{~cm}^{2}$ with high (7 to $23 \%$ ) precision. Dose measurements over smaller areas are presently subject to larger uncertainties. 
Appendix

\section{CONTENTS}

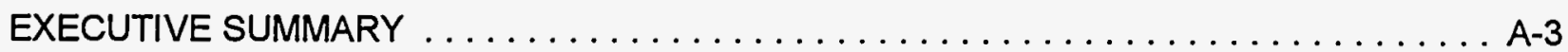

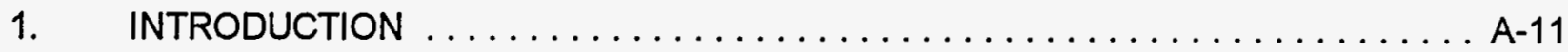

2. METHODS AND MATERIALS ....................... A-13

2.1 Hot Particle Source and Geometry Characteristics . . . . . . . . . . . A A-13

2.1.1 Descriptions of Sources . . . . . . . . . . . . . . A-13

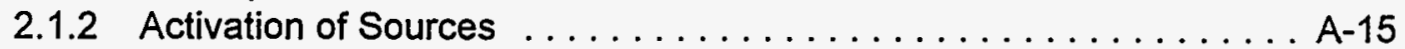

2.1 .3 Support of Sources . . . . . . . . . . . . . . . . . A-16

2.1 .4 Decay Corrections ......................... A-17

2.1 .5 Absorber's Materials . . . . . . . . . . . . . . . A-19

2.2 GafChromic Dosimetry .......................... A $\ldots \ldots$

2.2.1 Description ............................ A-19

2.2.2 Exposure of GafChromic Dye Film to Hot Particles . . . . . . . . . . . A-20

2.3 NIST Radiochromic Film Dosimetry System . . . . . . . . . . . . A-21

2.3.1 Readout of Films . . . . . . . . . . . . . . . . . . A A-21

2.3.2 Calibration .......................... A-22

2.3.3 Brookhaven Interpolated Tissue Doses . . . . . . . . . . . . . . A-22

2.4 UB Radiochromic Film Dosimetry System (M. Charles and P. Darley,

Birmingham) . . . . . . . . . . . . . . . . . . . . . A-23

2.4.1 Readout of UB Films . . . . . . . . . . . . . . . . A-23

2.4.2 UB Calculated Tissue Doses . . . . . . . . . . . . . . . . . . A A-23

2.5 Exoelectron Dosimetry System (J. S. Durham, Battelle, PNL) . . . . . . . . . A-24

2.5.1 Principles of Exoelectron Dosimetry . . . . . . . . . . . . . . . . A A-24

2.5.2 Exposure of EEDs to Hot Particles . . . . . . . . . . . . . . . . A-25

2.5 .3 Calibration of EEDs . . . . . . . . . . . . . . . . . A-27

2.5.4 EED Interpolated Tissue Doses . . . . . . . . . . . . . . . . A-27

2.6 Extrapolation Chamber Dosimetry System (M.J. Scannell, Yankee Atomic

Electric Company) ... . . . . . . . . . . . . . . . . . . . . A-27

2.6.1 The YAEC Extrapolation Chamber System . . . . . . . . . . . . . A-27

2.6.2 Exposure of the YAEC Extrapolation Chamber to Hot Particles . . . . A-28

2.6.3 Calibration of YAEC Extrapolation Chamber System . . . . . . . . . . A-29

2.6.4 Calculating Tissue Dose from YAEC Extrapolation Chamber

Measurements .......................A-29

2.7 NE Extremity Tape Dosimeters . . . . . . . . . . . . . . . . . . . . . . . A-29

2.7.1 Description of NE Extremity Tape Dosimeters . . . . . . . . . . . . . A-29

2.7.2 Exposure of NE Extremity Tape Dosimeters to Hot Particles . . . . . . A-32

2.7.3 Readout of NE Extremity Tape Dosimeters . . . . . . . . . . . . . A-32

2.7.4 Calibration of NE Extremity Tape Dosimeters . . . . . . . . . . . . A A-33

2.7.5 Calculation of Tissue Dose from NE Extremity Tape Dosimeter

Measurements ........................A-33 
Appendix

2.8 Eberline RO-2/2A Survey Meter . . . . . . . . . . . . . . . . . . A-33

2.8.1 Description of Eberline RO-2/2A . . . . . . . . . . . . . . A A-33

2.8.2 Exposure of Eberline RO-2/2A to Hot Particles . . . . . . . . . . . . A-34

2.8.3 Calibration of Eberline RO-2/2A . . . . . . . . . . . . . . . . A-34

2.8.4 Calculation of Tissue Dose from Eberline RO-2/2A Measurements . . A-34

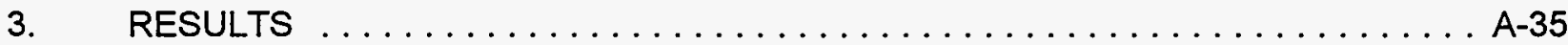

3.1 GafChromic Measurements . . . . . . . . . . . . . . . . . . A-35

3.2 Exoelectron Results . . . . . . . . . . . . . . . . . . . A-45

3.2.1 Results of EED Dose Measurements . . . . . . . . . . . . . A-45

3.2.2 Comparison of EED Measurements with Other Dosimeter Results . A A-49

3.3 Measurements With the YAEC Extrapolation Chamber . . . . . . . . . . . . . . A A-49

3.3.1 Results of YAEC Extrapolation Chamber Dose Measurements . . . . A A-49

3.3.2 Comparisons of YAEC Extrapolation Chamber Measurements with GafChromic Film Measurements . . . . . . . . . . . . . . . . . . A A-52

3.4 NE Extremity Tape Dosimeter Measurements . . . . . . . . . . . . . . . . . A-52

3.4.1 NE Extremity Tape Dosimeter Measurement Results . . . . . . . . . . A A-52

3.4.2 Comparison of NE Extremity Tape Dosimeter Measurements with GafChromic Film Measurements . . . . . . . . . . . . . . . . . . A A-52

3.5 Eberline RO-2/2A Measurements . . . . . . . . . . . . . . . . . . . . . . A-59

3.6 Interpolated Tissue Dose . . . . . . . . . . . . . . . . . . . . . . . A-60

3.6.1 Dose Averaged Over $1 \mathrm{~cm}^{2} \ldots \ldots \ldots \ldots \ldots \ldots$. . . . . . . . . . . A-60

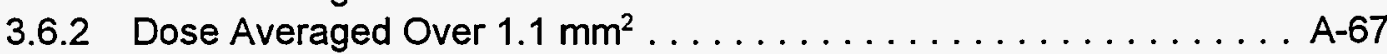

4. SUMMARY AND CONCLUSION $\ldots \ldots \ldots \ldots \ldots \ldots \ldots \ldots \ldots \ldots \ldots$

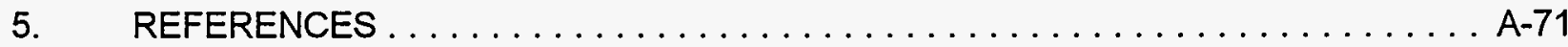

\section{LIST OF FIGURES}

Figure 1 The shape of the Tm-170, $\mathrm{Yb}-175$, and Sc-46 sources approximated that of a three-dimensional trapezoid.

Figure 2 Source mounting block for dosimetry measurements

Figure 3 Construction of GafChromic dye film with manufacturer-supplied dimensions except for the density of the polyester base, which was determined from measurements of the film

Figure 4 Radial dose profile for the Tm-170 particle at a film mass thickness of $1.8 \mathrm{mg} / \mathrm{cm}^{2}$ 
Appendix

Figure 5 Schematic representation of dose deposition through the thickness of the NE Extremity Tape dosimeter.

Figure 6 Dose rates from Tm-170 hot particle for selected GafChromic film depths ...

Figure 7 Dose rates from $\mathrm{Yb}-175$ hot particle for selected GafChromic film depths ....

Figure 8 Dose rates from Sc-46 hot particle for selected GafChromic film depths . . . . A-42

Figure 9 Dose rates from Co-60 hot particle for selected GafChromic film depths . . . . A-42

Figure 10 Ratio of Tm-170 dose rate measurements made by UB and BNL-NIST . . . A-43

Figure 11 Ratio of $\mathrm{Yb}-175$ dose rate measurements made by UB and BNL-NIST . . . . A-43

Figure 12 Ratio of Sc-46 dose rate measurements made by UB and BNL-NIST . . . . A A-44

Figure 13 Ratio of Co-60 dose rate measurements made by UB and BNL-NIST . . . . . A-44

Figure 14 Comparison of measured dose rates of the $\mathrm{Tm}-170$ particle averaged over $1 \mathrm{~cm}^{2}$ at different density thicknesses . . . . . . . . . . . . . . .

Figure 15 Comparison of measured dose rates of the $\mathrm{Yb}-175$ particle averaged over $1 \mathrm{~cm}^{2}$ at different density thicknesses . . . . . . . . . . . . . .

Figure 16 Comparison of measured dose rates of the Sc-46 particle averaged over $1 \mathrm{~cm}^{2}$ at different density thicknesses . . . . . . . . . . . . . . A A-54

Figure 17 Comparison of measured dose rates of the Co-60 particle averaged over $1 \mathrm{~cm}^{2}$ at different density thicknesses . . . . . . . . . . . . . . .

Figure 18 Comparison of measured dose rates of the Tm-170 particle averaged over $0.29 \mathrm{~cm}^{2}$ at different density thicknesses . . . . . . . . . . . . . .

Figure 19 Comparison of measured dose rates from the $\mathrm{Yb}-175$ particle averaged over

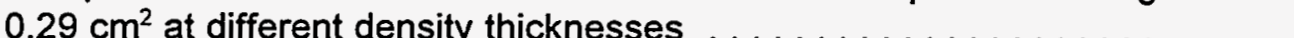

Figure 20 Comparison of measured dose rates of the Sc-46 particle averaged over $0.29 \mathrm{~cm}^{2}$ at different density thicknesses

Figure 21 Comparison of measured dose rates of the Co-60 particle averaged over $0.29 \mathrm{~cm}^{2}$ at different density thicknesses . . . . . . . . . . . .

Figure 22 Comparison of $\mathrm{Tm}-170$ tissue dose rates interpolated from measured values . 


\section{Appendix}

Figure 23 Comparison of $\mathrm{Yb}-175$ tissue dose rates interpolated from measured values . A-62

Figure 24 Comparison of Sc-46 tissue dose rates interpolated from measured values .. A-63

Figure 25 Comparison of Co-60 tissue dose rates interpolated from measured values .. A-63

Figure 26 Relative $\mathrm{Tm}-1701 \mathrm{~cm}^{2}$ tissue dose estimates normalized to the average value

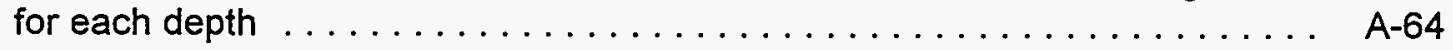

Figure 27 Relative $\mathrm{Yb}-1751 \mathrm{~cm}^{2}$ tissue doses normalized to the average value for each depth .

Figure 28 Relative Sc-46 $1 \mathrm{~cm}^{2}$ tissue dose estimates normalized to the average value

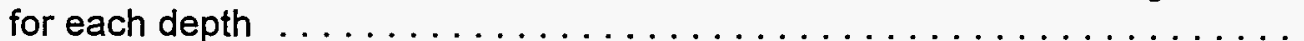

Figure 29 Relative Co-60 $1 \mathrm{~cm}^{2}$ tissue dose estimates normalized to the average value

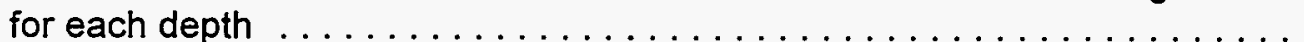

\section{LIST OF TABLES}

Table 1 Dosimeter(s) used by each research institution $\ldots \ldots \ldots \ldots \ldots \ldots \ldots \ldots$. $\ldots \ldots$

Table 2 Isotopic characteristics of the hot particles used in the BNL dosimetry studies. . A-13

Table 3 Characteristics of BNL particles before activation . . . . . . . . . . . A A-14

Table 4 Particle dimensions used for BNL-NIST VARSKIN MOD2 calculations $\ldots \ldots \ldots$ A-15

Table 5 Facilities and conditions used for neutron activation of particles $\ldots \ldots \ldots$ A-16

Table 6 Calculated activity in Bq of the different isotopes in the $\mathrm{Yb}-175$ particle on days when dosimetry exposures of this particle were made (September 1994). . . . . A-18

Table 7 Dosimeter exposure dates $(1994) \ldots \ldots \ldots \ldots \ldots \ldots \ldots \ldots \ldots$

Table 8 Absorber materials for hot-particle dosimetry exposures . . . . . . . . . . A-19

Table 9 Calculated correction factors for interpolating measured dose in GafChromic film to depths in tissue for dose averaged over $1 \mathrm{~cm}^{2} \ldots \ldots \ldots \ldots \ldots \ldots$ A-24

Table 10 Exposure geometries and times for the exoelectron dosimeters . . . . . . . A-26 
Table 11 Effective depth of NE Extremity Tape dosimeters $\ldots \ldots \ldots \ldots \ldots \ldots \ldots \ldots$ A-32

Table 12 GafChromic dose results for BNL-NIST and UB systems for the Tm-170 hot particle .......................... A-36

Table 13 GafChromic dose results for the BNL/NIST and UB systems for the $\mathrm{Yb}-175$ hot particle ........................ A-37

Table 14 GafChromic dose results for the BNL-NIST and UB systems for the Sc-46 hot particle

Table 15 GafChromic dose results for the BNL-NIST and UB systems for the Co-60 hot particle

Table 16 GafChromic film dose results for the BNL-NIST and UB systems for each particle at a film depth of $7.78 \mathrm{mg} / \mathrm{cm}^{2}$

Table 17 Exoelectron doses averaged over $1 \mathrm{~cm}^{2}$ based on PNL calibrations . . . . A A-46

Table 18 Exoelectron $1 \mathrm{~cm}^{2}$ averaged doses using ORNL reader for calibrations and PNL reader for dose measurements. . . . . . . . . . . . . . . . . A-47

Table 19 Ratio of PNL results to ORNL results $\ldots \ldots \ldots \ldots \ldots \ldots \ldots \ldots \ldots$

Table 20 YAEC extrapolation chamber ionization currents at various plate spacings . . . A-50

Table 21 YAEC extrapolation chamber results $\ldots \ldots \ldots \ldots \ldots \ldots \ldots \ldots \ldots \ldots \ldots$

Table 22 NE Extremity Tape dosimeter measurements . . . . . . . . . . . . . . A-55

Table 23 NE Extremity Tape dosimeter results $\ldots \ldots \ldots \ldots \ldots \ldots \ldots \ldots \ldots$. . . . . . . .

Table 24 Eberline $\mathrm{RO}-2 / 2 \mathrm{~A}$ results $\ldots \ldots \ldots \ldots \ldots \ldots \ldots \ldots \ldots \ldots \ldots \ldots$

Table 25 Doses to $1 \mathrm{~cm}^{2}$ of tissue at selected depths derived from interpolation of measured values

Table 26 Combined standard deviation of $1 \mathrm{~cm}^{2}$ tissue doses normalized to the average for each hot particle at each depth to determine precision of estimates for each depth

Table 27 Doses to $1.1 \mathrm{~mm}^{2}$ area of GafChromic film at a film depth of $1.8 \mathrm{mg} / \mathrm{cm}^{2}$ to enable comparisons of biology data with Hopewell (1991) and Charles (1991) 


\section{INTRODUCTION}

Previous investigators used various methods to determine the dose from the hot particles including extrapolation chamber and ionization chamber measurements supplemented by calculations in Forbes and Mikhail's work (1969); calculations for Forbes and Mikhail's studies, evaluated by the National Council on Radiation Protection and Measurements (NCRP, 1989); extrapolation chamber measurements employed by Hopewell et al. (1986), Soares et al. (1991; 1993), Reece et al. (1992), and McWilliams et al. (1992); exoelectron dosimeters employed by Reece et al. (1992); dye film dosimeters employed by McWilliams et al. (1992), Soares et al. (1991), Darley et al. (1991, 1994), Reece et al. (1994), and by Kaurin et al. (1995).

The difficulty with measuring dose from hot particles arises from their extremely non-uniform dose distribution. When measuring the dose with extrapolation chambers, a quadratic or more complicated regression fit of current as a function of electrode spacing is justified for small electrodes (i.e., 1-mm diameter) (Darley et al., 1991; Soares et al., 1991; Baum et al., 1992). When measuring the dose from hot particles using thermoluminescent dosimeters (TLDs), thin TLDs must be used that are calibrated to give dose averaged over a known area at some average depth in the TLD. GafChromic ${ }^{\mathrm{TM}}{ }^{2}$ dye film has many advantages over these systems in that dose averaged over different areas can be determined, as well as a depth-dose profile by covering the film with absorbers of different thicknesses. However, different researchers reading the same dye film have reported differences of up to $40 \%$ depending on the image analysis system used (Darley et al., 1991). The GafChromic film also under-responds by a factor of 0.54 for low energy I-125 X rays when compared with high energy photons (Sayeg et al., 1990).

To provide a firm basis for comparing the results from various studies and to validate BNL's dosimetry results, an intercomparison was undertaken. In this study, scientists from the University of Birmingham (UB), U.K. (Charles), the PNL group (Durham), a commercial nuclear power plant group with extensive experience with an extrapolation chamber and thin thermoluminescent dosimeters (Scannell), and from BNL each exposed dosimeters to Tm-170, Yb-175, Sc-46, and Co-60 sources. The majority of measurements were completed on September 13 and 14, 1994; BNL's GafChromic film dosimetry was concluded on September 28, 1994. Table 1 lists the dosimeters employed by each group.

For comparisons, measurements were made at eight depths in plastic from 1.8 to about 106 $\mathrm{mg} / \mathrm{cm}^{2}$, and results then were interpolated to yield doses at depths in tissue of $18,70,125$, and $400 \mu \mathrm{m}$ and averaged over $1 \mathrm{~cm}^{2}$. These depths are of interest since the $70 \mu \mathrm{m}$ depth is specified in 10 CFR 20 regulations, and the 125 and $400 \mu \mathrm{m}$ depths are midpoints of the depths suggested for averaging dose for acute ulceration and dermal effects, respectively, by the International Commission on Radiological Protection (ICRP, 1991).

${ }^{2}$ GafChromic is a registered trademark for the commercial dye film employed for dosimetry in these studies (GAF Chemical Corporation, Wayne, NJ). 


\section{METHODS AND MATERIALS}

\subsection{Hot Particle Source and Geometry Characteristics}

\subsubsection{Descriptions of Sources}

The isotopes used for the dosimetry intercomparisons were Tm-170, Yb-175, Sc-46, and Co-60 with a maximum beta-particle energy range of 0.97 to $0.32 \mathrm{MeV}$ (Table 2).

Table 2 Isotopic characteristics of the hot particles used in the BNL dosimetry studies ${ }^{\mathrm{a}, \mathrm{b}}$

\begin{tabular}{|c|c|c|c|c|c|}
\hline Isotope & $\begin{array}{c}\text { Half-life } \\
\text { (days) }\end{array}$ & $\begin{array}{c}\text { Maximum } \\
\text { B energy } \\
\text { (MeV) }\end{array}$ & $\begin{array}{c}\beta \text { abundance } \\
(\%)\end{array}$ & $\begin{array}{c}\text { y energy } \\
\text { (MeV) }\end{array}$ & $\begin{array}{c}Y \text { abundance } \\
(\%)\end{array}$ \\
\hline $\mathrm{Tm}-170$ & 129 & $\begin{array}{l}0.97 \\
0.88\end{array}$ & $\begin{array}{l}76 \\
24\end{array}$ & 0.084 & 3.25 \\
\hline$Y b-175$ & 4.2 & $\begin{array}{c}0.477 \\
0.35 \\
0.073\end{array}$ & $\begin{array}{c}86 \\
3.3 \\
10\end{array}$ & $\begin{array}{l}0.396 \\
0.282 \\
0.114\end{array}$ & $\begin{array}{c}6.5 \\
3.05 \\
1.9\end{array}$ \\
\hline$S c-46$ & 83.8 & $\begin{array}{c}1.48 \\
0.357\end{array}$ & $\begin{array}{c}0.004 \\
100\end{array}$ & $\begin{array}{c}1.12 \\
0.889\end{array}$ & $\begin{array}{l}100 \\
100\end{array}$ \\
\hline Co-60 & 1902 & $\begin{array}{c}1.48 \\
0.317\end{array}$ & $\begin{array}{c}0.12 \\
100\end{array}$ & $\begin{array}{l}1.332 \\
1.173\end{array}$ & $\begin{array}{l}100 \\
100\end{array}$ \\
\hline
\end{tabular}

a. From Weast, R.C., 1976.

b. From NCRP Report No. 58, 1978.

Before activation, $\mathrm{Tm}, \mathrm{Yb}$, and Sc particles were cut from metal foils that had a manufacturerstated purity of $99.9 \%$. The shape of these sources approximated three-dimensional trapezoids (Figure 1). The particles were measured under a microscope before activation. The cobalt source was spherical. Table 3 gives the measured dimensions, densities, and masses for the sources.

All sources were less than $1 \mathrm{~mm}$ in largest dimension, which the NCRP (1989) had defined as the upper limit for a "hot particle." 


\section{Appendix}

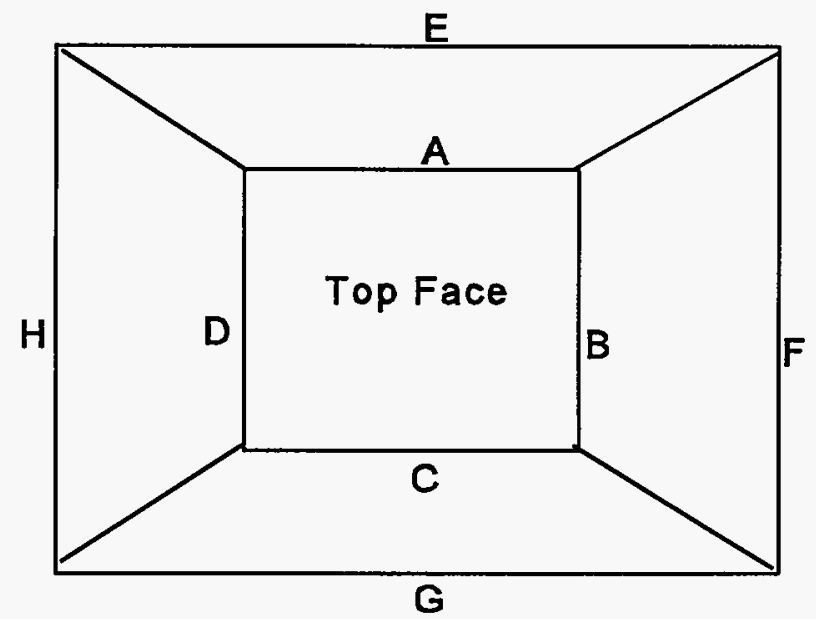

Figure 1 The shape of the Tm-170, Yb-175, and Sc-46 sources approximated that of a three-dimensional trapezoid. The length of each edge (not shown to scale), denoted by letters $\mathrm{A}-\mathrm{H}$ are given in Table 3 . It is not known if the top or bottom face was nearest the dosimeter.

Table 3 Characteristics of BNL particles before activation. The " $A$ " through " $H$ " headings refer to side edges shown in Figure 1.

\begin{tabular}{|c|c|c|c|c|c|c|c|c|c|c|c|c|}
\hline Particle & $\begin{array}{l}\text { Measured } \\
\text { Foil Density } \\
\text { (g/cc) }\end{array}$ & $\begin{array}{c}\text { Micro- } \\
\text { meter } \\
\text { Measured } \\
\text { Thick- } \\
\text { ness }(\mu \mathrm{m})\end{array}$ & $\begin{array}{l}\text { Balance } \\
\text { Mea- } \\
\text { sured } \\
\text { Mass } \\
\text { (g) }\end{array}$ & $\begin{array}{c}\text { Edge A } \\
(\mu \mathrm{m})\end{array}$ & $\begin{array}{c}\text { Edge B } \\
(\mu \mathrm{m})\end{array}$ & $\begin{array}{c}\text { Edge } C \\
(\mu \mathrm{m})\end{array}$ & $\begin{array}{c}\text { Edge D } \\
(\mu \mathrm{m})\end{array}$ & $\begin{array}{c}\text { Edge } E \\
(\mu \mathrm{m})\end{array}$ & $\begin{array}{c}\text { Edge } F \\
(\mu \mathrm{m})\end{array}$ & $\begin{array}{c}\text { Edge } G \\
(\mu \mathrm{m})\end{array}$ & $\begin{array}{l}\text { Edge } H \\
(\mu \mathrm{m})\end{array}$ & $\begin{array}{l}\text { Calcu- } \\
\text { lated Mass } \\
\text { from Foil } \\
\text { Density (g) }\end{array}$ \\
\hline$T m-170$ & 9.41 & 258 & 4.6E-04 & & & & & 450 & 410 & 430 & 390 & $4.2 \mathrm{E}-04$ \\
\hline Sc-46 & 2.90 & 130 & N/A & $\underset{\mathrm{a}}{510 \pm 93}$ & $\begin{array}{c}300 \pm 36 \\
a\end{array}$ & $\begin{array}{c}490 \pm 83 \\
a\end{array}$ & $\underset{a}{310 \pm 45}$ & $\begin{array}{c}420 \pm 49 \\
a\end{array}$ & $\begin{array}{c}370 \pm 15 \\
a\end{array}$ & $\begin{array}{c}420 \pm 45 \\
a\end{array}$ & $\begin{array}{c}360 \pm 12 \\
a\end{array}$ & $\begin{array}{c}(5.9 \pm 0.39) \mathrm{E}- \\
05\end{array}$ \\
\hline$Y b-175$ & 696 & 130 & N/A & 460 & 310 & 440 & 300 & 520 & 380 & 510 & 390 & $1.5 \mathrm{E}-04$ \\
\hline $\operatorname{Cos} 60$ & 8.4 & $208^{\circ}$ & & & & & & & & & & \\
\hline
\end{tabular}

a. Dimensions for each edge are averages $( \pm 1 \sigma)$ for three Sc-46 particles of similar size that were irradiated together. The particles could not be distinguished after irradiation.

b. The Co particles were approximately spherical, with diameters for individual particles varying within $\pm 3 \%$. The diameter of this particle is unknown, but the average diameter of the batch of nine particles including this particle was $208 \pm 11 \mu \mathrm{m}$. 
The computer code, VARSKIN MOD2 (Durham, 1992), was used by some of the researchers to interpolate between measured doses and, thereby, to estimate doses to skin depths of interest. It was suggested that the computer code has greater accuracy for three-dimensional disk sources, rather than for three-dimensional slab sources due to conditions of symmetry. Therefore, a simplified geometry was used for the Tm-170, Yb-175, and Sc-46 particles for the VARSKIN MOD2 calculations, and an equivalent disk diameter was used that yielded the same surface areas as the areas of the measured particles' faces (Table 4).

Table 4. Particle dimensions used for BNL-NIST VARSKIN MOD2 calculations. The "side 1" and "side 2" dimensions were used only to determine an equivalent face diameter.

\begin{tabular}{|l|l|c|c|c|c|c|}
\hline Particle & Geometry & $\begin{array}{c}\text { Density } \\
(\mathbf{g} / \mathbf{c c})\end{array}$ & $\begin{array}{c}\text { Thickness } \\
(\mu \mathrm{m})\end{array}$ & $\begin{array}{c}\text { Side 1 } \\
(\mu \mathrm{m})\end{array}$ & $\begin{array}{c}\text { Side 2 } \\
(\mu \mathrm{m})\end{array}$ & $\begin{array}{c}\text { Equivalent } \\
\text { Diameter } \\
(\mu \mathrm{m})\end{array}$ \\
\hline \hline \multirow{2}{*}{ Tm-170 } & Slab & 9.41 & 258 & 436 & 396 & \\
\cline { 2 - 7 } & 3D Disk & & 258 & & & 469 \\
\hline \multirow{2}{*}{ Sc-46 } & Slab & 2.90 & 130 & $460 \pm 74^{\mathrm{a}}$ & $330 \pm 42^{\mathrm{a}}$ & \\
\cline { 2 - 7 } & 3D Disk & & 130 & & & $440 \pm 14^{\mathrm{b}}$ \\
\hline \multirow{3}{*}{ Yb-175 } & Slab & 6.96 & 130 & 479 & 343 & \\
\cline { 2 - 7 } & 3D Disk & & 130 & & & 457 \\
\hline Co-60 & Sphere & 8.4 & & & & 208 \\
\hline
\end{tabular}

a. Average $( \pm 1 \sigma)$ from the particles.

b. Average computed by averaging equivalent diameter for each particle.

\subsubsection{Activation of Sources}

The sources were sealed in quartz ampules under a helium atmosphere and were neutronactivated, using either the BNL High Flux Beam Reactor (HFBR) or the University of Missouri Research Reactor (UMRR). The exposure times and fluence rates are given in Table 5. 
Appendix

Table 5. Facilities and conditions used for neutron activation of particles

\begin{tabular}{|c|c|c|c|c|c|c|}
\hline Particle & Facility & $\begin{array}{c}\text { Beam } \\
\text { port }\end{array}$ & $\begin{array}{c}\text { Thermal } \\
\text { neutron } \\
\text { fluence rate } \\
\text { (per } \mathrm{cm}^{2} / \mathrm{sec} \text { ) }\end{array}$ & $\begin{array}{l}\text { Beginning } \\
\text { date and } \\
\text { time }\end{array}$ & $\begin{array}{l}\text { Ending } \\
\text { date and } \\
\text { time }\end{array}$ & $\begin{array}{l}\text { Total time } \\
\text { (d) }\end{array}$ \\
\hline Tm-170 & BNL HFBR & $V-14$ & 4.15E14 & $\begin{array}{l}23-\text { Oct-91 } \\
13: 49\end{array}$ & $\begin{array}{l}30-\text { Oct-91 } \\
09: 38\end{array}$ & 6.8 \\
\hline Yb-175 & UMRR & $\mathrm{H}-1$ & $8.0 \mathrm{E} 13$ & $\begin{array}{l}06-\text { Sep-94 } \\
18: 09\end{array}$ & $\begin{array}{l}\text { 08-Sep-94 } \\
18: 09\end{array}$ & 2.0 \\
\hline \multirow[t]{2}{*}{ Sc-46 } & \multirow[t]{2}{*}{ BNL HFBR } & \multirow[t]{2}{*}{$V-14$} & \multirow[t]{2}{*}{ 4.15E14 } & $\begin{array}{l}28-J u n-94 \\
10: 55\end{array}$ & $\begin{array}{l}\text { 02-Jul-94 } \\
14: 10\end{array}$ & \multirow[t]{2}{*}{11.1} \\
\hline & & & & $\begin{array}{l}\text { 11-Jul-94 } \\
16: 15\end{array}$ & $\begin{array}{l}\text { 18-Jul-94 } \\
15: 35\end{array}$ & \\
\hline \multirow[t]{3}{*}{ Co-60 } & \multirow[t]{3}{*}{ BNL HFBR } & \multirow[t]{3}{*}{$V-14$} & \multirow[t]{3}{*}{ 4.15E 14} & $\begin{array}{l}\text { 16-Jun-93 } \\
17: 25\end{array}$ & $\begin{array}{l}29-J u n-93 \\
15: 45\end{array}$ & \multirow{3}{*}{43.7} \\
\hline & & & & $\begin{array}{l}\text { 01-Jul-93 } \\
14: 38\end{array}$ & $\begin{array}{l}\text { 17-Jul-93 } \\
12: 00\end{array}$ & \\
\hline & & & & $\begin{array}{l}27-J u l-93 \\
13: 13\end{array}$ & $\begin{array}{l}\text { 11-Aug-93 } \\
10: 30\end{array}$ & \\
\hline
\end{tabular}

\subsubsection{Support of Sources}

After activation, the sources were removed from the quartz ampule and mounted on double-sided foam tape adhering to a Styrofoam $\AA^{3}$ backing support. The Tm-170, Yb-175, and Co-60 sources then were covered with a $13-\mu \mathrm{m}$ layer of Kapton $\Theta^{4}$, a radiation-resistant plastic (illustrated in Figure 2).

The Styrofoam base had face dimensions of $2.5 \mathrm{~cm}$ by $2.5 \mathrm{~cm}$. The $\mathrm{Tm}-170$ and Co-60 particles were mounted on September 8, 1994, the Yb-175 source September 12, 1994, and the Sc-46 source on July 22, 1994.

The support of the Sc-46 source differed somewhat from that of the other sources in that a 15$\mu \mathrm{m}$-thick piece of aluminum (density of $2.7 \mathrm{~g} / \mathrm{cc}$ ) was placed on the foam tape and was covered with a 30- $\mu \mathrm{m}$-thick layer of $3 \mathrm{M}$ acrylic adhesive number 966 . The Sc-46 particle was mounted on the $3 \mathrm{M}$ adhesive and covered with Kapton. The thin aluminum foil backing ensured that the

${ }^{3}$ Styrofoam is a registered trademark for a light, resilient polystyrene plastic manufactured by the Dow Chemical Company.

${ }^{4}$ Kapton is a registered trademark of the Dupont Company. 


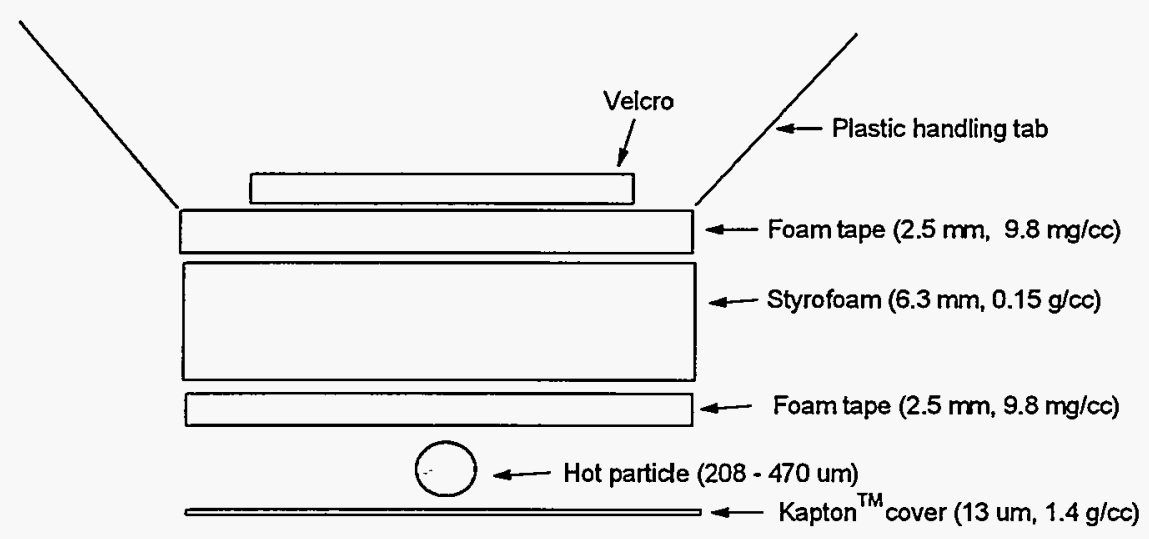

Figure 2. Source mounting block for dosimetry measurements. The Sc-46 particle had a $15-\mu \mathrm{m}-$ thick layer of aluminum foil (density of $2.70 \mathrm{~g} / \mathrm{cc}$ ) and a $30-\mu \mathrm{m}$-thick layer of adhesive between the source and the foam tape.

particle did not sink into the foam tape over the course of several months, which can occur as thefoam tape is damaged by radiation. The extent of backscatter from this foil is not known but is thought to be small (a few percent).

The Styrofoam-block and foam-tape mounting minimized backscatter and, thereby, simulated conditions of a particle on skin with air as a backscatter medium. Plastic tabs and Velcro $\otimes^{5}$ were attached to the back of the placement block to help manipulate the source.

\subsubsection{Decay Corrections}

Doses for the Yb-175 source were referenced to 13:30 on September 13, 1994, the first day of the workshop. Table 6 gives the calculated activities of the different isotopes in the $\mathrm{Yb}-175$ sources on days during which dosimetry measurements were made.

The majority of measurements were carried out at BNL on September 13 and 14, 1994; the visiting researchers made the particle exposures initially, and the BNL researchers exposed the GafChromic films as sources and facilities became available. Also, the GafChromic film was not as sensitive as the other dosimeters and required longer exposure times; thus, delay corrections for decay were necessary for the BNL-NIST measurements of Tm-170 and Sc-46 particles. The relatively long half-life of Co-60 made decay corrections unnecessary. Table 7 indicates when each particle was measured.

${ }^{5}$ Velcro is a registered trademark of Velcro Industries. 


\section{Appendix}

Table 6. Calculated activity in $\mathrm{Bq}$ of the different isotopes in the $\mathrm{Yb}-175$ Particle on days when dosimetry exposures of this particle were made (September 1994)

\begin{tabular}{|c|c|c|c|c|c|c|c|}
\hline Date & Time & $\begin{array}{c}\text { Cooling } \\
\text { time } \\
\text { (days) }\end{array}$ & $\begin{array}{c}\text { Yb-175 } \\
\text { Activity }\end{array}$ & $\begin{array}{c}\text { Yb-177 } \\
\text { Activity }\end{array}$ & $\begin{array}{c}\text { Lu-177 } \\
\text { Activity }\end{array}$ & $\begin{array}{c}\text { Yb-169 } \\
\text { Activity }\end{array}$ & $\begin{array}{c}\text { Sum of } \\
\text { Yb-175, } \\
\text { Lu-177 }\end{array}$ \\
\hline \hline $13-$ Sep-94 & $13: 30$ & 4.8 & $1.0 \mathrm{E}+08$ & $1.5 \mathrm{E}-11$ & $3.2 \mathrm{E}+06$ & $6.7 \mathrm{E}+06$ & $1.1 \mathrm{E}+08$ \\
\hline $14-$ Sep-94 & $13: 30$ & 5.8 & $8.8 \mathrm{E}+07$ & $2.3 \mathrm{E}-15$ & $2.9 E+06$ & $6.6 \mathrm{E}+06$ & $9.1 \mathrm{E}+07$ \\
\hline $15-$ Sep-94 & $13: 30$ & 6.8 & $7.4 \mathrm{E}+07$ & $3.6 \mathrm{E}-19$ & $2.6 \mathrm{E}+06$ & $6.5 \mathrm{E}+06$ & $7.7 \mathrm{E}+07$ \\
\hline $16-$ Sep-94 & $13: 30$ & 7.8 & $6.3 \mathrm{E}+07$ & $5.7 \mathrm{E}-23$ & $2.3 \mathrm{E}+06$ & $6.3 \mathrm{E}+06$ & $6.5 \mathrm{E}+07$ \\
\hline $17-$ Sep-94 & $13: 30$ & 8.8 & $5.3 \mathrm{E}+07$ & $9.0 \mathrm{E}-27$ & $2.1 \mathrm{E}+06$ & $6.2 \mathrm{E}+06$ & $5.6 \mathrm{E}+07$ \\
\hline $18-$ Sep-94 & $13: 30$ & 9.8 & $4.5 \mathrm{E}+07$ & $1.4 \mathrm{E}-30$ & $1.9 \mathrm{E}+06$ & $6.1 \mathrm{E}+06$ & $4.7 \mathrm{E}+07$ \\
\hline $19-$ Sep-94 & $13: 30$ & 10.8 & $3.8 \mathrm{E}+07$ & $2.2 \mathrm{E}-34$ & $1.7 \mathrm{E}+06$ & $5.9 \mathrm{E}+06$ & $4.0 \mathrm{E}+07$ \\
\hline $20-$ Sep-94 & $13: 30$ & 11.8 & $3.3 \mathrm{E}+07$ & $3.5 \mathrm{E}-38$ & $1.5 \mathrm{E}+06$ & $5.8 \mathrm{E}+06$ & $3.4 \mathrm{E}+07$ \\
\hline
\end{tabular}

Table 7. Dosimeter exposure dates (1994)

\begin{tabular}{|c|c|c|c|c|}
\hline Particle & Film BNL ${ }^{a}$ & Film $U^{a}$ & $\begin{array}{c}\text { Exoelectron, } \\
\text { Extrapolation, } \\
\text { and Eberline } \\
\text { Ro-2/2A }\end{array}$ & NE \\
\hline Tm-170 & $\begin{array}{l}\text { Stacks of } 8 \text { : } \\
\text { Sep } 16-17,17-21,26 \text {, } \\
26,26 \\
7.8 \mathrm{mg} / \mathrm{cm}^{2}: \text { Sep } 22-23 \text {, } \\
23,23,23-26\end{array}$ & $\begin{array}{l}\text { Stacks of } 8: \\
\text { Sept } 13,14,15,16 \\
7.8 \mathrm{mg} / \mathrm{cm}^{2}: \\
\text { Sep } 21,23,23,26\end{array}$ & Sep 14 & Sep 14 \\
\hline$Y b-175$ & $\begin{array}{l}\text { Stacks of } 8: \\
\text { Sep } 14,16,16,16,16 \\
7.8 \mathrm{mg} / \mathrm{cm}^{2}: \text { Sep } 19,19 \\
19-20,20\end{array}$ & $\begin{array}{l}\text { Stacks of } 8: \\
\text { Sep } 13,13,13,14 \\
7.8 \mathrm{mg} / \mathrm{cm}^{2}: \\
\text { Sep } 16,16,16,16-17 \\
17\end{array}$ & Sep 14 & Sep 14 \\
\hline Sc-46 & $\begin{array}{l}\text { Stacks of } 8 \text { : } \\
\text { Sep } 22,22,22,22 \\
7.8 \mathrm{mg} / \mathrm{cm}^{2}: \text { Sep } 23 \\
23,23,26\end{array}$ & $\begin{array}{l}\text { Stacks of } 8 \text { : } \\
\text { Sep } 14,14,1616 \\
7.8 \mathrm{mg} / \mathrm{cm}^{2}: \\
\text { Sep } 21,23,23,23,23\end{array}$ & Sep 13 & Sep 14 \\
\hline Co-60 & $\begin{array}{l}\text { Stacks of } 8: \\
\text { Sep } 21-22,22,22,22- \\
26 \\
7.8 \mathrm{mg} / \mathrm{cm}^{2}: \text { Sep } 26,26 \text {, } \\
26-27,28\end{array}$ & $\begin{array}{l}\text { Stacks of } 8: \\
\text { Sep } 14,14,14,14 \\
7.8 \mathrm{mg} / \mathrm{cm}^{2:} \\
\text { Sep } 20,21,21,21,21\end{array}$ & Sep 13 & Sep 14 \\
\hline
\end{tabular}

a. The multiple dates indicate days when each GafChromic film set was irradiated. The multiple sets then were combined to provide an area dose profile, as described in the following sections. 


\section{Appendix}

\subsubsection{Absorber's Materials}

Various materials were placed on the dosimeters to obtain the dose at different depths. The use of the absorbers is discussed for each dosimetry system in the following sections; each absorber is described in Table 8.

Table 8. Absorber materials for hot-particle dosimetry exposures

\begin{tabular}{|l|c|c|c|}
\hline \multicolumn{1}{|c|}{ Material } & $\begin{array}{c}\text { Thickness } \\
(\boldsymbol{\mu m})\end{array}$ & $\begin{array}{c}\text { Density } \\
(\mathbf{g} / \mathbf{c c})\end{array}$ & $\begin{array}{c}\text { Mass thickness } \\
\left(\mathbf{m g} / \mathbf{c m}^{2}\right)\end{array}$ \\
\hline Stack of 3 films & 322 & 1.39 & 44.6 \\
\hline Stack of 7 films & 745 & 1.38 & 103 \\
\hline $\begin{array}{l}\text { Plastic used as } \\
\text { absorber for } \\
\text { extrapolation } \\
\text { chamber }\end{array}$ & 48 & 1.1 & 5.4 \\
\hline $\begin{array}{l}\text { Two pieces of plastic, } \\
\text { nominally 7 mg/cm }\end{array}$ & 63 & 1.2 & 7.3 \\
\hline $\begin{array}{l}\text { Aluminized Mylar } \\
\text { used to cover } \\
\text { GafChromic }\end{array}$ & 9.8 & 1.4 & 1.3 \\
\hline Kapton & 13 & 1.4 & 1.8 \\
\hline $\begin{array}{l}\text { Extrapolation } \\
\text { chamber window }\end{array}$ & 5.7 & 1.4 & 0.80 \\
\hline
\end{tabular}

a. polyethylene terephthalate.

\subsection{GafChromic Dosimetry}

\subsubsection{Description}

GafChromic film dosimeters have a $6.5-\mu m$-thick layer of dye that turns blue upon irradiation (Figure 3). For the purposes of the present work, the dose is assigned to the middle of the dye layer. 


\section{Appendix}

To provide data for a depth-dose profile, films were cut into $4 \mathrm{~cm}$ by $4 \mathrm{~cm}$ pieces and placed in stacks of 8 , on an 8-mm-thick polymethyl methacrylate (PMMA) block, with the dye layers facing

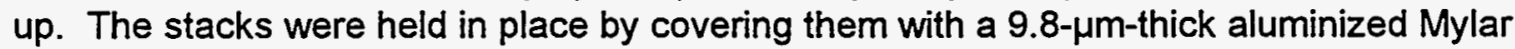
window $(1.4 \mathrm{~g} / \mathrm{cc})$, which was secured about the perimeter with transparent tape.

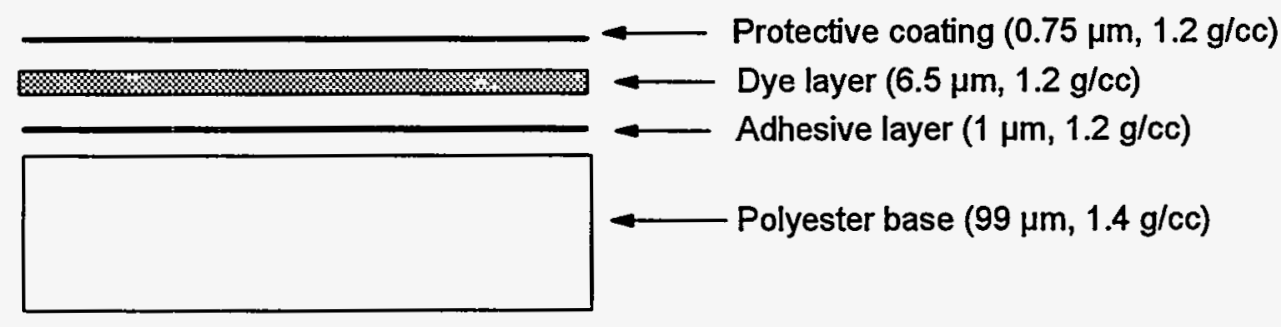

Figure 3. Construction of GafChromic dye film with manufacturersupplied dimensions except for the density of the polyester base, which was determined from measurements of the film.

\subsubsection{Exposure of GafChromic Dye Film to Hot Particles}

The source-mounting block was secured to the end of a 2.5-cm-diameter, 30-cm-long PMMA rod; both had pieces of Velcro to attach them together. The PMMA rod with the mounted source then was lowered vertically onto the stack of GafChromic dye films. The PMMA rod was supported by a ring stand for some exposures, and a specially made jig for others.

Three to five stacks of films were exposed to the same particle for different durations, thereby spanning two to four decades of dose; this allowed determination of the dose profile at each depth. The centerline dose immediately under the particle was obtained with the shorter (higher dose rate) exposures, and the dose at greater radial distance from the centerline with longer (lower dose rate) exposures. The short exposures were necessary to avoid saturating the film at the centerline (Soares and McLaughlin, 1993) which occurred for the longer exposures (see Figure 4).

In addition to the readings from stacks of 8 films, measurements to obtain the dose at an approximate mass thickness of $7 \mathrm{mg} / \mathrm{cm}^{2}$ were made by placing two pieces of plastic with a combined thickness of $63 \mu \mathrm{m}$ and mass thickness of $7.3 \mathrm{mg} / \mathrm{cm}^{2}$ over a single GafChromic film. Again, 3 to 5 irradiations were carried out with time durations selected to obtain 2 to 4 decades of dose.

Films exposed by the BNL researchers were read at NIST by C. Soares, and the resulting dose measurements are referred to as BNL-NIST GafChromic film measurements. Films exposed by 


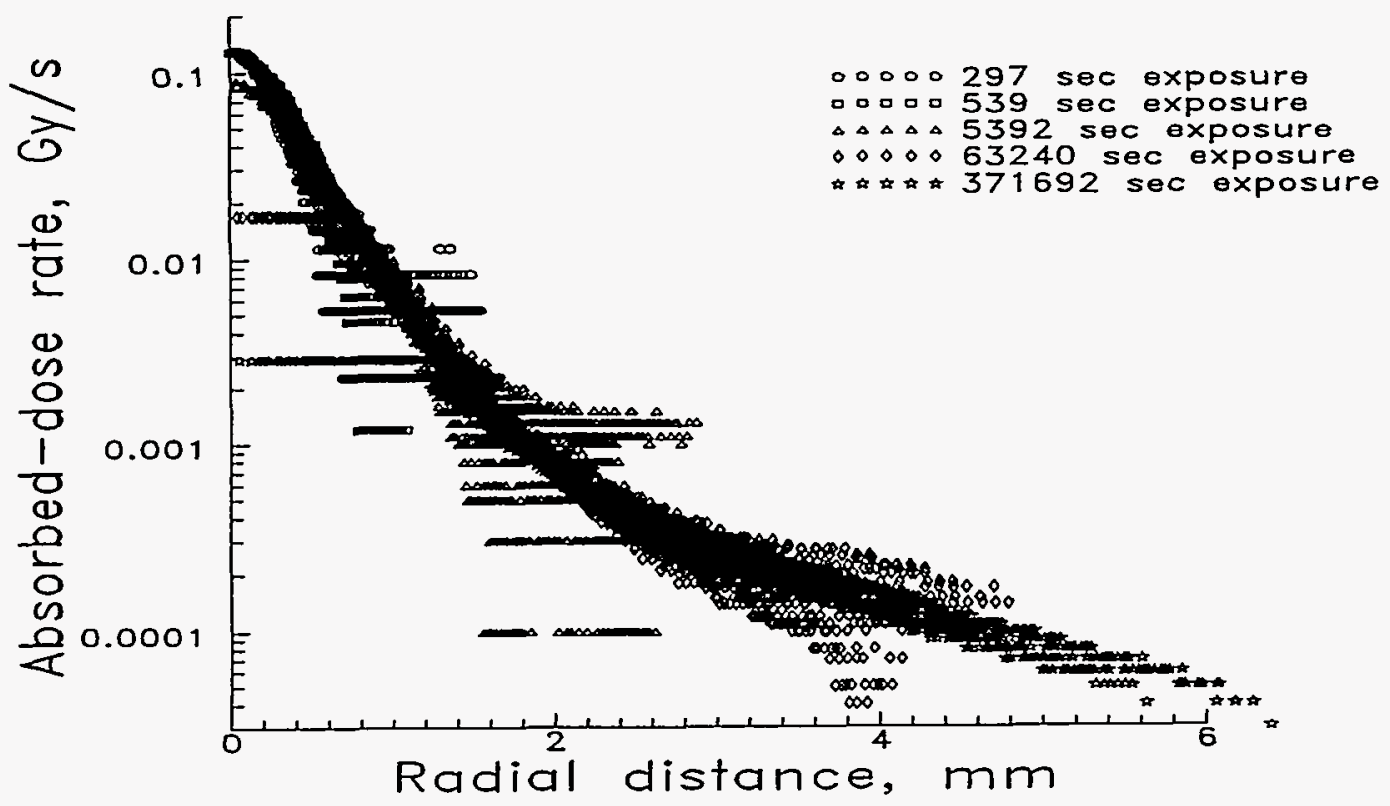

Figure 4. Radial dose profile for the Tm-170 particle at a film mass thickness of $1.8 \mathrm{mg} / \mathrm{cm}^{2}$. This example demonstrates the effect of combining films with different exposure times.

the UB researchers were read at the UB facility and are referred to as the UB GafChromic film measurements. The UB researchers read all eight films in their stacks. Only the first, second, fourth, and eighth films of the BNL film stacks were read.

\subsection{NIST Radiochromic Film Dosimetry System}

\subsubsection{Readout of Films}

Two-dimensional densitometry was performed with a commercial scanning laser densitometer using a HeNe laser at $633 \mathrm{~nm}$. The laser spot was $100 \mu \mathrm{m}$ in diameter and was stepped in increments of 40 to $160 \mu \mathrm{m}$ in both the $x$ and $y$ directions, depending on the size of the image being scanned. 


\section{Appendix}

\subsubsection{Calibration}

The GafChromic dosimeters were calibrated by exposing GafChromic films from the same film batch as that used for the dosimetry studies to selected doses from a Co-60 gamma source. Calibrations using both a Co-60 gamma-ray source and a Sr-Y-90 beta-ray source have shown no significant difference in their dose response (Soares and McLaughlin, 1993). The change in optical density is linear with dose between about 30 and 1,000 Gy. The delay between reading the calibration films and the films irradiated using the hot particles was about 2-3 weeks in both cases.

After reading the films, a radial dose-profile was determined from the 3 to 5 films at each depth by fitting a curve to the radial dose response data using the Tablecurve Version 3.10 computer code (Jandel Scientific, San Rafael, California). In some cases, only two films had been used for the $767 \mu \mathrm{m}$ depth measurements. Points where the films were saturated were not used in the fitting routine. The dose averaged over the area of interest was then integrated using Simson's rule (Fraleigh, 1980).

\subsubsection{Brookhaven Interpolated Tissue Doses}

Tissue doses were interpolated from the measurements in the following manner. The ratio of the expected tissue dose over area $A$ at some tissue depth, $d_{t}$, and the measured value from the film averaged over area $A$ at film depth, $d_{f}$, should be the same as that calculated using VARSKIN MOD2 (Durham, 1992). This ratio then can be used to calculate the expected tissue dose averaged over the area of interest using equation 1 :

$$
D\left(\begin{array}{c}
\text { area } A \text {, depth } d_{t} \\
\text { for tissue }
\end{array}\right)=D\left(\begin{array}{c}
\text { measured for film } \\
\text { at depth } d_{t} \\
\text { for area } A
\end{array}\right) \times \frac{D\left(\begin{array}{c}
\text { VARSKIN MOD2 } \\
\text { area } A_{1} \text { depth } d_{t}
\end{array}\right)}{D\left(\begin{array}{c}
\text { VARSKIN MOD2 } \\
\text { Film depth } d_{i} \\
\text { area } A
\end{array}\right)}
$$

To minimize the potential for errors, data from the film at a depth nearest to the tissue depth of interest was used in the calculations. 
Appendix

\subsection{UB Radiochromic Film Dosimetry System (M.W. Charles and P.J. Darley, Birmingham)}

\subsubsection{Readout of UB Films}

The UB GafChromic films were readout on a Joyce-Loebl MDM 6 scanning microdensitometer (JL Automation, Sunderland 3R5 3NX, United Kingdom), an object plane flat-bed scanner, using tungsten halogen illumination.

Under computer control, the instrument provides flexible scan patterns with stepping increments in multiples of $5 \mu \mathrm{m}$, and a maximum scan area of $25 \mathrm{~cm} \times 25 \mathrm{~cm}$. Scan apertures are also interchangeable, and with standard optics the effective sampling aperture can be varied from $5 \mu \mathrm{m} \times 5 \mu \mathrm{m}$, to $250 \mu \mathrm{m} \times 250 \mu \mathrm{m}$.

In the present study, a constant effective aperture size of $25 \mu \mathrm{m} \times 25 \mu \mathrm{m}$ and a step size of $25 \mu \mathrm{m}$ was used for all films, with the number of steps (typically 200 ) varied to match the exposed area of the film.

The observed optical density was converted to dose using a calibration curve generated with GafChromic samples from the same batch exposed in a calibrated $400 \mathrm{kVp}$ X-ray beam. Previous comparison with the NIST Co-60 and Sr-Y-90 calibrations showed a systematic difference between them of about 6-7\% (Soares et al., 1991). With the broad-band illumination used in the MDM 6, the optical density versus dose curve is sigmoidal rather than linear and presently is fitted over the range from 0 to $1,500 \mathrm{~Gy}$ by a fifth-order polynomial.

Scan data from different exposure films at a given stack position are combined automatically by a computer code which evaluates the centroid of each scan pattern, determines the radial distance of each data point from the centroid, converts measured optical density to dose, and rejects any data outside a user-defined dose range (typically 15-1,500 Gy); then, it assigns the resulting estimate of dose rate to an appropriate radial distance interval, calculates the mean and standard deviation of the estimates for each interval, and finally uses a weighted combination of the dose rate estimates for each annular interval to assess dose averaged over area. These numerical values generally are fitted using Tablecurve curve-fitting software (Jandel Scientific, San Rafael, California) for interpolation or extrapolation to any desired area.

\subsubsection{UB Calculated Tissue Doses}

Tissue doses also were estimated from the film measurements in a slightly different manner using the VARSKIN MOD2 code (Durham, 1992). For each required averaging area (A), a dose versus physical depth $(\mu \mathrm{m})$ curve was generated by fitting (again using Tablecurve) the dose estimates for the eight film positions in a stack. Dose estimates $D\left(d_{p}, G\right)$ in GafChromic film $(G)$ at the required physical depth $\left(d_{p}\right)$ then were obtained by interpolation, and corrected solely for the differing absorption in tissue and GafChromic film by using the ratio of the VARSKIN MOD2 dose 


\section{Appendix}

estimates for that area of tissue beneath a physical depth $d_{p}$ of tissue (t) and GafChromic film (G) as shown in equation 2:

$$
D\left(d_{p}, t\right)=D(d p, G) \times \frac{\left.D \text { VARMOD2(area } A_{1} \text { physical depth } d_{p}\right) t}{\text { D VARMOD2(area } \left.A_{1} \text { physical depth } d_{p}\right) G}
$$

Table 9 lists the predicted correction factors $D\left(d_{p}, t\right) / D\left(d_{p}, G\right)$ for $1 \mathrm{~cm}^{2}$ averaging area, based on the equivalent disc particle characteristics. The differences between the UB and BNL tissue dose estimation lie in the BNL extrapolating from a single film dose using VARSKIN MOD2, whereas the UB procedure interpolates between films.

The large difference between the Co-60 and Sc-46 factors arises as VARSKIN MOD2 does not estimate gamma doses for Sc-46. Therefore, in the present application, the correction factors for Co-60 were also used for Sc-46.

The dose values at $70 \mu \mathrm{m}\left(7 \mathrm{mg} / \mathrm{cm}^{2}\right)$ depth in tissue obtained in this way are in good agreement (maximum difference $<10 \%$ ) with the corrected values from under the nominal $7 \mathrm{mg} / \mathrm{cm}^{2}$ absorbers except in the case of $\mathrm{Yb}-175$ where the earlier stack exposures give a dose rate some $60 \%$ higher.

Table 9. Calculated correction factors for interpolating measured dose in GafChromic film to depths in tissue for dose averaged over $1 \mathrm{~cm}^{2}$

\begin{tabular}{|c|c|c|c|c|}
\hline Depth $(\mu \mathrm{m})$ & Co-60 & Sc-46a & Yb-175 & Tm-170 \\
\hline \hline 70 & 1.24 & 1.31 & 1.23 & 1.13 \\
\hline 125 & 1.33 & 1.66 & 1.44 & 1.21 \\
\hline 400 & 1.03 & 17.0 & 3.55 & 1.54 \\
\hline
\end{tabular}

a. The Co-60 values were used, rather than these tabular values for $\mathrm{Sc}-46$, as described in the text.

\subsection{Exoelectron Dosimetry System (J.S. Durham, Battelle, PNL)}

\subsubsection{Principles of Exoelectron Dosimetry}

The principles of exoelectron dosimetry are similar in many ways to those of thermoluminescent dosimetry. Upon exposure to ionizing radiation, electrons near the surfaces of certain crystals become elevated to higher energy states and a fraction is trapped at these elevated energies in 
Appendix

impurities. Upon heating the crystal, these electrons are released from the traps and are emitted from its surface. The emitted electrons, called exoelectrons, can be counted by standard detection methods, such as gas-flow counters (Merwin and Swinth, 1987). Exoelectron dosimetry differs from thermoluminescent dosimetry in that particles (electrons) rather than photons indicate the dose. Also, exoelectron emission is a surface phenomenon whereas thermoluminescent emission is a volume phenomenon; it is this fact that makes exoelectron dosimeters (EEDs) potentially useful for measuring dose from hot particles. Because the range of exoelectrons in the dosimeter material is very small (less than $100 \mathrm{~nm}$ ), the sensitive layer of an EED is extremely thin and does not significantly attenuate beta particles, even those from Co-60 (Merwin and Swinth, 1989). Furthermore, the dosimeter can be covered by any desired cover material to determine the dose rate to a specific depth of tissue. Ongoing research at PNL has suggested that EEDs can accurately measure the dose rate to $1 \mathrm{~cm}^{2}$ of skin from both fuel particles and cobalt particles (Merwin, Moeller and Swinth, 1988). Area correction factors were applied to the dose measurements, as described by these authors.

The active areas of the EEDs were made of beryllium oxide $(\mathrm{Be} 0)$ with an area of $0.23 \mathrm{~cm}^{2}$. The dosimeters were designed with a lip around the active area to help protect the delicate surface and aid in handling them. Having a lip results in a 0.4-mm air gap between the $\mathrm{BeO}$ and the cover material placed between the source and the EED.

\subsubsection{Exposure of EEDs to Hot Particles}

Before the BNL measurements, all but six of the EEDs were calibrated by exposing the dosimeters to known doses ranging from $1 \mathrm{mGy}$ to $5 \mathrm{mGy}$ from Tl-204 and Cs-137. The irradiations were carried out at PNL's secondary calibration facility, which maintains standards traceable to NIST. This facility also performs irradiations for both the National Voluntary Laboratory Accreditation Program (NVLAP) and the Department of Energy Laboratory Accreditation Program (DOELAP).

The dosimeters were exposed in an irradiation jig that allowed the EED to be loaded away from the source. The source then was aligned by placing it in the jig and measuring its location with a small piece of radiochromic dye film. The film exposures were repeated until the source was centered over the exposure position, and the mounting assembly for the source was marked. The cover materials then were placed over the exposure position and the source was placed in its position. The EED was inserted into the irradiation jig and the irradiation was timed using a stop watch. The dose desired for each EED was less than $0.01 \mathrm{~Gy}$, and irradiation times were calculated from estimated dose rates of each of the particles.

Measurements were taken at mass thicknesses of $1.3,7.3$, and 1.3 plus $44.4 \mathrm{mg} / \mathrm{cm}^{2}$ (a Mylar cover and three layers of radiochromic dye film). No additional materials were placed between the sources and the detectors. Table 10 summarizes the exposure times and geometries. Due to very short irradiation times associated with the $\mathrm{Yb}-175$ and Sc-46 measurements, 10 to $25 \%$ uncertainties were introduced into the measurements because of the significant transit times into and out of the irradiation position, which were estimated as 


\section{Appendix}

Table 10. Exposure geometries and times for the exoelectron dosimeters

\begin{tabular}{|l|r|r|r|r|r|}
\hline \multirow{2}{*}{ Source } & Geometry & \multicolumn{4}{|c|}{ Irradiation Times (sec) } \\
\hline \hline \multirow{3}{*}{ Tm-170 } & $9.8 \mu \mathrm{m}$ & $30.2^{\mathrm{b}}$ & 30.2 & 30.2 & $30.3^{\mathrm{c}}$ \\
\cline { 2 - 6 } & $63 \mu \mathrm{m}$ & $30.2^{\mathrm{b}}$ & 30.1 & 30.1 & 30.2 \\
\cline { 2 - 6 } & 3 films $+9.8 \mu \mathrm{m}$ & 60.0 & 60.1 & 60.2 & 60.2 \\
\hline \multirow{3}{*}{ Yb-175 } & $9.8 \mu \mathrm{m}$ & 5.1 & 5.3 & 5.2 & 5.2 \\
\cline { 2 - 6 } & $63 \mu \mathrm{m}$ & 5.3 & 5.3 & 5.3 & 5.2 \\
\cline { 2 - 6 } & 3 films $+9.8 \mu \mathrm{m}$ & 10.1 & 10.3 & 10.1 & 10.3 \\
\hline \multirow{3}{*}{ Sc-46 } & $9.8 \mu \mathrm{m}$ & 2.2 & $2.5^{\mathrm{b}}$ & $2.2^{\mathrm{b}}$ & 2.9 \\
\cline { 2 - 6 } & $63 \mu \mathrm{m}$ & 2.4 & 2.5 & 2.7 & 2.6 \\
\cline { 2 - 6 } & 3 films $+9.8 \mu \mathrm{m}$ & 4.2 & 4.2 & $4.3^{\mathrm{b}}$ & $4.3^{\mathrm{b}}$ \\
\hline \multirow{3}{*}{ Co-60 } & $9.8 \mu \mathrm{m}$ & 59.9 & 60.0 & 60.0 & 60.2 \\
\cline { 2 - 6 } & $63 \mu \mathrm{m}$ & 60.1 & 60.1 & 60.2 & 60.3 \\
\cline { 2 - 6 } & 3 films +9.8 $\mu \mathrm{m}$ & 120.0 & 120.0 & 120.1 & 120.1 \\
\hline
\end{tabular}

a. $9.8 \mu \mathrm{m}$ refers to the $9.8-\mu \mathrm{m}$-thick Mylar, $63 \mu \mathrm{m}$ refers to the $63-\mu \mathrm{m}$-thick Mylar, and 3 films refers to 3 GafChromic films. See Table 8 for additional information.

b. The EEDs used for these exposures were not calibrated before the intercomparison and the results from them are not included in Table 17.

c. The reader malfunctioned during readout of the EED for this exposure, and the results are not included in Tables 17 or 18.

0.1 to 0.5 second for a 5 -second exposure. To determine the dose rate from each particle to 1 $\mathrm{cm}^{2}$ at the specified depths, four EEDs were exposed to each particle at each specified depth.

The mean and the standard deviation of the mean were determined for each irradiation geometry, and a correction factor was applied to relate the dose to $1 \mathrm{~cm}^{2}$. The correction factor used was the ratio of the sensitive area of the EED $\left(0.23 \mathrm{~cm}^{2}\right)$ to the area of interest $\left(1 \mathrm{~cm}^{2}\right)$. It is assumed that all of the beta energy emitted from the particles was collected on the EED surface (Merwin, Moeller, and Swinth, 1988). 
Appendix

\subsubsection{Calibration of EEDs}

The results of the measurements were complicated by problems with PNL's readout equipment. Although readout of the EEDs exposed at BNL were completed using the PNL reader, its failure necessitated using a similar reader at Oak Ridge National Laboratory (ORNL) to calibrate some other EEDs. Consequently, the dosimeters were irradiated with $1 \mathrm{mSv}$ (100 mrem) of Cs-137 and sent to ORNL for readout. This procedure was carried out twice.

The measurements showed that using the calibration factor obtained with the ORNL reader gave results that were $33 \%$ lower than those obtained with calibration factors from the PNL reader. We believe that the appropriate results to use are those obtained using the PNL calibration factors.

\subsubsection{EED Interpolated Tissue Doses}

To interpolate the measured dose rates to obtain dose at the desired tissue depths averaged over $1 \mathrm{~cm}^{2}$, a "calibration" was performed with the VARSKIN MOD2 code (Durham, 1992). For each isotope, we calculated the dose rate for a $1 \mu \mathrm{Ci}$ source at a depth corresponding to each of the three geometries listed in Table 10 which was compared with the EED measurement at the same depth. From the comparison, a source activity for each geometry calculation was determined. Using this method, the source activity for each particle was determined and used to assess dose at the specific depths of interest. The calculated source activity for the "9.8- $\mu \mathrm{m}$ " geometry (Table 10) was used for tissue dose calculations at "18- $\mu$ " depth. The calculated source activity for the "63- $\mu \mathrm{m}$ " geometry (Table 10) was used for tissue dose calculations at 70 - and 125- $\mu \mathrm{m}$ depth. The calculated source activity for the "3 films $+9.8-\mu \mathrm{m}$ " geometry (Table 10) was used for tissue dose calculations at $400-\mu \mathrm{m}$ depth. This gave results that were more consistent than those given previously (Kaurin et al., 1996), in which only the activity from the "3 films $+9.8 \mu \mathrm{m}$ " geometry was used to determine dose to all tissue depths.

\subsection{Extrapolation Chamber Dosimetry System (M.J. Scannell, Yankee Atomic Electric Company)}

The YAEC extrapolation chamber is a custom-designed, fully automated system that was successfully applied previously in hot particle dosimetry (McWilliams et al., 1992).

\subsubsection{The YAEC Extrapolation Chamber System}

The YAEC extrapolation chamber has an active volume region which is described as follows. An $85-\mathrm{mm}$-diameter aluminized PTP entrance foil of $0.795 \mathrm{mg} / \mathrm{cm}^{2}$ mass thickness $(5.7 \mu \mathrm{m})$ is supported by a 23-mm-thick polystyrene ring that also forms the side walls of the chamber. The collecting electrode and guard ring assembly is an $80-\mathrm{mm}$-diameter by $25-\mathrm{mm}$-thick cylinder of PMMA parallel to the entrance foil. The PMMA surfaces are coated with a thin layer of colloidal graphite, and the collecting area is defined by a $0.3-\mathrm{mm}$ circular groove etched through the 


\section{Appendix}

graphite into the PMMA. This groove isolates the circular collecting area from the outer guard ring. The collecting electrode area is $1 \mathrm{~cm}^{2}( \pm 1 \%)$. A 1.7-mm-diameter central brass pin, pressed into the PMMA, provides the conducting path from the collecting area to the electrometer. A second pressed-in brass pin provides electrical contact with the guard ring to allow a bias voltage to be applied between the entrance foil and electrode.

A precision stepping motor ( $2.5 \mu \mathrm{m}$ per step resolution) controls the position of the collecting electrode relative to the entrance window and, therefore, the air gap in the extrapolation chamber. A thermocouple and pressure transducer monitor the ambient temperature and pressure. A Keithley Instruments Model 617 electrometer of $5 \mathrm{fA}$ sensitivity measures the ionization current generated in the active volume of the chamber. The DC voltage source in the electrometer supplies the bias to the chamber.

\subsubsection{Exposure of the YAEC Extrapolation Chamber to Hot Particles}

For measuring the dose rate, layers of absorber material were inserted between the hot particles and the entrance foil. The layers were either a sheet of $0.795 \mathrm{mg} / \mathrm{cm}^{2}$ aluminized polyethyleneterephthalate (PTP), a sheet of $0.795 \mathrm{mg} / \mathrm{cm}^{2}$ aluminized PTP plus a sheet of $5.4 \mathrm{mg} / \mathrm{cm}^{2} \mathrm{black}$ PTP, two sheets of $0.795 \mathrm{mg} / \mathrm{cm}^{2}$ aluminized PTP plus a sheet of $5.4 \mathrm{mg} / \mathrm{cm}^{2}$ black PTP, or a sheet of $0.795 \mathrm{mg} / \mathrm{cm}^{2}$ aluminized PTP plus three sheets $\left(44.6 \mathrm{mg} / \mathrm{cm}^{2}\right)$ of GafChromic film. Including the entrance foil, these absorbers yielded thicknesses of $1.59,6.99,7.78$, and $46.2 \mathrm{mg} / \mathrm{cm}^{2}(11.4,59.4,65.1$, and $333 \mu \mathrm{m})$. When placing the absorbers, care was taken to eliminate air gaps between them. The source was centered over the collecting electrode by manually moving it to maximize the ionization current measured by the electrometer.

Before taking measurements on the hot particles, the distance (plate spacing) between the entrance foil and collecting electrode surface was determined to approximately $\pm 5 \mu \mathrm{m}$ using capacitance techniques described by Loevinger and Trott (1966). The placement of sources and absorbers on the entrance foil was expected to have deformed the latter, thereby reducing the foil-to-electrode distance. While the investigation of this phenomena was beyond the scope of

the work, its effect on the dose-rate determination was expected to be minor. That determination is based on the fact that the dose-rate determination is based on the accurate movement of the collecting electrode relative to the entrance foil, not on its actual distance from the entrance foil.

The ionization current was measured at three plate spacings which were typically $0.5,0.6$ and $0.7 \mathrm{~mm}$. A constant $30 \mathrm{~V} / \mathrm{mm}$ voltage gradient between the electrode and entrance foil was maintained. Only negative ionization currents were collected. Previous testing at the YAEC showed that using a single polarity yields dose rates that are within $0.4 \%$ of the standard approach of using the average of positive and negative currents (McWilliams et al., 1992).

The measured currents were corrected to normal temperature and pressure (NTP) of $22^{\circ} \mathrm{C}$ and $101.3 \mathrm{kPa}(760 \mathrm{~mm} \mathrm{Hg})$. The relative humidity in the laboratory was between 60 and $70 \%$. 
Appendix

\subsubsection{Calibration of YAEC Extrapolation Chamber System}

The YAEC Extrapolation Chamber System is considered a primary instrument for measuring absorbed dose rate. Past comparisons with the NIST standard beta-particle sources (Pruitt et al., 1988) have been in agreement to within the measurements' uncertainties.

For accurate hot-particle dosimetry, certain operational aspects of the measurements should be considered, including the nonlinearity in the data, excess backscatter from the central brass pin, and the appropriate value of the relative mass stopping-power of tissue to that in air. Past work indicates that the corrections for these aspects tend to cancel each other out for Co- 60 beta particles (McWilliams et al., 1992). Since evaluating these aspects for the hot particles of this study was beyond the scope of the work, no corrections were applied. We expect that applying such corrections would not greatly alter the final results.

\subsubsection{Calculating Tissue Dose from YAEC Extrapolation Chamber Measurements}

The NTP-corrected ionization current, corrected for normal temperature and pressure, and plate spacing data were fit using a least-squares linear regression. The slope of the line $(J)$ in Ampere/mm was converted to an absorbed dose rate using equation 3 :

$$
\text { absorbed dose rate }(G y / s)=W * S_{m} * J / A / p
$$

where $A$ is the collecting electrode area of $100 \mathrm{~mm}^{2}, \mathrm{~S}_{\mathrm{m}}$ is the relative mass stopping power of tissue to air, 1.15 (an average value based on the collision-stopping powers of air and the International Commission on Radiation Units and Measurements (ICRU) adipose tissue in the 0.01 to $1.0 \mathrm{MeV}$ electron energy range) (ICRU, 1984), $W$ is 33.97 Joules/Coulomb in air, and $p$ is $1.197 \mathrm{E}-9 \mathrm{Kg} / \mathrm{mm}^{3}$ density for air at NTP.

For reported dose rates, the uncertainty in the measurement is based on the uncertainty in the value of $\mathrm{J}$. Normally, an additional $\pm 1.9 \%$ (at three sigma) is quoted for the systematic uncertainties related to the corrections applied to $\mathrm{J}$ in equation 3

\subsection{NE Extremity Tape Dosimeters}

\subsubsection{Description of NE Extremity Tape Dosimeters}

NE Extremity Tape dosimeters are produced by NE Technology Limited, United Kingdom. In the past, these dosimeters were identified by the original manufacturer as Vinten dosimeters.

A NE Extremity Tape dosimeter is a thin, flexible, lithium fluoride (LiF) TLD. The manufacturer indicates that the LiF phosphor is covered by a $3.32 \pm 0.33 \mathrm{mg} / \mathrm{cm}^{2}$ aluminized foil 


\section{Appendix}

$\left(23.7 \pm 2.4 \mu \mathrm{m}\right.$ ). The LiF phosphor is a $23.8 \pm 1.4 \mathrm{mg} / \mathrm{cm}^{2}$ powder (density of $2.64 \mathrm{~g} / \mathrm{cm}^{3}$ ). Since the LiF powder is partly imbedded in a glue substrate, only a portion of the thickness can transmit a TL signal. Testing at YAEC with Pm-147 indicates that the thickness of the radiationresponsive portion is $11.7 \mathrm{mg} / \mathrm{cm}^{2}(44.4 \mu \mathrm{m})$. The testing indicated that the response of the NE Extremity Tape dosimeters was about $20 \%$ lower than the $7 \mathrm{mg} / \mathrm{cm}^{2}$ dose from a Pm-147 calibration source. Iterative calculations were performed to determine what thickness of phosphor would cause such a reduced response. By using the mean value theorem to average the exponentially attenuated dose, the calculations revealed that a phosphor averaging between 3.32 and $15 \mathrm{mg} / \mathrm{cm}^{2}$ would account for this difference.

Previous measurements of hot particles gave a response about $16 \%$ lower than that obtained using the extrapolation chamber (McWilliams et al., 1992); this was attributed to the actual depth of measurement being greater than $7 \mathrm{mg} / \mathrm{cm}^{2}$. Therefore, for this study, an effective depth was calculated for each hot particle. Once again, the mean value theorem (Fraleigh, 1980) was used for dose averaging. The attenuation coefficients used in the calculations were based on the attenuation observed between the extrapolation chamber measurements at 1.59 and $6.99 \mathrm{mg} / \mathrm{cm}^{2}$. Using this information, the calculated effective depth was $8.94,8.74,8.63$, and $8.59 \mathrm{mg} / \mathrm{cm}^{2}(45.0,44.3,43.9$ and $43.7 \mu \mathrm{m})$ for $\mathrm{Tm}-170, \mathrm{Yb}-175, \mathrm{Sc}-46$, and Co-60, respectively.

The effective depth is the thickness in the TLD such that half of the dose is deposited at depths less than and half at depths greater than the effective depth. The relative attenuation factor of beta particles in the TLD at the effective depth is represented schematically in Figure 5 , and is calculated by:

$$
\begin{aligned}
R_{T L D} & =\frac{\int_{A}^{B} e^{-\mu t} d t}{\int_{A}^{B} d t} \\
& =\frac{e^{-\mu A}-e^{-\mu B}}{\mu(B-A)}
\end{aligned}
$$

where

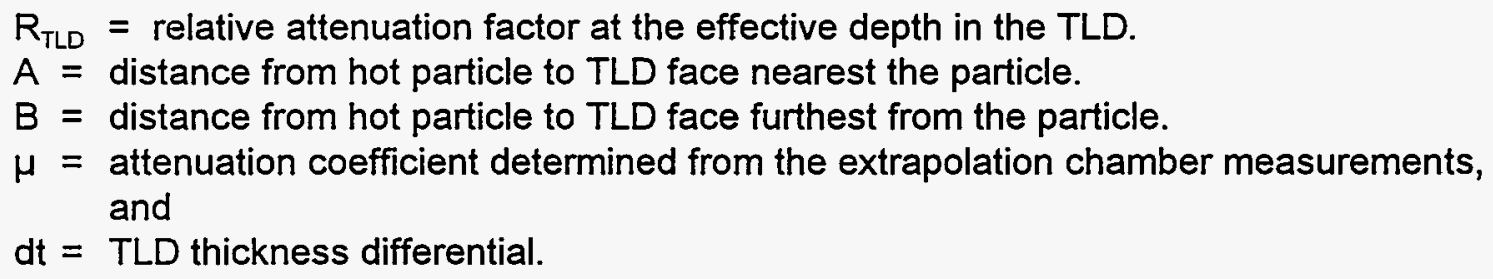




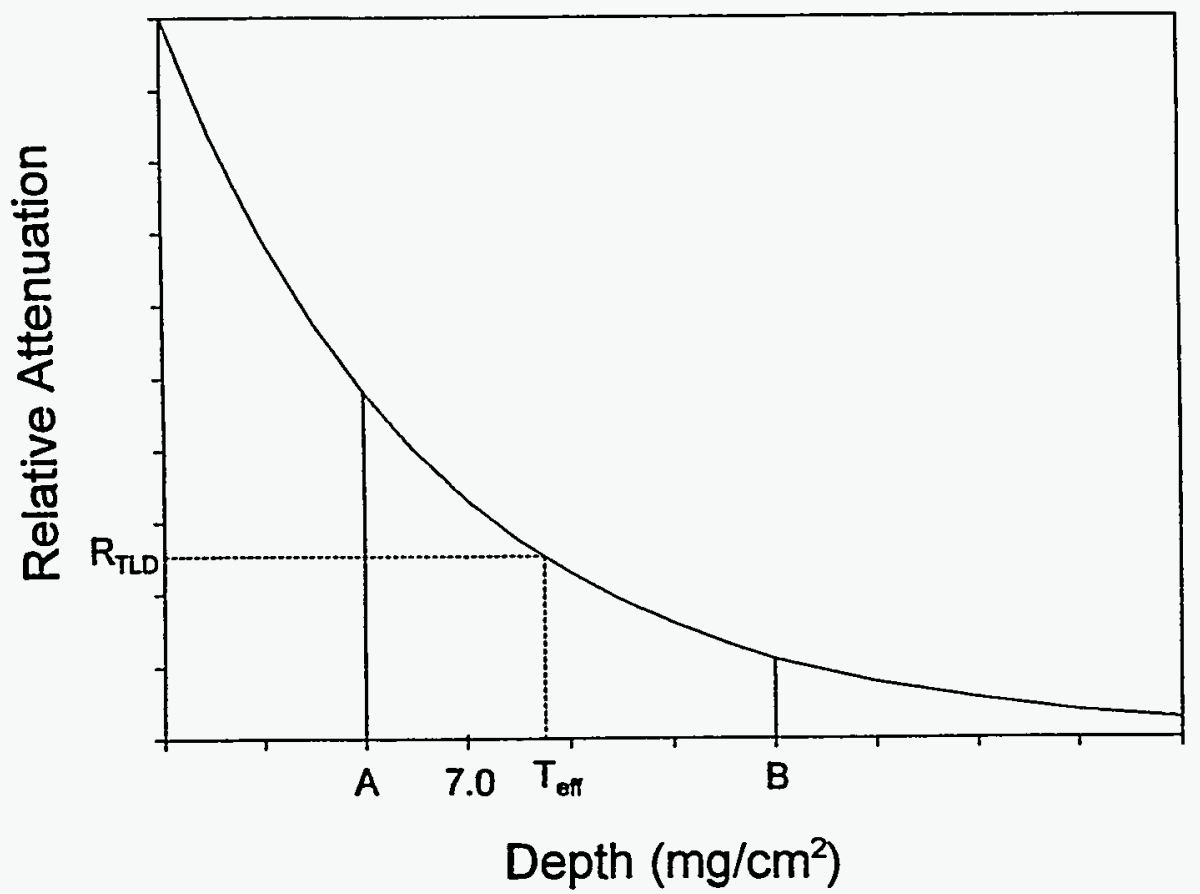

Figure 5 Schematic representation of dose deposition through the thickness of the NE Extremity Tape dosimeter. The A and B represent the top and bottom of the TLD, respectively. The depth corresponding to half the area under the curve between $A$ and $B$ is the depth where the dose is assigned.

In the measurements, $A$ was equal to $3.32 \mathrm{mg} / \mathrm{cm}^{2}$. The value of $B$ was calculated from previous comparisons of the NE Extremity Tape dosimeter and the Yankee Atomic extrapolation chamber for a Pm-147 calibration source.

The effective thickness of the TLD is calculated from $R_{T L D}$ using:

$$
T_{\text {off }}=\frac{\ln \left(R_{T L D}\right)}{-\mu}
$$

where $T_{\text {eff }}=$ effective depth of the TLD. Values for these calculations are given in Table 11. 


\section{Appendix}

Table 11. Effective depth of NE Extremity Tape dosimeters

\begin{tabular}{|l|c|c|c|c|c|}
\hline \multicolumn{1}{|c|}{ Isotope } & $\begin{array}{c}\mu^{\mathrm{a}} \\
\left(\mathrm{cm}^{2} / \mathrm{mg}\right)\end{array}$ & $\mathrm{R}_{\mathrm{TLD}}$ & $\begin{array}{c}\mathrm{e}^{-\mu} \\
\text { at } 7 \mathrm{mg} / \mathrm{cm}^{2}\end{array}$ & $T_{\text {eff }}\left(\mathrm{mg} / \mathrm{cm}^{2}\right)$ & $\begin{array}{c}\text { Expected under } \\
\text { response relative } \\
\text { to } 7 \mathrm{mg} / \mathrm{cm}^{2} \text { dose }\end{array}$ \\
\hline \hline $\mathrm{Pm}-147$ & 0.1836 & 0.224 & 0.277 & 8.154 & $0.81^{\mathrm{c}}$ \\
\hline Co-60 & 0.1019 & 0.417 & 0.490 & 8.587 & 0.85 \\
\hline Sc-46 & 0.0950 & 0.441 & 0.514 & 8.625 & 0.86 \\
\hline Yb-175 & 0.0742 & 0.523 & 0.595 & 8.741 & 0.88 \\
\hline Tm-170 & 0.0391 & 0.705 & 0.761 & 8.938 & 0.93 \\
\hline
\end{tabular}

a. Values of $\mu$ determined from the Yankee Atomic extrapolation chamber for each source.

b. This is the expected under-response without any correction in the effective depth of the NE Extremity Tape dosimeter. It is calculated by dividing the $R_{T L D}$ value by the value of $e^{-u}$ at $7 \mathrm{mg} / \mathrm{cm}^{2}$.

c. This value was used to calculate the value of "B" for the dosimeters. It is based on comparisons between the Yankee Atomic extrapolation chamber and the NE Extremity Tape dosimeters.

Values of $T_{\text {eff }}$ were calculated only for measurements carried out without any absorber material between the NE Extremity Tape and the hot particle covered with Kapton. Values of $T_{\text {eff }}$ from this calculation were assigned to measurements made at deeper depths.

\subsubsection{Exposure of NE Extremity Tape Dosimeters to Hot Particles}

The irradiations were performed by placing each NE Extremity Tape dosimeter under the hot particle using the same slide arrangement that was used for the exoelectron dosimeters that placed the source virtually in contact with the dosimeter's foil surface. The irradiation time was monitored with a stop watch. Additional measurement depths were achieved by inserting GafChromic film absorbers in stacks of one, three, seven, or eight films between the source and the dosimeter which added $14.8,44.6,103$, and $118 \mathrm{mg} / \mathrm{cm}^{2}(103,322,745$, and $852 \mu \mathrm{m})$ of absorption to the effective depth of the dosimeter.

\subsubsection{Readout of NE Extremity Tape Dosimeters}

The NE Extremity Tape dosimeters were processed at the YAEC facility using normal operating procedures and standard heat-cycle settings on a Toledo reader (McWilliams et al., 1992). An element correction factor (ECF) was generated to account for variations in phosphor sensitivity between individual dosimeters. The ECF was generated after the dosimeters were processed as follows: All of the dosimeters were annealed through a standard heat cycle and then irradiated to 
$0.01 \mathrm{~Gy}$ with ${ }^{137} \mathrm{Cs}$ photons. The dosimeters were processed again and the ECF for each was calculated as the ratio of its response to the average response of all the dosimeters.

\subsubsection{Calibration of NE Extremity Tape Dosimeters}

The NE Extremity Tape dosimeters are batch-calibrated with Cs-137 photons to convert the data from thermoluminescent signal to absorbed dose. The dosimeters are calibrated under electronic equilibrium conditions on a back-scatter phantom (McWilliams et al., 1992). For this study, the $C_{k}$ value applied was $1.21 \mathrm{~Sv} / \mathrm{Gy}$ in air.

\subsubsection{Calculation of Tissue Dose from NE Extremity Tape Dosimeter Measurements}

Previous testing indicated that the averaging area of the NE Extremity Tape dosimeters is defined by the $0.29 \mathrm{~cm}^{2}$ aperture of the photo-multiplier tube housing in the Toledo reader (McWilliams et al., 1992). Therefore, to convert the dosimeter results to the dose averaged over a $1 \mathrm{~cm}^{2}$ area, the measured doses are multiplied by 0.29 which is the ratio of the dosimeter averaging area and $1 \mathrm{~cm}^{2}$. The premise for this correction is that the majority of the dose is delivered to the $0.29 \mathrm{~cm}^{2}$ area of the dosimeter.

\subsection{Eberline RO-2/2A Survey Meter}

The Eberline RO-2/2A refers collectively to the Eberline RO-2 and RO-2A survey meters. These instruments are identical in design and differ only in electronics which allow the RO-2A to respond to a factor-of-ten higher radiation fields. The Eberline RO-2/2A survey meter (manufactured by Eberline Instruments, Santa Fe, New Mexico) is routinely used at most U.S. nuclear power stations. Many national laboratories and university radiation-safety departments also use this instrument. Other ion-chamber survey meters of similar design, such as the Eberline RO-20 and the Bicron RSO-5/50 (manufactured by Bicron Corporation, Newbury, Ohio) should respond similarly to hot particles as the Eberline RO-2/2A.

\subsubsection{Description of Eberline RO-2/2A}

The Eberline RO-2/2A is a cylindrical ionization chamber having $1.59-\mathrm{mm}$ phenolic walls contained within a $1.27-\mathrm{mm}$-thick aluminum housing. The chamber has a $73-\mathrm{mm}$ inner diameter and a $50-\mathrm{mm}$ length; it is divided centrally by a $80 \mathrm{mg} / \mathrm{cm}^{2}$ collecting electrode and has an effective volume of $208 \mathrm{~cm}^{3}$ which is vented to atmosphere. A shallow dose-response is obtained by retracting a $400 \mathrm{mg} / \mathrm{cm}^{2}$ phenolic shield from the bottom of the detector. With the shield retracted, two sheets of aluminized PTP comprise a nominal entrance-foil thickness of $7 \mathrm{mg} / \mathrm{cm}^{2}$. 


\section{Appendix}

\subsubsection{Exposure of Eberline RO-2/2A to Hot Particles}

When exposing the Eberline RO-2/2A, the hot particle was positioned at the rubber "feet" of the instrument along the major axis of the cylinder. In this position, the hot particle was $37 \mathrm{~mm}$ from the center of the detector. With the phenolic shield in place, a closed window (CW) response was recorded. The shield then was retracted and an open window (OW) response recorded.

Depending on the magnitude of the observed response, the data was recorded with either an Eberline RO-2 (serial number 5298) or a RO-2A (serial number 338). The instrument's responses were assigned an uncertainty of $\pm 20 \%$ which includes uncertainties in calibration and in the accuracy of reading the meter.

\subsubsection{Calibration of Eberline RO-2/2A}

The response of the Eberline RO-2/2A instruments was calibrated with $\mathrm{Cs}-137$ photons. The display of the instrument is calibrated to the quantity roentgen $(R)$ where $1 \mathrm{R}=2.58 \times 10^{-4} \mathrm{C} / \mathrm{kg}$ in air.

\subsubsection{Calculation of Tissue Dose from Eberline RO-2/2A Measurements}

Previous testing established some "rules of thumb" for interpreting the response of the RO-2/2A to hot particles (McWilliams et al., 1992; Lantz and Steward, 1988). Using Co-60 hot particles, the dose rate to a $1 \mathrm{~cm}^{2}$ area at a tissue depth of $7 \mathrm{mg} / \mathrm{cm}^{2}$ was about 150 times greater than the open window response (McWilliams et al., 1992), which translates into a correction factor of $1.50 \mathrm{~Gy} / \mathrm{R}$ (150 rad/R). This same value was applied for all the particles evaluated here.

While not directly related to calculations of tissue dose, other information can be inferred from the RO-2/2A data. Lantz and Steward (1988) indicated that the closed window response could be easily related to the activity of hot particles. They derived a relationship between the Co- 60 gamma constant and the source-to-detector geometry that showed that the closed window (CW) response in $\mathrm{R} / \mathrm{h}$ is essentially equivalent to the activity in $\mathrm{mCi}(3.7 \mathrm{E} 7 \mathrm{~Bq})$. The activity relationship is calculated using equation 7 :

$$
\text { Activity }(B q)=\frac{3.7 E 7 * C W * 1.1}{\Gamma / 3.7^{2}}
$$

where the gamma constant $\Gamma$ is in units $\left(R_{\star} \mathrm{cm}^{2}\right) /(h \star m C i)$ (Bureau of Radiological Health, 1970), 3.7 is the distance between the hot particle and the center of detection in $\mathrm{cm}$, the 1.1 is a geometry correction factor, and the $3.7 \mathrm{E} 7$ converts $\mathrm{mCi}$ to $\mathrm{Bq}$. The $\Gamma$ values applied to the data were $0.025,0.49,10.9$, and 13.2 for the $\mathrm{Tm}-170, \mathrm{Yb}-175$, Sc-46, and Co-60, respectively (Bureau of Radiological Health, 1970). 
Appendix

\section{RESULTS}

\subsection{GafChromic Measurements}

There is reasonable agreement between the GafChromic film measurements of dose rate made by BNL-NIST and UB for each hot particle (Tables 12 to 16 and Figures 6 to 9). BNL-NIST results generally are lower than those of UB for small averaging areas (Figures 10 to 13). Except for the Yb-175 source, the results are within $20 \%$ between 1 and $10 \mathrm{~mm}^{2}$, with the BNL-NIST results generally being slightly larger for areas greater than $10 \mathrm{~mm}^{2}$. For exposures made using a stack of eight films of which 4 films are compared $\left(1.8,16.7,46.4\right.$, and $\left.105.8 \mathrm{mg} / \mathrm{cm}^{2}\right)$, there is consistently better agreement between the two systems as film depth increases for the Tm-170, $\mathrm{Sc}-46$, and Co-60 particles. The maximum difference of about a factor of two between the two systems occurs when dose is averaged over $0.001 \mathrm{~mm}^{2}$ for the top film in the stacks $\left(1.8 \mathrm{mg} / \mathrm{cm}^{2}\right)$.

Excluding the Yb-175 results, the BNL-NIST dose values for $1 \mathrm{~mm}^{2}$ and $1 \mathrm{~cm}^{2}$ for all film depths were $1.04 \pm 0.11$ and $1.12 \pm 0.18$ times those of UB, respectively (the standard error is one sigma for a sample standard deviation). These values for $1 \mathrm{~mm}^{2}$ and $1 \mathrm{~cm}^{2}$ are consistent with a previous UB direct comparison between two systems involving readout of the same films irradiated by lower activity Co-60 and Tm-170 sources. Including the $\mathrm{Yb}-175$ results, the BNLNIST dose values for $1 \mathrm{~mm}^{2}$ and $1 \mathrm{~cm}^{2}$ for all hot particles for all film depths were $1.03 \pm 0.14$ and $1.13 \pm 0.22$, respectively (Darley, private communication).

Since the agreement between the two systems is good (within 20\%) for averaging areas of 1 to $100 \mathrm{~mm}^{2}$, it is unlikely that there is a significant difference in calibration between them. The difference in the diameter of the sampling spot between the two microdensitometers was thought to be the reason for the larger disparities for smaller averaging areas. The smaller sampling area $(25 \mu \mathrm{m} \times 25 \mu \mathrm{m})$ and smaller step increments $(25 \mu \mathrm{m})$ of the UB reader measure the centerline point dose with more accuracy than the larger laser spot (100 $\mu \mathrm{m}$ diameter) and step increments (40 to $160 \mu \mathrm{m}$ ) of the NIST system when the radial dose distribution is rapidly varying. Some confirmation of this interpretation is provided by the observed greater disparity for the physically smaller and lower energy Co-60 source. The decrease in dose for small to progressively larger areas for the UB system is also much greater than that of the BNL-NIST results. The difference between the two systems also decreases with increasing depth. These observations are consistent with the differences being due to spot size effects.

The differences between the two systems for the $\mathrm{Yb}-175$ particle are inconsistent with results for the other hot particles. The top film of the stack of eight films $\left(1.8 \mathrm{mg} / \mathrm{cm}^{2}\right)$ (Figure 11) does not show the greatest dose-rate difference between the two groups, as is seen with the other particles (Figures 10,12,13). UB film measurements for the $\mathrm{Yb}-175$ particle at $7.78 \mathrm{mg} / \mathrm{cm}^{2}$ are less than the BNL-NIST results for all averaging areas, which is not seen with the other particles. The UB group exposed film to this particle on September 13 and 14 using film stacks composed of 8 films. The BNL-NIST group then exposed film to the Yb-175 particle on September 15, 16, 
Table 12. GafChromic dose results for BNL-NIST and UB systems for the Tm-170 hot particle

\begin{tabular}{|c|c|c|c|c|c|c|c|c|c|c|c|c|}
\hline $\begin{array}{c}\text { Averaging } \\
\text { Area } \\
\left(\mathrm{mm}^{2}\right)\end{array}$ & $\begin{array}{c}\text { UB } \\
\text { Fllm } 1 \\
13.4 \mu \mathrm{m} \\
1.8 \mathrm{mg} / \mathrm{cm}^{2} \\
(\mathrm{~Gy} / \mathrm{s})\end{array}$ & $\begin{array}{c}\text { BNL-NIST } \\
\text { Film } 1 \\
13.4 \mu \mathrm{m} \\
1.8 \mathrm{mg} / \mathrm{cm}^{2} \\
\text { (Gy/s) }\end{array}$ & $\begin{array}{c}\text { UB } \\
\text { Film 2 } \\
121 \mu \mathrm{m} \\
16.7 \mathrm{mg} / \mathrm{cm}^{2} \\
\text { (Gy/s) } \\
\end{array}$ & $\begin{array}{c}\text { BNL-NIST } \\
\text { Film 2 } \\
121 \mu \mathrm{m} \\
16.7 \mathrm{mg} / \mathrm{cm}^{2} \\
(\mathrm{~Gy} / \mathrm{s}) \\
\end{array}$ & $\begin{array}{c}\text { UB } \\
\text { Film } 3 \\
228 \mu \mathrm{m} \\
31.6 \mathrm{mg} / \mathrm{cm}^{2} \\
(G \mathrm{~g} / \mathrm{s}) \\
\end{array}$ & $\begin{array}{c}\text { UB } \\
\text { Film } 4 \\
336 \mu \mathrm{m} \\
46.4 \mathrm{mg} / \mathrm{cm}^{2} \\
(\mathrm{~Gy} / \mathrm{s}) \\
\end{array}$ & $\begin{array}{c}\text { BNL-NIST } \\
\text { Film } 4 \\
336 \mu \mathrm{m} \\
46.4 \mathrm{mg} / \mathrm{cm}^{2} \\
(\mathrm{~Gy} / \mathrm{s}) \\
\end{array}$ & $\begin{array}{c}\text { UB } \\
\text { Film } 5 \\
442 \mu \mathrm{m} \\
61.2 \mathrm{mg} / \mathrm{cm}^{2} \\
(\mathrm{~Gy} / \mathrm{s}) \\
\end{array}$ & $\begin{array}{c}\text { UB } \\
\text { Film } 6 \\
660 \mu \mathrm{m} \\
76.1 \mathrm{mg} / \mathrm{cm}^{2} \\
(\mathrm{~Gy} / \mathrm{s}) \\
\end{array}$ & $\begin{array}{c}\text { UB } \\
\text { Film } 7 \\
667 \mu \mathrm{m} \\
90.9 \mathrm{mg} / \mathrm{cm}^{2} \\
(G \mathrm{~g} / \mathrm{s}) \\
\end{array}$ & $\begin{array}{c}\text { UB } \\
\text { Film 8 } \\
764 \mu \mathrm{m} \\
106 \mathrm{mg} / \mathrm{cm}^{2} \\
(\mathrm{~Gy} / \mathrm{s}) \\
\end{array}$ & $\begin{array}{c}\text { BNL-NIST } \\
\text { Film 8 } \\
764 \mu \mathrm{m} \\
106 \mathrm{mg} / \mathrm{cm}^{2} \\
(\mathrm{G} / \mathrm{s}) \\
\end{array}$ \\
\hline 0.001 & $2.08 E-01$ & $1.37 E-01$ & $8.89 E-02$ & $7.13 E-02$ & $5.09 E-02$ & $3.00 E-02$ & $2.63 E-02$ & $2.05 E-02$ & $1.33 E-02$ & $8.61 E-03$ & $6.05 E-03$ & $6.32 E-03$ \\
\hline 0.008 & 2.03E-01 & 1.36E-01 & $8.83 E-02$ & 7.13E-02 & $5.05 E-02$ & $2.98 E-02$ & 2.63E-02 & 2.04E-02 & 1.33E-02 & $8.59 E-03$ & 6.03E-03 & $6.32 E-03$ \\
\hline 0.01 & 2.01E-1 & $1.36 E-01$ & $8.80 E-02$ & 7.13E-02 & $5.04 E-02$ & $2.98 E-02$ & 2.62E-02 & $2.04 E-02$ & $1.32 E-02$ & $8.58 \mathrm{E}-03$ & $6.03 E-03$ & $6.32 E-03$ \\
\hline 0.1 & $1.53 E-01$ & $1.25 E-01$ & $7.65 E-02$ & $6.78 E-02$ & 4.63E-02 & $2.80 E-02$ & $2.60 E-02$ & $1.90 E-02$ & $1.27 E-02$ & $8.34 E-03$ & $5.88 E-03$ & $6.30 E-03$ \\
\hline 0.2 & $1.25 E-01$ & 1.12E-01 & $6.75 E-02$ & $6.27 E-02$ & $4.26 \mathrm{E}-02$ & $2.62 E-02$ & 2.52E-02 & $1.79 E-02$ & $1.22 E-02$ & $8.08 E-03$ & 5.71E-03 & $6.24 E-03$ \\
\hline 0.4 & $9.54 E-02$ & $9.25 \mathrm{E}-02$ & $5.56 \mathrm{E}-02$ & $5.42 E-02$ & 2.19E-02 & $3.68 E-02$ & $2.35 E-02$ & $2.34 \mathrm{E}-02$ & 7.61E-03 & $1.13 E-02$ & $5.41 E-03$ & $6.04 E-03$ \\
\hline 0.8 & $6.85 E-02$ & $6.84 \mathrm{E}-02$ & $4.22 E-02$ & $4.28 E-02$ & 2.91E-02 & $1.92 E-02$ & $1.99 E-02$ & $1.37 E-02$ & $9.76 E-03$ & $6.81 E-03$ & $4.89 E-03$ & $5.54 E-03$ \\
\hline 1 & $6.08 E-02$ & $6.07 E-02$ & 3.79E-02 & $3.88 E-02$ & 2.65E-02 & $1.76 E-02$ & $1.85 \mathrm{E}-02$ & $1.27 E-02$ & $9.15 E-03$ & $6.46 E-03$ & $4.66 E-03$ & $5.27 E-03$ \\
\hline 2 & $3.99 E-02$ & $3.94 E-02$ & 2.55E-02 & $2.64 E-02$ & $1.84 E-02$ & $1.27 E-02$ & $1.37 E-02$ & $9.60 E-03$ & $6.99 E-03$ & $5.15 \mathrm{E}-03$ & $3.77 E-03$ & $4.22 E-03$ \\
\hline 4 & $2.40 E-02$ & $2.36 \mathrm{E}-02$ & $1.57 E-02$ & $1.63 E-02$ & 1.16E-02 & $8.29 E-03$ & $9.06 E-03$ & $6.48 E-03$ & $4.79 E-03$ & $3.62 E-03$ & $2.66 \mathrm{E}-03$ & $3.00 E-03$ \\
\hline 8 & $1.34 E-02$ & $1.34 E-02$ & $8.94 E-03$ & $9.24 E-03$ & $6.63 E-03$ & $4.92 \mathrm{E}-03$ & $5.35 E-03$ & $3.88 E-03$ & $2.97 E-03$ & $2.21 E-03$ & $1.67 \mathrm{E}-03$ & $1.88 E-03$ \\
\hline 10 & 1.10E-02 & 1.11E-02 & 7.34E- 03 & $7.59 \mathrm{E}-03$ & 5.45E-03 & $4.06 \mathrm{E}-03$ & 4.43E-03 & $3.21 \mathrm{E}-03$ & 2.48E-03 & $1.83 E-03$ & $1.38 E-03$ & $1.58 E-03$ \\
\hline 23 & $5.08 E-03$ & $5.21 E-03$ & 3.38E-03 & $3.52 E-03$ & $2.50 E-03$ & $1.86 \mathrm{E}-03$ & $2.06 \mathrm{E}-03$ & $1.48 E-03$ & 1.17E-03 & $7.87 E-04$ & $6.00 \mathrm{E}-04$ & 7.44E-03 \\
\hline 29 & $4.08 E-03$ & 4.19E-03 & 2.71E-03 & $2.82 E-03$ & $2.00 E-03$ & $1.49 E-03$ & $1.64 \mathrm{E}-03$ & 1.18E-03 & $9.45 E-04$ & $5.99 \mathrm{E}-04$ & 4.59E-04 & $5.90 \mathrm{E}-04$ \\
\hline 50 & 2.44E-03 & 2.44E-03 & $1.60 E-03$ & $1.68 E-03$ & 1.17E-03 & $8.86 E-04$ & $9.50 E-04$ & $6.93 E-04$ & $5.62 E-04$ & $2.92 E-04$ & 2.31E-04 & $3.29 E-04$ \\
\hline 100 & $1.27 E-03$ & $1.16 \mathrm{E}-03$ & $8.12 E-04$ & $8.68 \mathrm{E}-0.4$ & $5.87 E-04$ & 4.36E-04 & 4.61E-04 & $3.50 E-04$ & $2.86 E-04$ & $9.63 E-05$ & $8.78 E-05$ & 1.41E-04 \\
\hline 200 & $6.54 E-04$ & $4.53 E-03$ & $4.09 \mathrm{E}-04$ & 4.62E-04 & $2.94 E-04$ & $2.18 E-04$ & 2.14E-04 & $1.76 E-04$ & $1.45 E-04$ & 2.26E-05 & $3.17 E-05$ & 4.56E-04 \\
\hline
\end{tabular}


Table 13. GafChromic dose results for the BNL-NIST and UB systems for the Yb-175 hot particle

\begin{tabular}{|c|c|c|c|c|c|c|c|c|c|c|c|}
\hline $\begin{array}{c}\text { Averaging } \\
\text { Area } \\
\left(\mathrm{mm}^{2}\right)\end{array}$ & $\begin{array}{c}\text { UB } \\
\text { Film } 1 \\
13.4 \mu \mathrm{m} \\
1.8 \\
\mathrm{mg} / \mathrm{cm}^{2} \\
\text { (Gy/s) }\end{array}$ & $\begin{array}{c}\text { BNL-NIST } \\
\text { Film } 1 \\
13.4 \mu \mathrm{m} \\
1.8 \\
\mathrm{mg} / \mathrm{cm}^{2} \\
\text { (Gy/s) } \\
\end{array}$ & $\begin{array}{c}\text { UB } \\
\text { Film } 2 \\
121 \mu \mathrm{m} \\
16.7 \\
\mathrm{mg} / \mathrm{cm}^{2} \\
(\mathrm{~Gy} / \mathrm{s}) \\
\end{array}$ & $\begin{array}{c}\text { BNL-NIST } \\
\text { Film } 2 \\
121 \mu \mathrm{m} \\
16.7 \\
\mathrm{mg} / \mathrm{cm}^{2} \\
(\mathrm{~Gy} / \mathrm{s}) \\
\end{array}$ & $\begin{array}{c}\text { UB } \\
\text { Film } 3 \\
228 \mu \mathrm{m} \\
31.5 \\
\mathrm{mg} / \mathrm{cm}^{2} \\
(\mathrm{~Gy} / \mathrm{s}) \\
\end{array}$ & $\begin{array}{c}\text { UB } \\
\text { Film } 4 \\
335 \mu \mathrm{m} \\
46.4 \\
\mathrm{mg} / \mathrm{cm}^{2} \\
(\mathrm{~Gy} / \mathrm{s}) \\
\end{array}$ & $\begin{array}{c}\text { BNL-NIST } \\
\text { Film } 4 \\
335 \mu \mathrm{m} \\
46.4 \\
\mathrm{mg} / \mathrm{cm}^{2} \\
\text { (Gy/s) }\end{array}$ & $\begin{array}{c}\text { UB } \\
\text { Film } 5 \\
442 \mu \mathrm{m} \\
61.2 \\
\mathrm{mg} / \mathrm{cm}^{2} \\
(\mathrm{~Gy} / \mathrm{s})\end{array}$ & $\begin{array}{c}\text { UB } \\
\text { Film } 6 \\
650 \mu \mathrm{m} \\
76.1 \\
\mathrm{mg} / \mathrm{cm}^{2} \\
(\mathrm{~Gy} / \mathrm{s})\end{array}$ & $\begin{array}{c}\text { UB } \\
\text { Film } 7 \\
667 \mu \mathrm{m} \\
909 \\
\mathrm{mg} / \mathrm{cm}^{2} \\
(\mathrm{~Gy} / \mathrm{s})\end{array}$ & $\begin{array}{c}\text { UB } \\
\text { Film } 8 \\
764 \mu \mathrm{m} \\
105.8 \\
\mathrm{mg} / \mathrm{cm}^{2} \\
(\mathrm{~Gy} / \mathrm{s})\end{array}$ \\
\hline 0.001 & $3.24 \mathrm{E}+00$ & $2.38 \mathrm{E}+00$ & $1.18 E+00$ & 5.96E-01 & 4.40E-01 & 1.62E-01 & 1.37E-01 & 6.37E-02 & $2.68 \mathrm{E}-02$ & $9.29 \mathrm{E}-03$ & 3.62E-03 \\
\hline 0.008 & $3.19 E+00$ & $2.38 \mathrm{E}+00$ & $1.16 E+00$ & 5.96E-01 & 4.34E-01 & $1.61 E-01$ & 1.37E-01 & $6.32 E-02$ & $2.66 \mathrm{E}-02$ & $9.23 E-03$ & $3.60 E-03$ \\
\hline 0.01 & $3.18 E+00$ & $2.38 \mathrm{E}+00$ & $1.16 E+00$ & $5.96 \mathrm{E}-01$ & 4.32E-01 & 1.61E-01 & 1.37E-01 & $6.30 E-02$ & $2.66 \mathrm{E}-02$ & $9.21 E-03$ & $3.60 E-03$ \\
\hline 0.1 & $2.69 E+00$ & $2.16 E+00$ & 9.88E-01 & 6.79E-01 & $3.74 E-01$ & 1.46E-01 & $1.34 E-01$ & $6.72 E-02$ & 2.46E-02 & $8.61 E-03$ & $3.36 E-03$ \\
\hline 0.2 & $2.28 E+00$ & $1.86 E+00$ & 8.48E-01 & 6.39E-01 & 3.27E-01 & 1.31E-01 & $1.28 \mathrm{E}-01$ & $6.21 E-02$ & 2.24E-02 & $7.84 E-03$ & 3.12E-03 \\
\hline 0.4 & 1.71E+00 & $1.42 E+00$ & $6.66 E-01$ & 4.56E-01 & 2.61E-01 & $1.08 E-01$ & 1.11E-01 & 4.46E-02 & $1.91 E-02$ & $6.79 \mathrm{E}-03$ & $2.72 E-03$ \\
\hline 0.8 & 1.11E+00 & 9.67E-01 & 4.44E-01 & $3.38 E-01$ & $1.83 E-01$ & $7.88 \mathrm{E}-02$ & $8.43 \mathrm{E}-02$ & $3.46 \mathrm{E}-02$ & $1.44 E-02$ & $6.36 \mathrm{E}-03$ & 2.16E-03 \\
\hline 1 & 9.38E-01 & 8.21E-01 & 3.81E-01 & 2.97E-01 & 1.69E-01 & $6.93 E-02$ & $7.46 E-02$ & $3.09 \mathrm{E}-02$ & $1.28 \mathrm{E}-02$ & $4.86 \mathrm{E}-03$ & $1.93 E-03$ \\
\hline 2 & 6.22E-01 & 4.76E-01 & 2.14E-01 & $1.82 E-01$ & $9.26 \mathrm{E}-02$ & 4.19E-02 & $4.61 E-02$ & $1.89 \mathrm{E}-02$ & 8.03E-03 & $3.22 \mathrm{E}-03$ & $1.27 E-03$ \\
\hline 4 & 2.73E-01 & 2.64E-01 & 1.13E-01 & $9.99 E-02$ & 4.91E-02 & $2.24 E-02$ & $2.63 E-02$ & 1.03E-02 & 4.47E-03 & $1.86 \mathrm{E}-03$ & 0.000761 \\
\hline 8 & 1.39E-01 & $1.30 \mathrm{E}-01$ & $6.74 E-02$ & 6.13E-02 & 2.49E-02 & 1.14E-02 & $1.30 \mathrm{E}-02$ & $6.30 E-03$ & 2.32E-03 & $1.04 E-03$ & 4.23E-04 \\
\hline 10 & 1.11E-01 & 1.05E-01 & $4.60 \mathrm{E}-02$ & 4.11E-02 & 2.01E-02 & 9.32E-03 & $1.05 E-02$ & 4.27E-03 & 1.87E-03 & 8.63E-04 & 3.49E-04 \\
\hline 23 & $4.88 E-02$ & 4.67E-02 & $2.02 E-02$ & $1.76 E-02$ & $8.76 E-03$ & 3.39E-03 & $4.63 E-03$ & $1.90 \mathrm{E}-03$ & 8.17E-04 & $3.93 \mathrm{E}-04$ & 1.63E-04 \\
\hline 29 & $3.88 E-02$ & $3.62 E-02$ & $1.60 E-02$ & $1.38 E-02$ & $6.96 E-03$ & $2.73 E-03$ & $3.68 \mathrm{E}-03$ & $1.61 E-03$ & $6.48 \mathrm{E}-04$ & $3.16 E-04$ & 1.31E-04 \\
\hline 60 & 2.26E-02 & $2.10 E-02$ & $9.32 E-03$ & $7.70 E-03$ & 4.03E-03 & $1.69 E-03$ & $2.05 E-03$ & $8.80 E-04$ & $3.76 \mathrm{E}-04$ & $1.86 \mathrm{E}-04$ & 7.76E-05 \\
\hline 100 & 1.16E-02 & $1.05 E-02$ & 4.67E-03 & $3.60 E-03$ & $2.02 E-03$ & 7.93E-04 & 9.94E-04 & 4.42E-04 & $1.88 E-04$ & $9.38 E-06$ & $3.93 E-05$ \\
\hline 200 & $6.20 \mathrm{E}-03$ & $6.28 \mathrm{E}-03$ & 2.34E-03 & $1.39 \mathrm{E}-03$ & $1.01 E-03$ & $3.96 E-04$ & 4.67E-04 & $2.22 E-04$ & $9.40 \mathrm{E}-05$ & $4.72 \mathrm{E}-06$ & $1.98 \mathrm{E}-05$ \\
\hline
\end{tabular}




\begin{tabular}{|c|c|c|c|c|c|c|c|c|c|c|c|c|}
\hline $\begin{array}{c}\text { Averaging } \\
\text { Area } \\
\left(\mathrm{mm}^{2}\right)\end{array}$ & $\begin{array}{c}\text { UB } \\
\text { Film } 1 \\
13.4 \mu \mathrm{m} \\
1.8 \\
\mathrm{mg} / \mathrm{cm}^{2} \\
\text { (Gy/s) } \\
\end{array}$ & $\begin{array}{c}\text { BNL-NIST } \\
\text { Film 1 } 1 \\
13.4 \mu \mathrm{m} \\
1.8 \\
\mathrm{mg} / \mathrm{cm}^{2} \\
(\mathrm{~Gy} / \mathrm{s}) \\
\end{array}$ & $\begin{array}{c}\text { UB } \\
\text { Film } 2 \\
121 \mu \mathrm{m} \\
16.7 \\
\mathrm{mg} / \mathrm{cm} \\
(\mathrm{Gy} / \mathrm{s}) \\
\end{array}$ & $\begin{array}{c}\text { BNL-NIST } \\
\text { Film 2 } \\
121 \mu \mathrm{m} \\
16.7 \\
\mathrm{mg} / \mathrm{cm}^{2} \\
(\mathrm{~Gy} / \mathrm{s}) \\
\end{array}$ & $\begin{array}{c}\text { UB } \\
\text { Film } 3 \\
228 \mu \mathrm{mm} \\
31.6 \\
\mathrm{mg} / \mathrm{cm}^{2} \\
(\mathrm{G} / \mathrm{s}) \\
\end{array}$ & $\begin{array}{r}\text { UB } \\
\text { Film } 4 \\
335 \mu \mathrm{m} \\
46.4 \\
\mathrm{mg} / \mathrm{cm}^{2} \\
\text { (Gy/s) } \\
\end{array}$ & $\begin{array}{c}\text { BNL-NIST } \\
\text { Film4 } \\
336 \mu \mathrm{m} \\
46.4 \\
\mathrm{mg} / \mathrm{cm}^{2} \\
(\mathrm{G} / \mathrm{s}) \\
\end{array}$ & $\begin{array}{c}\text { UB } \\
\text { Fllm } 5 \\
442 \mu \mathrm{m} \\
61.2 \\
\mathrm{mg} / \mathrm{cm}^{2} \\
(\mathrm{G} / \mathrm{s}) \\
\end{array}$ & $\begin{array}{c}\text { UB } \\
\text { Fllm } 6 \\
660 \mu \mathrm{m} \\
76.1 \\
\mathrm{mg} / \mathrm{cm}^{2} \\
(\mathrm{~Gy} / \mathrm{s}) \\
\end{array}$ & $\begin{array}{c}\text { UB } \\
\text { Fllm } 7 \\
667 \mu \mathrm{m} \\
909 \\
\mathrm{mg} / \mathrm{cm}^{2} \\
(\mathrm{gy} / \mathrm{s}) \\
\end{array}$ & $\begin{array}{c}\text { UB } \\
\text { Film 8 } \\
764 \mu \mathrm{mm} \\
105.8 \\
\mathrm{mg} / \mathrm{cm}^{2} \\
\text { (Gy/s) } \\
\end{array}$ & $\begin{array}{c}\text { BNL-NIST } \\
\text { Film 8 } \\
764 \mathrm{\mu m} \\
106.8 \\
\mathrm{mg} / \mathrm{cm}^{2} \\
(\mathrm{~Gy} / \mathrm{s}) \\
\end{array}$ \\
\hline 0.001 & $3.50 E+01$ & $2.00 E+01$ & $8.32 E+00$ & $6.11 \mathrm{E}+00$ & $2.32 E+00$ & $6.30 \mathrm{E}-01$ & $4.08 E-01$ & $1.46 \mathrm{E}-01$ & 6.67E-02 & $6.40 E-02$ & $3.76 E-02$ & $3.06 \mathrm{E}-02$ \\
\hline 0.008 & $3.41 \mathrm{E}+01$ & $2.00 E+01$ & $8.18 E+00$ & $6.11 E+00$ & $2.29 E+00$ & $6.22 \mathrm{E}-01$ & $4.07 E-01$ & $1.46 \mathrm{E}-01$ & $6.66 E-02$ & $6.39 E-02$ & $3.76 \mathrm{E}-02$ & $3.05 E-02$ \\
\hline 0.01 & $3.39 E+01$ & $2.00 E+01$ & $8.14 E+00$ & 6.11E+00 & $2.28 E+00$ & $6.20 E-01$ & $4.06 E-01$ & $1.46 \mathrm{E}-01$ & $6.66 E-02$ & $6.38 E-02$ & $3.76 E-02$ & $3.05 E-02$ \\
\hline 0.1 & $2.61 E+01$ & $1.92 E+01$ & $6.69 E+00$ & $4.76 E+00$ & $1.88 E+00$ & $6.34 E-01$ & $3.84 E-01$ & $1.32 E-01$ & 6.43E-02 & $6.23 E-02$ & $3.69 E-03$ & $3.03 E-02$ \\
\hline 0.2 & $2.08 E+01$ & $1.74 E+01$ & $5.66 E+00$ & $4.22 E+00$ & 1.68E+00 & 4.63E-01 & $3.66 \mathrm{E}-01$ & $1.21 E-01$ & $6.21 E-02$ & $6.08 E-02$ & $3.62 E-02$ & $3.00 E-02$ \\
\hline 0.4 & $1.49 E+01$ & $1.41 \mathrm{E}+01$ & $4.09 E+00$ & $3.36 E+00$ & $1.20 E+00$ & 3.67E-01 & $3.04 E-01$ & $1.04 E-01$ & $4.86 E-02$ & $4.80 E-02$ & $3.50 E-02$ & $2.94 E-02$ \\
\hline 0.8 & $9.00 E+00$ & $9.84 E+00$ & 2.64E+00 & $2.34 E+00$ & 8.03E-01 & $2.60 E-01$ & 2.34E-01 & $8.29 E-02$ & $4.31 E-02$ & $4.36 E-02$ & 3.29E-02 & $2.84 \mathrm{E}-02$ \\
\hline 1 & $7.52 E+00$ & $8.60 E+00$ & $2.23 E+00$ & $2.02 E+00$ & $6.90 E-01$ & 2.28E-01 & 2.10E-01 & $7.67 E-02$ & $4.10 E-02$ & $4.16 E-02$ & 3.19E-02 & $2.79 E-02$ \\
\hline 2 & $4.37 E+00$ & $4.96 E+00$ & $1.26 E+00$ & $1.20 E+00$ & $4.04 E-01$ & 1.42E-01 & $1.40 E-01$ & $5.48 E-02$ & $3.40 E-02$ & $3.49 \mathrm{E}-02$ & 2.82E-02 & 2.59E-02 \\
\hline 4 & $2.34 E+00$ & $2.64 E+00$ & $6.60 E-01$ & $6.60 E-01$ & 2.21E-01 & 8.34E-02 & $8.67 E-02$ & 3.82E-02 & $2.70 E-02$ & $2.76 E-02$ & $2.36 E-02$ & $2.27 E-02$ \\
\hline 8 & 1.19E+00 & $1.34 \mathrm{E}+00$ & $3.42 E-01$ & $3.36 E-01$ & 1.16E-01 & $4.83 E-02$ & 6.11E-02 & 2.63E-02 & $2.05 E-02$ & $2.06 E-02$ & $1.86 E-02$ & $1.86 E-02$ \\
\hline 10 & $9.82 E-01$ & $1.08 E+00$ & $2.76 E-01$ & $2.70 E-01$ & $9.41 E-02$ & $4.07 E-02$ & $4.28 E-02$ & 2.33E-02 & $1.86 \mathrm{E}-02$ & $1.86 E-02$ & $1.69 E-02$ & $1.71 E-02$ \\
\hline 23 & $4.36 E-01$ & $4.70 \mathrm{E}-01$ & $1.24 E-01$ & $1.20 E-01$ & $4.66 E-02$ & $2.29 E-02$ & 2.21E-02 & $1.42 E-02$ & 1.17E-02 & $1.20 E-02$ & 1.13E-02 & $1.16 \mathrm{E}-02$ \\
\hline 29 & $3.46 E-01$ & $3.73 E-01$ & $9.94 E-02$ & $9.68 E-02$ & $3.77 E-02$ & $1.97 E-02$ & $1.84 E-02$ & $1.22 E-02$ & $1.06 E-02$ & 1.05E-02 & $9.84 E-03$ & $1.02 E-02$ \\
\hline 50 & 2.02E-01 & 2.17E-01 & $6.88 \mathrm{E}-02$ & $6.70 \mathrm{E}-02$ & $2.38 E-02$ & 1.27E-02 & $1.22 E-02$ & $8.26 E-03$ & $7.28 E-03$ & $7.29 E-03$ & $6.86 E-03$ & $7.28 E-03$ \\
\hline 100 & $1.02 E-01$ & $1.09 E-01$ & $3.01 E-02$ & $3.01 E-02$ & $1.21 E-02$ & $7.22 E-03$ & $7.61 E-03$ & $4.82 E-03$ & 4.32E-03 & $4.29 E-03$ & $4.09 E-03$ & 4.43E-03 \\
\hline 200 & $6.12 E-02$ & $6.64 E-02$ & $1.64 E-02$ & $1.67 \mathrm{E}-02$ & 6.03E-03 & 4.01E-03 & $5.17 E-03$ & 2.63E-03 & $2.60 E-03$ & $2.36 E-03$ & 2.27E-03 & $2.46 E-03$ \\
\hline
\end{tabular}


Table 15. GafChromic dose results for the BNL-NIST and UB systems for the Co-60 hot particle

\begin{tabular}{|c|c|c|c|c|c|c|c|c|c|c|c|c|}
\hline $\begin{array}{c}\text { Averaging } \\
\text { Area } \\
\left(\mathrm{mm}^{2}\right)\end{array}$ & $\begin{array}{c}\text { UB } \\
\text { Film } 1 \\
13.4 \mathrm{\mu m} \\
1.8 \\
\mathrm{mg} / \mathrm{cm}^{2} \\
(\mathrm{~Gy} / \mathrm{s}) \\
\end{array}$ & $\begin{array}{c}\text { BNL-NIST } \\
\text { Film } 1 \\
13.4 \mu \mathrm{m} \\
1.8 \\
\mathrm{mg} / \mathrm{cm}^{2} \\
(\mathrm{~Gy} / \mathrm{s}) \\
\end{array}$ & $\begin{array}{c}\text { UB } \\
\text { Film } 2 \\
1201 \mu \mathrm{m} \\
16.7 \\
\mathrm{mg} / \mathrm{cm}^{2} \\
\text { (Gy/s) } \\
\end{array}$ & $\begin{array}{c}\text { BNL-NIST } \\
\text { Film } 2 \\
1201 \mu \mathrm{m} \\
16.7 \\
\mathrm{mg} / \mathrm{cm}^{2} \\
\text { (Gy/s) } \\
\end{array}$ & $\begin{array}{c}\text { UB } \\
\text { Film } 3 \\
228 \mu \mathrm{m} \\
31.6 \\
\mathrm{mg} / \mathrm{cm}^{2} \\
(\mathrm{~Gy} / \mathrm{s}) \\
\end{array}$ & $\begin{array}{c}\text { UB } \\
\text { Film } 4 \\
335 \mu \mathrm{m} \\
46.4 \\
\mathrm{mg} / \mathrm{cm}^{2} \\
(\mathrm{~Gy} / \mathrm{s}) \\
\end{array}$ & $\begin{array}{c}\text { BNL-NIST } \\
\text { Film } 4 \\
335 \mu \mathrm{m} \\
46.4 \\
\mathrm{mg} / \mathrm{cm}^{2} \\
\text { (Gy/s) } \\
\end{array}$ & $\begin{array}{c}\text { UB } \\
\text { Film } 6 \\
442 \mu \mathrm{m} \\
61.2 \\
\mathrm{mg} / \mathrm{cm}^{2} \\
\text { (Gy/s) } \\
\end{array}$ & $\begin{array}{c}\text { UB } \\
\text { Film } 6 \\
660 \mu \mathrm{m} \\
76.1 \\
\mathrm{mg} / \mathrm{cm}^{2} \\
(\mathrm{~Gy} / \mathrm{s}) \\
\end{array}$ & $\begin{array}{c}\text { UB } \\
\text { Film } 7 \\
667 \mu \mathrm{m} \\
90.9 \\
\mathrm{mg} / \mathrm{cm}^{2} \\
(\mathrm{~Gy} / \mathrm{s}) \\
\end{array}$ & $\begin{array}{c}\text { UB } \\
\text { Film } 8 \\
764 \mu \mathrm{m} \\
105.8 \\
\mathrm{mg} / \mathrm{cm}^{2} \\
(\mathrm{~Gy} / \mathrm{s}) \\
\end{array}$ & $\begin{array}{c}\text { BNL-NIST } \\
\text { Film } 8 \\
764 \mu \mathrm{m} \\
105.8 \\
\mathrm{mg} / \mathrm{cm}^{2} \\
\text { (Gy/s) } \\
\end{array}$ \\
\hline 0.001 & $2.94 E+00$ & $1.36 \mathrm{E}+00$ & $4.10 E-01$ & 2.34E-01 & $8.49 E-02$ & 2.03E-02 & $1.67 \mathrm{E}-02$ & 8.67E-03 & $6.88 \mathrm{E}-03$ & 4.73E-03 & 4.01E-03 & $3.66 E-03$ \\
\hline 0.008 & $2.76 E+00$ & $1.36 E+00$ & $3.94 \mathrm{E}-01$ & $2.34 E-01$ & 8.27E-02 & $2.00 E-02$ & $1.67 \mathrm{E}-02$ & 8.53E-03 & $6.87 E-03$ & $4.72 E-03$ & 4.01E-03 & $3.66 E-03$ \\
\hline 0.01 & $2.70 E+00$ & $1.36 \mathrm{E}+00$ & $3.90 \mathrm{E}-01$ & $2.34 E-01$ & 8.21E-02 & $1.99 E-02$ & $1.67 \mathrm{E}-02$ & $8.62 E-03$ & $5.86 E-03$ & 4.72E-03 & 4.01E-03 & $3.66 \mathrm{E}-03$ \\
\hline 0.1 & $1.47 E+00$ & $1.02 E+00$ & $2.62 E-01$ & $2.10 E-01$ & $6.16 E-02$ & $1.68 \mathrm{E}-02$ & 1.44E-02 & 8.02E-03 & 5.72E-03 & 4.64E-03 & $3.96 E-03$ & $3.63 E-03$ \\
\hline 0.2 & $9.79 E-01$ & $7.72 E-01$ & $1.93 \mathrm{E}-01$ & $1.79 E-01$ & 4.83E-02 & $1.46 E-02$ & $1.31 \mathrm{E}-02$ & $7.66 \mathrm{E}-03$ & 6.68E-03 & 4.66E-03 & $3.90 \mathrm{E}-03$ & $3.60 E-03$ \\
\hline 0.4 & $6.84 E-01$ & 6.16E-01 & $1.26 E-01$ & $1.34 E-01$ & $3.41 E-02$ & 1.16E-02 & 1.11E-02 & $6.84 E-03$ & 6.32E-03 & $4.40 E-03$ & 3.79E-03 & $3.63 E-03$ \\
\hline 0.8 & 4.07E-01 & $3.07 E-01$ & 7.49E-02 & 8.77E-02 & 2.20E-02 & $8.69 \mathrm{E}-03$ & $8.79 E-03$ & $6.90 E-03$ & $4.91 E-03$ & 4.13E-03 & $3.60 E-03$ & 3.39E-03 \\
\hline 1 & 2.77E-01 & $2.65 E-01$ & $6.24 E-02$ & $7.46 \mathrm{E}-02$ & $1.88 \mathrm{E}-02$ & $7.84 E-03$ & $8.07 E-03$ & 6.67E-03 & 4.74E-03 & $4.01 E-03$ & $3.62 E-03$ & 3.32E-03 \\
\hline 2 & $1.43 E-01$ & $1.36 \mathrm{E}-01$ & $3.43 E-02$ & $4.20 E-02$ & $1.13 \mathrm{E}-02$ & $6.64 E-03$ & $6.02 E-03$ & 4.66E- 03 & $4.10 \mathrm{E}-03$ & 3.66E-03 & $3.16 \mathrm{E}-03$ & $3.03 E-03$ \\
\hline 4 & 7.32E-02 & $7.01 E-02$ & $1.84 E-02$ & $2.23 E-02$ & $6.82 \mathrm{E}-03$ & 4.04E-03 & 4.33E-03 & $3.63 \mathrm{E}-03$ & $3.34 E-03$ & $2.96 \mathrm{E}-03$ & 2.67E-03 & 2.63E-03 \\
\hline 8 & $3.74 E-02$ & $3.66 \mathrm{E}-02$ & $9.90 E-03$ & $1.16 E-02$ & $4.20 E-03$ & $2.84 E-03$ & 3.02E-03 & 2.81E-03 & $2.64 E-03$ & 2.31E-03 & 2.11E-03 & 2.13E-03 \\
\hline 10 & $3.01 E-02$ & $2.86 E-02$ & $8.12 E-03$ & $9.36 E-03$ & 4.01E-03 & $2.62 E-03$ & 2.67E-03 & $2.66 \mathrm{E}-03$ & $2.20 \mathrm{E}-03$ & 2.10E-03 & 1.92E-03 & $1.96 \mathrm{E}-03$ \\
\hline 23 & $1.34 E-02$ & 1.27E-02 & $3.88 E-03$ & 4.39E-03 & $1.92 \mathrm{E}-03$ & $1.61 E-03$ & $1.64 E-03$ & 1.71E-03 & $1.47 E-03$ & $1.37 E-03$ & 1.27E-03 & $1.34 E-03$ \\
\hline 29 & $1.07 E-02$ & $1.02 \mathrm{E}-02$ & $3.16 \mathrm{E}-03$ & $3.69 \mathrm{E}-03$ & $1.60 \mathrm{E}-03$ & $1.29 E-03$ & $1.42 E-03$ & $1.61 E-03$ & 1.27E-03 & 1.19E-03 & 1.11E-03 & $1.18 E-03$ \\
\hline 60 & $6.33 E-03$ & $6.11 E-03$ & 1.93E-03 & $2.31 E-03$ & $1.02 \mathrm{E}-03$ & $8.69 E-04$ & $9.90 E-04$ & 1.10E-03 & $8.80 E-04$ & $8.36 E-04$ & 7.72E-04 & 8.47E-04 \\
\hline 100 & $3.21 E-03$ & $3.31 E-03$ & $1.01 E-03$ & $1.43 E-03$ & 6.66E-04 & $6.04 E-04$ & $6.82 E-04$ & $7.10 \mathrm{E}-04$ & $6.28 E-04$ & $6.01 E-04$ & 4.64E-04 & 6.26E-04 \\
\hline 200 & $1.62 E-03$ & $1.91 \mathrm{E}-03$ & $6.27 E-04$ & $9.90 \mathrm{E}-04$ & 2.91E-04 & $2.80 E-04$ & & 4.47E-04 & 2.97E-04 & $2.84 E-04$ & $2.60 E-04$ & $3.09 E-04$ \\
\hline
\end{tabular}


Appendix

Table 16. GafChromic film dose results (Gy/s) for the BNL-NIST and UB systems for each particle of $67 \mu \mathrm{m}$ at a film depth of $7.78 \mathrm{mg} / \mathrm{cm}^{2}$

\begin{tabular}{|c|c|c|c|c|c|c|c|c|}
\hline $\begin{array}{l}\text { Averaging } \\
\text { Area }\left(\mathrm{mm}^{2}\right)\end{array}$ & $\begin{array}{c}\text { Tm-170 } \\
\text { UB }\end{array}$ & $\begin{array}{c}\text { Tm-170 } \\
\text { BNL-NIST }\end{array}$ & $\begin{array}{c}\text { Yb-175 } \\
\text { UB }\end{array}$ & $\begin{array}{c}\text { Yb-175 } \\
\text { BNL-NIST }\end{array}$ & $\begin{array}{c}\mathrm{Sc}-46 \\
\mathrm{UB}\end{array}$ & $\begin{array}{c}\text { Sc-46 } \\
\text { BNL-NIST }\end{array}$ & $\begin{array}{c}\text { Co-60 } \\
\text { UB }\end{array}$ & $\begin{array}{c}\text { Co-60 } \\
\text { BNL-NIST }\end{array}$ \\
\hline 0.001 & 1.17E-01 & $1.03 E-01$ & $1.12 E+00$ & $1.53 E+00$ & $1.39 E+01$ & $1.01 E+01$ & $1.20 E+00$ & $6.12 \mathrm{E}-01$ \\
\hline 0.008 & 1.16E-01 & $1.03 E-01$ & $1.10 E+00$ & $1.63 E+00$ & 1.37E+01 & $1.08 E+01$ & $1.14 E+00$ & 6.11E-01 \\
\hline 0.01 & 1.14E-01 & 1.03E-01 & $1.10 E+00$ & $1.53 \mathrm{E}+00$ & $1.36 \mathrm{E}+01$ & $1.07 E+01$ & $1.12 E+00$ & 6.11E-01 \\
\hline 0.1 & $9.50 E-02$ & 9.62E-02 & $9.46 \mathrm{E}-01$ & $1.44 E+00$ & 1.13E+01 & $9.84 E+00$ & $6.85 E-01$ & 5.31E-01 \\
\hline 0.2 & 8.19E-02 & 8.79E-02 & $8.14 E-01$ & $1.29 E+00$ & $9.51 E+00$ & $8.96 E+00$ & $4.78 E-01$ & 4.37E-01 \\
\hline 0.4 & $6.60 E-02$ & 7.36E-02 & $6.28 E-01$ & $1.03 E+00$ & $7.16 \mathrm{E}+00$ & 7.37E+00 & $2.98 E-01$ & 3.15E-01 \\
\hline 0.8 & 4.93E-02 & 5.48E-02 & 4.21E-01 & 7.23E-01 & $4.72 E+00$ & 6.30E+00 & $1.70 E-01$ & $1.99 E-01$ \\
\hline 1 & $4.40 E-02$ & $4.86 E-02$ & $3.69 E-01$ & $6.27 E-01$ & $4.03 E+00$ & $4.61 \mathrm{E}+00$ & $1.40 E-01$ & 1.67E-01 \\
\hline 2 & 2.92E-02 & $3.13 E-02$ & 2.03E-01 & 3.71E-01 & $2.30 E+00$ & $2.72 E+00$ & $7.40 \mathrm{E}-02$ & $9.17 E-02$ \\
\hline 4 & $1.82 E-02$ & 1.87E-02 & $1.06 E-01$ & $2.00 E-01$ & $1.23 E+00$ & $1.44 \mathrm{E}+00$ & $3.79 E-02$ & $4.76 E-02$ \\
\hline 8 & $9.97 E-02$ & $1.06 \mathrm{E}-02$ & 5.36E-02 & $1.02 E-01$ & 6.10E-01 & $7.29 E-01$ & $1.96 E-02$ & $2.40 E-02$ \\
\hline 10 & 8.18E-03 & $8.69 E-03$ & $4.31 E-02$ & $8.16 E-02$ & $5.15 E-01$ & 6.84E-01 & $1.68 E-02$ & $1.93 E-02$ \\
\hline 23 & $3.79 E-03$ & $4.08 E-03$ & $1.89 E-02$ & $3.49 E-02$ & $2.28 E-01$ & $2.64 E-01$ & $7.26 \mathrm{E}-03$ & $8.47 E-03$ \\
\hline 29 & $3.04 E-03$ & $3.28 E-03$ & $1.60 \mathrm{E}-02$ & $2.76 E-02$ & $1.82 E-01$ & $2.01 E-01$ & 6.83E-03 & $6.74 E-03$ \\
\hline 50 & $1.80 E-03$ & $1.92 E-03$ & $8.72 E-03$ & $1.54 E-02$ & $1.06 E-01$ & 1.17E-01 & $3.49 E-03$ & $3.97 E-03$ \\
\hline 100 & $9.29 E-04$ & $9.30 \mathrm{E}-04$ & 4.34E-03 & 7.07E-03 & $5.36 E-02$ & $6.84 E-02$ & $1.80 E-03$ & $2.06 E-03$ \\
\hline 200 & $4.83 E-04$ & $4.07 E-04$ & $2.14 E-03$ & $2.91 E-03$ & $2.70 \mathrm{E}-02$ & $2.92 E-02$ & 9.26E-04 & $1.09 E-03$ \\
\hline
\end{tabular}


Appendix

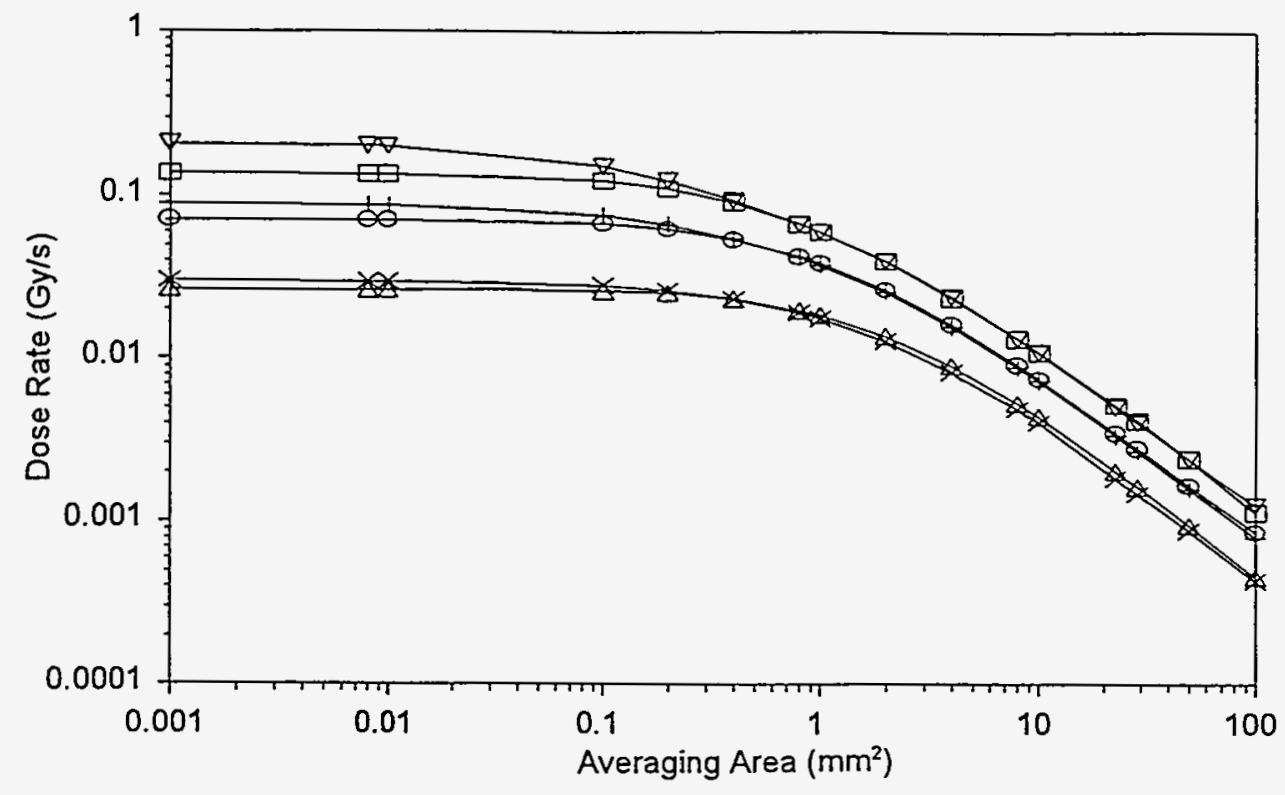

$\begin{array}{lll}\rightarrow \text { BNL-NIST } 1.8 \mathrm{mg} / \mathrm{cm}^{2} & - \text { BNL-NIST } 17 \mathrm{mg} / \mathrm{cm}^{2} & \triangle \text { BNL-NIST } 46 \mathrm{mg} / \mathrm{cm}^{2} \\ \rightarrow \text { UB } 1.8 \mathrm{mg} / \mathrm{cm}^{2} & + \text { UB } 17 \mathrm{mg} / \mathrm{cm}^{2} & \leftarrow \text { UB } 46 \mathrm{mg} / \mathrm{cm}^{2}\end{array}$

Figure 6. Dose rates from Tm-170 hot particle for selected GafChromic film depths.

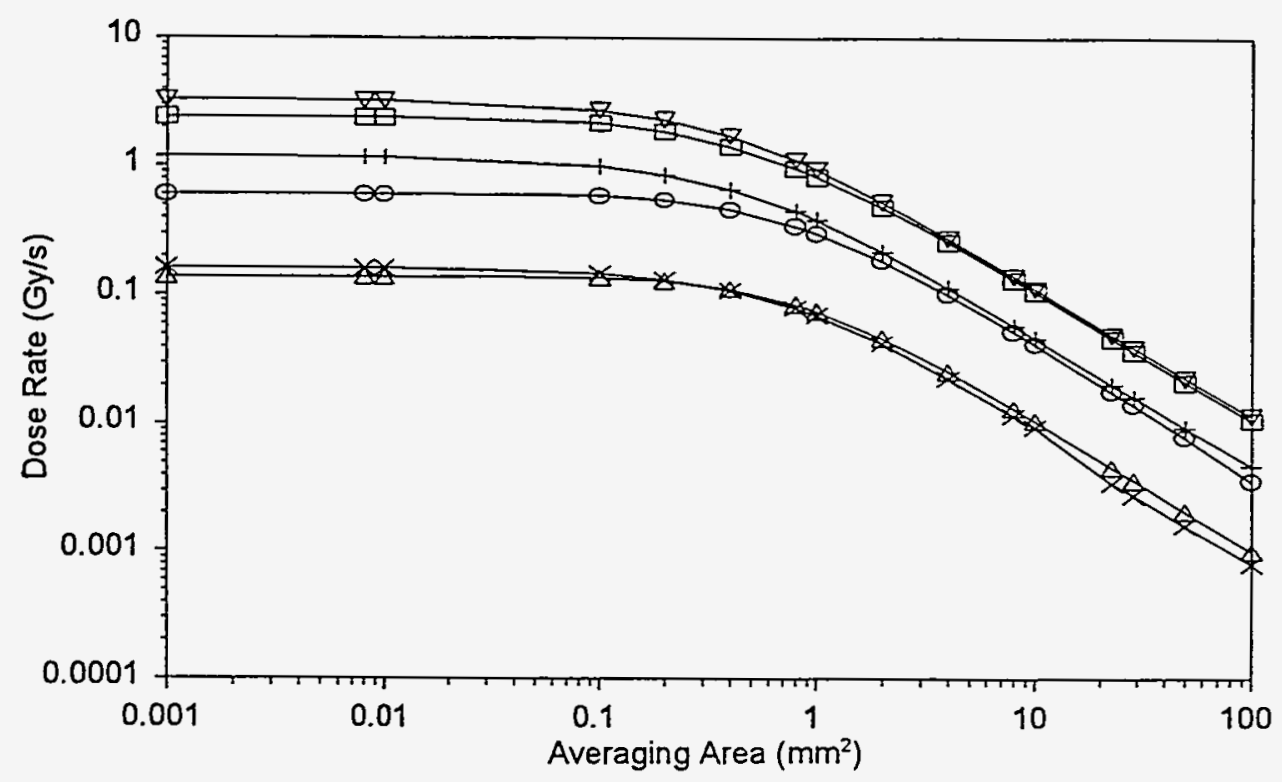

BNL-NIST $1.8 \mathrm{mg} / \mathrm{cm}^{2} \odot$ BNL-NIST $17 \mathrm{mg} / \mathrm{cm}^{2} \triangle$ BNL-NIST $46 \mathrm{mg} / \mathrm{cm}^{2}$

$\rightarrow$ UB $1.8 \mathrm{mg} / \mathrm{cm}^{2} \rightarrow$ UB $17 \mathrm{mg} / \mathrm{cm}^{2} \rightarrow$ UB $46 \mathrm{mg} / \mathrm{cm}^{2}$

Figure 7. Dose rates from Yb-175 hot particle for selected GafChromic film depths. 


\section{Appendix}

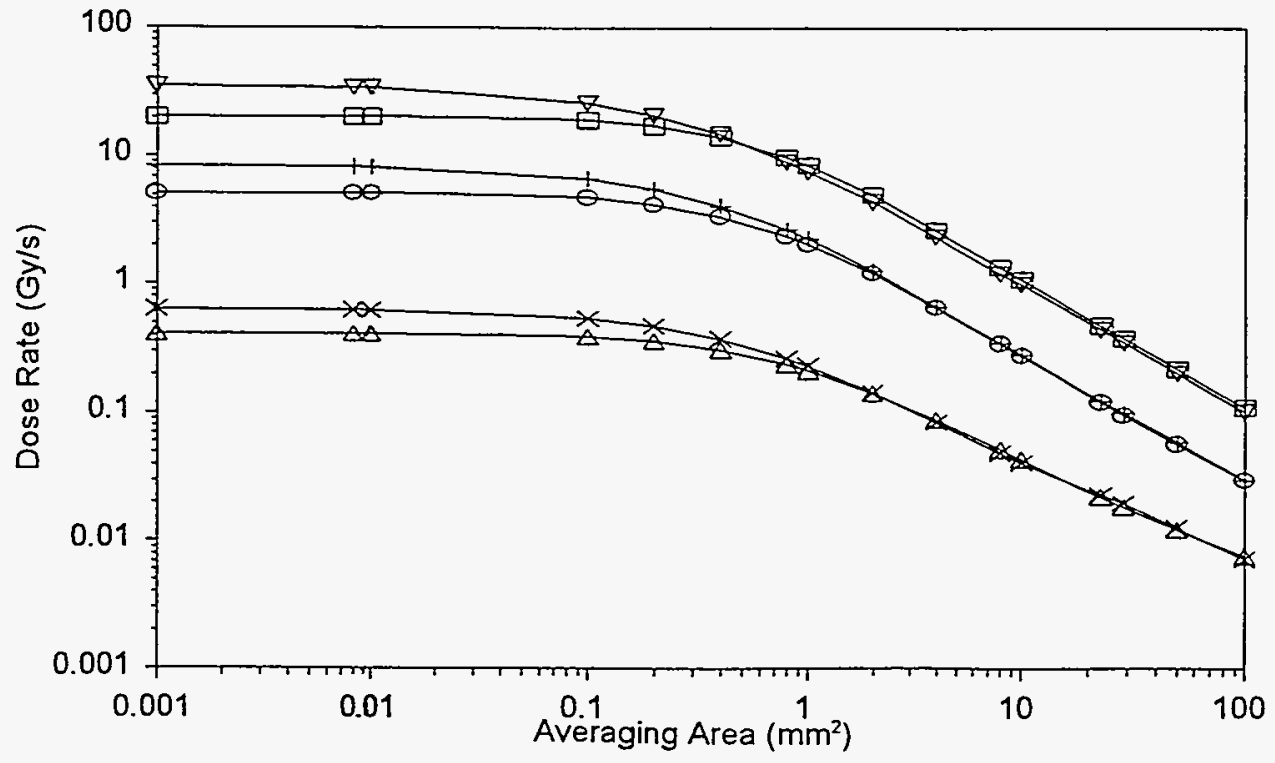

$\sqsubseteq$ BNL-NIST $1.8 \mathrm{mg} / \mathrm{cm}^{2} \ominus$ BNL-NIST $17 \mathrm{mg} / \mathrm{cm}^{2} \triangle$ BNL-NIST $46 \mathrm{mg} / \mathrm{cm}^{2}$ $\rightarrow$ UB $1.8 \mathrm{mg} / \mathrm{cm}^{2} \quad \rightarrow$ UB $17 \mathrm{mg} / \mathrm{cm}^{2} \quad \rightarrow$ UB $46 \mathrm{mg} / \mathrm{cm}^{2}$

Figure 8. Dose rates from Sc-46 hot particle for selected GafChromic film depths.

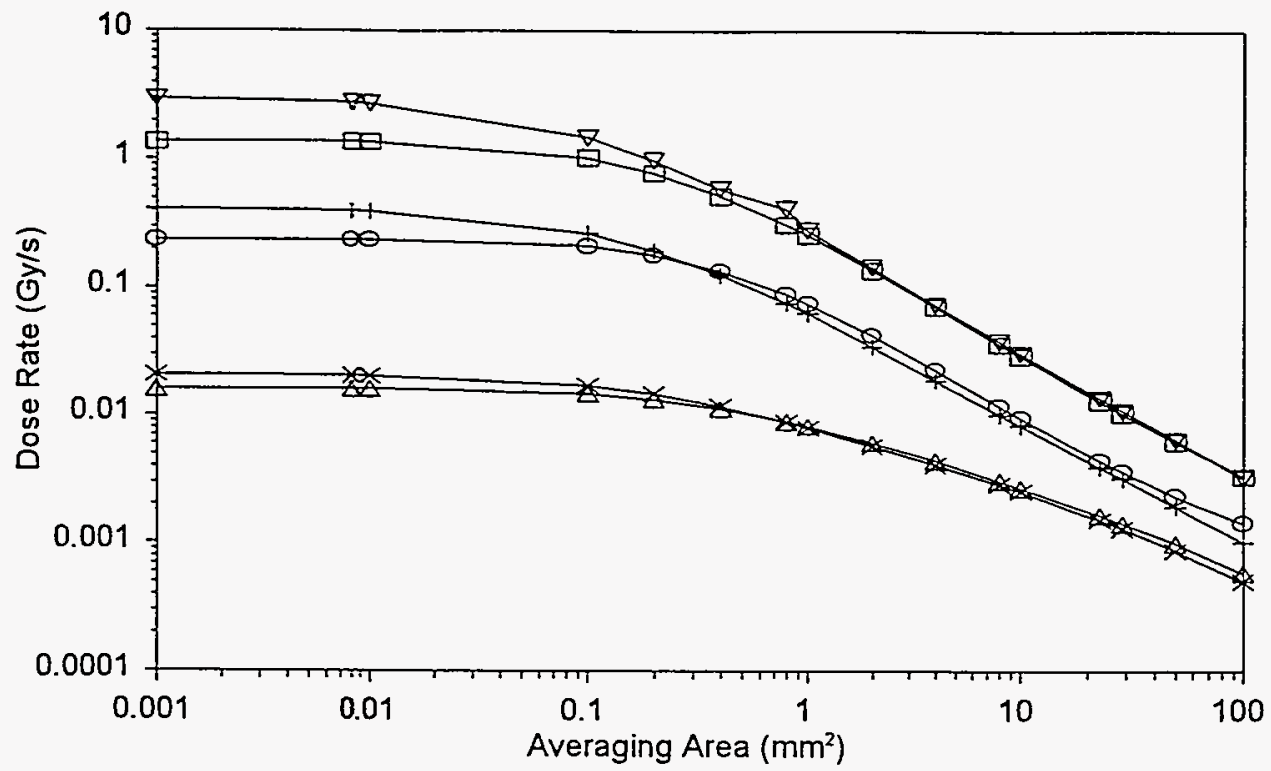

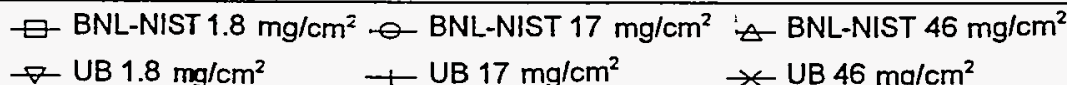

Figure 9. Dose rates from Co-60 hot particle for selected GafChromic film depths. NUREG/CR-6531 


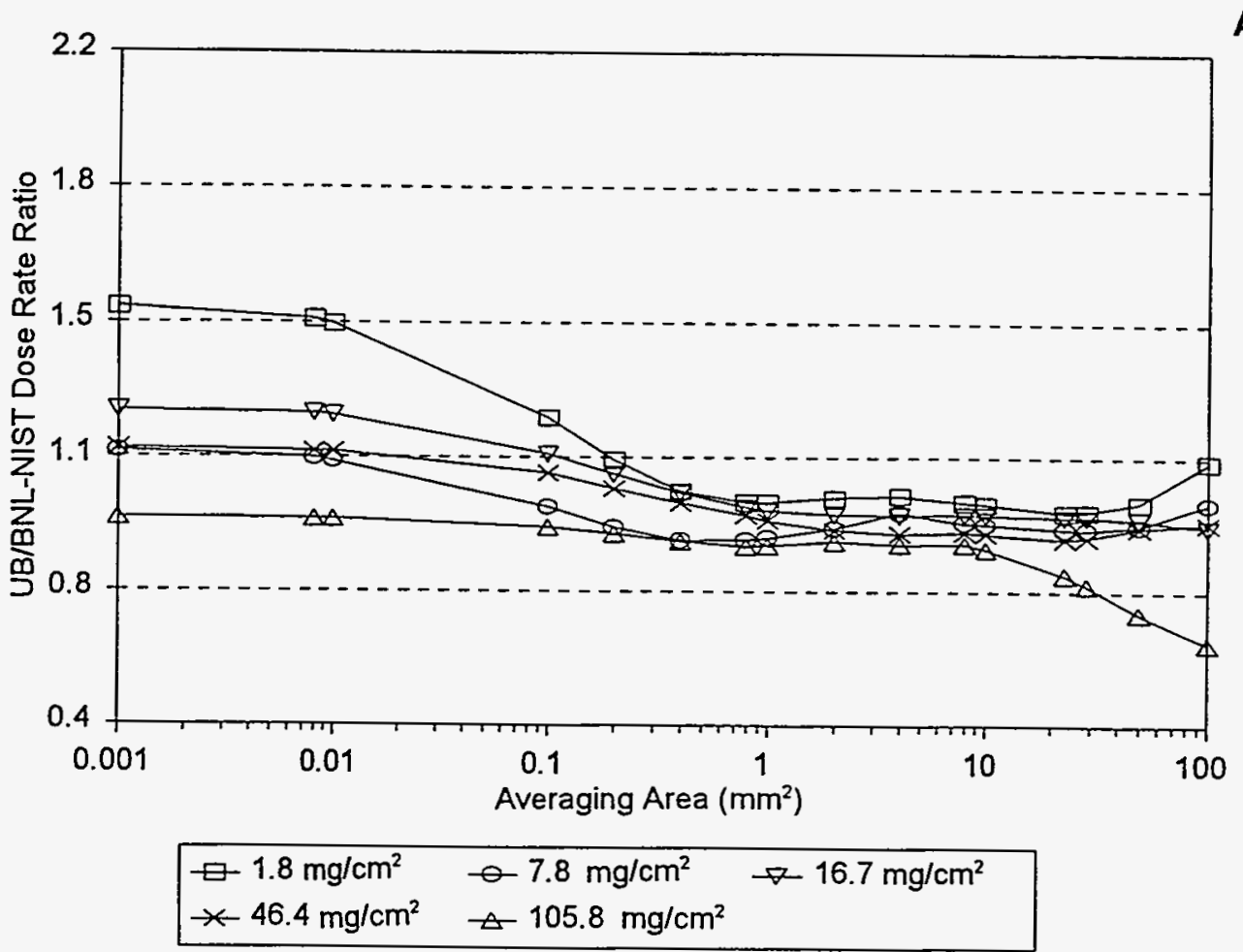

Appendix

Figure 10. Ratio of Tm-170 dose rate measurements made by UB and BNL-NIST.

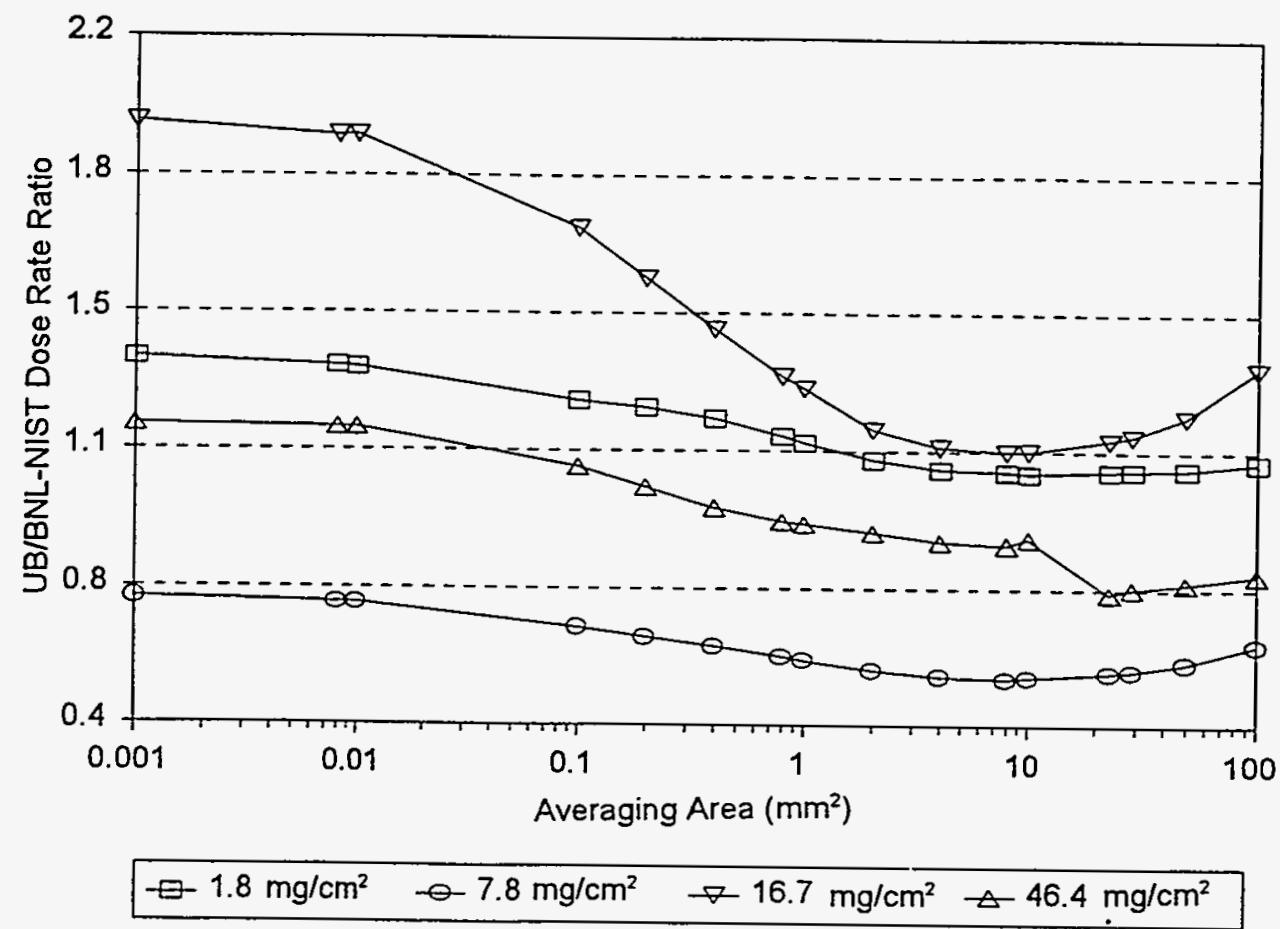

Figure 11. Ratio of $\mathrm{Yb}-175$ dose rate measurements made by UB and BNL-NIST. 


\section{Appendix}

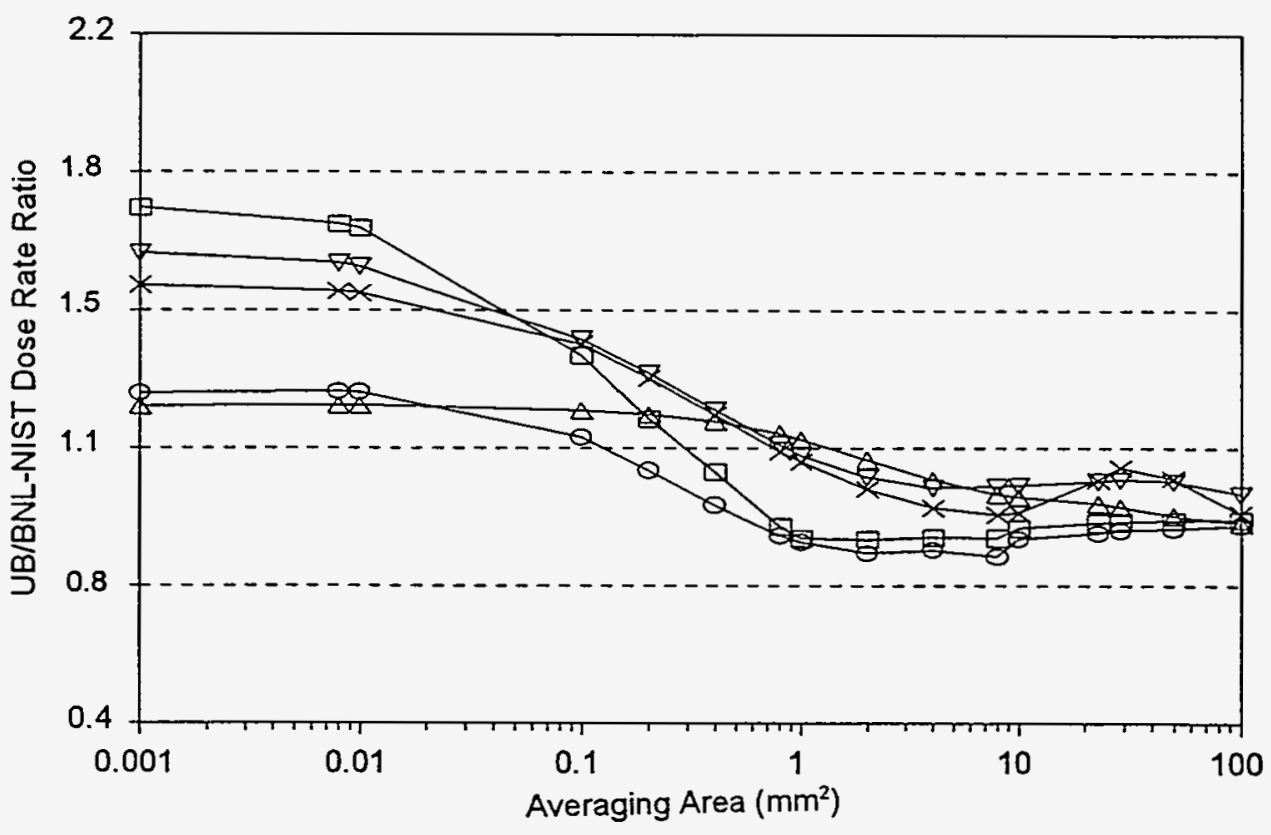

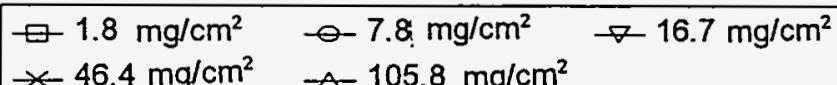

Figure 12. Ratio of Sc-46 dose rate measurements made by UB and BNL-NIST.

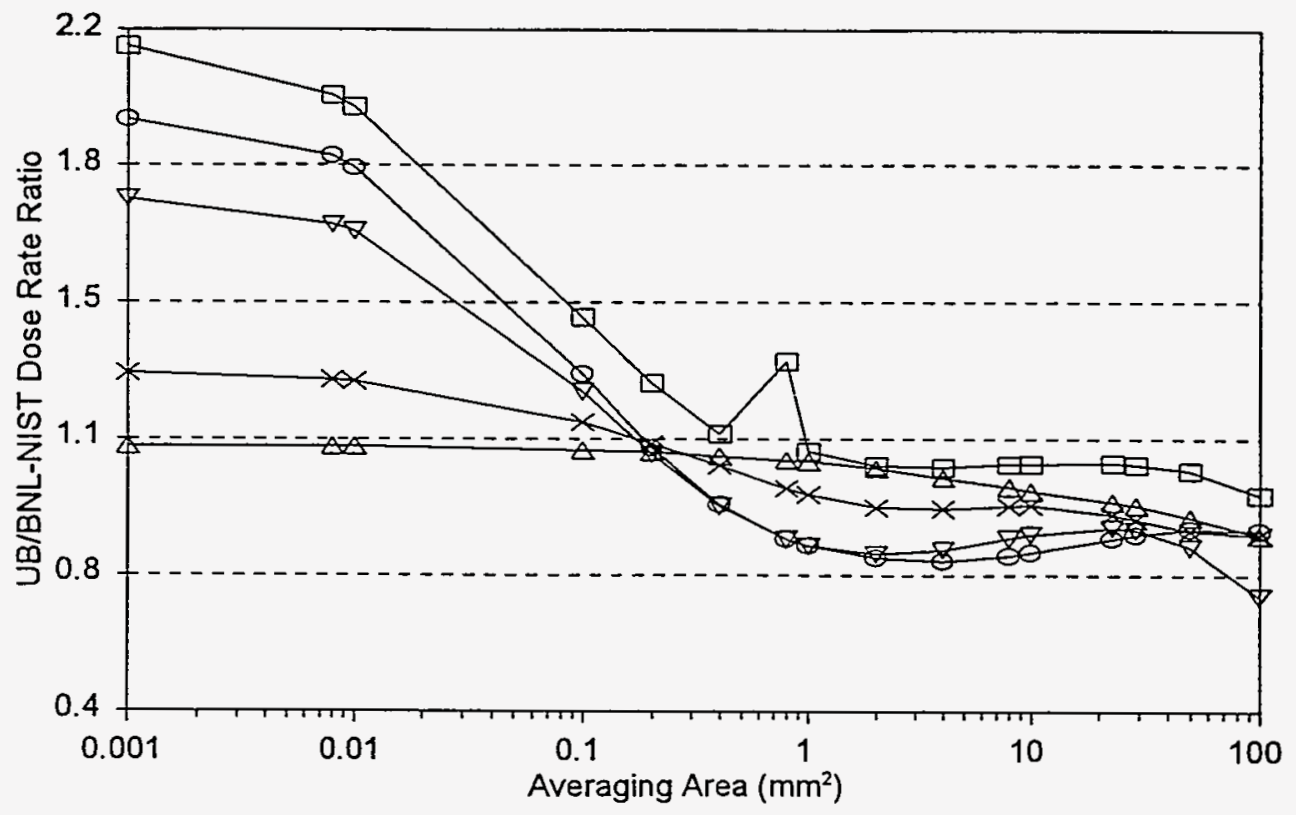

$\begin{array}{lll}Ð 1.8 \mathrm{mg} / \mathrm{cm}^{2} & \oplus 7.8 \mathrm{mg} / \mathrm{cm}^{2} & \nabla 16.7 \mathrm{mg} / \mathrm{cm}^{2} \\ \leftarrow 46.4 \mathrm{mg} / \mathrm{cm}^{2} & \triangle 105.8 \mathrm{mg} / \mathrm{cm}^{2}\end{array}$

Figure 13. Ratio of Co-60 dose rate measurements made by UB and BNL-NIST. 
Appendix

and 17 using similar stacks. Later, the UB group exposed single films of $7.8 \mathrm{mg} / \mathrm{cm}^{2}$ on September 16 and 17. Similar exposures were made by the BNL-NIST group on September 19 and 20.

It had been suggested that because the particle was activated several days before the workshop, it may have contained impurities which were not adequately accounted for in correcting the dosimetry to September 13, at 13:30 (Table 6). However, it seems unlikely that a short-lived impurity caused the discrepancies between the UB and BNL-NIST results because the UB results would be consistently larger than those of BNL, which was not the case. As shown in the following section 3.4 .2 , comparing these systems with the results from the NE extremity tape dosimeter show that the UB results at $7.8 \mathrm{mg} / \mathrm{cm}^{2}$ also are low compared to the tape dosimeter. However, as noted in section 2.4.2, the calculated dose for this film depth from the earlier stack of 8 films exposed by the UB group gave doses $60 \%$ higher than those measured later, which would indicate that an impurity may have been present. The results for the UB $7.8 \mathrm{mg} / \mathrm{cm}^{2}$ $\mathrm{Yb}-175$ measurements should be considered anomalous, and were not used in subsequent analysis.

The uncertainties associated with the BNL-NIST dosimetry are estimated to be $15 \%(95 \%$ confidence) for the results listed, except for the $1.8 \mathrm{mg} / \mathrm{cm}^{-2}$ and $7.8 \mathrm{mg} / \mathrm{cm}^{-2}$ measurements for Sc-46, which are 20 and $19 \%$, respectively. This uncertainty includes error terms for timing, calibration of dose rate, fit of calibration function, individual film sensitivity, readout of pixel values, and combining the films for the radial dose function.

\subsection{Exoelectron Results}

\subsubsection{Results of EED Dóse Measurements}

Table 17 shows the dose rate for each measurement geometry averaged over $1 \mathrm{~cm}^{2}$ determined using PNL calibration factors; Table 18 shows the same, but determined using ORNL calibration factors.

We believe that the results in Table 17 are more indicative of the actual dose rates from the hot particles because the same reader was used for all but six calibrations and the measurements. To compare the results obtained from both readers, Table 19 lists the results and their ratios using both calibrations (note, the results in Table 19 are dose rates averaged over $0.23 \mathrm{~cm}^{2}$, the active area of the EED). The PNL calibrations give dose rates that are a factor of $1.5 \pm 0.21 \mathrm{~Gy} / \mathrm{s}$ (standard deviation of the mean of 12 measurements) higher than those obtained using the ORNL calibrations. The $14 \%$ standard deviation associated with the ratio of the two results indicates that a systematic difference exists between the two readers, probably related to differences in their geometries. We suspect that the primary difference between the readers is that the distance between the stage and the collimator in the PNL reader is smaller than that of the ORNL reader. In addition, the collimator size in the PNL reader is larger than that in the ORNL reader. 
Appendix

Table 17. Exoelectron doses averaged over $1 \mathrm{~cm}^{2}$ based on PNL calibrations. Dosimeters that were not calibrated with the PNL reader are not included in these mean values.

\begin{tabular}{|c|r|r|c|c|}
\hline \multirow{3}{*}{ Source } & Measurement depth ${ }^{\mathrm{a}}$ & $\begin{array}{c}\text { Average } \\
\text { dose rate } \\
\text { (Gy/s) }\end{array}$ & $\begin{array}{c}\text { Standard } \\
\text { deviation } \\
\text { (Gy/s) }\end{array}$ & \% Uncertainty \\
\hline \hline \multirow{3}{*}{ Tm-170 } & $9.8 \mu \mathrm{m}$ & $2.4 \mathrm{E}-04$ & $6.7 \mathrm{E}-05$ & 29 \\
\cline { 2 - 5 } & $63 \mu \mathrm{m}$ & $1.3 \mathrm{E}-04$ & $4.7 \mathrm{E}-05$ & 37 \\
\hline \multirow{3}{*}{ Yb-175 } & 3 Films $+9.8 \mu \mathrm{m}$ & $3.9 \mathrm{E}-05$ & $5.6 \mathrm{E}-06$ & 15 \\
\cline { 2 - 5 } & $9.8 \mu \mathrm{m}$ & $5.0 \mathrm{E}-03$ & $1.8 \mathrm{E}-03$ & 36 \\
\cline { 2 - 5 } & $63 \mu \mathrm{m}$ & $1.9 \mathrm{E}-03$ & $1.7 \mathrm{E}-04$ & 9 \\
\hline \multirow{3}{*}{ Sc-46 } & 3 Films $+9.8 \mu \mathrm{m}$ & $2.1 \mathrm{E}-04$ & $5.6 \mathrm{E}-05$ & 26 \\
\cline { 2 - 6 } & $9.8 \mu \mathrm{m}$ & $1.0 \mathrm{E}-02$ & $2.8 \mathrm{E}-04$ & 28 \\
\cline { 2 - 6 } & $63 \mu \mathrm{m}$ & $5.3 \mathrm{E}-03$ & $1.8 \mathrm{E}-03$ & 33 \\
\hline \multirow{3}{*}{ Co-60 } & 3 Films $+9.8 \mu \mathrm{m}$ & $4.7 \mathrm{E}-04$ & $9.4 \mathrm{E}-05$ & 20 \\
\cline { 2 - 6 } & $9.8 \mu \mathrm{m}$ & $5.3 \mathrm{E}-04$ & $6.7 \mathrm{E}-05$ & 12 \\
\cline { 2 - 6 } & 3 Films $+9.8 \mu \mathrm{m}$ & $5.0 \mathrm{E}-05$ & $8.3 \mathrm{E}-06$ & 18 \\
\hline
\end{tabular}

a. 9.8 refers to the $9.8-\mu \mathrm{m}$-thick Mylar, $63 \mu \mathrm{m}$ refers to the $63-\mu \mathrm{m}$-thick Mylar, and 3 films refers to 3 GafChromic films. 
Table 18. Exoelectron $1 \mathrm{~cm}^{2}$ averaged doses using ORNL reader for calibrations and PNL reader for dose measurements. Differences in reader geometries may have affected the data for the dose measurements.

\begin{tabular}{|c|r|r|c|c|}
\hline \multirow{3}{*}{ Source } & Measurement depth ${ }^{\mathrm{a}}$ & $\begin{array}{c}\text { Average } \\
\text { dose rate } \\
\text { (Gy/s) }\end{array}$ & $\begin{array}{c}\text { Std. } \\
\text { deviation } \\
\text { (Gy/s) }\end{array}$ & \% Uncertainty \\
\cline { 2 - 5 } & $9.8 \mu \mathrm{m}$ & $1.2 \mathrm{E}-04$ & $3.1 \mathrm{E}-05$ & 25 \\
\hline \hline \multirow{3}{*}{ Tm-170 } & $63 \mu \mathrm{m}$ & $8.6 \mathrm{E}-05$ & $2.2 \mathrm{E}-05$ & 26 \\
\hline \multirow{3}{*}{ Yb-175 } & 3 Films $+9.8 \mu \mathrm{m}$ & $3.1 \mathrm{E}-05$ & $5.6 \mathrm{E}-06$ & 18 \\
\cline { 2 - 5 } & $9.8 \mu \mathrm{m}$ & $3.1 \mathrm{E}-03$ & $1.1 \mathrm{E}-03$ & 34 \\
\cline { 2 - 5 } & $63 \mu \mathrm{m}$ & $1.6 \mathrm{E}-03$ & $2.2 \mathrm{E}-04$ & 14 \\
\hline \multirow{3}{*}{ Sc-46 } & 3 Films $+9.8 \mu \mathrm{m}$ & $1.4 \mathrm{E}-04$ & $3.3 \mathrm{E}-05$ & 24 \\
\cline { 2 - 6 } & $9.8 \mu \mathrm{m}$ & $6.9 \mathrm{E}-03$ & $9.4 \mathrm{E}-04$ & 14 \\
\cline { 2 - 6 } & $63 \mu \mathrm{m}$ & $4.2 \mathrm{E}-03$ & $1.3 \mathrm{E}-03$ & 32 \\
\hline \multirow{3}{*}{ Co-60 } & 3 Films $+9.8 \mu \mathrm{m}$ & $2.8 \mathrm{E}-04$ & $6.9 \mathrm{E}-05$ & 25 \\
\cline { 2 - 6 } & $9.8 \mu \mathrm{m}$ & $3.5 \mathrm{E}-04$ & $3.3 \mathrm{E}-05$ & 10 \\
\cline { 2 - 6 } & $63 \mu \mathrm{m}$ & $2.7 \mathrm{E}-04$ & $5.0 \mathrm{E}-05$ & 19 \\
\hline & 3 Films $+9.8 \mu \mathrm{m}$ & $3.3 \mathrm{E}-05$ & $5.6 \mathrm{E}-06$ & 21 \\
\hline
\end{tabular}

a. 9.8 refers to the $9.8-\mu \mathrm{m}$-thick Mylar, $63 \mu \mathrm{m}$ refers to the $63-\mu \mathrm{m}$-thick Mylar, and 3 films refers to 3 GafChromic films. 


\section{Appendix}

Table 19. Ratio of PNL results to ORNL results. The results reflect the dose rate to the active area of an EED, $0.23 \mathrm{~cm}^{2}$. The mean ratio of the two calibrations is $1.50 \pm 0.21$.

\begin{tabular}{|l|r|r|c|c|}
\hline \multirow{3}{*}{ Source } & Measurement depth ${ }^{\mathrm{a}}$ & $\begin{array}{c}\text { PNL } \\
\text { Calibration } \\
\text { (Gy/s) }\end{array}$ & $\begin{array}{c}\text { ORNL } \\
\text { Calibration } \\
\text { (Gy/s) }\end{array}$ & Ratio \\
\hline \hline \multirow{3}{*}{ Tm-170 } & $9.8 \mu \mathrm{m}$ & $1.0 \mathrm{E}-03$ & $5.3 \mathrm{E}-04$ & 2.00 \\
\cline { 2 - 5 } & $63 \mu \mathrm{m}$ & $5.6 \mathrm{E}-04$ & $3.9 \mathrm{E}-04$ & 1.49 \\
\hline \multirow{3}{*}{ Yb-175 } & 3 Films $+12 \mu \mathrm{m}$ & $1.7 \mathrm{E}-04$ & $1.3 \mathrm{E}-04$ & 1.32 \\
\cline { 2 - 5 } & $9.8 \mu \mathrm{m}$ & $2.1 \mathrm{E}-02$ & $1.4 \mathrm{E}-02$ & 1.56 \\
\cline { 2 - 5 } & $63 \mu \mathrm{m}$ & $8.3 \mathrm{E}-03$ & $6.7 \mathrm{E}-03$ & 1.23 \\
\hline \multirow{3}{*}{ Sc-46 } & 3 Films $+9.8 \mu \mathrm{m}$ & $9.2 \mathrm{E}-04$ & $6.1 \mathrm{E}-04$ & 1.51 \\
\cline { 2 - 6 } & $9.8 \mu \mathrm{m}$ & $4.2 \mathrm{E}-02$ & $3.1 \mathrm{E}-02$ & 1.44 \\
\cline { 2 - 6 } & $63 \mu \mathrm{m}$ & $2.3 \mathrm{E}-02$ & $1.8 \mathrm{E}-02$ & 1.29 \\
\hline \multirow{3}{*}{ Co-60 } & 3 Films $+9.8 \mu \mathrm{m}$ & $2.1 \mathrm{E}-03$ & $1.2 \mathrm{E}-03$ & 1.68 \\
\cline { 2 - 6 } & $9.8 \mu \mathrm{m}$ & $2.3 \mathrm{E}-03$ & $1.5 \mathrm{E}-03$ & 1.52 \\
\cline { 2 - 6 } & $63 \mu \mathrm{m}$ & $1.7 \mathrm{E}-03$ & $1.2 \mathrm{E}-03$ & 1.40 \\
\cline { 2 - 6 } & 3 Films $+9.8 \mu \mathrm{m}$ & $2.1 \mathrm{E}-04$ & $1.4 \mathrm{E}-04$ & 1.53 \\
\hline
\end{tabular}

a. 9.8 refers to the $9.8-\mu \mathrm{m}$-thick Mylar, $63 \mu \mathrm{m}$ refers to the $63-\mu \mathrm{m}$-thick Mylar, and 3 films refers to 3 GafChromic films. 


\subsubsection{Comparison of EED Measurements with Other Dosimeter Results}

Since the EEDs have a $400-\mu \mathrm{m}$ air gap between the surface of the detector and the sensitive layer, direct comparisons made with the GafChromic dye film or other dosimeters are not presented graphically, as is done in the following sections for other dosimetry.

\subsection{Measurements with the YAEC Extrapolation Chamber}

\subsubsection{Results of YAEC Extrapolation Chamber Dose Measurements}

Table 20 contains ionization currents collected at the various plate spacings for the measurements of the hot particles. The ionization currents are normalized to NTP conditions and are reported at the reference time of $13: 30$ on September 13,1994; this required about a $18 \%$ correction for decay of the $\mathrm{Yb}-175$ source. Also included are the slope and intercept coefficients of the linear regression performed on the data.

Table 21 contains the measured dose rates and the dose rates interpolated for other tissue depths of interest. The logarithmic interpolation was based on the mass thickness $\left(\mathrm{mg} / \mathrm{cm}^{2}\right)$ of the measurements (not the $\mu \mathrm{m}$ values). The uncertainties quoted for the interpolated results are estimates based on the uncertainties observed for the measurements. Note that these uncertainties were based on three measurements, one at $0.7-\mathrm{mm}$, one at $0.6-\mathrm{mm}$, and one at $0.5-\mathrm{mm}$ plate spacing. Only three measurements could be made due to time constraints during the workshop. Thus, the listed measurement uncertainty should be interpreted with caution.

It has been noted that a plot of current as a function of plate spacing for hot particles may be better fit by a quadratic function, rather than a linear function, for small collecting electrode diameters. This non-linearity is due to the non-uniformity of the air volume irradiated from hot particles. The extrapolation curve becomes more linear with larger collecting electrode diameter (Darley et al. 1991, Soares et al. 1991, Baum et al. 1992). It was therefore desirable to test the linearity of the data present here. A comparison of the linear and quadratic fit, if a quadratic fit was justified, might also provide a better estimate of the measurement uncertainty.

For this data, the adequacy of the linear fit compared to a quadratic fit was tested by normalizing the measured current at each of the three plate spacing measurements at the shallowest absorber depth $\left(1.59 \mathrm{mg} / \mathrm{cm}^{2}\right)$ for each isotope to the $0.7 \mathrm{~mm}$ plate spacing value. Next, these 12 values ( 3 plate spacings for 4 hot particles) were combined together to generate a larger sample size. A linear and quadratic fit to the data was next carried out, and a statistical $F$ test for determining the optimal number of fitting terms, as described by Bevington (1969), was carried out. The test indicated that the additional quadratic term was not justified at the $95 \%$ confidence level $\left(F_{1,8}=0.90, P>0.10\right)$. A similar procedure was then carried out for the other measurement depths $\left(6.99\right.$ and $46.2 \mathrm{mg} / \mathrm{cm}^{2}$ ) with all the data being combined to give 36 data points ( 4 hot particles, 3 electrode spacings, 3 depth measurements). Again, the addition of the quadratic term was not justified at the $95 \%$ confidence level $\left(F_{1,32}=0.45, P>0.10\right)$. Thus, over the $0.5-$ to $0.7-\mathrm{mm}$ plate spacing used, the extrapolation was best fit by a linear function. Since the quadratic fit was not justified, no additional comparisons with between the quadratic fit and linear fit were made to better estimate the measurement uncertainty. 


\section{Appendix}

Table 20. YAEC extrapolation chamber ionization currents at various plate spacings ${ }^{a}$

\begin{tabular}{|c|c|c|c|c|c|c|c|c|}
\hline \multirow{6}{*}{ Depth ${ }^{\text {b: }}$} & \multicolumn{6}{|c|}{ Tm-170 Hot Particle } & & \\
\hline & \multicolumn{2}{|c|}{$1.59 \mathrm{mg} / \mathrm{cm}^{2}(11.4 \mu \mathrm{m})$} & \multicolumn{2}{|c|}{$6.99 \mathrm{mg} / \mathrm{cm}^{2}(59.4 \mu \mathrm{m})$} & \multicolumn{2}{|c|}{$46.2 \mathrm{mg} / \mathrm{cm}^{2}(333 \mu \mathrm{m})$} & & \\
\hline & $\begin{array}{c}\text { Plate } \\
\text { Spacing } \\
\text { (mm) }\end{array}$ & $\begin{array}{c}\text { Ionization } \\
\text { Current } \\
\text { (pA) }\end{array}$ & $\begin{array}{c}\text { Plate } \\
\text { Spacing } \\
\text { (mm) }\end{array}$ & $\begin{array}{c}\text { Ionization } \\
\text { Current } \\
\text { (DA) } \\
\end{array}$ & $\begin{array}{c}\text { Plate } \\
\text { Spacing } \\
\text { (mm) }\end{array}$ & $\begin{array}{c}\text { Ionization } \\
\text { Current } \\
\text { (pA) } \\
\end{array}$ & & \\
\hline & 0.70 & -3.026 & 0.70 & -2.558 & 0.70 & -1.063 & & \\
\hline & 0.60 & -2.630 & 0.60 & -2.231 & 0.60 & -0.937 & & \\
\hline & 0.50 & -2.200 & 0.50 & -1.884 & 0.50 & -0.805 & & \\
\hline Slope $^{c}(p A / m m):$ & \multicolumn{2}{|c|}{$-4.12 \pm 0.10$} & \multicolumn{2}{|c|}{$-3.37 \pm 0.06$} & \multicolumn{2}{|c|}{$-1.30 \pm 0.02$} & & \\
\hline Intercept $(\mathrm{pA}):$ & \multicolumn{2}{|c|}{$-0.143 \pm 0.061$} & \multicolumn{2}{|c|}{$-0.204 \pm 0.035$} & \multicolumn{2}{|c|}{$-0.162 \pm 0.010$} & & \\
\hline \multirow{6}{*}{ Depth: } & \multicolumn{6}{|c|}{ Yb-175 Hot Particle } & & \\
\hline & \multicolumn{2}{|c|}{$1.59 \mathrm{mg} / \mathrm{cm}^{2}(11.4 \mu \mathrm{m})$} & \multicolumn{2}{|c|}{$6.99 \mathrm{mg} / \mathrm{cm}^{2}(59.4 \mu \mathrm{m})$} & \multicolumn{2}{|c|}{$46.2 \mathrm{mg} / \mathrm{cm}^{2}(333 \mu \mathrm{m})$} & & \\
\hline & $\begin{array}{c}\text { Plate } \\
\text { Spacing } \\
\text { (mm) }\end{array}$ & $\begin{array}{c}\text { Ionization } \\
\text { Current } \\
\text { (pA) } \\
\end{array}$ & $\begin{array}{c}\text { Plate } \\
\text { Spacing } \\
\text { (mm) }\end{array}$ & $\begin{array}{c}\text { Ionization } \\
\text { Current } \\
\text { (pA) } \\
\end{array}$ & $\begin{array}{c}\text { Plate } \\
\text { Spacing } \\
\text { (mm) }\end{array}$ & $\begin{array}{c}\text { Ionization } \\
\text { Current } \\
\text { (pA) }\end{array}$ & & \\
\hline & 0.70 & -29.63 & 0.70 & -19.89 & 0.70 & -2.468 & & \\
\hline & 0.60 & -26.01 & 0.60 & -17.43 & 0.60 & -2.171 & & \\
\hline & 0.50 & -22.19 & 0.50 & -14.83 & 0.50 & -1.858 & & \\
\hline Slope $^{c}(p A / m m):$ & \multicolumn{2}{|c|}{$-37.2 \pm 0.6$} & \multicolumn{2}{|c|}{$-25.3 \pm 0.4$} & \multicolumn{2}{|c|}{$-3.05 \pm 0.05$} & & \\
\hline Intercept ${ }^{c}(p A):$ & \multicolumn{2}{|c|}{$-3.62 \pm 0.34$} & \multicolumn{2}{|c|}{$-2.21 \pm 0.24$} & \multicolumn{2}{|c|}{$-0.335 \pm 0.027$} & & \\
\hline \multirow{6}{*}{ Depth : } & \multicolumn{6}{|c|}{ Sc-46 Hot Particle } & & \\
\hline & \multicolumn{2}{|c|}{$1.59 \mathrm{mg} / \mathrm{cm}^{2}(11.4 \mathrm{um})$} & \multicolumn{2}{|c|}{$6.99 \mathrm{mg} / \mathrm{cm}^{2}(59.4 \mu \mathrm{m})$} & \multicolumn{2}{|c|}{$46.2 \mathrm{mg} / \mathrm{cm}^{2}(333 \mu \mathrm{m})$} & & \\
\hline & $\begin{array}{l}\text { Plate } \\
\text { Spacing } \\
\text { (mm) }\end{array}$ & $\begin{array}{c}\text { Ionization } \\
\text { Current } \\
\text { (pA) }\end{array}$ & $\begin{array}{l}\text { Plate } \\
\text { Spacing } \\
\text { (mm) }\end{array}$ & $\begin{array}{c}\text { Ionization } \\
\text { Current } \\
\text { (pA) }\end{array}$ & $\begin{array}{c}\text { Plate } \\
\text { Spacing } \\
\text { (mm) }\end{array}$ & $\begin{array}{c}\text { lonization } \\
\text { Current } \\
\text { (pA) }\end{array}$ & & \\
\hline & 0.70 & -254.3 & 0.70 & -157.2 & 0.70 & -11.12 & & \\
\hline & 0.60 & -221.8 & 0.60 & -137.4 & 0.60 & -9.78 & & \\
\hline & 0.50 & -187.9 & 0.50 & -116.6 & 0.50 & -8.35 & & \\
\hline Slope $^{c}(p A / m m):$ & \multicolumn{2}{|c|}{$-332 \pm 4$} & & & & 0.3 & & \\
\hline \multirow[t]{2}{*}{ Intercept ${ }^{\mathrm{c}}(\mathrm{pA})$ : } & & \pm 2.6 & & 1.7 & & 0.16 & & \\
\hline & & & Co-60 & Particle & & & & \\
\hline Depth: & $1.59 \mathrm{mo}$ & $n^{2}(11.4 \mu m)$ & $6.99 \mathrm{~m}$ & ${ }^{2}(59.4 \mu \mathrm{m})$ & $7.78 \mathrm{~m}$ & $I^{2}(65.1 \mu \mathrm{m})$ & $46.2 \mathrm{~m}$ & $m^{2}(333 \mu m)$ \\
\hline & $\begin{array}{c}\text { Plate } \\
\text { Spacing } \\
(\mathrm{mm})\end{array}$ & $\begin{array}{c}\text { Ionization } \\
\text { Current } \\
\text { (pA) } \\
\end{array}$ & $\begin{array}{l}\text { Plate } \\
\text { Spacing } \\
(\mathrm{mm})\end{array}$ & $\begin{array}{c}\text { Ionization } \\
\text { Current } \\
\text { (pA) } \\
\end{array}$ & $\begin{array}{c}\text { Plate } \\
\text { Spacing } \\
\text { (mm) }\end{array}$ & $\begin{array}{c}\text { Ionization } \\
\text { Current } \\
\text { (pA) } \\
\end{array}$ & $\begin{array}{c}\text { Plate } \\
\text { Spacin } \\
\mathbf{g} \\
(\mathrm{mm}) \\
\end{array}$ & $\begin{array}{c}\text { Ionization } \\
\text { Current } \\
\text { (pA) } \\
\end{array}$ \\
\hline & 0.70 & -8.672 & 0.75 & -5.313 & 0.70 & -4.833 & 0.70 & -0.703 \\
\hline & 0.60 & -7.560 & 0.60 & -4.528 & 0.60 & -4.219 & 0.60 & -0.623 \\
\hline & 0.50 & -6.399 & 0.50 & -3.698 & 0.50 & -3.571 & 0.50 & -0.535 \\
\hline Slope $^{c}(p A / m m):$ & & \pm 0.4 & & 0.11 & & 0.10 & -0.8 & \pm 0.019 \\
\hline Intercept ${ }^{c}(p A):$ & -0.7 & \pm 0.086 & -0.4 & 0.067 & -0.4 & 0.062 & -0.1 & \pm 0.011 \\
\hline
\end{tabular}

a. Negative ionization currents normalized to NTP. Most of the measurement uncertainties were less than $\pm 0.1 \%$ and none exceeded $\pm 0.2 \%$.

b. Measurement depth includes absorbers and the PTP entrance foil.

c. Slope and intercept of least-squares linear regression. 
Table 21. YAEC extrapolation chamber results

\begin{tabular}{|c|c|c|c|c|}
\hline \multirow[b]{2}{*}{ Hot Particle } & \multirow[b]{2}{*}{ Result } & \multicolumn{2}{|c|}{ Tissue Depth } & \multirow{2}{*}{$\begin{array}{c}1 \mathrm{~cm}^{2} \text { Dose Rate } \\
(G y / s)\end{array}$} \\
\hline & & $\left(\mathrm{mg} / \mathrm{cm}^{2}\right)$ & $(\mu \mathrm{m})$ & \\
\hline \multirow[t]{7}{*}{$\mathrm{Tm}-170$} & Measured & 1.59 & 15.9 & $(1.34 \pm 0.03) E-03$ \\
\hline & Interpolated & 1.8 & 18 & $(1.32 \pm 0.04) E-03$ \\
\hline & Measured & 6.99 & 69.9 & $(1.10 \pm 0.02) E-03$ \\
\hline & Interpolated & 7.0 & 70 & $(1.09 \pm 0.03) E-03$ \\
\hline & Interpolated & 12.5 & 125 & $(8.90 \pm 0.26) E-04$ \\
\hline & Interpolated & 40.0 & 400 & $(4.88 \pm 0.10) \mathrm{E}-04$ \\
\hline & Measured & 46.2 & 462 & $(4.19 \pm 0.05) E-04$ \\
\hline \multirow[t]{7}{*}{$Y b-175$} & Measured & 1.59 & 15.9 & $(1.21 \pm 0.02) E-02$ \\
\hline & Interpolated & 1.8 & 18 & $(1.19 \pm 0.03) E-02$ \\
\hline & Measured & 6.99 & 69.9 & $(8.22 \pm 0.13) \mathrm{E}-03$ \\
\hline & Interpolated & 7.0 & 70 & $(8.22 \pm 0.18) E-03$ \\
\hline & Interpolated & 12.5 & 125 & $(5.55 \pm 0.12) \mathrm{E}-03$ \\
\hline & Interpolated & 40.0 & 400 & $(1.39 \pm 0.03) \mathrm{E}-03$ \\
\hline & Measured & 46.2 & 462 & $(9.92 \pm 0.14) E-04$ \\
\hline \multirow[t]{7}{*}{ Sc-46 } & Measured & 1.59 & 15.9 & $(1.08 \pm 0.01) \mathrm{E}-01$ \\
\hline & Interpolated & 1.8 & 18 & $(1.06 \pm 0.02) \mathrm{E}-01$ \\
\hline & Measured & 6.99 & 69.9 & $(6.59 \pm 0.09) \mathrm{E}-02$ \\
\hline & Interpolated & 7.0 & 70 & $(6.58 \pm 0.12) E-02$ \\
\hline & Interpolated & 12.5 & 125 & $(3.98 \pm 0.08) E-02$ \\
\hline & Interpolated & 40.0 & 400 & $(6.88 \pm 0.16) E-03$ \\
\hline & Measured & 46.2 & 462 & $(4.50 \pm 0.09) E-03$ \\
\hline \multirow[t]{8}{*}{ Co-60 } & Measured & 1.59 & 15.9 & $(3.69 \pm 0.05) E-03$ \\
\hline & Interpolated & 1.8 & 18 & $(3.62 \pm 0.08) E-03$ \\
\hline & Measured & 6.99 & 69.9 & $(2.10 \pm 0.03) E-03$ \\
\hline & Interpolated & 7.0 & 70 & $(2.10 \pm 0.04) E-03$ \\
\hline & Measured & 7.78 & 77.8 & $(2.05 \pm 0.03) E-03$ \\
\hline & Interpolated & 12.5 & 125 & $(1.18 \pm 0.03) E-03$ \\
\hline & Interpolated & 40.0 & 400 & $(3.78 \pm 0.10) E-04$ \\
\hline & Measured & 46.2 & 462 & $(2.73 \pm 0.06) E-04$ \\
\hline
\end{tabular}

a. Uncertainties quoted at one sigma. For interpolated results, the uncertainty is estimated based on the uncertainty observed for the measurements used in the interpolation. At a minimum, an additional $\pm 1.9 \%$ (at three sigma) systematic uncertainty applies to the results. See text for additional discussion regarding on the uncertainty. 
Appendix

\subsubsection{Comparisons of YAEC Extrapolation Chamber Measurements with GafChromic Film Measurements}

The dosimetry measurements were compared for the extrapolation chamber and the GafChromic film for an averaging area of $1 \mathrm{~cm}^{2}$ at all measurement depths. The results for all three systems for this averaging area are within $30 \%$ except for the Sc-46 and Co-60 values at a depth of $45 \mathrm{mg} / \mathrm{cm}^{2}$ (Figures 14 to 17 ). At this depth, the extrapolation chamber measurements are about $60 \%$ lower than the GafChromic results.

\subsection{NE Extremity Tape Dosimeter Measurements}

\subsubsection{NE Extremity Tape Dosimeter Measurement Results}

Table 22 contains the response data for the NE Extremity Tape dosimeters. The indicated measurement depth includes the effective measurement depth of the dosimeter and any GafChromic film absorbers used. The dosimeter responses are reported at the reference time of 13:30 on September 13; this required about a 18\% decay correction for the $\mathrm{Yb}-175$ source. Certain dosimeters have been identified as "misirradiated." The low response they registered indicates that the hot particle was not properly centered over the dosimeter, and, therefore, the exposed portion of the dosimeter was not centered under the PMT aperture. Although these results are listed, they were excluded from the averaging. Where the result of only a single dosimeter was available, the uncertainty was quoted as $\pm 10 \%$ of the result. This level is typical for these dosimeters and consistent with the uncertainty in the other measurements.

Table 23 summarizes the dose rates measured by NE Extremity Tape dosimeter and the dose rates interpolated for other tissue depths of interest. The logarithmic interpolation was based on the mass thickness $\left(\mathrm{mg} / \mathrm{cm}^{2}\right)$ of the measurements (not the $\mu \mathrm{m}$ values). The uncertainties quoted for the interpolated results are estimates based on the uncertainties observed for the measurements.

\subsubsection{Comparison of NE Extremity Tape Dosimeter Measurements with GafChromic Film Measurements}

Comparisons were made between the dosimetry measurements for the NE Extremity Tape dosimeters and the GafChromic film results averaged over an area of $0.29 \mathrm{~cm}^{2}$ at all measurement depths. Agreement is within $20 \%$ for both the $\mathrm{Tm}-170$ and $\mathrm{Yb}-175$ particles for mass thicknesses of 10 to $100 \mathrm{mg} / \mathrm{cm}^{2}$ for $\mathrm{Tm}-170$, and from 20 to $60 \mathrm{mg} / \mathrm{cm}^{2}$ for $\mathrm{Yb}-175$ (Figures 18 and 19). The Sc-46 and Co-46 source measurements show agreement for the approximately 8 $\mathrm{mg} / \mathrm{cm}^{2}$ measurement (within 20\%), but the NE Extremity Tape dosimeters were a factor of 3 to 4 lower than that of the GafChromic film for mass thicknesses of 112 to $127 \mathrm{mg} / \mathrm{cm}^{2}$ (Figures 20 and 21). 
Appendix

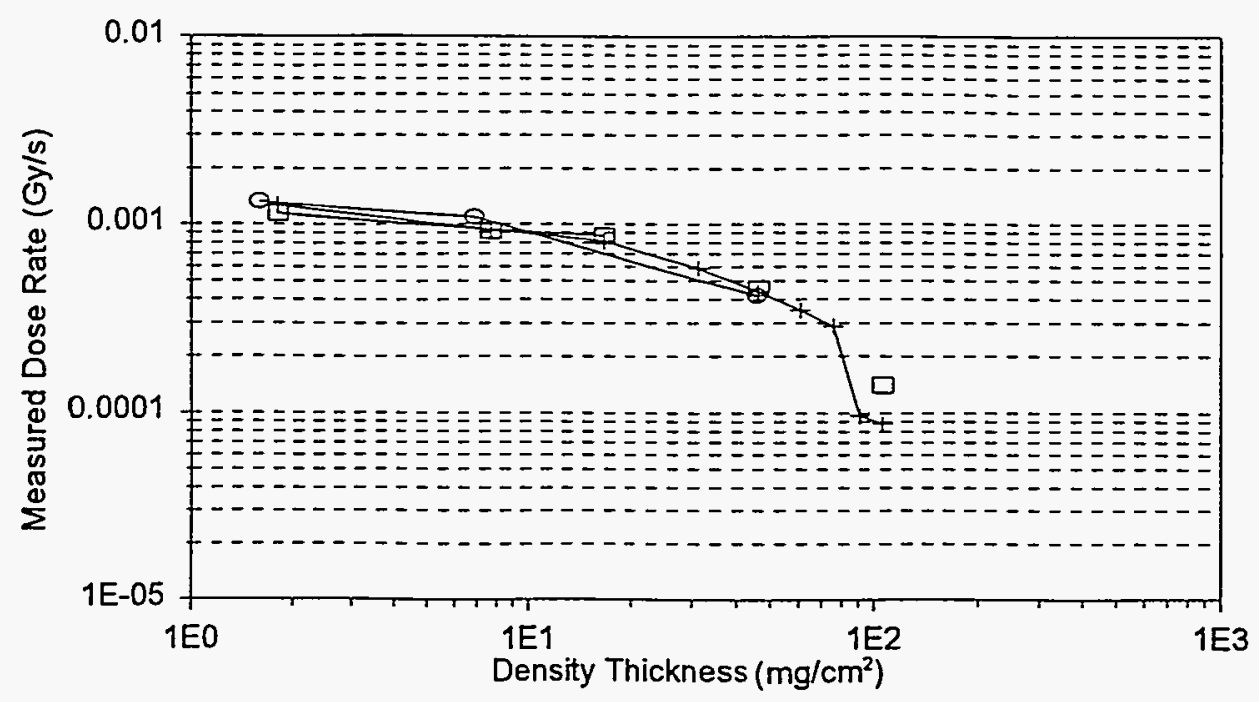

$\multimap$ BNL-NIST Film + UB Film - - Extrap. Chamber

Figure 14. Comparison of measured dose rates of the Tm-170 particle averaged over $1 \mathrm{~cm}^{2}$ at different density thicknesses.

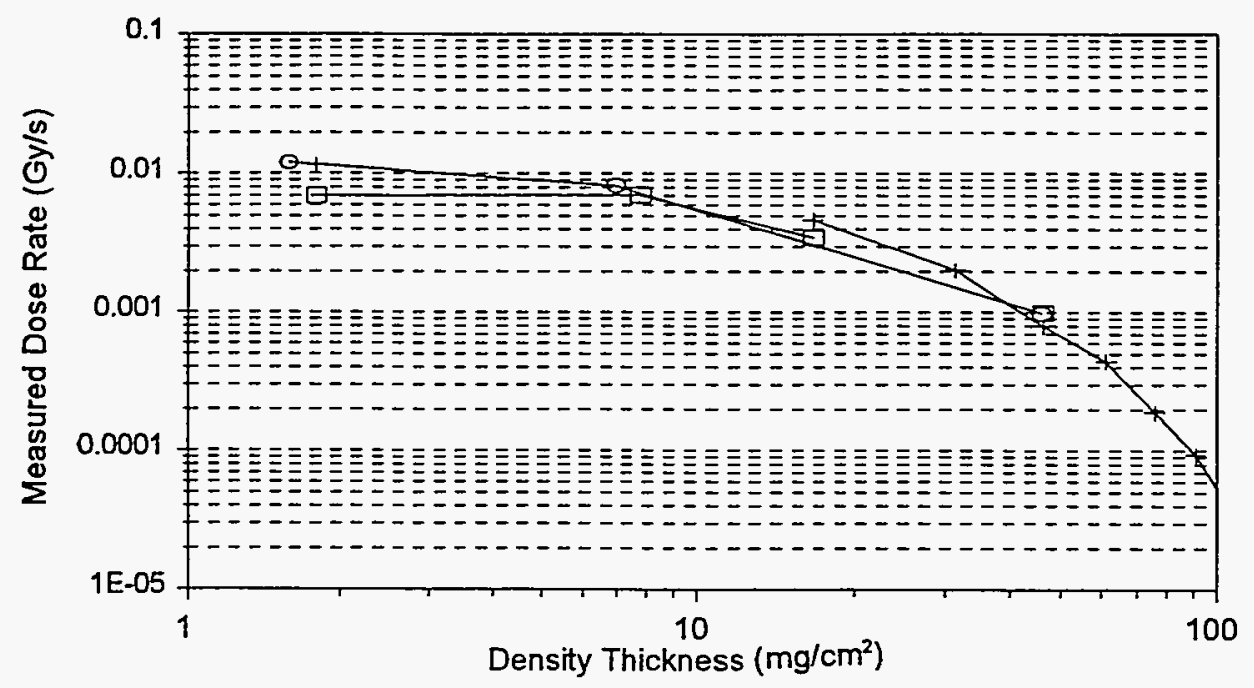

๑ BNL-NIST Film + UB Film $\quad-$ Extrap. Chamber

Figure 15. Comparison of measured dose rates of the $\mathrm{Yb}-175$ particle averaged over $1 \mathrm{~cm}^{2}$ at different density thicknesses. 


\section{Appendix}

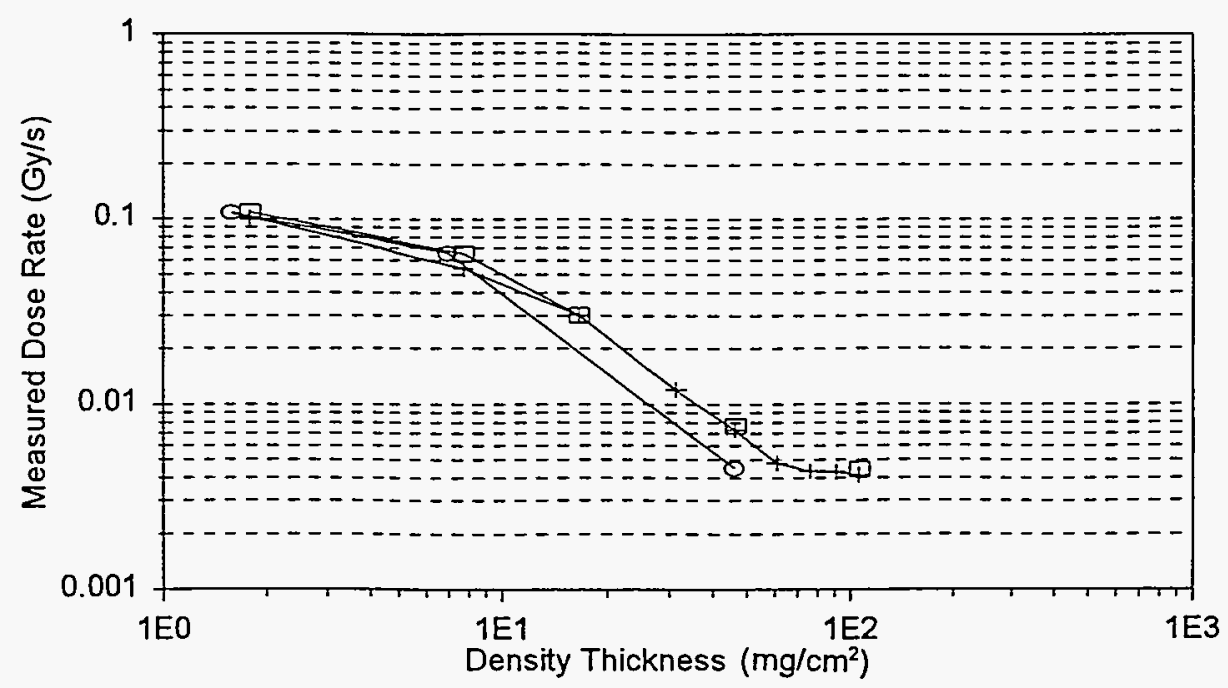

$\boxminus$ BNL-NIST Film + - UB Film $\frown$ Extrap. Chamber

Figure 16. Comparison of measured dose rates of the Sc-46 particle averaged over $1 \mathrm{~cm}^{2}$ at different density thicknesses.

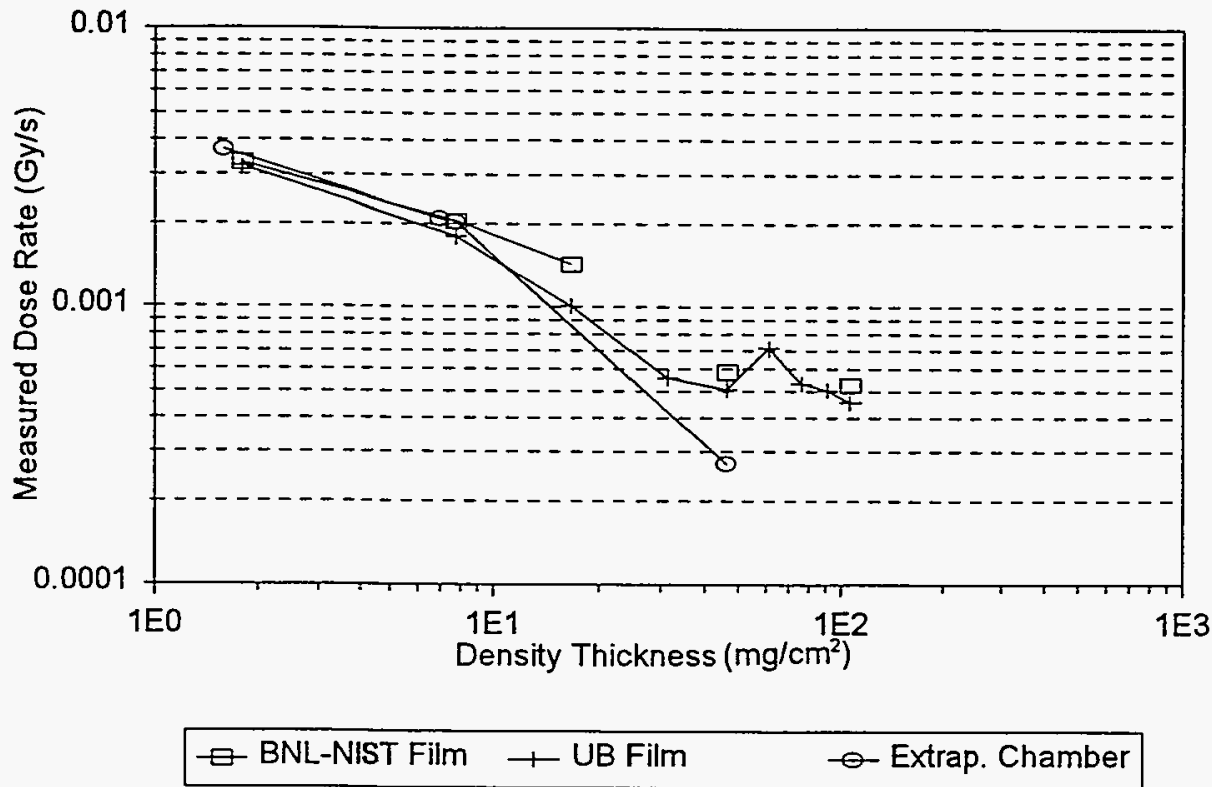

Figure 17. Comparison of measured dose rates of the Co-60 particle averaged over $1 \mathrm{~cm}^{2}$ at different density thicknesses. 
Appendix

Table 22. NE Extremity Tape dosimeter measurements

\begin{tabular}{|c|c|c|c|c|c|c|c|}
\hline \multirow[b]{2}{*}{ Hot Particle } & \multirow{2}{*}{$\begin{array}{c}\text { Tape } \\
\# \\
\end{array}$} & \multicolumn{2}{|c|}{ Measurement Depth } & \multirow{2}{*}{$\begin{array}{c}\text { Time } \\
\text { (s) }\end{array}$} & \multirow{2}{*}{$\begin{array}{c}\text { Response } \\
\text { (Gy) }\end{array}$} & \multirow{2}{*}{$\begin{array}{c}\text { Dose Rate } \\
(\mathrm{Gy} / \mathrm{s}) \\
\end{array}$} & \multirow{2}{*}{$\begin{array}{c}\text { Average Dose Rate } \\
\text { (Gy/s) }\end{array}$} \\
\hline & & $\left(\mathrm{mg} / \mathrm{cm}^{2}\right)$ & $(\mu \mathrm{m})$ & & & & \\
\hline \multirow[t]{3}{*}{$T m-170$} & 2137267 & 8.94 & 45.0 & 30.25 & 0.120 & $3.95 E-3$ & \\
\hline & 2137268 & 8.94 & 45.0 & 30.00 & 0.114 & $3.80 \mathrm{E}-3$ & $(3.90 \pm 0.08) E-3$ \\
\hline & 2137269 & 8.94 & 45.0 & 30.07 & 0.118 & $3.94 \mathrm{E}-3$ & \\
\hline \multirow[t]{3}{*}{ Tm-170 } & 2137270 & 53.5 & 367 & 30.03 & 0.0475 & $1.58 \mathrm{E}-3$ & \\
\hline & 2137271 & 53.5 & 367 & 30.06 & 0.0415 & $1.38 \mathrm{E}-3$ & $(1.41 \pm 0.16) E-3$ \\
\hline & 2137273 & 53.5 & 367 & 30.03 & 0.0383 & $1.27 \mathrm{E}-3$ & \\
\hline \multirow[t]{3}{*}{$\mathrm{Tm}-170$} & 2137274 & 112 & 790 & 30.03 & 0.0148 & $4.92 \mathrm{E}-4$ & \\
\hline & 2137275 & 112 & 790 & 30.00 & 0.0158 & $5.25 E-4$ & $(5.14 \pm 0.20) E-4$ \\
\hline & 2137276 & 112 & 790 & 30.00 & 0.0158 & $5.26 \mathrm{E}-4$ & \\
\hline \multirow[t]{3}{*}{$Y b-175$} & 2137264 & 8.74 & 44.3 & 5.12 & 0.153 & $3.00 E-2$ & \\
\hline & 2137265 & 8.74 & 44.3 & 5.28 & 0.126 & 2.39E-2 & $(2.65 \pm 0.30) E-2$ \\
\hline & 2137266 & 8.74 & 44.3 & 5.09 & 0.142 & 2.79E-2 & \\
\hline \multirow[t]{3}{*}{ Yb-175 } & 2137260 & 23.5 & 151 & 7.97 & 1.00 & $1.25 E-2$ & \\
\hline & 2137261 & 23.5 & 151 & 5.94 & 0.0696 & 1.17E-2 & $(1.17 \pm 0.08) E-2$ \\
\hline & 2137263 & 23.5 & 151 & 5.10 & 0.0560 & 1.10E-2 & \\
\hline \multirow[t]{3}{*}{ Sc-46 } & 2137237 & 8.63 & 43.9 & 3.04 & 0.0363 & $1.20 \mathrm{E}-2^{\mathrm{a}}$ & \\
\hline & 2137238 & 8.63 & 43.9 & 3.03 & 0.00739 & $2.44 \mathrm{E}-3^{\mathrm{a}}$ & $(1.58 \pm 0.16) E-1$ \\
\hline & 2137240 & 8.63 & 43.9 & 2.19 & 0.346 & $1.58 \mathrm{E}-1$ & \\
\hline \multirow[t]{3}{*}{ Sc- 46} & 2137242 & 53.2 & 366 & 3.34 & 0.0274 & $8.20 \mathrm{E}-3$ & \\
\hline & 2137243 & 53.2 & 366 & 3.35 & 0.00915 & $2.73 \mathrm{E}-3^{2}$ & $(8.20 \pm 0.82) E-3$ \\
\hline & 2137244 & 53.2 & 366 & 3.50 & 0.00899 & $2.57 \mathrm{E}-3^{a}$ & \\
\hline \multirow[t]{3}{*}{ Sc-46 } & 2137245 & 127 & 896 & 5.22 & 0.0130 & $2.48 \mathrm{E}-3$ & \\
\hline & 2137246 & 127 & 896 & 5.25 & 0.0140 & $2.66 \mathrm{E}-3$ & $(2.36 \pm 0.38) E-3$ \\
\hline & 2137250 & 127 & 896 & 5.22 & 0.0101 & $1.94 \mathrm{E}-3$ & \\
\hline \multirow[t]{3}{*}{ Co-60 } & 2137251 & 8.59 & 43.7 & 30.41 & 0.202 & $6.65 \mathrm{E}-3$ & \\
\hline & 2137252 & 8.59 & 43.7 & 30.13 & 0.180 & $5.96 \mathrm{E}-3$ & $(6.09 \pm 0.51) E-3$ \\
\hline & 2137253 & 8.59 & 43.7 & 30.03 & 0.170 & $5.66 \mathrm{E}-3$ & \\
\hline \multirow[t]{3}{*}{ Co-60 } & 2137257 & 53.2 & 366 & 40.25 & 0.0130 & $3.24 E-4$ & \\
\hline & 2137258 & 53.2 & 366 & 40.16 & 0.0120 & $2.99 E-4$ & $(3.13 \pm 0.13) E-4$ \\
\hline & 2137259 & 53.2 & 366 & 40.00 & 0.0127 & $3.17 \mathrm{E}-4$ & \\
\hline \multirow[t]{3}{*}{ Co-60 } & 2137254 & 112 & 789 & 29.97 & 0.0109 & $3.62 \mathrm{E}-4$ & \\
\hline & 2137255 & 112 & 789 & 30.06 & 0.0110 & $3.65 \mathrm{E}-4$ & $(3.69 \pm 0.10) E-4$ \\
\hline & 2137256 & 112 & 789 & 30.18 & 0.0115 & $3.80 \mathrm{E}-4$ & \\
\hline
\end{tabular}

a. Misirradiated dosimeter. Not included in dose averaging.

b. Measurement depth includes any GafChromic film absorbers and the effective depth of measurement of the dosimeter.

c. Uncertainty quoted at one sigma. When the result is based on a single dosimeter $a \pm 10 \%$ uncertainty is quoted. 


\section{Appendix}

Table 23. NE Extremity Tape dosimeter results

\begin{tabular}{|c|c|c|c|c|c|}
\hline \multirow[b]{2}{*}{ Hot Particle } & \multirow[b]{2}{*}{ Result } & \multicolumn{2}{|c|}{ Tissue Depth } & \multirow{2}{*}{$\begin{array}{c}0.29 \mathrm{~cm}^{2} \text { Dose Rate } \\
(\mathrm{Gy} / \mathrm{s})\end{array}$} & \multirow{2}{*}{$\begin{array}{c}1.0 \mathrm{~cm}^{2} \text { Dose Rate } \\
(\mathrm{Gy} / \mathrm{s})\end{array}$} \\
\hline & & $\left(\mathrm{mg} / \mathrm{cm}^{2}\right)$ & $(\mu \mathrm{m})$ & & \\
\hline \multirow[t]{7}{*}{$\mathrm{Tm}-170$} & Interpolated & 1.8 & 18 & - & $(1.33 \pm 0.15) E-3$ \\
\hline & Interpolated & 7.0 & 70 & - & $(1.18 \pm 0.13) \mathrm{E}-3$ \\
\hline & Measured & 8.94 & 89.4 & $(3.90 \pm 0.083) E-3$ & $(1.13 \pm 0.02) E-3$ \\
\hline & Interpolated & 12.5 & 125 & - & $(1.04 \pm 0.12) E-3$ \\
\hline & Interpolated & 40.0 & 400 & - & $(5.57 \pm 0.63) E-4$ \\
\hline & Measured & 53.5 & 535 & $(1.41 \pm 0.16) \mathrm{E}-3$ & $(4.09 \pm 0.45) E-4$ \\
\hline & Measured & 112 & 1120 & $(5.14 \pm 0.20) \mathrm{E}-4$ & $(1.49 \pm 0.06) E-4$ \\
\hline \multirow[t]{6}{*}{ Yb-175 } & Interpolated & 1.8 & 18 & - & $(1.17 \pm 0.15) E-2$ \\
\hline & Interpolated & 7.0 & 70 & - & $(8.7 \pm 1.1) E-3$ \\
\hline & Measured & 8.74 & 87.4 & $(2.72 \pm 0.31) E-2$ & $(7.90 \pm 0.90) E-3$ \\
\hline & Interpolated & 12.5 & 125 & - & $(6.38 \pm 0.84) E-3$ \\
\hline & Measured & 23.5 & 235 & $(1.17 \pm 0.08) \mathrm{E}-2$ & $(3.40 \pm 0.22) E-3$ \\
\hline & Interpolated & 40.0 & 400 & - & $(1.33 \pm 0.17) E-3$ \\
\hline \multirow[t]{7}{*}{ Sc-46 } & Interpolated & 1.8 & 18 & - & $(7.2 \pm 1.0) \mathrm{E}-2$ \\
\hline & Interpolated & 7.0 & 70 & - & $(5.11 \pm 0.72) E-2$ \\
\hline & Measured & 8.63 & 86.3 & $(1.58 \pm 0.16) \mathrm{E}-2$ & $(4.58 \pm 0.46) E-2$ \\
\hline & Interpolated & 12.5 & 125 & - & $(3.54 \pm 0.50) \mathrm{E}-2$ \\
\hline & Interpolated & 40.0 & 400 & - & $(5.72 \pm 0.81) \mathrm{E}-3$ \\
\hline & Measured & 53.2 & 532 & $(8.20 \pm 0.82) E-3$ & $(2.38 \pm 0.24) E-3$ \\
\hline & Measured & 127 & 1270 & $(2.36 \pm 0.38) E-3$ & $(6.8 \pm 1.1) \mathrm{E}-4$ \\
\hline \multirow[t]{7}{*}{$\mathrm{Co}-60$} & Interpolated & 1.8 & 18 & - & $(2.77 \pm 0.26) \mathrm{E}-3$ \\
\hline & Interpolated & 7.0 & 70 & - & $(1.96 \pm 0.18) E-3$ \\
\hline & Measured & 8.59 & 85.9 & $(6.09 \pm 0.51) \mathrm{E}-3$ & $(1.77 \pm 0.15) E-3$ \\
\hline & Interpolated & 12.5 & 125 & - & $(1.36 \pm 0.13) E-3$ \\
\hline & Interpolated & 40.0 & 400 & - & $(2.19 \pm 0.20) \mathrm{E}-4$ \\
\hline & Measured & 53.2 & 532 & $(3.13 \pm 0.13) E-4$ & $(9.09 \pm 0.37) E-5$ \\
\hline & Measured & 112 & 1120 & $(3.69 \pm 0.096) \mathrm{E}-4$ & $(1.07 \pm 0.03) E-4$ \\
\hline
\end{tabular}

a. Results from Table 21 .

b. Uncertainties are quoted at one sigma. For interpolated results, the uncertainty is estimated based on the uncertainty observed for the measurements used in the interpolation. 


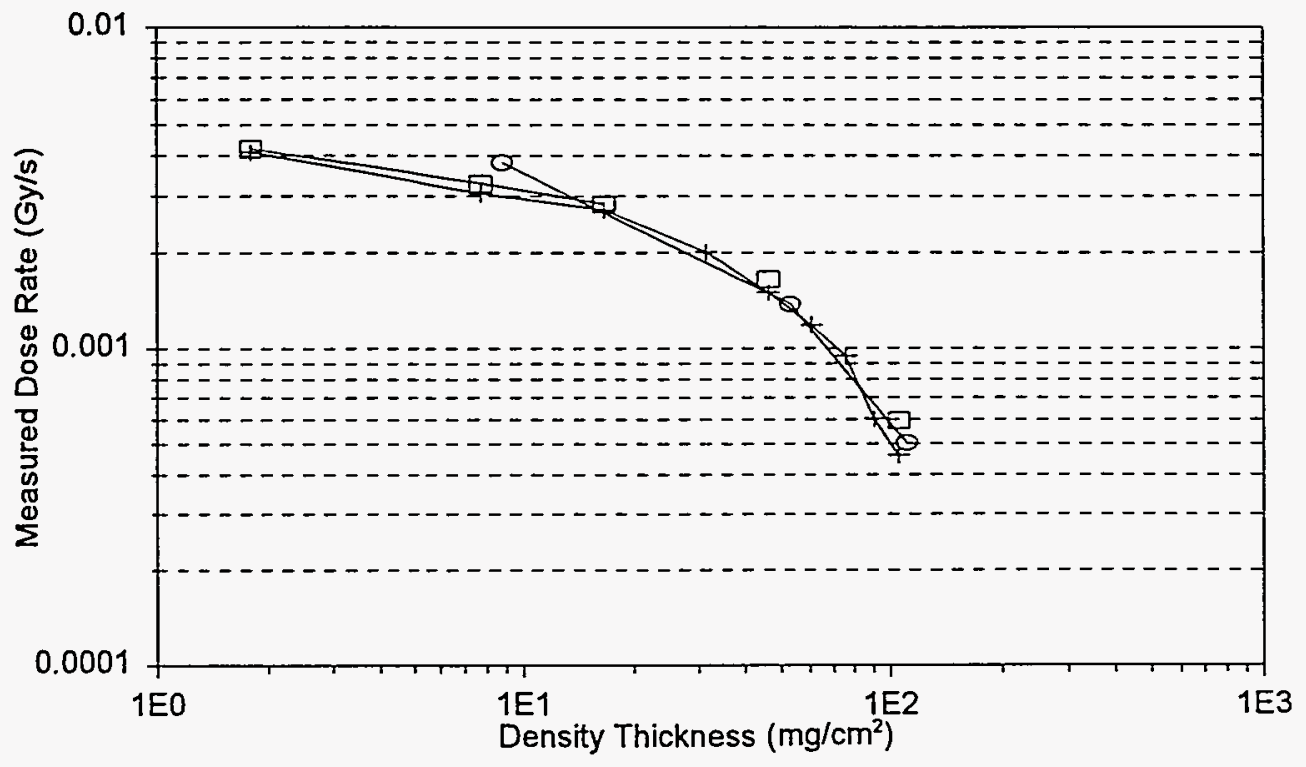

$\because$ BNL-NIST Film † UB Film $\quad \odot$ NE Extremity Tape

Figure 18. Comparison of measured dose rates of the Tm-170 particle averaged over $0.29 \mathrm{~cm}^{2}$ at different density thicknesses.

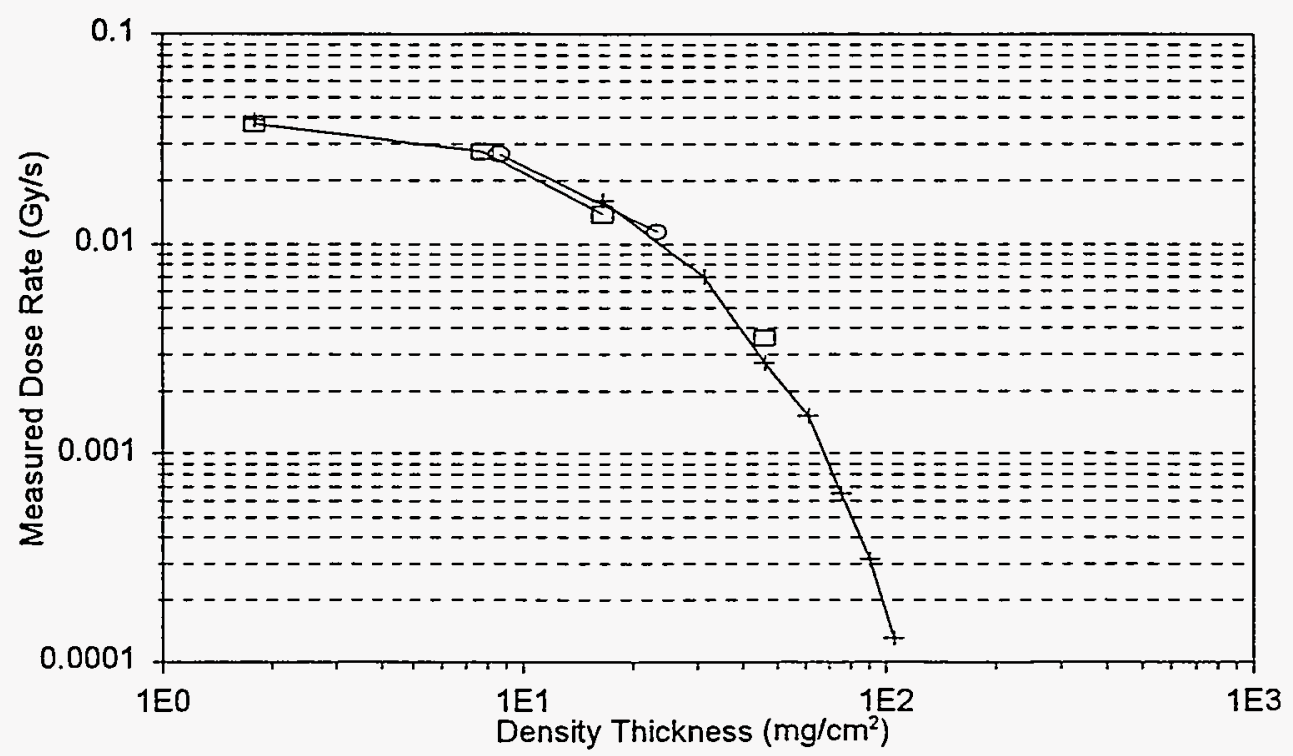

- BNL-NIST Film —U UB Film $\quad$ - NE Extremity Tape

Figure 19. Comparison of measured dose rates from the $\mathrm{Yb}-175$ particle averaged over $0.29 \mathrm{~cm}^{2}$ at different density thicknesses. 


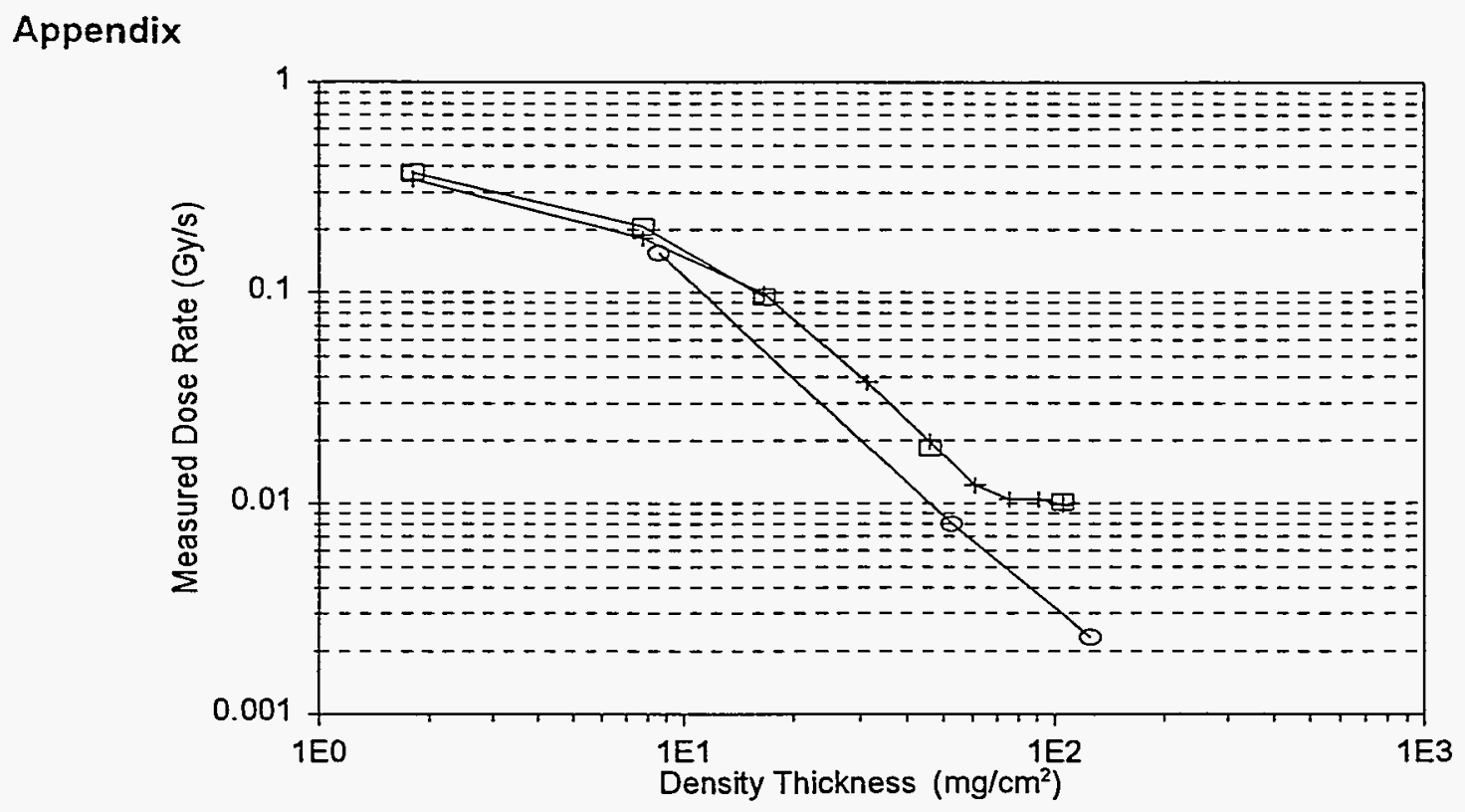

$\because$ BNL-NIST Film $\rightarrow$ UB Film $\quad$ NE Extremity Tape

Figure 20. Comparison of measured dose rates of the Sc-46 particle averaged over $0.29 \mathrm{~cm}^{2}$ at different density thicknesses.

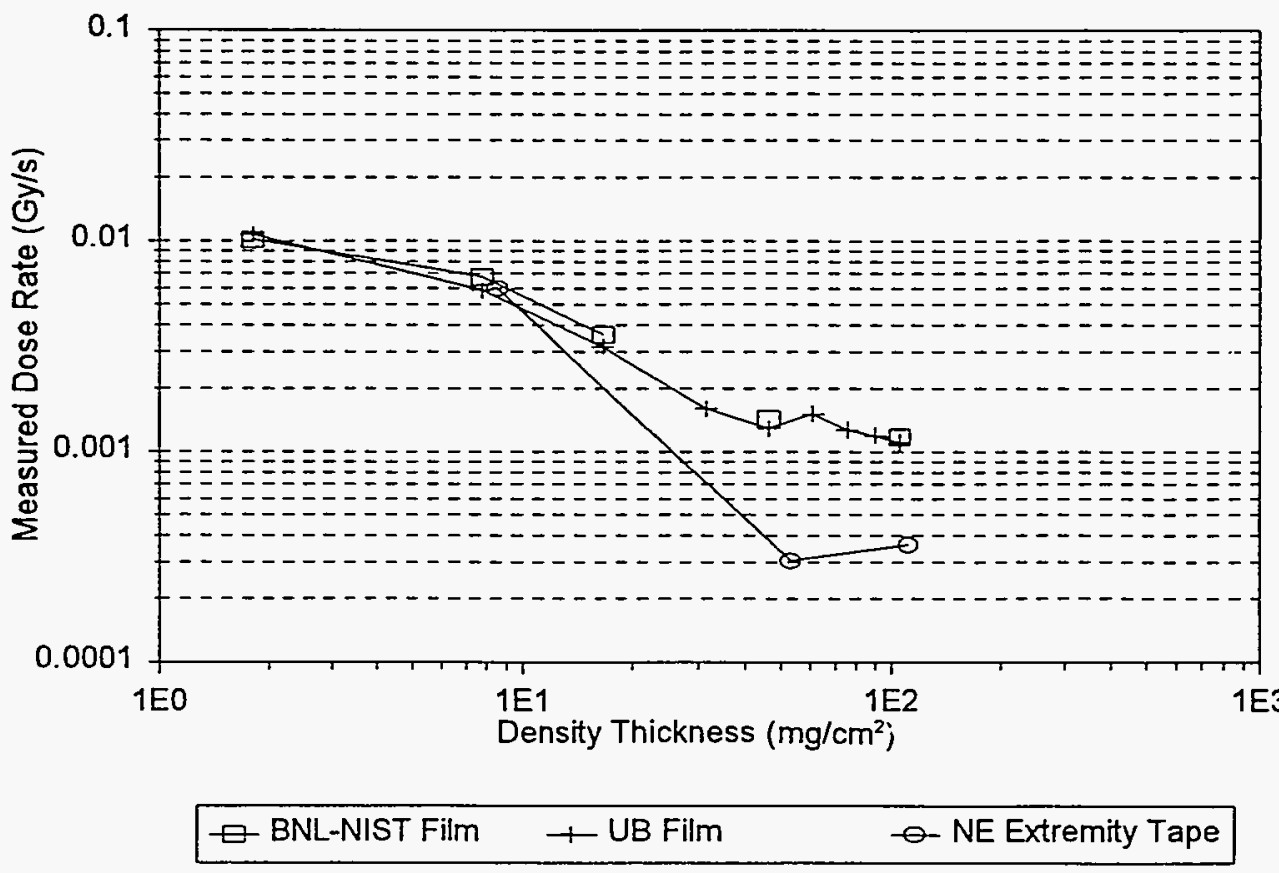

Figure 21. Comparison of measured dose rates of the Co-60 particle averaged over $0.29 \mathrm{~cm}^{2}$ at different density thicknesses. 
The disparity between the NE Extremity Tape dosimeter and the GafChromic film at density thicknesses greater than $53 \mathrm{mg} / \mathrm{cm}^{2}$ for the Sc-46 and Co-60 particles may be partly attributable to the assumed volume irradiated. As discussed in section 2.7.1, an effective dosimeter depth for each isotope was calculated from extrapolation chamber measurements based on no additional absorbing material between the sources and the TLD. Placing additional material between the source and the dosimeter would shift the effective thickness to shallower depths in the TLD for beta particles significantly attenuated in the absorbing material. The $95 \%$ range of Co-60 beta particles in water is $38.2 \mathrm{mg} / \mathrm{cm}^{2}$ (Berger, 1971). While this is less than the $53 \mathrm{mg} / \mathrm{cm}^{2}$ measurement, the beta particle dose is deposited at a much shallower depth, and thus smaller volume and mass, than was used in the dose calculation.

\subsection{Eberline RO-2/2A Measurements}

Table 24 contains the $\mathrm{RO}-2 / 2 \mathrm{~A}$ results of the measurements. The instrument's responses were reported at the reference time of $13: 30$ on September 13; this required about an $18 \%$ correction for decay of the $\mathrm{Yb}-175$ source. The $1 \mathrm{~cm}^{2}$ absorbed dose rates at $7 \mathrm{mg} / \mathrm{cm}^{2}$ are quoted along with the $\pm 20 \%$ estimated uncertainty for all but the Sc-46 hot particle. The open window reading for this hot particle exceeded the $50 \mathrm{R} / \mathrm{h}$ upper limit of the RO-2A. All that can be inferred is that the $1 \mathrm{~cm}^{2}$ absorbed dose rate at $7 \mathrm{mg} / \mathrm{cm}^{2}$ is greater than $2.1 \mathrm{E}-2 \mathrm{~Gy} / \mathrm{s}$. In hindsight, valid data could have been obtained by introducing absorbers between the instrument and the source until the readings were on scale. Then, by using a series of absorbers, the hypothetical open window response, without absorbers, could have been obtained by extrapolation.

Table 24. Eberline RO-2/2A results

\begin{tabular}{ccccc}
\hline $\begin{array}{c}\text { Hot } \\
\text { Particle }\end{array}$ & $\begin{array}{c}\text { RO-2/2A } \\
\text { Open Window } \\
(\mathrm{R} / \mathrm{h})\end{array}$ & $\begin{array}{c}\text { RO-2/2A } \\
\text { Closed } \\
\text { Window } \\
(\mathrm{R} / \mathrm{h})\end{array}$ & $\begin{array}{c}\text { Estimated }^{\mathrm{b}} \\
\text { Activity } \\
(\mathrm{Bq})\end{array}$ & $\begin{array}{c}1 \mathrm{~cm}^{2} \text { Dose Rate }^{\mathrm{c}} \\
\text { at } 7 \mathrm{mg} / \mathrm{cm}^{2} \text { Depth } \\
(\mathrm{Gy} / \mathrm{s})\end{array}$ \\
\hline Tm-170 & 2.65 & 0.001 & $<2.2 \mathrm{E} 7$ & $(1.10 \pm 0.22) \mathrm{E}-3$ \\
Yb-175 & 19 & 0.14 & $<1.6 \mathrm{E} 8$ & $(7.9 \pm 1.6) \mathrm{E}-3$ \\
Sc-46 & $>50^{\mathrm{a}}$ & 12 & $6.1 \mathrm{E} 8$ & $>2.1 \mathrm{E}-2$ \\
Co-60 & 6.0 & 1.2 & $5.1 \mathrm{E} 7$ & $(2.5 \pm 0.5) \mathrm{E}-3$ \\
\hline
\end{tabular}

a. Instrument reading was off-scale high (greater than $50 \mathrm{R} / \mathrm{h}$ ).

b. Calculated as $\mathrm{Bq}=3.7 \mathrm{E} 7 \star \mathrm{CW} \star 1.1 /\left(\Gamma / 3.7^{2}\right)$, where $\Gamma$ equals $0.025,0.49,10.9$ and 13.2 for the $\mathrm{Tm}-170$, $\mathrm{Yb}-175, \mathrm{Sc}-46$, and $\mathrm{Co}-60$, respectively. The < symbol indicates that the true activity is probably less than the value given (see text).

c. Dose rate calculated as $\mathrm{Gy} / \mathrm{s}=\mathrm{OW}+1.50 / 3600$ with $\mathrm{a} \pm 20 \%$ uncertainty for all results. For $\mathrm{Sc}-46$, the $>$ symbol indicates that the dose rate is greater than the value given (see text). 


\section{Appendix}

\subsection{Interpolated Tissue Dose}

\subsubsection{Dose Averaged Over $1 \mathrm{~cm}^{2}$}

Comparisons between the different dosimetry systems were made by calculating from measurement data the dose to selected depths in tissue averaged over $1 \mathrm{~cm}^{2}$ (Table 25). The results were within about $30 \%$ for the GafChromic film, extrapolation chamber, and Eberline RO$2 / 2 \mathrm{~A}$ measurements at $70-\mu \mathrm{m}$ and $125-\mu \mathrm{m}$ tissue depth (Figures 22 to 25). Results for the BNLNIST measurements for the Yb-175 $18 \mu \mathrm{m}$ depth and Sc-46 $70 \mu \mathrm{m}$ depth are different from those presented previously (Kaurin et al., 1996) due to improvements in the fits to the radial dose profile and more accurate decay corrections. The BNL-NIST results were $25 \%$ greater than the UB film, extrapolation chamber, and NE Extremity Tape dosimeter for the Co-60 dose at 125- $\mu \mathrm{m}$ depth in tissue and the Sc-46 dose at 400- $\mu \mathrm{m}$ in tissue, but agreed with the UB film results for the Co-60 source at $400-\mu \mathrm{m}$ depth in tissue. The extrapolation chamber and NE Extremity Tape dosimeters both under-responded compared to the GafChromic film by 40 and $70 \%$, respectively, for the dose at $400 \mu \mathrm{m}$ depth in tissue from the Co-60 source. The NE Extremity Tape results for 18 and $70 \mu \mathrm{m}$ tissue depth for the Sc-46 source (Figure 24) are based on a single $2.2 \mathrm{~s}$ measurement assuming a timing uncertainty of $0.5 \mathrm{~s}$, the standard deviation for this measurement is $23 \%$.

The tissue doses determined using exoelectron dosimeters were less than those from the other systems by factors of 2 to 12 . No apparent trend with depth was evident. These results, using all three measurement geometries (section 2.5.4) are more consistent than those given previously (Kaurin et al., 1996) in which only the deepest measured dose was used to extrapolate doses.

To better understand these differences in response, the tissue dose rate estimates were normalized to the average value for each depth (Figures 26 to 29). The results indicate that the BNL-NIST tissue estimates tend to underestimate the tissue dose compared to the other systems at shallow depths by $10 \%$ for $\mathrm{Tm}-170$ and $\mathrm{Yb}-175$ (Figures 26 and 27 ).

Normalized results shown in Figures 26 to 29 were further quantified by calculating the relative standard deviation of the tissue dose estimates. This was carried out by assuming that each dose measurement from each hot particle could be used as an independent measurement of the precision of the tissue dose estimate for the depth in question. With this assumption, the standard deviation of the normalized tissue dose rates was calculated for the combined set of normalized tissue dose estimates at each depth, irrespective of hot particle source. This gave 16 measurements each for the 18-, 125-, and 400- $\mathrm{mm}$ depths, and 19 measurements for the 70- $\mu \mathrm{m}$ depth. The resulting standard deviation was 11 to $23 \%$ for the relative tissue dose rates (Table 26).

The uncertainties of some of the dose measurements were much larger than that of other measurements. The values in question include the Sc-46 tissue dose estimates carried out using the NE Extremity Tape dosimeter which are based on either a single $2.2 \mathrm{~s}$ measurement or 
Appendix

Table 25. Doses to $1 \mathrm{~cm}^{2}$ of tissue at selected depths derived from interpolation of measured values

\begin{tabular}{|c|c|c|c|c|c|c|c|}
\hline $\begin{array}{c}\text { Hot } \\
\text { Particle }\end{array}$ & $\begin{array}{c}1 \mathrm{~cm}^{2} \\
\text { Depth } \\
(\mu \mathrm{m})\end{array}$ & $\begin{array}{c}\text { BNL-NIST } \\
\text { GafChromic } \\
\text { (Gy/s) }\end{array}$ & $\begin{array}{c}\text { UB (Charles) } \\
\text { GafChromic } \\
\text { (Gy/s) }\end{array}$ & $\begin{array}{c}\text { PNL } \\
\text { (Durham) } \\
\text { ExoElectron } \\
\text { (Gy/s) }\end{array}$ & $\begin{array}{c}\text { Yankee } \\
\text { (Scannell) } \\
\text { Extrapolation } \\
\text { (Gy/s) }\end{array}$ & $\begin{array}{c}\text { Yankee } \\
\text { (Scannell) } \\
\text { NE Extremity } \\
\text { Tape } \\
\text { (Gy/s) }\end{array}$ & $\begin{array}{c}\text { Yankee } \\
\text { (Scannell) } \\
\text { RO-2/2A } \\
\text { thumb rule } \\
\text { (Gy/s) }\end{array}$ \\
\hline $\mathrm{Tm}-170$ & 18 & $1.2 \mathrm{E}-03$ & 1.3E-03 & $3.2 \mathrm{E}-04$ & 1.3E-03 & 1.3E-03 & \\
\hline Tm-170 & 70 & $9.8 E-04$ & 1.1E-03 & 1.6E-04 & 1.1E-03 & $1.2 \mathrm{E}-03$ & 1.1E-03 \\
\hline $\mathrm{Tm}-170$ & 125 & $1.0 E-03$ & $9.6 \mathrm{E}-04$ & 1.3E-04 & $8.9 E-04$ & $1.0 \mathrm{E}-03$ & \\
\hline $\mathrm{Tm}-170$ & 400 & $5.6 \mathrm{E}-04$ & 5.9E-04 & 4.5E-05 & 4.9E-04 & $5.6 E-04$ & \\
\hline$Y b-175$ & 18 & 1.1E-02 & 1.2E-02 & 4.5E-03 & $1.2 \mathrm{E}-02$ & $1.2 \mathrm{E}-02$ & \\
\hline Yb-175 & 70 & 7.5E-03 & 8.8E-03 & $1.8 \mathrm{E}-03$ & $8.2 E-03$ & 8.7E-03 & $7.9 \mathrm{E}-03$ \\
\hline$Y b-175$ & 125 & 4.8E-03 & $6.5 \mathrm{E}-03$ & $1.2 \mathrm{E}-03$ & $5.6 \mathrm{E}-03$ & $6.4 \mathrm{E}-03$ & \\
\hline$Y b-175$ & 400 & 1.7E-03 & 1.9E-03 & $3.2 \mathrm{E}-04$ & $1.4 \mathrm{E}-03$ & 1.3E-03 & \\
\hline Sc- 46 & 18 & $1.1 \mathrm{E}-01$ & 1.0E-01 & $9.6 \mathrm{E}-03$ & 1.1E-01 & 7.2E-02 & \\
\hline Sc- 46 & 70 & $6.5 \mathrm{E}-02$ & $6.6 \mathrm{E}-02$ & 5.7E-03 & $6.6 \mathrm{E}-02$ & 5.1E-02 & \\
\hline Sc-46 & 125 & 4.2E-02 & $3.8 E-02$ & $3.6 \mathrm{E}-03$ & 4.0E-02 & $3.5 \mathrm{E}-02$ & \\
\hline Sc-46 & 400 & $8.4 \mathrm{E}-03$ & 5.7E-03 & $2.0 E-03$ & $6.9 \mathrm{E}-03$ & 5.7E-03 & \\
\hline Co-60 & 18 & 3.3E-03 & $3.2 E-03$ & $6.5 E-04$ & 3.7E-03 & $2.8 \mathrm{E}-03$ & \\
\hline Co-60 & 70 & $2.2 \mathrm{E}-03$ & $1.8 \mathrm{E}-03$ & $5.6 \mathrm{E}-04$ & $2.1 \mathrm{E}-03$ & $2.0 E-03$ & $2.5 \mathrm{E}-03$ \\
\hline $\mathrm{Co}-60$ & 125 & $1.8 E-03$ & 1.3E-03 & $3.5 \mathrm{E}-04$ & $1.2 \mathrm{E}-03$ & $1.4 \mathrm{E}-03$ & \\
\hline $\mathrm{C}_{0}-60$ & 400 & 5.7E-04 & $6.2 E-04$ & $2.8 \mathrm{E}-04$ & 3.8E-04 & $2.2 E-04$ & \\
\hline
\end{tabular}


Appendix

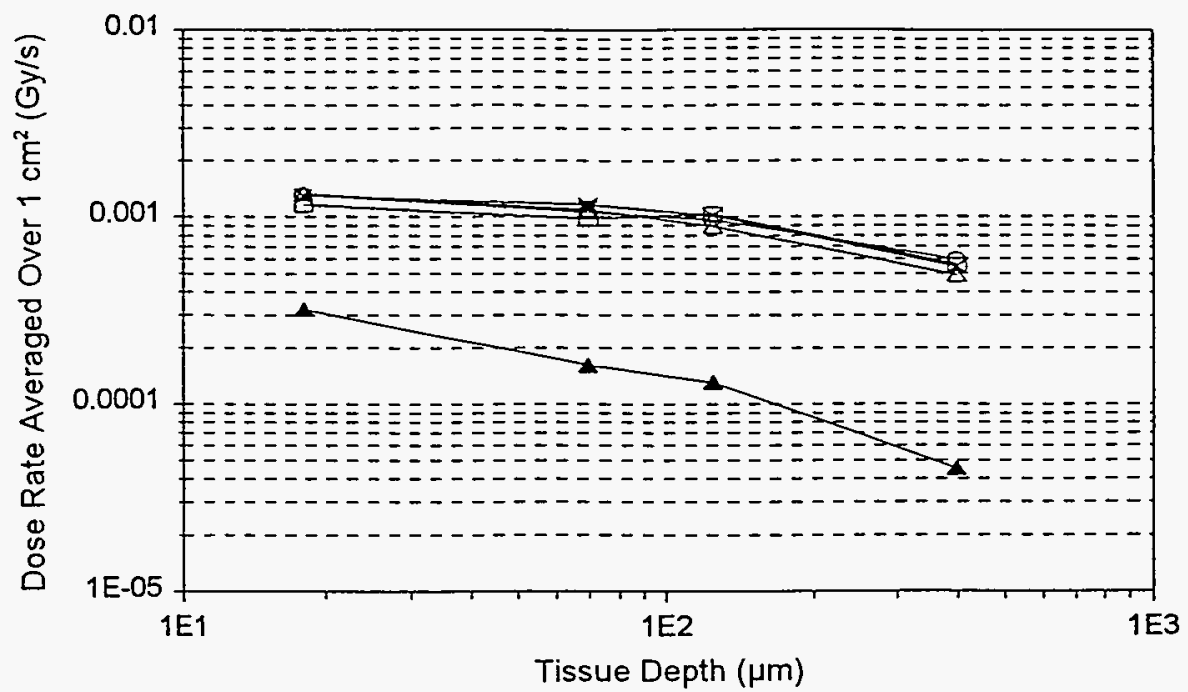

$\because$ BNL-NIST Film $\theta$ UB Film - Exoelectron

$\triangle$ Extrap. Chamber $\rightarrow$ NE Extremity Tape $-\varangle$ RO-2/2A

Figure 22. Comparison of $\mathrm{Tm}-170$ tissue dose rates interpolated from measured values.

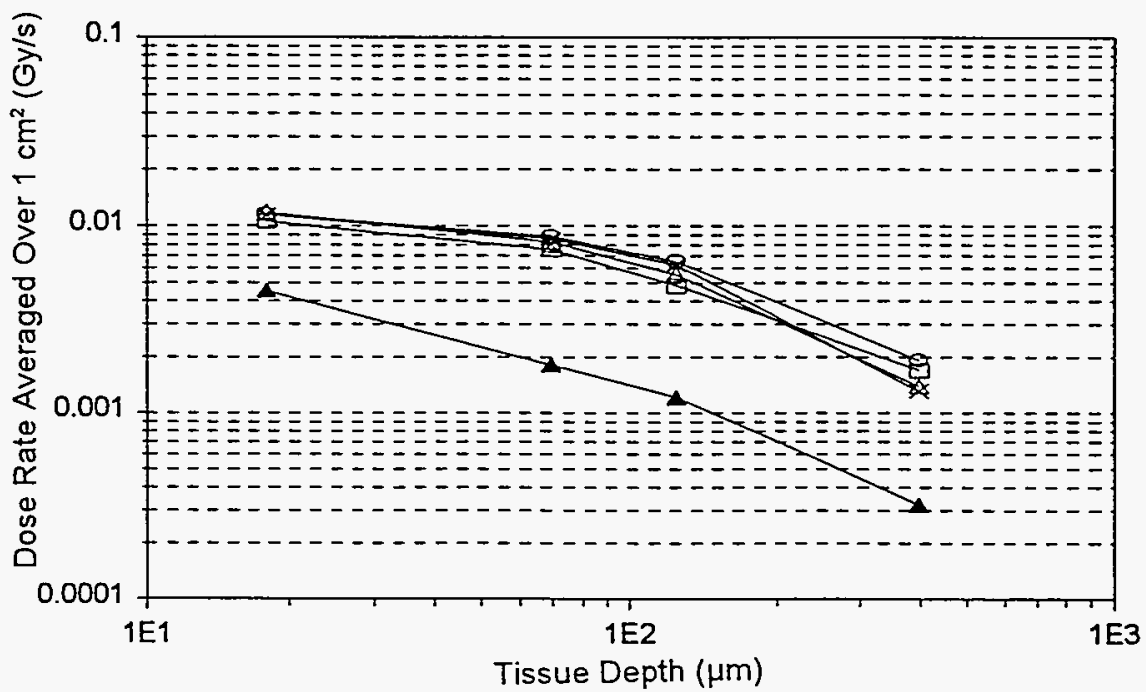

E- BNL-NIST Film - - UB Film $\quad$ - Exoelectron

$\triangle$ Extrap. Chamber $\rightarrow$ NE Extremity Tape $\&$ RO-2/2A

Figure 23. Comparison of $\mathrm{Yb}-175$ tissue dose rates interpolated from measured values. 
Appendix

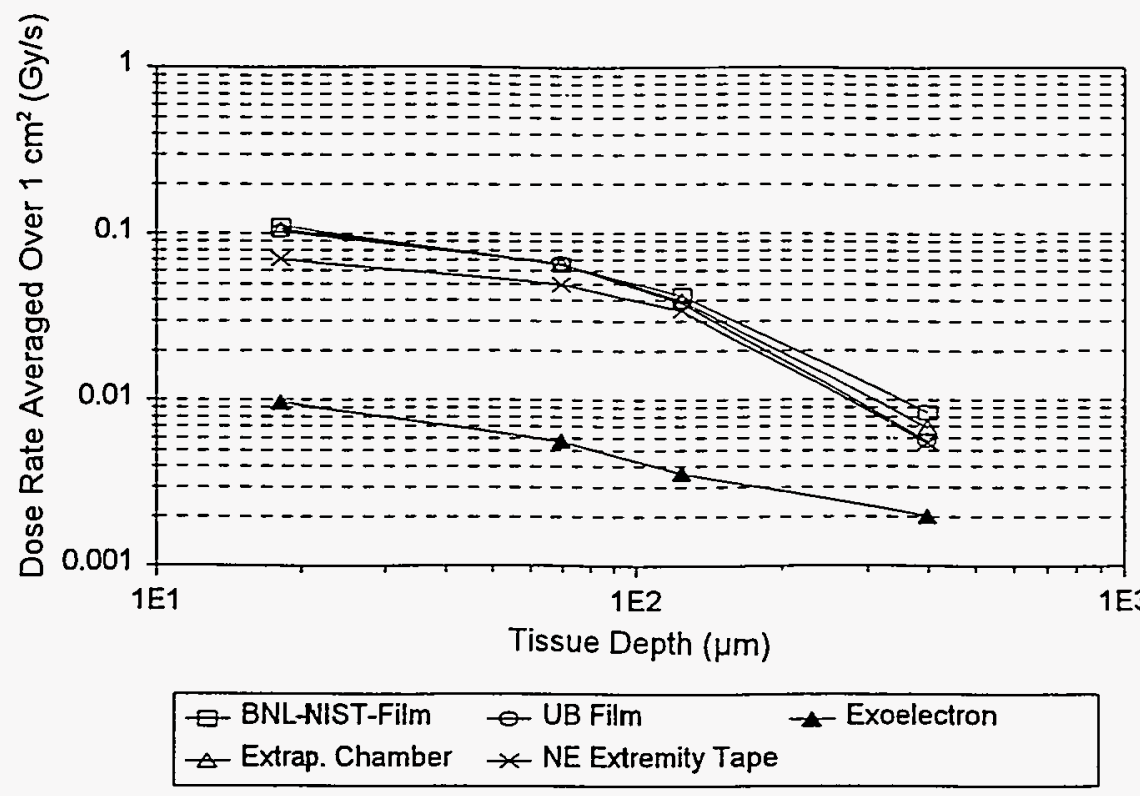

Figure 24. Comparison of Sc-46 tissue dose rates interpolated from measured values.

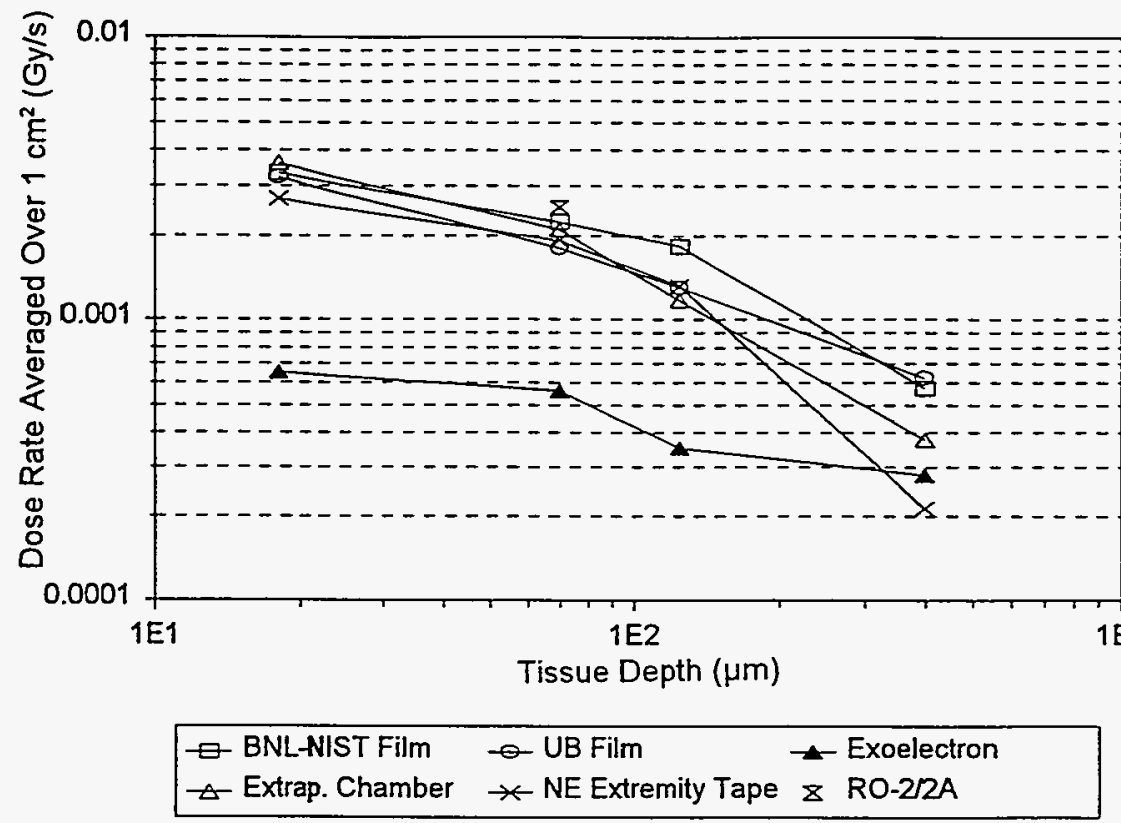

Figure 25. Comparison of Co-60 tissue dose rates interpolated from measured values. 
Appendix

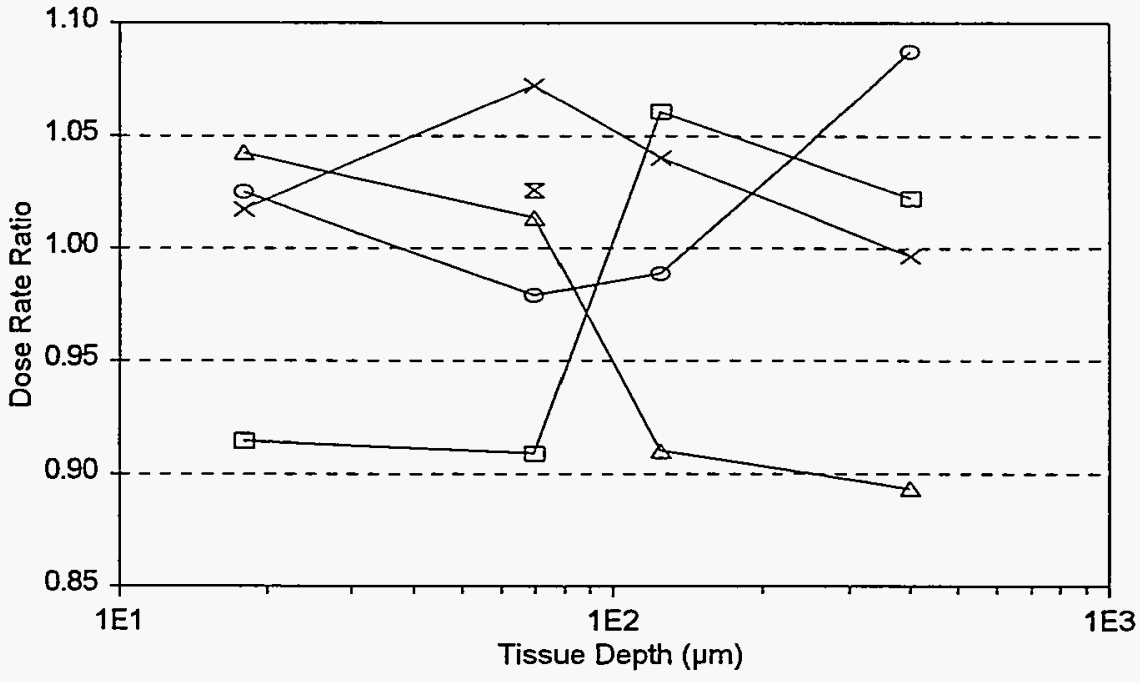

$\square$ BNL-NIST Film $-\theta$ - UB Film $\triangle$ Extrap. Chamber

$\rightarrow$ NE Extremity Tape $\&$ RO-22A

Figure 26. Relative $\mathrm{Tm}-1701 \mathrm{~cm}^{2}$ tissue dose estimates normalized to the average value for each depth. Lines connecting the data points are to aid the eye.

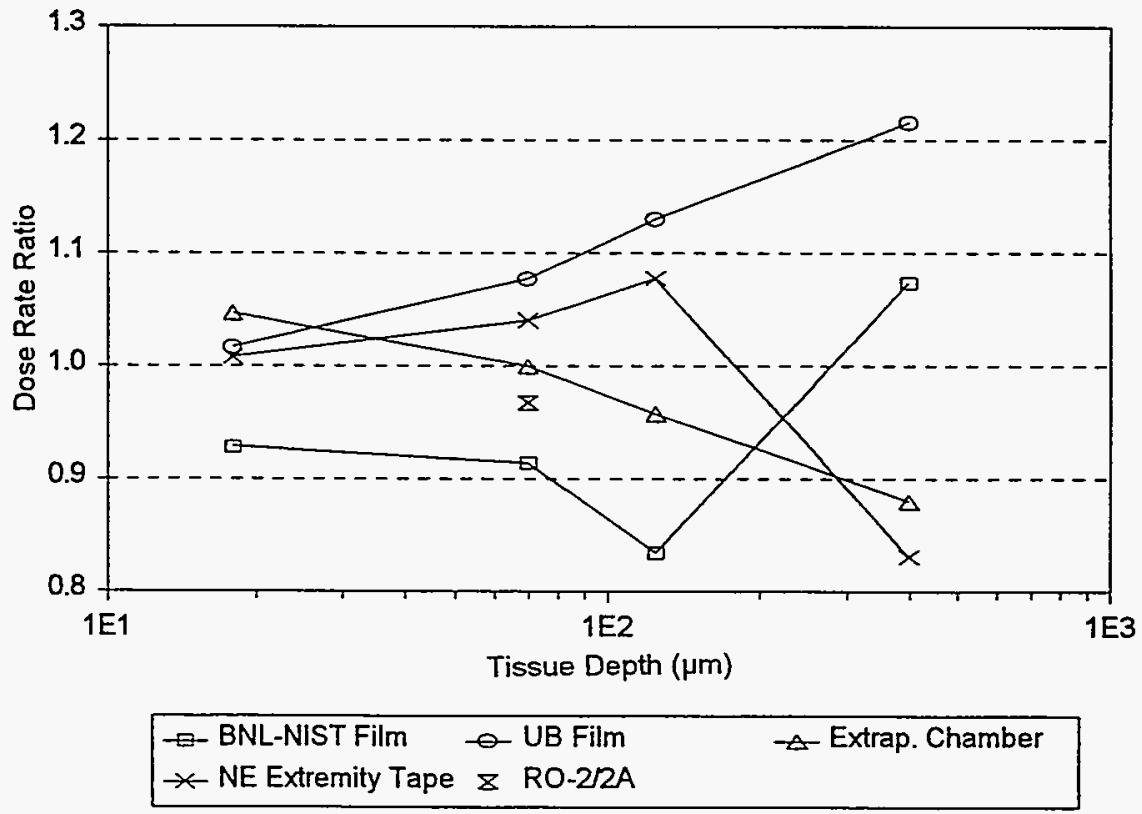

Figure 27. Relative $Y b-1751 \mathrm{~cm}^{2}$ tissue doses normalized to the average value for each depth. Lines connecting each data point are to aid the eye. 


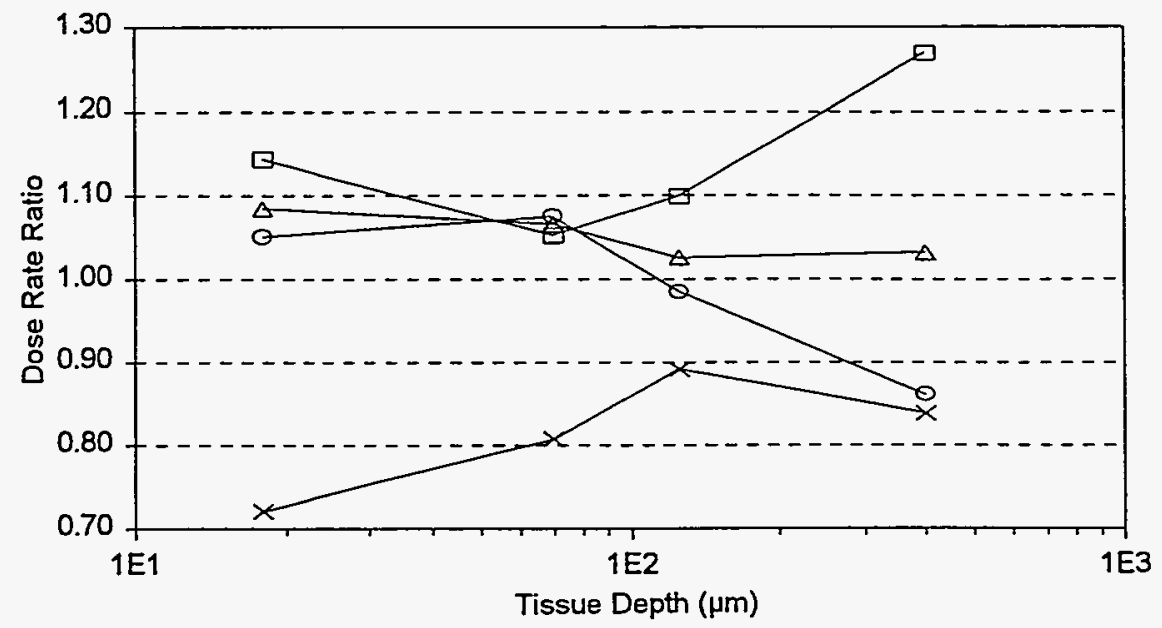

Figure 28. Relative Sc-46 $1 \mathrm{~cm}^{2}$ tissue dose estimates normalized to the average for each depth. Lines connecting each data point are to aid the eye. The 18 and $70 \mu \mathrm{m}$ depth values for the NE Extremity Tape dosimeter are based on a single $2.2 \mathrm{~s}$ measurement.

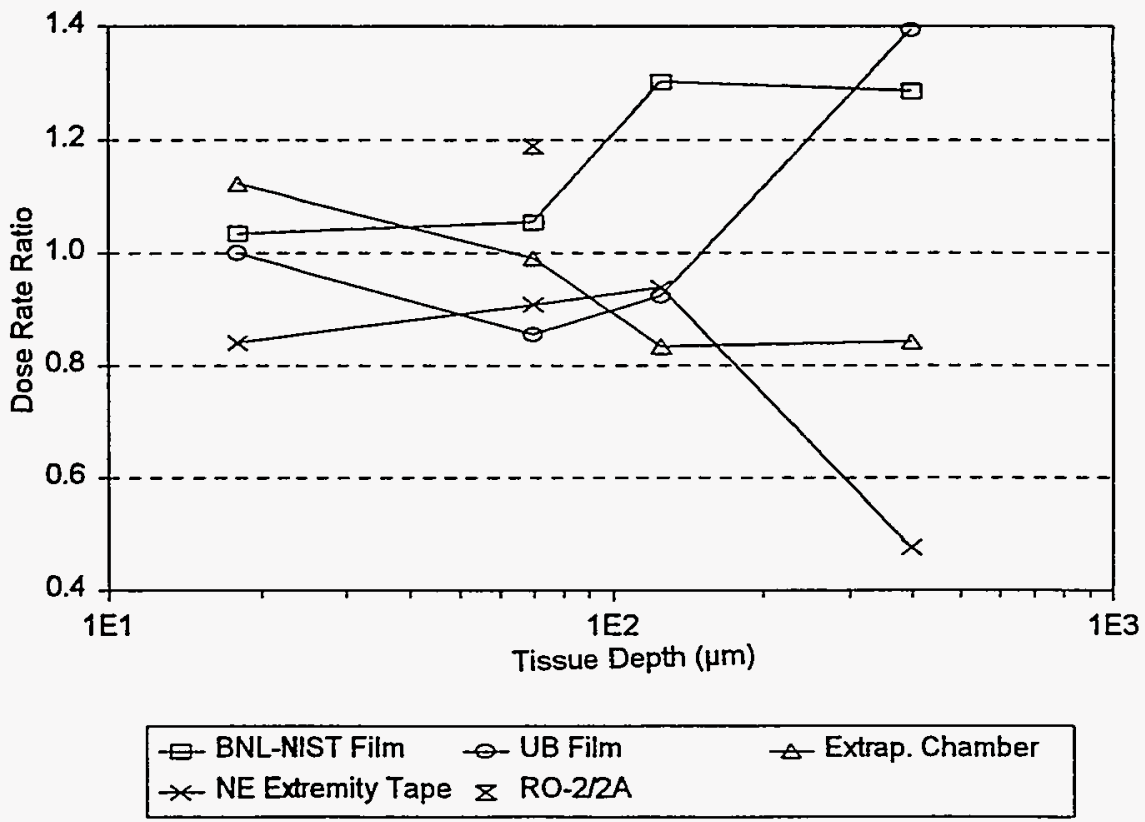

Figure 29. Relative Co-60 $1 \mathrm{~cm}^{2}$ tissue dose estimates normalized to the average value for each depth. Lines connecting the data points are to aid the eye. 


\section{Appendix}

Table 26. Combined standard deviation of $1 \mathrm{~cm}^{2}$ tissue doses normalized to the average for each hot particle at each depth to determine precision of estimates for each depth. All normalized values from each hot particle (Figures 26-29) are combined to determine the standard deviation for each measurement depth. The results from the exoelectron ${ }^{2}$ measurements are excluded.

\begin{tabular}{|c|c|c|}
\hline \multirow{2}{*}{$\begin{array}{c}\text { Tissue depth } \\
(\mu \mathrm{m})\end{array}$} & $\begin{array}{c}\text { No further exclusions } \\
\text { Relative standard deviation of } \\
\text { dose rates for all hot particles } \\
\text { combined } \\
(\%)\end{array}$ & $\begin{array}{c}\text { Relative standard deviation of } \\
\text { dose rates for all hot particles } \\
\text { combined } \\
(\%)\end{array}$ \\
\hline \hline 18 & 11 & $6.6^{\mathrm{c}}$ \\
\hline 70 & 9.1 & $7.6^{\mathrm{c}}$ \\
\hline 125 & 12 & $12^{\mathrm{d}}$ \\
\hline 400 & 23 & $23^{\mathrm{d}}$ \\
\hline
\end{tabular}

a. Results from the exoelectron measurements were factors of 2 to 12 less than the other systems.

b. Sample standard deviation divided by the sample mean times $100 \%$. All measured doses were normalized to the average for each hot particle for each depth, so the mean was equal to 1.

c. Excludes the Sc-46 NE Extremity Tape estimate based on a single $2.2 \mathrm{~s}$ exposure.

d. Excludes the NE Extremity Tape estimate for Sc-46 based on single exposures (2.2 and $3.3 \mathrm{~s}$ ) at two different depths.

interpolation between the single $2.2 \mathrm{~s}$ exposure and a single $3.3 \mathrm{~s}$ exposure. Excluding these tissue dose estimates decreased the standard deviation for the 18- and 70- $\mu \mathrm{m}$ tissue depths to 6.6 and $7.6 \%$, respectively, with negligible reduction for the deeper depths (Table 26 ).

The larger uncertainty for the deeper depth may be dosimeter-dependent. The extrapolation chamber and NE Extremity Tape under-responded relative to the GafChromic film for 3 of the 4 hot particles for the $400 \mu \mathrm{m}$ depth (Figures 26, 27, 29). Thus, certain dosimeters may be more suited to measuring dose at different depths. Since the experiment was strictly an intercomparison, for the example just cited it is not known which system was most accurate. 


\section{Appendix}

\subsubsection{Dose Averaged Over $1.1 \mathrm{~mm}^{2}$}

Also of interest was dose averaged over $1.1 \mathrm{~mm}^{2}$ of tissue at a depth of $1.8 \mathrm{mg} / \mathrm{cm}^{2}$, the location of the top GafChromic dye film. Hopewell (1991) and Charles (1991) reported doses for the incidence of ulcers in pig skin as dose averaged over $1.1 \mathrm{~mm}^{2}$, which was the area of the extrapolation chamber electrode used for the source dosimetry. It was desirable to compare the BNL-NIST dosimetry for this area with those from other systems to validate comparisons of the BNL-NIST pig skin results with those of Hopewell et al. (1986) and Charles (1991); they are listed in Table 27.

Table 27. Doses to $1.1 \mathrm{~mm}^{2}$ area of GafChromic film at a film depth of $1.8 \mathrm{mg} / \mathrm{cm}^{2}$ to enable comparisons of biology data with Hopewell (1991) and Charles (1991)

\begin{tabular}{|c|c|c|}
\hline $\begin{array}{c}\text { Hot } \\
\text { Particle }\end{array}$ & $\begin{array}{c}\text { BNL-NIST } \\
\text { GafChromic } \\
\text { (Gy/s) }\end{array}$ & $\begin{array}{c}\text { UB (Charles) } \\
\text { GafChromic } \\
\text { (Gy/s) }\end{array}$ \\
\hline \hline$T m-170$ & $5.9 \mathrm{E}-02$ & $6.1 \mathrm{E}-02$ \\
\hline Yb-175 & $7.0 \mathrm{E}-01$ & $9.4 \mathrm{E}-01$ \\
\hline Sc-46 & $8.6 \mathrm{E}+00$ & $7.5 \mathrm{E}+00$ \\
\hline Co-60 & $2.5 \mathrm{E}-01$ & $2.8 \mathrm{E}-01$ \\
\hline
\end{tabular}


Appendix

\section{Summary and Conclusion}

Measurements were made of four different hot particles using GafChromic dye film, exoelectron, extrapolation chamber, and NE Extremity Tape dosimeters, as well as with Eberline RO-2/2A ion chamber survey instruments (Eberline RO-2/2A was used only for the 70- $\mu \mathrm{m}$ measurement). Tissue dose rate estimates calculated from GafChromic dye films, the YAEC extrapolation chamber, NE Extremity Tape dosimeters, and an Eberline RO-2/2A measurements averaged over $1 \mathrm{~cm}^{2}$ normalized to the average value had relative standard deviations of $11,9.1,12$, and $23 \%$ for $18,70,125$, and $400 \mu \mathrm{m}$ depths, respectively. Excluding data with large uncertainties decreased the relative standard deviation to 6.6 and $7.6 \%$ for 18 and $70 \mu \mathrm{m}$ depths, respectively, with negligible reduction for the two deeper tissue depths. Use of a properly calibrated hand-held ion chamber can provide reasonably accurate measurements for dose averaged over $1 \mathrm{~cm}^{2}$ at $70 \mu \mathrm{m}$ depth comparable to more sophisticated devices. 
Appendix

\section{REFERENCES}

Baum, J.W., D.G. Kaurin, M. Waligorski, R. Bird and L.C. Sun, "Progress Report on Hot Particle Studies," NUREG/CR-5725, U.S. Nuclear Regulatory Commission, Washington, DC, 1992.

Berger, M.J., "Distribution of absorbed dose around point sources of electrons and beta particles in water and other media," J. Nuc. Med., Medical Internal Radiation Dose Committee, Supp. 5 (12), Pamphlet \# 7, 1971.

Bevington, P.R., Data Reduction and Error Analysis of the Physical Sciences, McGraw Hill, Inc., New York, 1969.

Bureau of Radiological Health, Radiological Handbook, U.S. Department of Health, Education, and Welfare, U.S. Government Printing Office, Washington, D.C., 1970.

Charles, M.W., "The hot particle problem," Radiat. Prot. Dosim., 39 (1-3), 39-47 (1991).

Darley, P.J., M.W. Charles and C.D. Hart, "Validation of theoretical models for calculating doses from hot particles," in Proceedings of the IRPA Regional Congress on Radiological Protection, W. Nimmo-Scott and D.J. Golding (Eds.), Nuclear Technology Publishing, 153-156, 1994.

Darley, P.J., M.W. Charles, C.D. Hart, J. Wells and M.S.E. Coleby, "Dosimetry of planar and punctiform beta sources using an automated extrapolation chamber and radiochromic dye films," Radiat. Prot. Dosim., 39 (1-3), 61-66 (1991).

Durham, J.S., "VARSKIN MOD2 and SADDE MOD2: computer codes for assessing skin dose from skin contamination," NUREG/CR-5873, U.S. Nuclear Regulatory Commission, Washington, D.C., 1992.

Forbes, P.D. and S.Z. Mikhail, "Acute lesions in skin produced by radioactive microspheres," presented at the Annual Meeting of the Radiation Research Society, 1970, abstract in Radiat. Res., 39, 493 (1969).

Fraleigh, J.B., Calculus with Analytic Geometry. Addison-Wesley Publishing Company, Inc., Reading, MA, 1980.

Hopewell, J.W., "Biological effects of irradiation on skin and recommended dose limits," Radiat. Prot. Dosim., 39 (1/3), 11-24 (1991).

Hopewell, J.W., J.E. Coggle, J. Wells, R. Hamlet, J.P. Williams and M.W. Charles, "The acute effects of different energy beta emitters on pig and mouse skin," Brit. J. Radiol. Suppl., 19, 47-51 (1986). 


\section{Appendix}

ICRP, "Biological Basis for Dose Limitation in the Skin," ICRP Publication 59, Annals of the ICRP, Vol. 22, No. 2, Pergamon Press Inc., New York, 1991.

ICRU, "Stopping Powers for Electrons and Positrons," ICRU Report 37 (ICRU, Bethesda, MD), 1984.

Kaurin, D.G.L., J.W. Baum, A.L. Carsten and C.W. Schaefer, "Ulcer induction as a function of beta particle energy due to 'hot particles' on the skin," abstract in Health. Phys., Suppl. to 68, (6), 577-78 (1995).

Kaurin, D.G.L., J.W. Baum, M.W. Charles, D.P.J. Darley, J.S. Durham, M.J. Scannell and C.G., Soares, "Hot Particle Intercomparison Dosimetry Measurements," Proceedings of Ninth International Congress of the International Radiation Protection Association, Vol. 3, 3-28 to 3-20, Vienna, Austria, April 14-19, 1996 (IRPA, c/o Austrian Research Center Seibersdorf, A-2444 Seibersdorf, Austria).

Lantz, M.W. and J.B. Steward, "New data on the self-absorption of betas in Co-60 "hot particles'," Radiat. Prot. Manag., 5 (4), 57-58 (1988).

Loevinger, R. and N.G. Trott, "Design and operation of an extrapolation chamber with removable collecting electrodes," Int. J. Appl. Radiat. and Isot., 17, 103-111 (1966).

McWilliams, F.F., M.J. Scannell, C.G. Soares, B.M. Coursey and G.E. Chabot. "Hot particle dosimetry using Co-60 spheres," Radiat. Prot. Dosim., 40 (4), 223-234 (1992).

Merwin, S. E., and K. L. Swinth, "Performance of an Exoelectron dosimeter badge for personnel beta dosimetry," Radiat. Prot. Dosim., 28 (3), 219-222 (1989).

Merwin, S. E., and K. L. Swinth, "Exoelectron Emission and its potential applications in personnel dosimetry." Paper presented at the 32nd Annual Meeting of the Health Physics Society, July 5-10, 1987, Salt Lake City, Utah, 1987.

Merwin, S. E., M. P. Moeller, and K. L. Swinth, "A new dosimeter for measuring hot particle dose rates." Radiat. Protec. Manag., 6 (3), 27-36 (1988).

NCRP, "Limit for Exposure to "Hot Particles" on the Skin," NCRP Report No. 106 (National Council on Radiation Protection and Measurements, Bethesda, MD), 1989.

NCRP, "A Handbook of Radioactivity Measurements Procedures," NCRP Report No. 58, p. 7 (National Council on Radiation Protection and Measurements, Bethesda, MD), 1978.

Pruitt, J.S., C.G. Soares, and M. Ehlich, "Calibration of Beta-Particle Radiation Instrumentation and Sources," NBS Special Publication 250-21, U.S. Government Printing Office, Washington, D.C., 1988. 
Reece, W.D., J.S. Durham, S.E. Mervin and M.P. Moeller, "Threshold Levels for Nonstochastic Skin Effects from Low-Energy Discrete Radioactive Particles," Electric Power Research Institute, EPRI-TR-100048, Project 3099-3, 1992.

Reece, W.D., J.W. Poston, Sr. and D.L. McFarlane. "Skin Injuries from Discrete Radioactive Particles," EPRI TR-104781 (Electric Power Research Institute, Palo Alto, CA), December 1994.

Sayeg, J.A., C.W. Coffey, and W.L. McLaughlin, "The Energy Response of "GafChromic" Radiation Detectors," 1990 AAPM Annual Meeting, Medical Physics, 17 (3) (1990).

Soares, C.G., P.J. Darley, M.W. Charles, and J.W. Baum, "hot particle dosimetry using extrapolation chambers and radiochromic foils," Radiat. Prot. Dosim., 39 (1-3), 55-59 (1991).

Soares, C.G., and W.L. McLaughlin, "Measurement of Radial dose distributions around small beta particle emitters using high resolution radiochromic foil dosimetry," Radia. Prot. Dosim., 47 $(1-4), 367-372$ (1993).

Weast, R.C. (Editor), CRC Handbook of Chemistry and Physics, CRC Press, Inc., Cleveland, Ohio, 1976. 
2. TITLE AND SUBTITLE

Effects of Radioactive Hot Particles on Pig Skin

Darryl G.L. Kaurin, John W. Baum, Arland L. Carsten, John O. Archambeau*, and Charles W. Schaefer

\begin{tabular}{ll|c|}
\hline 3. & \multicolumn{2}{|c|}{ DATE REPORT PUBLISHED } \\
\hline $\begin{array}{l}\text { MONTH } \\
\text { JUne }\end{array}$ & $\begin{array}{c}\text { YEAR } \\
1997\end{array}$ \\
\hline 4. & $\begin{array}{c}\text { FIN OR GRANT NUMBER } \\
\text { A3990 }\end{array}$ \\
\hline 6. TYPE OF REPORT \\
Final \\
7 PERIOD COVERED (Inclusive Dates) \\
July 1, 1988 - June 30, 1997
\end{tabular}

8. PERFORMING ORGANIZATION - NAME AND ADDRESS (II NRC, provide Division, Office or Region, U.S. Nuclear Regulatory Commission, and malling address, if contractor, provide name and malling address.)

Department of Advanced Technology

Brookhaven National Laboratory

Upton, NY 11973-5000
* Loma Linda University Medical Center Loma Linda, CA 92354

9. SPONSORING ORGANIZATION - NAME AND ADDRESS (If NRC, type "Same as above'; if contractor, provide NRC Division, Office or RegIon, U.S. Nuclear Regulatory Commission, and mailing address.)

Division of Regulatory Applications

Office of Nuclear Regulatory Research

U.S. Nuclear Regulatory Commission

Washington, D.C. 20555-0001

10. SUPPLEMENTARY NOTES

Stewart Schneider, NRC Project Manager

11. ABSTRACT (200 word's or less)

The purpose of these studies was to determine the incidence and severity of lesions resulting from very localized deposition of dose to skin from small $(<0.5 \mathrm{~mm})$ discrete radioactive particles as produced in the work environments of nuclear reactors. Hanford mini-pigs were exposed, both on and slightly off the skin, to localized replicate doses from 0.31 to $64 \mathrm{~Gy}$ (averaged over $1 \mathrm{~cm}^{2}$ at $70 \mu \mathrm{m}$ depth unless noted otherwise) using Sc-46, $\mathrm{Yb}-175, \mathrm{Tm}-170$, and fissioned $\mathrm{UC}_{2}$ isotopes having maximum beta-particle energies from about 0.3 to $3 \mathrm{MeV}$. Erythema and scabs (indicating ulceration) were scored for up to 71 days post-irradiation. The responses followed normal cumulative probability distributions, and therefore, no true threshold could be defined. Hence, 10 and $50 \%$ scab incidence rates were deduced using probit analyses. The lowest dose which produced $10 \%$ incidence was about $1 \mathrm{~Gy}$ for $\mathrm{Yb}-175$ (0.5 MeV maximum energy) beta particle exposures, and about 3 to $9 \mathrm{~Gy}$ for other isotopes. The histopathology of lesions was determined at several doses. Single exposures to doses as large as 1,790 Gy were also given, and results were observed for up to 144 days post-exposure. Severity of detriment was estimated by analyzing the results in terms of lesion diameter, persistence, and infection. Over 1,100 sites were exposed. Only two exposed sites became infected after doses near $500 \mathrm{~Gy}$; the lesions healed quickly on treatment.

12 KEY WORDSIDESCRIPTORS (List words or phrases that will assist researchers in locating the report)

13 AVAILABILITY STATEMENT

Dose Limits, Beta Particles - Dose Limits, Dose-Response Relationships, Dosimetry, Swine, Skin, Ulcers, Radiation Doses - Skin, Biological Radiation Effects - Skin, Threshold Doses, Erythema, Radiation Injuries, Thulium 170, Scnadium 46, Ytterbrium 175 Unclassified 14. SECURITY CLASSIFICATION (This Page) Unclassified (ThisReport) Unclassified

15. NUMBER OF PAGES 